

\section{R. Barnss}

4282 Maple Avenue

Oakland, Calif. 94602

From the collection of the

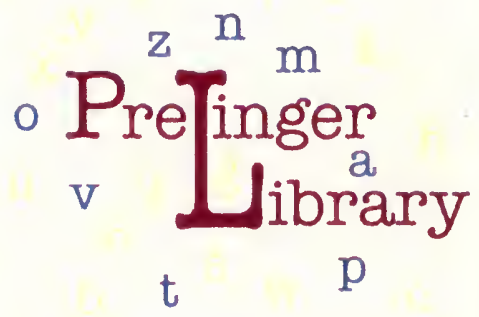

San Francisco, California 2006 

Digitized by the Internet Archive in 2007 with funding from Microsoft Corporation 


\title{
Native Woody Plants of the United States
}

\section{Their Erosion-Control and Wildlife Values}

\author{
By \\ WILLIAM R. VAN DERSAL \\ Biologist \\ Division of Conservation Operations \\ Soil Conservation Service
}

UNITED STATES

GOVERNMENT PRINTING OFFICE

WASHINGTON : 1939

For sale by the Superintendent of Documents, Washington, D. C. - . - . - Price $\$ 1.50$ (paper) 


\section{ACKNOWLEDGMENT}

Since the initial appearance of this work in preliminary mimeographed form in 1936, a great many people have contributed original information and suggestions without which the present publication would be much less complete. To all of these people, the author wishes to express his sincere thanks.

$\mathrm{He}$ is particularly indebted to Ernest G. Holt for his advice, suggestions, and criticism, as well as his very considerable assistance during the prepuration of the manuscript; to 'T. H. Kearney, for permission to use his manuscript on the flora of Arizona; to V. L. Cory and H. B. Parks for the use of their manuscript catalog of the Texas flora, and Mr. Parks' manuscript on the useful properties of Texas plants; to F. L. Mulford for the plant-growth region map, together with his chapter on its development; to C. W. Thornthwaite for the map of the climatic regions; to Clarence Cottam and his assistants, Phoebe Knappen, F. M. Uller, Neil Hotchkiss, and A. L. Nelson, for their very great help in making available considerable data from the Section of Food Habits Research of the Bureau of Biological Survey; to E. P. Killip for advice on the taxonomic problems; to E. L. Crandall for his help with some of the photograplis and to C. R. Ball, who assisted materially in the preparation of the section on Satix.

Suggestions and criticisms concerning the botanical material have been offered by E. J. Alexander, M. L. Fernald, E. J. Palmer, H. M. Raup, H. A. Gleason, W. H. Camp, H. E. McMinn, F. J. Crider, C. V. Morton, M. Van Rensselaer, E. H. Graham, Mildred Mathias, H. L. Shantz, E. V. Komarek, Hilda Cumniff, Fred Gibson, and his assistant, J. Whitehead, H. S. Yates, M. G. Netting, P. B. Sears, H. L. Whitaker, C. F. Swingle, and Russell Albright.

Suggestions and criticisms concerning the wildlife material were received from W. L. McAtee, H. L. Stoddard, Aldo Leopold, D. M. Gorsuch, F. N. Hamerstrom, Jr., C. B. Terrell, R. T. King, Gardiner Bump, R. O. Stevens, A. M. Pearson, Logan Bennett, P. D. Dalke, V. E. Davison, N. W. Hosley, W. E. C. Todd, R. E. Yeatter, and H. D. Ruhl. 


\title{
UNITED STATES DEPARTMENT OF AGRICULTURE
}

\author{
MisCELLANEOUS PUBLICATION No. 303
}

Washington, D. C.

Issued June 1938

Stightly revised May 1939

\section{NATIVE WOODY PLANTS OF THE UNITED STATES, THEIR EROSION-CONTROL AND WILDLIFE VALUES}

By William R. Van Dersal, biologist, Division of Conservation Operations, Soil Conservation Service

\begin{tabular}{|c|c|c|}
\hline Page & & Page \\
\hline & Plant-growth regions-Continued. & \\
\hline 2 & Length of the growing season..... & \\
\hline & Snow cover...................... & \\
\hline $\begin{array}{l}4 \\
5\end{array}$ & $\begin{array}{l}\text { Climates of growth regions .- } \\
\text { Nitrogen-fixing bacteria }\end{array}$ & 1 \\
\hline 6 & Explanation of the list.......... & 28 \\
\hline 7 & Scope & 28 \\
\hline 8 & Latin names and synonyms. & 28 \\
\hline 9 & Vernacular names of plants... & 29 \\
\hline 9 & Range-1-1 & 30 \\
\hline 10 & Site designations...... & 30 \\
\hline 11 & 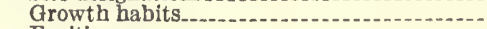 & 31 \\
\hline 11 & Fruiting & 31 \\
\hline 12 & Propagation & 32 \\
\hline 13 & Utilization by wildllfe & 34 \\
\hline 14 & List of woody plants. & $=$ \\
\hline 15 & Bibllography & 293 \\
\hline 16 & Mímeographed and unpublished refer- & \\
\hline 17 & List of common names of woody plants...... & $\begin{array}{l}321 \\
322\end{array}$ \\
\hline & & \\
\hline
\end{tabular}

Introduction

Evaluation of plants for erosion control and wildlife.

Planting for soil and wildife conservation. Planting for wildlifo.

Highwey planting A gronossive plants.

Plants harboring fungi or insect pests

Selection of specles for planting Primary succession

Secondary succession and pioneer species

Native versus introduced species.

Fruit production

The porrelation of solitand plant growthDevelopment of the plant-growth region map Plant-growth regions

Factors in plant distribution

Thornthwaite's climatic provinces

\section{INTRODUCTION}

At no time has the need for conservation of our natural resources been as apparent as it is at present. We have seen the wasteful destruction of our most basic resource, the soil, take place at an everincreasing rate within a comparatively short span of years. The original vegetation of the country has in large part been removed, and as a consequence of this, not only has soil become increasingly subject to erosion, but wildlife, being dependent on vegetation for existence, has also become severely depleted.

The same forces that cause soil losses have destroyed wildlife habitats. The removal of the vegetative cover has permitted washing away of topsoil, and this in turn has prevented the return of vegetation and the consequent restoration of wildlife. It is only natural, therefore, that revegetation should be relied upon to conserve soil, and since the same vegetation can be made to provide more wildlife habitats, it is possible to conserve two resources with one operation. It becomes apparent that soil conservation, if properly managed, call mean wildlife conservation. 
But to carry out a program of soil and wildlife conservation vegetation must be utilized intelligently. Where considerable numbers of plants are to be employed, it is essential to know as much as possible about every species of tree, shrub, or herb we propose for planting. We should know where and on what soils a species will grow, what degree of drought or moisture it can endure, the nature and extent of its root system, its susceptibility to insects and disease, its aggressiveness, its relation to other species, its value to the landowner as a crop-producing plant, and its use as food or cover by wildlife.

In other words, the time is opportune to take inventory of the stock on hand; not to show how much has been lost, but to determine what is left to build with, and how most wisely to employ it. There exists a widely distributed mass of information concerning plants, which, if assembled and properly classified, may assist materially in dealing with soil and wildlife conservation.

This publication presents an indexed list of woody plants growing in the United States, naming each species as unmistakably as possible, and giving all available data pertinent to its use in erosion control and wildlife conservation. Such an inventory as this shows not only what is known about each species of plant but by inference what is not known. Every species is potentially a valuable resouroe in itself. The development of each plant resource eventually may disclose a crop as yet unsuspected.

It may be noted that this indexed list is not intended for use in the identification of plants, although characters listed here may assist in making determinations. There are manuals to cover the entire country, with the exception of Arizona and Texas. After identification is certain, this publication may be consulted for data on the use of any given woody plant.

\section{THE RELATION OF VEGETATION TO SOIL CONSERVATION}

Under our present agricultural system we are concerned with the manipulation of cultivated crops in such a manner as to keep the maximum of cover on the soil as much of the time as is possible. Such manipulated, cultivable crops may be classed as temporary vegetation. The permanent class will include plants that are permitted to remain on the ground without disturbance, except that incident to gathering from them such periodic crops as they may produce. It is with the permanent class that this publication deals.

As every soil conservationist knows, there is a very definite relation between the density of the plant cover on the soil, the amount of soil lost through erosion, and the productivity of that soil. These three functions vary in a regular and direct manner, and there is no reason to believe that they have not always done so. Soil is formed partly by vegetation, and regetation is in good part a product of the soil. Reasoning from our observation of natural conditions, we must expect to direct our efforts to control erosion toward revegetation, since it is known that erosion starts with the destruction of the plant cover and that the kind and density of vegetation is more important in influencing run-off and erosion than is steepness of slope or intensity of rainfall. ${ }^{1}$

1 Data from the U. S. Forest Service, Intermountain Station, Ogden, Utah. 
Many workers are of the opinion that a plant with a large root system is necessarily the best one to hold soil in place. This idea is so universally held that it may not be amiss to review briefly just what takes place when a soil is eroded, especially by water. In doing this we may come to understand more clearly how erosion can be prevented by restoring vegetation.

In exceptional and rare instances, washing may take place below the surface, but under ordinary conditions the washing away of soil occurs at the surface. It is the movement of soil particles downhill in water or into the air as dust that we wish to prevent. Since such movements start in the very uppermost layer of the soil, our efforts must of necessity be directed to holding topsoil in position. Roots of woody plants do not, in themselves, offer much help in the top inch or so of soil; they penetrate deeper and may be said to be holding the soil in place below but not necessarily at the surface.

Observations in the field show that soil easily washes away from roots and that the better the surface of the soil is covered, the less the soil washes. Experimental evidence has confirmed such observations. Kramer and Weaver $(346)^{2}$ conducted a series of tests on many kinds of plants, mostly grains and other herbs. In their experiments they discovered that it was not the soil-binding effect of roots that produced the best protection, but the plant cover, which prevented most of the water from coming in direct contact with the soil. When the plant cover was intact its effectiveness in controlling erosion exceeded that of underground parts alone many times, and comparatively little relation was found between the quantity of underground parts and resistance to erosion. They found also that cover need not be living to be effective; any kind of cover protects the soil. In the course of their experiments they noticed aecidentally that a single elm leaf protected the soil below it until a column over 3 inches high, capped by the leaf, remained after the surrounding soil had been washed away. Undercutting eventually toppled the column. These experiments would appear to justify the use of a mulch in planting on eroded lands.

It is clear that since erosion is greatest at the surface the roots of woody plants have comparatively little to do with its prevention. As a matter of fact, when water washes the covering soil off and begins cascading over roots, they may only aggravate soil washing.

The surface layer of the soil can best be held in place by some sort of protective cover. This may consist of close-growing plants, litter, or a combination of the two. An effective protection for soil is afforded by a mat of grasses, which are among the best of all plants for erosion control. An equally good cover consists of an established forest and the duff produced by it. A third type might be made up of close-growing, thicket-forming shrubs and the litter produced by them or of a mat of entangled vines. Run-off and removal of soil are reduced to a minimum under such covers as these. It is almost unnecessary to mention that grass sod can be formed more quickly than can a thicket of shrubbery and that the establishment of a forest and forest litter takes longer than either of these.

2 Italic numbers in parentheses refer to Bibliography, p. 293. 


\section{EVALUATION OF PLANTS FOR EROSION CONTROL AND WILDLIFE}

Knowing that it is the surface layer of the soil that is susceptible to erosion and that root systems may therefore be largely neglected except as they serve to hold plants in place, the plant characteristics that are useful in erosion control may be indicated. In considering these it should be kept in mind that as land on which planting is to be done may have a certain value, species that produce a valuable crop as well as furnish erosion control should be used whenever possible. The qualifications of plants valuable in erosion control may be summarized as follows:

1. Such plants must be able to thrive under the climatic conditions and in the soil in which they are to be grown; and they must be able to hold their own in competition with other plants.

2. The farther their stolons, suckers, or rhizomes spread, or the more matted the condition of their growth, the greater space they will cover and the more soil they may be expected to hold in place. Thicket-forming or mat-forming plants or those that root from decumbent or declined branches, or that form suckers or root shoots are of this class.

3. With tall-growing plants, the more litter they produce and the greater the water-holding capacity of the litter, the more effectively will the plants control erosion.

4. The bushier the plants, the denser their foliage, and the nearer evergreen they are, the more protection from wind and rain they will offer to the soil.

5. The plants should be comparatively easy to propagate. If they can be purchased on the open market they are often easier to obtain for planting.

6. The more rapid-growing species will provide protection sooner than slower-growing species.

7. If plants furnish food and cover for wildlife, their usefulness is increased through the aid they give in conserving the valuable wildlife resource.

8. The possession of such characteristics as resistance to grazing, drought, insect damage, and diseases, and the ability to grow rapidly on and to tolerate many kinds of soil, particularly alkaline, acid, saline, barren, or sterile soil, is valuable.

9. The production of some crop, as timber, pulpwood, tannin, sugar, dye, comestible or ornamental fruit, or ornamental flowers enhances the value of erosion-control plants.

10. Resistance to fire or ability to coppice after burning or cutting enables plants to maintain a cover othewise easily destroyed.

Leopold (356) has discussed the properties that make plants valuable as winter cover for game. The first and most important character is dense winter foliage or thorns, preferably close to the ground Second, species easily propagated, and hence easy to establish, are those that can be propagated by stem or root cuttings. This gives, he says, a great advantage to such plants as Osage-orange, willows, grapes, plum, and roses. The third important property is vigor. This includes ability to reproduce by sprouts if cut or burned, ability to spread by means of root sprouts, and ability to make quick growth. Next comes resistance to grazing, drought, shade, and fire. Finally. 
cover plants should be unobjectionable from the agricultural standpoint. The striking similarity of Leopold's criteria for game-cover plants and the characters valuable in erosion control is at once apparent.

It has been pointed out that the restoration of cover, important alike for soils and for wildlife, is the objective sought in soil conservation as well as in wildlife conservation. The correlation of erosion eontrol with wildlife planting, therefore, is obviously an easy one to make. Furthermore, the utilization for wildlife production of submarginal lands upon which man-made erosion is unusually severe is a sound economic practice.

\section{PLANTING FOR SOIL AND WILDLIFE CONSERVATION}

It is obvious to those who have had experience in landscaping or forestry that the old maxim about putting all of the eggs in one basket applies very well to the planting of woody species. The most important rule to follow, whether planting for timber, pulpwood, erosion control, wildlife, or any combination of these, is that the species used must be varied-- that the planting must be a mixture, not a pure stand. This is true for several reasons (486), namely:

1. Solid stands of plants favor the rapid spread of disease and insect pests. Fungi, as well as insects, find it easy to travel from one plant to another of the same kind. In mixed plantings spread is slower and control is consequently easier. Isolation of individuals and groups from others of their own kind is the natural safeguard against infection.

2. Solid plantations of one species have for some time been known to result in depletion of the soil. Further, pure stands do not represent the maximum productive capacity of the soil.

3. Maximum interspersion of species ensures that all ecological niches will be filled. This results in a greater utilization of space and better erosion control. Competition between individuals, and therefore waste of energy, is at its highest in pure stands.

4. In planting for wildlife, variety is essential. What one species of plant may lack, another may possess. The effort should be made to attain a well-balanced habitat, approaching as nearly as possible the "orderly confusion of nature." Insectivorous birds are generally discouraged by pure stands, but encouraged by mixtures. The encouragement of such birds leads to greater control of injurious insects. In several European countries it has been found an economically justifiable practice to put up bird houses in forest plantations to attract insectivorous birds and thereby to ensure some control of insects. The idea is extending even to this country, but proper mixing of species in planting should make such a practice unnecessary.

It is very essential that careful planning precede actual field operations. Press of work and the need that considerable planting be done in a short time are often advanced as excuses for improper spacing, poor selection of site and species, and faulty organization of the work. Actually such excuses are never valid, for the planting seasons are preceded by periods sufficiently long to permit of careful planning. Because of the impossibility of obtaining sufficient planting stock of the kind desired, it may often be necessary to substitute 
other species, but this should be done most carefully. If the proper species for the required job are lacking, the planting should be partially or entirely deferred until the next season.

\section{PLANTING FOR WILDLIFE}

In planting for wildlife the aim is "**** the creation of such an environment that the maximum of food and cover is available at all seasons of the year for the particular birds or mammals considered" $(138, p .16)$. It follows that considerable care is called for in the selection of proper plant species. This is not a simple matter. Many species may be adapted for planting in a given area. Discarding those that are of little value in the control of erosion, we are left with a list of plants that have diverse values as food for wildlife.

To date, recommendations of a species for planting have rested upon the utilization of its fruit by birds or mammals. There is a difference between the importance of a certain item of food in the diet of a given bird and the value of a species of plant for wildlife in general. The one relates to the welfare of a particular species of bird, the other to the extent to which a plant is used by mammals as well as various species of birds. When the welfare of wildlife in general is to be considered we can scarcely limit our choice to a species of importance to the bobwhite alone, for example, although such use will naturally influence our choice. Furthermore, we can scarcely ignore other forms of wildlife even if we wish to encourage the production of only one.

McAtee (369) has said the importance of food items in the diet of a bird is not indicated by statements as to the frequency with which the items are taken. It is only under the percentage-by-bulk system (the proportion of one food taken to the total amount of all foods taken) combined with the counting of individuals, insofar as this is possible, that the nearest approximation to the truth can be made. Under the percentage-by-bulk system, he explains, comparison of one part of the diet with another or of the food of one species or group of species with that of another is possible.

But he goes on to say $\left(369, p_{0} 464\right),{ }^{6 * * * *}$ statements of the frequency of occurrence of food items in bird stomachs may perhaps be taken as rough indices of availability of the food or relish for it." And in the publications so well known to biologists engaged in wildlife management, he employs as his criterion of use the number of birds known to have eaten the fruits, buds, catkins, or other parts.

Examination of the record of the species of plants listed in this publication will show some to have been utilized by a great many species of birds and mammals. Such species should undoubtedly be given priority in making planting lists. Other species may have very poor records. This may be true often because they are actually not. used by wildlife. On the other hand, they may occur in a region from which only a few bird stomachs have been examined. They may bear fruits difficult to identify by ordinary methods of stomach analysis. The fleshy fruit of Prunus americana, for instance, has been found only once, in the stomach of a pine grosbeak, but observers have noted that many birds eat this fruit. 
It seems clear that records showing a given species to be much utilized can be accepted by technicians as proof of the value of the plant for wildlife. Poor records indicate either that a plant is worthless or that we do not know enough about it. If a species is found to have a very poor or limited record, recourse should be had to the records of the genus as a whole, exclusive of specific records, or to records of very similar species, for assistance in determining its value. Certainly, when in a genus of many species, such as Chrysothamnus or Aplopappus, few or no records of utilization by wildlife appear, it is not unreasonable to exclude the species from planting programs.

There are two available sources of information relative to the use of a plant by wildlife-stomach analyses and field observations. In most instances, the more reliable is a stomach analysis made by the Bureau of Biological Survey or other responsible agency. The lack of stomach records necessitates using reports of field observations. These are open to some criticism since accurate determination of the birds or mammals and plants involved is often not made, and since interpretation of the common names in which the records are so often made is neither easy nor certain. In this publication if the names were not thought to be clear, they have been referred to the genus. Cottam (138) has mentioned also that in an actual instance field observations alone were much less than 50-percent accurate in appraising food values in the diet of a bird.

The exact nutritive value of any given plant food has not yet been determined. We are yet scarcely far enough along to examine the chemical composition of various fruits and seeds of wild plants and their place in the diet of any animal. Hosley (290) has considered the chemical composition of some, and has noted the obvious fact that fruits may furnish vitamins. The staple value of acorns and the seed of conifers, such as pines, is well known. This field of investigation should indeed be a valuable one.

\section{HIGHWAY PLANTING}

The increasing use of vegetation for the beautification of highways makes it of interest here to mention that such work can be turned to the benefit of wildlife as well as to the control of erosion. Indeed, the conservation of soil on highway cuts can very profitably be planned with a view to beautifying the road.

Certain fundamental principles relating to highway planting have been clearly enunciated by Simonson, senior landscape architect of the Bureau of Public Roads. In the following statement he sets forth the basic ideas to be kept in mind in such work (513, pp. 172174):

The primary purpose of highway planting is to enhance the peculiar qualities in the views and scenery of the surroundings through which a highway passes so that the development within the highway limits will be properly consistent and appropriate to that which lies over the fence or beyond the highway borders, and will, therefore, present to the motorist the bost of the landscape qualities inherent in it.

The creation of landscape effects on the usually limited highway areas with little or almost no attention to the surroundings is not the correct approach and cannot be considered satisfactory roadside improvement. A systematic study of the native flora along and immediately adjacent to the highway will indicate 
the most appropriate plant materials to be used, and such an analytical process should develop selectlve appreciation of natural plantings upon the highways.

The ecological or natural landscape approach to the highway planting program aims to avoid the typical static, or garden-estate type of plantation design in favor of fitness with the more dynamic requircments of highway travel.

Nature is to be followed as closely as possible with fullest utilization of native materials or harmonizing types if the landscape development of highways is to proceed ***. It is imperative, therefore, that the landscape technician adopt the broadest ecological viewpoint concerning the planting phases of the landscape development of highways.

The use of shrubs bearing beautiful fruits automatically provides food for wildlife. As Howard (293, $p .103$ ) has mentioned, if roadside improvement designed primarily to improve the scenery is made with "due regard *** to ecological associations and as much diversity as is consistent with natural groupings $* * *$ * in the plantings, it will in all probability contribute materially to the increase of bird life in the immediate vicinity.

Plantings of species effective in erosion control provide excellent cover for wildlife. The danger of luring birds and mammals to highways where wildlife mortality is undoubtedly great can be obviated by placing plantings made for the production of wildlife food well back from the roadway. This is ordinarily done since on highway rights-of-way, plantings made too close to the road may easily become a hazard for motorists.

Highway plantings are generally given more than ordinary care. Fertilizers are often used to ensure that the plants start; and watering, pruning, and cultivating are commonly employed to assist them in growing and producing flowers or seed. Under such conditions the remarks on plant competition and succession in the section treating of the selection of species for planting may apply only partially or not at all.

The utilization of vegetation in highway planting is comparatively new, but is rapidly increasing in importance. A recent report for one State (1) mentions, for instance, that 700 miles of planting on main highway rights-of-way have nearly been completed. Future work may well be directed along the lines so clearly drawn by Simonson.

\section{PLANTS OF OBJECTIONABLE CHARACTERISTICS}

Certain species of plants possess characters that may partially or entirely preclude their use in many kinds of planting. A list of these would include plants that are:

1. Poisonous to man, either when taken internally or through skin irritations.

2. Poisonous to livestock, usually internally.

3. Secondary hosts to economically injurious fungi or insects.

4. Susceptible to the ravages of insects the control of which is difficult.

5. So exceedingly vigorous and aggressive as to crowd ont more valuable or useful species.

It is rare to find a situation in which plants possessing one or several of the above characteristics cannot be used. However, it may often be advantageous to substitute forms less objectionable, a procedure which is usually easy since the site is very unusual upon which at least two species of good character cannot be grown. 


\section{POISONOUS PLANTS}

Plants dermatitically poisonous to man ordinarily will not be planted, because collection of seed or cuttings cannot be made without exposure to the irritants. In many places such plants may be spontaneous. If they are of value in erosion control or as wildlife food or cover and particularly if they are sufficiently removed from habitations, they may often be left to perform a useful function.

The subject of livestock poisoning has been admirably treated by Chesnut and Wilcox (119) and by Marsh (392). Their authoritative generalizations are paraphrased here.

It may be stated as a general fact that the popular idea that range animals will voluntarily seek out poisonous plants and eat them from preference is not true. Animals seldom eat poisonous plants except as they are driven to do so by lack of other food. Almost all poisonous plants are distasteful to livestock and under ordinary circumstances will be avoided. Loco plants, which are herbaceous, are an exception to this rule.

The state of the local vegetation as affected by weather conditions ordinarily exercises considerable influence on the occurrence or nonoccurrence of poisoning. In the early spring certain poisonous plants may start to grow before the native grasses. If these poisonous plants are at all conspicuous or offer any considerable amount of succulent material, livestock may be tempted to eat them. The acrid, bitter, or otherwise disagreeable taste of such plants seems not to deter livestock. Sheep and cattle may often eat large quantities of plants that are extremely distasteful to the human palate.

In seasons of unusual drought, grasses on the range may become thoroughly dry while other plants remain green and tempting. It is obvious that livestock will be more apt to eat poisonous plants when such plants offer more tempting forage than the grasses. It is equally obvious that when grasses and other harmless forage plants are present in abundance and in good condition, sheep and cattle less often make the mistake of eating poisonous plants.

To prevent poisoning of livestock, reliance should be placed on prevention rather than remedies. Animals must be so well cared for that they will not be tempted to eat poisonous plants. They must be prevented from eating such plants by careful handling of the herds. It must always be borne in mind that animals seldom eat poisonous plants by preference, but that under starvation conditions they may be driven to do so with disastrous results.

Usually, in selecting stock for planting, nontoxic species can be chosen. In rare instances, however, certain toxic forms may be the only ones capable of doing the job. In such event, great care should be exercised to see that plantings will not be available to livestock. This can be accomplished either by fencing or by proper management of the herd.

\section{AGGRESSIVE PLANTS}

Whether to include or exclude a species that may become a pest is often a difficult decision to make. Extreme aggressiveness may be the character necessary for successfully controlling a given site, but if such aggressive species spread and become a nuisance because they are difficult to eradicate, the planter may often regret having used them. 
No species of woody plant is a pest throughout the country, and native species are far less troublesome than introduced ones. Symphoricarpos is considered a weed in places and a boon in others. Rubus and Smilas are a nuisance where they cover large areas. Lonicera japonica is a very pernicious weed in woodlands, Campsis radicans and Potentilla fruticosa in pastures. Ailanthus altissima has been known to supplant native forest trees, and Cytisus scoparius may run wild on sandy soil.

Such plants as these form cover for soil and some produce a secondary crop. Again, as with poisonous plants, common sense and caution should be used. If a species is really pernicious in a given region, if it easily escapes and quickly becomes widespread, and particularly if other species can be used, the better decision would be to discard it.

\section{PLANTS HARBORING FUNGI OR INSECT PESTS}

At the present time there are nine Federal domestic quarantines affecting interstate movement of plants and plant products. These quarantines have been established to protect crops and forests from pests of major importance. Most regulations permit movement after inspection or treatment of the material to ensure freedom from infestation. The recognition by planting technicians of the fact that certain plants may assist in spreading diseases or insects that may cause serious loss of farm crops or forest trees as well as the plantings themselves, is essential. Familiarity with State and Federal regulations before plans are made is very necessary, and the technician should cooperate in preventing the spread of pests.

The recognition of rust hosts is of particular importance. Among the rust fungi the separate development of spore forms on unrelated hosts has taken place. Approximately one-twelfth of the species of rust fungi exhibits this character of heteroecism. The completion of their life cycle depends on two host species, either or both of which may be an important or valued crop. It is thus evident that certain secondary hosts to economically important fungi must be eliminated from plans for planting woody species if the agricultural crop attacked by the fungus is of any importance in the vicinity of the planting. The more important woody species that act as secondary hosts are indicated in the list of woody plants.

One of the measures taken to prevent the spread of rusts is the eradication of the secondary host that is of less importance economically. Such eradication programs are now in effect under various State agencies and the Bureau of Entomology and Plant Quarantine. Any technician engaged in planting operations should consult with State and Federal plant quarantine officials before making actual plantings whenever there is any doubt as to the legality of the operations.

Eradication measures intended for the destruction of wild species known to harbor insect pests are also being carried on. Plants known to harbor a serious insect pest during that portion of the year in which nearby crops are materially damaged by that insect should be used with great discretion. Authorities of agencies engaged in control and eradication of pests should always be consulted. 


\section{SELECTION OF SPECIES FOR PLANTING}

\section{PRIMARY SUCCESSION}

The factors governing survival must be recognized when a plant is placed among others to compete with them for a place in the sun. These factors or survival values are measured in terms of species requirements, although we often state them by speaking of the tolerance of a plant for shade, sun, acid or alkaline soil, drought, and moisture. Because no experiments have been conducted, it has been assumed by some technicians that there is no scientific basis on which to judge the ability of one species to compete on the same ground and under the same conditions with another species. This is by no means true.

For at least 20,000 years in the northern United States, and for a much longer time in the southern part, the species comprising the flora of the country have been competing for position, settling themselves little by little into their respective ecological niches and associations. On any given area of ground there has grown a succession of associations of plants which, as they have contributed to the gradual modification of the soil (or rock) on which they grew, have eventually been replaced by plants of a different association. After sufficient time, an association of plants has appeared which, under the existing environmental conditions appears to be the best adapted to the area. This group is often known as a climax, and although it is recognized that a completely stabilized environment never exists, the climax regions for the country have been more or less accurately mapped. Associations of grasses are considered to be the climax for the Plains region; certain climax associations of deciduous trees appear in the eastern part of the country; evergreen trees constitnte a climax for the western coastal region; and there is a xerophilous association of succulents and leathery species that forms the climax in the deserts of the Southwest. It should be kept clearly in mind that every plant association, whether climax or preclimax, is the outcome of long ages of natural selection.

Enough work has been done to enable us to predict the climax for most areas with some confidence, but it may be many years before the date of the climax can be predicted, if that ever becomes possible. In a general way we know what species tend to occur together, and on what sites they are to be expected, in any given succession in any part of the country. Careful observation of a species in its native, undisturbed (or disturbed) habitat will usually demonstrate where and how it fits into its environment. According to Shantz $(504, p$. $357)$ :

A thorough understanding of the natural vegetation climax and of the secomdary stages leading to its re-establishment when it is once destroyed is the best basis for a revegetation and erosion-control program.

For many years plant ecologists have been engaged in determining the fundamental principles concerned with the initiation, development, and maturity of plant associations on given sites. The slow encroachment of lichens and mosses on bare rock, followed by gradual appearance of higher plants, the development of soil, and the invasion and succession of later associations tending toward a stable inter- 
relation between soil, vegetation, and climate has long been known. Similarly, the accumulation of debris causing submerged water plants eventually to give way before the advancing shore plants, and these in turn before the successful competition of swamp forests and later dry land forests, has been studied in considerable detail.

\section{SECONDARY SUCCESSION AND PIONEER SPECIES}

In primary successions, as delineated above, the orderly and slow process of replacement of one association by another proceeds under natural conditions. As a consequence of the activities of man, however, these successions are often violently interrupted for shorter or longer periods, and new plant associations very different in composition from the original ones may initiate secondary successions. These may be started as a result of fire, overgrazing, logging, cultivation, road building, coal stripping or other digging operations, blowing of sand, and even the activities of mound-building animals. The climax toward which they develop, however, is the same as would have been developed by the original vegetation. It is with these secondary successions that technicians have most to deal.

It is no longer new to point out that we are now dealing not with biologic areas as they were, but as man's activities have changed them. Students of plant ecology and geography have long recognized that existing vegetation and fauna do not represent original conditions. As time goes on, studies of original vegetation must deal more and more with old records, historical documents, travel sketches of earlier periods, early surveys, and consideration of the few remaining virgin areas. Original faunal and floral areas can be determined only in this manner. Man has been relocating species of animals and plants to suit himself from the time the first settlers arrived in the country. Brief consideration of the changing face of the land surface of the country shows this very clearly. Furthermore, it is obvious that because most vegetation has been disturbed by man, associations comprising secondary successions are the rule rather than the exception.

It is regrettable but true that it is not known with certainty just why one association gives way to another. It seems probable that changes in the substratum play a considerable part, but those changes cannot be measured accurately enough to say that at one time certain plants will succeed; at another, different plants will thrive. So far it has simply been noted that in any type of succession a series of what appears to be preparatory stages must precede the climax. It may also be noted that as a consequence, or perhaps as a parallel phenomenon, the food of wildlife and the fauna itself changes. Certain pioneer plants lead the way and very rarely persist through all stages to the climax. Conversely, climax species almost never act as pioneers. Edaphic factors appear to be very important in the preliminary stages of secondary successions.

In applying these facts to planting, where no further care is to be given to the plants, one may with reason select for use pioneer species that have demonstrated their ability to succeed on areas variously disturbed by man. This is of great importance. We see that under natural conditions the preparation of an area for occupation by climax species is undertaken by pioneer species. They do not last long, con- 
sidering the length of time required for the appearance of the climax stages; if they are planted, we can rely upon their being replaced, sooner or later, by other species. But the initiation of a secondary succession will ensure the control of erosion on a given area and the production of habitats useful for wildlife.

A list of pioneer species for various areas throughout the United States could easily be drawn up here. A much more certain manner of determining them, however, is to examine eroded areas where pioneers have already begun to grow. The identification of the species informs the technician what to plant. And, it may be emphasized that the pioneers observed on such places are the results of long ages of natural selection of a sort that permits the survival of only those best adapted to initiate successions. With proper interpretation of the results of such long-time, natural "experimental plantings" the reclamation of eroded land can be carried out with confidence.

With these ideas in mind a principle may be stated that any technician who wishes to plant woody species to control erosion would do well to remember; namely, that careful observation of local vegetational successions, coupled with accurate determination of the species involved, will often indicate the best means to employ. As Shantz $(504, p$. 355) has said: "Wherever one looks, nature has pointed the way to recovery."

We have in this country one vast testing ground, comprising many kinds of climate, soil, and site, wherein species have failed or succeeded for significantly long periods. As long as a species is planted within its known range of occurrence, in its proper site as determined by observation of its so-called preferences, and is intermingled with other species in a ratio and position approaching natural conditions, we may be satisfied that except for failures attributable to serious local variations in environment our plants will grow and thrive. Aldous and Shantz (9) point out that the natural or normal plant cover is a result of all the growing conditions of the area wherein it is produced. It is, therefore, an index or measure of the factors influencing its growth, and it serves as an indicator of the possibilities of producing other plants on the same land.

\section{NATIVE VERSUS INTRODUCED SPECIES}

A clear distinction should be made between crop plants that must ke planted and cultivated each year, or every several years, and woody plants, which are untended and uncultivated (if planted in the wild) and which must depend for their existence upon any ability they may have to compete successfully with the native species that will eventually grow around them or that are already there. In planting species on sites where they must be able to survive competition, it is hazardous to select plants other than those that have already shown them. selves capable of succeeding in similar sites. If all competition is to be removed through cultivation, then such an argument would necessarily be invalid. Erosion cannot be controlled by cultivation alone, however, and most sites needing revegetation with woody plants are those that are being retired from cultivation, not those on which cultivation is still to be practiced.

Many technicians engaged in planting apparently do not understand that our first choice of species for planting on a given site 
should be those that have already been tested for such a site; that is, species native to the region in question. Our second choice should be species that are not native; that is, exotic or introduced plants. If it is certainly known that there is no native species that can grow on a chosen site, then we are justified in turning to exotic forms. Clements $(121, p .360)$ summarized this: “**** nature is to be followed as closely as possible, and hence native materials alone are to be employed, preferably from the outset, but invariably in the final composition." Chapman (118) claims further that until additional data can be obtained we are justified in making large-scale plantings only on the basis of ecological principles applied to the native species of the region.

This should not be interpreted to mean that the introduction of a foreign species is inherently undesirable. It is recognized, of course, that the introduction of some non-native woody species has already been successfully accomplished, and these are excepted from the preceding statements. But large-scale plantings should be limited to species proved to be adaptable to a given area and known to be able. to compete with plants that now largely occupy the territory. In forest planting, Toumey and Korstian (5\%3) characterize the selection of exotics and species from widely different regions as very hazardous. In ornamental planting, where each plant is protected and given special protection, the use of exotics may be justified, but unless actual experimental plantings have been made or unless site factors can definitely be shown to be similar to those of the region from which the species is introduced, exotic species should be excluded from forest crops. The extensive use of Scotch pine and Norway spruce for instance, in the eastern United States is much to be regretted in the opinion of these workers, since results from such use are still problematical.

\section{FRUIT PRODUCTION}

Wherever dioecious species are used, if fruit production is desired, a few staminate (pollen-bearing) plants must be included in the planting. Monoecious plants, on the other hand, since both staminate and pistillate flowers are present on each bush, necessitate no such precaution. Examples of dioecious plants include Baccharis, Ilex, Maclura, Maprica, Shepherdia, Taxus, and some species of Juniperus.

There are, in addition, some species that are partly dioecious, that, is, some of the plants may be entirely staminate and some slightly polygamous. In the latter, sufficient staminate flowers are present on pistillate plants to ensure reasonably complete fertilization. The genera Celastrus, Aitanthus, Morus, Rhus, and Vitis, furnish species of this sort (619). With these, the addition of staminate forms to a planting may often be advantageous although not always necessary.

At present there is no way to distinguish readily the seeds that will produce staminate from those that will produce pistillate plants. Therefore, to ensure getting fruit-bearing plants it may be necessary to use cuttings only, selecting them mainly from pistillate plants. In reproducing such plants from seed, the proportion of staminate to pistillate plants is often unknown.

Other sorts of dioecism are known. Perfect flowers may often produce pollen that for various reasons may be more or less incapable 
of fertilization of the pistil in the same flower or even of those on the same plant. An instance of such a condition is found in the wild plums where one plant often gives rise vegetatively to a colony. The pollen in the flowers of the whole colony may be unable to effect fertilization, and it is thus necessary in planting for wildlife food, to ensure that stock planted is collected from at least several different colonies and well mixed before using. According to Paul B. Sears, who has experimented with plums, it is nearly always possible to induce better fruit production in one colony by introducing a few plants from a neighboring colony, or even by throwing flowering branches from a different colony into the first.

Production of fruit depends also on such environmental factors as temperature or cloudiness and precipitation during flowering. These conditions may very often be local, and certainly account in part for the patchy distribution of fruit production of the same species. Also, many plants that produce fruit freely in the sun will produce very little in the shade, as Corylus, Symphoricarpos, and Parthenocissus. For this reason where fruit for wildlife is desired, a variety of species, blooming at different times, is necessary for ultimate production.

THE CORRELATION OF SOILS AND PLANT GROWTH

Many statements that a given species will grow on a certain kind of soil will be found herein. These statements are based for the most part on observations of plants in their native habitats, made by many different workers. They are extremely general, the correlation of vegetation with soils being by no means certain. Soil studies that have been made deal with factors that are not directly related to plants, or else the relation of plants to such factors is not yet clear (363).

The distribution of some plants appears to depend directly on certain edaphic characters. Many species are almost entirely confined to acid or to alkaline soils. The near absence of legumes from very acid soils may be attributed to the inability of their symbiotic bacteria to succeed under acid conditions. Similarly, the ability of certain fungi to succeed under varying degrees of hydrogen-ion concentration may condition the ecesis of woody plants on the roots of which they form mycorrhiza. The presence of toxic substances, the release of which may depend also on acidity, may prevent a plant from growing on a soil that under different local conditions might easily support that plant. The break-down of litter, for example, is not at all understood. For such reasons as these, and for many others, we are far from having identified the factors in soil whose variations are responsible for the local variations in plant distribution.

Certain physical factors of soil, however, are worth mentioning here. Shallow soils on an impervious subsoil may endanger the stability of trees by restricting root growth. Heavy soils may act in the same way. Soils of spring-fed swamps and northern slopes are generally colder than other soils, and sandy soils and soils of southern slopes are generally warmer (573). Higher and lower soil temperatures have respectively a stimulating and retarding effect on plant metabolism.

$130186^{\circ}-39-2$ 


\section{DEVELOPMENT OF THE PLANT-GROWTH REGION MAP ${ }^{3}$}

The need for a map that designates zones or areas having fairly uniform growing conditions for plants was recognized when an attempt was made to discuss where in the United States different roses could be grown and also when recommendations for the planting of trees on city streets throughout the country were desired.

To show regions where the different types of roses could be grown with a minimum of attention a rose zone map was prepared and was published in the Atlas of American Agriculture (45) and in the American Rose Annual (17). It raised a storm of protest by growers and occasioned much discussion among them because roses were being successfully grown far beyond the zones indicated for each group. This success was due to the fact that special attention had been given to their culture, particularly to winter protection. Eventually it was generally conceded that the map showed what it purported to show.

A map was made as a basis for recommending street trees and was published in a Department Bulletin, Street Trees (4.17), and again in a Farmers' Bulletin, 'Trees for Town and City Streets (418). This map divided the country into 13 zones. The zoning was based on a combination of field studies in different parts of the country and a review of the literature of tree planting. Before the tree lists to accompany the map were completed it became evident that more zones would have been desirable but this limited number was what seemed. practicable at the time.

The aim in preparing these maps, and the later one appearing in this publication (fig. 1), is to delimit areas with growing conditions sufficiently similar so that a large proportion of the plants that will grow in any one part of each zone will grow reasonably well in all of it. This makes it possible to draw up lists of plants that can be recommended for growing in each region.

Factors influencing growing conditions are latitude and altitude, which have a direct bearing on temperature, frosts, and length of growing season as well as extremes of temperature; rainfall, totals and distribution through the year; humidity as influenced by rainfall and winds; soil type and character; and amount and intensity of sunshine. Often these factors change very gradually so that there is no sharp natural line of demarcation. In such instances almost arbitrary limits must be established in order that the regions shall not be too large to have reasonably uniform conditions throughout. Examples of areas thus delineated are those included in regions 15 and 16 and in regions 18,19 , and 20 . In each of these two groups of regions the changes are so gradual from north to south that it is difficult to know where to draw the separating line or lines, but the total difference between the northern parts and the southern appears to call for separation. In the absence of other marked factors the north and south limits of these regions have been determined by the characteristic farm crops of each.

It is seldom that the range of natural distribution of any two plants is exactly the same; nor is the range of successful cultivation of any two plants more likely to coincide. Although the lines on the growthregion map give the approximate limit of distribution of plants it

$\mathbf{3}$ This section was written by Furman Lloyd Mulford, associate horticulturist, Bureau of Plant Industry. 


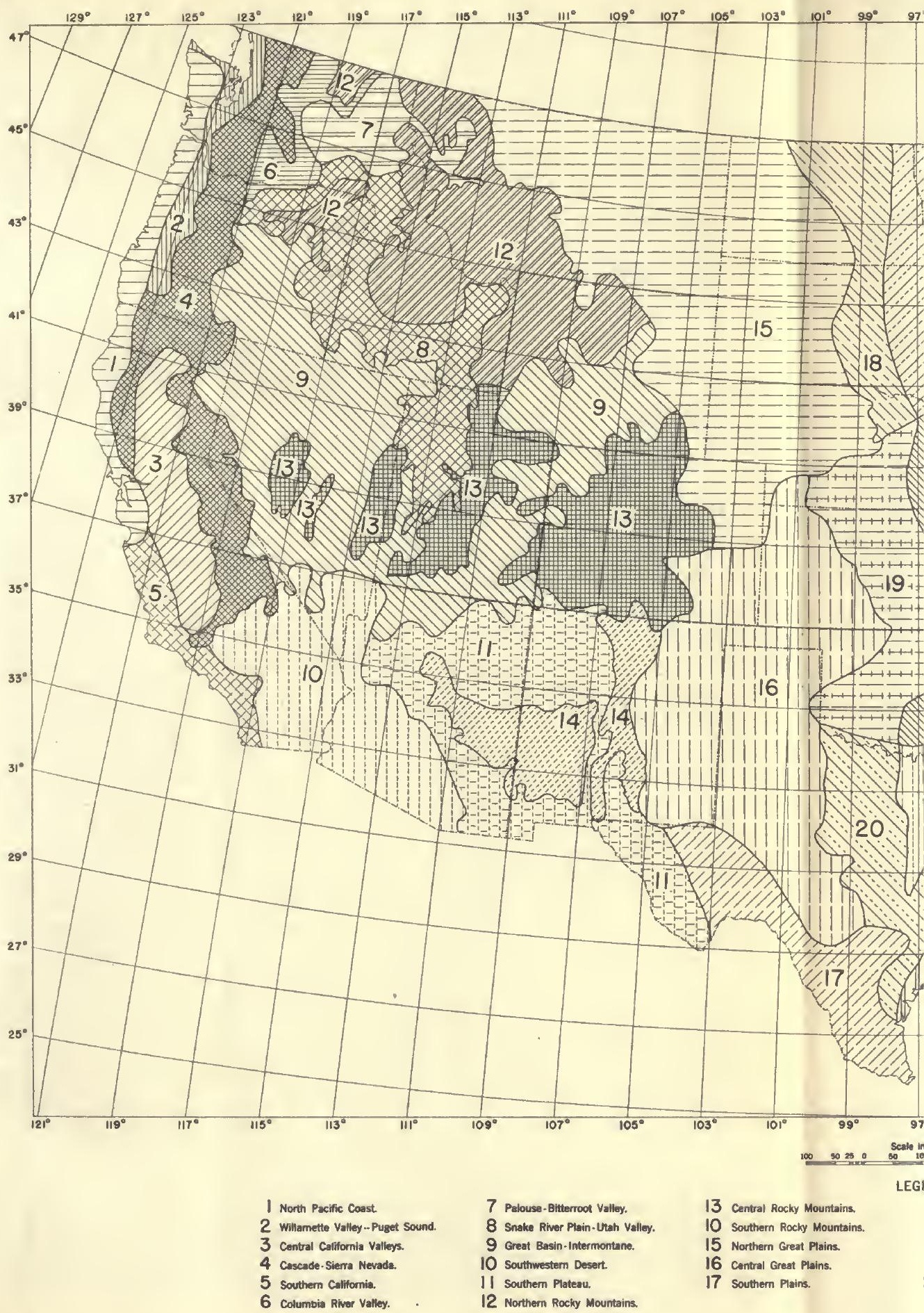


will be found that the natural distribution, or the area of usual cultivation, often does not coincide with the area that is shown on the map to be adapted to them. As a matter of fact, the growing of the plants may often occur beyond the area designated for them, or they may not be known over all the area suggested for them even though conditions are apparently satisfactory for their success. This overlapping of adjacent areas may be only slight, but again it may extend much beyond the zone lines.

It must also be recognized, however, that some plants will grow only under special conditions and that only in areas providing these conditions can they be expected to thrive. Bog, marsh, and water plants will grow only near or in water in whatever region they are found. Likewise plants adapted to dry knolls, ridges, or to sandy areas grow only in such locations, and those needing acid soils, alkaline soils, shade, or full sunlight can be expected to thrive only when those conditions are provided. Recommendations of plants having special requirements can be made for the different regions in the same way that plants thriving under more general conditions are listed, with notations concerning their special requirements.

When the 13-zone map was published it was recognized that some of the regions were too inclusive but for various reasons it was not deemed desirable to subdivide them at that time. Studies were immediately begun, however, looking toward making the regions smaller and more informing without going into too much detail. The number of regions was doubled, but as the study progressed it became obvious that important differences in plant reaction and plant associations would be ignored unless more regions were included, so the number was increased to 29 zones, then to 30 , and eventually to 32 .

The subdivision was begun by combining the known natural distribution of plants with regions of successful cultivation of trees, shrubs, and herbaceous perennials. Careful consideration was given to Weather Bureau maps of rainfall totals and distribution through the year and of temperatures, not only maximum and minimum but frost dates and length of growing season. These results were carefully checked with O. E. Baker, of the Bureau of Agricultural Economics, in relation to his crop-geography studies, and the resulting modifications were later made in the growth-region limits.

Subsequently the map was checked with the late Curtis F. Marbut, of the Bureau of Chemistry and Soils, and the zone lines were made to conform to the outline of soil types where there were no apparent discrepancies between the field studies and these modified outlines.

Since the original publication of the 32-zone map in 1922 there have been many opportunities to consult with students having intimate knowledge of relatively local areas and all such opportunities have been utilized to check the accuracy of details. This has resulted in a few slight modifications.

\section{PLANT-GROWTH REGIONS}

\section{FACTORS IN PLANT DISTRIBUTION}

There are three factors of great importance in the distribution of any given plant. Each may act separately, although they commonly operate in combination. They are climate, soil, and time. 
Climate, which is an expression of temperature and moisture conditions, is without question of first importance. It is, in fact, a summary of factors pertaining to water and to heat. Such factors may be further subdivided into amount and distribution of water or heat; or where the two interact the terms of the analysis are evaporation, kind of precipitation, and humidity.

Soil, which involves both chemical and physical structure, is undoubtedly of second importance. Plant distribution within areas of uniform climate may be modified within each area by soil factors, but it seems obvious that the climate plays the major role in preventing vegetation from spreading. The interaction of soil and climate (the latter is often a contributing factor in the formation or modification of the former) may be of great importance. With sufficient rainfall, for instance, the leaching out of certain bases may produce an acid or neutral soil; with insufficient rainfall the soil may be alkaline.

Both the preceding factors may operate provided sufficient time has elapsed. A newly-formed species must have time to spread before its range can be delimited by changes in climate or soil. If a species is young, its climatic and edaphic boundaries may not yet be operating. In its distribution, time is still a very important factor. If a species is old enough so that its further distribution is limited by factors of climate or soil, time has ceased to be an important factor in its present distribution.

It is true that climatic and soil factors may be uniform or may change very slightly over a given area of country, as in any of Mulford's plant-growth regions. Knowing empirically that a number of cultivated plants succeeded about equally well throughout such a growth region, we are reasonably safe in assuming that in general the range of a native species can coincide with boundaries of such growth regions provided it has had the necessary time to spread. It is significant that where there is a large number of endemics and where great variation in characters is evident the growth-region boundaries do not coincide at all well with limits of distribution, but where there are few endemics and variation is much less, the boundaries coincide much better.

The correlation of Mulford's plant-growth regions with natural vegetation areas has as yet not appeared in print. The present author has been interested in the idea for the last 5 or 6 years, has checked a few species with care, and a great many in a general manner. The subject cannot be dealt with adequately here, but it can be said that in a general way correspondence of the lines bounding the range of a given woody species with the lines bounding Mulford's plant-growth regions is very close. Correspondence of the growthregion lines with climatic and soil boundary lines is also close, where either the temperature, precipitation, or soil condition, or any combination of them, acts as a limiting factor in plant distribution.

A line bounding a growth region may be considered to consist of series of attached shorter lines, each representing a change in soil condition, in average precipitation, in average temperature, or some other change displayed by plant distribution. On the map (fig. 1), the lines must be considered not as sharply delimiting one region, but as being drawn to separate two regions differing in one or more 
factors of the environment. They take no cognizance of local physiographic areas, which may themselves cause a change in soil, temperature, or rainfall. Major physiographic areas only are recognized. In other words, the map is generalized.

Vegetation areas, as they can be delineated from the notes of old surveyors and travelers, are more or less understood, but growth areas must be better and better known as we proceed to apply ecological principles to land use. Anyone thoroughly familiar with local conditions in a smaller area, such as a county or even a State, can point at once to places on Mulford's map where the conditions are not as represented. Mountain tops in region 11, for instance, should all be characterized as 14, with the growing conditions of which they more nearly coincide. But the expression of more or less average conditions over the whole country is fairly accurate.

In the following characterizations of conditions in the growth regions, three main items are included for each: (1) The climate, expressed in terms of Thornthwaite's climatic provinces (5\%0), (2) the length of the growing season, that is, the average number of days between the last killing frost in the spring and the first killing frost in the fall, and (3) the average annual number of days with snow cover. All three items have a considerable influence upon the growth of plants.

\section{THORNTHWAITE'S CLIMATIC PROVINCES}

Consideration of the map showing climatic regions superimposed on plant-growth region (fig. 2 , in pocket) or of Thornthwaite's original work $(5 \% 0)$ will show the climatic provinces to be characterized by three factors; humidity, temperature, and seasonal distribution of precipitation. The combination of these three forms a climatic province.

The five major humidity provinces are characterized as $\mathbf{A}$ (wet), B (humid), C (subhumid), D (semiarid), and E (arid). To determine them, the procedure was as follows: The total monthly precipitation divided by the total evaporation was determined for every station whose temperature and precipitation records extended through a range of 10 years or more. The sum of the 12 monthly $\mathrm{P}-\mathrm{E}$ ratios was called the $\mathrm{P}-\mathrm{E}$ index, or the precipitation effectiveness of the station. Through field observation and study of vegetation maps and monographs the five major humidity provinces were recognized and defined. Where the P-E index was 128 and above, the humidity province was designated as A (wet). Similarly, P-E index 64-127 defines B (humid); 32-63, C (subhumid); 16-31, D (semiarid); and less than 16, $\mathrm{E}$ (arid). Characteristic vegetation for $A$ is rain forest; for B, forest; for C, grassland; for D, steppe; and for $\mathrm{E}$, desert.

Four subtypes were recognized:

$$
\begin{aligned}
\mathbf{r} & =\text { moisture abundant at all seasons. } \\
\mathrm{s} & =\text { moisture deficient in summer. } \\
\mathrm{w} & =\text { moisture deficient in winter. } \\
\mathrm{d} & =\text { moisture deficient at all seasons. }
\end{aligned}
$$

The determination of the four subtypes depends upon the relation existing between the $\mathrm{P}-\mathrm{E}$ index and the sum of the $\mathrm{P}-\mathrm{E}$ ratios of summer or winter, depending upon which is greater. 
The limiting effect of temperature on plants was expressed in the same manner. The coefficient for temperature efficiency Thornthwaite called the T-E ratio. The sum of the 12 monthly ratios for any station he called the T-E index. Determining by empirical means an equation that gave the poleward limit of tundra a T-E index of zero and the poleward limit of the tropical rain forest and savannah a $\mathrm{T}-\mathrm{E}$ index of 128 (which was the same as the $\mathrm{P}-\mathrm{E}$ index of the arid margin of the rain forest), six temperature provinces were defined as follows:

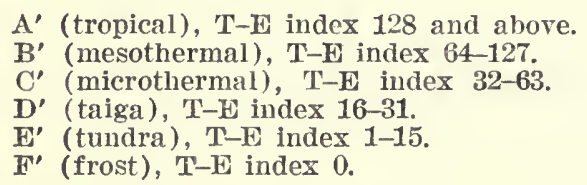

The sixth province rarely occurs in the United States.

Where temperature efficiency is adequate, variations in precipitation effectiveness establish the primary climatic boundaries; otherwise temperature efficiency is the limiting factor and determines the boundaries. The combination of the two produces a climatic province, in which various combinations of temperature effectiveness, precipitation effectiveness, and seasonal distribution of precipitation are possible, as shown in figure 2.

\section{LENGTH OF THE GROWING SEASON}

The figures for the length of growing season are taken from the Atlas of American Agriculture (45). Reference to the map showing average annual frost-free season will show any portion of the country to be included between lines that indicate the average length of growing season. Between any two such lines is an area wherein the average annual frost-free season changes with the distance from any designated line. It is obvious that an average or mean cannot vary, but it is equally plain that it may be different in one place from what it is in another. Therefore, in the characterizations under each region when the statement is made, for instance, that the average is from 10 to 20 in the northern portion and from 40 to 50 in the southern, it is meant that in the northern portion of the region in question the average of the extreme north may be 10 , but at a short distance south it may be 20 . In the southern portion likewise, the average may be 50 in the extreme south and a certain number of miles north only 40 . But it should be clear from this example that the growing season in the northern portion, changing in length from one place to another, varies from 10 to 20 and that the growing season of the southern portion varies likewise from 40 to 50 .

\section{SNOW COVER}

The figures for number of days with snow cover are taken from the Atlas of American Agriculture (45). Here, as in the discussion of the growing season, the average annual figure is said to vary. Again it is obvious that averages do not vary, but may change with distance. When it is said, for instance, that the average annual number of days with snow cover is from 1 to 10 , it is to be understood that the average figure changes with distance; that somewhere 
in between the lines expressing 1 and 10 will be places where the average may be $2,3,4$, or any number between 1 and 10 .

With this explanation, the climatic characters of each region may now be considered very briefly, bearing in mind that the values given are averages, not absolute figures. Study of the two maps (figs. 2 and 3 , in the pocket) may assist in a better understanding of the climate and soil in any given plant growth region. In figure 2 the climatic regions of Thornthwaite (in color) are superimposed on Mulford's plant-growth regions (hachured). In figure 3 the important soil regions (in color) are superimposed upon Mulford's plantgrowth regions (hachured).

\section{CLIMATES OF GROW'TH REGIONS}

\section{REGION 1, NORTH PACIFIC 'COAST}

Climate wet, microthermal, with adequate precipitation at all seasons in all portions, except for two areas with a summer deficiency, one extending for 100 miles south of the Oregon-California line, the other extending the same distance north from San Francisco Bay. Between these two areas is a mesothermal area of some 150 miles in north-south extent. Fogs are frequent and winter rainfall is heavy. The lowest temperatures are $22^{\circ}$ to $24^{\circ} \mathrm{F}$. in the north, to about $32^{\circ}$ in the south.

The average annual growing season is from 210 days to less than 90 days in the higher northern portions and more than 240 days in the extreme south. The average annual number of days with snow cover ranges from 1 to 10 over most of the region, increasing to as many as 60 in the central portion.

BEGION 2, WILLAMETTE VALLEY-PUGET SOUND

A humid, microthermal climate throughout, with adequate precipitation at all seasons in the north, but with a summer deficiency south of the Columbia River. Summers warmer and drier than those of region 1. Commonest low temperatures range from $10^{\circ}$ to $20^{\circ} \mathrm{F}$.

The average growing season is 210 days in the south and 150 days in the north. Average annual number of days with snow cover ranges from 1 to 10 .

REGION 3, CENTRAL CALIFORNIA VALLEYS

A subhumid, mesothermal climate throughout except for the semiarid to arid southwestern third. Precipitation is deficient in the summer through the northern two-thirds but deficient at all seasons in the semiarid to arid third. Winters mild; lowest temperature $22^{\circ}$ to $24^{\circ} \mathrm{F}$., with slightly higher temperatures on the hillsides.

Average annual frost-free season more than 240 days. Number of days with snow cover less than 1 annually.

REOION 4, CASCADE-STERRA NEVADA

A mountainous region where conditions vary with elevation and slope, the eastern side being drier than the western side. Southward the eastern side is decidedly arid; northward less so. The 
western side varies from wet to humid. Precipitation is adequate at all seasons in the northern portion but deficient in summer from central Oregon southward. The climate is microthermal in the northern portion, varying to mesothermal in the more southern part.

Average annual number of days with snow cover ranges from 10 to 60 , increasing with altitude; more than 60 at very high elevations. Average growing season is less than 90 to 150 days, somewhat shorter northward and on the eastern side and decreasing with altitude.

\section{RHCAON 5, SOUTHERN CALIFORNIA}

Climate subhumid, mesothermal, with a summer deficiency of rainfall northward. Southward the climate becomes semiarid with a rainfall deficiency at all seasons.

Average growing season 210 to more than 240 days. Snow cover is rare.

\section{REGION 6, COLUMBIA RIVER VALLEY}

In the north subhumid; in the south semiarid; or arid in the southeast corner. A microthermal climate with a deficiency of rainfall at all seasons.

Average annual number of days with snow cover 10 to 60 , lowest southward; highest, northward. Average annual growing season, 120 to 150 days.

\section{REGION 7, PALOUSE-BITTERROOT VALLEY}

A microthermal climate, varying from semiarid on the extreme west to subhumid in the central portion, humid in the central part of the narrowest portion, and subhumid in the extreme eastern portion. Rainfall deficient at all seasons except in the very center of the area where it is deficient during the summer only.

Average annual number of days with snow cover 10 to 90 , the southern half with 10 to 30 , but with the number increasing northward. Average annual growing season 180 days in the south to 90 days in the north or at higher elevations.

\section{REGTON 8, SNATE RIVER PLAIN-UTAH VALLEY}

Northward generally subhumid, passing to semiarid and arid southward; microthermal and with a deficiency of rainfall at all seasons.

Average annual number of days with snow cover 10 to 30 in the northwestern portion, 30 to 60 most common, especially southward. Average annual frost-free season 90 to more than 180 days, shorter with altitude, longer near large bodies of water and in the northern portion.

\section{REGION 9, GREAT BASIN-INTERMONTANE}

Generally semiarid, microthermal, with a deficiency of rainfall at all seasons, but with local arid portions, especially in the southwestern part.

Average annual number of days with snow cover, 30 to 60 in the larger western and southern portions; 60 to 90 days in the northern half of the eastern portion. Average annual frost-free season less than 90 days in the northwestern portion; between 90 and 120 in cen- 
tral and western Nevada, and between 120 and 150 on the east side of the Sierras; in the southernmost portion more than 240 days along the Colorado River, increasingly shorter farther from the river to less than 90 days, depending upon elevation.

\section{REGTON 10, SOUTHWESTLERN DESERT}

Arid, mesothermal, with a deficiency of rainfall at all seasons. Growing season averages more than 240 days annually, locally somewhat less with high altitude.

REGION 11, SOUTHERN PLATEAU

Climate semiarid in the northern and southwestern portions to arid in the south-central and southeastern portions; microthermal in the northern portion, elsewhere mesothermal; rainfall deficient throughout.

Annual number of days with snow cover averages less than 1 in the southern and western portions, but ranges from 10 to 30 in the northern part. Proximity to mountains increases the figure locally. Annual growing seasons range from 90 to 150 days in the north, or with altitude, to more than 240 days in the south.

\section{REGION 12, NORTHERN ROCKY MOUNTAINS}

Great variation because of elevation and exposure. Generally subhumid except for the semiarid western extension and extreme eastern and south-central portions; microthermal and with an all-season deficiency of precipitation except in the extreme northwest where rainfall is adequate at all seasons.

Annual number of days with snow cover ranges from 30 to over 120 , the number increasing with altitude. Somewhat less in southcentral Idaho and the Blue Mountains. Average frost-free season generally less than 90 days; or with decreasing altitude, longer.

\section{REGION 13, CENTRAL ROCKY MOUNTATNS}

Climate similar to that of region 12 , but temperatures for the same elevation about $7^{\circ}$ warmer. Generally arid to semiarid at lower elevations, approaching subhumid to humid climate at higher elevations; microthermal, with rainfall adequacy at all seasons reached with altitude.

Annual number of days with snow cover, 30 to 120 , increasing with altitude. Average annual growing season less than 90 days; or at much lower elevations, longer.

\section{REGION 14, SOUTHERN ROCKY MOUNTAINS}

Climate similar to that of region 13 , but temperatures for the same elevation about $6^{\circ}$ warmer. Arid or semiarid at low elevations to subhumid or humid at higher ones; microthermal except for the mesothermal southeastern portion. Precipitation deficient at all, seasons except at very high altitudes.

Average annual number of days with snow cover, 10 to 60, increasing with altitude, but fewer southward. Average frost-free season 
in the western section 210 to less than 120 with altitude; in the eastern section from 180 in the south to less than 90 in the higher parts of the extreme northern portion.

REGION 15, NORTHERN GREAT PLAINB

Except for the subhumid eastern portion and the Black Hills, semiarid throughout; microthermal and with a deficiency of rainfall at all seasons. In the Black Hills, with altitude a humid microthermal climate occurs, with adequate precipitation at all seasons.

Average annual number of days with snow cover 30 to 60 in the south, but 60 to more than 120 over most of the central and northern portions, increasing northward. Average growing season 110 to 120 days in the extreme north, 120 to 150 in the south and southwest, and 90 to 120 in Wyoming, northwestern South Dakota, southwestern North Dakota, and southeastern Montana. Extremely cold in winter, usually $-30^{\circ}$ to $-40^{\circ} \mathrm{F}$.

\section{REGION 16, CENTRAL, GREAT PLAiNg}

Climate warmer than that of region 15 and with greater evaporation. Generally semiarid except for the subhumid northeastern and southeastern portions; microthermal in the northern fringe and in the northeastern and southeastern portions, elsewhere mesothermal; precipitation generally deficient at all seasons except in the northeast and southeast where there is a summer deficiency only.

Average annual number of days with snow cover from less than 1 in the extreme southern portion to 30 to 60 in the extreme north. Average growing season 150 days in the north to 210 days in the south.

REGION 17, SOUTHERN PLAINS

Semiarid, except for a small arid area west of the mouth of the Pecos River; mesothermal, with rainfall deficient at all seasons. Average annual growing season 210 to more than 260 days, the longer season southward. Evaporation high throughout.

REGION 18, NORTHERN BLACK SOILS

Subhumid, except for the extreme semiarid northwestern portion; microthermal, rainfall deficient at all seasons. Intermediate in moisture between regions 15 and 21 .

Average annual number of days with snow cover from 30 to 60 in the south to over 120 in the north. Average annual growing season 110 to 150 days, or slightly more in the extreme southern portion.

\section{REGION 19, CENTRAL BLACK SOILS}

Subhumid throughout; microthermal in the western portions, mesothermal in the eastern; precipitation deficient at all seasons in the northern portion, in summer in the southwestern and west-central portions, but adequate at all seasons in the eastern portion. Sudden variations common in winter; hot winds often blowing in summer; moisture conditions intermediate between those of regions 16 and 22 . 
Average annual number of days with snow cover from 1 to 10 in the extreme south to 30 to 60 in the extreme north. Average annual frost-free season from 150 days northward to 220 days southward.

\section{REGION 20, SOUTHERN BLACK SOILS}

Subhumid and mesothermal throughout; precipitation deficient at all seasons in the northwestern portion, adequate at all seasons in the eastern fringe and southeastern portion. Intermediate in moisture conditions between regions 16,25 , and 29.

Average annual number of days with snow cover, 1 to 10 in the north to less than 1 in the south. Average frost-free season, 220 to more than 260 days, longest southward.

\section{REGION 21, NORTHERN PRAIRIES}

Subhumid, microthermal; precipitation deficient at all seasons in the north, changing to adequate at all seasons southward; drying" winds and frequent droughts of more than 30 days occur in the western portion.

Average annual number of days with snow cover from 60 to 90 in the south to more than 120 in the north. Average annual frost-free season from 100 days in the north to 160 in the south.

\section{REGION 22, CENTRAL PRAIRIES}

Northwestern portion and western fringe subhumid, remaining portions humid; northern portion microthermal, southern mesothermal; precipitation adequate at all seasons throughout.

Average annual number of days with snow cover 30 to 60 except in the southern part of the western portion, where it decreases southward, ranging from 1 to 10 . Average growing season 150 to 160 days in the northern portion to 180 in the southeastern portion and 230 in the extreme southwestern portion.

REGION 23, WESTERN GREAT LAKES

Western portion subhumid, eastern portion humid; microthermal; rainfall adequate at all seasons.

Average annual number of days with snow cover, 60 to 90 in the southern and southwestern portions to more than 120 in the northerm and northeastern portions. Average annual growing season 100 days in the north to 150 days in the south, or in the southwest, 170 days. Upper Peninsula of Michigan, 110 to 140 days.

\section{REGION 24, CENTRAL GREAT I AKES}

Humid, microthermal, with adequate precipitation at all seasons. Winter temperatures more moderate than in region 23.

Average annual number of days with snow cover from 60 to 90 in the southern half, from 90 to 120 in the northern half. Frost-free season averaging 110 days in the north to over 150 in the south longest close to the lakes. 


\section{REGION 25, OZARK-OHIO-TENNESSEE RIVER VAILEYS}

Humid, mesothermal, with adequate precipitation at all seasons. In the extreme southwestern portion subhumid. Much alternatei freezing and thawing in winter.

Average annual number of days with snow cover, 10 to 30 in the north, 1 to 10 in the south. Average annual frost-free season 160 days in the north to 200 in the southeast and 240 in the southwest.

\section{REGION 26, NORTHERN GREAT LAKES-ST. LAWRENCE}

Humid, microthermal, with adequate precipitation at all seasons. There are two local portions in northern and southern New York that are wet rather than humid.

Average annual number of days with snow cover, 90 to 120 in the southern portions to more than 120 northward. Average annual growing season less than 100 days in the north and at higher elevations to about 130 in the south.

\section{REGION 27, APPALACHIAN}

Northern portion humid, microthermal; southwestern and southcentral portions humid, mesothermal. Local areas of wet microthermal climates are distributed along the backbone of the mountains, and there is a wet mesothermal area in the southeastern portion.

Average annual number of days with snow cover 1 to 10 in the extreme southern portion to as much as 90 in the extreme north. In the central portion 30 to 60 days is commonest. Average annual frost-free season 130 days in the north, especially at higher elevations, to 210 days in the extreme southern portion. Throughout, the season is shorter with increasing altitude.

\section{REGION 28, PIEDMONT}

Generally humid, mesothermal, but microthermal in the extreme northern portion, with adequate precipitation at all seasons. Warmer than region 27.

Average annual number of days with snow cover 1 to 10 , decreasing southward to less than 1, increasing northward from 10 to 30 . Average annual growing season from 170 days in the north to 220 or more in the south, longer coastward.

\section{REGTON 29, UPPER COASTAL PLAIN}

Humid, mesothermal, rainfall adequate at all seasons. Average annual number of days with snow cover less than 1 in the southern half, 1 to 10 in the northern half. Growing season 200 days in the north to 260 days in the south, longer coastward.

\section{REGION 30 , SWAMPY COASTAL PLAIN}

Humid, mesothermal, with adequate precipitation at all seasons except in the extreme west where it gradually diminishes to a deficiency at all seasons. In central Florida the climate is subhumid, rather than humid. 
Average annual frost-free season 230 days in the extreme northeast to more than 260 days in the south-central and southwestern portions. Snow cover rare.

REGION 31, SOUTH CENTRAL FLORIDA

Subhumid, mesothermal, with rainfall adequate at all seasons. Killing frost likely on the average in half the years; frost-free season well over 260 days. Snow cover extremely rare.

REGION 32, SUBTBOPICAL FLORIDA

Humid, tropical, with adequate rainfall at all seasons. In the north, killing frosts are apt to occur in half the years; in the south there is no record of a killing frost.

\section{NITROGEN-FIXING BACTERIA}

Technicians engaged in planting for erosion control often very wisely choose species that are able, by means of a symbiotic relationship with a species of Rhizobium to enrich the soil by the addition of certain nitrogen compounds. With some exceptions, such plants belong to the Leguminosae. Because the soils left after considerable washing has taken place are often poor and unproductive, the incorporation of nitrogen is of great importance in their reclamation. Lespedezas, alfalfa, vetch, clover, acacias, black locust, and Scotch broom are legumes and have been advocated for use particularly on account of their root associations with nitrogen-fixing bacteria.

The decay of various parts of the legume as well as of the root nodules housing the bacteria results in the addition of nitrogen compounds to the soil. Vetch, peas, beans, clover, and other annual plants, or those on which nodules are produced each spring to develop through the season and decay in the autumn enrich the soil to the extent of about 100 pounds of nitrogen per acre annually if the crop is plowed under. In black locust, Sophora, some species of Acacia, and others, the nodules may last for more than one growing period, and often become woody. Part of the time during the life of the nodules the nitrogenous compounds may be used by the plant.

Not only do members of the Leguminosae form these symbiotic relationships, but they are formed also by shrubs and trees of the genera Alnus, Ceanothus, Elaeagnus, Shepherdia, and Myrica, besides members of the Cycadaceae and Podocarpaceae. Members of the latter two families will, of course, rarely be used to any great extent in planting in the United States.

The nodules formed in nonleguminous plant roots are by some believed to be caused by species of Rhizobium, although this is denied by others. But that the nodules of nonlegumes play a part in the fixation of atmospheric nitrogen very similar to that performed by legume nodules appears to be fairly well established. Cross-inoculation of legumes with strains from Alnus and Elaeagnus is claimed to have been accomplished successfully, but ordinarily certain strains or races are specific for the host-plant species. Inoculation of planting sites with the proper strain is an established farm practice although the bacteria are probably distributed as wind-borne dust 
under natural conditions. The rotation of legumes with nonlegumes for soil enrichment is also a common practice. In Taiwan (Formosa), according to $\mathrm{R}$. Kent Beattie, alders are included in the rotation of rice fields in much the same manner, presumably for the benefit derived from the nitrogen-fixing bacteria of the shrub's roots.

In general, plants producing such nodules are able to live in very poor soils, since lack of nitrogen is not as great a factor in their success as it may be for other plants. For this reason the leguminous plants are particularly satisfactory for planting on poor, eroded land, the soil of which will with difficulty support other plants. Many legumes are unsuccessful on acid soils, doing better on neutral or alkaline soils, where calcium appears to be of importance in the nutrition of the bacteria of the nodules. This is not always true, however, as in Lupinus.

There are a number of exceptions to the rule that nodule formation caused by Rhizobium occurs in all leguminous plants. Those of interest here are Cercis canadensis, Gleditsia triacunthos, and Gymnocladus dioica (13). The question at once arises whether these species enrich the soil since they bear no nodules. According to L. T. Leonard, of the Bureau of Plant Industry, as well as other authorities, they probably do not. The synonymity of legumes and nitrogen fixers is by no means certain; possibly there are many more legumes that do not fix nitrogen.

\section{EXPLANATION OF THE LIST}

\section{SCOPE}

In the alphabetical list are considered all species of woody plants known to grow in the continental United States and on the California islands, with the following exceptions:

1. Plants of the southern, subtropical portion of Florida.

2. In general, species not woody throughout; that is, woody only at the base.

3. Species not native to the United States, unless definitely known to have become naturalized to such an extent as to prove their ability to compete with native species.

4. The cacti, since, as Britton and Schafer ( $\% 1)$ have said, stem structure is such that no criterion other than size is available to determine which to include as trees or shrubs and which to regard as herbs."

5. Species of parasitic or partially parasitic habit, as Phoradendron, Razoumof skya, Pyrularia, since growing or using them presents difficulties that in effect exclude them from planting programs.

6. Hybrid forms, except for occasional mention under the parent species.

\section{LATIN NAMES AND SYNONYMS}

The species making up the list of woody plants have been selected from two sources: (1) Regional and local floras, and (2) monographs of families or genera. But from whatever manual or monograph the names were taken, a decision had to be made regarding the proper name to use, since taxonomists are not always agreed on the correct technical name. Furthermore, manuals published earlier in the century, but still in common use, employ names not in accepted

\footnotetext{
4 Cacti, especially the opuntias, have been used with considerable success in controlling gully heads. The stem sections are simply dumped into the eroding gully, and on taking root they form thickets that contrlbute materially to the control of the eroding soil. Many species are very important as a source of food and water for desert animals. As some 20 specles of mammals and a like number of birds have been observed to eat cacti, their importance to wildlife appears to be considerable.
} 
use under the International Code of Botanical Nomenclature. To avoid confusion, all important synonyms are included in the list in their proper alphabetical order with a cross reference to the current preferred name. The species in this list may readily be found, therefore, no matter with what code or manual one may be most familiar.

It might be mentioned that synonyms often show relationships otherwise hidden. As an example: Vitis helleri, the roundleaf grape, was first described as a variety of $V$. rotundifolia, the muscadine grape. In the synonymy under Vitis helleri one finds $V$. rotundijotia var. helleri, which indicates that $V$. helleri is close enough to $V$. rotundifolia to have been considered a variety of it. Other examples could be cited to show the same thing, but this will suffice to indicate that records of utilization by wildlife may often have been applied, especially in earlier days, to both the original species and its variety. Thus 28 species of birds are recorded as having eaten $V$. rotundifotia. None is recorded for $V$. helleri. But that the birdstomach record should apply partially to the latter species, changed recently from its varietal rank, is fairly certain. In examining plant characterizations, particularly with respect to wildlife foods, technicians will do well to remember the possible interrelationships expressed in the synonymy.

\section{VERNACULAR NAMES OF PLANTS}

The problem of choosing vernacular names for species of plants is a difficult one. The very old prejudice against the use of a Latin name is as pronounced as ever, and technicians are universally faced with the necessity of using a so-called "common name" in order to be understood. And yet no exact or careful work can ever be done unless a name is used that applies to one species of plant and no other. The tremendous numbers of vernacular names of plants in common use do not satisfy this requirement. If they could be standardized, as the names of birds have been so that there would be no question of the identity implied by a name, there would be less confusion.

Very laudable attempts to standardize vernacular names have been made, but we are still a great way from completeness. Not the least reason for this is that no committee having the sanction of botanists throughout the country has ever been organized to deal with the matter. If the botanists of the United States were to deal with common names somewhat after the nanner in which the botanical congresses have dealt with Latin nomenclature, perhaps in time definite and complete understanding might be achieved.

Standardized Plant Names (15) treats horticultural plants for the most part. This and Sudworth's Checklist of the Forest Trees of the United States (554) are the best attempts made so far to choose standard vernacular names for woody plants. Although in each there are names that could be much improved, yet by and large the names presented in them have much to recommend them. Many names of woody plants from these two sources have been used in this publication.

A great many names have been taken from Dayton's Important Western Browse Plants (158). The various manuals of the flora 
of different sections of the country have supplied others. A few names have been collected by the author, more notably in the Southwest where, incidentally, a great many plants as well as towns, river's, and mountains, are called by Mexican or Spanish names.

Nevertheless, there yet remain several hundred species that do not bear distinctive vernacular names. They appear in the list with no other than a Latin name, the author believing that one person is not armed with sufficient authority to coin names for them.

Many species appear under a number of different vernacular names, some of which may also be applied indiscriminately to various other species. In this work the selection of the most descriptive name has been made after careful consideration of the characters of the plant. The common name is placed opposite the Latin name; the remaining synonymous vernacular names may be found in the list of common and scientific names of woody plants (p. 322). The more commonly used vernacular names are there referred to the species that often bears them. Incidentally, this discussion should inform those less familiar with plant names that the use of a common name, where exactitude is desired, is never as satisfactory as the use of the correct Latin name.

\section{RANGE}

The user of the woody plant list will find a series of numbers under each species after Range. Each number refers to a plant-growth region shown on Mulford's map (fig. 1). The series of numbers under any given species expresses its approximate geographic range.

To determine the plant-growth regions in which a plant can be planted with most confidence, the geographic range of the particular species was superimposed upon a map of Mulford's growth regions. The numbers were then read off. In many instances a plant may be found growing naturally in only a portion of a growth region, but assuming conditions within a given region to be reasonably constant, the plant is stated to be able to grow anywhere in the entire growth region. For this reason, it is obvious that the actual geographic range of any native species is not necessarily expressed with exactitude.

Interpretation of distribution with respect to the plant-growth regions has been conservative. The range of each species has been checked against records in local floras and published citations of specimens. Where a question exists, the growth region involved has been omitted. The growth regions herein published, therefore, depend in no way upon any belief the author may have that the planting of a given species will probably be safe in adjacent growth regions. If a growth region is listed for a species it has been ascertained that the plant actually does grow there.

Comparison of climatic and soil conditions in one growth region with those in others may point the way to the introduction of a species from one region to another. Here as with other considerations, in this work the facts only are presented; any conclusions drawn from them must be those of the user of the list.

\section{SITE DESIGNATIONS}

Plants grow in dry soil, moist soil, or in fresh or well-drained soil. They are to be found in the sun, or in the shade, or in both, or some- 
times in half shade. In the list under Site these facts are designated by the single words "dry," "moist," "well-drained," "sun," "shade," and "half shade." Certain species of sagebrush, ordinarily occurring on plains, for instance, would be characterized as "dry, sun." Certain species of osiers, ordinarily growing along streams, would be noted as "Moist, sun." Species of spice-bush, ordinarily occurring in rich woodlands, would be noted as "Well-drained, moist, shade."

Designation of a soil as dry, well-drained, or moist, depends to some extent on the opinion of the worker and the region in which he may be. Dry soil in the Great Plains or Piedmont is presumably much drier than dry soil in New England or western Oregon. Even moist soil might be considered wetter in New England than in Arizona. For this reason, only general designations are placed under each species in the list. Some common sense and a good deal of additional information about a plant may be needed, or further observation of its native habitat, especially when an unusually difficult position is to be its site.

\section{GROWTH HABITS}

Woody plants are here considered under growth-habit categories characterized as small shrubs, large shrubs, small trees, large trees, or vines. Small shrubs do not grow higher than 5 feet; large shrubs are 5 feet or more in height; small trees grow to 20 feet; large trees are more than 20 feet in height. The intermingling of such types must be done with care, since taller forms easily overshadow and repress smaller ones.

The habit of a plant may be materially altered by its habitat. Some grapes, for instance, are definitely shrubs on poor, dry soil while on better, more moist soil they may become vines. Certain shrubs become trees if plenty of moisture and good soil is available. Many species that are ordinarily large trees, may be only small ones or large shrubs in poor soils. Some species are shrubby in the northern part of their range and treelike in the southern part, or vice versa. The ability of species to change habit should be considered in planting.

Consideration of the general habit of a plant may assist the technician in selecting species to suit his needs. If he desires a cover on the soil during the winter, he will necessarily choose an evergreen species. If escape cover for wildlife is desired, his choice will be a plant with thorns, dense foliage, or one intricately branched. He may want a species that will permit the growth of herbaceous vegetation beneath it, in which case he will look for a sparsely branched type with thin foliage.

In the list, unless a plant is stated to be evergreen, it is understood to be deciduous. If it is not mentioned as spiny or thorny, it is understood to be free of any sort of spines or thorns. Otherwise characteristics are definitely stated for each plant.

\section{FRUITING}

Under each species in the list will be found the designation, "Fruit." Here the kind of fruit is indicated, as pome (applelike), drupe (cherrylike), berry (drupelike but with more than one seed), achene (seedlike), capsule, nut. Immediately after the kind of fruit is designated the time of availability, very often expressed by 2

$130186^{\circ}-39-3$ 
months, as August-April. The first month indicates when the fruit ripens and is available for collection either by man or wildlife; the second month shows approximately how long the fruit persists on the plant.

The data in this publication concerned with time of availability of fruit must be used with caution. The average dates of ripening of the fruit of a species with a considerable north-south range may have a range of several months, beginning earliest in the south and occurring later in the north. Furthermore, local weather conditions or other factors may delay or hasten the usual period of ripening. Therefore, when fruit is said to be available from August to April, it is meant that this appears to be the usual time. It does not mean that fruit always occurs on a particular bush during all that time. Only local field studies can discover when fruits are usually available in any given region.

Seed collectors know also that fruits particularly attractive to birds may not remain on the plant for any length of time if birds are plentiful. The seeds of Juniperus ashei, for instance, ordinarily persist like most other juniper fruits, but in 1936 the ripe fruits in the Ozarks were nearly cleaned off by immense flocks of robins.

\section{PROPAGATION}

A work of this sort can hardly deal in detail with methods of propagation, but certain fundamental principles should be stated that may contribute to a better understanding of propagation. Occasional notes indicating usual methods will be found under genera; if methods vary with species, under the species.

In general, propagation of plants from seed produces more vigorous plants. Because of this, plants intended for use on difficult, eroded sites should preferably be grown from seed. Reproduction in this manner involves determination of species and collection, storage, and planting.

Proper collection of good, viable seed demands care and a knowledge of the fruiting period of the plant. Seed falling earliest is usually of poorest quality. In the list of woody plants the date of seed ripening is indicated first, but it may vary considerably from one place to another. In fact, as far as seed collection is concerned, it would be sufficient to say that the fruit of a species ripens in early or late spring, summer, or fall. A seed collector wisely gets to the plants at the earliest date of ripening to be sure that he, instead of birds, squirrels, or other rodents, gets the major share of the crop. Even so, when seed is retained well into the winter, collection may often be deferred until later. But in any event, before seed is collected its soundness and worth should always be determined by cutting tests. The fruit should be mature, as slightly unripe seed has a decidedly poorer keeping quality than fully ripe seed.

Storage of seed depends on the species of plant. Some seed must be sown at once for best results; others must be stratified. Seed with fleshy parts usually must be cleaned by fermentation, washing, and drying before being stored dry. Preservation of the moisture content of seed is of great importance during handling and storing. Some seed, such as that of red and silver maples, willows, and poplars, is killed if the water content drops below 35 percent. Seed of many 
species of the rose family will germinate readily if planted at once, but if dried will fall into a state of secondary dormancy necessitating stratification to assure germination (313). Seed of birches and basswood germinates much more poorly when permitted to dry out after maturity.

Temperature greatly influences the keeping quality of seed (351). For most woody plant seed, $35^{\circ}-40^{\circ} \mathrm{F}$. is considered the best temperature. At these levels the moisture content may vary somewhat without harm to the seed. Freezing should be guarded against. Low oxygen content can be obtained by storage in airtight containers; this should be watched, since high oxygen content reduces keeping quality.

"Stratifying," as here used, means placing the seed in layers of peat and holding them at $35^{\circ}-40^{\circ} \mathrm{F}$. or, in specific instances, at the temperature noted in the list under the species. If seed is to be stratified, it should first be treated with a disinfectant. Potassium permanganate in 5 to 10 percent solution is useful for this purpose.

All of these operations and also those that follow are treated admirably in The Modern Nursery (351). Seeding and Planting in the Practice of Forestry (573) treats particularly of tree species.

Seed may fail to germinate because of incompletely organized embryos or hard seed coats, or because certain internal chemical changes that must take place before germination have not occurred. Additional food in the form of a dilute sugar solution may assist embryo organization during stratification. Seeds with hard seed coats are treated with hot water or agitated with sharp sand to assist them in germinating. Seed requiring a rest period must be stratified in the manner described.

Such of these practices as are known to apply are indicated for each species or genus in the list. In addition, data on the number of seeds per pound, the germination percentage, and the approximate number of usable plants to be expected from each pound of seed are given. These notes are intended to assist the technician in large-scale operations by giving him some idea of the nursery space he may require. Obviously, they can be only approximate.

The number of seeds per pound depends on individual variation in size of seed. This in turn depends on the age and vigor of the plant, the fullness of the crop, differences in site of the individual plants, and place of collection. Trees on good sites produce larger seeds than those on poor ones, and seeds collected at the northern extension of the tree range or from ligher elevations are usually smaller than those collected from the southern part of the range or from lower altitudes (5\%3). This is probably true also of shrubs.

It can thus be seen that the reported number of seeds per pound may vary tremendously. However, some indication is better than none at all.

Theoretically, the number of seeds per pound multiplied by the percentage of germination should give the number of usable plants to be expected per pound of seed. Actually, this is rarely true. Too many other factors are involved and the number of usable plants is often only one-third to one-fifth or less of the theoretical figure. For several hundred species the actual approximate number of usable plants per pound of seed, determined empirically in the Section of 
Nurseries of the Soil Conservation Service, is given, but all figures of this sort must be used with caution.

In large-scale operations, planting stock is most often propagated from seed, but other methods of obtaining plants, such as lifting wild stock, propagation by cuttings, or direct seeding, are all useful. Transplanting wild stock has little to recommend it. It is costly, especially from a labor standpoint, and the percentage of survival is all too often low.

The practice of direct seeding over all or part of a given area would seem to merit more investigation. The elimination of all storage and nursery operations has much appeal, but too little is known of direct seeding either to recommend or to discourage it. Toumey and Korstian (573) note that when an area is seeded properly, the cost is usually high. They claim that in direct seeding, as might be expected, germination is usually lower and more uneven than in nurseries. Proper preparation and protection of the site is no small item in the cost. They give a table showing the number of pounds of seed required for planting an acre with each of 23 species of trees, including black cherry, which requires 10 to 25 pounds; black locust, 6 to 8 pounds; white oak, 600 to 800 ; beech, 50 to 150 ; and white pine, 5 to 9 . Examples of successful direct seeding of woody plants are rare, but with increasing demand for large-scale planting, perhaps methods may be developed to overcome present obstacles. If it is known that direct seeding is successful, the information is included in the present list.

\section{UTILIZATION BY WILDLIFE}

The first paragraph under each species after the designation of fruit deals with characters directly or indirectly related to erosion control; the second deals wholly with utilization of the species by wildlife, livestock, and bees. The latter paragraph is divided into two portions headed "Stomach records" and "Observations."

Under Stomach records are placed all records of utilization based on examination of stomach contents. Most of such records are taken from the files of the Bureau of Biological Survey. A few are from identifications of stomach materials made by other agencies.

It has not seemed advisable to name all the species of birds known to thave eaten the fruit. The total number of birds utilizing the species of plant is listed, and a statement is added indicating which game birds are included.

Under each genus characterization the paragraph dealing with wildlife utilization lists stomach records and observations in addition to those listed under species. They are not summaries. Identification of plant parts found in stomachs is often possible only as far as the genus. These must hence be recorded only for the genus. The same may be true of observations, where identification is uncertain or possibly inaccurate. Therefore, genus records in this publication are used only because such records cannot be referred to a particular species.

All records of woody-plant utilization known to the author are included. The Biological Survey records, the literature, and many. field workers have supplied information for this work. It is, how- 
ever, very clearly recognized that there may be other records extant, and corrections and additional material are earnestly solicited by the author.

Under Observations are placed all records obtained from the literature. These cannot be considered as reliable as stomach records; but as indicated in the section Planting for Wildlife (p. 6), considerable care has been exercised to see that those stated actually do apply to the species under which they are placed. The animals listed under Stomach records and Observations should not be added to give the total number of animals feeding upon the plant since they are two separate and distinct items, and since the same species of animal may often have been observed to eat a part of the plant as well as to have had a portion of the plant found in its stomach or crop.

\section{LIST OF WOODY PLANTS}

Abies spp.

Firs.

About 23 species of firs are known, of which 10 occur in the United States. All are evergleen forest trees producing soft perishable wood of great importance commercially, and balsamic exudations; the seeds at each end of the cone are usually not fertile; cones break up at maturity; seed germination is usually under 50 percent and viability endures no longer than one season; propagation is entirely by seed sown in spring after stratifying at $32^{\circ}-41^{\circ} \mathrm{F}$.

Stomach records (in addition to specific records) : 10 species of birds including dusky and ruffed grouse; elk, Coeur d'Alene chipmunk, black-tailed deer. observations (in addition to the speciflc records) : Four species of birds including spruce and dusky grouse; Fremont pine squirrel, Arizona porcupine.

Ables amabilis (Dougl.) Forbes

Silver fir.

Picea amabilis Dougl.

Range: $1,4$.

Site: Well-drained, sun.

Fruit: Cone; ripe in September, breaks up in October.

A very large, long-lived evergeen tree; slow growing; susceptible to fire damage because of its thin bark; somewhat attacked by rot; wood of importance commercially, especially as pulp; grows poorly in cultivation; seeds borne heavily every 2 or 3 years, vitality transient, germination low; 11,000 seeds per pound.

Abies arizonica Merr.

Corkbark fir.

A. lasiocarpa arizonica Lemm.

Range: 13, 14.

Site: Dry, well-drained, sun.

Fruit: Cone, ripe in September.

A large evergreen tree; wood of no importance commercially; good seed years every third year; germination rate low, 25,000-45,000 seeds per pound.

observations: Porcupine, squirrels, and other rodents.

Abies aromatica, see Abies grandis.

Abies balsamea (L.) Mill.

Range : 23, 24, 26, 27.

Site: Well-drained, moist, sun.

Fruit: Cone; ripe in September, breaks up soon afterwards.

A large, fairly rapid-growing evergreen tree with a very shallow root system; intolerant of shade except for the first 6 to 8 years; age limit about 150 years; easily wind-thrown and damaged by fire and rot; short-lived and generally not satisfactory in cultivation; some 10 varieties distinguished in cultivation, one bearing larger cones; wood important for pulp, rarely lumber; seed borne abundantly at intervals of 2 to 4 years, shaded trees generally not bearing; 55,000 seeds per pound, germination 25 percent.

Stomach records: Five species of birds, including spruce and ruffed grouse. Observations: Six species of birds including ruffed, spruce and prairie sharptailed grouse; porcupine, snowshoe hare; highly important winter food of moose, white-tailed deer; rarely cut for building material, not food, by beaver. 
Abies concolor Lindl, and Gord.

A. loviana (Gord.) Murr., A concolor loviana Lenm.

White fir.

Range : 4, 5, 9, 10, 11, 12, 13, 14.

Site: Well-drained, sun, shade.

Fruit: Cone; mature in September, soon breaks up.

A very large evergreen tree with a shallow root system; at first rapid growing; later slower; long-lived; resistant to fire, heat, and drought; wood used commercially; good seed years every 2 to 4 years, seed vitality transient; 10,000-15,000 seeds per pound, germination 22-42 percent; five varieties distinguished in cultivation.

Stomach records: Mount Pinos grouse; Inyo chipmunk, black-tailed deer. Observations: Sooty grouse; porcupine; of outstanding importance for mule deer, California pine squirrel; much eaten by squiriels and other rodents.

Abies fraseri (Pursh.) Poir.

Southern balsam fir.

Range: 27.

Site: Well-drained, moist, sun.

Fruit: Cone; mature in September, soons breaks up.

A large evergreen tree, growth rate at first rapid, later slower; wood somewhat used for pulp, larely lumber; seed produced annually but heavy crops only at long intervals; short-lived both in the wild and in cultivation; 44,000 seeds per pound, germination about 68 percent.

Abies grandis Lindl.

A. aromatica Raf.

Lowland white fir.

Range: 1, 2, 4, 6, 7, 12 .

Site: Well-drained, sun.

Fruit: Cone; mature September-October, soon breaks up.

A very large evergreen tree with a deep root system; lapid growing at first, later slower; long-lived; intolerant of shade; wood of little importance commercially, potentially of greater value; ornamental; seed produced abundantly every 2 or 3 years; $20,000-34,000$ seeds per pound, germination about 50 percent.

Stomach records: Plains white-tailed deer. Observations: Richardson's pine squirrel.

Abies lasiocarpa (Hook.) Nutt.

Pinus lasiocarpa Hook.

Alpine fir.

Range: 4, 9 (at higher elevations only), 12, 13, 14 .

Site: Dry, well-drained, sun.

Fruit: Cone, mature in September.

A very large evergreen tree; slow growing, moderately long-lived; wood little used commercially; lower branches may root, but new trees seldom develop from them; not successfully cultivated in the Eastern States; seed produced abundantly every 3 years; seed vitality transient; 50,000 seeds per pound, germination 24 percent; about 5,000 usable plants per pound of seed.

Stomach records: Three species of birds, including Richardson's grouse; mountain sheep, black-tailed deer. Observations: Cascade pine squirrel.

Abies lowiana, see Abies concolor.

Abies magnifica Murr.

California red fir.

Range: 4.

Site: Well-drained, sun.

Fruit: Cone; mature in August, breaks up in September.

A very large evergreen tree; slow growing, especially with age; long-lived; intolerant of shade, but more resistant with age; ornamental; wood little used commercially, potentially of greater use; good seed crops produced every 2 or 3 years; seed vitality transient; 67,000 seeds per pound.

Observations: Sooty.grouse, California pine grosbeak; of slight importance for mule deer.

Var. shastensis Lemmon, Shästa red fir; very similar to the species and occurring within its range, but less common.

Abies nobilis Lindl.

Noble fir.

Range: 1, 4 .

Site: Well-drained, sun.

Fruit: Cone; ripe in September, begins to break up by October.

A very large evergreen tree with a shallow or deep root system; long-lived, fairly rapid growing; intolerant of shade; easily fire-damaged because of its 
thin bark; insect damage very rare; wood little used commercially, potentially of greater value; does well in cultivation in the Eastern States; good seed years infrequent and at long intervals; vitality of seed transient; 16,000 seeds per pound, germination $40-50$ percent.

Abies renusta (Dougl.) Koch.

Bristlecone fir.

Pinus venusta Dougl.

Range: 5 .

Site: Well-drained, sun, shade.

Fruit: Cone; ripe in August, breaks up in September.

A large evergreen tree not used commercially; seed produced abundantly at intervals of 3 to 5 or more years, of low and transient vitality.

Abutilon newberryi, see Horsfordia newberryi

Acacia spp.

Some 450 species are known, most of them tropical; majority rapid growing and short-lived; propagation is by seeds or cuttings from half-ripe wood taken with a heel; the seeds are treated with hot water and sown in March or April.

Stomach records (in addition to specific records): Mearn's quail. Observations (in addition to specific records): Texas antelope squirrel, cedar-belt cottontail.

Acacia amentacea DC.

Blackbrusll.

Acaciopsis amentacea (DC.) Britt. and Rose.

Range: 11, 16, 17, 20.

Site: Dry, sun.

Fruit: Legume. soils.

A large shrub to small tree, bearing spines; often found on sandy or other

Acacia angustissima (Mill.) Kuntze.

Prairie acacia.

Mimosa angustissima Mill., M. filicnloides (Cav.) Trel., A. filicina Willd., A. filiculoides Trel., A. hirta (Nutt.) Robins., Acaciella hirta (Nutt.)

Britt. and Rose., Acaciella filiculoides (Cav.) Britt. and Rose.

Range: 11, 16, 17, 20, 22, 25, 30.

Site: Dry, well-drained, sun.

Fruit: Legume, available July-August.

A small to usually large shrub or rarely a small tree; unarmed; blooms May-July and often grows in sandy and other soils.

Stomach records: Masked bobwhite. Somewhat browsed, pods relished by cattle and horses.

Acacia berlandieri Benth.

Senegalia berlandieri (Benth.) Britt. and Rose.

Guajillo.

Range: $11,16,17$.

Site: Dry, sun.

Fruit: Legume, available June-July.

A small to large sping shrub, occasionally unarmed; flowers NovemberMarch; root system very deep; wood used for fuel locally; an important source of honey.

Acacia constricta Benth.

Acaciopsis constricta (Benth.) Britt. and Rose.

Mescat acacia.

Range: 10, 11, 14, 16, 17.

Site: Dry, sun.

Fruit: Legume, available July-September.

A small to large, spiny shrub, often with sticky foilage, adapted to a wide range of soil conditions but often found in sand; seed germination about 45 percent; about 400 usable plants per pound of seed.

Var. paucispina Woot. and Standl., is a larger and less spiny form usually found at higher elevations than the species.

Stomach records: Masked bobrvhite, Gambel quail. Observations: Jack rabbit. Inferior to worthless forage for livestock, except that pods are taken. A source of honey.

Acacia cuspidata Schlecht.

Range: 11.

Site: Dry, sun.

Fruit: Legume, available in June. 
Acacia emoryana Benth.

Senegalia emoryana (Benth.) Britt. and Rose.

Range: 17.

Site: Well-drained, sun.

Fruit: Legume, available in July.

A large shrub to small or large tree, unarmed, or with few prickles; flowers in March.

Acacia farnesiana (L.) Willd.

Mimosa farnesiana L., Vachellia farnesiana (L.). Wight and Arnott.

Range: $5,10,11,17,20,29,30$.

Site: Dry, sun.

Fruit: Legume, available July-August.

A small shrub to large tree, depending on the degree of moisture; spiny; flowers February-March; will withstand several degrees of frost; drought and heat-reslstant; wood very durable, used commercially; very common and ornamental in cultivation; naturalized from the Gulf coast region to southern Californla; seed germination about 30 percent.

Considered a valuable stock forage, especially in winter; said to impart a bad flavor to cattle flesh. An important honey plant.

Acacia flicina, see Acacia angustissima.

Acacia filiculoides, see Acacia angustissima.

Acacia flexicaulis, see Pithecolobium ficxicaule.

Acacia greggii Gray.

Senegalia greggii (Gray) Britt. and Rose.

Long-flowered catclaw.

Range: $5,9,10,11,16,17,20$.

Site: Dry, well-drained, sun.

Fruit: Legume, available July-spring.

A small to large shrub or small tree, short-spined, straggling, and thicket forming; flowers April-October; very drought resistant; wood very durable, used locally; furnishes a gum similar to gum arabic; seed germination about 60 percent; about 200 usable plants per pound of seed.

Stomach records: Gambel quail. Observations: Sometimes used as roosts by Gambel quail and a favorite hiding place for jack rabbits and other animals; eaten by jack rabbits especially in drier seasons. A useful bee plant; furnishes much browse to livestock on depleted range; less used on range covered with good stand of grass; pods of low palatabllity to livestock; when of tree habit much value for shade; withstands heavy grazing.

Acacia hirta, see Acacia angustisssima.

Acacia lemmonli Rose.

Acaciella lemmonii (Rose) Britt. and Rose.

Iemmon acacia.

Range: 10, 11.

Site: Dry, sun.

Fruit: Legume, ripe in September.

A small shrub, browsed to some extent; pods relished by cattle and horses.

Acacia millefolia Wats.

Range: 10.

Site: Dry, sun.

Fruit: Legume.

A large, short-spined shrub.

Acacia pulverulenta, see Leucaena pulverulenta.

Acacia reticulata Willd.

Range: 11.

Netrein acacia.

Site: Dry, sun.

Fruit: Legume.

A smali shrub, considered good browse for cattle.

Acacia roemeriana Scheele.

Senegalia roemeriana (Scheele) Britt. and Rose.

Round-flowered catclaw.

Range: 11, 16, 17, 20.

Site: Dry, sun.

Fruit: Legume. 
A small to large, spiny shrub, generally rather stout.

Stomach records: Scaled quall. Observations: Sonora deer. Considered a valuable honey plant in western Texas.

Aoacia subtortuosa, see Acacia tortuosa.

Acaeia tortuosa (L.) Willd.

Catclaw.

A. subtortuosa Shafer, Popanax tortuosa (L.) Raf., P. schaffneri (Wats.)

Britt. and Rose.

Range: 11, 17, 20.

Site: Dry, sun.

Fruit: Legume.

A small shrub to small tree; spiny; blooms in March.

Acacia vernicosa Standl.

Acaciopsis vernicosa (Standl.) Britt. and Rose.

Range: 11.

Site : Dry, sun.

Fruit: Legume.

A small to rarely large shrub.

Stomach records: Scaled quail.

Acacia wrightii Benth.

Senegalia vrightii (Benth.) Britt. and Rose.

Texas catclaw.

Range: $10,11,16,17,20$.

Site: Dry, well-drained, sun.

Fruit: Legume, ripe June-September.

A large shrub to small or large tree; short-spined and with dense foliage; blooms March-May; wood used locally for fuel. A good honey plant.

Acaciella filicoldes, see Acacia angustissima.

Acaciella hirta, see Acacia angustissima.

Acaciella lemmonii, see Acacia lemmonii.

Acaciopsis amentacea, see Acacia amentacea.

Acaciopsis constricta, see Acacia constricta.

Acaciopsis vernicosa, see Acacia vernicosa.

Acalypha californica Bentl.

Range: 5.

California copperleaf.

Site: Dry, sun.

Frult: Capsule.

A small monoecious shrub.

Acalypha pringlei Wats.

Range: 10.

Site: Dry, well-drained, sun.

Fruit: Capsule.

A small shrub.

Acamptopappus microcephalus, see Aplopappus eooperi.

Acamptepappus sphaerocephalus (Harv. and Gray) Gray.

Range: 10.

Site: Dry, sun.

Fruit: Achene.

A small, many-stemmed shrub.

Acamptopappus schockleyi Gray.

Range: 10.

Site: Dry, sun.

Fruit: Achene.

A small shrub.

Acer spp.

Maples.

About 110 species of trees or shrubs, of which 12 occur in the United States; many in cultivation; most with fine autumn coloration; the majority grow in neutral soil ; propagation by seeds sown as soon as ripe, or stratifled at $41^{\circ}$ F. and sown in spring; vitality of seeds transient.

Stomach records (in addition to specific records) : White-tailed deer, opossum. observations (in addition to specific records): Thirteen species of birds; an 
emergency food of pinnated grouse; brown mountain beaver, fox squirrel, moose; species other than $A$. pennsylvanicum and $A$. spicatum (q. v.) in times of necessity are cut for food and building materials by beaver. Laten to some extent by muskrat. The western species furnish good browse for livestock.

Acer barbatum, see Acer saccharum.

Acer bernardinum, see Acer glabrum.

Acer brachypterum, see Acer floridanum.

Acer californicum, see Acer negundo.

Acer circinatum Pursh.

Range: $1,2,4$.

Vine maple.

Site: Well-drained, moist, sun, shade.

Fruit: Samara, available in September.

A large shrub to a small or rarely large tree; branches commonly rest on the ground, where they may root; slow growing, lives 80 to 90 years; wood used to some extent locally; will not furnish maple sugar; about 5,000 seeds per pound.

Observations: Considered to rank with $A$. macrophyllum as third in importance as browse for Olympic wapiti; Pacific mountain beaver. Of some importance as livestock browse.

Acer dasycarpum, see Acer saccharinum.

Acer donglasii, see Acer glabrum.

Acer floridanum (Chapm.) Pax.

Southern sugar maple.

A. saccharinum floridanum Chapm., Saacharodendron floridanum (Chapm.)

Nieuwl.

Range : 28, 29, 30 .

Site: Well-drained, moist, sun.

Fruit: Samara.

A large tree closely related to $A$. saccharum.

Var. villipes Rehder (A. brachypterum Woot. and Standl.), occurs also in region 11.

Acer glabrum Torr.

Dwarf maple.

A. tripartitum Nutt., A. bernardinum Abrams, A. neomexicanum Greene.

Range: $4,9,12,13,14,15$.

Site: Dry, well-drained, sun.

Fruit: Samara; available in late autumn.

Rarely a large shrub, commonly a small to large tree; usually dioecious and growing in poor soils; $13,000-20,000$ seeds per pound.

Var. donglasii (Hook.) Dippel, (A. douglasii Hook.) occurs with the species in regions 4 and 12 .

Stomach records: Mountain sheep, plains white-tailed deer. Observations: Fair browse for mule deer.

Acer grandidentatum Nutt.

A. śaccharum grandidentatum (Nutt.) Sudw.

Bigtooth maple.

Range: $7,8,9,11,12,13,14,16,19$.

Site: Well-drained, sun.

Fruit: Samara; available in September.

A large shrub to large tree; flowers April-May.

Acer interior, see Acer negundo.

Acer kingii, see Acor negundo.

Acer leucoderme Small.

Saccharodendron leucoderme (Small) Nieuwl.

Whitebark maple.

Range: 28, 29.

Site: Dry, well-drained, shade.

Fruit: Samara, available in September.

A large shrub to small or large tree often with a crooked trunk; flowers in April.

Acer macrophyllum Pursh.

Range: $1,2,3,4,5$.

Bigleaf maple.

Site: Well-drained, moist, sun, shade.

Fruit: Samara, available July-September or persistent until winter. 
A large tree; usually occurs only on good solls; root system shallow; longlived; wood strong, not durable, much used commercially; not successfully cultivated in the eastern United States; will produce maple sugar in nearly exactly as good quality and as great quantity as the eastern sugar maple; 2,700 seeds per pound, germination 90 percent, about 2,000 usuable plants per pound of seed.

Observations: Western evening grosbeak; listed with the vine maple as third in importance as browse for Olympic wapiti ; California mule deer.

Acer negundo $\mathbf{L}$.

Negundo negundo (L.) Karst, Rulac negundo Small, Negundo Boxelder.

Moench.

Range: $17,18,19,20,21,22,23,24,25,26,27,28,29,30$.

Site: Dry, well-drained, moist, sun.

Fruit: Samara, available September-October and persistent until spring.

A large shrub, or more commonly, a small to large tree; dioecious; root system generally shallow, deeper in deep solls; rapid growing; short-lived; easily storm-damaged, injured by heart rot, fire, and insects; wood soft, weak, used commercially ; shoots appear on exposed or injured roots; $10,000-14,000$ seeds per pound, germination 40-60 percent; about 2,000 usable plants per pound of seed; easily transplanted when young.

The justification for separating this species from the genus Acer and placing it in a separate genus, Negundo, is very good. The species is placed here merely for convenience but further study will very likely show this species to be generically different from the maples.

Var. violaceum Kirchner. (Negundo nuttallii (Nieuwl.) Rydb., Rulac nuttallii Nieuwl.) occurs in regions $8,15,18,21,22,23,24$, and 27.

Var. texanum Pax. (Rulac texana (Pax) Small, Acer texanum Pax, Negundo texanum (Pax) Rydb.) occurs in regions 19, 20, 25, and 29.

Var. interius (Britt.) Sarg. (Acer interior Britt., Rulac interior (Britt.) Nieuwl., Negundo interius (Britt.) Rydb., A kingii Britt.) occurs in regions 8, $9,11,12,13,14$, and 22.

Var. arizonicum Sarg. occurs in region 11.

Var. californicum (Torr. and Gray) Sarg. (Negundo californicum Torr. and Gray, Acer californicum Dietr., Negundo aceroides californicum Sarg., Rulao californicum (Torr. and Gray) Nieuwl.) occurs in regions 3,4 , and 5 .

Observations: Four species of birds, including ring-necked pheasant ; fox squirrels; many additional squirrels and birds; California mule deer.

Acer neomexicanum, see Acer glabrum.

Acer nigrum Michx. f.

Black maple.

A. saccharum nigrum (Michx. f.) Small, saccharodendron nigrum (Michx.

f.) Small, A. barbatum nigrum Sarg.

Range : 21, 22, 24, 25, 26, 27, 28, 29.

Site: Dry, well-drained, moist, sun, shade.

Fruit: Samara, available in September.

A large tree, resembling and very closely related to A. saccharum, and intergrading with it; often considered with good reason merely a variety of the sugar maple; grows in rich soils; wood of importance commercially; produces maple sugar.

Wildlife records for the sugar maple may apply equally well to this species.

Acer pennsylvanicum $\mathrm{L}$.

Range: $21,23,24,26,27$.

Site: Well-drained, moist, shade.

Fruit: Samara, available in September.

A large shrub to small or large tree, usually found in acid soil ; wood sometimes used commercially.

Observations: Cottontail rabbit; beaver food where Populus is lacking; moose, white-tailed deer.

Acer rubrum $\mathrm{L}$.

Rufacer rubrum (L.) Small, A. stenocarpum Britt. and Shafner.

Range : 19, 20, 21, 22, 23, 24, 25, 26, 27, 28, 29, 30 .

Site: Dry, well-drained, moist, sun, shade.

Fruit: Samara, available March-April.

A large dioecious or monoeclous tree; occurs on a variety of soils; root system shallow on moist sites, deeper on dry sites; rapid growing, short-lived; not seriously injured by insects but subject to heart rot; severely injured by fire; 
coppices freely, especially when young; very brilliant red in autumn; wood much used commercially; 18,000 seeds per pound, germination 70 percent, about 2,000 usable plants per pound of seed; vitality of seeds transient; easily transplanted. Several varieties have been described, all occurring within the range of the species.

Stomach records: Palm warbler; eastern chipmunk, white-tailed deer. $\mathrm{Ob}$ servations Ten species of birds; cottontail rabbit; considered the fifth most important winter food of white-tailed deer in Massachusetts.

Acer saccharinum $\mathrm{L}$.

A. dasycarpum Ehrh., Argentacer saccharinum (L.) Small.

Silver maple.

Range: $18,19,20,21,22,23,24,25,26,27,28,29,30$.

Site: Well-drained, moist, sun.

Fruit: Samara, available April-June.

A large monoecious or dioecious tree; taproot small, lateral roots well developed; grows in a rariety of soils; at first rapid growing, later slower; shortlived; much subject to fungus diseases; wind-firm, but easily storm-damaged; easily damaged by fire; coppices freely when young; grows successfully on coalstripped land in Illinois; wood hard, strong, not durable, of importance commercially; much cultivated, with some six outstanding varieties known; seed vitality transient; about 2,400 seeds per pound, germination 50 percent, about 400 usable plants per pound of seed.

Stomach records: Gray eastern chipmunk, eastern chipmunk. Observations: Four species of birds; cottontail rabbit, snowshoe hare, red squirrel, whitetailed deer.

Acer saccharum Marsh.

Sugar maple.

A. barbatum (Michx.) Nieuwl., Saccharodendron barbatum (Michx.) Nieuwl.

Range: $15,18,21,22,23,24,25,26,27,28,29$.

Site: Dry, well-drained, moist, sun, shade.

Fruit: Samara, available July-December.

A large monoecious or dioecious tree; usually occurs on rich soil ; root system shallow, wide spreading; slow growing, long-lived; seriously injured by fire; wind-firm; attacked by numerous insects; wood hard, strong, not rery durable, much used commercially; produces maple sugar; easily transplanted when small ; 7,000 seeds per pound, germiuation 50-60 percent, about 1,500 usable plants per pound of seed.

Four varieties are listed, varying among other things in the amount of hairiness of the leaves. All occur within the range of the species except var. sinuosum (Rehd.) Sarg., (A. sinuosum Rehd.), which occurs in regions 17 and 20.

Stomach records: White-tailed deer. Observations: Four species of birds including ring-necked pheasant; porcupine, red squirrel, cottontail rabbit; heavily utlized by moose on Isle Royale; white-tailed deer.

Acer sinuosum, see Acer saccharum.

Acer spicatum Lam.

Range: $23,24,26,27$.

Site: Dry, well-drained, moist, sun, shade.

Fruit: Samara, available August-November.

A large shrub to small or large tree; ordinarily occurs on acid soil; clump forming; wood used to some extent commercially.

Stomach rocords: White-tailed deer. Observations: Cottontail rabbit, moose; beaver, where Populus is lacking.

Acer stenocarpum, see Acer rubrum.

Acer texanum, see Acer negundo.

Acer tripartitum, see Acer glabrum.

Adelia acuminata, see Forestiera acuminata.

Adelia angustifolia, see Forestiera angustifolia.

Adelia ligustrina, see Forestiera ligustrina.

Adelia neomexicana, see Forestiera neomexicana.

Adelia parvifolia, see Forestiera neomexicana.

Adelia pubescens, see Forestiera pubescens. 
Adelia raseyi, see Ricinella vaseyi.

Adenostoma fasciculatum Hook. and Arn.

Chamiso.

Range: 5 .

Site: Dry, sun.

Frnit: Achene.

A large, spreading shrub with small fasicled leaves; branches very close to the ground, and stems are practically without permanent branches; produces little shade and does not protect the ground from hot or dry winds; very inflammable; colony forming; root system consists of deep taproot and well developed laterals; heavy root crown developed, which when large enough enables plant to survive fire; common chaparral dominant on dry slopes and ridges, Invading and occupying burns quickly; generally regarded as a pest; worthless on the range; propagation by seeds or green-wood cuttings taken in spring.

Observations: Californla mule deer.

Adenostoma sparsifolium Torr.

Shankbush.

Range: 10.

Site: Dry, sun.

Fruit: Achene.

A large, very inflammable shrub; flowers July-August; propagated by seeds or green-wood cuttings taken in spring. Of no value as stock forage.

Observations: California mule deer.

Adolphia californica Wats.

Range: 5.

Slte: Dry, well-drained, sun.

Fruit: Capsule.

A small to large, spiny shrub without forage value; generally considered a local range pest.

Adolphia infesta (H. B. K.) Meisn.

Ceanothus infesta H. B. K., Colletia multifora DC.

Range: 11.

Site: Dry, well-drained, sun.

Fruit: Drupe.

A small to large, extremely spiny, densely branched shrub without forage value.

Aesculus spp.

Buckeyes.

Most species grow in neutral soil; propagation is by seed sown in the fall or, after stratifying, in the spring.

Aesculus arguta, see Aesculus glabra.

Aesculus austrina, see Aesculus discolor.

Aesculus callfornica (Spach) Nutt.

Range: $1,3,4,5$.

California buckeye.

Site: Dry, well-drained, sun.

Fruit: Capsule, avallable September-October.

A large shrub to small or rarely large tree; very broad-headed; coppices freely when cut; foliage early burning brown, falling or persistent; very ornamental, flowers during May-August; wood used for fuel to some extent; reputed to be very durable for fence posts.

Observations: Redwood chipmunk, many squirrels; dead leaves fair forage for mule deer. Poisonous to stock; not eaten by swine; bees poisoned by the nectar.

Aesculus discolor Pursh.

Range: $16,17,20,29,30$.

Site: Well-drained, sun.

Fruit: Capsule; available in October, seeds fall at once.

A large shrub to a small or rarely large tree, ordinarily growing in rieh soil; flowers April-June.

Var. mollis (Raf.) Sarg., ( $A$, austrina Small) the scarlet buckeye, is a small tree with red flowers, occurring within the range of the specles.

Aesculus flava, see Aesculus octandra.

Aesculus georgiana, see Aesculus neglecta. 
Aesculus glabra Willd.

Range: 22, 24, 25, 27, 29.

Ohio buckeye.

Site: Well-drained, moist, sun, shade.

Fruit: Capsule, available in September.

A large, rapid-growing tree; flowers ApriI-May; short-lived; wood sometimes used commercially; flowers not showy. Young shoots poisonous to cattle and if forage is poor in spring cattle will eat them; later not attractive to livestock; hogs poisoned by the seeds.

Several varieties have been described, a white-barked form, one with more pubescent leares, and one with more leaflets. All are of more or less local occurrence within the range of the species except var. arguta (Buckl.) Robinson, (A. arguta Buckl.), the shrubby buckeye, found also in region 30.

Aesculus humilis, see Aesculus neglecta.

Aesculus michanxii, see Aesculus neglecta.

Aesculus neglecta Lindl.

Range: 28.

Site: Well-drained, sun.

Fruit: Capsule, available in September.

A large, very rare tree; flowers April-May.

Var. georgiana Sarg. (A. georgiana Sarg.) Georgia buckeye; usually shrubby; occurs in regions 28,29 , and 30 .

Var. tomentosa Sarg. (A. michauxii Hort., not Spach, A. humilis Hort., not Lindl., A. rubra carnea superba Hort., and A. rubra carnea pubescens Hort.) in region 28 has very showy flowers.

Aesculus octandra Marsh.

Yellow buckeye.

A. Aava Ait.

Range: 20, 22, 23, 24, 25, 27, 28, 29.

Site: Dry, well-drained, sun.

Fruit: Capsule, available in September.

A large shrub to small or large tree; root system shallow; rapid growing, short-lived; wood used commercially; subject to dry rot and stem borers; blooms April-May; a red-flowered form is known.

Aesculus parviflora Walt.

Range: $29,30$.

Site: Well-drained, shade.

Fruit: Capsule, available in October.

A large spreading shrub, very showy during the July flowering period; commonly occurs on rich soil.

Aesculus pavia L.

Red buckeye.

Range: $20,25,27,28,29,30$.

Site: Moist, shade.

Fruit: Capsule, available in September.

A large shrub to small or rarely large tree; ordinarily occurs on slightly acid soil; flowers April-May; very handsome in cultivation; a form with dark-red flowers is known. Poisonous to livestock.

Aesculus rubra vars., see Aesculus neglecta.

Ailanthus altissima (Mill.) Swingle.

Ailanthus.

A. glandulosa Desf.

Range: $1,2,3,5,6,8,11,17,20,22,24,25,27,28,29$.

Site: Dry, well-drained, moist, sun.

Fruit: Samara; ripe in September, long persistent.

A large tree introduced from China but aggressively spontaneous and wellestablished in the range indicated; easily storm-damaged; rapid growing; coppices freely; immune to the effects of smoke, dust, or insect pests ; $14,000-22,000$ seeds per pound, germination 60 percent, about 3,000 usable plants per pound of seed; withstands considerable abuse in handling; staminate plant odoriferous in flower. This species produces wood even on poor soll more than twice as fast as any native tree having wood of anything like the same fuel value; wood ranked with that of black walnut or oak for fuel, excellent for cabinetmaking.

Observations: Pine grosbeak, crossbill; white-tailed deer.

Ailanthus glandulosa, see Ailanthus altissima. 
Albizzia julubrissin Duraz.

Range: $29,30$.

Silktree.

Site: Dry, well-drained, sun, shade.

Fruit: Legume, available September-November.

A large tree introduced from Asia and Africa; 11,000 seeds per pound, 3,000 usable plants per pound of seed.

Alhagi camelorum Fisch.

Camelthorn.

Range: 10, 11.

Site: Dry, well-drained, sun.

Fruit: Legume, available August-September.

A small, spiny shrub naturalized from Asia Minor; rapid growing; aggressive and thicket forming; root system deep and extensive; eradication operations for this species have been in progress.

Allenrolfea occidentalis (Wats.) Kuntze.

Inkweed.

Spirostachys occidentalis Wats.

Range: $8,9,10,11,16$.

Site: Well-drained, moist, sun.

Fruit: Achenelike.

A small to large, succulent, almost leafless shrub, usually confined to and an indicator of alkaline soil. Sparingly eaten by livestock.

Aluus spp.

Alders.

Generally rapid growing; commonly occurring in neutral soil; wood durable in water; nitrogen-fixing bacteria form nodules on the roots of alder in somewhat the same manner as on the legumes; propagated by seeds sown in fall or spring; or in the shrubby species, by hard-wood cuttings and layers.

Stomach records (in addition to specific records) : 20 species of birds, including sharp-tailed grouse, ruffed grouse, bobwhite, woodcock, and ptarmigan. Composed 2.5 percent of the food of northern sharp-tailed grouse in winter in Quebec and Ontario; Illiuols skunk, opossum. Ouservations (in addition to specific records): Sixteen species of birds; an emergency food of prairie sharptailed grouse, northern sharp-tailed grouse; snowshoe hare, Pacific mountain beaver, brown mountain beaver, porcupine, Olympic wapiti; beaver, where Populus is lacking; moose, white-tailed deer. Palatability to livestock not high but considered an important secondary forage, especially for cattle. A source of pollen for bees.

Alnus alnobetula, see Alnus crispa.

Alnus crispa (Ait.) Pursh.

A. alnobetula of Amer. auth., not Koch.

Green alder.

Range : 26, 27.

Site: Dry, well-drained, moist, sun.

Fruit: Nutlet, borne in a cone.

A large shrub with somewhat decumbent branches.

Var. mollis (Fern.) Rehd., (A. mollis Fern.) is a small tree occurring in regions $23,24,26$, and 27 .

Observations: Redpoll; an important summer browse of moose on Isle Royale. Alnus fruticosa, see Alnus sinuata.

Alnus glutinosa (L.) Gaertn.

European black alder.

A. vulgaris Hill, A. rotundifolia Mill.

Range : $26,27$.

Site: Well-drained, sun.

Fruit: Nutlet, borne in a cone.

A small tree introduced from Europe, with many varieties known in cultivation; about 10,000 usable plants per pound of seed.

Observations: Much eaten by ruffed grouse in New York.

Alnus incana (L.) Moench.

Range: 21, 22, 23, 24, 26, 27.

Speckled alder.

Site: Well-drained, moist, sun, shade.

Fruit: Nutlet, borne in a cone, available August-September.

A large shrub to small tree with very thick and dense foliage; rapid growing; thicket forming; a naturally occurring stream-bank protector; $256,000-625,000$ seeds per pound, about 10,000 usable plants per pound of seed; easily transplanted. 
Stomach records: Three species of birds, including ptarmigan and sharptailed grouse ; muskrat. Observations: Redpoll; cottontail rabbit; ignored by deer in Massachusetts; summer but not winter food of moose on Isle Royale; casually browsed by northern white-tailed deer.

Alnus maritima (Marsh.) Muhl.

Seaside alder.

Range: 25, 28.

Site: Well-drained, moist, sun.

Fruit: Nutlet, borne in a cone, available October-November.

A large shrub to small or large tree; sometimes forms thickets.

Alnus mollis, see Alnus crispa.

Alnus oblongifolia Torr.

Range: 11, 14.

Mexican alder.

Site: Well-drained, sun.

Fruit: Nutlet, borne in a cone.

A small to large tree; usually occurs at higher elevations.

Alnus occidentalis, see Alnus tenuifolia.

Alnus oregona, see Alnus rubra.

Alnus rhombifolia Nutt.

Range: $1,3,4,5,6,7,8,10,12$.

White alder.

Site: Moist, shade.

Fruit: Nutlet, borne in a cone that remains until spring.

A large tree, often thicket forming; wood rots quickly in soil and is of very little value commercially.

Observations: Of slight importance as food for mule deer.

Alnus rotundifolia, see Alnus glutinosa.

Alnus rubra Bong.

A. oregona Nutt.

Red alder.

Range: 1, 2, 5, 6.

Site: Well-drained, moist, sun, shade.

Fruit: Nutlet, borne in a cone; seeds shed in autumn, cones persistent.

A large tree; rapid growing, especially the first 10 to 15 years; short-lived; root system shallow, superficial ; wood of increasing value commercially ; 363,000 seeds per pound, germination 40 percent; about 10,000 usable plants per pound of seed.

Stomach records: Four species of birds; California mule deer. Observations: Pine siskin. Fair browse for cattle and sheep.

Alnus rugosa (Du Roi) Spreng.

Smooth alder.

A. serrulata Willd.

Range: $20,22,23,24,25,26,27,28,29$.

Site: Well-drained, moist, sun.

Fruit: Nutlet, borne in a cone.

A large, thicket-forming shrub with very thick foliage; 400,000 seeds per pound, about 40,000 usable plants per pound of seed.

Observations: Four species of birds, inciuding mourning dove; white-tailed deer.

Alnus serrulata, see Alnus rugosa.

Alnus sinuata (Regel) Rydb.

Sitka alder.

A. viridis sinuata Regel., A. sitchensis Sarg., A. fruticosa auths. not Rupr.

Range: 2, 4, 6, 7, 12.

Site: Moist, sun.

Fruit: Nutlet, borne in a cone.

A small to large shrub, or northward a small to large tree. Considered fair browse for sheep.

Alnus sitchersis, see Alnus sinuata.

Alnus tenuifolia Nutt.

Mountain alder.

A. occidentalis Dippel.

Range: $4,7,11,12,13,14$.

Site: Well-drained, moist, sun.

Fruit: Nutlet, borne in a cone. 
A large, thicket-forming shrub to small or large trees; about 10,000 usable plants per pound of seed.

Observations: Captive Columbian sharp-tailed grouse; of slight importance for mule deer. A fair sheep browse of high palatability.

Alnus vulgaris, see Alnus glutinosa.

Aloysia ligustrina, see Lippia ligustrina.

Amarolea americana, see Osmanthus americana.

Amelanchier spp.

Serviceberries.

Between 20-25 species are known, most of them occurring in North America; in slightly acid soil; many are very closely related and often difficult to distinguish; very ornamental; generally irregular in time of ripening of the berries; propagated by seeds sown as soon as ripe or in the spring after stratifying 90 days at $32^{\circ}-50^{\circ} \mathrm{F}$., or the stoloniferous types by suckers; seedlings should remain in seedbeds 3 to 4 years before planting in the field. All are alternate hosts for the cedar apple fungus.

Stomach records (in addition to specific records) : 36 species of birds, including ruffed grouse, dusky grouse, turkey; composed 0.16 percent of vegetable food of eastern skunk in Michigan; gray-tailed chipmunk, gray-necked chipmunk, golden-mantled marmot, black-tailed deer, white-tailed deer; mountain sheep. Observations (in addition to specific records): Eighteen specles of birds, including mountain quail, dusky grouse, and prairie sharp-tailed grouse; skunk; heavily browsed by moose; of first importance for red fox; goldenmantled ground squirrel, Arizona chipmunk, Say chipmunk, Wasatch chipmunk; favorite food of pale chipmunk; raccoon, black bear, cottontail rabbit, pica, beaver; an important food of white-tailed deer.

Amelanchier alnifolia Nutt.

\section{A. oreophila Nels.}

Range : 4, 10, 11, 12, 13, 14, 15, 18, 19, 21, 23, 24, 26.

Site : Dry, well-draíned, moist, sun.

Fruit: Pome, available July-September.

A large shrub to small tree or rarely a large tree with a deep and spreading root system; blooms April-June; very variable, and the complex of forms not yet clear botanically. Among others, var. pallida (Greene) Jeps. (A. pallida Greene), var. venulosa (Greene) Jeps. ( $A$. venulosa Greene), var. covillei (Greene) Jeps. (A. covillei Standl.) and var. cuyamacensis Munz, have been described.

Stomach records: Six species of birds, including sooty grouse, Richardson's grouse; plains white-tailed deer, Bitterroot valley chipmunk, black-tailed deer. Observations: Mountain quail, captive Columbian sharp-tailed grouse, blue grouse; California mule deer. A forage species of the first rank; younger foilage more palatable; of great importance to stock on the range.

Amelanchier amabilis Wieg.

A. sanguinea grandiflora Rehd.

Range: 24, 26, 27.

Site: Dry, well-drained, sun.

Fruit: Pome, available July-August.

A small to large shrub, heretofore probably confused with $A$. sanguinea. Probably a calciphile.

Amelanchier bakeri Greene.

A. purpusii Koehne.

Range: 11, 13, 14.

Site: Dry, well-dralned, sun.

Fruit: Pome.

A small to large shrub; flowers in May; about 31,000 seeds per pound.

Amelanchier bartramiana (Tausch.) Roem.

A. oligocarpa (Michx.) Roem.

Range: $23,24,26,27$.

Site: Well-drained, moist, sun.

Fruit: Pome, available July-August.

A large shrub; fiowers in May.

Amelanchier botryapium, see Amelanchier canadensis and A. oblongifolia.

$130186^{\circ}-39-4$ 
Amelanchier canadensis (L.) Medic (pl. 1, A).

Serviceberry.

A. botryapium Borkh., A. ovalis subcordata DC., A. canadensis botryapium Torr. and Gray, A. canadensis oblongifolia Gray's Man. A. canadensis obovalis Sarg., in part, A. canadensis pomentula Sarg., A. canadensis Britt.

Range: $20,21,22,23,24,25,26,27,28,29,30$.

Site: Well-drained, moist, sun, shade.

Fruit: Pone, available June-August.

A small, or usually large shrub or small tree; rarely a large tree; usually occurs in rich soil; flowers before the leaves form, March-May; about 50,000 seeds per pound; germination about 70 percent, about 10,000 usuable plants per pound of seed.

Stomach records: Twenty-seven species of birds including ruffed grouse; white-tailed deer. Observations: Eight species of birds, including bobwhite and mourning dove; cottontail rabbit, white-tailed deer.

Amelanchier covillei, see Amelanchier alnifolia.

Amelanchier crenata Greene.

Range: 11.

Site: Dry, sun.

Fruit: Pome.

A small to large shrub or small tree with dense foilage; flowers in April.

Amelanchier cusickii Fern.

Range: 6, 7, 8, 12.

Cusick serviceberiy.

Site: Dry, sun.

Fruit: Pome.

A large shrub; flowers April-June.

Observations: Sooty grouse.

Amelanchier elliptica, see Amelanchier florida.

Amelanchier/fiorida Lindl.

A. elliptica Nels.

Range: $1,2,4,7$.

Site: Dry, well-drained, moist, sun.

Fruit: Pome, available July-September.

Usually a large shrub, occasionally a small tree or rarely a large tree; blooms April-June; often forms extensive thickets; sprouts promptly when browsed; very fire resistant; reproduces mainly by sprouts; leaves fall comparatively early.

Stomach records: Three species of birds. Observations: Sooty grouse; of outstanding importance as browse for mule deer. Very valuable stock forage.

Amelanchier goldmanii Woot. and Standl.

Goldman serviceberry.

Range: $9,11,14$.

Site: Well-drained, sun.

Fruit: Pome.

A large shrub to small tree.

Amelanchier humilis Wieg.

A. spicata Amer. auths. not (Lam.) Koch.

Small serviceberry.

Range : 21, 22, 23, 24, 25, 26, 27.

Site: Dry, well-drained, sun.

Fruit: Pome, avallable July-August.

A small stoloniferous shrub; forms extensive patches; usually occurs in sandy soil; flowers May-June; flowering and fruiting generally earlier northward; about 63,000 seeds per pound

Amelanchier huronensis Wieg.

Range: 23, 24.

Site: Well-drained, sun.

Fruit: Pome, available July-August.

A large shrub or small tree; usually occurs on sandy and limestone soil.

Amelanchier intermedia, see also Amelanchier oblongifolia.

Amelanchier intermedia Spach.

Range: 23, 24.

Site: Well-drained, moist, sun.

Fruit: Pome, avallable June-July. 
A large shrub or rarely a small tree; clump-forming or widely branched near the ground. This species has formerly been confused with either $A$. oblongi. folia or A. canadensis and records of wildlife utilization for these last species probably apply to this one as well.

Amelanchier laevis Wieg.

Range: 21, 22, 23, 24, 25, 26. 27, 28.

Site: Well-drained, moist, sun, shade.

Fruit: Pome, available June-July.

A small to large shrub or usually a small tree, less commonly a large tree; shrubbier northward; may occur on calcareous or noncalcareous soil; very handsome in cultivation; fruit very irregular in time of ripening.

Observations: Generally attractive to birds.

Amelanchier macrocarpa Lunell.

Range: 18,21 .

Site: Dry, well-drained, sun.

Fruit: Pome.

A small shrub; flowers April-June.

Amelanchier mormonica Schneid.

Range: 11, 13, 14.

Site: Well-drained, sun.

Fruit: Pome.

A small to large shrub or small tree; flowers May-June.

Amelanchier oblongifolia, see also Amelanchier stolonifera.

Amelanchier oblongifolia (Torr. and Gray) Roem.

Serviceberry.

A. canadensis oblongifolia Torr. and Gray, A. botryapium Britt. and Brown,

in part, A. obovalis Ashe, in part, A. intermedia Blanchard, in part, not Spach.

Range: 15, 18, 21, 22, 23, 24, 27, 28, 29.

Site: Dry, well-drained, moist, sun, shade.

Fruit: Pome, available June-July.

A large shrub to a small, or rarely large, tree; not stoloniferous, but often clump-forming.

Var. micropetala Robins., is a dwarf on exposed ledges or dry sandy soil near the coast in region 27.

Amelanchier obovalis, see Amelanchier oblongifolia.

Amelanchier oligocarpa, see Amelanchier bartramiana.

Amelanchler oreophila, see Amelanchier alnifolia.

Amelanchier ovalis, see Amelanchier stolonifera.

Amelanchier pallida, see Amelanchier alnifolia.

Amelanchier polycarpa Greene.

Cluster serviceberry.

Range: 11, 13, 14.

Site: Well-drained, moist, shade.

Fruit: Pome, available in August.

A small to large shrub or small tree; flowers in May-July and bears an abundance of fruit.

Browse value for livestock varies in different localities and at different seasons; excellent in southwestern Utah; inferior in southeastern Utah.

Amelanchier prunifolia Greene.

Redbud serviceberry.

A. rubescens Greene.

Range: $9,11,13,14$.

Site: Dry, sun.

Fruit: Pome.

A small to large shrub or small tree, reported to be evergreen; flowers AprilJune.

Generally worthless forage for livestock in summer but of some value to sheep and goats in the spring; not injured by as much as 25 percent grazing.

Amelanchier pumila Nutt.

Range: 13.

Site: Dry, well-drained, sun.

Fruit: Pome.

A small shrub with depressed branches; flowers June-July. 
Amelanchier purpusil, see Amelanchier bakeri.

Amelanchier rotundifolia, see Amelanchier sanguinea.

Amelanchier rubescens, see Amclanchier prunifolia.

Amelanchier sanguinea (Pursh) DC.

Serviceberry.

A. spicata Robins. and Fern., A, rotundifolia (Michx.) Roem., A. canadensis rotundifolia Torr. and Gray, A. canadensis spicata Sarg., A. spicata (Lam.) Koch.

Range: 23, 24, 26, 27.

Site: Dry, well-drained, moist, sun, shade.

Fruit: Pome, available July-August.

A small to large shrub; flowers May-June; not stoloniferous and not colonyforming.

Observations: Red squirrel.

Amelanchier spicata, see Amelanchier humilis, A. sanguinea and A. stolonifera.

Amelanchier stolonifera Wieg.

Creeping shadbush.

A. spicata Britt. and Brown, in part, A. ovalis of European auths., in part,

A. oblongifolia Robins. and Fern.

Range: 23, 24, 26, 27, 28.

Site: Dry, well-drained, moist, sun.

Fruit: Pome, available in July.

A small stoloniferous shrub; flowers in May; colony forming; often occurs on sand or noncalcareous soil or gravel; foliage dense.

Obscrvations: Cottontail rabbit.

Amelanchier utahensis Koehne.

Utah serviceberry.

Range: 6, 7, 8, 9, 11 .

Site: Dry, well-drained, sun.

Fruit: Pome.

A small/to large shrub; flowers May-June.

Observations: : Black-tailed deer. Good to excellent forage for sheep and goats; grazed moderately to heavily by cattle, especially in early spring.

Amelanchier venulosa, see Amelanchier alnifolia.

Amoreuxia wrightii Gray.

Range: 10, 11, 17, 30.

Site: Dry, sun.

A small shrub.

Fruit: Capsule, available August-September.

Amorpha spp.

Indigobushes.

Propagation of all species is by seeds sown as soon as ripe, greenwood cuttings made in early summer, hardwood cuttings made in fall, or by layers and suckers.

Stomach records (in addition to specific records) : Antelope jack rabbit, Texas jack rabbit.

Amorpha angustifolia, see Amorpha fruticosa.

Amorpha californica Nutt.

A. hispidula Greene.

Callfornia indigobush.

Range: 3, 5, 10, 11, 14.

Site: Dry, well-drained, moist, sun.

Fruit: Legume.

A large, rapid-growing shrub with thick foliage; flowers May-July.

Observations: Particularly palatable to captive deer. Not used by livestock.

Amorpha canescens Pursh.

Range: 14, 15, 16, 18, 19, 20, 21, 22, 23, 24, 25, 29.

Leadplant.

Site: Dry, well-drained, sun.

Fruit: Legume, available August-September.

A small shrub, leafy to the base; roots 6-16 feet deep; behaves as an herb under annual mowing; flowers July-August; occurs in sandy or in other soils; very handsome in cultivation; often considered a weed in pastures; about 105,000 seeds per pound, germination about 30 percent. Sparingly grazed by livestock.

Amorpha fragrans, see Amorpha fruticosa. 
Amorpha fruticosa $L$.

Indigobush.

A. occidentalis Abrams, A. fragrans Sweet, A. fruticosa angustifolia Pursh, A. angustifolia (Pursh) Boynton.

Range: $5,10,11,15,16,17,18,19,20,21,22,23,24,25.27,28,29$.

Site: Well-drained, moist, sun, shade.

Fruit: Legume, available in August.

A small to large shrub with rather sparse foliage; flowers May-July; often grows in clumps; rarely attacked by insects or disease; often occurs on calcareous soil ; very variable and with a number of varieties in cultivation; grows on coal-stripped lands in Illinois; $55,000-60,000$ seeds per pound, germination 60-70 percent, about 10,000 usable plants per pound of seed.

Stomach records: Bobwhite. Possibly poisonous to livestock.

Amorpha glabra Desf.

A. montana Boynton.

Mountain-indigo.

Range : 29, 30.

Site: Dry, well-drained, moist, sun.

Fruit: Legume.

A small to large shrub; flowers May-June.

Amorpha herbacea Walt.

Range: 29,30 .

Site: Dry, well-drained, sun.

Fruit: Legume.

A small shrub; flowers June-July; ordinarily occurs on sandy or sterile soil Amorpha hispidula, see Amorpha californica.

Amorpha laevigata Nutt.

Range: 20, 25, 29, 30.

Site: Well-drained, moist, sun.

Fruit: Legume.

A large shrub; pods one-seeded.

Amorpha microphylla Pursh.

Dwarf indigobush.

A. nana Nutt.

Range: 14, 15, 18, 22, 23.

Site: Dry, sun.

Fruit: Legume, available in July.

A small shrub; flowers May-June; about 60,000 seeds per pound; germination about 50 percent.

Amorpha montana, see Amorpha glabra.

Amorpha nana, see Amorpha microphylla.

Amorpha nitens Boynton.

Range: 29.

Site: Moist, sun.

Fruit: Legume.

A small to large shrub; flowers in July.

Amorpha occidentalis, see Amorpha fruticosa. .

Amorpha paniculata Torr. and Gray.

Range: 11, 20, 29, 30.

Site: Well-drained, moist, sun.

Fruit: Legume.

A large shrub; often occurs in salt marshes.

Amorpha schwerinil Schneid.

Range: 28.

Schwerin-indigo.

Site: Dry, well-drained, sun.

A large shrub.

Fruit: Legume.

Amorpha tennesseensis Shuttlew.

Range: 25, 27, 29.

Site: Well-drained, moist, sun.

Fruit: Legume.

A large shrub.

Tennessee-indigo. 
Amorpha texana Buckl.

Range: 16, 17, 20.

Site: Well-drained, sun.

Fruit: Legume.

A small to large shrub.

Amorpha virgata Small.

Mountain-indigo.

Range: 29, 30.

Site: Dry, well-drained, shade.

Fruit: Legume.

A small to large, very rare shrub.

Ampelopsis arborea, see Cissus arborea.

Ampelopsis cordata, see Cissus ampelopsis.

Ampelopsis heptaphylla, see Parthenocissus heptaphylla.

Ampelopsis quinquefolia, see Parthenocissus quinquefolia.

Amphiachyris fremontil, see Amphipappus fremontii.

Amphipappus fremontii (Gray) Torr. and Gray.

Amphiachyris fremontii Gray.

Fremont chaffbush.

Range: 10.

Site: Dry, sun.

Fruit: Achene.

A small shrub with rigid branches; occurs in gravel or rocky soil.

Amygdalus andersonil, see Prunus andersonii.

Amygdalus fasciculata, see Prunus fasciculata.

Anygdalus fremontii, see Prunus eriogyna.

Amygdalus glandulosa, see Prunus texana.

Amygdalus minutiflora, see Prunus minutifiora.

Amygdalus texana, see Prunus texana.

Amyris madrensis Wats.

Range: 17.

Site: Dry, well-drained, sun.

Fruit: Drupe.

A small to large, very leafy shrub.

Amyris parvifolia, see Amyris texana.

Amyris texana (Buckl.) Wilson.

Xanthoxylum texanum Buckl., Amyris parvifolia Gray.

Chapatillo.

Range: 17.

Site: Dry, well-dralned, sun.

Fruit: Drupe.

A small to large shrub.

Andrachne phyllanthoides (Nutt.) Coult.

Lepidanthus phyllanthoides Nutt., Savia phyllanthoides (Nutt.) Pax. and Hoffm.

Range : 16, 17, 20, 25 .

Site: Dry, well-drained, sun.

Fruit: Capsule, available September-October.

A small, straggling, much-branched shrub; flowers Julj-August.

Andrachne reverchonii Coult.

Savia phyllanthoides reverchonii (Coult.), Pax and Hoffm.

Range: 16, 25.

Site: Dry, well-drained, sun.

Fruit: Capsule.

A small, densely leafy shrub.

Andromeda acuminata, see Leucothoë acuminata.

Andromeda arboreum, see Oxydendrum arboreum.

Andromeda axillaris, see Leucothoë axillaris.

Andromeda baccata, see Gaylussacia baccata. 
Andromeda caerulea, see Phyllodoce caerulea.

Andromeda calyculata, see Chamaedaphne calyculata.

Anüromeda canescens, see Andromeda glaucophylla.

Andromeda cassinefolia, see Zenobia cassinefolia.

Andromeda catesbaei, see Leucothoë catesbaei.

Andromeda floribunda, see Pieris fioribunda.

Andromeda glaucophylla Link.

A. canescens Small.

Range: 23, 24, 26, 27.

Site: Well-drained, moist, sun.

Fruit: Capsule, avallable September-November. July.

A small, evergreen shrub; ordinarlly occurs in very acid peat; flowers May-

Andromeda ligustrina, see Xolisma ligustrina.

Andromeda mertensiana, see Cassiope mertensiana.

Andromeda polifolia $\mathrm{L}$.

Range: $4,12,23,24,26,27$.

Bog-rosemary.

Suite: Moist, sun.

Fruit: Capsule.

A small to large evergreen shrub; flowers May-July; possesses creeping rootstocks; occurs on acid peat; rarely attacked by insects or disease.

Stonach records: Ptarmigan. Normally rejected by grazing animals; but poisonous to stock, especially in spring.

Andromeda pulverulenta, see Zenobia pulverulenta.

Andromeda racemosa, see Leucothoë racemosa.

Andromeda recurva, see Leucothoë recurva.

Anisacanthus insignis Gray.

A. pumilus Wats.

Range: 11.

Site: Dry, sun.

Fruit: Capsule.

A small shrub, palatable to stock but not as much so as $A$. thurberi.

Anisacanthus pumilus, see Anisacanthus insignis.

Anisacanthus thurberi (Torr.) Gray.

Taparosa.

Drejera thurberi Torr.

Range: 11.

Site: Dry, well-drained, moist, sun.

Fruit: Capsule.

A small shrub with fairly good to very good palatability as stock forage; often closely browsed by sheep and cattle.

Anisacanthus wrightii (Torr.) Gray.

Drejera urightii (Torr.) Gray.

Range: $11,16,17,20,30$.

Site: Dry, well-drained, sun.

Fruit: Capsule.

A small shrub; palatable to stock but not as much so as the preceding.

Anisostichus capreolata, see Bignonia capreolata.

Anneslia eriophylla, see Calliandra eriophylla.

Anona triloba, see Asimina triloba.

Apinus albicaulis, see Pinus albicaulis.

Apinus flexilis, see Pinus flexilis.

Aplopappus acradenius (Greene) Blake.

Bigelovia acradenius Greene, Isocoma acradenius Greene.

Goldenbush.

Range: 10.

Site: Dry, sun.

Fruit: Achene.

A small, tufted shrub; flowers September-October. 
Aplopappus arborescens Hall.

Goldenfleece. Bigelovia arborescens Gray, Chrysoma arborescens Greene, Ericameria arborescens Greene.

Range: $1,4,5$.

Site: Dry, well-drained, sun.

Frult: Achene.

A small or usually large evergreen shrub; flowers September-November. Grazlng value nil.

Aplopappus bloomeri Greene.

Chrysothamnus bloomeri (Gray) Greene.

Bloomer goldenbush.

Range: 4.

Site: Dry, sun.

Fruit: Achene.

A small shrub; flowers August-September; grazing value small.

Aplopappus brachylepis, see Aplopappus propinquus.

Aplopappus canus (Gray) Blake.

Diplostephium canum Gray, Corethrogyne detonsa Greene, C. cana Greene, Hazardia cana Greene, $H$. detonsa ${ }_{1}$ Greene, $H$. serrata Greene.

Range: 5.

Site: Dry, well-drained, sun.

Frult: Achene.

A small shrub; flowers July-August; very handsome; somewhat cultivated.

Aplopappus cooperi (Gray) Hall.

Cooper goldenbush.

Ericameria monactis (Gray) McClatch., Acamptopappus microcephalus

Jones, Chrysothamnus corymbosus Elmer, Tumionella monactis Greene.

Range: 10.

Site : Dry, sun.

Fruit: Achene.

A small, very leafy shrub.

Aplopappus cuneatus Gray.

Wedgeleaf goldenbush.

Ericameria cuneatus McClatch., Bigelovia cuneata spathulata (Gray) Hall,

Bigelovia spathulata Gray.

Range: 4, 5, 10.

Site: Dry, sun.

Fruit: Achene.

A small shrub.

Aplopappus ericoldes (Less.) Hook. and Arn. (pl. 2, A).

Mock-heather.

Ericameria ericoides (Less.) Jeps.

Range: $5,9$.

Site: Well-drained, sun.

Fruit: Achene.

A small shrub; flowers August-September; usually occurs on sand dunes; stems decumbent.

Aplopappus interior, see A. linearifolius.

Aplopappus laricifolius Gray.

Chrysoma laricifolius (Gray) Greene, Bigelovia nelsonii Fern., Ericameria nelsonii Blake.

Range: 10, 11.

Site: Dry, sun.

Fruit: Achene.

A small shrub, exceedingly handsome in flower.

Aplopappus linearifollus DC.

Narrowleaf goldenbush.

Stenotopsis linearifolius (DC.) Rydb., Stenotus linearifolius Torr. and Gray.

Range: 5, 9, 10.

Site: Dry, sun.

Fruit: Achene.

A small to large shrub; flowers March-May.

Var. interior (Cov.) Jones (Aplopappus interior Cov., Stenotopsis interior Rydb.) extends the range to regions 9 and 10. 

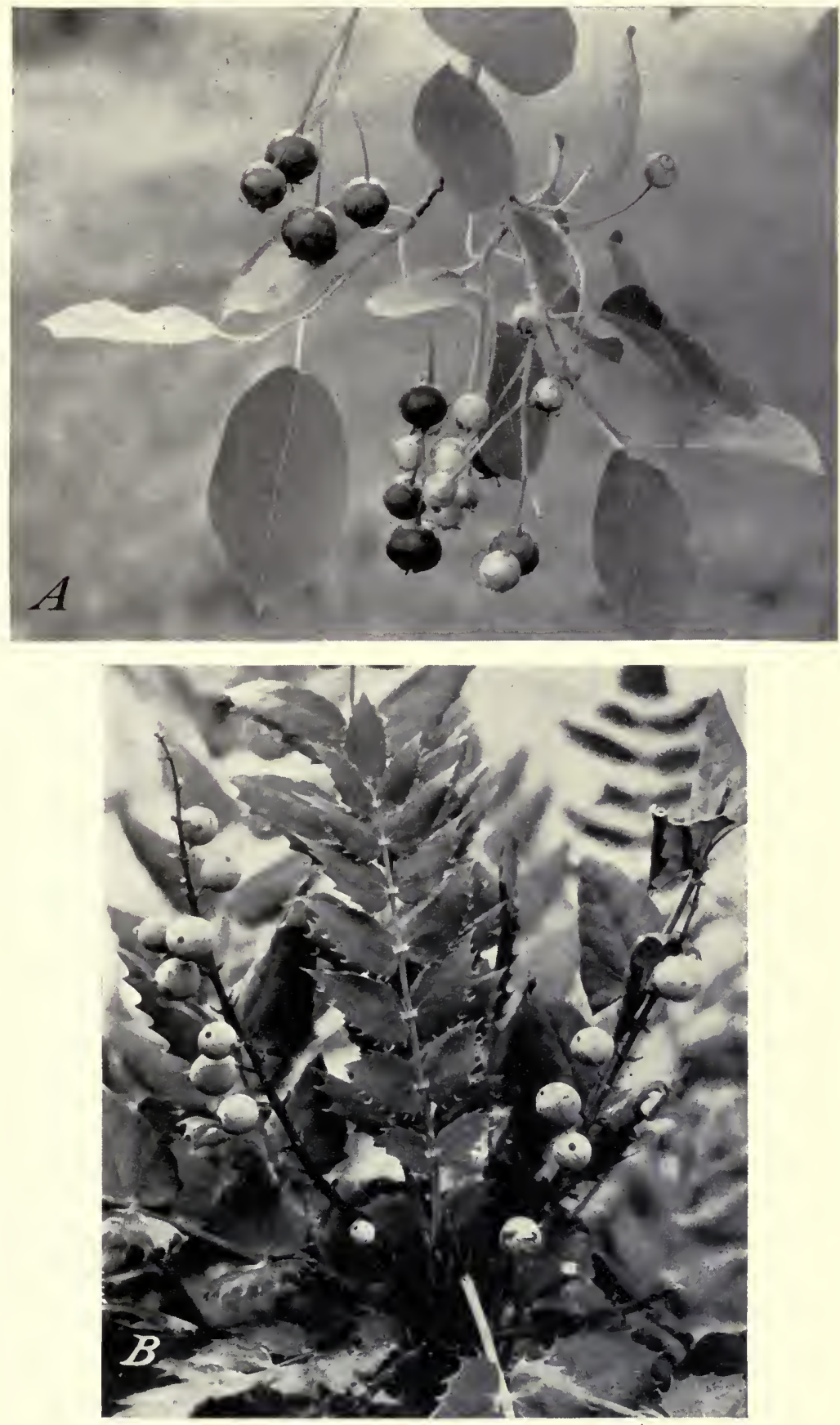

A, Amelanchier canadensis. The pomes of this plant attract many birds to woodland borders where it often fruits abundantly. $B$. Berberis nervosa. The thicket-forming habit of this species even under the shade of trees suggests its possible use as a woodland ground cover. Its wildlife value is probably greater than recorded. 

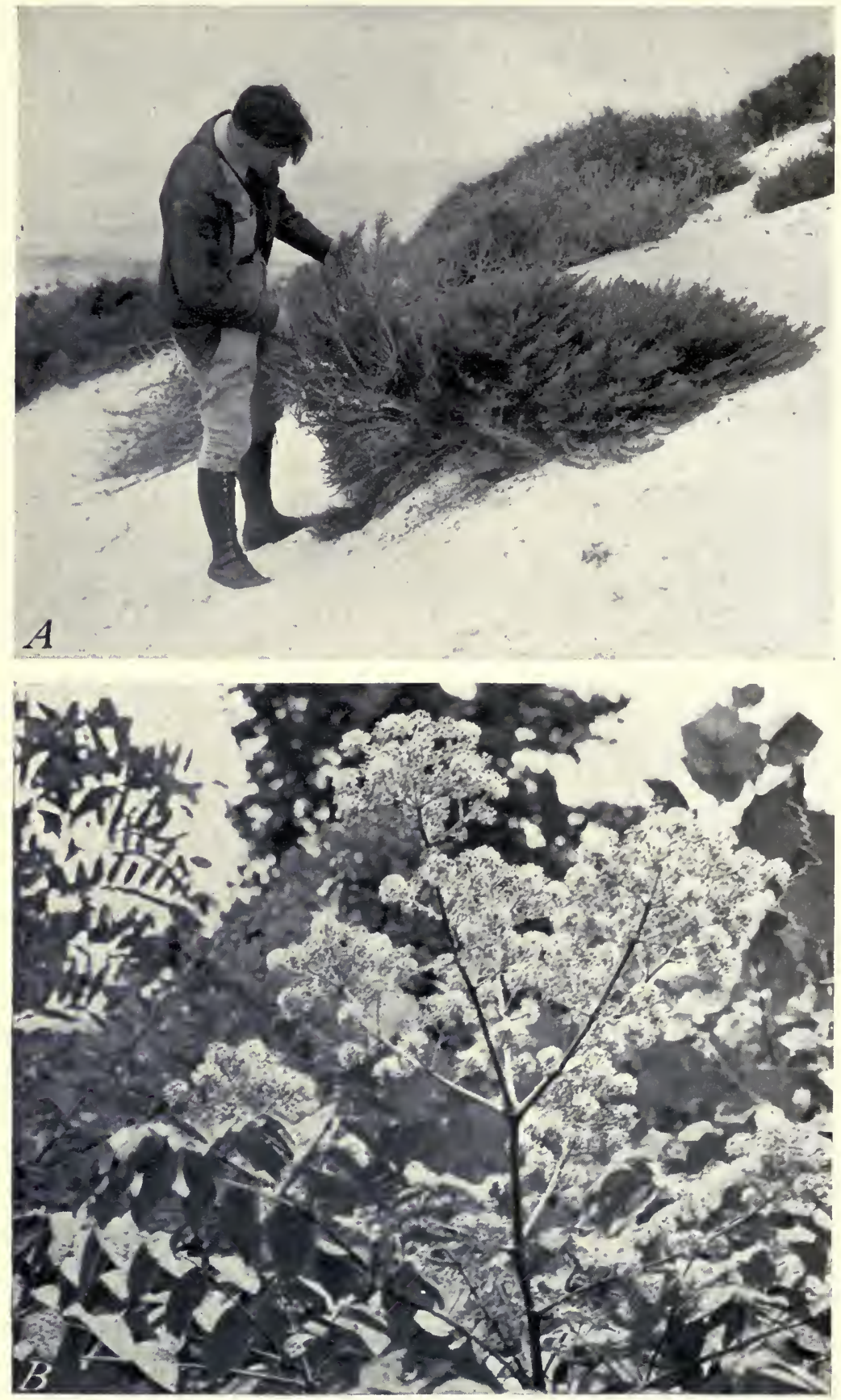

A, Aplopappus ericoides, a species well adapted to sand-dune planting. B, Aralia spinosa. The great flower sprays, followed by equally large fruit clusters, suggest the use of this species in highway planting; however, it provides poor cover for soil unless thickly planted. (Photograph by Department of the Interior.) 
Aplopappus nanus Eaton.

Dwarf goldenbush. Greene.

A. resinosus Gray, Ericameria nana Nutt., E. resinosa Nutt., Chrysoma nana

Range: $4,6,7,8,12$.

Site: Dry, sun.

Fruit: Achene.

A small shrub.

Aplopappus palmerl Gray.

Ericameria palmeri (Gray) Hall, Chrysoma palmeri Greene.

Range: 5.

Site: Dry, sun.

Fruit: Achene.

A large, much-branched, bushy, evergreen shrub.

Aplopappos parishil (Greene) Blake. Greene.

Ericameria parishii Hall, Bigelovia parishii Greene, Chrysoma parishii

Range: 10.

Site: Dry, sun.

Fruit: Achene.

A large, resinous, densely leafy shrub.

Aplopappus pinifolius Gray.

Ericameria pinifolia (Gray) Hall.

Pineleaf goldenbush.

Range: 10.

Site: Dry, sun.

Fruit: Achene.

A small to large, bushy shrub.

Aplopappus propinquus Blake .

Chaparral goldenbush.

Ericamoria brachylepis Hall, Bigelovia brachylepis Gray, Chrysoma brachylepis Greene, Haplopappus brachylepis brachylepis Hall.

Range: $5,10$.

Site: Dry, sun.

Fruit: Achene.

A large, very leafy, brittle-stemmed shrub.

Aplopappus resinosus, see Aplopappus nanus.

Aplopappus scopulorum (Jones) Blake.

Bigelovia menziesii scopulorum Jones, Isocoma scopulorum (Jones) Rydb., Hesperodoria scopulorum Greene.

Range: 9.

Site: Dry, sun.

Fruit: Achene.

A small shrub; flowers August-September.

Aplopappus squarrosus Hook. and Arn.

Hazardia squarrosa Greene.

Range: 5, 10.

Site: Dry, well-drained, sun.

Fruit: Achene.

A small shrub; flowers freely September-October; openly branched; occasionally somewhat herbaceous.

Aralia humilis Cav.

Range: 10 .

Site: Dry, sun.

Fruit: Berry.

A small to large shrub.

Aralia spinosa L. (pl. 2, B).

Range: $20,25,27,28,29,30$.

Coast goldenbush.

Site: Dry, well-drained, sun, shade.

Fruit: Berry, available August-November.

Usually a large shrub or a small tree or rarely large tree; flowers JuneAugust; very spiny; leaves very large; suckers freely if killed above ground; 
seriously attacked in cultivation by the lilac borer; propagation is by seed sown as soon as ripe or stratified and sown in spring, or by root cuttings.

Stomach records: Turkey. Observations: Much eaten by birds; white-tailed deer.

Arbutus spp.

Madrones.

Propagation is by seeds sown under glass in fall or spring.

Stomach records (in addition to specific records): Mearn's quail. Observations (in addition to specific records): Band-tailed pigeon.

Arbutus arizonica (Gray) Sarg.

A. xalapensis arizonica Gray.

Range: 11, 14.

Site: Dry, well-drained, sun.

Fruit: Berry, available July-December.

A large evergreen tree; flowers in May. Not grazed, except rarely by goats.

Arbutus menziesii Pursh.

Range: $1,2,3,5,10$.

Madrone.

Site: Dry, well-drained, moist, sun.

Fruit: Berry, available July-January.

A small to generally large and widely-branched tree; flowers March-May; commonly shrubby southward; stump sprouts after injury; wood somewhat used commercially; bark used for tanning; seeds $25-30$ per berry; about 1,000 usable plants per pound of seed; difficult to transplant; very handsome and commonly cultivated.

Stomach records: Two species of birds. Observations: Five species of birds including dove, band-tailed pigeons, and turkey; extensively eaten by deer; of slight importance as browse for mule deer; raccoon, ring-tailed cat. Lightly grazed by cattle or heavily grazed by goats. A good bee plant.

Arbutus texana Buckl.

A. xalapensis texana Gray.

Texas madrone.

Range: 11, 16, 17, 20.

Site: Dry, well-drained, sun.

Fruit: Berry, available August-June.

A large shrub or small tree or rarely a large tree; evergreen; often found on limestone soil; wood used commercially to some extent; berries palatable. Occasionally browsed by stock.

Arbutus uva-ursi, See Arctostaphylos uva-ursi.

Arctostaphylos spp.

Manzanitas.

Ordinarily chaparral shrubs; many species hold the leaves rertically; most reproduce extensively by root shoots; propagated by seeds sown in spring after stratification for 140 days at $41^{\circ}-50^{\circ} \mathrm{F}$.

Stomach records (in addition to specific records) : Seventeen species of birds, including dusky grouse, California quail, sharp-tailed grouse; gray fox, raccoon, striped skunk, coyote, Inyo chipmunk, western skunk. Observations (in addition to specific records): Seven species of birds includling dusky grouse, bandtailed plgeon, Merriam's turkey; mountain sheep, New Mexico black bear, Allen's chipmunk, golden-mantled ground squirrel, Oregon gray fox, ring-tailed cat, Californla gray squilrel. Usually of small value as forage except for goats.

Arctostaphylos andersonii Gray.

Heartleaf manzanita.

A. pechoensis Dudl., Uva-ursi pechoensis (Dudl.) Abrams, U. andersonii (Gray) Abrams.

Range: 1,5 .

Site: Dry, well-drained, sun.

Fruit: Berry, avallable January-September.

A large evergreen shrub; does not crown sprout after fire.

Arctostaphylos bicolor (Nutt.) Gray.

A. veatchii Kell., Xylococcus bicolor Nutt.

Range: 5 .

Site: Dry, well-drained, sun.

Fruit: Berry.

A small, densely-branched evergreen shrub. 
Arctostaphylos canescens Eastw.

Range: 4,5 .

Site: Dry, well-drained, sun.

Fruit: Berry, available all year round.

A large evergreen shrub; often grows on gravelly slopes; apparently does not sprout after fires.

Arctostaphylos cinerea Howell.

Range: 4.

Site: Dry, sun.

Fruit: Berry.

A large evergreen shrub.

Arctostaphylos columbiana Piper.

Hairy manzanita.

Range: 1,5 .

Site: Well-drained, sun.

Fruit: Berry.

A large evergreen shrub that does not crown sprout after fire.

Arctostaphylos crustacea Eastw.

Range: 1 .

Site: Dry, sun.

Fruit: Berry.

A small to large evergreen shrub.

Arctostaphylos diversifolia Parry.

A. arguta diversifolia Parry, Comarostaphylos diversifolia Greene.

Range: 5 .

Site: Dry, sun.

Fruit: Berry, available all year round.

A large shrub to small evergreen tree; about 16,000 seeds per pound.

Arctostaphylos drupacea $\mathrm{McBr}$.

Uva-ursi drupacea (McBr.) Abrams.

Roughleaf manzanita.

Range: $4,5,10$.

Site: Dry, well-drained, sun.

Fruit: Berry, available June-July.

A large evergreen shrub; does not stump sprout. This species is possibly only a variety of $A$. pringlei.

Observations: Fair browse for mule deer.

Arctostaphylos glandulosa Eastw.

Eastwood manzanita.

A. vestita Eastw., A. virgata Eastw.

Range: 1, 5 .

Site: Dry, well-drained, sun.

Fruit: Berry, available February-November.

A small to large evergreen shrub, often found on sandstone; root crown broad and woody, giving rise to numerous sprouts after chaparral fires; decumbent branches root.

Observations: Of slight importance as browse for mule deer.

Arctostaphylos glauca Lindl.

Uva-ursi glauca (Lindl.) Abrams.

Great-berried manzanita.

Range: 3, 5, 8, 9, 10.

Site: Dry, well-drained, sun.

Fruit: Berry.

A large shrub to small tree; evergreen; colony forming; slow growing; thrives on many kinds of soil; does not recover rapidly after burning.

Observations: Fair browse for mule deer.

Arctostaphylos hookeri Don.

Uva-ursi hookeri (Don) Abrams.

Range: 1.

Site: Dry, well-drained, sun.

Fruit: Berry.

A smali evergreen shrub growing on sandy or other soils; decumbent branches root at the nodes. 
Arctostaphylos insularis Greene.

Uva-ursi insularis (Greene) Abrams.

Range: 5.

Site : Dry, well-drained, sun.

Fruit: Berry.

A large evergreen shrub.

Arctostaphylos manzanita Parry. (pl. 3, A, B).

Parry manzanita.

Uva-ursi manzanita (Parry) Abrams.

Range: 1, 4 .

Site: Dry, well-dralned, sun.

Fruit: Berry, available all year round.

A large, slow-growing evergreen shrub; killed by fire and does not crown sprout.

Stomach records: Four species of birds, including dusky grouse and sharptailed grouse. An important honey plant.

Arctostaphylos mariposa Dudl.

Uva-ursi mariposa (Dudl.) Abrams.

Mariposa manzanita.

Range: 4.

Site: Dry, well-drained, sun.

Fruit: Berry, avallable August-September.

A large evergreen shrub; does not sprout after fire.

Observations: Mountaln quail; of slight value as forage for mule deer; mountain coyote, California gray fox.

Arctostaphylos mewukka Merr.

A. pastillosa Jeps.

Range: 4.

Site: Dry, sun.

Frult: Berry.

A large evergreen shrub: stump sprouts after fire.

Arctostaphylos montana Eastw.

Uva-ursi montana (Eastw.) Abrams.

Range: 1 .

Site: Dry, sun.

Fruit: Berry.

A small shrub to small tree; bushy and evergreen; does not survive fire except as seed; apparently restricted to serpentine areas.

Arctostaphylos myrtifolia Parry.

Uva-ursi myrtifolia (Parry) Abrams.

Range: 4.

Site: Well-drained, sun.

Fruit: Berry.

A small evergreen shrub.

Arctostaphylos nevadensis Gray.

Uva-ursi nevadensis (Gray) Abrams.

Pine-mat manzenita.

Range: 4.

Site: Dry, well-drained, sun.

Fruit: Berry, available July-September.

A small evergreen shrub; often low and procumbent, rooting where the branches touch the ground.

Stomach records: Three species of birds including sooty and dusky grouse.

Observations: Fair browse for mule deer. Sparingly browsed by cattle.

Arctostaphylos nummularia Gray.

Uva-ursi nummularia (Gray) Abrams.

Range: 1.

Site: Well-drained, sun.

Frult: Berry.

A small evergreen shrub.

Arctostaphylos oblongifolia Howell.

Range: 4.

Site: Dry, sun.

Fruit: Berry.

A large shrub to small tree; evergreen. 
Arctostaphylos parryana Lemmon.

Uva-ursi parryana (Lemmon) Abrams.

Range: $4,5$.

Site: Dry, well-drained, sun.

Fruit: Berry.

A small evergreen shrub. Very closely related to A. manzanita and possibly better made a variety of that species.

Arctostaphylos pastillosa, see Arctostaphylos mewukka.

Arctostaphylos patula Greene.

Greenleaf manzanita.

A. platyphylla (Gray) Kuntze, Uva-ursi patula (Greene) Abrams.

Range: 1, 3, 4, 9, 11, 13.

Site : Dry, well-drained, sun.

Fruit: Berry; available May-September, occasionally persists all year round.

A large evergreen shrub; repeated burnings cause the formation of a large root crown, which sprouts after each fire; heavy snowfall may force its brauches to the ground, where they root; attempts have been made to eradicate it with concentrated goat feeding, but these have proved impracticable.

Observations: Of outstanding importance as browse for mule deer. An emergency winter feed for livestock.

Arctostaphylos pechoensis, see Arctostaphylos andersonii.

Arctostaphylos platyphylla, see Arctostaphylos patula.

Arctostaphylos pringlei Parry.

Uva-ursi pringlei (Parry) Abrams.

Range: 10, 11, 14.

Site: Dry, sun.

Fruit: Berry.

A large evergreen shrub.

Observations: Mearn's and Gambel quail; skunks, foxes, coyotes.

Arctostaphylos pumila Nutt.

Uva-ursi pumila (Nutt.) Abrams.

Sandmat manzanita.

Range: 1 .

Site: Dry, well-drained, sun.

Fruit: Berry.

A small evergreen shrub or sometimes a vinelike plant; stems prostrate, forming mats; occurs most often on sandy soil.

Arctostaphylos pungens H. B. K.

Uva-ursi pungens (H. B. K.) Abrams.

Range: 9, 10, 11, 13, 14 .

Site: Dry, well-drained, sun.

Fruit: Berry, available July-April.

A small to large evergreen shrub; root system flbrous, generalized, not deep, but taproots well developed in light sandy soil; decumbent branches root; germination of seed about 35 percent or less.

Stomach records: Sooty glouse; northern hooded skunk, black-tailed deer. observations: Blue grouse, Mearn's and Gambel quail; bear, pigeons, skunks, foxes, coyotes. Freely grazed by goats.

Arctostaphylos sensitiva Jeps.

Range: 1 .

Site: Dry, well-drained, sun.

Fruit: Berry.

A small evergreen shrub; often invades burnt-over areas; root system shallow; colony-forming; killed outright by chaparral fires.

Arctostaphylos setosissima Eastw.

Range: 1.

Site: Dry, well-drained, sun.

Fruit: Berry.

A large evergreen shrub. 
Arctostaphylos stanfordiana Parry.

Uva-ursi stanfordiana (Parry) Abrams.

Range: 4 .

Site: Dry, sun.

Fruit: Berry.

A large evergreen shrub : killed in shaparral fires.

Arctostaphylos tomentosa (Pursh) Lindl. (pl. 4, A).

Uva-ursi tomentosa (Pursh) Abrams.

Range: $1,4,5,11$.

Site: Dry, well-drained, sun.

Fruit: Berry, available all year round.

A small to large evergreen shrub; forms very good soil cover.

Var. crassifolia Jeps. occurs in region 5 and is killed entirely by fire.

Arctostaphylos uva-ursi (L.) Spreng.

Arbutus uva-ursi L., Uva-ursi uva-ursi (L.) Britt.

Bearberry.

Range: 1, 4, 12, 13, 14, 18, 21, 22, 23, 24, 26, 27, 28.

Site: Dry, well-drained, sun, shade.

Fruit: Berry, available Angust-March or rarely persistent all year round.

A small evergreen shrub or, more properly, a woody vine; occurs most commonly ou sandy soil, but may occur on loam; propagation by cuttings taken in late summer and rooted under glass or by seed.

Stomach records: Eighteen species of birds, including ruffed grouse and dusky grouse; mountain sheep, black-tailed deer. Observations: Ruffed grouse, Richardson's grouse, spruce grouse, turkey, dusky grouse, sharp-tailed grouse, black bear; browsed to some extent by northern white-tailed deer. Of little value for livestock.

Arctostaphylos veatchii, see Arctostaphylos bicolor.

Arctostaphylos vestita, see Arctostaphylos glandulosa.

Arctostaphylos virgata, see Arctostaphylos glandulosa.

Arctostaphylos viscida Parry.

Uva-ursi viscida (Parry) Abrams.

Whiteleaf manzanita.

Range: 1, 4.

Site : Dry, well-drained, sun.

Fruit: Berry, available all year round. fire.

A large evergreen shrub or rarely a small tree; does not crown sprout after

Argentacer saccharinum, see Acer saccharinum.

Aristolochia spp.

Pipe-vines.

Stomach records (in addition to specific records): Gambel quail, but this record may apply to $A$. watsonii, a nonwoody vine.

Aristolochia californica Torr.

California pipe-vine.

Range: 1, 3, 4 .

Site: Well-drained, sun, shade.

Fruit: Capsule.

A vine; flowers March-April; ordinarily climbs on shrubs.

Aristolochia durior Hill.

Aristolochia macrophylla Lam., A. sipho L'Her.

Dutchman's pipe-vine.

Range: 22, 23, 25, 27.

Site: Well-drained, sun.

Fruit: Capsule, available in September.

A vigorous vine; flowers May-June; propagation by seeds stratified 140 days at $50^{\circ} \mathrm{F}$. before sowing; much cultivated; probably introduced into region 23.

Aristolochia macrophylla, see Aristolochia durior.

Aristolochia sipho, see Aristolochia durior.

Aristolochia tomentosa Sims.

Woolly pipe-vine.

Range: $22,25,29,30$.

Site: Well-drained, moist, sun, shade.

Fruit: Capsule, available September-November. 

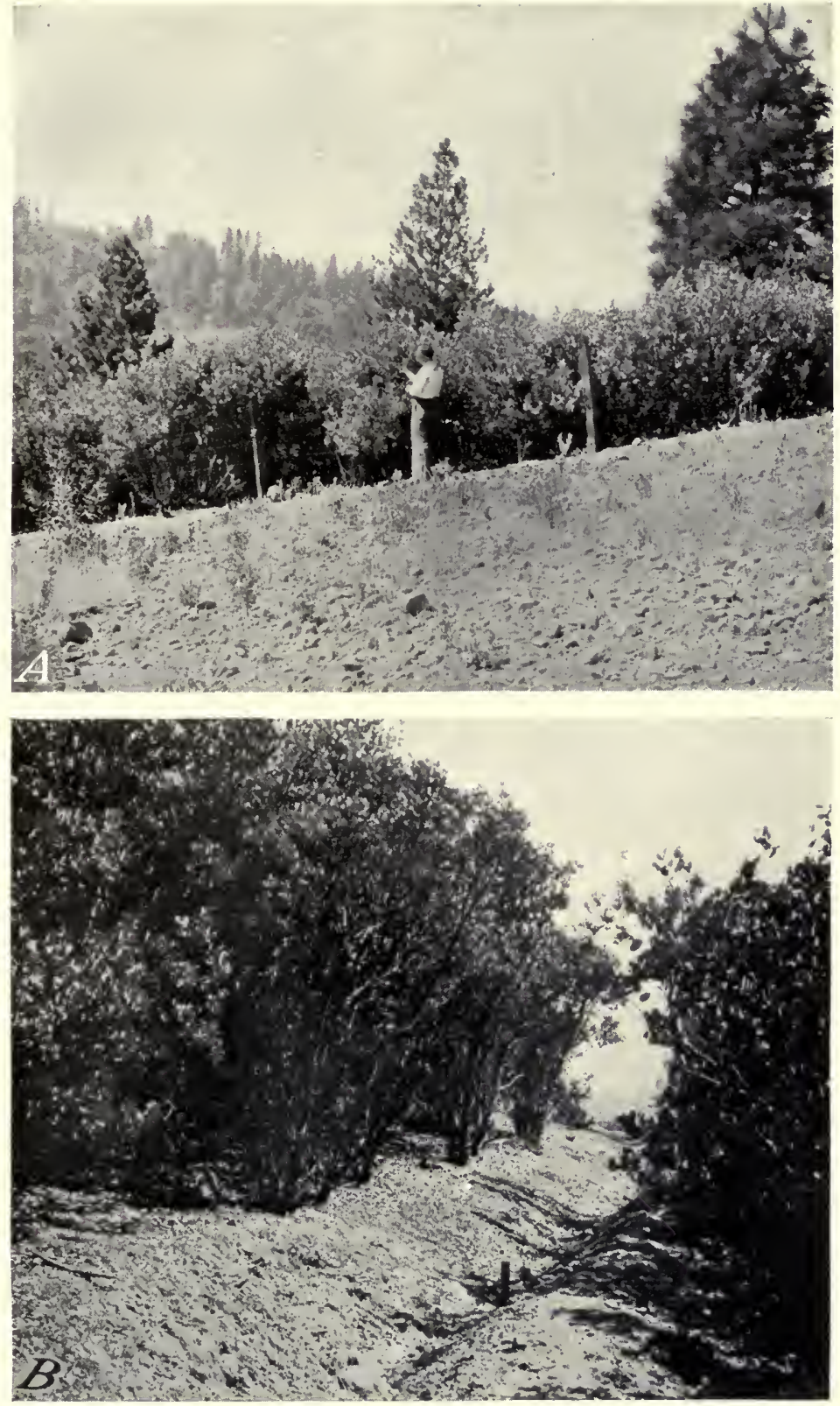

Arctostaphylos manzanita. A, Prevention of erosion on part of this central-California hillside is assured by a dense thicket of manzanita. Young plants pioneering in the worn-out cultivated field in the foregound may soon afford protection to the rest of the hillside. $B, \mathrm{~A}$ view in the interior of the same thicket showing the dense cover and litter accumulation. The cleared drainage ditch carries water from a cultivated field. 

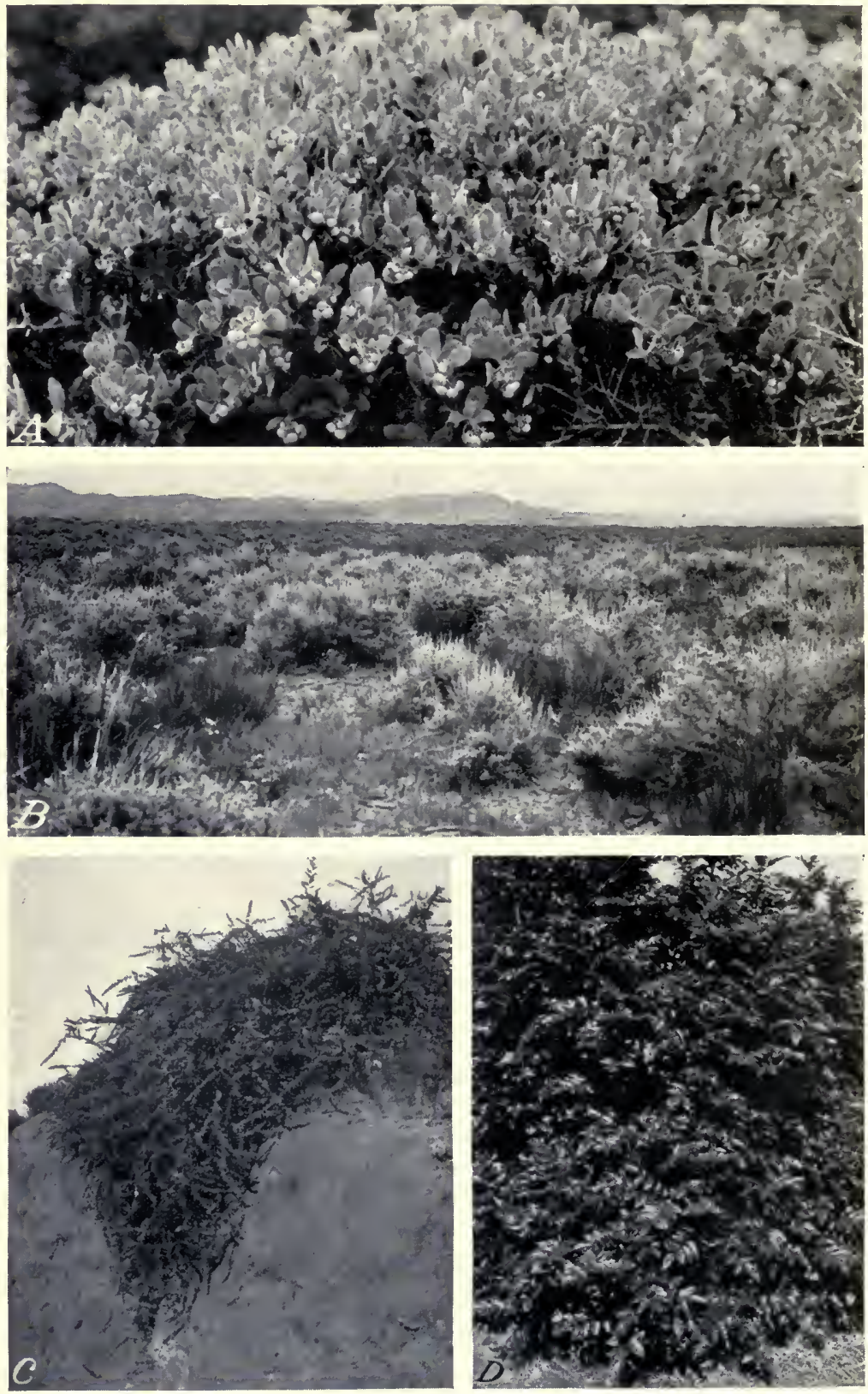

A, Arctostaphulos tomentosa. The ability of most species of Arctostaphylos to grow in poor soils, their thicketforming habit, and their abundant fruit production, makes the majority of them of great value in plantings for erosion control and wildlife. B, Artemisia tridentata. Typical sagebrush country. The lighter colored bushes are the big sagebrush, important alike as soil and wildlife cover and as food for wildlife and livestock. $C$, Atriplex canescens. This plant, of considerable importance for wildlife and livestock, and without question a valuable soil cover, merits considerable use in planting operations in the Southwest. $D$, Berberis aquifolium. A cover of such density as this should prove exceptionally valuable for soil as well as wildlife. The Oregon-grape is fairly resistant to black stem. rust. 
A high-climbing vine; flowers May-June; in Alabama has shown a tendency to spread.

Aronia spp.

Chokeberries.

Shrubs; commonly occur in acid soil; propagation by seed stratified 90 days at $22^{\circ}-41^{\circ} \mathrm{F}$. before sowing.

Stomach records (in addition to specific records): 12 species of birds, including ruffed grouse, bobwhite, sharp-tailed grouse, ring-necked pheasant, prairie chicken; composed 1.0 percent of food of prairie chicken in Wisconsin. Observations (in addition to specific records): Eight species of birds including ruffed grouse, bobwhite, sharp-tailed grouse; an important pheasant food, especially in late winter, in southern Michlgan; cottontail rabbit.

Aronia arbutifolia (L.) Ell.

Red chokeberry.

Pyrus arbutifolia $\mathrm{L}$. f.

Range : 22, 23, 25, 27, 28, 29, 30 .

Site: Dry, well-drained, moist, sun, shade.

Fruit: Berry; available August-October, persistent, especially southward.

A small to rarely large shrub; flowers March-May; somewhat subject to blight and borer attack; will withstand city smoke; leaves fall very late; propagation by seeds stratified 90 days at $32^{\circ}-41^{\circ}$ F.; about 10,000 usable plants per pound of seed; probably introduced into region 23.

Var. atropurpurea (Britt.) Robins., (A. atropurpurea Britt., A. floribunda Spach), the purple chokeberry, is often separated as a distinct species. Intergrading forms are common, field identification difficult, seeds in birds' stomachs are indistinguishable, and there appears to be no ecological differentiation between this and the species. Observations: Ruffed grouse, ring-necked pheasant.

Stomach records: 13 species of birds, including ruffed grouse. Observations: Cedar waxwing; captive marsh rabbit.

Aronia atropurpurea, see Aronia arbutifolia.

Aronia floribunda, see Aronia arbutifolia.

Aronia melanocarpa (Michx.) Ell.

Black chokeberry.

Pyrus arbutifolia melanocarpa Michx., P. melanocarpa Willd., P. nigra Sarg., A. nigra Sarg.

Range: $22,23,24,25,26,27,28,29$.

Site : Dry, well-drained, moist, sun, shade.

Fruit: Berry, available August-September, often persistent until June-July.

A small or rarely large shrub; flowers March-June; somewhat subject to blight and borer attack; has been observed to grow on cinder dumps where fruit crops are often heavy.

Stomach records: Ruffed grouse, sharp-tailed grouse, prairie chicken; composed 5.3 percent of fall food of sharp-tailed grouse in Wisconsin. Observations: Eaten to some extent by cottontail rabbit; white-tailed deer.

Aronia nigra, see Aronia melanocarpa.

Arsenococcus frondosus, see Xolisma ligustrina.

Arsenococcus ligustrinus, see Xolisma ligustrina.

Artemisia spp.

Most species harbor the burdock borer and common stalk borer.

Stomach records (in addition to specific records): Five species of birds, including ruffed grouse and Gambel quail (these recorts apply to both herbaceous and shrubby species); mountain sheep, antelope jack rabbit, gray-sided jack rabbit, black-tailed deer. Observations (in addition to specific records): Hepburn's rosy finch; used extensively by sage grouse for cover, roosting cover and food, about 69 percent of their food consisting of composites, most of which are species of sagebrush, which are eaten particularly in winter and during times of scarclty of other foods; western white-tailed jack rabbit, Oregon jack rabbit; pygmy rabbit, especially in winter when the diet may be exclusively sagebrush; much eaten and furnishes cover and shelter to sage chipmunk; pronghorn antelope. Of great importance as forage for livestock.

Artemisia abrotanoides, see Artemisia californica. 
Artemisia arbuscula Nutt.

A. tridentata arbuscula (Nutt.) Hall and Clem.

Scabland sagebrush.

Range: $4,7,8,9,12$.

Site: Dry, sun.

Fruit: Achene.

A small, much-branched, stiff, straggling shrub; seed germination about 40 percent.

Observations: Of slight value as forage for mule deer. Locally of some value as forage for livestock.

Artemisia bigelovii Gray.

A. petrophila Woot. and Standl.

Flat sagebrush.

Range : 9, 10, 11, 16 .

Site: Dry, well-drained, sun.

Fruit: Achene.

A small, many-stemmed, spreading shrub considered more palatable to stock than the common sagebrush; very good spring browse, especially for sheep.

Artemisia bolanderi Gray.

A. tridentata bolanderi (Gray) Hall and Clem.

Range: 4.

Site: Dry, well-drained, sun.

Fruit: Achene.

A small, much-branched, leafy-twigged shrub. Browse value about the sameas that of A. tridentata.

Artemisia californica Less.

Coastal sagebrush.

A. fischeriana Bess., A. abrotanoides Nutt., Crossostephium californicum Rydb., C. foliosum Rydb., C. insulare Rydb.

Range: 5, 10.

Site: Dry, sun.

Frult: Achene.

A small to large, many-stemmed, xerophytic shrub; freely branched; a climax or subclimax dominant; casts very little shade; inflammable; browsed only by sheep and goats in times of scarcity.

Artemisia cana Pursh.

A. columbiana Nutt., A. viscidula (Osterh.) Rydb.

Silver sagebrush.

Range: 4, 8, 9, 11, 12, 13, 15, 19, 21.

Site : Dry, well-drained, sun.

Fruit: Achene.

A small or rarely large shrub; freely branched; found on plains and lower mountains; generally occurs on north and sheltered sides of hills; requires more water than $A$. tridentata.

Stomach records: One species of bird. Observations: Important food of sage grouse. A very important local browse for livestock.

Artemisia columbiana, see Artemisia cana.

Artemisia filifolia Torr.

Range: 9, 11, 15, 16.

Site: Dry, sun.

Fruit: Achene.

A small, freely-branched shrub; occurs only on sandy soil; experiments in New Mexico in range seeding with this species were unsuccessful ; fruiting hoads often transformed into galls; a sand indicator, changes in its abundance indicating the amounts of sand in the soil; germination of seed 40-50 percent. Palatable to livestock and locally used as forage but seldom browsed in grassland districts.

Artemisia fischeriana, see Artemisia californica.

Artemisia frigida Willd.

Range: $7,8,9,11,12,13,14,15,16,18,19,21,23$.

Estafiata.

Site: Dry, sun.

Fruit: Achene.

A small shrub often only woody at the base or even entirely herbaceous; stems decumbent at base; a mat-forming species, especially when not shrubby; 
an indicator of overgrazing; direct seeding experiments with this species were unsuccessful in New Mexico; not poisonous to livestock.

Observations: An important food of sage grouse; important winter food for elk, bighorn. Of high rank as forage for stock, the forage value increasing southward.

Artemisia nova Nels.

A. tridentata nova (Nels.) Hall and Clem.

Small sagebrush.

Range: $7,8,9,10,11,13$.

Site: Dry, sun.

Fruit: Achene.

A small shrub; often occurs on shallow, stony soils. Of importance southward as forage for livestock.

Artemisia parishii Gray.

A. tridentata parishii (Gray) Hall and Clem.

Range: $9,10$.

Site: Dry, sun.

Fruit: Achene.

A small to usually large shrub; very much like $A$. tridentata and perhaps not specifically distinct; resembles that species in practically all ecological aspects. For browse value refer to A. tridentata.

Artemisia petrophila, see Artemisia bigelovii.

Artemisia rigida (Gray) Nutt.

A. trifida rigida Nutt.

Stiff sagebrush.

Range: $7,8,12$.

Site: Dry, sun.

Fruit: Achene.

A small shrub; very often occurs on lava outcrops.

A locally valuable browse plant, particularly palatable to horses; fair sheep forage.

Artemisia rothrockii Gray.

A. tridentata rothrockii (Gray) Hall and Clem.

Range: 4, 7, 8, 9, 10, 12, 13.

Site: Dry, well-drained, sun.

Fruit: Achene.

A small shrub, usually confined to higher zones in the mountains. Browse value for livestock similar to that of $\boldsymbol{A}$. triäentata.

Artemisia spinescens Eaton.

Picrothannus desertorum Nutt.

Range: 7, 8, 9, 10, 11, 12 .

Site: Dry, well-drained, sun.

Fruit: Achenc.

A small, spiny, much-branched, rigid shrub with crowded stems; occurs on alkaline soil and indicates alkali in the soil; root system very extensive; extremely resistant to drought and overgrazing. An important forage for livestock, but poisonous or fatal to calves when eaten in quantity.

Artemisia tridentata Nutt. (pl. $4, B$ ).

Range: $4,5,6,7,8,9,10,11,12,13,15$.

Big sagebrush.

Site: Dry, well-drained, sun.

Fruit: Achene, available in October.

A small to large shrub, or in very good soil with plenty of water, a small tree; root system two storied with shallow fibrous, and deep-spreading roots; an indicator of deep soils largely free from alkali; seldom occurs on granitic soils; forms root sprouts to some extent; fairly rapid growing; direct seeding experiments with this species in New Mexico were unsuccessful ; germination of seed 35 percent or less.

Stomach records: Dusky grouse, sage grouse; black-tailed deer. Observations: Columbian sharp-tailed grouse; mule deer, bighorn. A most important stock browse of special value in autumn and winter; variously reported as poor to excellent forage; however, it enables stockmen to carry enormous numbers of cattle through the winter months. Reported as mildly poisonous to sheep and horses but there appears to be no direct evidence of its toxicity.

Artemisia trifida, see Artemisia tripartita.

$130186^{\circ}-39-5$ 
Artemisia tripartita Rydb.

$A$. trifida Nutt., $A$. tridentata trifida (Nutt.) Hall and Clem.

Range: $7,8,9,10,12$.

Site: Dry, sun.

Fruit: Achene, avallable in October.

A small shrub of value as winter livestock browse.

Artemisia viscidula, see Artemisia cana.

Ascyrum cuneifolium Chapm.

Range: $29,30$.

Site: Well-drained, sun.

Fruit: Capsule.

A small shrub.

Ascyrum hypericoides L.

A. linifolium Spach.

St.-Andrew's-cross.

Range: 17, 20, 25, 27, 28, 29, 30 .

Site: Dry, well-drained, moist, sun.

Fruit: Capsule, available September-October.

A small, much-branched, erect or decumbent shrub; flowers June-September; occurs on sterile soil ; short-lived; in cultivation.

observations: White-tailed deer.

Ascyrum linifolium, see Ascyrum hypericoides.

Ascyrum microsepalum, see Crookea microsepala.

Ascyrum pumilum Michx.

Range: 29,30 .

Site: Well-drained, sun.

Fruit: Capsule.

A small, diffusely-branched shrub; flowers spring to summer; stems short, often matted; occurs on sand.

Ascyrum stans Michx.

Range: 27, 28, 29, 30 .

St.-Peter's-wort.

Site: Moist, sun.

Fruit: Capsule.

A small shrub; generally occurs on acid, sandy soil; flowers summer to fall.

Ascyrum tetrapetalum (Lam.) Vail.

Range: $29,30$.

Site: Well-drained, moist, sun.

Fruit: Capsule.

A small shrub with very showy flowers produced from spring to fall or all year; usually occurs in sand.

Asimina angustifolia Gray.

Pityothamnus angustifolius (Gray) Small.

Narrow-leaved papaw.

Range: 29, 30.

Site: Dry, well-drained, sun, shade.

Fruit: Berry.

A small shrub.

Asimina grandiflora, see Asimina incana.

$\Lambda$ simina incana Bartr.

Flag papaw.

A. grandiflora (Michx.) Gray. A. speciosa Nash, Pityothamnus incanus (Bartr.) Small.

Range: 29, 30.

Site: Well-drained, sun, shade.

A small shrub.

Asimina parviflora (Michx.) Dunal.

Range: $20,28,29,30$.

Dwarf papaw.

Site: Dry, well-drained, sun, shade.

Fruit: Berry, a vailable August-September.

A large shrub with spreading branches; usually occurs in sand. 
Asimina pygmaea (Bartr.) Gray.

Pityothamnus pygmaeus (Bartr.) Small.

Range: 30.

Site: Well-drained, sun, shade.

Fruit: Berry, available July-August.

A small shrub with arching or decumbent stems.

Asimina speciosa, see Asimina incana.

Asimina triloba (L.) Dunal.

Anona triloba L.

Range : $20,22,24,25,27,28,29,30$.

Site: Well-drained, moist, sun, shade.

Fruit: Berry, available August-October.

Commonly a large shrub to small tree, or rarely a iarge tree; flowers MarchApril; thicket forming by means of suckers; shrubby northward; often persistent and difficult to eradicate from fields; thickets often vigorous and dense; a lepidoterous larva infures the flowers throughout a good portion of its range, but when not attacked, fruit is abundantly produced; otherwise generally free from insect enemies; two forms are known, one with white, insipid fruit; the other with a yellow pulp, but these are not recognized botanically; propagation is by seed sown as soon as ripe; suckers are generally difficult to transplant; about 1,200 seeds per pound, germination about 50 percent, about 250 usable plants per pound of seed.

Stomach records: Gray fox, opossum. Observations: Probably much eaten by birds; opossum, squirrel, raccoon; leaves refused by captive marsh rabbits. Astrophyllum dumosum, see Choisya dumosa.

Atragene americana, see Clematis verticillaris.

Atragene columbiana, see Clematis columbiana.

Atragene occidentalis, see Clematis pseudoalpina.

Atragene pseudoalpina, see Clematis pseudoalpina.

Atriplex spp.

Saltbushes.

Monoecious or dioecious shrubs with a salty taste; the species harbor the spinach mildew and consequently should not be planted where spinach is a commercial crop.

Stomach records (in addition to specific records): Twenty-nine species of birds, including Gambel quail ; white-sided jack rabbit, gray-sided jack rabbit; black-tailed deer. Observations (in addition to specific records) : Three species of birds, including ring-necked pheasant; Oregon jack rabbit, in dry seasons. In general, of considerable importance as cover for plains wildlife. The salty taste may flavor milk and possibly have a bad effect on unweaned calves, lambs, and kids, although the same taste appears to increase the palatability to livestock.

Atriplex breweri Wats.

Brewer saltbush.

A. lentiformis breweri (Wats.) Hall and Clem., A. orbicularis Wats.

Range : 1, 5 .

Site: Dry, well-drained, sun.

Fruit: Achene.

A large monoecious or dioecious shrub with abundant foliage; rapid growing; very tolerant of salinity; foliage subject to leaf-mining insects; much cult1vated, especially as a clipped hedge plant; seeds produced in abundance; occurs on sand, clay, and other soils.

Observations: California mule deer. Freely browsed by livestock.

Atriplex canescens (Pursh) Nutt. (pl. 4, $C$ ). Wingscale.

Calligonum canescens Pursh, A. garrettii Rydb., A. macropoda Rose and

Standl., A. linearis Wats.

Range: $7,8,9,10,11,15,16,17$.

Site: Dry, sun.

Fruit: Achene, available August-September.

A small or rarely large, rapid-growing evergreen shrub; dioecious or rarely monoecious; tolerates alkali but not necessarily found on alkaline soil; root system extensive; taproots 30-40 feet deep; extremely drought resistant; will 
withstand comparatively low temperatures; rery brittle; for range planting sow seeds 14-16 pounds per acre in March-April; can be seeded, if local seed is used, as soon as seed is ripe; germination $30-60$ percent.

Observations: Depended upon to a high degree by scaled quail for shade, cover, roost, and food; captive porcupine, rock squirrel, gray-spotted ground squirrel, Arizona jack rabbit. Produces great quantities of seeds, which are fattening and highly palatable to stock and have a high nutritional value. Browsed extensively by cattle, sheep, and goats, especially when other forage is scarce; has been known in a few instances to poison sheep, and concentrated feeding may cause scours in cattle.

Atriplex collina, see Atriplex confertifolia.

Atriplex confertifolia (Torr. and Frem.) Wats.

Shadscale.

Obione confertifolia Torr. and Frem., A. collina Woot. and Standl., A. subconferta Rydb.

Range: 8, 9, 10, 11, 15, 16.

Site: Dry, sun.

Fruit: Achene, available in September.

A small, spiny, rigid, dioecious, thickly-branched, densely clump-forming shrub; may occur on alkaline soil to $\mathrm{pH} 8.0$; about 15,000 seeds per pound.

Observations: Three species of birds; California mule deer. Of great importance as browse for sheep and, to some extent, cattle; spines often interfere with browsing by cattle.

Atriplex garrettii, see Atriplex canescens.

Atriplex hymenelytra (Torr.) Wats.

obione hymenelytra Torr.

Desert holly.

Range: 10 .

Site : Dry, sun.

Fruit: Achene.

A small, compact, rounded, dioecious evergreen shrub; in demand for Christmas decorations. Apparently not browsed.

Atriplex lentiformis (Torr.) Wats.

Lenscale.

Obione lentiformis Torr.

Range: $3,9,10,11$.

Site: Dry, sun.

Fruit: Achene, available September-October.

A large dioecious or rarely monoecious shrub; branches wide-spreading; foliage very thick and dense; rapid growing; usually occurs on alkaline soil ; about 412,000 seeds per pound.

Observations: Fairly important as browse for mule deer; of great importance as a corer for wildlife. Much browsed by cattle, especially from December to July, when other feed is scarce.

Atriplex linearis, see Atriplex canescens.

Atriplex macropoda, see Atriplex canescens.

Atriplex orbicularis, see Atriplex breweri.

Atriplex parryi Wats.

Range: 10.

Site: Dry, sun.

Fruit: Achene.

A small, spiny, rigid, dioecious shrub; occurs on alkaline soil.

Atriplex polycarpa (Torr.) Wats.

Obione polycarpa Torr.

Range: 3, 9, 10, 11.

Site: Dry, sun.

Fruit: Achene, available in October.

A small to large dioecious shrub; intricately and much branched; leaves early deciduous; a most important food of Eutettix tenella, the beet leafhopper, an insect carrying curly top disease of sugar beets; will grow on alkaline, but generally occurs on the richest of the desert soils; sometimes fruits abundantly when only 1 foot high; withstands up to 3 percent salt content of soil; germination of seed $30-60$ percent.

stomach records: California jack rabbit. Of great importance as browse for stock, especially since it so often occurs with unpalatable species; killed by excessive browsing. 
Atriplex spinifera MacBr.

Spinescale.

Range: 3, 10.

Site: Dry, sun.

Fruit: Achene.

A small to large, spinescent, dioecious shrub; broader leaves deciduous during the summer; found on moderately alkaline soil; important winter-food plant of Eutettix tenella, the beet leafhopper, an insect carrying the curly top disease of sugar beets.

Occasionally browsed by sheep.

Atriplex subconferta, see Atriplex confertifolia.

Atriplex torreyi Wats.

A. lentiformis torreyi (Wats.) Hall and Clem.

Torrey lenscale.

Range: 9,10 .

Site : Dry, sun.

Fruit: Achene.

A small, spiny, dioecious shrub; occurs on alkaline soil.

Audibertia capitata, see Salvia mohavensis.

Audibertia incana, see Salvia carnosa.

Audibertia pachystachya, see Salvia pachyphylla.

Audibertia polystachya, see Salvia apiana.

Audibertia stachyoides, see Salvia mellifera.

Audibertiella incana, see Salvia carnosa.

Ayenia microphylla Gray.

Range: 11.

Site: Dry, well-drained, sun.

Fruit: Pod, available in September.

A small, mucli-branched shrub with very small leaves.

Ayenia pusilla L.

Range : 11, 17, 30 .

Site: Dry, sun.

Fruit: Capsule.

A small, often prostrate shrub; often occurs in sand.

Observations: Gambel quail.

Azalea alabamense, see Rhododendron alabamense.

Azalea albiflora, see Rhododendron albiflorum.

Azalea arborescens, see Rhododendron arborescens.

Azalea atlantica, see Rhododendron atlanticum.

Azalea austrina, see Rhododendron austrinum.

Azalea calendulacea, see Rhododendron calendulaceum.

Azalea californica, see Rhododendron occidentale.

Azalea canescens, see Rhododendron canescens and $R$. roseum.

Azalea lapponica, see Rhododendron lapponicum.

Azalea Iutea, see Rhododendron calendulaceum.

Azalea nudiflora, see Rhododendron nudiflorum.

Azalea oblongifolia, see Rhododendron oblongifolium.

Azalea occidentalis, see Rhododendron occidentale.

Azalea pilosa, see Menziesia pilosa.

Azalea prinophylla, see Rhododendron roseum.

Azalea prunifolia, see Rhododendron prunifolium.

Azalea rosea, see Rhododendron roseum.

Azalea serrulata, see Rhododendron serrulatum.

Azalea speciosa, see Rhododendron speciosum.

Azalea vaseyi, see Rhododendron vaseyi. 
Azalea viscosa, see Rhododendron viscosum.

Azaleastrum albiflorum, see Rhododendron albiflorum.

Baccharis spp.

Dioecious shrubs usually growing in neutral soil; propagation is by seed sown in fall or spring or by soft or hard wood cuttings; the seed is hardcoated and may need treatment before sowing.

Baccharis angustifolla, see also Baccharis neglecta.

Baccharis angustifolia Michx.

Range: 20, 29, 30 .

Site: Moist, sun.

Fruit: Achene.

A small to large shrub; flowers in the fall, or all year southward; often grows near or in brackish marshes.

Baccharis consanguinea, see Baccharis pilnlaris.

Baccharis emoryi Gray.

Range: 5, 8, 9, 10, 11, 16, 17.

Waterwillow.

Site: Dry, well-drained, or more commonly moist, sun.

Fruit: Achene.

A large, loosely-branched shrub; grazed by livestock in summer and fall in southeastern Arizona.

Baccharis glomeruliflora Pers.

Range: 29,30 .

Site: Moist, sun.

Fruit: Achene.

A large shrub; flowers fall to winter or all year; ordinarily occurs in salt marshes and swamps.

Baccharis glu'tinosa Pers.

Range: $5,9,10,11,16,17$.

Seepwillow.

Site: Well-drained, moist, sun.

Fruit: Achene.

A small to large, thicket-forming shrub; stems slender, erect, or straggling; sometimes only herbaceous; root system deep and wide-spreading; has been recommended for erosion control; readily propagated by cuttings.

Baccharis halimifolia $\mathbf{L}$.

Groundsel tree.

Range: 17, 20, 27, 28, 29, 30 .

Site: Moist, sun.

Fruit: Achene, available November-December.

A small to large, much-branched shrub; flowers August-October; may ocenr in salt marshes.

Observations: Captive marsh rabbit.

Baccharis neglecta Britt.

B. ungustifolia Gray, not Michx.

Range: 11, 16, 17, 20.

Site: Dry, sun.

Fruit: Achene.

A small evergreen shrub; flowers July-September; often occurs in saline soil; grows in sandy and other soils; invades abandoned farm lands.

Baccharis pllularis DC.

$B$. consanguinea $\mathrm{DC}$.

Kidneywort

Range: 1, 5 .

Site: Dry, well-drained, sun.

Fruit: Achene.

A small to large evergreen shrub; flowers August-October; usually colonyforming; certain forms are prostate-spreading; has been observed to pioneer In gullies; grows on sandy or other solls; foliage very dense; has been recommended for sand-dune fixation.

Stomach records: California quail. Observations: California mule deer.

Baccharis pteronioides, see Baccharis ramulosa. 
Baceharis ramulosa Gray.

B. pteronioides DC.

Range: 11, 14.

Site: Dry, sun.

Fruit: Achene.

A small to large dioecious shrub; rarely grazed by stock except on overgrazed range; poisonous to sheep.

Baccharis salicina Torr. and Gray.

Range: 11, 15, 16.

Willow baccharis.

Site: Moist, sun.

Fruit: Achene, available in August.

A large shrub; flowers May-July and occurs in saline soil.

Baccharis sarothroides Gray.

Rosinbrush.

Range: 5, 10, 11.

Site: Dry, well-drained, moist, sun.

Fruit: Achene.

A small to large, broomlike, much-branched shrub with few leaves. Not palatable to livestock.

Baccharis viminea DC.

Range: $3,5,9,10$.

Mulefat.

Site: Well-drained, moist, sun.

Fruit: Achene.

A large, loosely-branched shrub; flowers July-August.

Observations: California mule deer.

Batodendron arboreum, see Vaccinium arboreum.

Bebbia juncea (Benth.) Greene.

Carphephorus junceus Benth.

Range: 5, 9, 10, 11.

Site: Dry, well-drained, moist, sun.

Fruit: Achene.

A small to large shrub with rushlike branches.

Befaria racemosa Vent.

Tarflower.

Range: $29,30$.

Site: Well-drained, sun, shade.

Fruit: Capsule.

A small to large evergreen shrub; flowers spring-fall; very ornamental in flower.

Beloperone californica Benth.

Chuperosa.

Range: 10, 11.

Site: Well-drained, moist, sun.

Fruit: Capsule, available in April.

A small, spreading shrub; leafless in dry seasons; the capsules, which break open violently, are sometimes infested with seed-destroying larvae.

observations: Very attractive to hummingbirds. Locally browsed by livestock.

Benzoin aestivale (L.) Nees.

Range: 20, 22, 24, 25, 26, 27, 28, 29.

Spicebush.

Site: Well-drained, moist, sun, shade.

Fruit: Drupe, available August-September, earlier southward, persistent or not.

A large, bushy shrub; flowers March-May; usually occurs in slightly acid soil; a rich soll species but often persistent in clearings; propagated by seeds sown as soon as ripe; fruit crops ordinarily light, locally heavy.

Stomach records: Seventeen species of birds, including ruffed grouse, bobwhite, and ring-necked pheasant; opossum. Observations: Seven species of birds ; cottontail rabbit, marsh rabbit, white-tailed deer.

Benzoin melissaefolium (Walt.) Nees.

Southern spicebush.

Range: $25,27,28,29,30$.

Site: Well-drained, moist, sun.

Fruit: Drupe, available September-October.

A small to large shrub; very showy in the February-March flowering season.

Observations: Marsh rabbit. 
Berberis spp.

Barberries.

Certain quarantines apply to the species here listed except B. thunbergii, since they are secondary hosts for the black stem rust of grains. Although species are individually characterized as immune or susceptible to the disease, Federal quarantine officials should always be consulted before the species are used, planted, or shipped.

Stomach records (in addition to specific records) : Ten species of birds, including ruffed grouse and ring-necked pheasant; gray-sided jack rabbit.

(in addition to specific records) : Six specles of birds; jack rabbit.

Berberis aquifolium Pursh. (pl. 4,D).

Mahonia aquifolium (Pursh) Nutt, Odostemon aquifolius (Puregon-grape. Odostemon nutkanus Rydb.

Range: $1,2,4,6,7,11,12,13,14,15,16$.

Site: Dry, well-drained, sun, shade.

Fruit: Berry, available September-October.

A small to large evergreen shrub with very thick foliage; flowers April-May; several varieties in cultivation; fairly, but not completely, resistant to black stem rust.

Stomach records: Three species of birds, including ruffed grouse and dusky grouse; mountain sheep. Observations: Rocky Mountain black-talled deer.

Berberis californicum Jeps.

Odostemon dictyotus Abrams.

California hollygrape.

Range: 3, 4, 5, 10.

Site: Dry, well-drained, sun.

Fruit: Berry.

A small to large evergreen shrub; slightly susceptible to black stem rust. observations: Of slight importance as browse for mule deer.

Berberis canadensis Pursh.

Range : 25, 27, 28.

American barberry.

Site: Dry, well-drained, sun.

Fruit: Berry ; available in September, long persistent.

A small to large, spiny shrub; flowers in June; occul's on limestone, sandstone, or acid soils; susceptible to black stem rust.

Berberis fendleri Gray.

Range: 11, 13, 14.

Fendler barberry.

Site: Dry, well-drained, sun.

Fruit: Berry, available in September.

A small to large, spiny shrub; flowers May-June; susceptible to black stem rust.

Berberis fremontii Torr.

Fremont hollygrape.

Mahonia fremontii (Torr.) Fedde, Odostemon fremontii (Torr.) Abrams.

Range: $9,10,11,13,14$.

Site: Dry, well-drained, sun.

Fruit: Berry, available August-September.

A small to large evergreen shrub; flowers May-June; often forms dense clumps; very tolerant of arid conditions of soil and atmosphere; susceptible to black stem rust; seed germination 90 percent or less.

Stomach records: Black-tailed deer. Observations: Mule deer, New Mexico black bear.

Berberis haematocarpa Woot.

Red hollygrape.

Odostemon haematocarpus (Woot.) Heller, Mahonia haematocarpa Fedde.

Range: 10, 11, 14.

Site: Dry, sun.

Fruit: Berry, available in August.

A small to large erergreen shrub; susceptible to black stem rust; abont 103,000 seeds per pound.

Observations: Numerous birds, including Gambel quail; mule deer.

Berberis japonica, see Berberis thunbergii.

Berberis nana, see Berberis repens. 
Berberis nervosa Pursh. (pl. 1, B).

Mahonia nervosa (Pursh) Nutt., Odostemon nervosus Rydb.

Oregon-grape.

Range: 1, 2, 4, 12.

Site: Dry, well-drained, sun, shade.

Fruit: Berry, available July-August.

A small evergreen shrub; flowers May-June; spreads by ereeping rootstocks to form thickets; resistant to black stem rust.

Observations: Rocky Mountain black-tailed deer.

Berberis nevinii Gray.

Mahonia nevinii (Gray) Fedde, Odostemon nevinii (Gray) Abrams.

Range: 4, 5, 10.

Site: Dry, well-drained, sun.

Fruit: Berry.

A small to large evergreen shrub; occurs on sand, clay loam, and other soils; at first loosely branched, later more compact; root system shallow; drought resistant; rare and local; susceptible to black stem rust.

Berberis pinnata Lag.

Wavyleaf hollygrape.

ILahonia pinnata Fedde, Mahonia fascicularis DC., Odostemon fascicularis

(DC.) Abrams.

Range: 1, 3, 5 .

Site: Dry, well-drained, sun.

Fruit: Berry.

A small to large evergreen shrub with thick foliage; preliminary tests indicate that this species is resistant to black stem rust. Of some importance as a honey plant.

Berberis pumila Greene.

Mahonia pumila (Greene) Fedde, Odostemon pumilus Heller.

Dwarf hollygrape.

Range: 4.

Site: Well-drained, sun.

Fruit: Berry.

A small evergreen shrub; occurs from 3,000-5,000 feet; susceptibility to attack of black stem rust uncertain, although apparently resistant.

Berberis repens Lindl.

Odostemon repens (Lindl) Cockerell,

beris nana Greene.

Range : $4,5,7,9,11,12,13,14,15,16$.

Site: Dry, well-drained, sun, shade.

Fruit: Berry, available in September.

A small evergreen shrub; flowers in May; the rhizomes produce shoots and deep roots at intervals ; resistant to black stem rust.

Stomach records: Black-tailed deer, plains white-tailed deer. Reputed to be poisonous to stock but probably not very serlously so.

Berberis sinensis, see Berberis thunbergii.

Berberis swaseyi Buckl.

Mahonia swaseyi Fedde.

Range: 16.

Site: Dry, well-drained, sun.

Fruit: Berry, available May-June.

A small evergreen shrub; flowers in May; grows on many soils, including limestone; resistant to cold and drought; berries large, borne abundantly almost every year; very ornamental; a good hedge plant; susceptible to black stem rust.

Berberis thunbergii DC.

$B$. japonica, $B$. sinensis of some.

Thunberg barberry.

Range: $1,2,4,21,23,24,25,27,28,29$.

Site: Well-drained, sun.

Fruit: Berry; available in August, persistent all year round.

A small to large, somewhat straggling, spiny shrub; native of Japan, but more or less naturalized in the regions indicated; evergreen southward; grows in many kinds of soils; has not demonstrated its ability to compete with native vegetation, including grasses; on dry banks has been repeatedly observed to die 
gradually; branches root where they touch the ground; not subject to black stem rust and not under quarantine; berries soften over winter and become more available to birds; much cultivated, and many cultivated varieties known; $25,000-28,000$ seeds per pound, germination 80 percent, about 4,000 usable plants per pound of seed.

Stomach records: Ruffed grouse. Observations: Seven species of birds, including ring-necked pheasant, ruffed grouse (of value during winter), and bobwhite; cottontail rabbit.

Berberis trifoliolata Moric.

Odostemon trifoliolatus (Moric.) Heller, Mahonia trifoliolata Fedde,

Agarita.

Range : 11, 16, 17, 20.

Site: Dry, well-drained, sun.

Fruit: Berry, available April-May.

A smail to large evergreen shrub; thicket forming; occurs on gravelly and other soils; fruit edible; susceptible to black stem rust. A good honey plant.

Berberis vulgaris $\mathrm{L}$.

Range: 22, 27.

Site: Well-drained, sun.

Fruit: Berry; available August-September, persistent through the winter.

A smali to large shrub introduced from Europe but naturalized in the regions indicated; much cultivated, and many varieties known; most susceptible of all species to the black stem rust; being eradicated in some areas.

Stomach records: Six species of birds, including ruffed grouse and bobwhite. Observations: Ring-necked pheasant, mockingbird.

Berberis willcoxii Kearn.

Odostemon wilcoxii (Kearn.) Heller.

Range: 10, 11.

Site: Dry, weili-dralned, sun.

Fruit: Berry.

A smail shrub; has not been tested for susceptibllity to black stem rust.

Berchemia scandens (Hill) Trel.

Range: $20,25,28,29,30$.

Rattan vine.

Site: Well-drained, moist, sun.

Fruit: Drupe, available Juily-October.

A vigorous, much-branched vine; flowers March-June; occurs in sandy and other soils.

Stomach records: 14 species of birds, including wood duck, mallard, bobwhite, and turkey. Observations: Much eaten by migratory birds.

Bernardia myricaefoiia (Scheele) Wats.

Tyria myricaefolia Scheele.

Range: 10, 11, 16, 17, 20.

Site: Dry, sun.

Fruit: Capsule.

A small to large shrub; flowers in April; wlli grow under extremely adverse conditions. Eaten at times by very hungry stock.

Berthelotia sericea, see Pluchea sericea.

Betula spp.

Birches.

Trees or shrubs; generally short-lived; propagation is by seeds sown as soon as ripe or stored dry and after stratification at $32^{\circ}-50^{\circ} \mathrm{F}$., for 6 weeks, planted in spring.

Stomach records (in addition to specific records): Tweive species of birds, including gray and eastern ruffed grouse, ptarmigan, sharp-tailed grouse, and woodcock; composed 0.8 percent of entire fall food of prairie chickens in Wisconsin, 0.73 percent of entire fall food of sharp-tailed grouse in Wisconsin, 46.9 percent of all winter food of northern sharp-tailed grouse in Ontario and Quebec, 12.26 percent of winter food of ruffed grouse in New York, and 5.6 percent of winter food of ruffed grouse in the northeastern United States; northern white-tailed deer, plains white-tailed deer. Observations (in addition to specific records): Twenty-one species of birds, including spruce grouse, ptarmigan, sharp-tailed grouse; staple winter food of greater prairie chicken, pinnated grouse, and ruffed grouse; important food of snowshoe hare, porcuplne; an important food of beaver where Populus is iacking. The western species are browsed fairly well by livestock. 
Betula alleghaniensis, see Betula lutea.

Betula coerulea Blanch.

B. pendula Fern., not Roth.

Blueleaf birch.

Range: 15, 18, 21, 23, 24, 26, 27.

Site: Well-drained, moist, sun.

Fruit: Small samara or nutlet, available September-October.

A large tree.

Betula cordifolia, see Betula papyrifera.

Betula fontinalis Sarg.

Red birch.

$B$. occidentalis Nutt., not Hook., B. utahensis Britt., B. microphylla Bunge.

Range: 4, 7, 8, 9, 12, 13, 14, 15.

Site: Well-drained, moist, sun.

Fruit: Small samara or nutlet.

A small to rarely large tree; fair to good browse for sheep and goats; about $1,134,000$ seeds per pound.

Var. piperi (Britt.) Sarg., (B. piperi Britt.) is smaller than the species, occurs in region 7 , and is clump-forming.

Betula glandulifera, see Betula pumila.

Betula glandnlosa Michx.

B. hallii Howell.

Bog birch.

Range: 2, 4, 12, 13, 15, 23, 24, 26.

Site: Wet, sun.

Fruit: Small samara or nutlet.

A small to large shrub; usually occurs in sphagnum bogs.

observations: White-tailed ptarmigan, northern sharp-tailed grouse, greater prairie chicken. Palatability good for cattle and sheep in most western sections, but plants are often inaccessible because of their occurrence in bogs.

Betula hallil, see Betula glandulosa.

Betula lenta $\mathrm{L}$.

Range: 22, 24, 25, 26, 27, 28, 29.

Sweet birch.

Site: Dry, well-drained, moist, sun, shade.

Fruit: Small samara or nutlet, available September-October.

A large tree with open foliage; rapid growing when young, later slower; long-lived; root system fibrous, deep, and spreading; not fire resistant; windfirm; little attacked by disease except in old age; rarely attacked by insects; appears to flourish best in association with other species; wood used commercially to some extent; oil of wintergreen, produced by distillation of the leaves, is of importance commercially ; about 500,000 seeds per pound, germination about 26 percent.

Stomach records: Ruffed grouse, greater prairie chicken. Observations: Redpoll, sharp-tailed grouse; important food of white-tailed deer, moose, cottontail rabbit.

Betula lutea Michx. f.

B. alleghaniensis Britt.

Range: 21, 22, 23, 24, 25, 26, 27, 28. •

Site: Well-drained, moist, sun, shade.

Fruit: Small samara or nutlet, available September-October.

A large tree; rapid growing, especially when young; moderately long-lived; root system widespread; taproot usually developed in a lateral direction; not fire resistant; wood of importance commercially; 400,000-440,000 seeds per pound.

Stomach records: Merganser, ruffed grouse. Observations: Seven species of birds, including sharp-tailed grouse, ruffed grouse, prairie chicken; important food of white-tailed deer; red squirrel, cottontall rabbit, moose.

Betula microphylla, see Betula fontinalis.

Betula montanensis, see Betula papyrifera.

Betula nigra L.

Range: 20, 22, 23, 25, 26, 27, 28, 29.

River birch.

Site: Moist, sun.

Fruit: Small samara or nutlet, available July-September. 
A large tree with open foliage; rapid growing when young; short-lived; little attacked by insects or disease; coppices when cut; wood used commercially to some extent.

Stomach records: Ruffed grouse. Observations: Five species of birds including ruffed grouse and wild turkey; white-tailed deer.

Betula occidentalis, see Betula fontinalis and $B$. papyrifera.

Betula papyrifera Marsh.

B. alba papyrifera (Marsh) Spach.

Paper birch.

Range: $12,13,15,18,21,22,23,24,26,27$.

Site: Dry, well-drained, sun.

Fruit: Small samara or nutlet, available August-September.

A large, short-lived tree; rapid growing when young, later slower; root system shallow, superficial; a pioneer on burned-over areas; free from insects and disease; easily fire-damaged; wood used commercially to some extent; about 700,000 seeds per pound, germination about 21 percent, seed vitality transient.

Var. subcordata (Rydb.) Sarg., (B. subcordata Rydb.), the paper birch, occurs in region 12. Var. cordifolia (Regel) Fern., (B. cordifolia Regel) occurs in regions 18, 21, 23, 24, 26, and 27. Var. occidentalis (Hook.) Sarg., (B. occidentalis Hook.), the western paper birch occurs in regions 1, 2, and 12. Var. montanensis (Butler) Sarg., ( $B$. montanensis Butler) occurs in region 12. Var. minor (Tuckerm.) Fern., (B. papyracea var. Tuckerm.), is a shrub occurring in regions 23 and 27 , strictly in bogs.

Stomach records: Ruffed grouse, sharp-tailed grouse, Observations: Redpoll, preferred food of ruffed grouse in Maine; snowshoe hare; important food of moose on Isle Royale; sparingly browsed by northern white-tailed deer.

Betula pendula, see Betula coerulea.

Betula piperi, see Betula fontinalis.

Betula populifolia Marsh.

Range: $24,26,27,28$.

Gray birch.

Site: Dry, well-drained, moist, sun.

Fruit: Small samara or nutlet, available in September.

A small to large short-lived tree; fairly rapid growing; free from insects and disease; easily storm-damaged; coppices freely when cut; wood used commercially to some extent; generally occurs in poor sandy or gravelly soils.

Stomach records: Three species of birds including ruffed grouse. Observations: Five species of birds; white-tailed deer.

Betula pumila L.

Range: 18, 21,.22, 23, 24, 26, 27.

Swamp birch.

Site : Moist, sun.

Fruit: Small samara or nutlet, arailable September-October.

A small to large shrub.

Var. glandulifera Regel (B. glandulifera (Regel) Butter), is a shrub occurring in regions $18,21,23$, and 24 .

Betula subcordata, see Betula papyrifera.

Betula utahensis, see Betula fontinalis.

Bigelovia acradenius, see Aplapappus acradenius.

Bigelovia arborescens, see Aplopappus arborescens.

Bigelovia brachylepis, see Aplopappus propinquus.

Bigelovia depressa, see Chrysothamnus depressus.

Bigelovia douglasii, see Chrysothamnus viscidiflorus.

Bigelovia greenei, see Chrysothamnus greenei.

Bigelovia nelsonii, see Aplopappus laricifolius.

Bigelovia paniculata, see Chrysothamnus paniculatus.

Bigelovia parishii, see Aplopappus parishii.

Bigelovia parryi, see Chrysothamnus parryi.

Bigelovia pulchella, see Chrysothamnus pulchellus. 
Bigelovia spathulata, see Aplopappus cuneatus.

Bignonia capreolata L.

Anisostichus capreolata (L.) Bur., Bignonia crucigera L., in part.

Range: 25, 28, 29, 30 .

Site: Moist, well-drained, sun, shade.

Fruit: Capsule.

An evergreen, tree-climbing vine; blooms April-June; very handsome in cultivation; usually occurs in rich soil.

Bignonia crucigera, see Bignonia capreolata.

Bignonia linearis, see Chilopsis linearis.

Bignonia radicans, see Campsis radicans.

Bignonia sempervirens, see Gelscmium sempervirens.

Bignonia stans, see Tecoma stans.

Biltia vaseyi, see Rhododendron vaseyi.

Borrichia frutescens (L.) DC.

Buphthalmium frutescens $\mathrm{L}$.

Sea oxeye.

Range: 17, 30.

Site: Dry, well-drained, moist, sun.

Fruit: Achene.

A small shrub; blooms July-September, or all year southward; may occur in sandy soil, salt marshes, or on prairies.

Brahea minima, see Sabal minor.

Brayodendron texanum, see Diospyros texana.

Brickellia arguta, see Brickellia atractyloides.

Brickellia atractyloides Gray.

B. venulosus arguta (Robins.) Jeps., B. arguta Robins., Coleosanthus atractyloides (Gray) Kuntze, C. venulosus Nels.

Range: $9,10$.

Site: Dry, sun.

Fruit: Achene.

A small, much-branched shrub; flowers April-June.

Brickellia desertorum Cov.

Coleosanthus desertorum Cov.

Desert brickellbush.

Range: 9, 10.

Site: Dry, sun.

Fruit: Achene.

A small, intricately-branched shrub; blooms October-November.

Brickellia frutescens Gray.

Coleosanthus frutescens (Gray) Kuntze.

Rigid brickellbush.

Range: 5, 10.

Site: Dry, sun.

Fruit: Achene.

A small, rigid, spinose shrub; blooms April-May.

Brickellia grayana, see Brickellia microphylla.

Brickellia knappiana Drew.

Range: 10.

Site: Dry, suu.

Fruit: Achene.

A small to large, willowlike, slender shrub; flowers August-September; a rare species.

Brickellia laciniata Gray.

Coleosanthus laciniatus (Gray) Kuntze.

Range: 11.

Site: Dry, sun.

Fruit: Achene.

A small shrub. 
Brickellia microphylla (Nutt.) Gray.

Littleleaf brickellbush. Bulbostylis microphylla Nutt., Brickellia grayana Hieron., Coleosanthus
microphyllus (Nutt.), Kuntze, C. cedrosensis Greene.

Range: 8, 9, 10, 12.

Site: Dry, sun.

Fruit: Achene.

A small shrub or occasionally not entirely woody; flowers August-October; usually occurs in sand.

Brickellia multifiora Kell.

Coleosanthus multiflorus (Kell.) Kuntze.

Range: 4, 5, 10.

Site: Dry, sun.

Fruit: Achene.

A large shrub; usually occurs in saud.

Brickellia nevinii Gray.

Range: 10.

Site: Dry, sun.

Fruit: Achene.

A small shrub with thick foliage.

Brickellia squamulosa Gray.

Coleosanthus squamulosus (Gray) Kuntze.

Range: 11.

Site: Dry, sun.

Fruit: Achene.

A small shrub.

Brongniartia minutifolia Wats.

Range: 11.

Site: Dry, sun.

Fruit: Legume.

A small, much-branched shrub.

Broussonetia papyrifera (L.) Vent.

Papyrius papyrifera (L.) Kuntze.

Paper mulberry.

Range: 17, 20, 25, 27, 28, 29.

Site: Dry, well-drained, moist, sun, shade.

Fruit: Compound drupe, available in September.

A large shrub to small or large dioecious tree; flowers in May; naturalized from Japan and commonly escaped in the regions indicated; rapid growing; root sprouts produced copiously; very drought resistant; has spread very commonly in gullies or occasionally in moist, shady places; fruits are borne seldom; about 200,000 seeds per pound.

Stomach records: Three species of birds.

Broussonetia secundiflora, see Sophora secundiflora.

Brunnichia cirrhosa Banks.

Range: $25,28,29,30$.

Site: Well-drained, moist, sun, shade.

Fruit: Achene, available September-October, occasionally persistent all winter.

A vine; blooms July-August; has colonized railroad embankments in the South.

Stomach records: Mallard.

Bryanthus taxifolius, see Phyllodoce caeruler.

Buddleia hnmboldtiana Roem. and Schult.

Range: 17.

Site: Dry, sun.

A shrub.

Fruit: Capsule.

Buddleia marrubiifolia Benth.

Range: 11, 17.

Woolly butterflybush.

Site: Well-drained, sun.

Fruit: Capsule.

A small shrub; may possibly furnish some browse for livestock. 
Buddleia racemosa Torr.

Range: 11, 17, 20.

Site: Dry, sull.

Fruit: Capsule.

A small, loosely-branched shrub ; flowers spring-summer.

Buddleia scordioides H. B. K.

Range: 11, 17.

Site: Dry, sun.

Fruit: Capsule.

A small shrub; palatability fairly good to good for sheep, goats, and cattle.

Buddleia sessiliflora H. B. K.

Range: 10, 11.

Site: Dry, well-drained, sun.

Frult: Capsule.

A small or large shrub to small tree.

Buddleia utahensis Cov.

Range: $9,10$.

Site: Dry, sun.

Fruit: Capsule.

A small shrub; possibly furnishes some browse for livestock.

Bulbostylis microphylla, see Brickellia microphylla.

Bumelia angustlfolia see Bumelia spiniflora.

Bumelia cassinifolia Small.

Buckthorn.

Range: $29,30$.

Site: Well-drained, sun, shade.

Fruit: Drupe.

Commonly a large shrub or small to large tree; spiny; often occurs in sandy woods.

Bumelia lanuginosa (Michx.) Pers.

Woolly buckthorn.

Sideroxylon lanuginosa Michx.

Range: $11,14,17,19,20,22,25,29,30,31,32$.

Site: Dry, well-drained, sun.

Fruit: Drupe; available September-November, sometimes persistent.

A large shrub to small or large spiny tree, evergreen southward; flowers June-July; somewhat thicket forming, especially westward; occurs on rocky, gravelly, sandy, and other solls; $3,500-6,700$ seeds per pound.

Observations: Curve-billed thrasher, Sennett thrasher.

Bumelia lucida Small.

Range: 29, 30.

Shining bumelia.

Site: Well-drained, sun.

Fruit: Drupe.

A large shrub to small tree; evergreen, thorny; branches rigid.

Bumelia lycioides (L.) Pers.

Range: $17,25,27,28,29,30$.

Site: Well-drained, moist, sun.

Fruit: Drupe, available September-November.

A large shrub to small or large tree; semievergreen; unarmed or spiny; flowers June-August; coppices when cut.

Stomach records: Lesser scaup. Browsed to some extent by livestock.

Bumelia monticola Buckl.

Range: 11, 17, 20.

Mountain buckthorn.

Site: Dry, well-drained, sun.

Fruit: Drupe, avallable in September.

A large shrub to small or large tree; largest forms occur on best sites; spiny and straggling; flowers June-July; usually occurs on limestone soil.

Bumelia reclinata Vent.

Range: 29, 30.

Site: Well-drained, sun.

Fruit: Drupe.

A small to large, spiny evergreen shrub; may be erect or depressed; flowers upring-summer or the year round; often occurs on sand. 
Bumelia schottii, see Bumelia spiniflora.

Bumelia spiniflora DC.

B. angustifolia Nutt., B. schottii Britt.

Saffron-plum.

Range: 17, 31, 32 .

Site: Well-drained, sun.

Fruit: Drupe, available April-May.

A large shrub to a small or rarely large tree; evergreen; flowers NovemberJanuary; propagated by seed.

Bumelia tenax Willd.

Range: $29,30,31,32$.

Tough buckthorn.

Site: Dry, well-drained, sun.

Fruit: Drupe, available September-November.

Most commonly a small to large shrub; sometimes a small to large tree; evergreen southward; flowers May-July; spiny or unarmed; may occur on sand.

Bumelia texana Buckl.

Range: 16, 17.

Site: Dry, sun.

Fruit: Drupe.

A large shrub to small tree; evergreen; branches rigid and thorny.

Buphthalmium frutescens, see Borrichia frutescens.

Bursera lonchophylla, see Bursera odorata.

Bursera odorata Brandeg.

B. lonchophylla Sprague and Riley, B. tenuifolia Rose, B. purpusii Brandeg., Elaphrium covillei Rose, $E$. confusum Rose, $E$. brachypodum Rose, $E$. odoratum (Brandeg.) Rose.

Range: 10.

Site: Dry, well-drained, sun.

Fruit: Drupe, resembling a capsule.

A small tree; usually occurs on calcareous soil.

Bursera microphylla Gray.

Elaphrium microphyllum (Gray) Rose.

Elephant tree.

Range: 5,10 .

Site: Dry, sun.

Fruit: Drupe; resembling a capsule, arailable in October.

A large shrub to small or large tree; flowers in June.

Butneria fertilis, see Calycanthus fertilis.

Butneria florida, see Calycanthus florida.

Butneria mohri, see Calycanthus mohri.

Butneria nana, see Calycanthus fertilis.

Butneria occidentalis, see Calycanthus occidentalis.

Buxella brachycera, see Gaylussacia brachycera.

Buxus chinensis, see Simmondsia chinensis.

Calliandra chamaedrys, see Calliandra eriophylla.

Calliandra conferta, see Calliandra eriophylla.

Calliandra eriophylla Benth.

C. chamaedrys Engelm., C. conferta Benth., Anneslia eriophylla (Benth.) Britt.

Range : 10, 11, 16, 17.

Site: Dry, sun.

Fruit: Legume, available May-August.

A small, somewhat prostrate, densely-branched shrub; occurs on sandy and other soils; flowers March-May; seed germination 64 percent.

Stomach records: Masked bobwhite, bobwhite, antelope jack rabbit. Observations: Gambel, scaled, and Mearn's quail. Highly palatable to lirestock. 
Callicarpa americana L. (pl. 5, A).

Range: $17,20,25,28,29,30$.

French mulberry.

Site: Dry, well-drained, moist, sun, shade.

Fruit: Berrylike drupe, available August-November.

A large, bushy shrub, or rarely somewhat viny; flowers June-July; commonly occurs in rich soil, but grows also in poor ones; may grow in sand, clay, loam, and other neutral soils; propagated by seed or cuttings, 85,000 seeds per pound, germination about 40 percent; about 10,000 usable plants per pound of seed.

Stomach records: 10 species of birds, including bobwhite. Observations: Five species of birds, including bobwhite; ranked as forty-first on the list of quail food plants of the southeastern United States; captive marsh rabbits.

Calligonum canescens, see Atriplex canescens.

Calycanthus fertilis Walt.

Mountain spicewood.

C. nanus Loisel., Butneria fertilis (Walt.) Kearn., B. nana (Loisel.) Small. Range: 27, 28, 29.

Site: Well-drained, moist, sun.

Fruit: Capsule; arailable in September, persistent through the winter.

A large shrub; flowers March-August; usually occurs on rich, nearly neutral soil; propagation is by seeds sown in spring. Considered deleterious to cattle. Calycanthus floriảus $\mathrm{I}$.

Butneria florida (L.) Kearn.

Carolina allspice.

Range: 29,30 .

Site: Well-drained, moist, sun, shade.

Fruit: Capsule.

A large shrub; flowers April-August; usually occurs in rich, neutral soil; propagation is by seed sown in spring.

Calycanthus mohri Small.

Butneria mohri Small.

Range: 27.

Site: Well-drained, sun.

Fruit: Capsule.

A small to large shrub.

Calycanthus nanus, see Calycanthus fertilis.

Calycanthus occidentalis Hook. and Arn.

Butneria occidentalis (Hook. and Arn.) Greene.

Callornia sweetshrub.

Range: 4.

Site: Well-drained, sun.

Fruit: Capsule.

A small to large shrub; flowers June-August; occurs from 800 to 3,800 feet.

Observations: Of slight importance as browse for mule deer. Reputed to be poisonous to stock, but this may be questionable.

Calycocarpum lyonii (Pursh) Nutt.

Menispermum lyonii Pursh.

Range: $22,25,28,29,30$.

Site: Well-drained, moist, sun, shade.

Fruit: Drupe, available August-October.

A high-climbing and twining vine; flowers May-June; often for the most part herbaceous; fruit ripens irregularly; commonly climbs over bushes along stream banks.

Campsis radicans (L.) Seem.

Tecoma radicans (L.) Juss., Bignonia radicans (L.) DC.

Trumpetcreeper.

Range: $20,22,25,27,28,29,30$.

Site: Dry, well-drained, moist, sun.

Fruit: Cansule; available August-October or persistent through the winter.

An exceedingly rapid-glowing tree-climbing vine; flowers all summer; somewhat herbaceous in cultivated fields where it is often considered a troublesome weed, especially southward; grows on coal-stripped lands in Illinois; said to be narcotic, but not known to be eaten by domestic animals; much cultlvated and with several varieties known.

$130186^{\circ}-39-6$ 
Canotia holacantha Torr.

Range: 10, 11.

Site : Dry, sun.

Fruit: Capsule.

Mohave thorn.

A large shrub, or sometimes a small or large tree with rushlike branches; somewhat spinose; often occurs in pure stands of an acre or more; grows on gravelly or sandy soll. Worthless as forage for stock.

Capsicum baccatum L.

Range: 17, 20, 30.

Chilltpiquin.

Site: Well-drained, shade.

Fruit: Berry, available in September, long persistent.

A small to large shrub.

Carlowrightia arizonica Gray.

Range: 10.

Site: Dry, sun.

Fruit: Pod.

A small, wide-spreading shrub; cropped to some extent by sheep and cattle. Carlowrightia linearifolta (Torr.) Gray.

Range: 11.

Site: Dry, sun.

Fruit: Pod.

A small shrub with small leaves; worthless as forage.

Carpenteria californica Torr.

Range: 4.

Site: Well-drained, sun.

Fruit: Capsule.

A small to large, many-stemmed, spreading evergreen shrub; flowers MayJuly; commonly cultivated.

Foliage very bitter, seldom grazed even ly sheep.

Carphephorus junceus, see Bebbia juncea.

Carpinus caroliniana Walt.

Range: $20,21,22,23,24,25,26,27,28,29,30$.

Blue beech.

Site: Dry, well-drained, moist, sun, shade.

Fruit: Nutlet; available August-October, often persistent.

A small to large bushy tree; slow growing; rarely attacked by insects; wood very hard and durable, somewhat used commercially; propagated by seeds sown as soon as ripe; germination very irregular; about 300 usable plants per pound of seed.

Stomach records: Nine species of birds, including ruffed grouse, bobwhite, turkey, and sharp-tailed grouse; composed 4.08 percent of winter food of ruffed grouse in New York. Observations: Ring-necked pheasant, ruffed grouse, bobwhite; cottontail rabbit, white-tailed deer, gray squirrel.

Carya spp.

Hickories.

Large trees; usually grow on neutral soil; propagation is by seed stratifled and sown in spring; because of their long taproots they are ordinarily hard to transplant; will not stand much trampling by stock.

Stomach records (in addition to specific records) : Eleven species of birds, including wood duck, mallard, ruffed grouse, bobwhite, turkey, ring-necked pheasant; gray fox, white-tailed deer. Observations (in addition to speciflc records) : Four species of birds, including bobwhite; white-tailed deer, cottontail rabbit, and many squirrels; gray fox, red squirrel, southwestern chipmunk, gray squirrel, flying squirrel.

Carya alba, see also Carya ovata.

Carya alba (L.) Koch.

Hicoria alba (L.) Britt., C. tomentosa (Lam.) Nutt.

Mockernut hickory.

Range: $20,22,24,25,27,28,29,30$.

Site: Well-drained, sun, shade.

Fruit: Nut; available September-Norember.

A large tree; taproot much developed; rapid growing when young, rather long-lived; generally occurs on richer soils; wind-firm; easily fire-damaged; much attacked by insects; stump and root sprouts produced freely ; may occur on sandstone, chert, or igneous areas; wood of importance commercially ; seed produced abundantly about every other year; 110 seeds per pound, germination about 85 percent; about 35 usable plants per pound of seed.

Observations: White-tailed deer. 

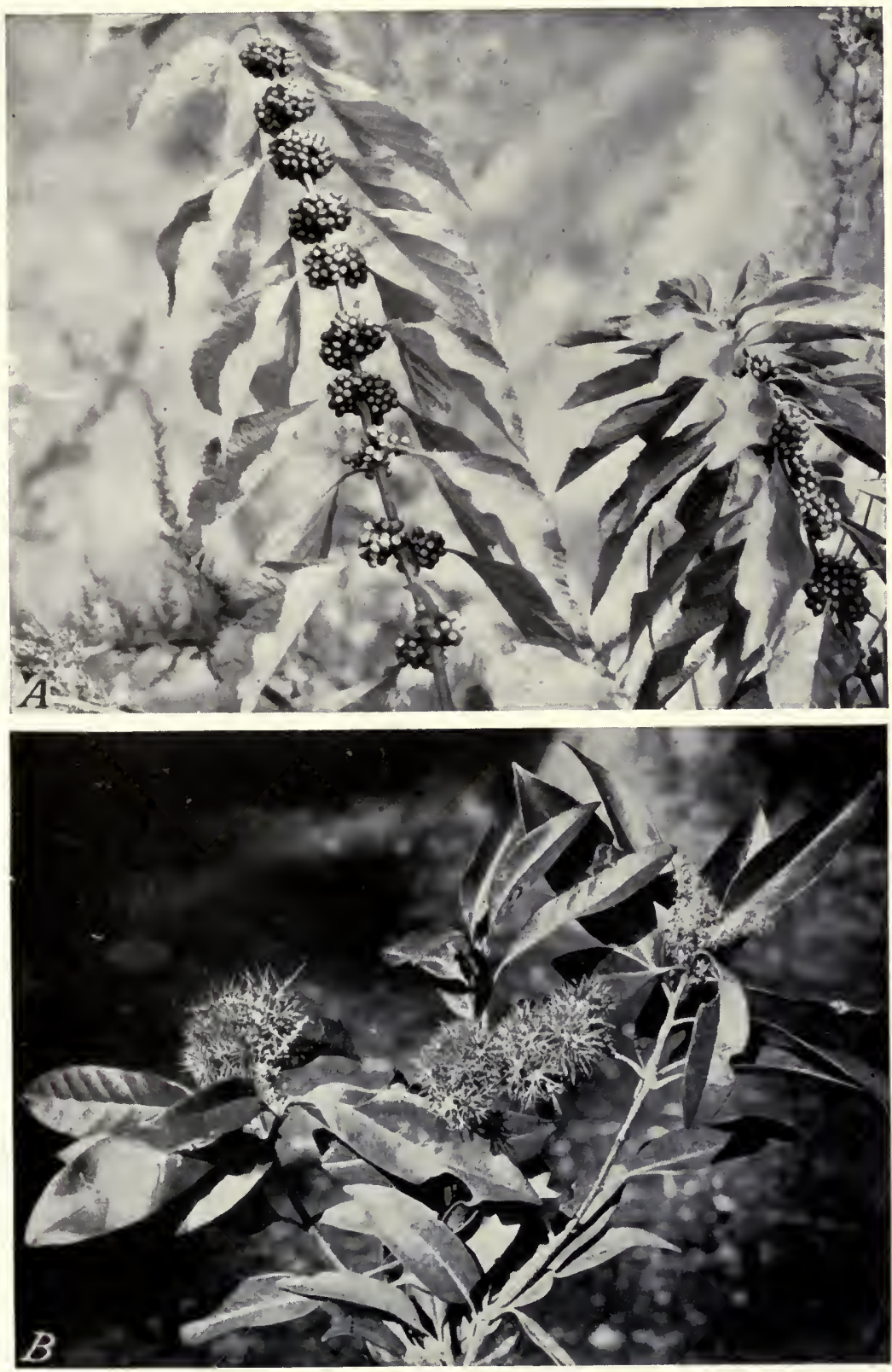

A, Callicarpa americana, a valuable species for soil and wildlife conservation in the Southeast. $B, C o s^{-}$ tanopsis chrysophylla. This bushy evergreen, the golden chinquapin, should prove a valuable soil cover and wildlife food plant. 

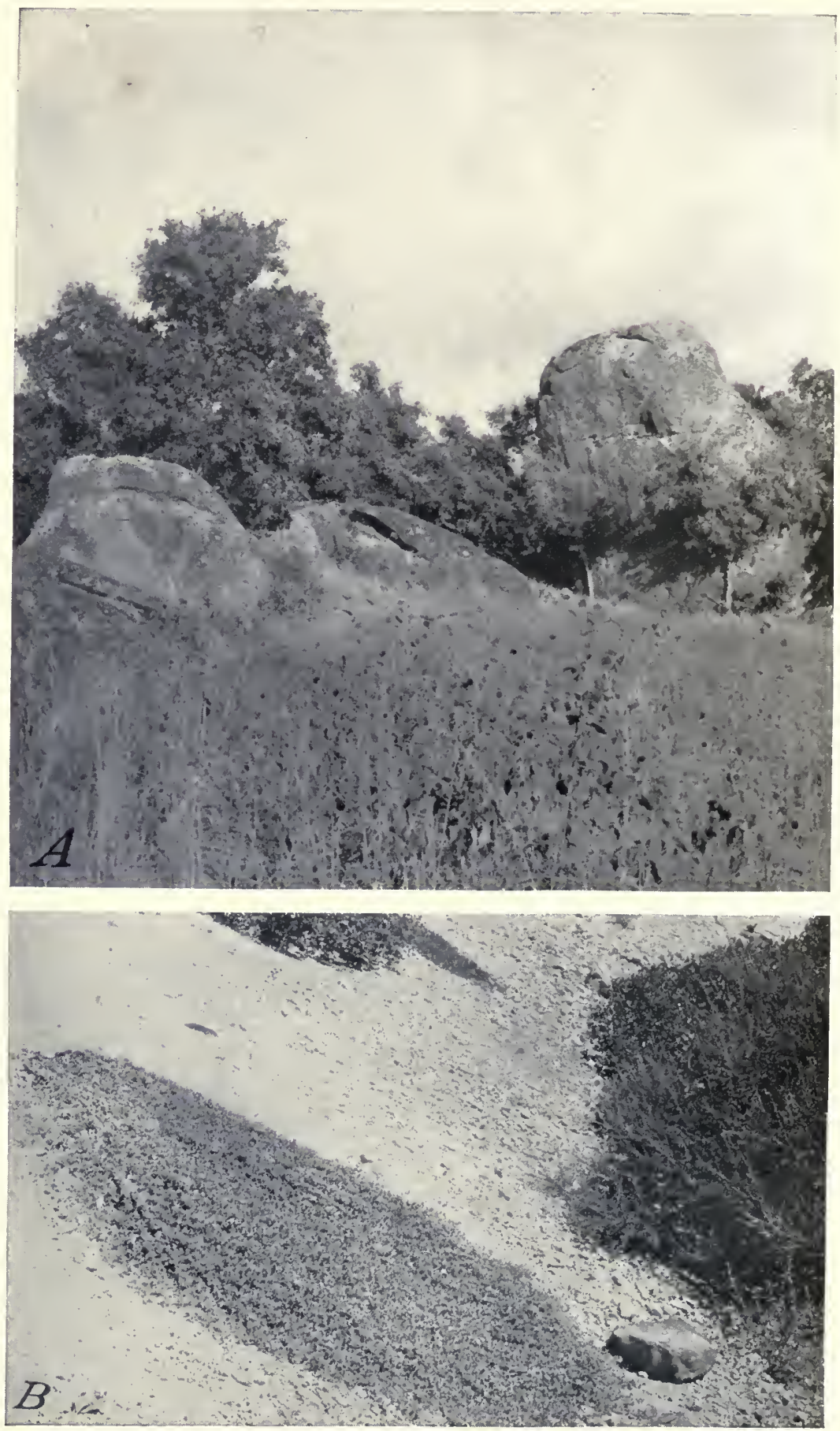

$A$, Celtis douglasii. This hackberry, like others in the genus, thrives in extremely arid regions. Its value as cover in an otherwise barren country is very great. $B$, Ceanothus prostratus forms perfect cover on part of a dry railroad embankment. 
Carya amara, see Carya cordiformis.

Carya aquatica (Michx. f.) Nutt.

Hicoria aquatica (Michx. f.) Britt.

Water hickory.

Range: $20,25,28,29,30$.

Site: Well-dralned, moist, sun.

Fruit: Nut; available September-October.

A large tree; ordinarily grows in alluvial soil; taproot small, lateral roots well developed; wood of little importance commercially.

Stomach records: Wood duck, mallard.

Carya arkansana, see Carya buckleyi.

Carya buckleyi Durand.

Hicoria buckleyi (Durand) Sudw.

Texas hickory.

Range: 16, 20, 29, 30 .

Site: Dry, well-drained, sun.

Fruit: Nut.

A large tree; occurs in sandy or other soils.

Var. arkansana (Sarg.) Ashe, (C. arkansana Sarg.) occurs also in region 25.

Carya carolinae-septentrionalis (Ashe) Engelm. and Graebn.

Hicoria carolinae-septentrionalis Ashe.

Southern shagbark hickory.

Range : $27,28,29$.

Site: Well-drained, sun.

Fruit: Nut.

A large tree; occurs on sandy, rocky, or rich soll.

Carya cordiformis (Wang.) Koch.

Bitternut hickory:

Hicoria cordiformis (Wang.) Britt., H. minima (Marsh.) Brltt., C. amara Nutt.

Range : 20, 22, 23, 24, 25, 26, 27, 28, 29, 30 .

Site: Well-drained, moist, sun.

Fruit: Nut, available September-October.

A large tree; usually occurs on slightly acid, very fertile soil; the most rapid growing of all the hickories, especially when young, later slower; taproot and laterals well developed; long-lived; easily frost- and fire-damaged when young; stump and root sprouts produced; has been noted to be dying out in Indiana supposedly because of a root disease; attacked by hickory borer, otherwise generally free from insects and fungi; wood very tough, of some importance commercially; about 110 seeds per pound, germination 80-90 percent.

Observations: Cottontail rabbit; fruit claimed to be generally distasteful to wildlife.

Carya floridana Sarg.

Hicoria floridana (Sarg.) Sudw.

Scrub hickory.

Range: 30,31 .

Site: Well-drained, sun.

Fruit: Nut.

A large shrub to small tree; usually occurs on sandy soil; fruit usuails produced abundantly.

Carya glabra (Mill.) Sweet.

Pignut hickory.

C. porcina Nutt., Juglans glabra Mill., Hicoria glabra (Mill.) Blitt.

Range : $20,22,24,25,27,28,29,30$.

Site: Dry, well-drained, sun, shade.

Fruit: Nut, available September-October.

A large tree; ordinarily occurs in fertile, slightly acid soil; slow growing, long-lived ; root system deep; wind-firm; easily frost- and fire-damaged; somewhat injured by bark beetles; root sprouts produced; often invades land after the virgin forest is cut to form pure stands; difficult to transplant; 210 seeds per pound, germination about 85 percent; about 70 usable plants per pound of seed.

Var. megacarpa (Sarg.) Sudw., (C. megacarpa Sarg.) has larger fruits and occurs within the range of the species.

Observations: Cottontail rabbit. 
Carya illinoensis, see Carya pecan.

Carya laciniosa (Michx f.) Loud.

Big shellbark hickory.

C. sulcata Nutt., Hicoria laciniosa (Michx. f.) Sarg., H. sulcata (Willd.)

Britt.

Range : 22, 24, 25, 27, 28, 29.

Site: Well-drained, moist, sun, shade.

Fruit: Nut, available September-October.

A large tree; ordinarily occurs on fertile soils ; taproot much developed; slow growing, long-lived; wind-firm; much injured by insects ; root sprouts ordinarily grow faster than seedlings; wood valuable commercially; difficult to transplant.

Observations: Cottontail rabbit.

Carya leiodermis Sarg.

Hicoria leiodermis (Sarg.) Sudw.

Pignut hickory.

Range: 29.

Site: Moist, sun.

A large tree.

Fruit: Nut, available September-October.

Carya megacarpa, see Carya glabra.

Carya microcarpa Nutt.

Little pignut hickory.

Hicoria microcarpa (Nutt.) Britt., $\boldsymbol{H}$. ovatu nuttallii (Sarg.) Sudw.

Range: 22, 24, 25, 27, 28, 29.

Site: Well-drained, sun.

Fruit:Nut, available September-October.

A large tree; ordinarily occurs on rich soil.

Carya myristicaeformis (Michx. f.) Nutt.

Michx. f., H. fernowiana Sudw.

Range: 20, 25, 29.

Site: Well-drained, sun.

Fruit: Nut, available September-October.

A large tree; taproot strongly developed; difficult to transplant. The Fernow hickory has recently been listed as distinct from this species; its range is, as yet, not clear.

Carya olivaeformis, see Carya pecan.

Carya ovalis (Wang.) Sarg.

Hicoria ovalis (Wang.) Sudw.

Small pignut.

Range: 22, 25, 27, 28, 29.

Site: Well-drained, sun.

Fruit: Nut.

Six varieties are recognized, one of which extends the range of the species to region 24.

Carya ovata (Mill.) Koch.

Shagbark hickory.

C. alba Nutt. not Koch, Hicoria ovata (Mill.) Britt., H. carolinae-septentrionalis australis Ashe, Juglans ovata Mill.

Range: 21, 22, 23, 24, 25, 26, 27, 28, 29, 30.

Site: Dry, well-drained, sun, shade.

Fruit: Nut, available September-October.

A large, slow-growing, long-lived tree; taproot much developed; young trees easily frost-damaged; wind-firm; severely injured by fire; much attacked by insects; root sprouts decrease with age of trees; wood important commercially, tough, but not durable when exposed; difficult to transplant; often oceurs in limestone hills; five recognized varieties occur within the range of the species; $80-90$ seeds per pound, germination about 85 percent; about 30 usable plants per pound of seed.

Observations: Cottontail rabbit, white-tailed deer.

Carya pallida (Ashe) Engl. and Graebn.

C. glabra villosa (Sarg.) Robins., Hicoria pallida Ashe.

Pignut hickory.

Range: 25, 28, 29, 30.

Site: Dry, well-drained, sun.

Fruit: Nut, available September-October.

A small to large tree; occurs on sterile, sandy, or rocky soil; wood used commercially. 
Carya pecan (Marsh.) Engl. and Graebn.

Pecan.

C. illinoensis (Wang.) Koch, C. olivaeformis Nutt., Hicoria pecan (Marsh.) Britt.

Range: $16,20,22,25,29,30$.

Site: Dry, well-drained, moist, sun.

Fruit: Nut, available September-Octoher.

A large tree; taproot short, root system spreading; usually occurs on fertile soil; comparatively rapid growing (for a hickory), long-lived; ability to stump sprout decreases with age; easily frost-damaged; somewhat injured by bark beetles; wood much inferior to other hickories, unimportant commercially although somewhat used for fuel; nuts probably do not mature northward because of frost; difficult to transplant; most cultivated forms, of which there are about 100 named varieties, have larger nuts with thinner shells than the wild species; 100 seeds per pound, germination about 85 percent; about 35 usable plants per pound of seed; a hybrid between this and $C$. laciniosa is recognized as the Nussbaumer hickory and between this and $C$. cordiformis as Brown's hickory.

Stomach records: Six species of birds; opossum. Observations: Three species of birds including wild turkey; bassariscus, peccary.

Carya porcina, see Carya glabra.

Carya sulcata, see Carya laciniosa.

Carya texana DC.

Hicoria texana (Le Conte) Britt.

Bitter pecan.

Range: 29, 30 .

Site: Well-drained, moist, sun.

A large tree.

Fruit : Nut, available September-October.

Carya tomentosa, see Carya alba.

Carya villosa Schneid.

C. buckleyi villosa Sarg., Hicoria villosa (Sarg.) Ashe, H. glabra villosa Sarg.

Range : 20, 22, 25.

Site: Dry, well-drained, sun.

Fruit: Nut, available October-November.

A large, drought-resistant tree; occurs on sandy or other soils.

Caryopitis edulis, see Pinus edulis.

Caryopitis monophylla, see Pinus monophylla.

Cassandra calyculata, see Chamaedaphne calyculata.

Cassia armata Wats.

Xerocassia armata (Wats.) Britt. and Rose.

Senna.

Range: 10.

Site: Dry, well-drained, sun.

Fruit: Legume.

A small, much-branched shrub, leafless most of the year; may occur on sandy or other soils.

Cassia covesii Gray.

Earleocassia covesii (Gray) Britt.

Senna.

Range: $9,10,11$.

Site: Dry, sun.

Fruit: Legume.

A small shrub; often only herbaceous in the eastern part of its range.

Cassia wislizenii Gray.

Palmerocassia wislizenii (Gray) Britt.

Range: 11.

Site: Dry, sun.

Fruit: Legume.

A small to large, much-branched, spreading shrub.

Cassiope hypnoides (L.) Don.

Range: $23,24,26,27$.

Site: Dry, well-drained, sun.

Fruit: Capsule.

A small, evergreen shrub; flowers June-July; procumbent and tufted, somewhat mosslike; occurs on aipine summits. 
Cassiope mertensiana (Bong.) Don.

Andromeda mertensiana Bong.

Range: 1, 4, 12.

Site: Well-drained, sun.

Fruit: Capsule.

A low shrub; stems prostrate, more or less matted; occurs at high altitudes. Stomach records: Mountain sheep.

\section{Castanea spp.}

The chinquapins are susceptible to the chestnut blight, although that disease has not been as destructive of them as of the chestnut; propagation is by seed sown in fall or spring.

Stomach records (in addition to specific records): Eastern flying squirrel, gray squirrel, red squirrel, eastern chlpmunk. Observations (in addition to specific records) : Bluejay, pileated woodpecker; opossum, white-tailed deer.

Castanea alabamensis Ashe.

Range: 29.

Alabama chinquapin.

Site: Dry, well-drained, sun.

A large tree.

Fruit: Nut, available September-October.

Castanea alnifolia Nutt.

C. nana Muhl.

Dwarf chinquapin.

Range: 29, 30.

Site: Well-drained, sun.

Fruit: Nut, available September-October.

A small shrub; occurs in sandy and other soils; forms great patches by means of stolons.

Castanea arkansana, see Castanea ozarkensis.

Castanea ashei Sudw.

C. pumila ashei Sudw.

Coastal chinquapin.

Range: 28, 29, 30.

Site: Well-drained, sun.

Fruit: Nut, available in September.

A large shrub to small tree; usually occurs in sand. A form with more pointed leaves has been described as $C$. margaretta Ashe.

Castanea dentata (Marsh.) Borkh.

American chestnut.

Range: 24, 25, 26, 27, 28, 29, 30.

Site: Dry, well-drained, sun.

Fruit: Nut, available September-October.

A large tree, very nearly extinct through ravages of the chestnut blight; root system deep, taproot well developed.

Stomach records: Three species of birds, including bobwhite and wild turkey ; white-tailed deer.

Castanea floridana (Sarg.) Ashe.

C. alnifolia floridana Sarg.

Range : 29, 30.

Site: Well-drained, sun.

Fruit: Nut, available in August.

A large shrub to small or large tree; often many-stemmed eren when arborescent.

Castanea margaretta, see Castanea ashei.

Castanea nana, see Castanea alnifolia.

Castanea ozarkensis Ashe.

C. arkansana Ashe.

Ozark chinquapin.

Range: 25.

Site: Dry, well-drained, sun.

Fruit: Nut.

A small to large tree, commonly several-stemmed.

Castanea pumila (L.) Mill.

Range: $25,27,28,29,30$.

Chinquapin.

Site: Dry, well-drained, moist, sun, shade.

Fruit: Nut, available September-November. 
A large shrub to small or large tree; grows in sand, loam, clay, and other soils; coppices freely when cut; wood used to some extent commercially; 250 seeds per pound, germination about 60 percent, about 50 usable plants per pound of seed.

Stomach records: Three species of birds.

Castanopsis spp.

Chinquapins.

The species have been found experimentally susceptible to the chestnut blight. This disease is present in Californla in three commercial chestnut plantings where the burning of attacked individuals as a control measure is being actively pursued with success.

Observations (In addition to spesific records): Allen's chipmunk, goldenmantled ground squirrel.

Castanopsis chrysophylla (Dougl.) DC. (pl. 5, B). Golden chinquapin.

Range: $1,4,6$.

Site: Dry, well-drained, sun.

Fruit: Nut, available in September of the second season.

A small to large evergreen tree; thicket-forming; wood rarely used commercially; fruits sparingly.

Var. minor (Benth.) DC., the golden chinquapin, is a large shrub in region 4. observations: Of fair importance for mule deer.

Castanopsis sempervirens (Kell.) Dudl.

C. chrysophylla minor Wats.

Range: 4,5 .

Site: Dry, well-drained, sun.

Fruit: Nut, available September-October of the second season.

A small to large, spreading evergreen shrub.

Observations: Bighorn. Seldom touched by livestock; concentrated feeding may result in poisoning.

Castela nicholsonii Hook.

Goatbush.

Range: 11, 17.

Site: Dry, sun.

Fruit : Drupe.

A small, spiny, rigid shrub.

Castela texana (Torr. and Gray) Rose.

C. nicholsonii texana Torr. and Gray.

Goatbush.

Range: 11, 16, 17, 20.

Site: Dry, well-drained, sun.

Fruit: Drupe.

A small to large, rigid, spinescent shrub; thicket-forming; resistant to cattle as a hedge.

Castilleja hololeuca Greene.

Range: 5 .

Site: Dry, sun.

A small shrub.

Fruit: Capsule.

Catalpa spp.

Propagation of all species is by seed sown in spring after stratification.

Bush paintbrush.

Catalpa bignonioides Walt.

$$
\text { C. catalpa (L.) Karst. }
$$

Range: 22, 25, 27, 28, 29, 30.

Site: Well-drained, sun.

Fruit: A long capsule, available September to spring.

A large tree; flowers May-June; wood highly valued for fence posts. The original range is now uncertain, having been extended by plantings.

Catalpa catalpa, see Catalpa bignonioides.

Catalpa speciosa Engelm.

Range: $21,22,23,25,29$.

Site: Well-drained, moist, sun.

Fruit: A long capsule, available September to spring.

A large tree; flowers May-June; extenslvely planted and probably escaping in many places; rapid growing, relatively short-lived; easily injured by frost, storms, insects, and fungi; coppices freely; wood seldom used commercially although much used for fence posts; about 23,000 seeds per pound, germination about 80 percent; about 5,000 usable plants per pound of seed. 
Caudoleucaena retusa, see Leucaena retusa.

Ceanothus spp.

Ceanothus.

Generally large shrubs to small trees; ordinarily occur on more or less acid soil; nodules on the roots of the species assist in nitrogen fixation in the same manner as in the legumes; the deciduous forms are generally characteristic of drier soil and lower slopes; evergreen forms more characteristic of higher moisture slopes. Propagation is by seed treated with hot water followed by stratification as given for each species; seed can be germinated without any treatment, but low percentage of germination must be expected; many species can also be propagated by stem or root cuttings.

Stomach records (in addition to specific records) : 15 species of birds, including bobwhite, 2 species of western quail and mourning dove; mountain sheep, Columbian chipmunk, Mono chipmunk, gray-sided jack rabbit, black-tailed deer. Observations (in addition to specific records): Olympic wapiti, Rocky Mountain black-tailed deer, mule deer, alpine chipmunk. The deciduous forms are generally palatable to livestock but the evergreen forms are usually worthless.

Ceanothus americanus $\mathbf{L}$.

Range: $17,20,22,24,25,26,27,28,29,30$.

Jersey-tea.

Site: Dry, well-drained, sun, shade.

Fruit: Capsule, available September-November.

A small, bushy shrub; flowers May-July; root system very large, taproot very well developed, deep penetrating in sandstone, limestone, sand, clay, and other soils.

Stomach records: Four species of birds including bobwhite and wild turkey.

Ceanothus arboreus Greene.

Range: 5 .

Site: Dry, well-drained, sun.

Fruit: Capsule, available August-September.

A large shrub to small tree; flowers Ferbruary-March; crown open; foliage very ample; 90 percent germination of seeds may be obtained by treating with hot water at $194^{\circ} \mathrm{F}$; ; about 48,000 seeds per pound.

Ceanothus californicus, see Ceanothus integerrimus.

Ceanothus cordulatus Kellogg.

Range: 4, 5, 10.

Site: Dry, well-drained, sun, shade.

Fruit: Capsule, available August-September.

A small, wide-spreading, intricately-branched, thorny shrub; flowers JuneJuly; thicket forming; occurs from 6,000 to 9,000 feet; stump sprouts and reproduces by seed very well after fires; seeds treated with hot water to $176^{\circ} \mathrm{F}$., then stratified $3 \frac{1}{2}$ months at $36^{\circ}$ germinate up to 65 percent; seeds boiled 1 minute and stratified 3 months germinate up to 60 percent.

Observations: Mountain quail ; of outstanding importance as browse for mule deer; mountain beaver. Considered inferior browse for cattle, but much used by sheep; fairly resistant to grazing.

Ceanothus crassifolius Torr.

Deer brush.

C. insularis Eastw.

Range: 5 .

Site: Dry, sun.

Fruit: Capsule.

A large, much-branched evergreen shrub; flowers January-April; occurs below 3,500 feet; foliage rather open; very inflammable; rarely coppices; intolerant of shade; propagation by seed heated to $70^{\circ} \mathrm{C}$. in water, then cooled, and stratified 3 months at $35^{\circ} \mathrm{F}$.; germination of 76 percent is thus obtained; about 33,000 seeds per pound.

Observations: Fair browse for mule deer.

Ceanothus cuneatus (Hook.) Nutt.

Range: 3, 4, 5 .

Site: Dry, well-drained, sun.

Frult: Capsule.

A small to large evergreen shrub; flowers March-May; occurs below 5,000 feet; spreading, rigid, intricately branched and with dense foliage; thicket forming; often sprawling; crown sprouts abundantly after fires; forms impenetrable thickets but seldom makes a continuous cover; regenerates from 
exposed roots; 92-percent germination of seeds is obtained when they are heated to $158^{\circ} \mathrm{F}$. in water, allowed to cool, and stratified $3 \frac{1}{2}$ months at $36^{\circ}$; about 54,000 seeds per pound.

Stomach records: Valley quail. Observations: Mountain quail, mariposa brush rabbit; of outstanding importance for mule deer. If grazed extensively by stock, may cause kidney trouble in males; generally not browsed by stock.

Ceanothus cyaneus, see Ceanothus tomentosus.

Ceanothus dentatus Torr. and Gray.

Range: 1,5 .

Site: Dry, well-drained, sun.

Fruit: Capsule.

A small, densely-branched shrub; flowers April-June; occurs on sandy and other soils; 83-percent germination of seeds may be obtained when they are treated with hot water to $158^{\circ} \mathrm{F}$, cooled, and stratified 3 months at $36^{\circ}$. Sereral varieties occur within the range of the species, one of which, var. impressus Trel., is prostrate.

Ceanothus divaricatus, see Ceanothus leucodermis and $C$. oliganthus.

Ceanothns diversifolius Kellogg.

Trailing ceanothus.

Range: 4.

Site: Dry, well-drained, sun, shade.

Fruit: Capsule.

A small, trailing or prostrate, matlike shrub; flowers May-June; occurs from 300 to 600 feet elevation.

Observations: Fair browse for mule deer. Considered fair sheep browse.

Ceanothus fendleri Gray.

Range: $9,11,13,14,15$.

Fcndler ceanothus.

Site: Dry, well-drained, sun, shade.

Fruit: Capsule, available August-September.

A small to large shrub; branches spiny, sometimes procumbent; flowers JuneAugust; may form dense thickets; occurs on sandy and other soils; root system somewhat shallow, taproot not deep; germination of seed not less than 16 percent.

Stomach records: Porcupine, black-tailed deer. Observations: A famous deer browse; heavily utilized by porcupines during summer. An important browse in the southwest for livestock.

Ceanothus ferrisae McMinn.

Range: $1,3$.

Site: Dry, well-drained, sun.

Fruit: Capsule.

A small to large evergreen shrub; branches stiff, divergent.

Ceanothus foliosus Parry.

Range: 4 .

Site: Dry, sun.

Fruit: Capsule, available April-May.

A small to large shrub; flowers April-May; occurs at 200 to 3,500 feet elevation; foliage dense; often procumbent or nearly prostrate; root nodules well developed; 92-percent germination of seeds may be obtained when they are treated in hot water at $158^{\circ} \mathrm{F}$., cooled, and stratified 3 months at $36^{\circ}$.

Ceanothus greggii Gray.

C. verrucosus greggii (Brandeg.) Gray.

Gregg ceanothus.

Range: $4,9,10,11$.

Site: Dry, sun.

Fruit: Capsule, available in Juiy.

A small to large evergreen shrub; flowers March-May; spinj, rigid, and intricately branched. Considered by some to be $C$. vestitus Greene for California. Fair to good browse in winter and early spring for stock, especially goats.

Var. perplexans (Trel.) Jeps. (C. perplexans Trel.), occurs within the range of the species.

Ceanothus hirsutus, see Ceanothus oliganthus. 
Ceanothus incanus Torr. and Gray.

Coast whitethorn.

Range: 4.

Site: Well-drained, moist, sun.

Fruit: Capsule.

A large shrub; flowers April-May; forms extensive thickets; pioneers in logged woodland areas; stump sprouts after cutting; propagation is by seeds treated in hot water to $176^{\circ} \mathrm{F}$., cooled, and stratified $3 \frac{1}{2}$ months at $36^{\circ}$; by this process 70-percent germination may be obtained.

Ceanothus infesta, see Adolphia infesta.

Ceanothus insularis, see Ceanothus crassifolius.

Ceanothus integerrimus Hook. and Arn.

C. californica Kellogg, C. integerrimus puberulus Abrams.

Deer brush.

Range : 4, 11.

Site: Dry, well-drained, sun.

Fruit: Capsule.

A small to large, widely branched shrub; flowers June-Angust; occurs from 2,000 to 5,000 feet northward and from 4,000 to 6,500 feet southward; foliage dense; some leaves persist all winter; rapid growing; stump sprouts after cutting or fire; withstands grazing well; reproductire power good; easily shaded out by pine and fir; 85-percent germination of seed is obtained by heating to $176^{\circ} \mathrm{F}$. in water, cooling, and stratifying $3 \frac{1}{2}$ months at $36^{\circ}$; 68-percent germination obtained with seeds boiled 1 minute and stratified 3 months.

Stomach records: Gambel quail. Observations: Of outstanding importance for mule deer; porcupine. The most important browse species for stock in California. Considered poisonous by some but probably of little significance physiologically. A valuable honey plant.

Ceanothus intermedius Pursh.

O. americanus intermedius Koch.

Redroot.

Range: 28, 29, 30 .

Site: Well-drained, sun.

Fruit: Capsule, available in September.

A small shrub; flowers April-May.

Ceanothus jepsonii Greene.

Range: 4.

Site: Dry, well-drained, sun.

Fruit : Capsule.

A small to large, rigid, erect shrub; flowers in April ; colony forming; completely killed by chaparral fires.

Var. purpurea Jeps. (C. purpurea Jeps.), the hollyleaf ceanothus, occurs in the southern part of the range.

Ceanothus lemmonii Parry.

Plumas-brusl.

Range: 4.

Site: Well-drained, sun.

Fruit: Capsule.

A small, spreading shrub; flowers Aprll-May.

Ceanothus leucodermis Greene.

Jepson ceanothus.

C. divaricatus of auth., not Nutt., $C$. divaricatus grosse-serratus Torr.

Range : 4, 5, 10.

Site: Dry, sun.

Fruit: Capsule.

A large shrub to small tree; spreading and spinose, flowers April-May; occurs from 1,000 to 5,000 feet; persists in spite of fire; 67-percent germination of seed obtained by heating in water to $158^{\circ} \mathrm{F}$., cooling, stratifying at $36^{\circ}$ for 3 months; 43-percent germination obtained by heating to $194^{\circ}$, cooling, and sowing for 4 months; about 77,000 seeds per pound.

Observations: Of outstanding importance as browse for mule deer. Value for livestock limited.

Ceanothus macrocarpus Nutt.

Big-pod ceanothus.

O. megacarpus Nutt., C. cuneatus macrocarpus (Nutt.) Brandeg.

Range: 5 .

Site: Dry, well-drained, sun.

Fruit: Capsule. 
A large shrub to small tree: flowers January-March; occurs at low altitudes. Observations: California mule deer.

Ceanothus martinli Jones.

Martin ceanothus.

C. sorediatus glabra Wats.

Range : 9, 13.

Site: Dry, well-drained, sun.

Eruit: Capsule.

A small to large shrub; flowers June-July. Highly palatable to sheep and eattle.

Ceanothus megacarpus, see Ceanothus macrocarpus.

Ceanothus microphyllus Michx.

Range: $29,30$.

Site: Dry, well-drained, sun.

Eruit: Capsule.

A small, spreading, much-branched evergreen shrub; flowers April-May; occurs in sandy and other soils.

Ceanothus oliganthus Nutt.

Hairy ceanothus.

C. hirsutus Nutt., C. divaricatus Nutt., not of auth., C. orcuttii Parry.

Range : 5 .

Site: Dry, well-drained, sun, shade.

Fruit: Capsule.

A large shrub; flowers May-June; occurs below 3,500 feet.

Observations: California mule deer.

Ceanothus orcuttii, see Ceanothus oliganthus.

Ceanothus oregonus, see Ceanothus sanguineus.

Ceanothus ovalis, see Ceanothus ovatus.

Ceanothus ovatus Desf.

C. ovalis Bigel.

Redroot.

Range: $15,16,17,18,20,21,22,23,24,25,26,27,28,29,30$.

Site: Dry, well-drained, sun.

Fruit: Capsule available September-November.

A small shrub; flowers May-June; occurs in sandy and other soils.

Stomach records: Bobwhite (?). One of the best stock browse species in the Black Hills.

Ceanothus palmeri Trel.

C. spinosus palmeri Jeps.

Cuyamaca bush.

Range: 4, 5 .

Site: Dry, well-drained, sun.

Fruit: Capsule.

A large shrub; flowers May-June; occurs from 4,500 to 5,700 feet; stump sprouts after cutting. Browsed by cattle in times of scarcity of other feed.

Ceanothus papillosus Torr. and Gray.

Bennie bush.

Range: 1,5 .

Site: Well-drained, sun.

Fruit: Capsule.

A small to rarely large shrub of open habit; flowers May-June; inflammable; 75-percent germination of seed is obtained by treating with hot water to $176^{\circ} \mathrm{F}$., cooling, and stratifying $3 \frac{1}{2}$ months at $36^{\circ}$; about 200,000 seeds per pound.

Ceanothus parryi Trel.

Range: 4.

Lady-bloom.

Site: Dry, well-drained, sun.

Fruit: Capsule.

A small to large shrub; flowers April-June; very openly branched.

Ceanothus parvifolius Trel.

Range: 4.

Littleleaf ceanothus.

Site: Dry, sun.

Fruit: Capsule.

A small shrub; flowers in June; occurs from 4,700 to 6,500 feet.

observations: Fair browse for mule deer.

Ceanothus perplexans, see Ceanothus greggii. 
Ceanothus pinetorum Cov.

Range: 4 .

Kern ceanothus.

Site: Well-drained, sun.

Fruit: Capsule.

A small, spreading or erect shrub; flowers in June; occurs from 7,000 to 8,800 feet; procumbent or prostrate forms are known.

Observations: Rocky Mountain mule deer.

Ceanothus prostratus Benth. (pl. $6, B$ ).

Mahala mat.

Range: 4, 9, 12 .

Site: Dry, well-drained, sun.

Fruit: Capsule.

A small, prostrate evergreen shrub; branches root where in contact with the soil, and form a matlike ground cover; forms are known that are not as prostrate as the species.

Var. grandifolius Jeps. occurs in region 1.

Observations: Fair browse for mule deer. Forage value for livestock slight or negligible.

Ceanothus pubescens (Torr. and Gray) Rydb.

C. ovatus pubescens Torr. and Gray.

Range: 15, 16, 18, 21, 22, 24, 25, 29, 30.

Site: Dry, sun.

Fruit: Capsule.

A small shrub; flowers May-July; occurs in sandy soils.

Ceanothus purpurea, see Ceanothus jepsonii.

Ceanothus rigidus Nutt.

O. verrucosus rigidus Brandeg.

Range: 1,4 .

Site: Dry, well-drained, sun.

Fruit: Capsule.

A small to large shrub; flowers February-April; rigidly and divaricately branched; occurs in sandy and other soils; closely related to C. cuneatus (q. v.), possibly only a blue-flowered variety; 92 percent germination of seed obtained by treating in hot water to $158^{\circ} \mathrm{F}$., cooling, and sowing for 16 weeks.

Var. fresnensis Jeps. extends the range to region 3.

observations: Fair browse for mule deer.

Ceanothus sanguineus Pursh.

C. oreganus Nutt.

Redstem ceanothus.

Range : 1, 2, 4, 12, 24.

Site: Dry, well-drained, sun.

Fruit: Capsule.

A small to large shrub; flowers May-June.

Stomach records: Valley quail. Palatability to stock, fair to fairly good.

Ceanothus serpyllifolius Nutt.

Range: 30 .

Site: Well-drained, sun.

Fruit: Capsule.

A small, diffusely-branched, decumbent, evergreen shrub; flowers April-May. Ceanothus sorediatus Hook. and Arn.

Jim brush.

Range: 4.

Site: Dry, sun.

Fruit: Capsule.

A large, thicket-forming, spiny shrub; flowers April-May; coppices vigorously after cutting or burning; produces little shade; occurs from 500 to 2,500 feet; practically 100-percent germination of seed can be obtained by boiling 5 minutes and stratifying 3 months at $36^{\circ} \mathrm{F}$.

Ceanothus spinosus Nutt.

Greenbark ceanothus.

Range: 5 .

Site: Dry, well-drained, sun, shade.

Fruit: Capsule.

Commonly a large shrub or rarely a small tree; partly evergreen, often wide spreading and straggling; sometimes spiny; colony forming; occurs below 2,000 feet; practically 100-percent germination of seed is obtained by heating in water to $158^{\circ} \mathrm{F}$., cooling, and sowing for 16 weeks; about 48,000 seeds per pound.

Observations: Of fair importance as browse for mule deer. 
Ceanothus subsericeus Rydb.

Range: 13.

Site: Dry, sun.

Fruit: Capsule.

A small shrub; flowers in July.

Ceanothus thyrsiflorus Esch.

Range: 1.

Blueblossom.

Site: Dry, well-drained, sun, shade.

Fruit: Capsule, available July-December.

A large shrub to small tree; evergreen; flowers April-June; nitrogen nodules very abundant; forms dense thickets after fires; a pioneer in cut-over areas, often to the exclusion of other species; not successful in heavy soils; root system shallow; 83-percent germination of seed obtained by treating in hot water to $158^{\circ} \mathrm{F}$., cooling, and stratifying 3 months at $36^{\circ}$; about 182,000 seeds per pound.

Observations: An important food of Roosevelt elk.

Ceanothus tomentosus Parry.

Range: 4.

Site: Dry, well-drained, sun.

Fruit: Capsule.

A large, loosely-branched shrub; flowers in May; occurs up to 3,000 feet; stump sprouts after cutting.

Var. olivaceus Jeps. (C. cyaneus Eastw.), Ramona bush, occurs in region 5.

observations: Of slight importance as browse for mule deer.

Ceanothus velutinus Dougl.

Range: $2,4,6,7,12,13,15$.

Snowbrush.

Site: Dry, sun.

Fruit: Capsule.

A small to large evergreen shrub; flowers May-July; spreading and many stemmed from the base; possesses a single large taproot which may make transplanting difficult; root system spreading, deep; a pioneer, forming vast thickets in logged or burned-over areas; 68 percent germination of seed is obtained by treatment in hot water at $176^{\circ} \mathrm{F}$, , and stratification for 3 months at $36^{\circ}$, or 63 percent when boiled 5 minutes and stratified 3 months.

Stomach records: Plains white-tailed deer.

Observations: A fair browse for mule deer; pica. Usually grazed only slightly by stock; much grazing indicates poor range; attempts to eradicate the species by overgrazing by goats have failed.

Ceanothus verrucosus Nutt.

Barranca bush.

Range: 5 .

Site: Dry, sun.

Fruit: Capsule.

A small to large, wide-spreading shrub; flowers January-April; occurs in sandy soils, not successful in heavy soils; 20-percent germination of seed obtained when sown directly.

Ceanothus vestitus, see Ceanothus greggii.

Cebatha carolina, see Cocculus carolinus.

Cebatha diversifolia, see Cocculus diversifolius.

Celastrus scandens L.

Climbing bittersweet.

Range: 11, 15, 16, 18, 21, 22, 23, 24, 25, 26, 27, 28, 29, 30 .

Site: Dry, well-drained, sun, shade.

Fruit: Pod, seeds with pulpy arils, available September-December, rarely later.

A twining, high-climbing, or thicket-forming vine; essentially dioecious but pistillate plants have enough staminate flowers to ensure fertilization; injures trees by constriction; very common along fence rows; occurs in loam, sand, clay, and other soils; propagation is by seeds sown in fall or stratified and sown in spring, or by layers and root cutting; 12,000 seeds per pound, germination 80 percent, about 3,000 usable plants per pound of seed.

Stomach records: Eight species of birds, including ruffed grouse and bobwhite.

Observations: Seven species of birds, including ring-necked pheasant; cottontail rabbit, fox squirrel, songbirds. Not browsed by livestock; poisonous to horses but apparently not attractive to them. 
Celosia palmeri Wats.

Range: 17.

Site: Well-drained, sun.

A small shrub.

Fruit: Achenelike.

Celtis spp.

Hackberries.

Propagation of all species is by seeds sown as soon as ripe.

Stomach recorls (in addition to specific records): Twenty-four species of birds, including mallard.

Observations (in addition to specific records) : Twenty species of birds; cliff squirrel, rock squirrel, snowshoe hare. Except for $C$. douglasii, western hackberries are without range significance for livestock.

Celtis aculeata, see Celtis iguanaea.

Celtis anfractuosa, see Celtis iguanaea.

Celtis canina, see Celtis occidentalis.

Celtis crassifolia, see Celtis occidentalis.

Celtis douglasii Planch. (pl. 6, A.).

C. rugosa Rydb.

Range: 5, 7, 8, 9, 11, 12, 13.

Site: Dry, well-drained, moist, sun, shade.

Fruit: Drupe, available July-January.

A small or large shrub to small tree; larger form found only on very good soil or in cultivation.

Stomach records: Two species of birds. An important secondary browse for cattle and sheep, especially in early spring and winter; galls on the leaves, a general condition in Utah, reduces palatability to livestock.

Celtis georgiana Small.

C. pumila georgiana (Small) Sarg.

Georgla hackberry.

Range: 25, 28, 29, 30.

Site: Well-drained, moist, sun.

Fruit: Drupe.

A small shrub to small tree.

Celtis helleri, see Celtis lindheimeri.

Celtis iguanaea (Jacq.) Sarg.

C. platycaulis Greenm., C. anfractuosa Liebm., C. aculeata Sw., Momisia aculeata Kl.

Range: 17,32 .

Site: Well-dralned, sun.

Fruit: Drupe.

A large shrub to small tree with spiny branches; somewhat climbing; commonly occurs on sandy soll.

Celtis laevigata, see Celtis mississippiensis.

Celtis lindheimeri Koch.

C. helleri Small.

Paloblanco.

Range: 17, 20.

Site: Well-drained, sun.

Fruit: Drupe; available in September, perslstent until spring.

A small to large tree.

Celtis mississippiensis Bosc.

C. laevigata Willd., C. smallii Beadle.

Range: $11,16,17,20,22,25,29,30$.

Site: Dry, well-drained, moist, sm, shade.

Fruit: Drupe; available September-October, more or less persistent.

A large shrub to small or large tree; wood used to some extent commercially; 2,500-4,000 seeds per pound.

Var. anomala Sarg. is a shrub occurring in region 20, commonly in sand.

Stomach records: Ten species of birds. Observations: Wild turlrey; eaten as a last resort by marsh rabbits. 
Celtis occidentalis $\mathbf{L}$.

Range: $15,16,18,20,21,22,23,24,25,26,27,28,29,30$.

Hackberry.

Site: Dry, well-drained, moist, sun, shade.

Fruit: Drupe; available September-October, often persistent until June.

A large shrub to more commonly a small or large tree; much spread by introduction as a drought-resistant plant; root system medium deep to shallow; rapid growing; short-lived; in general free from serious insect enemies and diseases, except for a witches'-broom caused by the mite Eriophyes and a powdery mildew fungus; the witches'-broom does not cause serious damage to the tree; very resistant to drought; wood somewhat used commercially; propagated by layering, cuttings, and seed; easily transplanted when young; 1,500-2,000 seeds per pound, germination 86 percent, about 500 usable plants per pound of seed; seeds treated with concentrated sulphuric acid 1 hour, washed in water, and treated an additional hour in concentrated sulphuric acid, give 84-percent germination in 55 days, as against 22 percent in 65 days after stratification at $41^{\circ} \mathrm{F}$. for 2 months; fruit produced sparingly. Very variable in size, form, and color of fruit.

Several varieties have been described, such as var. canina Sarg. (C. canina Raf.), a tree occurring with the species, var. crassifolia (La Marck) Gray, (C. crassifolia Lam.) and var. pumila Muhl., a low, straggling shrub.

Stomach records: Twenty-five species of birds, including bobwhite and lesser prairie chicken. Observations: Twenty species of birds, including wild turkey, ring-necked pheasant, and prairie sharp-tailed grouse.

Celtis pallida Torr. (pl. 7, A).

Desert hackberry.

Momisia pallida (Torr.) Plancl.

Range: 10, 11, 16, 17, 20.

Site: Dry, sun.

Fruit: Drupe, available July-November.

A large, spiny, densely-branched, evergreen shrub; forms dense thickets; wood useful for fence posts; seed germination apparently low.

Stomach records: Six species of birds, including Gambel and scaled quail ; antelope jack rabbit. Observations: Scaled quail, mocking bird, thrasher, phainopeplas, cactus wren, cardinal, pyrrholoxia, towhee, Gambel quail; used almost to the exclusion of other species as roosts by Gambel quail; Mexican raccoon, jack rabbit, captive deer. A good honey plant.

Celtis platycaulis, see Celtis iguanaea.

Celtis reticulata Torr.

C. mississippiensis reticulata Sarg.

Thick-leaved hackberry.

Range: $5,9,10,11,14,16,17,19,20$.

Site: Dry, well-drained, moist, sun.

Fruit: Drupe, available in September.

A large shrub to small or large tree; grows in limestone and other soils including rocky and gravelly ones; wood locally used for fence posts; berries rich in calcium; formerly a staple Indian food; seed germination about 80 percent, about 400 usable plants per pound of seed.

Var. vestita Sarg. (C. rugulosa Rydb.) occurs in the northeastern portions of the range.

Celtis rugulosa, see $C$. reticulata.

Celtis rugosa, see Celtis douglasii.

Celtis smallil, see Celtis mississippiensis.

Cephalanthus occidentalis $\mathbf{L}$.

Buttonball bush.

Range: $3,4,5,11,16,17,19,20,21,22,23,24,25,26,27,28,29,30$.

Site: Well-drained, moist, sun, shade.

Fruit: Nutlike capsule, avallable September-December or even later.

Commonly a large shrub, rarely a small or even a large tree; flowers in May northward, Angust southward; generally occurs in neutral soil; will grow in fresh soil under cultivation but in the wild state usually dies out for lack of moisture; propagation is by seed sown in fall or stratified and sown in spring, probably also by cuttings.

Stomach records: Twenty-five species of birds, most of them water or shore birds; composed 1.76 percent of food of 1,725 mallards. Observations: Ringnecked pheasant. Probably poisonous to livestock if eaten. A good bee plant. 
Cerasus borealis, see Prunus nigra.

Cerasu's caroliniana, see Prunus caroliniana.

Cerasus demissa, see Prunus demissa.

Cerasus emarginata, see Prunus emarginata.

Cerasus mahaleb, see Prunus mahaleb.

Cerasus minutiflora, see Prunus minutiflora.

Cerasus nigra, see Prunus nigra.

Cerasus trichopetala, see Prunus corymbulosa.

Ceratiola ericoides Michx.

Range: 29, 30, 31 .

Rosemary.

Site: Dry, well-drained, sun.

Fruit: Drupe.

A small, much-branched, aromatic evergreen shrub; often occurs in very acid soil; easily destroyed by fire.

Stomach records: Lesser scaup.

Cercidiopsis microphylla, see Cercidium microphyllum.

Cercidium spp.

All species are propagated by seed.

Stomach records (in addition to specific records): Mountain sheep.

Cercidium floridum, see Cercidium macrum, and $C$. torreyanum.

Cercidium macrum Johnst.

C. floridum of auth.

Texas paloverde.

Range: 11, 17.

Site: Dry, well-drained, sun.

Fruit: Legume.

A small tree; thorny but not as much so as $C$. texanum; flowers throughout the summer.

Cercidium microphyllum (Torr.) Rose and Johnst.

Littleleaf horsebean.

Parkinsonia microphylla Torr., Cercidiopsis microphylla (Torr.) Britt. and Rose.

Range: 10, 11.

Site: Dry, sun.

Fruit: Legume, persistent for at least a year after ripening.

A small to large shrub or rarely small tree; spiny; somewhat used locally for food.

Observations: Jack rabbit. Of local importance as an emergency forage for livestock.

Ccrcidium texanum (Wats.) Gray.

Parkinsonia texana Wats.

Range: 11, 17.

Site: Dry, well-drained, sun.

Fruit: Legume.

A small or rarely a large shrub; thorny and often intricately branched; leaves early deciduous; often forms dense thickets; easily grown from seed; said to be a honey plant.

Cercidium torreyanum (Wats.) Sarg. (pl. 7, B).

O. floridum Torr. not Benth., Parkinsonia torreyana Wats.

Paloverde.

Range: 10, 11.

Site: Dry, sun.

Fruit: Legume; available July, falls immediately.

A small to large tree; flowers April-May; occurs in sandy and other soils; leafless most of the year.

Stomach records: Gambel quail. Observations: A favorite food of burro deer. Of local importance as an emergency forage for livestock. A good bee plant. 

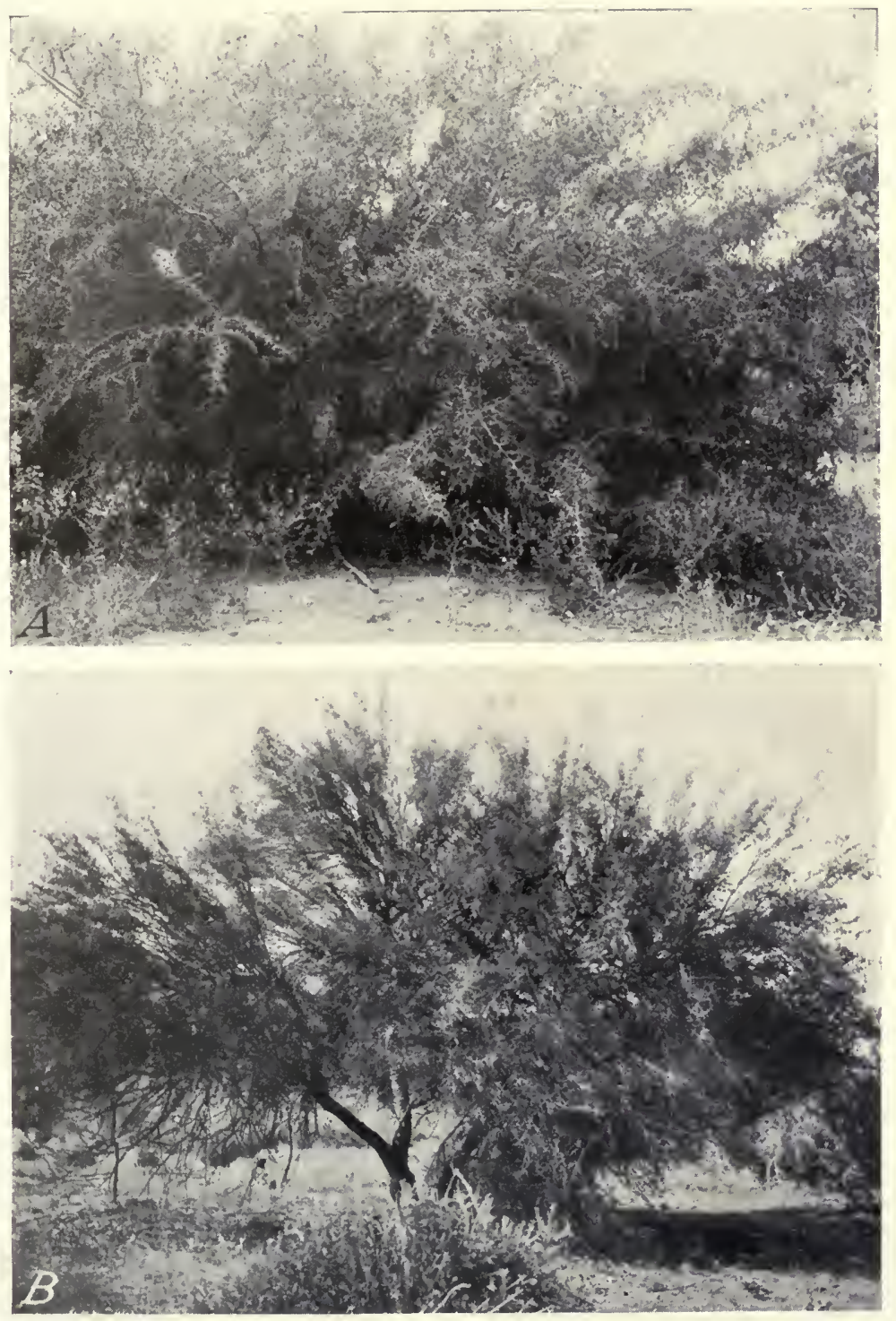

A. Celtis pallida, the desert hackberry, because of its great importance for wildlife and the dense cover it produces, should prove of outstanding value in planting for soil and wildlife conservation. $R$, Cercidium torreyanum. The recorded value of the paloverde as food for wildlife is not great, but as cover for soil and wildlife in arid regions its value is obvious. (Photograph by U.S. Forest Service.) 

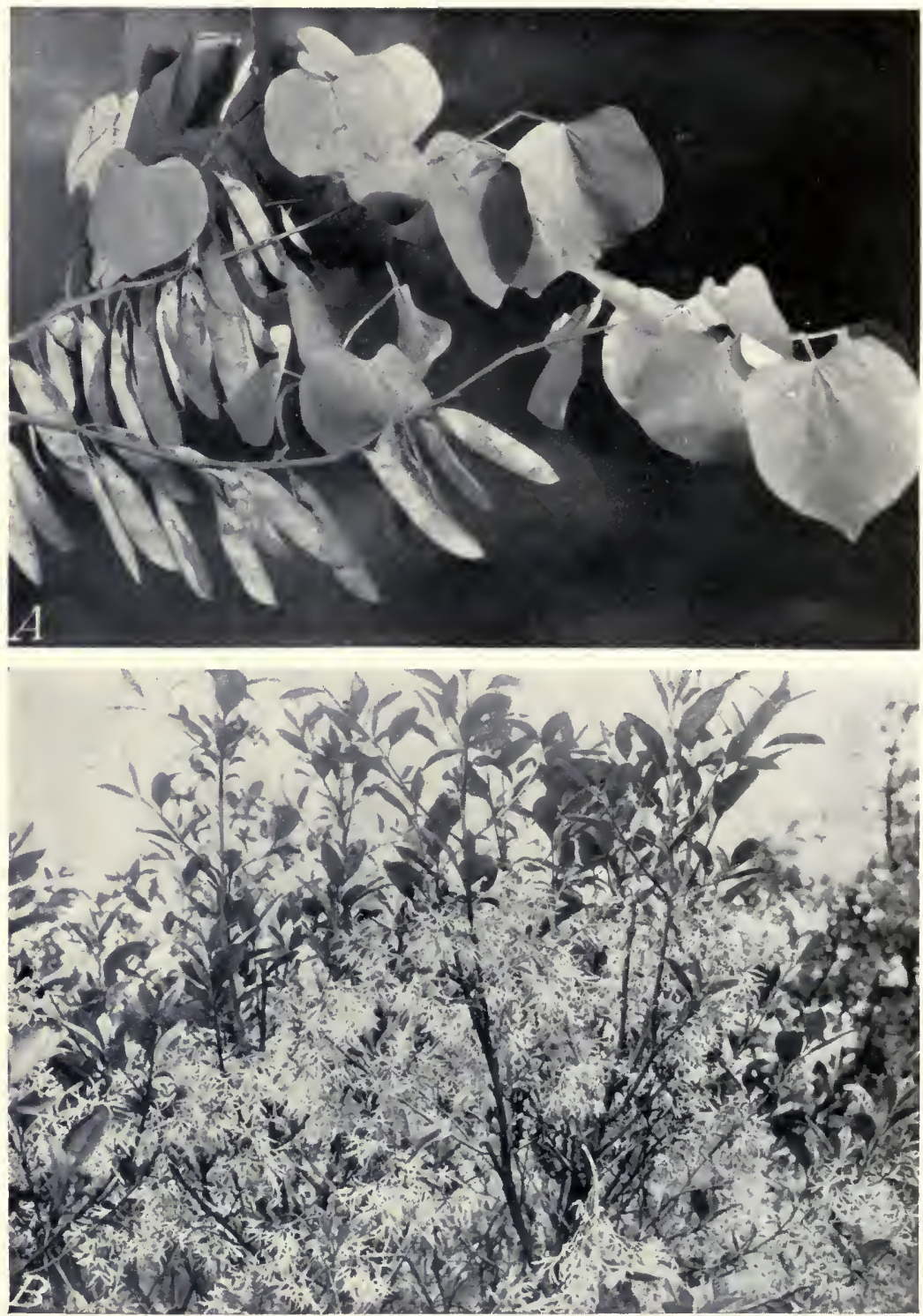

A, Cercis canadensis. The pods of the redbud often remain unopened throughout the winter, except those opened by birds. $B$, Chionanthus virginica. The beauty and fragrance of the flowers of the fringe tree entitle it to a place in highway plantings. 
Cercis canadensis L. (pl. $8, A$ ).

Redbud.

Range: $22,23,24,25,27,28,29,30$.

Site: Dry, well-drained, sun, shade.

Fruit: Legume; available July-August, pods persist throughout winter, seeds fall or not.

A small tree; flowers March-April; occurs in slightly acid, sand, loam, calcareous, and other soils; root nodules are not formed by this legume; propagation is by seed treated with hot water and sown in spring; about 25,000 seeds per pound; seed germination 80 percent, about 2,000 usable plants per pound of seed.

Stomach records: Three species of birds, including bobwhite; white-tailed deer. Observations: Bobwhite; captive marsh rabbit.

Cercis occidentalis Torr.

Range: $3,4,5,9,11,14,16,17$.

Site: Dry, well-drained, moist, sun.

Fruit: Legume, available July-August.

A large shrub to small tree; flowers February-April ; occurs in slightly acid soil; roots very long laterally; propagation is by seed treated with hot water and subsequently chilled for 3 months before sowing.

Observations: Rocky Mountain mule deer. Without forage value for livestock.

Cercis reniformis Engl.

C. texensis Sarg.

Texas redbud.

Range: 17, 20.

Site: Dry, well-drained, sun.

Fruit: Legume.

Commonly a small to large shrub, more rarely a small to large tree; occurs on limestone or slightly acid soil ; forms dense thickets; propagation is by seed treated with hot water and sown in spring.

Cercis tezensis, see Cercis reniformis.

Cercocarpus spp.

Mountain-mahoganies.

Stomach records (in addition to specific records): Black-tailed deer. $O b$ servations (in addition to specific records): A favorite food of Rocky Mountain mule deer and of Columbian black-tailed deer; yellow-halired porcupine. The species generally furnish much forage for cattle, sheep, and goats at all seasons.

Cercocarpus alnifolius Rydb.

C. parvifolius Sarg., in part.

Alderleaf mountain-mahogany.

Range: 5 .

Site : Dry, well-drained, sun.

Fruit: Achene, available July-September.

A large shrub or small tree; semievergreen; flowers in March; 33,000-60,000 seeds per pound.

Cercocarpus argenteus Rydb.

Range: 14, 16.

Site: Dry, sun.

Fruit: Achene, available in August.

A large evergreen shrub, flowers in May: An excellent browse for goats, relished also by cattle and sheep.

Cercocarpus arizonicus, see Cercocarpus intricatus.

Cercocarpus betuloides Nutt.

C. parvifolius betuloides Sarg., C. rotundifolius

Range: 4, 5, 9, 11.

Site: Dry, sun.

Fruit: Achene, available July-September.

A large shrub to small or rarely large tree; evergreen; flowers April-June; exceedingly variable; crown sprouts with vigor after fire or with advance of old age; seed germinates well as soon as planted; in the mountain regions generally occurs below 6,000 feet.

Observations: Of fair importance as browse for mule deer. An important browse for cattle and sheep.

Site: Dry, sun.

$130186^{\circ}-39-7$ 
Cercocarpus breviflorus Gray.

Range: 11, 14, 17.

Site: Dry, sun.

Fruit: Achene.

A large evergreen shrub.

Cercocarpus douglasii, see Cercocarpus betuloides.

Cercocarpus eximius, see Cercocarpus paucidentatus.

Cercocarpus flabellifolius, see Cercocarpus montanus.

Cercocarpus fothergilloldes, see Cercocarpus montanus.

Cercocarpus hypoleucus Rydb.

Range: 12.

Site: Well-drained, sun.

Fruit: Achene.

A large shrub to small tree; evergreen; flowers June-July.

Cercocarpus intricatus Wats.

C. intricatus villosus Schneid., C. arizonicus Jones.

Range: 9, 10.

Site: Dry, sun.

Fruit: Achene, available July-August.

A small evergreen shrub, flowers in May; densely branched, spinescent; generally occurs at elevations of $4,000-5,000$ feet. A poor browse for livestock. Cercocarpus ledifolius Nutt.

Range: 4, 9, 10, 12, 13, 14 .

Curlleaf mountain-mahogany.

Site: Dry, sun.

Fruit: Achene, available August-September.

A large shrub to small tree; evergreen; flowers July-August; occurs in gravelly and rocky soils.

Observations: Sonora deer; of outstanding importance as browse for mule deer. Very poor livestock forage.

Cercocarpus minutiflorus Abrams.

Range: 5.

Small-flowered mountain-mohagony.

Site: Dry, sun.

Fruit: Achene.

A large evergreen shrub.

Cercocarpu's montanus Raf.

Mountain-malıgany.

C. fothergilloides H. B. K., C. parvifolius Nutt. C. fabellifolius Rydb.

Range: 9, 11, 12, 13, 14, 15, 16.

Site: Dry, well-drained, sun.

Fruit: Achene, available August-October.

A large shrub or rarely a small tree; evergreen; flowers May-July; root system deep, spreading; slow growing; casts little shade; $30,000-60,000$ seeds per pound, germination not less than 22 percent.

Stomach records: Black-tailed deer, mountain sheep. Observations: Say chipmunk, Mexican bighorn, deer, and other herbivorous game animals. One of the most important western livestock browse species; palatability good for all livestock; reputed to be poisonous, but this appears to be doubtful; killed by overgrazing.

Cercocarpus parvifolius, see Cercocarpus montanus, and $C$. alnifolius.

Cercocarpus paucidentatus (Wats.) Britt.

Hairy mountain-malogany.

C. parvifolius paucidentatus Wats., C. eximius (Schneid.) Rydb.

Range: 11, 14.

Site: Dry, sun.

Fruit. Achene.

A large shrub to small tree; evergreen; flowers March-May and again in August. A flrst-class goat browse.

Cercocarpus rotundifolius, see Cercocarpus betuloides.

Cercocarpus traskiae Eastw.

Bigleaf mountain-mahogany.

Range: 5 .

Site: Dry, sun.

Fruit: Achene, available in August.

A large shrub to small tree; evergreen; flowers in May.

Cerothamnus carolinenses, see Myrica carolinensis. 
Cerothamnus ceriferus, see Myrica cerefera.

Cerothamnus inodorus, see Myrica inodora.

Cerothamnus pumilus, see Myrica: pumila.

Chamaebatia australis, see Chamaebatia foliolosa.

Chamaebatia foliolosa Benth.

Mountain misery.

Range: 4 .

Site: Well-drained, sun, shade.

Fruit: Achene.

A small, very leafy evergreen shrub; flowers in July; forms large mats by means of rootstocks; in cultivation. Worthless as livestock forage.

Var. australis Brandeg. (C. australis (Brandeg.) Abrams), which occurs in region 5 , is somewhat taller than the species.

Chamaebatiaria glutinosa, see Chamaebatiaria millefolium.

Chamaebatiaria millefolium (Torr.) Maxim.

Fern-bush.

C. glutinosa Rydb., Spiraea millefolium Torr., S. glutinosa (Rydb.) Fedde.

Range: 4, 9, 10, 12, 13, 14 .

Site: Dry, well-drained, sun.

Fruit: Pod.

A small to large, densely branched, aromatic shrub; flowers June-August.

Observations: Of slight importance as browse for mule deer. A falr browse for sheep and goats.

Chamaecyparis spp.

Monoecious, evergreen trees of importance in the production of timber. Six species are known, of which three occur in the United States; propagation is by seeds sown in spring.

Stomach records (in addition to specific records) : three species of birds.

Chamaecyparis lawsoniana (Murr.) Parl.

Range: 1, 2.

Site: Dry, well-drained, sun, shade.

Fruit: Cone, maturing in September-October of the second season, some opening, others holding seed until spring.

A large evergreen tree; moderately rapid growing; long-lived; resistant to fungi and insects, but not to fire; wood very durable, of importance commercially; seed crops heavy; vitality transient; about 70 varieties recognized in cultivation; seeds per pound variously stated from 80,000 to 234,000 , germination about 40 percent, slow, about 129,000 usable plants per pound of seed.

Chamaecyparis nootkatensis (Lam.) Spach.

Alaska cedar.

Range: $1,4$.

Site: Well-drained, sun.

Fruit: Cone; avallable September-October of the second season.

A large evergreen tree; slow growing, long-lived; root system shallow; little subject to fungus attack; wood of importance commercially, very durable; seeds produced sparingly, of transient vitality; 106,000 seeds per pound; some 15 varieties in cultivation.

Chamaecyparis thyoides (L.) BSP.

Range : 26, 27, 28, 29, 30, 31.

Site: Well-drained, moist, sun, shade.

Fruit: Cone; matures and opens September-October of the first season; persistent 2 to 3 years.

A large evergreen tree; root system shallow; easily damaged by fire; nearly free from insect attack; only slightly susceptible to fungi ; not wind-firm; somewhat storm-damaged northward; generally occurs on sandy loam and other soils; wood of considerable importance commercially, very durable; large crops of seed produced annually from an age of 4 or 5 years; $420,000-470,000$ seeds per pound; 3.64 pounds of seed per bushel of fruit; germination 70-90 percent; 12 varieties distinguished in cultivation.

Observations: Very little eaten by birds or rodents.

Chamaedaphne calyculata (L.) Moench.

Andromeda calyculata L., Cassandra calyculata Don.

Cassandra.

Range: 21, 22, 23, 24, 26, 27, 28.

Site: Well-drained, moist, sun.

Fruit: Capsule, available August-September. 
A small evergreen shrub; occurs only on acid peat; flowers April-June; forms dense thickets; propagation is by seeds sown under glass in winter or spring.

Observations: A staple winter food of prairle sharp-tailed grouse in Wisconsin ; cottontail rabbit.

Chamaerops acaulis, see Sabal minor.

Chamaerops glabra, see Sabal minor.

Chamaerops hystrix, see Rhapidophyllum hystrix.

Chamaerops louisiana, see Sabal louisiana.

Chenopodium spinosum, see Grayia spinosa.

Chilopsis linearis (Cav.) Sweet.

C. saligna Don, Bignonia linearis Cav.

Desertwillow.

Range: $5,9,10,11,16,17,20$.

Site: Dry, well-drained, moist, sun.

Fruit: Capsule, available September-October, persistent.

A large shrub to small or large tree; flowers May-June, showy; wood durable in contact with soil, of no commercial value; 50,000-100,000 seeds per pound, germination $40-60$ percent, about 4,000 usable plants per pound of seed.

stomach records: Gambel quail. Browsing of this species denotes overstocking or overgrazing of the range.

Chilopsis saligna, see Chilopsis linearis.

Chiogenes hispidula (L.) Torr. and Gray.

Vaccinium hispidulum $\mathrm{L}$.

Creeping snowberry.

Range: $12,23,24,26,27$.

Site: Well-drained, moist, sun, shade.

Fruit: Berry, available August-September.

A small prostrate evergreen vine; occurs in peat bogs and mossy woods; flowers May-June; roots at the nodes.

Stomach records: Ruffed grouse. Observations: Olive-backed thrush, spruce grouse.

Chionanthus virginica L. (pl. $8, B$ ).

Range: $20,25,27,28,29,30$.

Fringetree.

Site: Well-drained, moist, sun, shade.

Fruit: Drupe, available September-October.

A large shrub to small or large tree; flowers May-June; occurs in sandy and other soils, often acid ones; loses foliage early ; propagation is by seed stratified and sown in spring; about 2,000 seeds per pound; very ornamental in cultivation.

Stomach records: Pileated woodpecker.

Choisya dumosa (Torr.) Gray.

Starleaf.

Astrophyllum dumosum Torr.

Range: 11, 17.

Site: Dry, sun.

Fruit: Follicle.

A small much-branched shrub. Ordinarily not browsed by livestock; reputed poisonous, but this apparently is questionable.

Chrysactinia mexicana Gray.

Damianita.

Pectis taxifolia Greene.

Range: 11, 17.

Site: Dry, sun.

Fruit: Achene.

A small, much-branched, aromatic evergreen shrub ; heathllke ; flowers springsummer. Not known to be grazed, but since it is medicinal with Mexicans and Indians may possibly have injurious properties.

Chrysobalanus oblongifolius Michx.

Deer-plum.

Geobalanus oblongifolius (Michx.) Small.

Range: 29, 30 .

Site: Dry, well-drained, sun.

Fruit: Drupe, available in September.

A small shrub; flowers May-June; often forms thickets of considerable size by means of a dense network of underground stems; quickly recovers from burning; often occurs in sand.

Observations: Gophers, turtles, and other short-legged animals. 
Chrysobotrya aurea, see Ribes aureum.

Chrysobotrya odorata, see Ribes odoratum.

Chrysocoma nauseosa, see Chrysothamnus nauseosus.

Chrysoma arborescens, see Aplopappus arborescens.

Chrysoma brachylepis, see Aplopappus propinquus.

Chrysoma laricifolius, see Aplopappus laricifolius.

Chrysoma nana, see Aplopappus nanus.

Chrysoma palmeri, see Aplopappus palmeri.

Chrysoma parishii, see Aplopappus parishii.

Chrysothamnus spp. (pl. 9, $A$ ).

Rabbitbrush.

The members of this genus display great variation, and as many as 6 genera have been described and 88 forms, nearly all of which have been given specific rank at one time or another. Intergrading characters are many, and in this treatment we follow that of Hall and Clements (2/7).

The following records apply not only to woody species but to herbaceous ones, of which there are many:

Stomach records (in addition to specific records): Mountain sheep; blacktailed deer. Observations (in addition to specific records): A reserve food of western white-tailed jack rabbit; Oregon jack rabbit, mule deer, Arizona jack rabbit, western chipmunk, bighorn; generally of considerable importance as cover for plains birds and mammals. Palatability worthless to fairly good for livestock.

Chrysothamnus albidus (Jones) Greene.

Range : 8,9 .

Site: Dry, sum.

Fruit: Achene. fiats.

A small, brittle-twigged, very leafy shrub; a pronounced halophyte of alkali

Chrysothamnus asper, see Chrysothamnus parryi.

Chrysothamnu's baileyi, see Chrysothamnus pulchellus.

Chrysothamnus bigelovii, see Chrysothamnus nauseosus.

Chrysothamnus bloomeri, see Aplopappus bloomeri.

Chrysothamnus collinus, see Chrysothamnus nauseosus.

Chrysothamnus concolor, see Chrysothamnus nauseosus.

Chrysothamnus consimilis, see Chrysothamnus nauseosus.

Chrysothamnus corymbosus, see Aplopappus cooperi.

Chrysothamnus depressus Nutt.

Bigelovia depressa Gray, Linosyris depressa Torr.

Dwarf rabbitbrush.

Range: 9, 10, 11.

Site: Dry, sun.

Fruit: Achene.

A small, densely clump-forming shrub. Closely cropped, apparently by sheep, but scarcely of importance as browse.

Chrysothamnus douglasii, see Chrysothamnus viscidiflorus.

Chrysothamnus elatior, see Clrysothamnus pulchellus.

Chrysothamnus elegans, see Chrysothamnus viscidiflorus.

Chrysothamnus filifolius, see Chrysothamnus greenei.

Chrysothamnus glareosus, see Chrysothamnus nauseosus.

Chrysothamnus glaucus, see Chrysothamnus viscidiflorus.

Chrysothamnus graveolens, see Chrysothamnus nawseosus.

Chrysothamnus greenel (Gray) Greene.

C. filifolius Rydb., Bigelovia greenei Gray.

Range: $9,11$.

Site: Dry, sun.

Fruit: Achene. 
A small shrub; occurs on sandy, alkaline plains; flowers August-September; greatly increased by overgrazing. Of some slight value as browse for livestock where other feed is not available.

Chrysothamnus humilis, see Chrysothamnus viscidifiorus.

Chrysothamnus latifolius, see Chrysothamnus viscidiflorus.

Chrysothamnus leiospermus, see Chrysothamnus nauseosus.

Chrysothamnus linifolius, see Chrysothamnus viscidiflorus.

Chrysothamnus marianus, see Chrysothamnus viscidiflorus.

Chrysothamnus monocephalus, see Chrysothamnus parryi.

Chrysothamnus nauseosus (Pallas) Britt.

Rubber rabbitbrush.

Chrysocoma nauseosa Pallas.

Range : $4,6,7,8,9,11,12,13,14,15$.

Site: Dry, sun.

Fruit: Achene.

A small to large shrub; flowers September-December; root system deep; reproduces readily from seed and grows vigorously when transplanted, even when crowns are divided; forms basal sprouts after cutting; contains on the average 2.8 percent of rubber, although this may increase to 6.5 percent in individual plants; the most constant producers are those forms inhabiting alkali soils; it has been estimated that 300 million pounds of good-grade rubber are represented in this country by this species, but extraction is not yet commercially profitable.

Twenty subspecies or varieties are included within this species; they represent the species in various sections of the Great Basin and adjacent areas. O. nauseous includes the following forms:

$C$. bigelovii (Gray) Greene, $C$. collinus Greene, $C$. concolor Rydb., C. consimilis Greene, C. glareosus Rydb., C. graveolens (Nutt.) Greene, C. leiospermus (Gray) Greene, $C$. occidentalis Greene, $C$. oreophilus Nels., $C$. pinifolius Greene, O. pulcherrimus Nels. (more robust), C. salicifolius Rydb., C. speciosus Nutt., C. turbinatus Rydb.

Certain forms, as consimilis and viridulus, form pure stands on alkali flats; in general the important varieties are subclimax dominants of the sagebrush association.

Observations: Northward it furnishes an important winter browse for elk and perhaps moose; California mule deer. Value as browse for livestock depends on local conditions; palatability ordinarlly very low; probably poisonous when eaten exclusively; a not infrequent indicator of overgrazing.

Chrysothamnus newberryi, see Chrysothamnus parryi.

Chrysothamnu's occidentalis, see Chrysothamnus nauseosus.

Chrysothamnus oreophilus, see Chrysothamnus nauseosus.

Chrysothamnus paniculatus (Gray) Hall.

Sticky rabbitbrush.

Bigelovia paniculata Gray, Ericameria paniculata (Gray) Rydb.

Range: 10.

Site: Dry, sun.

Fruit: Achene.

A small to large, brittle-twigged shrub; flowers May-October; resistant to low temperatures; grows in extremely poor soils; rubber content about 2.5 percent, but straius may be found containing a higher percentage.

Chrysothamnus parryi (Gray) Greene.

Linosyris parryi Gray, Bigelovia parryi Gray.

Range: $4,8,9,10,11,12,13,15$.

Site: Dry, well-drained, sun.

Fruit: Achene.

A small shrub occurring on sandy or gravelly solls; an indicator of overgrazing. Ten subspecies or varieties are recognized which do not separate on stable characters but which are more or less separated geographically; the whole complex is here considered a single major species. It includes among others: $C$. asper Greene, $C$. newberryi Rydb. C. vulcanicus Greene, $C$. monocephalus Nels. and Ken., and C. wyomingensis Nels.

Chrysothamnus pinifolius, see Chrysothamnus nauseosus. 
Chrysothamnus pulchellus (Gray) Greene.

C. baileyi Woot. and Standl., Bigelovia pulchella Gray, Linosyris pulchella Gray.

Range: 9, 11, 16.

Site: Dry, sun.

Fruit: Achene.

A small shrub; usually occurs in sand.

Var. elatior (Standl.) Hall and Clem. (C. elatior Standl.) is taller than the species and occurs in region 11.

Chrysothamnu's pulcherrimus, see Chrysothamnus nauseosus.

Chrysothamnus pumilus, see Chrysothamnus viscidiflorus.

Chrysothamnus saliclfolius, see Chrysothamnus nauseosus.

Chrysothamnus serrulatu's, see Chrysothamnus viscidiflorus.

Chrysothamnus speciosus, see Chrysothamnus nauseosus.

Chrysothamnus stenolepis, see Chrysothamnus viscidiflorus.

Chrysothamnus teretifolius (Dur. and Hilg.) Hall.

Linosyris teretifolia Dur. and Hilg., Ericameria teretifolia (Dur. and Hilg.) Jeps.

Range: 5, 8, 10 .

Site: Dry, sun.

Fruit: Achene.

A small or rarely a large, brittle-twigged shrub; irregularly much branched and spreading to form a flat or rounded plant; rubber content 2.5 percent or 5 percent in certain strains. Resinous, and not browsed by livestock.

Chrysothamnus turbinatu's, see Chrysothamnas nauseosus.

Chrysothamnus viscidiflorus (Hook.) Nutt.

Douglas rabbitbrush.

Bigelovia douglasii Gray.

Range: $4,5,6,7,8,9,10,11,12,13,15$.

Site: Dry, sun.

Fruit: Achene.

A small or rarely a large shrub; about 20 segregates, 16 of which have been accorded specific rank, have been published; they pass insensibly into one another and cannot be easily or satisfactorily defined; the species as here treated includes:

C. douglasii Clem. and Clem., C. elegans Greene, $C$. glaucus Nels., O. humilis Greene, C. latifolius (Eaton) Rydb., C. linifolius Greene, C. marianus Rydb., C. pumilus Nutt., C. serrulatus Rydb., C. stenolepis Rydb.

This species also contains rubber, the highest content being found in forms inhabiting alkali solls.

All forms are browsed to a limited extent by sheep and cattle, except where other feed is fairly plentiful.

Chrysothamnus vulcanicus, see Chrysothamnus parryi.

Chrysothamnus wyomingensis, see Chrysothamnus parryi.

Cissus ampelopsis Pers.

Ampelopsis cordata, Michx.

Heartleaf ampelopsis.

Range: 19, 20, 22, 25, 27, 28, 29, 30.

Site: Well-dralned, moist, shade.

Fruit : Berry, available August-November.

A rapid-growing vine; flowers May-June; berry inedible; produces a great deal of cover; propagated by seeds sown after stratiflcation; 9,600 seeds per pound.

Stomach records: Three species of birds, including bobwhite. Observations: A favorite fruit of brown thrasher, wood thrush, and flicker.

Cissus arborea (L.) Des Moul. (pl. 9, B).

C. stans Pers., Ampelopsis arborea (L.) Rusby.

Peppervine.

Range: $17,20,25,27,28,29,30$.

Site: Dry, well-drained, moist, sun.

Fruit: Berry, available September-November.

A slender, bushy vine; ordinarily occurs in rich soil; flowers June-July; will grow under most difficult conditions; has been noted as common along roads and railroads in Alabama. 
Cissus incisa (Nutt.) Des Moul.

Treebine.

Vitis incisa Des Moul.

Range : 11, 16, 17, 20, 22, 25, 29, 30, 31.

Site: Dry, well-drained, sun.

Fruit: Berry, available in October.

A vigorous evergreen vine occurring in sandy and other soils; flowers JuneAugust; easily transplanted; propagation is by seed or by division of the woody tubers.

Observations: Birds especially fond of the berries.

Cissus stans, see Cissus arborea.

Citharexylum brachyanthum Gray.

Range: 11, 17.

Site: Dry, sun.

Fruit: Drupe.

$\Lambda$ small, much-branched, somewhat spinose evergreen shrub.

Citharexylum fru'ticosum $\mathrm{I}_{\text {s }}$.

C. villosum Jacq.

Range: 17, 30, 31, 32.

Site: Dry, sun.

Fruit: Drupe.

A large shrub to small tree; evergreen; flowers all year round; ordinarily occurs in sandy soil.

Citharexylum villosum, see Citharexylum fruticosum.

Citrus trifoliata $\mathrm{L}$.

Poncirus trifoliata (L.) Raf.

Bitter orange.

Range: 17, 20, 29, 30 .

Site: Well-drained, sun.

Fruit: Berry, available September-October.

A small, thorny, thicket-forming tree; flowers April-May; a native of China but naturalized in the regions indicated; used as grafting stock for oranges; much cultivated.

Cladothamnus campanulatus, sce Rhododendron albiflorum.

Cladrastis lutea (Michx.) Koch.

Range: 25, 27, 29.

Site: Dry, well-drained, sun.

Fruit: Legume, arailable September-October, persistent through winter or soon falling.

A small to large tree; flowers May-June; ordinarily occurs on rich, calcareous or neutral soil; propagated by seeds sown in spring; very handsome in flower and much cultivated.

Clematis spp.

The species are propagated by seeds sown under glass in spring.

Stomach records (in addition to specific records): Black-tailed deer. $O b$ servations (in addition to specific records): Goldfinch.

Clematis addisonii Britt.

Viorna addisonii (Britt.) Small.

Smooth clematis.

Range: 27, 28.

Site: Well-drained, sun.

Fruit: Achene.

A shrubby vine; flowers in May; root system deep; stems weak.

Clematis arizonica Heller.

Viorna arizonica Heller.

Range: 11.

Site: Dry, sun.

$\Lambda$ vine.

Fruit: Achene.

Clematis bigelovii Torr.

Viorna bigelovii (Torr.) Heller.

Range: 14.

Site: Well-drained, sun.

Fruit: Achene.

A vine.

Clematis brevifolia, see Clematis ligusticifolia, 
Clematis catesbyana Pursh.

Satin-curls.

Range: 29, 30.

Site: Well-drained, sun, shade.

Fruit: Achene.

A vine; ordinarily occurs on sandy soil.

Clematis coccinea, see Clematis tcxcnsis.

Clematis columbiana (Nutt.) Torr.

Atragene columbiana Nutt.

Range: 2, 4, 12, 13 .

Site: Well-drained, sun.

Fruit: Achene.

A vine, browsed to some extent by cattle in northwestern Montana when the foliage is young.

Clematis crispa $\mathbf{L}$.

C. cylindrica Sima, Viorna crispa (L.) Small.

Curly clematls.

Range: 17, 29, 30.

Site: Well-drained moist sun.

Fruit: Achene.

A slender vine; flowers June-September; often occurs on acid soil.

Clematis cylindrica, see Clematis crispa.

Clematis drummondii Torr. and Gray.

Drummond clematis.

Range: 10, 11, 16, 17, 20.

Site: Dry, well-drained, sun.

Fruit: Achene, available in August.

A climbing or clambering vine.

Clematis filifera, see Clematis pitcheri.

Clematis flaccida, see Clematis viorna.

Clematis gattingeri Small.

Viorna gattingeri Small.

Range: 25.

Site: Well-drained, sun.

Fruit: Achene.

A slender vine, flowering in July.

Clematis glaucophylla, see Clematis viorna.

Clematis lasiantha Nutt.

Range: $3,4,5$.

Site: Well-drained, moist, sun, shade.

Fruit: Achene.

A climbing or clambering vine; flowers April-May; about 103,000 seeds per pound.

Clematis ligusticifolia Nutt.

C. brevifolia Howell.

Range: $1,2,3,4,5,6,7,8,9,11,12,13,14,15,16,18,19,22$.

Site: Well-drained, sum.

Fruit: Achene, available September-November.

A vigorous climbing or clambering vine; flowers June-August; root system shallow, fibrous; rootstocks produced; seed germination about 80 percent.

Stomach records: Black-tailed deer. Observations: Of slight importance as browse for mule deer.

Clematis missouriensis, see Clematis virginiana.

Clematis neo-mexicana Woot. and Standl.

Range: 11.

Site: Dry, sun.

A vine.

Fruit: Achene.

Clematis obliqua (Small) Schneid.

Viorna obliqua Small.

Range: 29,30 .

Site: Well-drained, sun.

Fruit :" Achne.

Pipestem.

Virgins-bower. 
Clematis palmeri Rose.

Viorna palmeri (Rose) Woot. and Standl.

Palmer clematis.

Range: 14.

Site: Dry, well-drained, sun.

A vine.

Fruit: Achene.

Clematis pauciflora Nutt.

Range: 5 .

Rope-vine.

Site: Dry, well-drained, sun.

Fruit: Achene.

A trailing, clambering, or climbing vine; flowers March-April.

Clematis pitcheri Torr. and Gray.

Red-flowered clematis.

C. filifera Benth., O. simsii of auth., not Sweet, Viorna pitcheri (Torr. and

Gray) Britt., V. filifera (Benth.) Woot. and Stand1.

Range: 11, 16, 17, 20, 25, 30.

Site: Dry, well-drained, sun.

Fruit: Achene.

A high-climbing vine; flowers June-September.

Clematis pseudoalpina (Kuntze) Nels.

o. pseudoatragene pseudoalpina Kuntze, O. alpina occidentalis (Hornem.)

Gray, Atragene occidentalis Hornem., A. pseudoalpina (Kuntze.) Rydb.

Range: $9,12,13,14$.

Site: Well-drained, sun.

Fruit: Achene.

A vine; flowers April-June; commonly occurs at high elevations.

Clematis reticulata Walt.

Viorna reticulata (Walt.) Small.

Range: $11,20,29,30$.

Site: Dry, well-drained, sun.

Fruit: Achene.

A branching vine; flowers in Juiy; occurs on sandy and other soils.

Clematis simsii, see Clematis pitcheri.

Clematis subreticulata Harb.

Viorna subreticulata Harb.

Range: 29,30 .

Site: Dry, well-drained, sun.

Fruit: Achene.

A vine; occurs on sandy and other soils.

Clematis texensis Buckl.

C. coccinea Engelm., Viorna coccinea (Engelm.) Small.

Range: 17, 20.

Site: Well-drained, sun.

Fruit: Achene.

A branching vine; flowers July-September.

Clematis versicolor Smail.

Viorna versicolor Small.

Range: 25.

Site: Dry, well-drained, sun.

A vine.

Fruit: Achene.

Clematis verticiliaris DC.

Atragene americana Sims.

Mountain clematis.

Range : $23,24,26,27,28$.

Site: Well-drained, moist, shade.

Fruit: Achene, available July-August.

A trailing or climbing vine; flowers May-Jume; often occurs on calcareous soil ; a comparatively weak climber without great luxuriance.

Clematis viorna $\mathrm{L}$.

C. glaucophylla Small, C. flaccida Small, Viorna viorna (L.) Small.

Range: 25, 27, 28, 29, 30.

Site: Dry, well-drained, sun.

Fruit: Achene.

A vine; flowers May-August; usually occurs in rich soil. 
Clematis virginiana $\mathrm{L}$.

Range: 21, 22, 23, 24, 25, 26, 27, 28, 29.

Virginia clematis.

Site: Dry, well-drained, sun.

Fruit: Achene, available August-September.

A climbing vine; flowers July-September.

Var. missouriensis (Rydb.) Palm. and Steyerm., (C. missouriensis Rydb.) occurs in regions 22,24 , and 25.

Clethra acuminata Michx.

White-alder.

Range : 27.

Site: Well-drained, shade.

Fruit : Capsule.

A large shrub to small tree; ordinarily occurs on noncalcareous soil; flowers July-August; rarely attacked by insects or diseases; propagated by seeds sown under glass in winter or spring.

Clethra alnifolia $\mathrm{L}$.

Range: $26,27,28,29,30$.

Sweet pepperbush.

Site: Well-drained, moist, sun, shade.

Fruit: Capsule.

A large shrub; flowers July-Angust; may occur in acid swamps or sandy woods; commonly persistent on sandy soil in the Sonth; rarely attacked by insects or diseases; propagated like the preceding.

Clethra tomentosa Lam.

C. alnifolia tomentosa Michx.

Range: 29, 30.

Site: Moist, sun.

Fruit: Capsule.

A small to large shrub; flowers August-September, and occasionally in winter; propagated like the preceding.

Cliftonia monophylla (Lam.) Sarg.

Titi.

Range: 29,30 .

Site: Moist, sun.

Fruit: A dry drupe, available August-September.

A large shrub to small or large tree; evergreen; flowers in April; stems often contorted. Browsed somewhat by livestock. A honey plant.

Clinopodium carolinianum, see Clinopodium georgianum.

Clinopodium coccineum (Nutt.) Kuntze.

Range: $29,30$.

Site: Well-drained, sun.

Fruit: Nutlet.

A small shrub; flowers all year, and ordinarily occurs in sand.

Clinopodium georgianum Harper.

C. carolinianum (Michx.) Heller.

Range: 28, 29, 30.

Site: Dry, well-drained, sun.

Fruit: Nutlet.

A small shrub; flowers summer-fall.

Cneoridium dumosum (Nutt.) Hook. f.

Pitavia dumosa Nutt.

Range: 5.

Site: Dry, sun.

Fruit: Fleshy, drupelike capsule.

A small to large, much-branched evergreen shrub; flowers March-April.

Cocculus carolinus DC.

Cebatha carolina Britt., Epibaterium carolinum (L) Britt.

Range: 11, 17, 20, 25, 28, 29, 30.

Site: Dry, well-drained, moist, sun, shade.

Fruit: Drupe; available September-October, persistent over winter southward.

A climbing, bushy vine; semievergreen southward; commonly found along hedgerows and roadways.

Stomach records: Three species of birds. 
Cocculus diversifolius DC.

Cebatha diversifolia (DC.) Kuntze.

Snailseed.

Range: 11, 30.

Site: Well-drained, sun.

Fruit: Drupe.

A semievergreen, clambering vine very like the preceding.

Coldenia greggii, see Ptilocalyx greggii.

Coleogyne ramosissima Torr.

Blackbush.

Range: 9, 10, 11.

Site: Dry, sun.

Fruit: Achene.

A small to large, much-branched, wlde-spreading, spinescent shrub; flowers April-August; occurs on sand5, gravelly and other soils; thicket forming. Furnishes some feed for cattle and sheep in winter.

Coleosanthus atractyloides, see Brickellia atractyloides.

Coleosanthus cedrosensis, sce Brickellia microphylla.

Coleosanthus desertorum, see Brickellia desertorum.

Coleosanthus frutescens, see Brickellia frutescens.

Coleosanthus laciniatus, see Brickellia laciniata.

Coleosanthus microphyllus, see Brickellia microphylla.

Coleosanthus multifiorus, see Brickellia multiflora.

Coleosanthus squamulosus, see Brickellia squamulosa.

Coleosanthus venulosus, see Brickellia atractyloides.

Colletia multiflora, see Adolphia infesta.

Colubrina californica, see Colubrina texensis.

Colubrina texensis (Torr. and Gray) Gray.

C. californica Johnst., Rhamnus texensis Torr. and Gray.

Hog-pIum.

Range: 10, 11, 20.

Site: Dry, sun.

Fruit: Drupelike capsule, available in June.

A large shrub to small tree; much branched; thicket forming; flowers AprilMay; adapted to a wide range of soil conditions; forage value unknown.

Comarostaphylos diversifolia, see Arctostaphylos diversifolia.

Comptonia peregrina, see Myrica asplenifolia.

Condalia spp.

Stomach records (in addition to specific records): Masked bobwhite, Gambel quail. Observations (in addition to specific records): Mexicall raccoon, longtailed Texas skunk, jack rabbit. Generally of low palatability to livestock.

Condalia lycioides (Gray) Weberb.

Lotebush.

Zizyphus lycioides Gray.

Range: 9, 10, 11, 17 .

Site: Dry, well-drained, sun.

Fruit: Drupe.

A small to large, straggling shrub; very rigid, spiny, most often without leaves; thicket forming; sometimes considered a range pest.

Observations: Taken by various birds, including Gambel and scaled quail, and band-tailed pigeon.

Condalia mexicana Schlecht.

Mexican bluewood.

Range: 11, 17.

Site: Dry, well-drained, sun.

Fruit: Drupe.

A large shrub with spinose branches.

Condalia obovata Hook.

Bluewood.

Range: 11, 16, 17, 20, 30.

Site: Dry, sun.

Fruit: Drupe, ripening irregularly through the summer. 

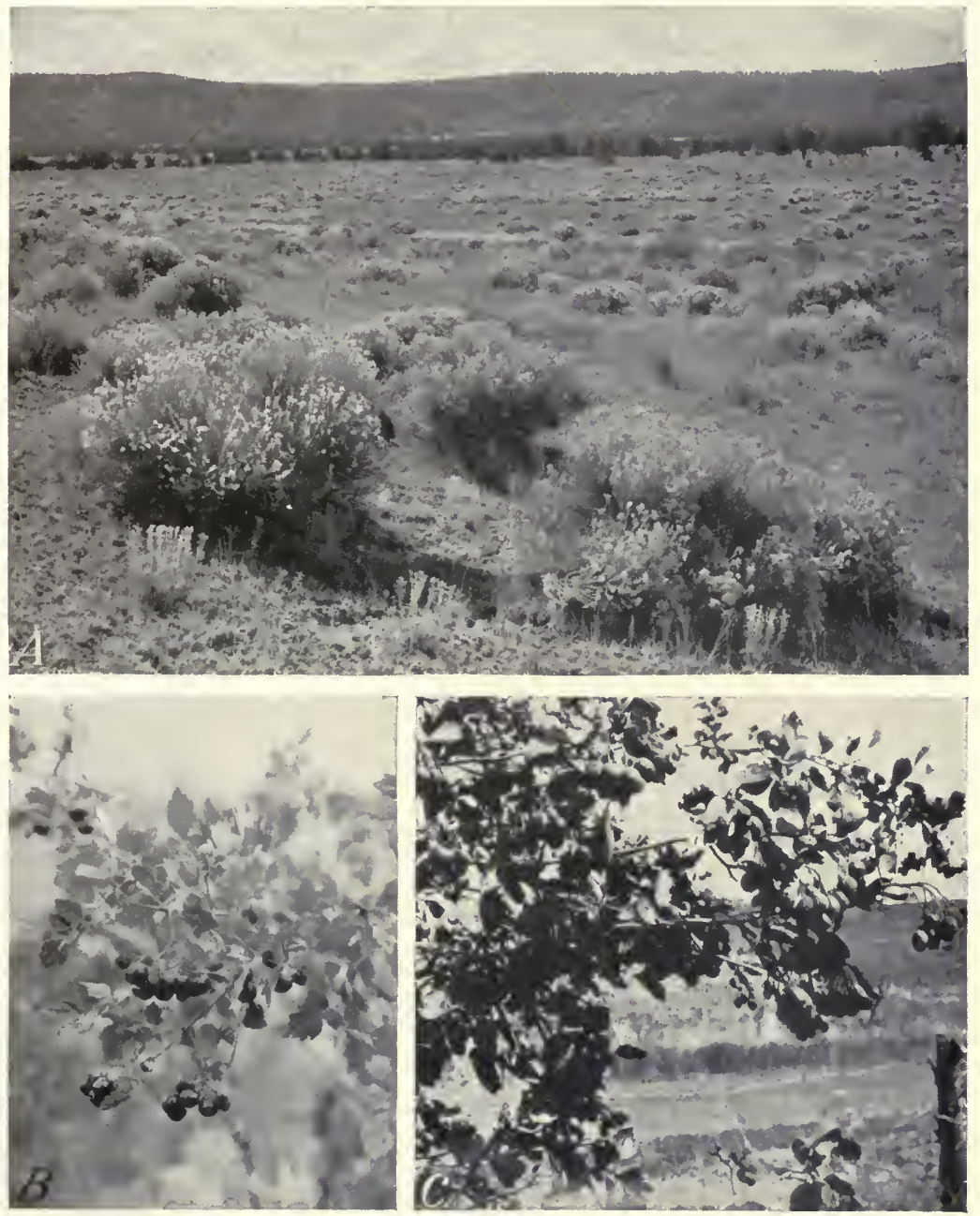

A, Chrysothamnus spp. A view in Grand Canyon National Park showing the characteristic growth habit of rabbitbrush. The species are of importance as cover for plains wildlife and of value to livestock. (Photograph by Department of the Interior.) B, Cissus arborea. 'The beautiful pepper-vine's ability to grow in the poor soils along railroad embankments and roadsides suggests its use in controlling erosion on highway cuts. C, Crataegus brevispina. This important species for erosion control and wildlife plantings in the arid portions of the Northwest is distinctive in having blue-black fruit. The abundant crop, however, is characteristic of most hawthorns. 

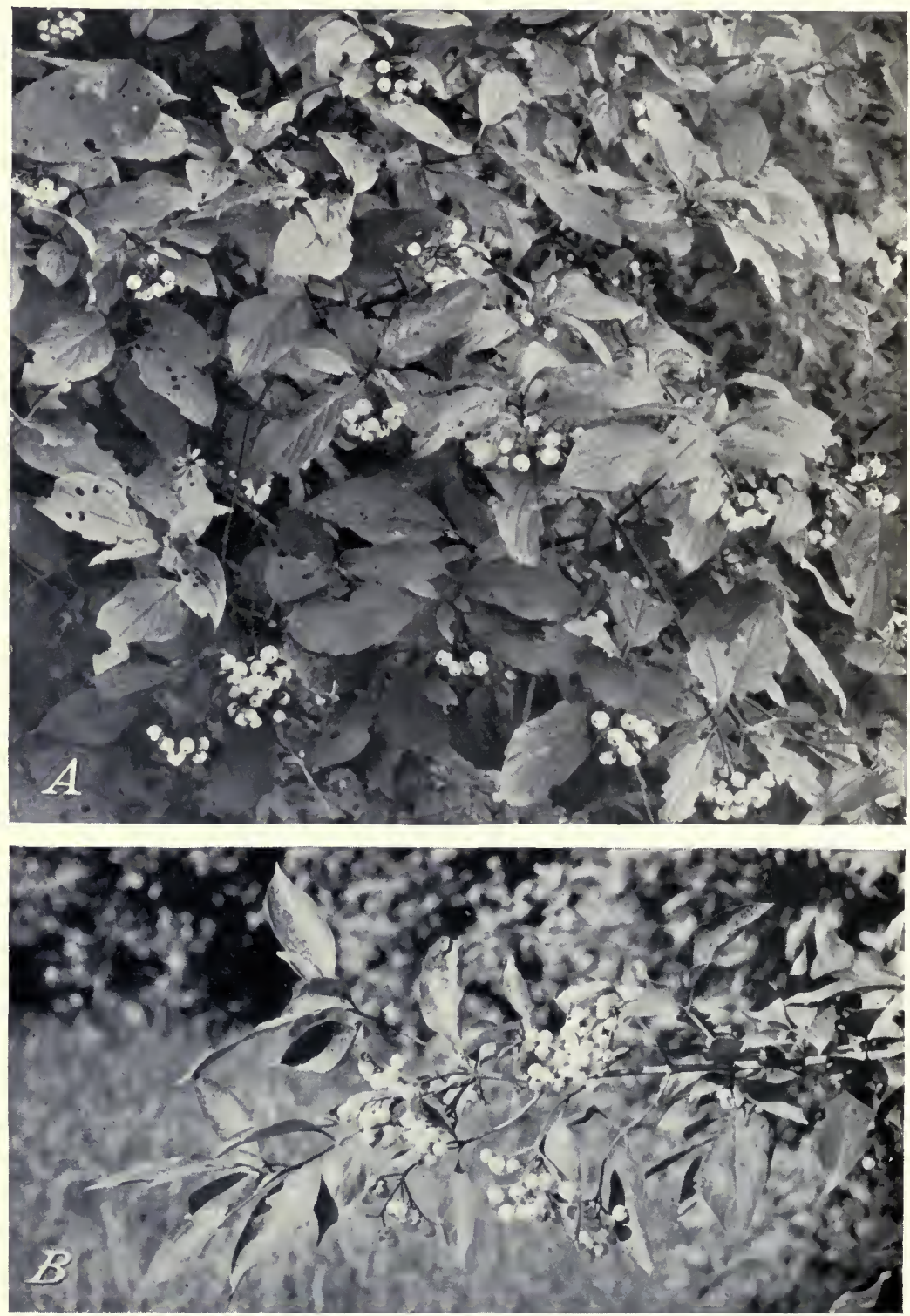

A, Cornus amomum. Streambank plantings of this species may provide excellent food and cover for wildlife frequenting stream edges. $B, C$. paniculata. The thicket-forming habit of this as well as many of the other shrub dogwoods or osiers recommends them for erosion control planting. Records show the fruits of this species to be particularly acceptable to birds. 
A large shrub to small or large tree; flowers May-June; spiny; often leafless in the dry season; forms dense impenetrable thickets; wood valued as fuel.

Stomach records: Six species of birds. Observations: Much sought after by birds. Somewhat browsed by livestock.

Condalia obtusifolia (Hook.) Weberb.

Lotebush.

Rhamnus obtusifolia Hook., Zizyphus obtusifolia (Hook.) Gray.

Range: 11, 16, 17, 20, 29, 30.

Site: Dry, sun.

Fruit: Drupe, available in June.

A small to large, spiny shrub; very persistent when established.

Stomach records: Phainopepla. Observations: Extensively eaten by gray fox.

Condalia parryi (Torr.) Weberb.

Zizyphus parryi Torr.

Parry jujube.

Range: 10.

Site: Dry, sun.

Fruit: Drupe.

A large, spiny shrub; flowers in April.

Condalia spathulata Gray.

Range: 10, 11, 16, 17 .

Squawbush.

Site: Dry, sun.

Fruit: Drupe.

A large, more or less evergreen shrub; densely branched, rigid; occurs in sandy and other soils.

Stomach records: Gambel quail.

Conradina canescens (Torr. and Gray) Gray.

Range: 30.

Site: Well-drained, sun, shade.

Fruit: Nutlet.

A small, much-branched, stiff shrub; flowers May-July; occurs in sandy and other soils.

Cordia boissieri DC.

Range: 11, 17.

Anacahuita.

Site: Dry, well-drained, sun.

Fruit: Drupe, available August-September.

A large shrub to small or rarely large tree; evergreen; flowers April-June ; may occur on limestone soils; fruit edible but said to cause dizziness; very ornamental in cultivation.

Livestock are apparently fond of the fruit; seed eaten by hogs.

Corema conradii Torr.

Empetrum conradii Torr.

Range : 26, 27, 28.

Site: Well-drained, sun.

Fruit: Dry drupe, available July-August.

A small, evergreen shrub; flowers April-May; diffusely branched; usually dioecions; staminate plants very handsome in flower; occurs in sandy and other soils; forms large patches.

Coreopsis gigantea (Kellogg) Hall.

Range: 5 .

Giant coreopsis.

Site: Dry, well-drained, sun.

Fruit: Achene.

A small robust, evergreen, single-stemmed shrub.

Coretlirogyne cana, see Aplopappus canus.

Corethrogyne detonsa, see Aplopappus canus.

Cornus spp.

Cornels, dogwoods.

The species are often difficult to separate, the characters used to distinguish them often being very minor; probably some species will eventually be reduced to synonyms; most species grow in neutral soil ; propagation is by seed stratified at $32^{\circ}-50^{\circ} \mathrm{F}$. for 120 to 140 days and sown in spring. Seeds of many germinate the first year if planted promptly on ripening; many species more easily propagated by cuttings.

Stomach records (in addition to speclfic records) : Sixty species of birds, including bobwhite and Richardson's grouse; gray fox, Virginia deer; composed 
56.69 percent of food of eastern skunk in Michigan. Observations (in addition to specific records) : Thirty-four species of birds, including bobwhite, ruffed and pinnated grouse; an important winter food of white-tailed deer; bearer ; rabbit ; skunk; eastern chipmunk.

Cornus alternifolia L. f.

Svida alternifolia (L. f.) Small.

Blu'e cornel.

Range: 22, 23, 24, 25, 26, 27, 29.

Site: Dry, well-drained, sun, shade.

Fruit: Drupe, available July-September.

A small to large shrub or rarely a small to large tree; flowers May-July; subject to a serious twig blight.

Stomach records: Eleven species of birds, including ruffed grouse. Observa. tions: Warbling vireo; white-tailed deer, cottontail rabbit.

Cornus amomum Mill. (Pl. 10, A)

C. sericea L., Svida amomum (Mill.) Small.

Silky cornel.

Range: $15,18,21,22,23,24,25,26,27,28,29,30$.

Site: Well-drained, moist, sun, shade.

Fruit: Drupe, available August-September.

A small to large, spreading shrub; flowers May-July; grows on coal-stripped lands in Illinois.

Stomach records: Ten species of birds, including ruffed grouse and bobwhite. observations: Ring-necked pheasant.

Cornus asperifolia Michx.

Svida asperifolia (Michx.) Small.

Roughleaf cornel.

Range: $17,20,21,22,23,24,25,27,28,29,30$.

Site: Well-drained, moist, sun.

Fruit: Drupe, available August-October.

Usually a large shrub or rarely a small to large tree; flowers May-June; often occurs on sandy soil ; 16,600-21,000 seeds per pound.

Stomach records: Forty-one species of birds, including ruffed grouse, bobwhite, sharp-tailed grouse, and greater prairie chicken; composed 3.5 percent of fall food of prairie chicken in Wisconsin; armadillo. Observations: Wild turkey, ring-necked pheasant, cottontail rabbit.

Cornus balleyi Coult. and Evans.

Bailey cornel.

Svida baileyi (Coult. and Evans) Rydb.

Range: 15, 18, 21, 23, 24, 26, 27.

Site: Moist, sun.

Fruit: Drupe, available July-October.

A small to large shrub; ordinarily occurs in sand; flowers May-June.

Stomach records: Bobwhite.

Cornus californica Mey.

Svida californica (Меy.) Abrams.

Range: $3,4,5$.

Site: Well-drained, moist, sun.

Fruit: Drupe, available July-November.

A large shrub; flowers April-August; very closely related to $C$. slolonifera and perhaps more properly considered as a variety of that species.

Observations: Of outstanding importance as browse for mule deer in California.

Cornus candidissima, sec Cornus foemina.

Cornus circinata L'Her.

C. rugosa Lam., Svida rugosa (Lam.) Rydb.

Round-leaved cornel.

Range: 18, 21, 22, 23, 24, 25, 26, 27.

Site: Dry, well-drained, sun, shade.

Fruit: Drupe, available July-October.

A large shrub; flowers May-July; occurs in sandy and other soils.

Stomach records: Ruffed grouse, sharp-tailed grouse. Observations: Blueheaded vireo; cottontail rabbit, moose.

Cornus florida $\mathrm{L}$.

Cynoxylon floridum (L.) Raf.

Flowering dogwood.

Range : 20, 22, 23, 24, 25, 27, 28, 29, 30.

Site: Dry, well-drained, sun, shade.

Frult: Drupe, available September-February. 
A small to large tree; flowers April-June; root system not deep; slow growing, long-lived; relatively free from insects and diseases; coppices freely; often occurs in slightly acid soil; wood used commercially; difficult to transplant; propagation is by seed stratified 120 to 140 days at $32^{\circ}-50^{\circ} \mathrm{F}$. and sown in spring, or by cuttings which root best in peat after treatment with potassium permanganate ; $3,500-4,000$ seeds per pound, germination about 70 percent, about 1,000 usable plants per pound of seed.

Stomach records: Thirty-six species of birds, including ruffed grouse, bobwhite, and wild turkey; eastern chipmunk. Observations: Twenty-eight species of birds including bobwhite and wild turkey; ranks twenty-first on the list of quail food plants of the Southeast; preferred food of wild turkey; much eaten by squirrels; white-tailed deer; gray squirrel.

Cornus foemina Mill.

C. stricta Lam., C. candidissima Marsh., Svida foemina (Mill.) Rydb., S. stricta (Lam.) Small.

Range: 21, 22, 23, 24, 25, 27, 28, 29.

Site: Well-drained, moist, sun.

Fruit: Drupe, avallable September-October.

A large shrub; flowers May-June.

Cornus glabrata Benth.

Svida catalinensis Millsp.

Brown dogwood.

Range : $1,3,4,5$.

Site: Moist, sun.

Fruit: Drupe, available August-September.

A large, thicket-forming shrub; flowers May-June; procumbent or drooping branches root where they touch the ground.

Cornus instolonea, see Cornus stolonifera.

Cornus interior Rydb.

Svida interior Rydb.

Range: $15,16,18,19$.

Site: Moist, sun.

Fruit: Drupe, available September-October.

A large shrub; flowers June-July.

Cornus microcarpa Nasin.

Svida microcarpa (Nash) Small.

Range: 29, 30 .

Site: Well-drained, sun.

Fruit: Drupe, available in September.

A large shrub; flowers April-May.

Cornu's nuttallii Aud.

Cynoxylon nuttallii (Aud.) Schaf.

Range: $1,2,3,4,5$.

Site: Well-drained, sun, shade.

Fruit: Drupe, avallable October-November.

Usually a small tree, more rarely a large one; flowers in April and again in August-September; ordinarily grows best when somewhat shaded by adjacent trees, the removal of which often brings on the death of the plant; coppices freely; wood very little used commercially; cultivated to some extent; about 6,000 seeds per pound.

Stomach records: Four species of birds ; Townsend's chipmunk. Observations: Cooper's chipmunk; of sligbt importance as browse for mule deer.

Cornus obliqua Raf.

C. purpusii Koehne.

Pale dogwood.

Range : 21, 22, 23, 24, 25, 26.

Site: Well-drained, moist, sun, shade.

Fruit: Drupe, available July-September.

A small to large, spreading shrub; flowers May-June; foliage dense; posslbly better considered as a form of $C$. amomum (q. v.).

Cornus occidentalis Cov.

C. pubescens Nutt., Svida pubescens (Nutt.) Standl.

Western osier.

Range: $1,2,3,4,7,12,13$.

Site: Well-drained, moist, sun.

Fruit: Drupe, available July-October. 
A large shrub to small tree; $14,000-17,500$ seeds per pound.

Stomach records: Twelve species of birds. Observations: Mountain beaver. Occasionally grazed in the fall by cattle, less so by sheep and goats.

Cornus paniculata L'Her. (pl. 10, B).

Gray dogwood.

C. racemosa of nurserymen.

Range : 21, 22, 23, 24, 25, 26, 27, 28, 29.

Site: Dry, well-drained, moist, sun, shade.

Fruit: Drupe; available August-November, occasionally persistent.

A small shrub; flowers in June; occurs on sandy, clay, gravelly and other soils; forms extremely dense thickets; successful on very difficult sites; endures city smoke; easily propagated by seeds, or particularly by cuttings; about 3,500 uncleaned seeds per pound.

Stomach records: Twenty-two species of birds, including ruffed grouse, bobwhite, sharp-tailed grouse and ring-necked pheasant; composed 0.4 percent of total annual food and 5.3 percent of fruit food of ring-necked pheasant in Michigan. Observations: An important pleasant food in southern Michigan as late in the season as May; cottontail rabbit.

Cornus priceae Small.

Svida priceae Small.

Range: 25 .

Site: Dry, well-drained, sun.

Fruit : Drupe, available in September.

A small to large shrub; flowers April-May; very similar to C. asperifolia (q. v.).

Cornus pubescens, see Cormus occidentalis.

Cornus purpusii, see Cornus obliqua.

Cornus racemosa, see Cornus paniculata.

Cornus rugosa, see Cornus circinata.

Cornus sericea, see Cornus amomum.

Cornus sessilis Torr.

Range: 3, 4.

Site: Moist, sun.

Fruit: Drupe, available August-September.

A large shrub to small tree; flowers in April ; thicket forming.

Cornus stolonifera Michx.

Svida stolonifera (Michx.) Rydb.

Range: 4, 7, 8, 9, 11, 12, 13, 14, 15, 18, 21, 22, 23, 24, 25, 26, 27, 28.

Site: Well-drained, moist, sun, shade.

Fruit: Drupe; available July-September, occasionally persistent until May.

A large, erect or spreading shrub; flowers May-July; thicket forming by means of rootstocks; occurs in sand or wet swamps; generally erect or spreading; prostrate branches root; tolerates alkaline soil; about 17,300 seeds per pound.

Var. coloradensis Schneid. ( $O$. instolonea Nels.) is a variety without stolons.

Stomach records: Twelve species of birds including ruffed grouse, bobwhite, sharp-tailed grouse; plains white-tailed deer. Observations: Four species of birds including sharp-tailed grouse, Hungarian partridge; white-tailed deer, mule deer, elk, moose, cottontail rabbit snowshoe hare. Not at all or slightly browsed by livestock.

\section{Cornus stricta, see Cornus foemina.}

Corylus spp.

Hazelnuts.

The species are ordinarily propagated by seeds stratified and sown in spring or sown directly in the fall; propagation by cuttings is often unsuccessful.

stomach records (in addition to specific records): Four species of birds including ruffed grouse and sharp-tailed grouse; composed 1.0 percent of fall food of sharp-tailed grouse in Wisconsin. Observations (in addition to specific records): Seven species of birds including ring-necked pheasant; a staple winter food of greater prairie chicken, pinnated grouse, and ruffed grouse; white-tailed deer, moose, red squirrel, pale chipmunk, gray chipmunk, beaver, flying squirrels. 
Corylus americana Walt.

Range: $15,18,21,22,23,24,25,26,27,28,29$.

American hazelnut.

Site: Dry, well-drained, sun, shade.

Fruit. Nut, available July-September, occasionally persistent until December-February.

A large, thicket-forming shrub; coppices very freely after cutting; seldom bears fruit in the shade; easily transplanted; foliage generally dense; 250 seeds per pound, germination 80 percent, about 60 usable plants per pound of seed.

Stomach records: Ruffed grouse, bobwhite. Observations: Ring-necked pheasant; blue jay; squirrels, white-tailed deer. Somewhat grazed by sheep.

Corylus californica (DC.) Rose.

California hazelnut.

C. rostrata californica $\mathrm{DC}$.

Range: $1,2,3,4$.

Site: Well-drained, moist, sun, shade.

Fruit: Nut, available September-November.

A large shrub to small tree; thicket forming; foliage more or less dense.

Observations: Staple winter food of Steller's jay; Douglas' squirrel, Townsend's chipmunk, Allen's chipmunk, golden-mantled ground squirrel, digger squirrel; of slight importance as browse for mule deer. Extensively or not at all browsed by livestock.

Corylus cornuta, see Corylus rostrata.

Corylus rostrata Ait.

C. cornuta Marsh.

Beaked hazelnut.

Range: $15,18,21,22,23,24,25,26,27,28,29$.

Site: Dry, well-drained, sun.

Fruit: Nut, available August-September.

A small to large, thicket-forming shrub, often occurs on acid soil.

Stomach rccords: Ruffed grouse, bobwhite; sharp-tailed grouse, prairie chicken; composed 2.7 percent of winter food of the northern sharp-tailed grouse in Quebec and Ontario. Observation: Blue jay; moose, southwestern chipmunk, eastern chipmunk, squirrels; eighth most important preferred winter food of white-tailed deer.

Corypha hystrix, see Rhapidophyllum hystrix.

Corypha minor, see Sabal minor.

Corypha palmetto, see Sabal palmetto.

Corypha pumila, see Sabal minor.

Corypha repens, see Serenoa repens.

Cotinus americanus Nutt.

C. cotinoides (Nutt.) Britt., Rhus cotinoides Nutt.

Smoketree.

Range: 16, 17, 20, 25, 29.

Site: Dry, well-drained, sun.

Fruit: Drupe, available August-September.

A large shrub to small or large tree; flowers April-May; ordinarily occurs on calcareous soil; fruit produced very sparingly; wood very durable as fence posts; very brilliant scarlet in autumn.

\section{Cotinus cotinoides, see Cotinus americanus.}

Cotoneaster pyracantha (L.) Spach.

Pyracantha coccinea Roem., Crataegus pyracantha Medic.

Firethorn.

Range : 27, 28, 29.

Site: Dry, well-drained, sun.

Fruit: Pome; available October, persistent through winter.

A small to large evergreen shrub with dense foliage; flowers in May; very spiny; difficult to transplant except when small.

observations: Robin; generally attractive to birds.

Coursetia axillaris Coult. and Rose.

Range: 17 .

Site: Dry, sun.

Fruit: Legume.

A large shrub to small tree; densely branched.

$130186^{\circ}-39-8$ 
Covillea glutinosa, see Covillea tridentata.

Covillea tridentata (DC.) Vail.

Creosotebush.

C. glutinosa (Engelm.) Rydb., Larrea mexicana Moric., L. glutinosa Engelm., L. tridentata (DC.) Cov., L. tridentata glutinosa Jeps.

Range: $9,10,11,16,17$.

Site: Dry, sun.

Fruit: Capsule.

A small to large evergreen shrub; slow growing; sparsely branched and with thin foliage, especially when older; inhabits the most xeric areas in North America; makes successful and persistent growth in thin bodies of soil over layers of hardpan; transplants ordinarily require considerable water to start them growing; very inflammable.

Stomach records: Gambel quail. Observations: Texas antelope squirrel, jack rabbit. Not eaten by livestock; poisonous to sheep.

Cowania alba, see Cowania stansburiana.

Cowania davidsonil, see Cowania stansburiana.

Cowania ertcaefolia Torr.

Heath cliffrose.

Range: 11, 17.

Site: Dry, sun.

Fruit: Achene.

A small, straggling, much-branched evergreen shrub found on limestone soils.

Cowania havardii Wats.

Range: 11.

Site: Dry, sun.

Fruit: Achene.

A small, much-branched evergreen shrub.

Cowanla stansburiana Torr.

Quinine bush.

C. mexicana dubia Brandeg., C. davidsonii Rydb., C. mexicana stansburiana

(Torr.) Jeps., $C$. alba Good.

Range: $9,10,11,13,14$.

Site: Dry, well-drained, sun.

Fruit: Achene, avallable in October.

A small to large shrub or small to rarely large tree; evergreen; freely branched, stiff; flowers in June; increased branching occurs under grazing; seed germination 10-80 percent.

Stomach records: Black-tailed deer. Observations: A staple food of mule deer. An important and valuable browse for cattle and sheep. Browsing to 65 percent stimulates beneficially the reproduction of the plant; more than 80 percent causes deterioration.

Crataegus spp.

Hawthorns.

These species are small shrubs to small trees growing in many sites, in all kinds of soil, in all parts of the country, most of them being almost impossible of identification except by specialists. No effort is here made to separate the various species. Somewhat more than 1,200 species have been listed for the country, the majority of these occurring in the northeastern United States; other studies have reduced this number to less than 100 . Owing possibly to hybridization and great variation, the actual number of species has not been determined up to the present time. Nevertheless, these plants are of considerable value for erosion control and for wildlife food and cover. A great many of them are thicket forming and many species hold the fruit over the winter. Most species are thorny and provide a dense cover valuable for soil and wildlife alike. The best way in which to discover the utility of these species is to examine the wild forms occurring in any particular region and to collect such ones as seem to be able to grow on eroded sites and to produce the maximum amount of cover and food.

Most species grow in neutral soil, often on very poor soils; young plants often form long taproots and hence are often difficult to transplant; $6,000-40,000$ seeds per pound, germination about 40 percent, about 2,500 usable plants per pound of seed; propagation is by seed stratified and sowu in spring; alternate hosts for the cedar apple rust. 
Special mention should be made of Crataegus brevispina (Dougl.) Heller, (C. douglasii Lindl.) (pl. 9, C) occurring in the northwest. This form makes dense thickets in more moist soils and produces its blue-black fruit in great abundance. Observers have noted that the ring-necked pheasant, Hungarian partridge and various western quails feed extensively on the berries. Two other western hawthorns, $C$. columbiana Howell, and $C$. piperi Britt, both red-fruited, occur in extremely dry situations and appear to be potentially of value in erosion control, more notably in the more arid sections of Oregon, Washington, and Idaho.

Stomach records (summary) : Thirty-six species of birds, including bobwhite and eastern ruffed grouse; composed 9.63 percent of food eaten by ruffed grouse in the northeastern United States; gray fox, white-tailed deer. Observations (summary): Seventeen species of birds including Hungarian partridge, sharptailed grouse, ring-necked pheasant; white-tailed deer (in some localitles, ignored in others), cottontail rabbit. Browsed somewhat by livestock. Considered valuable honey plants, especially where they occur in abundance.

Crataegus pyracantha, see Cotoneaster pyracantha.

Crookea microsepala (Torr. and Gray) Small.

Ascyrum microsepalum Torr. and Gray, Hypericum microsepalum (Torr. and Gray) Gray.

Range: 29, 30 .

Site: Dry, well-drained, sun.

Fruit: Capsule.

A small evergreen shrub; often occurs in sandy soil.

Crossosoma bigelovii Wats.

Range: 10, 11.

Site: Dry, sun.

Fruit: Follicle.

A small, spreading, spinescent shrub; flowers in April.

Crossosoma californicum Nutt.

Range: 5.

Site: Dry, sun.

Fruit: Follicle.

A small to large shrub or small tree; flowers in May.

Crossosoma parviflorum Robins. and Fern.

Range: 9, 10, 11 .

Site: Dry, well-drained, sun.

Fruit: Follicle.

A small to large shrub.

Crossostephium californicum, see Artemisia californica.

Crossostephium foliosum, see Artemisia californica.

Crossostephium insulare, see Artemisia californica.

Croton spp.

Stomach records (in addition to specific records, and including herbaccous as well as woody species) : Thirty-six species of birds, including bobwhite, California quail, greater and lesser prairie chicken, and mourning dove.

Croton alabamensis Smith.

Alabama croton.

Range: 29.

Site: Dry, well-drained, sun.

Fruit: Capsule.

A large, much-branched thicket-forming erergreen shrub; flowers May-June; very rare.

Croton berlandieri, see Croton humilis.

Croton cortesianus H. B. K.

C. trichocarpus Torr.

Range: 17.

Site: Dry, sun.

A large shrub.

Fruit: Capsule. 
Croton gonzalezii, see Croton sonorae.

Croton humilis $\mathrm{L}$.

C. berlandieri Torr.

Range: 17, 32.

Site: Dry, well-drained, sun.

Fruit: Capsule.

A small shrub; occurs in sandy and other soils.

Croton pringlei, see Croton sonorae.

Croton sonorae Torr.

C. pringlei Wats., O. gonzalezii Greenm.

Range: 10.

Site: Dry, sun.

Fruit: Capsule.

A small to large, much-branched shrub.

Croton suaveolens Torr.

Range: 11, 16, 17.

Site: Dry, sun.

Fruit: Capsule.

A small, stout, much-branched shrub.

Croton trichocarpus, sce Croton cortesianus.

Croton torreyanus Muell.

C. suaveolens oblongifolius Torr.

Range: 11, 17.

Site: Dry, well-drained, sun.

Fruit: Capsule.

A small, slender shrub.

Cupressus spp.

Cypress.

Evergreen, monoecious trees of comparatively little value commereially. Seven species occur in North America, of which five are found in California and two in the southern Rocky Mountain region; propagation is by seed sown in spring.

Stomach records (in addition to specific records) : Four species of birds.

Cupressus arizonica (Mast.) Greene.

Arizona cypress.

Range: 11, 14.

Site: Dry, well-drained, sun.

Fruit: Cone, ripe in September of the second season, persistent many years.

A large evergreen tree; rapid growing in good soil, slow growing in poorer soils; long-lived; susceptible to fire; wood valuable locally, durable when seasoned; seeds remaining in unopened cones viable, at least for several years; germination percentage of seeds high, irregular; seed produced abundantly annually; 100,000 seeds per pound; much spread by cultivation.

Cupressus bakeri, see Cupressus macnabiana.

Cupressus forbesii, see Cupressus guadaloupensis.

Cupressus glabra Sudw.

Range: 11, 14.

Smooth cypress.

Site: Well-drained, moist, sun, shade.

Fruit: Cone; ripening at the end of the second season, persistent unopened 14-18 years.

A large evergreen tree; slow glowing, long-lived; wood of limited use commercially, moderately durable; seed germination moderately high, vitality of seed declining rapidly after fifth year.

Cupressus goveniana Gord.

C. pygmaea Sarg.

Gowen cypress.

Range: 1.

Site: Dry, well-drained, moist, sun, shade.

Fruit: Cone; mature in September of the second season; seeds shed

September-October, cones persistent many years.

A large shrub to small or rarely large trees; evergreen; slow growing, longlived; root system shallow; thrives on rocky or sandy soils; of no importance 
commercially; seeds abundantly produeed amually when plant is ouly 2 or 3 feet high; vitality of seeds persistent; ornamental in cultivation.

Cupressus guadaloupensis Wats.

Forbes' cypress.

C. forbesii Jeps.

Range: 5 .

Site: Well-drained, sun.

Fruit: Cone.

A small evergreen tree.

Cupressus macnabiana Murr.

C. nevadensis Abrams, C. bakeri Jeps.

Macnab cypress.

Range: 1, 3, 4 .

Site: Dry, well-drained, sun.

Fruit: Cone; mature in autumn of the second season; seeds shed immediately, cones persistent several years.

A small to rarely large evergreen tree; slow growing, moderately long-lived; wood of no importance commercially; seeds produced annually; ornamental in cultivation.

Cupressus macrocarpa Gord.

Range: 5 .

Site: Dry, well-drained, sun, shade.

Fruit: Cone; mature in August of the second season, opens slowly, persistent several seasons.

A large evergreen tree; at first rapid growing, later slower; long-lived; free from insects and most diseases; susceptible to fires beeause of its thin bark; forms a eover on wind-swept coasts to the water's edge; wood of little importance commereially ; resistant to drought and mildly saline conditions; will withstand considerable abuse in handling; seeds produced annually in abundance; 93,000 seeds per pound, germination 16 percent; much spread by plantings; ornamental in cultivation.

Cupressus nevadensis, see Cupressus macnabiana.

Cupressus pygmaea, see Cupressus goveniana.

Cupressus sargentii Jeps.

Sargent cypress.

Range: 1, 5.

Site: Well-drained, sun.

Fruit: Cone.

A small to large evergreen tree; seven varietics in eultivation.

Cyanococcus amoenus, see Vaccinium corymbosum.

Cyanococcus angustifolius, see Vaccinium angustifolium.

Cyanococcus atrococcus, see Vaccinium atrococcum.

Cyanococcus corymbosus, see Vaccinium corymbosum.

Cyanococcus elliottii, see Vaccinium elliottii.

Cyanococcus hirsutus, see Vaccinium hirsutum.

Cyanococcu's myrsinites, see Vaccinium myrsinites.

Cyanococcus pallidus, see Vaccinium corymbosum.

Cyanococcus pennsylvanicus, see Vaccinium angustifolium.

Cyanococcus tenellus, see Vaccinium virgatum.

Cyanococcus vacillans, see Vaccinium vacillans.

Cyanococcus virgatus, see Vaccinium virgatum.

Cynoxylon floridum, see Cornus florida.

Cynoxylon nuttallii, see Cornus nuttallii.

Cyrilla racemiflora $\mathrm{L}$.

Range: 28, 29, 30.

Swamp ironwood.

Site: Moist, sun, shade.

Fruit: Corky drupe, available August-September.

A large shrub to small or large tree; semievergreen; much branched; flowers May-July; may occur on sandy or other soils; considered a good honey plant. 
Cytisus scoparius (L.) Link.

Scotch broom.

Range: $1,2,4,27,28,29$.

Site: Dry, well-drained, sun.

Fruit: Legume, available August-September.

A large evergreen shrub introduced from Europe but spreading in the regions indicated; flowers May-June; occurs most commonly on sand, but also on loam and clay; drought resistant; will grow on very poor soils; tolerant of saline conditions; will withstand considerable abuse in handling; claimed to be a weed in fields, especially sandy ones, but ordinarily regarded by farmers as not dangerous because it is easily burned off; has been used very successfully for erosion control on highway embankments along the Oregon coast; has been adrocated as a renovater of barren soils because of the high potash content of Its ash; considered by some authorities as in part parasitic on oak roots, but if so, is not an obligate parasite; 65,000 seeds per pound; propagated by seeds treated with hot water and sown in spring or by cuttings.

Stomach records: California quail. Observations: Captive bobwhite; cottontail rabbit. Poisonous to livestock, but seldom touched by grazing animals.

Dalea amoena, see Parosela fremontii.

Dalea arborescens, see Parosela arborescens.

Dalea argyrea, see Parosela argyrea.

Dalea californica, see Parosela fremontii.

Dalea emoryi, see Parosela emoryi.

Dalea formosa, see Parosela formosa.

Dalea fremontii, see Parosela fremontii.

Dalea frutescens, see Parosela frutescens.

Dalea greggii, see Parosela greggii.

Dalea humilis, see Parosela thyrsiflora.

Dalea johnsonil, see Parosela fremontii.

Dalea polyadenia, see Parosela polyadenia.

Dalea saundersii, see Parosela fremontii.

Dalea schottii, see Parosela schottii.

Dalea scoparia, see Parosela scoparia.

Dalea spinosa, see Parosela spinosa.

Dalea thyrsifiora, see Parosela thyrsiflora.

Dalea wheeleri, see Parosela fremontii.

Daphne mezerenm $\mathrm{L}$.

Mezereum.

Range: 26, 27.

Site: Well-drained, sun, shade.

Fruit: Drupe, available August-September.

A small to large, sparse shrub; introduced from Europe and western Asia but locally established in the regions indicated; flowers March-April.

Observations: Eaten by songbirds.

Dasiphora fruticosa, see Potentilla fruticosa.

Datisca hirta, see Rhus typhina.

Daubentonia cavanillesii, see Daubcutonia drummondii.

Daubentonia drummondii Rydb.

$D$. cavanillesii Standl., D. longifolia of auth.

Poisonbean.

Range: 17, 20, 29, 30 .

Site: Moist, sun.

Fruit: Legume.

A large shrub; often occurs in sand; seeds very poisonous to sheep and goats but pods and green plants apparently not harmful.

Daubentonia longifolia, see Daubentonia drummondii.

Daubentonia thurberi, see Diphysa thurberi.

Decachaena baccata, see Gaylussacia baccata. 
Decachaena frondosa, see Gaylussacia frondosa.

Decachaena nana, see Gaylussacia nana.

Decachaena tomentosa, see Gaylussacia tomentosa.

Decachaena ursina, see Gaylussacia ursina.

Decumaria barbara $\mathrm{L}$.

Climbing hydrangea.

Range: 28, 29, 30 .

Site: Moist, sun, shade.

Fruit: Capsule, available July.

A vine. Reputedly dermatitically poisonous.

Dendrium buxifolium, see Leiophyllum buxifolium.

Dendrium hugeri, see Lciophyllum hugeri.

Dendrium lyonif, see Leiophyllum lyonii.

Dendromecon rigida Benth.

Treepeppy.

Range: 4, 5 .

Site: Dry, sun.

Fruit: Capsule.

A small to large, rigid, freely-branched evergreen shrub; stems usually several from the base; common in burned-over territory.

Observations: California mule deer.

Desmothamnus lucidus, see Xolisma lucida.

Dicraurus leptocladus Hook. $f$.

Range: 17.

Site: Dry, sun.

Fruit: Achenelike.

A small dioecious shrub.

Diervilla diervilla, see Diervilla lonicera.

Diervilla lonicera Mill.

D. diervilla (L.) MacBr., D. triflda Moench.

Bush-honeysuckle.

Range: 23, 24, 26, 27.

Site: Dry, well-drained, sun.

Fruit: Capsule.

A small shrub; flowers June-August; propagation is by seed sown under glass in spring.

Observations: An important summer food of moose on Isle Royale.

Diervilla rivularis Gatt.

Range: 27.

Site: Well-drained, moist, sun.

Fruit: Capsule.

A small to large shrub; flowers July-A ugust.

Diervilla sessilifolia Buckl.

Range: 27.

Site: IVell-drained, sun.

Fruit: Capsule.

A small to large, loosely-branched shrub; flowers July-August.

Diervilla trifida, see Diervilla lonicera.

Diospyros texana Scheele.

Brayodendron texanum Small.

Range: 11, 16, 17, 20, 29, 30.

Site: Dry, well-drained, moist, sun, shade.

Frult: Berry, available July-August.

A large shrub to small or large tree; dioeclous; flowers April-May; wood used to some extent commercially; bears an abundance of fruit which supplles a black stain.

Observations: Wild turkey; Mexican raccoon, long-tailed Texas skunk; relished by many wild animals.

Diospyros virginiana L. (pl. 11).

Range: $20,22,25,27,28,29,30,31$.

Persimmon.

Site: Dry, well-drained, moist, sun.

Fruit: Berry; avallable August-October, sometimes perslstent. 
A large shrub to small or large tree; flowers May-June; often forms dense thickets on dry, eroded slopes; stoloniferous; root system, including taproot, and stolons deep and wide spreading; trees produced from stolons usually do not reach large size; survives on extremely adverse sites; often difficult to eradicate from cultivated fields and pastures; fruits prolifically; various forms have been described varying in habit, fruit production, etc.; will grow in standing water for several months; forms have been observed which hold the fruit until March; fruits while still very young; occurs in sand, clay, loam, and other soils; occurs on coal-stripped lands in southern Illinois; wood used to some extent commercially; propagation is by seed stratified at $41^{\circ}-50^{\circ} \mathrm{F}$. for 365 days and sown in spring; 1,000 seeds per pound, germination about 80 percent.

Stomach records: Six species of birds, including bobwhite; raccoon, spotted skunk, gray fox, red fox, white-tailed deer. Observations: Sixteen species of birds, including wild turkey; gray fox, red fox ; much eaten by Virginia opossum ; flying squirrel, spotted skunk; leaves refused by captive marsh rabbits; whitetailed deer. Not browsed by cattle; frult greedily eaten by hogs.

Diphysa echinata, see Diphysa thurberi.

Diphysa thurberi (Gray) Rydb.

D. echinata Rose, Daubentonia thurberi Gray.

Range : 11.

Site: Dry, well-drained, sun.

Fruit: Legume.

A small to large shrub.

Diplacus arachnoides, see Mimulus longiflorus.

Diplacus aridus, see Mimulus aridus.

Diplacus aurantiacus, see Mimulus aurantiacus.

Diplacus longiflorus, see Mimulus longiflorus.

Diplacus parviflorus, see Mimulus femingii.

Diplacus puniceus, see Mimulus puniceus.

Diplostephium canum, see Aplopappus canus.

Dirca occidentalis Gray.

Western leatherwood.

Range: 1 .

Site: Dry, well-drained, sun.

Fruit: Drupe, available in June.

A small to large shrub; flowers February-March; colony forming; fruit rarely developed in any quantity; spreads by means of shoots developed from long roots; propagated by seed sown in fall or spring; difficult to transplant.

Dirca palustris $\mathrm{L}$.

Range: $22,23,24,25,27,28,29$.

Leatherwood.

Site: Dry, well-drained, sun, shade.

Fruit: Drupe, available May-June, dropping at once or occasionally persistent.

A small to large shrub; widely branching when old; flowers March-April; free from insects and disease; ordinarily occurs in sterile soil of all kinds; propagation is by seed sown in fall or spring; berries said to be narcotic.

Observations: Moose; poorly eaten by white-tailed deer.

Distegia Involucrata, see Lonicera involucrata.

Dodonaea arizonica Nels.

D. viscosa angustifolia (L. f.) Benth.

Hopbush.

Range: 11.

Site: Dry, sun.

Fruit: Capsule.

A large shrub or rarely a small tree; often occurs on calcareous soils; produces seed abundantly; germination of seed at least 44 percent. Sometimes nibbled by stock but since it is a fish poison containing saponin it should be closely watched in time of scarcity of food for livestock.

Observations: Relished by Gambel quail and other birds.

Drejera thurberl, see Anisacanthus thurberi. 


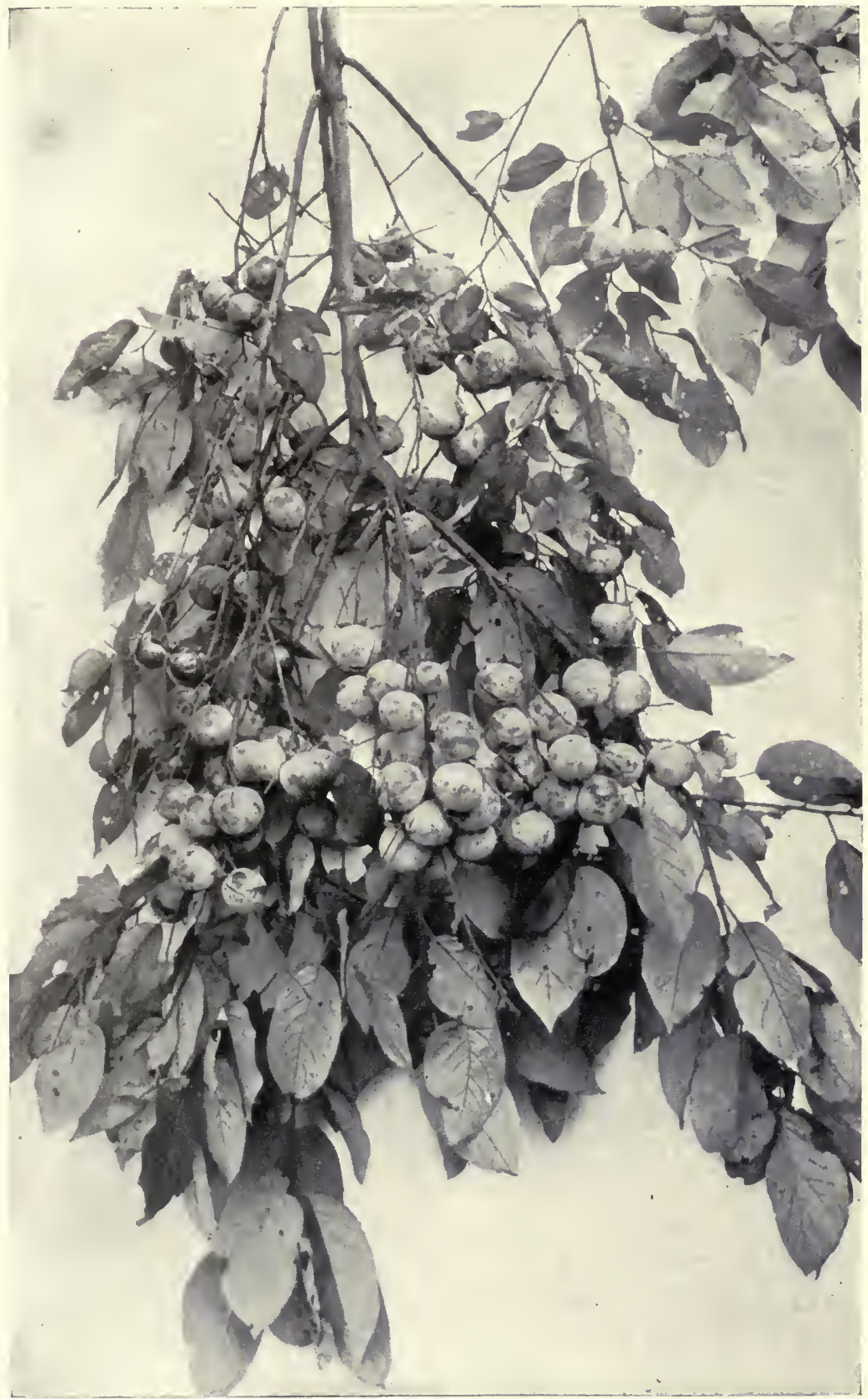

Diospyros virginiana, the ubiquitous persimmon, displays many characters of value in an erosion control program. Its fruits are of great importance to many forms of wildlife. 

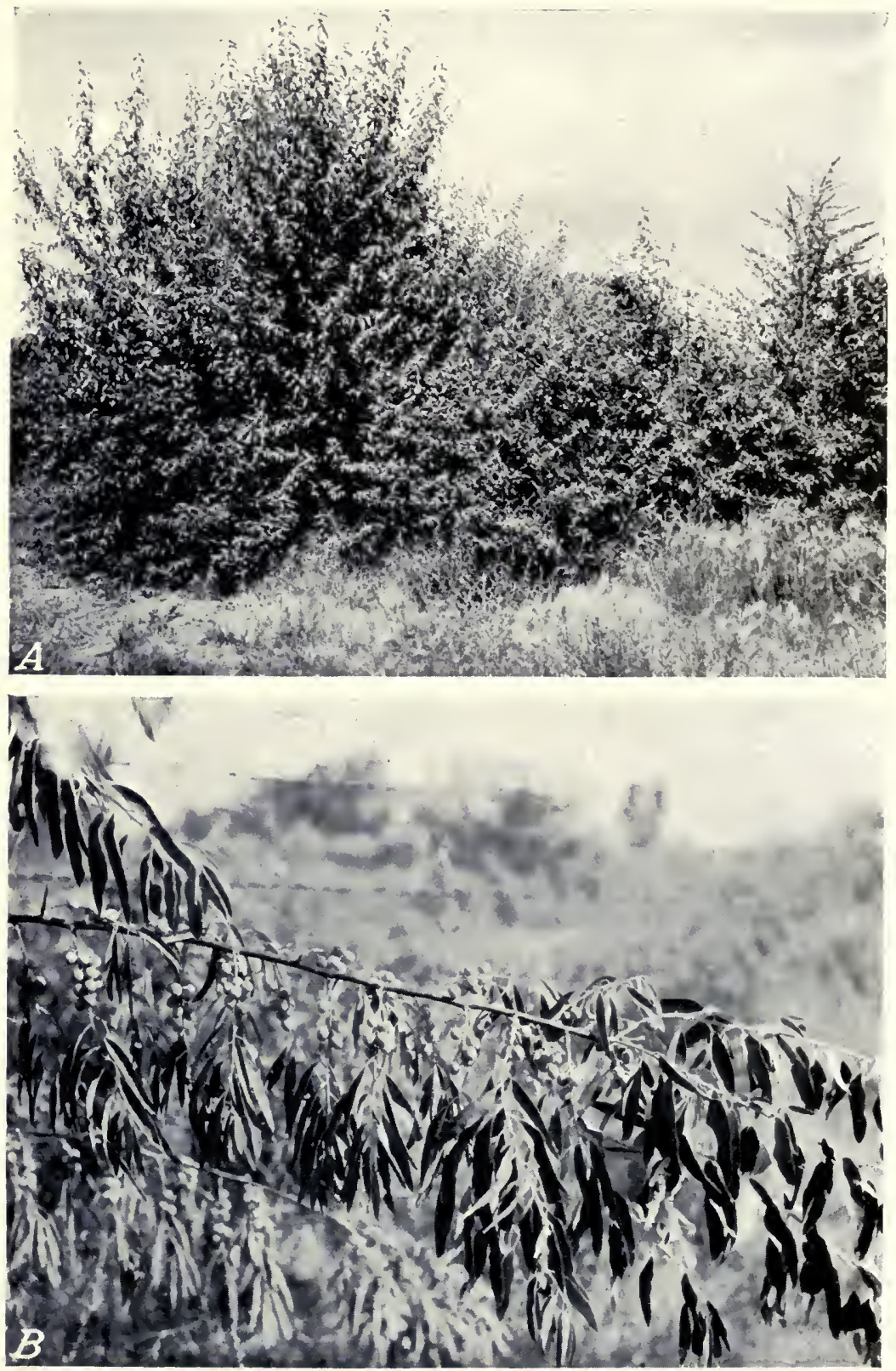

A, Elaeagnus angustifolia. A colony of escaped plants thriving on soil abandoned because of extreme alkalinity. Particularly while young, this species forms excellent soil cover. $B$, A branch showing the abundant fruit crop produced by the introduced Russian-olive. Reports indicate that native birds and mammals are taking the fruits wlth increasing frequency. 

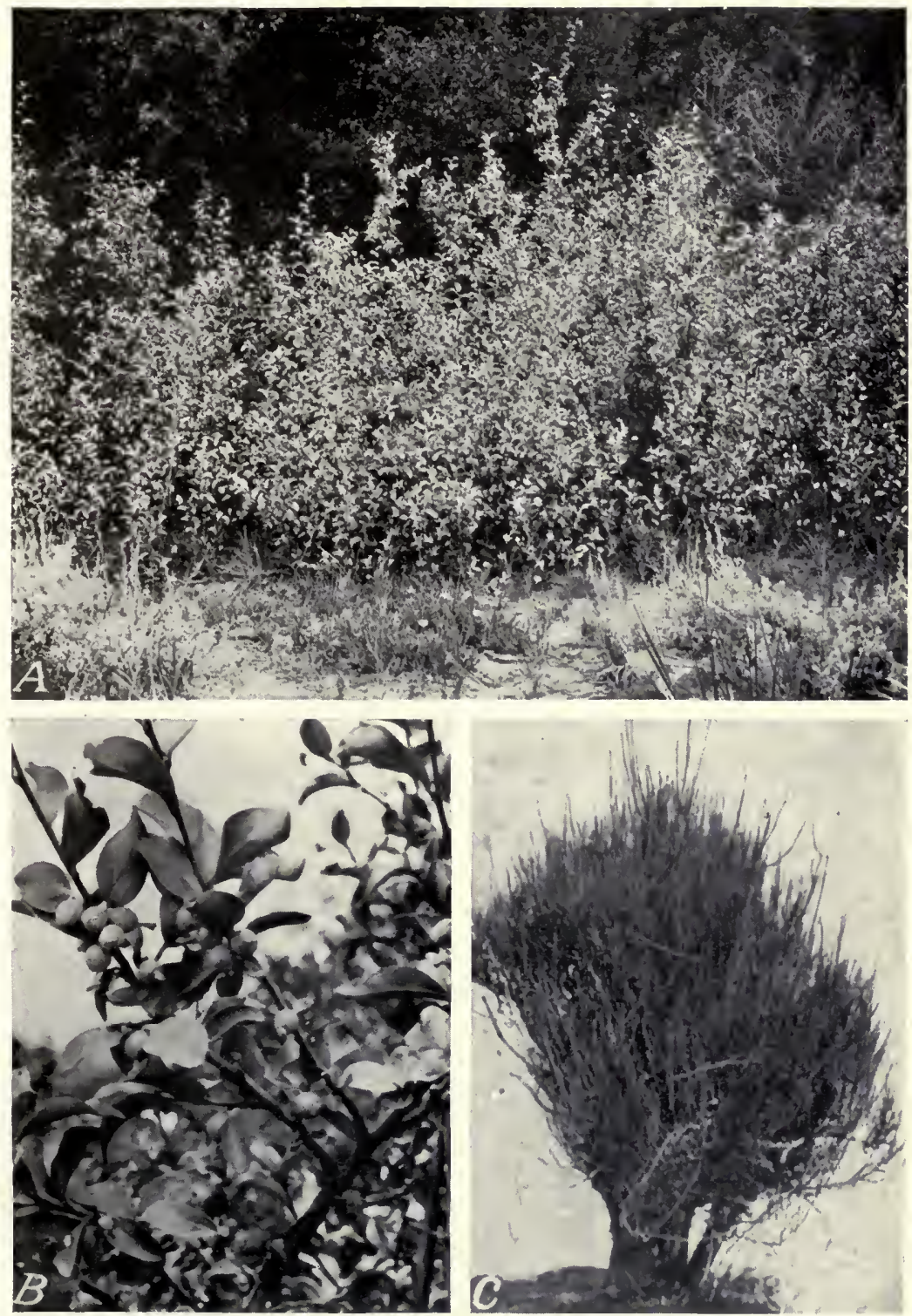

A, Elaeagnus argentea. A natural thicket providing protection for a stream bank as well as for wildlife. $B, E$. argentea. The fruit of the silverberry as well as that of Russian-olive is of value for game birds. $C$, Ephedra spp. The broomlike habit of this plant is characteristic of many othere phedras. In the Southwest they may prove of value in soil and wildlife conservation plantings. (Photograph by Department of the Interlor.) 

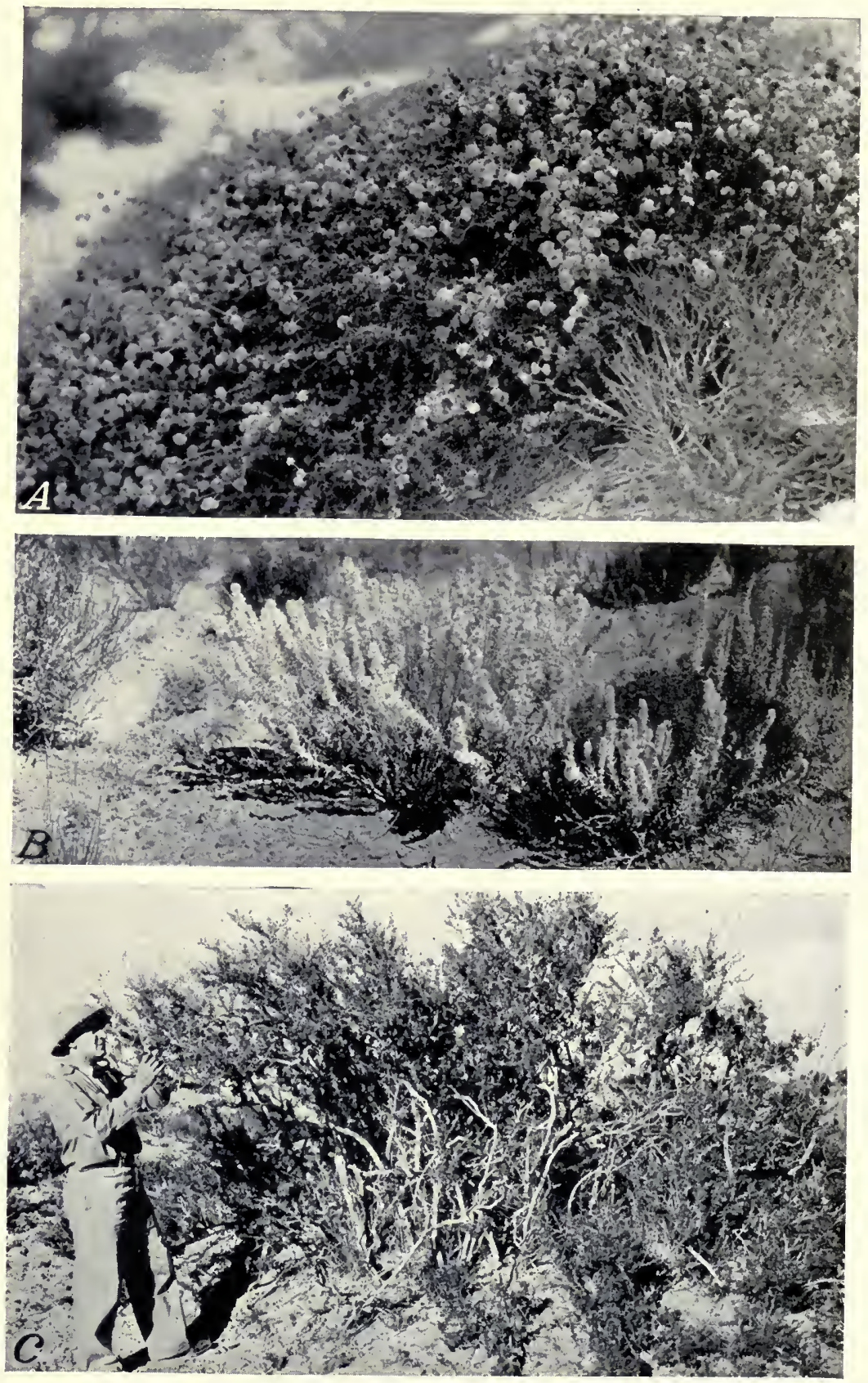

$A$, Eriogonum parrifolium, a species particularly adapted to planting on sand dunes. $B$, Eurotia lanata, a valuable forage plant capable of direct seeding for erosion control. $C$, Fallugia paradora. The apacheplume is a plant with great possibilities for erosion control in the Southwest. This specimen has been
much browsed by llvestock. 
Drejera wrightii, sce Anisacanthus wrightii.

Duranta plumieri, see Duranta repens.

Duranta repens $\mathrm{L}$.

D. plumieri Jacq.

Range: 11, 17, 32.

Site: Well-drained, sun.

Fruit: Drupe.

A large shrub to small tree; sping or unarmed; occurs in sandy and other soils

Earleocassia coresii, see Cassia covesii.

Ebenopsis flexicaulis, sce Pithecolobium flexicaule.

Echinopanax horridum, see Oplopanax horridum.

Echites macrosiphon, see Macrosiphonia macrosiphon.

Edwinia americana, see Jamesia americana.

Edwinia californica, see Jamesia americana.

Ehretia anacua (Berl.) Johnst.

E. elliptica DC.

Range: 11, 17, 20, 30 .

Site: Dry, well-drained, sun.

Fruit: Drupe, available June-April.

Often a large shrub, occasionally a small or large tree; almost evergreen; flowers March-April; suckers freely from the roots and thus forms clumps; rigorous and difficult to eradicate when established; not subject to disease; grows well under semidesert conditions; usually shrubby on drier soils; suckers casily transplanted.

Observations: Attractive to birds.

Ehretia elliptica, see Ehretia anacua.

Elaeagnus spp.

Propagation of these species is by seed stratified and sown in spring or sown directly in the fall; most occur on neutral soil.

Stomach records (in addition to specific records): Sharp-tailed grouse. $O b$ scrvations (in addition to specific records): Pinnated and sharp-tailed grouse, songbirds.

Elaeagnus angustifolia L. (pl. 12, $A, B)$.

Russian-olive.

Range: $7,9,15,18,21,22$.

Site: Dry, well-drained, sun.

Fruit: Drupe; available Angust-October, often persistent until March.

A large shrub to small tree; introduced from Europe and western Asia and locally established in the regions indicated; tolerates considerable alkalinity or salinity; very resistant to drought; rarely attacked by insect pests; $1,000-4,000$ seeds per pound; germination about 90 percent, about 500 usable plants per pound of seed.

Stomach records: Ring-necked pheasant. Observations: Eight species of birds, Including sharp-tailed grouse, eaten by numerous birds in Europe; fox squirrel.

Elaeagnus argentea Pursh. (pl. 13, $A, B$ ).

Silverberry.

E. commutata Bernh.

Range: 9, 15, 18, 21, 23, 24, 26.

Site: Dry, well-drained, moist, sun, shade.

Fruit: Drupe; available July-October.

A small to large, bushy shrub or small tree; flowers May-July; stoloniferous and thicket forming; will grow on limestone soil; 2,000 seeds per pound; germination about 90 percent, about 500 usable plants per pound of seed.

Observations: Ring-necked pheasant, prairie chicken; snowshoe ha1 ${ }^{n}$. Fruit but not foliage taken by livestock.

Elaeagnus canadensis, see Shepherdia canadensis.

Elaeagnus commutata, see Elaeagnus argentea.

Elaeagnus rotundifolia, see Shepherdia rotundifolia. 
Elaeagnus utilis, see Shepherdia argentea.

Elaphrium, see Bursera.

Elliottia racemosa Muhl.

Range : 29.

Site: Dry, well-drained, sun.

Fruit: Capsule.

A large shrub; flowers June-July; commonly occurs on sandy soil; one of the rarest of American shrubs; spreads by rootstocks to form large colonies, which are known at only a few stations, many having been exterminated; selfpollination appears to be impossible and hence, because of the separation of clumps as they now exist, propagation by seed seems to have ceased; in cultivation.

Empetrum conradii, see Corema conradii.

Empetrum nigrum L.

Range: 1, 4, 24, 26, 27.

Crowberry.

Site: Well-drained, moist, sun, shade.

Fruit: Berry; available August-September; often persistent the year round.

A small evergreen, procumbent shrub; monoecious or dioecious; forms dense colonies; occurs in sand or peat.

Stomach records: Forty-one species of birds, including ruffed grouse, Alaska spruce grouse, ptarmigan, and many water birds.

Emplectocladus andersonii, see Prunus andersonii.

Emplectocladus fasciculatus, see Prunus fasciculata.

Ephedra spp. (pl. 13, C).

Shrubby, usually dioecious gymnosperms with scalelike leaves; fruit conelike or nutlike, sometimes fleshy.

Stomach records (in addition to specific records): Mountain quail, Arizona cottontail, Holzner cottontail. Observations (in addition to specific records) : Captive porcupine; much grazed by mule deer; Sacramento cottontail rabbit. Generally eaten by livestock.

Ephedra antisyphilitica Меy.

Canatilla.

Range: 11, 16, 17, 19, 20.

Site: Dry, sun.

Fruit: Nutlike; available April-May.

A small to large shrub; branches lax, occasionally reclining or prostrate.

Ephedra californica Wats.

Range : 5, 10.

California jointfir.

Site: Dry, sun.

Fruit: Nutlike.

A small, prostrate or ascending shrub.

Observations: Of slight importance as browse for mule deer.

Ephedra coryi Reed.

Range: 16.

Site: Dry, well-drained, sun.

Fruit: Berrylike; available spring-early summer.

A small, slender-stemmed, profusely-branched shrub; often occurs in sandy solls; produced from an underground stem whose origin is from a node of an extensive rhizome system; readily adjusts itself to shifting sands, seeds apparently not viable.

Ephedra fasciculata Nels.

Range: 10.

Site: Dry, sun.

Fruit: Nutlike.

A small evergreen shrub; stems slender, prostrate.

Ephedra funerea Cov. and Mort.

Range: 10.

Site: Dry, sun.

Fruit: Berrylike.

A small, much-branched, spinose shrub. 
Ephedra nevadensis Wats.

Nevada jointfir.

Range: 9, 10, 11, 16, 17, 20.

Site: Dry, sun.

Fruit: Nutlike.

A small, nearly leafless, shrub with spreading branches. Much grazed by livestock.

Ephedra pedunculata Engelm.

Range: 11, 16, 17, 20.

Site: Dry, sun.

Fruit: Berrylike, available September-November.

A shrub or small vine; stems often reclining or climbing over surrounding shrubs.

Ephedra texana Reed.

Texas jointfir.

Range : 16.

Site: Dry, well-drained, sum.

Fruit: Berrylike.

A small to large shrub with erect branches; fruit comparatively fleshy.

Ephedra torreyana Wats.

Range: 9, 10, 11, 14, 16.

Torrey jointflr.

Site: Dry, sun.

Fruit: Nutlike.

A small shrub; branches flexuous. Grazed by cattle, especially in winter.

Ephedra trifurca Torr.

Range: 10, 11.

Popotillo.

Site: Dry, sun.

Fruit: Nutlike, available April-May.

A small, much-branched, often spinescent shrub; germinatiou of seed at least 34 percent.

Stomach records: Scaled quail; mountain sheep. Observations: Jack rabbit, Mexican bighorn. Grazed by cattle, especially in winter.

Ephedra viridis Cov.

Range: 9, 10, 11.

Site: Dry, sun.

Fruit: Nutlike; available in May.

A smail shrub with crowded, erect, rigid, broomlike branches; flowers MarchJune; root system deep, fibrous, but scarcely spreading.

Stomach records: Black-tailed deer. Observations: Mule deer. An important browse for livestock.

Epibaterium carolinum, see Cocculus carolinus.

Ericameria arborescens, see Aplopappus arborescens.

Ericameria brachylepis, see Aplopappus propinquиs.

Ericameria cuneatus, see Aplopappus cuneatus.

Ericameria ericoides, see Aplopappus ericoides.

Ericameria monactis, see Aplopappus cooperi.

Ericameria nana, see Aplopappus nanus.

Ericameria nelsonii, see A plopappus laricifolius.

Ericameria palmeri, see Aplopappus palmeri.

Ericameria paniculata, see Chrysothamnus paniculatus.

Ericameria parishii, see Aplopappus parishii.

Ericameria pinifolia, see Aplopappus pinifolius.

Ericameria resinosa, see Aplopappus namus.

Ericameria teretifolia, see Chrysothamnus teretifolius.

Eriodictyon angustifolium Nutt.

Nàrowleaf yerba-santa.

Range: 9, 10, 11.

Site: Dry, sun.

Fruit: Capsule.

A small to large evergreen shrub of very little value as forage, except to goats. 
Eriodictyon californicum (Hook. and Arn.) Greene. California yerba-santa E. glutinosum Benth.

Ra11ge: 1, 4.

Site: Dry, well-drained, sun.

Fruit: Capsule.

A large evergreen shrub; flowers May-June; forms colonies, the plants of which may often be connected by lateral roots 3-4 inches deep; occurs on clay, sandy, rocky and other soils.

Observations: A fair browse for mule deer. Practically worthless as forage for livestock. A valuable honey plant.

Eriodictyon crassifolium Benth.

Range: 5.

Site: Dry, sun.

Fruit: Capsule.

A large colony-forming, evergreen shrub; occurs in sandy or gravelly soils.

Var. traskiae (Eastw.) Jeps., (E. traskiae Eastw.) is very similar to and occurs with the species. Var. niveum Brandeg., ( $E$. niveum Eastw., $E$. tomentosum Benth.) occurs also in region 1.

Eriodictyon glutinosum, see Eriodictyon californicum.

Eriodictyon lanatum, see Eriodictyon trichocalyx.

Eriodictyon niveum, see Eriodictyon crassifolium.

Eriodictyon tomentosum, see Eriodictyon crassifolium.

Eriodictyon traskiae, see Eriodictyon crassifolium.

Eriodictyon trichocalyx Heller.

Yerba-santa.

E. angustifolium pubens Brandeg.

Range: $5,10$.

Site: Dry, sun.

Fruit: Capsule.

A small openly-branched evergreen shrub; occurs on sandy, stony, and other soils; older leaves are often black with fungal growth; colony-forming.

Var. lanatum (Brandeg.) Jeps., (E. lanatum (Brandeg.) Abrams) occurs in region 10 .

Eriogonum spp.

Available records of utilization by wildlife referred only to the genus may include more herbaceous than shrubby species.

Stomach records (in addition to specific records): Richardson's grouse; mountain sheep, antelope jack rabbit, California jack rabbit, Texis jack rabbit, black-tailed deer, Arizona cottontail. Observations (in addition to specific records) : Bighorn.

Eriogonum arborescens Greene.

Range: 5 .

Site: Dry, well-drained, sun.

Fruit: Achene.

A small to large, loosely branched, ornamental shrub.

Eriogonum cinereum Benth.

Range: 5 .

Site: Dry, sun.

Fruit: Achene.

A small to large, freely branched shrub; occurs on coastal bluffs.

Eriogonum corymbosum Benth.

Range: 9, 11, 16.

Site: Dry, sun.

Fruit: Achene.

A small shrub; flowers June-September.

Eriogonum deserticola Wats.

Range: 10.

Site: Dry, well-drained, sun.

Fruit: Achene.

A small, much-branched shrub; occurs in sandy and other soils; branches leafless with age. 
Eriogonum divergens Small.

E. corymbosus divaricatus Torr.

Range: $9,11$.

Site: Dry, sun.

Fruit: Achene.

A small shrub; flowers July-August.

Eriogonum effusum Nutt.

Range: 9, 15, 16.

Site: Dry, sun.

Fruit: Achene.

A small shrub; flowers July-September.

Eriogonum fasciculatum Benth.

Range: 5, 10.

Site: Dry, sun.

Fruit: Achene.

A small shrub; stems more or less decumbent; grows on the poorest soils and in the most exposed situations; casts a poor shadc.

Var. foliolosum (Nutt.) Stokes, ( $E$. foliolosum Nutt.) occurs in region 5. Var. polifolium (Benth.) Torr. and Gray ( $E$. polifolium Benth.), occurs in region 10. Var. flavoviride Munz and Johnst., occurs in region 10 and is smaller than the species.

An important early spring feed for sheep, especially in times of scarcity of other forage. Of first importance as a honey plant.

Eriogonum fendlerianum, see Eriogonum microthecum.

Eriogonum foliolosum, see Eriogonum fasciculatum.

Eriogonum giganteu'm Wats.

Range: 5.

Site: Dry, well-drained, sun.

Fruit: Achene.

A small to large, coar'se shrub.

Eriogonum heermannii Dur. and Hilg.

Range: 9, 10.

Site: Dry, sun.

Fruit: Achene.

A small shrub.

Eriogonum microthecum Nutt.

Range: $4,5,7,8,9,10,11,12,13,14,15$.

Slender buckwheatbrush.

Site: Dry, sun.

Fruit: Achene, available September-November.

A small, much-branched shrub; flowers July-September. Of small importance as browse for livestock.

Var. fendlerianum Benth. (E. fendlerianum (Benth.) Small), occurs from Colorado to New Mexico.

Eriogonum nebraskense Rydb.

Range: 15.

Site: Dry, sun.

Fruit: Achene.

A small, spreading shrub with short branches; flowers in July.

Eriogonum nodosum Small.

Range: 10.

Site: Dry, sun.

A small shrub.

Fruit: Achene.

Eriogonum parvifolium Smith. (pl. 14, A).

Range: 5 .

Site: Dry, sun.

Fruit: Achene.

A small, loosely-branched, decumbent to prostrate shrub; taproot deep and with lateral roots spreading out three times as far as the parts above ground; occurs on sand dunes or hillsides. 
Eriogonum pollfolium, see Eriogonum fasciculatum.

Eriogonum salinum Nels.

Range: 9.

Site: Dry, sun.

Fruit: Achene.

A small shrub; flowers June-July; oceurs on saline soil.

Eriogonum simpsonii Benth.

E. microthecum leptophyllum Torr. and Gray.

Range: 9, 11.

Site: Dry, sun.

Fruit: Achene.

A small shrub; flowers July-August.

Eriogonum sulcatum Wats.

Range: 9, 10.

Site: Dry, sun.

Fruit: Achene.

A small, diffusely-branched shrub; flowers April-May.

Eriogonum wrightii Torr.

Range: $3,9,10,11,14$.

Wright's buckwheatbrush

Site: Dry, sun.

Fruit: Achene.

A small, much-branched shrub; leafy in the lower half; flowers June-November; germination of seed not less than 22 percent.

Var. subscaposum Wats. makes a dense, leafy mat, has leafy branches shorter than the species, and oceurs in reglons 9 and 10.

Observations: An excellent forage for deer; highly palatable to captive deer; characterized as the most important single forage for large game animals in Arizona. Fair browse for livestock.

Erythrina arborea (Chapm.) Small.

Red-cardinal.

E. herbacea arborea Chapm.

Range: $17,30,31,32$.

Site: Well-drained, sun.

Fruit: Legume.

A large shrub to small or large tree, or vine; stems solitary or thiclsly tufted; thorny; occurs in sandy soils.

Erythrina flabelliformis Kearney.

E. purpusii Brandeg.

Coralbean.

Range : 11.

Site: Dry, sun.

Fruit: Legume.

A large shrub to small tree; spiny; seed germination $20-40$ percent; of some value as forage for livestock; seed, bark, and stems are more or less poisonous, but probably do not cause much trouble to livestock except on overgrazed range.

Erythrina purpusii, see Erythrina flabelliformis.

Esenbeckia runyonii Mort.

Range: 17.

Site: Well-drained, sun.

Fruit: Woody capsule, available in April.

A small or rarely a large tree; flowers in July.

Eubotrys elongata, see Leucothoë elongata.

Eubotrys racemosa, see Leucothoë racemosa.

Eubotrys recurva, see Leucothoë recurva.

Eucnide urens Parly.

Range: 9, 10.

Rock-nettle.

Site: Dry, sun.

Fruit: Capsule.

A small shrub; flowers in May; armed with stinging hairs; stems often decumbent. 
Eurphorbia misera Benth.

Range: 5, 10.

Site: Dry, well-drained, sun.

Fruit: Capsule.

A small shrub or rarely a large shrub to small tree; much branched; straggling.

Eurotia lanata (Pursh) Moq. (pl. 14, B).

Winterfat.

E. subspinosa Rydb.

Range: $3,4,6,7,8,9,10,11,14,15,16$.

Site: Dry, well-drained, sun.

Fruit: Achene, available September-October.

A small dioecious or monoecious shrub; occurs on subalkaline soils; branches slender, many from the base; very rapid growing; root system spreading but deep; seed produced in great abundance; 91,000 seeds per pound, vitality transient; in direct seeding sown 3 to 4 pounds per acre; germination of seed 30-70 percent.

Obscrvations: Important winter browse for elk; California mule deer. Very valuable forage for sheep and cattle, particularly in the winter and fall; considered very fattening for livestock.

Eurotia subspinosa, see Eurotia lanata.

Evonymus sp.

Observations (in addition to specific records) : Fox sparrow, mockingbird.

Evonymus americanus $\mathbf{L}$.

Strawberrybush.

Range: $20,25,27,28,29,30$.

Site: Dry, well-drained, sun, shade.

Fruit: Capsule; avallable September-October; seeds with a fleshy aril.

A small to large shrub; flowers May-June; stems often creeping or trailing, rooting at the nodes, or semierect; propagation is by seed stratified and sown in spring; 30,000 seeds per pound.

Stomach records: Five species of birds.

Evonymus atropurpureus Jacq.

Range: $20,21,22,23,24,25,26,27,28,29,30$.

Burningbush.

Site: Dry, well-drained, moist, sun, shade.

Fruit: Capsule; avallable August-November; seeds with a fleshy aril.

A small to large shrub or rarely a small tree to large tree; flowers May-June; subject to scale and fungus attack; bark medicinal; propagation is by seed stratified and sown in spring; 40,000 seeds per pound, germination about 70 percent, about 8,000 usable plants per pound of seed.

Stomach records: Three species of birds including Hungarian partridge. observations: Palatable to rodents, possibly to deer. A drastic purgative to livestock but seldom browsed.

Eronymus obovatus Nutt.

Range: 24, 25, 27.

Site: Well-drained, sun, shade.

Fruit: Capsule, available August-October; seed with a fleshy aril.

A small, spreading shrub or trailing vine; thicket or mat forming; branches rooting at the nodes; flowers April-May; propagation is by seed stratifled and sown in spring.

Evonymus occidentalis Nutt.

Range: $1,2,4,12$.

Site: Well-drained, moist, shade.

Fruit: Capsule, available July-October; seed with a fleshy aril.

A large shrub or rarely small tree; branches slender, straggling; flowers May-June; propagation is by seed stratified and sown in spring.

Var. parishii Jeps., (E. parishii Trel.) is found in the southern California mountains.

Stomach records: Robin. Not browsed by stock.

Evonymus parishil, see Evonymus occidentalis.

Eysenhardtia amorphoides, see Eysenhardtia polystachya.

Eysenhardtia cobriformis, see Eysenhardtia polystachya. 
Eysenhardtia orthocarpa, see Eysenhardtia polystachya.

Eysenhardtia polystachya (Orteg.) Sarg.

Kidneywood.

E. amorphoides H. B. K., E. orthocarpa (Gray) Cockerell, E. orthocarpa

Wats., $E$. reticulata Penn., $E$. subcoriacea Pennell, $D$. cobriformis Pennell,

E. texana Schecle, Viborquia polystachya Orteg.

Range: 10, 11, 17, 20.

Site: Dry, sun.

Fruit: Legume, available in September.

A large shrub to small or rarely large tree; flowers in May; fruit borne sparingly; germination. of seed about 50 percent.

Observations: Particularly palatable to captive deer. A valuable honev plant. Good goat browse, and in southeastern Arizona one of the best summer and fall browses for horses and cattle.

Eysenhardtia reticulata, see Eysenhardtia polystachya.

Eysenhardtia subcoriacea, see Eysenhardtia polystachya.

Eysenhardtia texana, see Eysenhardtia polystachya.

Fagara clava-herculis, see Xanthoxylum clava-herculis.

Fagara fagara, see Xanthoxylum fagara.

Fagara pterota, see Xanthoxylum fagara.

Fagu's americana, see Fagus grandifolia.

Fagus grandifolia Ehrh.

F. americana Sweet.

Beech.

Range : $20,22,23,24,25,26,27,28,29,30$.

Site: Well-drained, sun, shade.

Fruit: Nut, available September-October.

A large tree; occurs on many slightly acid soils except sand; root system shallow and spreading; subject to sunscald; easily injured by fire and late frosts; root sprouts common; generally free from insect attack; wood used commercially; grass ordinarily will not grow under this tree; seeds often abortive; 1,400-1,800 seeds per pound, germination 80 percent, about 250 usable plants per pound of seed.

Stomach records: Ten species of birds, including ruffed grouse; opossum, raccoon, gray and red fox, white-tailed deer; found in 21.3 percent of raccoon stomachs examined November-January in New York. Observations: Fifteen species of birds, including bobwhite, ruffed grouse, wild turkey, and ring-necked pheasant; black bear; preferred food of flying squirrel ; white-tailed deer, Virginia opossum, cottontail rabbit, red squirrel, red fox, gray fox, porcupine; a most important food of raccoon in fall and early winter.

Fallugia acuminata, see Fallugia paradoxa.

Fallugia paradoxa (Don) Endl. (pl. 14, $C$ ).

Apache-plume.

$F$. acuminata Cockerell, $F$. paradoxa acuminata Woot., $F$. micrantha Cockerell, Sieversia paradoxa Don.

Range: 9, 10,11, 13, 14, 16, 17, 20.

Site: Dry, well-drained, sun.

Fruit: Achene, available August-November.

A small to large, freely-branched, somewhat straggling, shrub; evergreen; flowers May-September; rapid growing when supplied with water; does not reach full height unless protected from grazing; seeds germinate well as soon as planted at $60-70^{\circ}$ F.; direct seeding experiments in New Mexico were unsuccessful ; germination of seed $30-60$ percent.

Palatability fair to low for sheep, goats, and cattle; endures grazing well.

Fatsia horrida, see Oplopanax horridum.

Fendlera falcata Thornb.

Range: 13, 14.

Site: Dry, sun.

Fruit: Capsule.

A small to large shrub; flowers May-July. 
Fendlera rupicola Gray.

Range: 9, 11, 16, 17, 20.

Site: Dry, well-drained, sun.

Fruit: Capsule, available July-August.

A large shrub; flowers May-June; will endure intense heat and considerable drought.

Observations: Much used by captive deer. Palatability high for goats in New Mexico, and closely grazed by cattle in central Arizona.

Fendlera tomentella Thornb.

Range: 11, 13, 14.

Site: Dry, well-dralned, sun.

Fruit: Capsule.

A small to large shrub.

Fendlera wrightii (Gray) Heller.

$F$. rupicola wrightii Gray.

Range : 11.

Site: Dry, sun.

Fruit: Capsule.

A small shrub; flowers May-June.

Fendlerella cymosa, see Fendlerella utahensis.

Fendlerella utahensis (Wats.) Heller.

F. cymosa Greene, Whipplea utahensis Wats.

Range: 9, 10, 11, 13, 14.

Site: Dry, sun.

Fruit: Capsule.

A small, spreading, densely-branched shrub.

Stomach records: Black-tailed deer.

Flourensia cernua DC.

Helianthus cernuus Benth. and Hook.

Blackbrush.

Range: 11, 16, 17.

Site: Dry, sun.

Fruit: Achene.

A small to large, much-branched, erect or procumbent shrub; occurs on sandy and other soils.

Observations: Somewhat eaten by jack rabbits. Not browsed by livestock except under extreme conditions.

Forestiera spp.

Observations (in addition to specific records) : Mexican raccoon.

Forestiera aouminata (Michx.) Poir.

Adelia acuminata Michx.

Range: $20,22,25,29,30$.

Site: Well-drained, moist, sun, shade.

Frult: Drupe, available May-October.

A large shrub, less commonly a small to large tree; flowers March-April; somewhat spiny; thicket forming; fruit much attacked and distorted by insects, but on falling into water keeps in perfect condition far into the succeeding spring.

Stomach records: Wood duck, mallard. Observations: A good duck food.

Forestiera angustifolia Torr.

Adelia angustifolia (Torr.) Kuntze.

Range: 11, 17, 30.

Site: Dry, well-drained, sun.

Fruit: Drupe, available in June.

A small to large, densely branched, stiff evergreen shrub.

Stomach records: Scaled quall. Observations: Much eaten by scaled quail; extensively eaten by gray fox.

Forestiera ligustrina (Michx.) Poir.

Adelia ligustrina Michx.

Range: 29, 30 .

Site: Dry, well-drained, moist, sun.

Fruit: Drupe.

A large, widely branched shrub; often occurs on limestone or sandy solls.

$130188^{\circ}-39-9$ 
Forestiera neomexicana Gray.

Paloblanco.

F. parvifolia Small, $F$. acuminata parvifolia Gray, Adelia neomexicana

(Gray) Kuntze., A. parvifolia (Gray) Small.

Range: 4, 9, 10, 11, 13, 16, 17, 20.

Site: Dry, well-drained, sun.

Fruit: Drupe, available June-September.

A small or commonly large, spiny, much-branched, spreading shrub; germination of seed $40-70$ percent.

Forestiera parvifolia, see Forestiera neomexicana.

Forestiera phillyreoides (Benth.) Torr.

Piptolepis phillyreoides Benth.

Range: 10.

Site: Dry, well-drained, sun.

Fruit: Drupe.

A large shrub to small tree; thicket-forming; fruit dropped as soon as ripe.

Forestiera pubescens Nutt.

Adelia pubescens (Nutt.) Kuntze.

Elbow bush.

Range: 11, 16, 17, 20, 29, 30 .

Site: Well-drained, moist, sun.

Fruit: Drupe, available June-October.

A small to large, widely branched shrub; recurved branches root where they touch the ground; propagation is by cuttings or seeds; has been recommended as a good erosion control and wildlife cover plant.

Forestiera reticulata Torr.

Range: 16, 17.

Site: Well-drained, sun.

Fruit: Drupe.

A large shrub to small tree; evergreen.

Forestiera sphaerocarpa Torr.

Range: 17.

Site: Dry, well-drained, sun.

Fruit: Drupe.

A small evergreen shrub.

Forsellesia mionandra (Koehne) Heller.

Glossopetalon mionandrum Koehne.

Range: 13.

Site: Dry, sun.

Fruit: Follicle.

A small, spinescent, intricately-branched shrub.

Forsellesia nevadensis, see Forsellesia spinescens.

Forsellesia pungens (Brandeg.) Heller.

Dwarf greasebush.

Glossopetalon pungens Brandeg.

Range: 10 .

Site: Dry, sun.

Fruit: Follicle.

A very small shrub with weak branches; often occurs in rocky soils.

Forsellesia spinescens (Gray) Greene.

Spiny greasebush.

F. nevadensis (Gray) Greene, Glossopetalon spinescens Gray, G. nevadense Gray.

Range: 7, 8, 9, 10, 11, 16.

Site: Dry, sun.

Fruit: Follicle.

A small, spiny, intricately-branched shrub; flowers February-May; occurs most commonly on limestone, but can grow on granite; a pioneer species.

Observations: Mule deer. Close-cropped by sheep in Utah.

Fothergilla spp.

Propagation of all species is by seeds which do not germinate until the second jear or by layers which take 2 years to root.

Fothergilla alnifolia, see Fothergilla gardenii.

Fothergilla carolina, see Fothergilla gardenii. 
Fothergilla gardenii Murr.

\section{$F$. carolina Britt., $F$. alnifolia $\mathrm{L}$. $\mathbf{f}$.}

Dwarf witch-alder.

Range: 29, 30 .

Site: Well-drained, moist, sun.

Fruit: Capsule, available July-August.

A small shrub; flowers April-May; usually occurs in sandy soll; free from insects and disease; propagation is by seed stratified and sown in spring, or by suckers or root cuttings.

Fothergilla major Lodd.

Range: 27.

Site: Molst, shade.

Fruit: Capsule, available in September.

A small to large, much-branched shrub; flowers in May; foliage rather dense; free from insects and disease; propagation is by seed stratified and sown in spring.

Fothergilla monticola Ashe.

Range: 29, 30.

Site: Well-drained, sun.

Fruit: Capsule.

A small to large shrub; flowers April-May; very like F. major but more spreading.

Fothergilla parvifolia Kearney.

Creeping witch-alder.

Range: 29, 30 .

Site: Well-drained, sun, shade.

Fruit: Capsule.

A small shrub; occurs in sandy and other soils; forms extensive climps by means of long underground stems; free from insects and disease; propagation is by seed stratified and sown in spring.

Fouquieria splendens Engeim.

Range: 10, 11, 16 .

0cotillo.

Site: Dry, sun.

Fruit: Capsule.

A large, spiny shrub; stems simple, several from one base; leafless most of the year; of no recorded forage value; flowers and fruit a source of food for Indians.

Frankenia jamesii Torr.

Range: 11.

Site: Dry, sun.

Fruit: Capsule.

A small shrub; occurs on alkaline soll.

Frankenia palmeri Wats.

Range: 5 .

Site: Well-drained, moist, sun.

Fruit: Capsule.

A small shrub; flowers June-July; often occurs in salt marshes.

Franseria albicaulis, see Franseria dumosa.

Franseria ambrosioides Cav.

Range: 5, 10, 11.

Ambrosia bur-sage.

Site: Dry, well-drained, sun.

Fruit: Bur.

A small to large shrub.

Franseria dumosa Gray.

F. albicaulis Torr., Gaertneria dumosa Kuntze.

Yerba reuma.

Range: 5, 9, 10.

Site: Dry, sun.

Fruit: Bur.

A small, much-branched, compact, spiny shrub; locally valuable as feed for cattle and sheep. 
Franseria eriocentra Gray.

Gaertneria eriocentra Kuntze.

Woolly bur-sage.

Range: 9, 10.

Site: Dry, sun.

Fruit: Bur.

A small, rigid, spreading shrub; usually occurs on sandy soil.

Franseria ilicifolla Gray.

Gaertneria ilicifolia Kuntze.

Hollyleaf bur-sage.

Range: 10.

Site: Dry, well-drained, sun.

Fruit: Bur.

A small, rigid, much-branched, evergreen shrub; usually occurs on sand; leaves somewhat spiny.

Fraxinus spp.

Ash.

All species usually occur on neutral soil; propagation is by seed stratified at $32^{\circ}-50^{\circ} \mathrm{F}$. for 30 to 90 days and sown in spring, or sown directly in the fall although seeds sometime remain dormant until the second year; rapid growing when young; usually easily transplanted.

Stomach records (in addition to specific records): Seven species of birds, including bobwhite; white-tailed deer. Observations (in addition to specific records): Five species of birds; an important food of white-tailed deer in Massachusetts; porcupine; a reserve food and building material for beaver. Important source of pollen for bees.

Fraxinus americana $\mathrm{L}$.

Range: $20,22,23,24,25,27,28,29,30$.

White ash.

Site: Well-drained, sun.

Fruit: Samara, avallable October-November.

A large tree; occurs on many kinds of soll; flowers April-June; root system flbrous, deep; rapid growing; much attacked by borers; not extensively damaged by fungi; much cultivated; wood of great importance commercially; 6,000 seeds per pound, germination of seed 40 percent, about 1,500 usable plants per pound of seed.

Var. microcarpa Gray is a shrub ordinarily growing in drier situations and bearing smaller fruit.

Observations: Purple finch, pine grosbeak; cottontail rabblt, porcupine, whitetailed deer.

Fraxinus anomala Wats.

Dwarf ash.

Range: 9, 10, 11, 13, 14.

Site: Dry, well-drained, sun.

Fruit: Samara.

A large shrub to small tree; 22,000 seeds per pound, about 5,000 usable plants per pound of seed. Provides at least poor and sometimes fair to fairly good browse for goats, sheep, and cattle.

Fraxinus attenuata, see Fraxinus velutina.

Fraxinus berlandieriana DC.

Mexican ash.

Range : 11, 16, 17, 20, 30.

Site: Well-drained, sun.

Fruit: Samara, avallable in May.

A large dioecious tree.

Fraxinus biltmoreana Beadle.

Range: 22, 25, 27, 28, 29.

Site: Dry, well-drained, sun.

Fruit: Samara.

A large dioecious tree; flowers April-May; very similar to F. americana but more hairy.

Fraxinus californica, see Fraxinus oregona.

Fraxinus caroliniana Mill.

Water ash.

F. caroliniana rehderiana Sarg., F. platycarpa Michx.

Range : $28,29,30$.

Site: Well-drained, moist, sun, shade.

Fruit: Samara.

A large dioecious tree; flowers March-April.

Blltmore white ash. 
Fraxinus coriacea, see Fraxinus velutina.

Fraxinus cuspidata Torr.

Range: $11,14,17$.

Flowering ash.

Site: Well-drained, sun.

Fruit: Samara.

Usually a large shrub, more rarely a smail or large tree; flowers April-May; commonly arborescent southward but mostly in Mexico; often thicket-forming; 16,000 seeds per pound. Provides poor and sometimes fair to fairly good browse for goats, sheep, and cattle.

Var, macropetala (Eastw.) Rehder, ( $F$. macropetala Eastw.) differs from the species in bearing three, five, and seven foliate leaves.

Fraxinus darlingtonii, see Fraxinus pennsylvanica.

Fraxinus dipetala Hook. and Arn.

Range: 1, 3, 4, 5 .

Flowering ash.

Site: Dry, well-drained, sun.

Fruit: Samara.

A large shrub.

Observations: California mule deer.

Fraxinus floridana, see Fraxinus pauciflora.

Fraxinus glabra, see Fraxinus velutina.

Fraxinus greggii Gray.

F. schiedeana parvifolia Torr.

Littleleaf ash.

Range: 11, 17.

Site: Dry, well-drained, sun.

Fruit: Samara.

A small to large tree.

Fraxinus lanceolata, see Fraxinus pennsylvanica.

Fraxinus lowellii Sarg.

Range: 11.

Site: Dry, well-drained, sun.

Fruit: Samara, avallable in July.

A small to large tree; possibly closely related to $F$. anomala.

Fraxinus macropetala, see Fraxinus cuspidata.

Fraxinus michauxii Britt.

Range: $25,27,28,29,30$.

Site: Well-drained, moist, sun.

Fruit: Samara.

A large tree; fiowers April-May.

Fraxinus nigra Marsh.

Black ash.

\section{F. sambucifolia Lam.}

Range: 22, 24, 25, 26, 27, 28.

Site: Well-drained, moist, sun.

Fruit: Samara; available June-September, falling or persistent until spring.

A large perfect or dioecious tree; flowers April-May; root system shallow; easily wind thrown; severely damaged by fire but quite free from fungus and insect damage; coppices poorly; wood used commercially; vitality of seeds low; 3,000 seeds per pound.

Observations: Evening grosbeak; cottontail rabbit.

Fraxinus oregona Nutt.

F. californica Hort.

Oregon ash.

Range: 1, 2, 3, 4, 5 .

Site: Well-drained, moist, sun.

Fruit: Samara; available September-October, partially persistent 3 to 12 months.

A large dioecious tree; flowers April-May; rapid growing, relatively longlived; free from disease; wood of importance commercially; comes into leaf late in spring and sheds its foliage early in the fall; fruit produced in great quantities ; 10,000 seeds per pound, vitality persistent.

observations: Western evening grosbeak. A fairly important cattle browse and good local browse for sheep and goats. 
Fraxinus papillosa, see Fraxinus velutina.

Fraxinus pauciflora Nutt.

$F$. floridana Sarg.

Water ash.

Range: 29, 30, 31.

Site: Moist, sun.

Fruit: Samara.

A large dioecious tree; flowers in March; more abundant southward.

Fraxinus pennsylvanica Marsh.

$F$. darlingtonii Britt., $F$. smallii Britt.

Red ash.

Range: $15,18,20,21,22,23,24,25,26,27,28,29,30$.

Site: Well-drained, sun.

Fruit: Samara, available September-October.

A large dioecious tree; flowers April-May; root system shallow; fairly immune from insects and fungus diseases; easily injured by fire; rapid growing when young, later slower; coppice does not develop into large trees; wood used commercially; 11,000 seeds per pound, germination 50 percent. Between this and its varieties occur many intergrading forms.

Var. lanceolata Sarg., the green ash (F. viridis Michx. f., F. lanceolata Borkh.) will grow in much drier situations than the species and occurs in regions 12 and 17 in addition to the areas noted for the species; root system shallow, widespreading; rapld growing when young, later slower; grows on coalstripped lands in Illinois ; not short-lived; generally free from insects and diseases; easily injured by fire; $16,000-17,000$ seeds per pound, germination about 85 percent, about 3,000 usable plants per pound of seed. Also considered a separate species and rather distinct in the East but much less so westward.

observations: Three species of birds; white-talled deer, cottontail rabbit, snowshoe hare.

Fraxinus pistaciaefolia, see Fraxinus velutina.

Fraxinus platycarpa, see Fraxinus caroliniana.

Fraxinus profunda Bush.

$F$. americana profunda Britt.

Range: $25,27,29,30$.

Site: Well-drained, sun.

Fruit: Samara, available September-October.

A large dioecious tree; flowers April-May; leaves very large.

Fraxinus quadrangulata Michx.

Range: 22, 23, 24, 25, 27, 29.

Site: Dry, well-drained, sun.

Fruit: Samara, avallable June-October.

A large, perfect or dioecious tree; fiowers March-April; occurs on limestone and other soils; root system shallow, spreading; grows on drier soils than any other of the ashes in their native habitats; rapld growing, rather short-lived; wood most durable of all ashes, used commercially; 7,000 seeds per pound.

Fraxinus sambucifolia, see Fraxinus nigra.

Fraxinus smallii, see Fraxinus pennsylvanica.

Fraxinus standleyi, see Fraxinus velutina.

Fraxinus texensis (Gray) Sarg.

$F$. americana texensis Gray.

Pumpkin ash.

Range: 16, 17, 20, 25 .

Site: Dry, well-drained, sun.

Fruit: Samara.

A large dioecious tree; flowers in March; often occurs on limestone soil.

Fraxinus toumeyi, see Fraxinus velutina.

Fraxinus velutina Torr.

Velvet ash.

F. pistaciaefolia Torr., $F$. glabra Thornb., $F$. velutina glabra (Thornb.)!

Rehd., $F$. papillosa Lingels., $F$. standleyi Rehder., $F$. standleyi lasia Rehder.

Range: 9, 10, 11, 14, 16, 17, 20.

Site: Well-drained, moist, sun.

Fruit: Samara, available in September. 
A small to large, dioecious, almost evergreen tree; flowers March-April; $13,000-40,000$ seeds per pound. An extremely variable species, the following apparently reasonably well separated; Var. toumeyi (Britt.) Rehd. (F. attenuata Jones in part., $F$. toumeyi Britt.) occurs with the specles but is most common in Arizona; said to be the most alkali- and drought-resistant form; 10,000 seeds per pound.

Var. coriacea (Wats.) Rehd. ( $F$. coriacea Wats., $F$. pistaciaefolia coriacea Gray, $F$. americana pistaciaefolia Wenz), the desert ash, occurring in regions 9 and 10 , is of some value as early-spring and late-fall browse for stock; 29,000 seeds per pound. Var. glabra (Thornb.) Rehder (F. glabra Thornb.), the smooth ash, occurs within the range of the species.

Fraxinus viridis, see Fraxinus pennsylvanica.

Fremontia californica Torr.

California fremontia.

F. mexicanum McBr., Fremontodendron californicum Cov., F. mexicanum

Davids.

Range: 3, 4, 5, 10, 11.

Site: Dry, sun.

Fruit: Capsule.

A large shrub to small tree; evergreen; flowers May-July; foliage thin; grows on very poor soils; not tolerant of excess moisture or poor drainage; an abundant seeder.

Observations: Of slight forage value for mule deer. Fair to good browse for cattle and goats.

Fremontia mexicana, see Fremontia californica.

Fremontodendron californicum, see Fremontia californica.

Fremontodendron mexicanum, see Fremontia californica.

Gaertneria dumosa, see Franseria dumosa.

Gaertneria eriocentra, see Franseria eriocentra.

Gaertneria ilicifolia, see Franseria ilicifolia.

Garrya spp.

Propagation of all species is by seeds, layers, or half-ripe cuttings under glass.

Garrya buxifolia, see Garrya flavescens.

Garrya elliptica Dougl.

Tasseltree.

Range: $1,4$.

Site: Dry, well-drained, sun.

Fruit: Berry, available June-August.

Commonly a small to large shrub, rarely a small tree; flowers JanuaryMarch.

Garrya flavescens Wats.

G. pallida Eastw.

Silktassel.

Range: 4, 5, 9, 10, 11, 13.

Site: Dry, sun.

Fruit: Berry, available July-August.

A large, dioecious, spreading shrub; flowers April-May.

Browsed to some extent by livestock and suffers no injurious effects from grazing up to 25 percent.

Var. buxifolia (Gray) Jeps., (G. buxifolia Gray) occurs in reglons 1 and 4 and is lower than the species.

Garrya fremontii Torr.

Fremont silktassel.

Range: 4, 5 .

Site: Dry, sun.

Fruit: Berry, available August-September.

A large evergreen shrub; flowers February-March. Considered a good browse for cattle.

Observations: California mule deer.

Garrya goldmanii, see Garrya ovata.

Garrya lindheimeri, see Garrya ovata. 
Garrya lindheimeri Torr.

Range: $16,17,20$.

Silktassel bush.

Site: Dry, well-drained, sun.

Fruit: Berry, available September-October.

A small to large shrub, or where moisture is plentiful, a small to large tree; almost evergreen; flowers April-May.

Garrya ovata Benth.

G. goldmanii Woot. and Standl., G. lindheimeri Torr.

Range: 11, 16, 20.

Site: Dry, sun.

Fruit: Berry.

A small to large evergreen shrub; occurs on limestone and other soils. Con. sidered a good feed for goats.

Garrya pallida, see Garrya flavescens.

Garrya veatchii Kellogg.

G. flavescens palmeri Wats., G. veatchii palmeri Eastw.

Canyon tasselbush.

Range: 1, 4, 5 .

Site: Dry, sun.

Fruit: Berry.

A large shrub; flowers January-May.

Observations: Of slight importance as browse for mule deer.

Garrya wrightii Torr.

Range: 11, 14.

Site: Dry, sun.

Fruit: Berry, available August-September.

A large evergreen shrub; flowers June-August; resistant to drought; apparently the hardiest of all species of Garrya; transplantation difficult; cuttings rarely successful.

Stomach records: Mountain sheep. Observations: Arizona white-tailed deer, Mexican bighorn. Locally of some forage value for livestock.

Gaultheria humifusa (Graham) Rydb.

G. myrsinites Hook., Vaccinium humifusa Graham.

Range: 1, 4, 12, 13.

Site: Well-drained, sun.

Fruit: Berry, available August-September.

A small evergreen shrub or vine; flowers in August; stems procumbent, rooting; propagation is by seed sown under glass in winter or spring. deer.

Stomach records: Plains white-tailed deer. Observations: Quail, grouse;

Gaultheria myrsinites, see Gaultheria humifusa.

Gaultheria ovatifolia Gray.

Bush wintergreen.

Range: 4, 12.

Site: Well-drained, sun.

Fruit: Berry, avallable August-September.

A small evergreen shrub; propagation is by seed sown under glass in winter cr spring.

Observations: Grouse, quail ; deer.

Gaultheria procumbens L.

Range: $21,22,23,24,25,26,27,28,29$.

Teaberry.

Site: Dry, well-drained, sun, shade.

Fruit: Berry, available August-June.

A small evergreen shrub; flowers May-September; occurs in sandy or other soils; stems creeping on or below the surface, forming mats; berry gradually increasing in size over winter; 1 ton of leaves produces 1 pound of oil of wintergreen; propagation is by seed sown under glass in winter or spring, or by division; 2,800 fresh berries per pound.

Stomach records: Seven species of birds, including ruffed grouse, bobwhite, sharp-tailed grouse, and ring-necked pheasant; mountain sheep, white-tailed deer. Observations: Six species of birds, including bobwhite, ruffed and spruce grouse; white-tailed deer; a favorite food of eastern chipmunk. 
Gaultheria shallon Pursh. (pl. 15, A. B).

Salal.

Range: $1,2,4,12$.

Site: Dry, well-drained, sun, shade.

Fruit: Berry, available July-December.

A small to large evergreen shrub; flowers May-June; when occurring in dry, sunny situations the species becomes much dwarfed; apparently needs a very humld atmosphere for best growth; forms a dense cover, more especially on sandy soil; most robust near the sea; propagation is by seed sown under glass in winter or spring.

Stomach records: Wren tit. Observations: Blue grouse, band-tailed pigeon, sooty grouse; Columbian black-tailed deer, Townsend's chipmunk, brown mountain beaver, Olympic black bear; emergency ration for Olympic wapiti, an important food of Roosevelt elk. Not palatable to livestock.

Gaylussacia spp.

Propagation of all species is by seed sown under glass in winter or spring.

Stomach records (in addition to specific records): Fifty-one species of birds, including ruffed grouse, bobwhite, wild turkey, sharp-tailed grouse, ring-necked pheasant; opossum. Observations: White-winged crossbill; ranked with Vaccinium as twenty-ninth on the list of quail food plants in the Southeast; bear.

Gaylussacia baccata (Wang.) Koch.

Black huckleberry.

G. resinosa (Ait.) Torr, and Gray, Andromeda baccata Wang., Decachaena baccata (Wang.) Small.

Range: $22,23,24,25,26,27,28,29$.

Site: Dry, well-drained, moist, sun.

Fruit: Berry; available July-September.

A small, much-branched, rigid shrub; flowers May-June; occurs In sandy and other, usually acid soils; many fruit-color varieties occur within the range of the species.

Stomach records: Six species of birds, including ruffed grouse, sharp-tailed grouse, greater prairie chicken; composed 1.9 percent of entire amount of fall food taken by sharp-tailed grouse in Wisconsin; taken by 3 out of 17 fall-collected prairie chickens in Wisconsin; white-tailed deer. Observations: Ruffed grouse, bobwhite, wild turkey, mourning dove.

Gaylussacia brachycera (Michx.) Gray.

Box huckleberry.

Vaccinium brachycerum Michx., Buxella brachycera (Michx.) Small.

Range : 27, 28.

Site: Dry, well-drained, sun.

Fruit: Berry; available July-August.

A small evergreen shrub; flowers May-June; forms extremely dense colonies, each representing a single plant; usually occurs in acid solls, including very poor ones; seed often produces sterile fruit; best developed in southeastern West Virginia.

Observations: Ruffed grouse.

Gaylussacia dumosa (Andr.) Torr. and Gray.

Vaccinium dumosum Andr., Lasiococcus

Dwarf huckleberry.

Range : 24, 26, 27, 28, 29, 30.

Site : Dry, well-drained, moist, sun.

Fruit: Berry; available June-October.

A small shrub; evergreen southward; flowers May-June; occurs in sandy and other soils, often swamps; stems are produced from a creeping rootstock.

Var. hirtella (Ait.f.) Gray, (G. hirtella (Ait.) Klotz., Lasiococcus mosieri Small), occurs within the range of the species.

Gaylussacia Prondosa (L.) Torr. and Gray.

Vaccinium frondosum L., Decachaena frondosa (L.) Torr. and Gray.

Dangleberry.

Range: 25, 27, 28, 29 .

Site: Dry, well-drained sun.

Fruit: Berry; available June-September.

A small to large, widely-branched, shrub; flowers May-June. A dwarf form has been described as var. tomentosa Gray.

Stomach records: Two species of birds. Observations: Ruffed grouse, bobwhite, cedar waxwing.

Gaylussacia hirtella, see Gaylussacia dumosa. 
Gaylussacia nana (Gray) Small.

Decachaena nana (Gray) Small.

Range: 29, 30.

Site: Dry, well-drained, sun.

Fruit: Berry.

A small shrub; usually occurs in sand; spreads by meuns of underground stems.

Gaylussacia resinosa, see Gaylussacia baccata.

Gaylussacia tomentosa (Pursh) Chapm.

Decachaena tomentosa (Pursh) Small.

Range: 29, 30.

Site: Well-drained, sun.

Frult: Berry.

A small shrub; occurs in sandy soil; stem unbranched; spreading by underground stems.

Gaylussacia ursina (Curtis) Torr. and Gray.

Derachaena ursina (Curtis) Small.

Bear huckleberry.

Range: 27, 28.

Site: Well-drained, sun, shade.

Fruit: Berry ; available July-August.

A small, loosely-branched shrub; flowers May-June; often occurs in acid humus.

Gelsemium rankinli Small.

Range: 29,30 .

Site: Well-drained, moist, sun, shade.

Fruit: Capsule.

An evergreen vine.

Gelsemium sempervirens (L.) Ait.

Bignonia sempervirens $\mathrm{L}$.

Range: $28,29,30$.

Site: Dry, well-drained, sun.

Fruit: Capsule.

An evergreen vine; flowers March-October; stems and branches often tangled and matted. Poisonous to livestock.

Stomach records: Bobwhite. Observations: Captive marsh rabbit.

Genista tinctoria L.

Range: 27.

Dyer's greenweed.

Site : Dry, well-drained, sun.

Fruit: Legume.

A small shrub; flowers June-July; introduced from Europe but naturalized in the region indicated; free from insects and disease; propagation is by seed.

Geobalanus oblongifolius, see Chrysobalanus oblongifolius.

Glabraria geniculata (Walt.) Britt.

Litsea geniculata (Walt.) B. and $\mathrm{H}$.

Pond spice.

Range: 25, 28, 29, 30 .

Site: Moist, sun.

Fruit: Drupe.

A large, much-branched shrub; flowers March-Aprll.

Gleditsia aquatica Marsh.

Range: 20, 25, 28, 29, 30 .

Site: Moist, sun.

Fruit: Legume, available August-September.

A large tree; flowers in July; sometimes forms large thickets in comparatively deep water; rarely attacked by insect pests; wood somewhat used for fence posts; propagation is by seed stratified and soaked in hot water before sowing in spring.

Gleditsia texana, see Gleditsia triacanthos.

Gleditsia triacanthos $\mathbf{L}$.

Range: 16, 20, 22, 23, 24, 25, 26, 27, 29, 30.

Waterlocust.

Site: Dry, well-drained, moist, sun.

Frult: Legume, available September-February. 

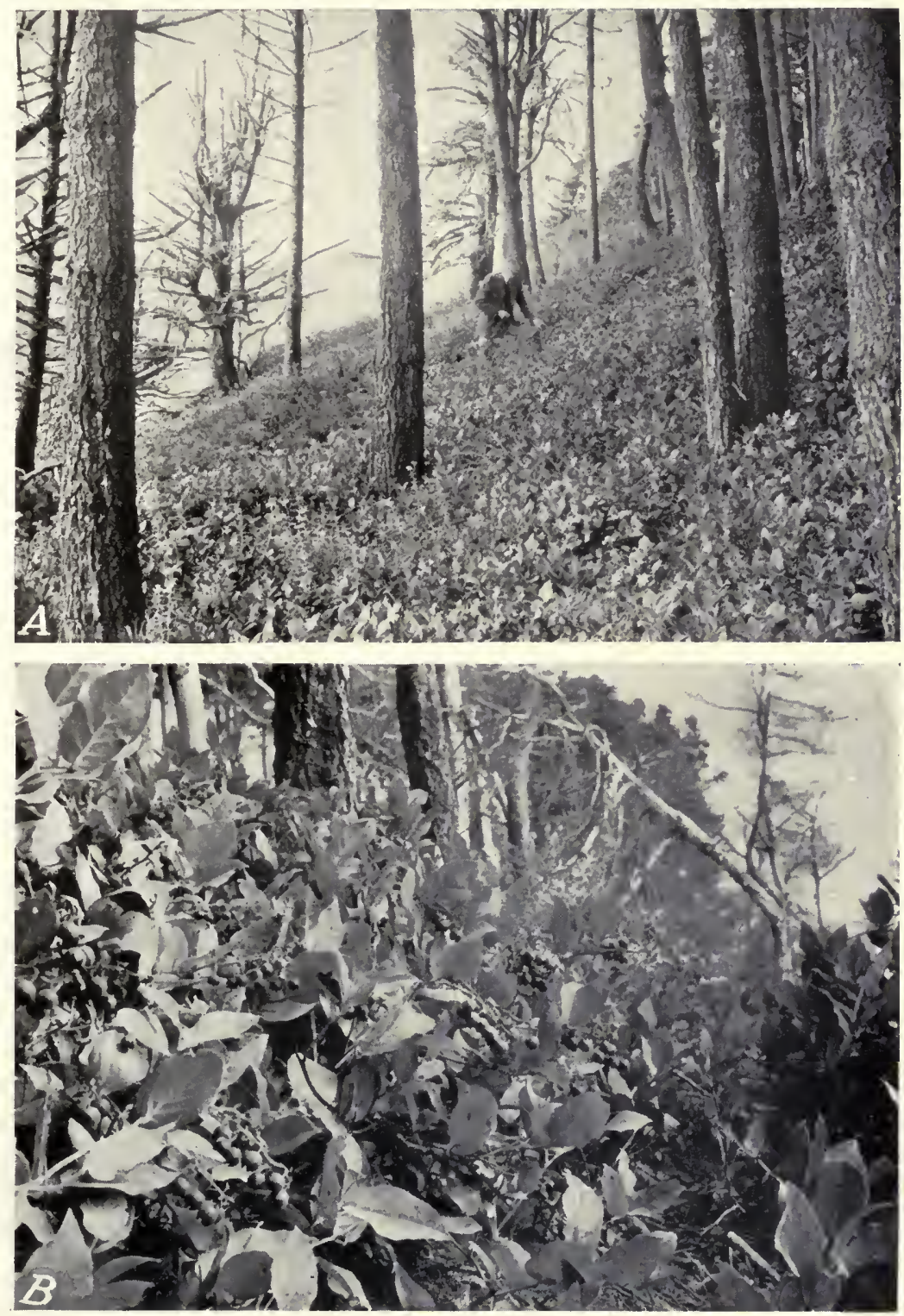

Gaultheria shallon: $A$, Effective stabilization of sand on the Oregon coast accomplished by a dense ground cover of salal. $B$, A near view of the fruit borne abundantly by the salal plants in $A$. These fruits are relished by man as well as by wildlife. 

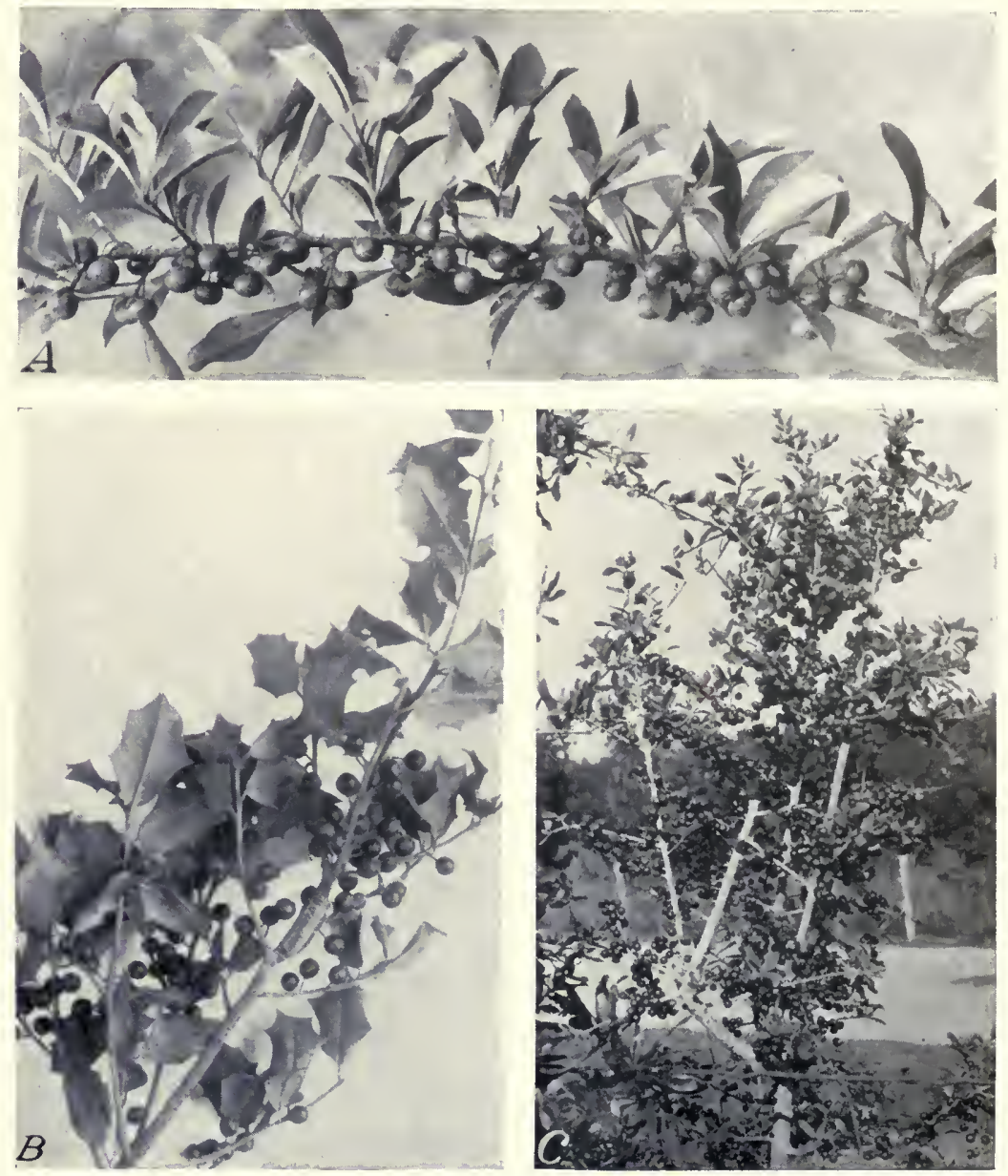

$A$, Ilex longipes. The fruit of this holly is produced in great abundance and is undoubtedly of some wildlife value. $B, I$, opaca. Fruiting branches of this dense-foliaged species find a ready market at Christmas time. The berries are relished by many kinds of birds. $C, 1$. vomitoria. Yaupon in the sandy soil of northern Florida. Its fruit, relished by birds and produced in great quantity, should assure it an important place in wildlife plantings. 
A iarge thorny tree; flowers May-July; foliage sparse; usually occurs on alluvial soils; very resistant to drought; somewhat tolerant of salinity; root system deep, widespreading or superficial; rapid growing, rather long-lived; wind-firm; free from disease and insects; badly injured by fire; widely cultivated; root nodules not formed; coppices freely ; grows in many kinds of solls; wood very durable, used commercially; easily transplanted; propagation is by seeds stratified and soaked in hot water before sowing in spring; about 3,000 seeds per pound, germination 73-90 percent, about 1,000 usable plants per pound of seed. A probable hybrid between this and $G$. aquatica has been described as $G$. texana Sarg. There is a thornless variety (var. inermis Pursh.)

Stomach records: Bobwhite, starling. Observations: White-tailed deer, snowshoe hare, cottontail rabbit, gray squirrel. Fruit greedily eaten by cattle.

Glossopetalon mionandrum, see Forsellesia mionandrum.

Glossopetalon nevadense, see Forsellesia spinescens.

Glossopetalon pungens, see Forsellesia pungens.

Glossopetalon spinescens, see Forsellesia spinescens.

Gordonia lasianthus (L.) Ellis.

Range: $29,30$.

Loblolly bay.

Site: Moist, sun.

Fruit: Capsule.

A large shrub to small or large tree; flowers in July; short-lived.

Grayia branđegei Gray.

Range: 9.

Spineless hop-sage.

Site: Dry, sun.

Fruit: Achene.

A small shrub. Considered a valuable winter forage for livestock.

Grayia polygaloides, see Grayia spinosa.

Grayia spinosa (Hook.) Moq.

G. polygaloides Hook. and Arn., Chenopodium spinosum Hook.

Spiny hop-sage.

Range: $7,8,9,10,12,13$.

Site: Dry, well-drained, moist, sun.

Fruit: Achene, available July-August.

A small, much-branched, spinose, stiff, monoecious or dioecious shrub; flowers April-May; may occur on alkaline soil.

Observations: Somewhat eaten in dry seasons by Oregon jack rabbit. Browsed by livestock and considered good forage for sheep and cattle.

Grossularia amara, see Ribes amarum.

Grossularia binominata, see Ribes binominatum.

Grossularia californica, see Ribes californicum.

Grossularia cognata, see Ribes cognatum.

Grossularia curvata, see Ribes curvatum.

Grossularia cynosbatii, see Ribes cynosbatii.

Grossularia divaricata, see Ribes divaricatum.

Grossularia hesperia, see Ribes hesperium.

Grossularia hirtella, see Ribes hirtellum.

Grossularia inermis, see Ribes inerme.

Grossularia irrigua, see Ribes irriguum.

Grossularia lasianthum, see Ribes leptanthum.

Grossularia leptantha, see Ribes leptanthum.

Grossularia lobbii, see Ribes lobbii.

Grossularia marshallii, see Ribes marshallii.

Grossularia menziesii, see Ribes menziesii.

Grossularia missouriensis, see Ribes missouriense.

Grossularia nivea, see Ribes niveum.

Grossularia oxyacantholdes, see Ribes oxyacanthoides. 
Grossularia parishii, see Ribes divaricatum.

Grossularia pinetorum, see Ribes pinetorum.

Grossularia quercetorum, see Ribes quercetorum.

Grossularla roezlil, see Ribes roezlii.

Grossularia rotundlfolia, see Ribes rotundifolium.

Grossularia sericea, see Ribes sericeum.

Grossularia setosa, see Ribes setosum.

Grossularia speciosa, see Ribes speciosum.

Grossularia velutina, see Ribes velutinum.

Grossularia victoris, see Ribes victoris.

Grossularia watsoniana, see Ribes vatsonianum.

Gulacum angustifolium, see Porlieria augustifolia.

Gutierrezia linearis Rydb.

Range: 15, 16.

Site: Dry, sun.

Fruit: Achene.

Turpentine weed.

A small shrub; flowers July-September.

Gutierrezia longifolia Greene.

Range: 9, 11, 13, 14, 16.

Turpentine weed.

Site: Dry, sun.

Fruit: Achene.

A small shrub; flowers in August.

Gyminda grisebachii, see Gyminda latifolia.

Gyminda latifolia Sw.

G. grisebachii Sarg.

Range : 17, 32 .

Site: Well-drained, sun.

Fruit: Drupe.

A large shrub to small tree; evergreen.

Gymnocladus dioica (L.) Koch.

Range: 19, 21, 22, 23, 24, 25, 27.

Kentucky coffeetree.

Site: Well-drained, sun.

winter

Fruit: Legume; available in September, persistent unopened through the

A large tree; ordinarily occurs in rich soil ; flowers May-June; root system deep, widespreading; root nodules not formed; wind-firm; wood very durable, used to some extent commercially; rarely attacked by insects or disease. Seed germination high but irregular and slow, vitality high ; 200-300 seeds per pound. Leaves poisonous to cattle, but cases of poisoning are infrequent, often happening when pods fall into drinking pools.

Gymnolomia tenulfolia, see Viguiera stenoloba.

Halesia spp.

Observations (in addition to specific records) : Gray squirrel.

Halesia carolina $\mathrm{L}$.

H. tetraptera L., Mohrodendron carolinum Britt.

Silverbell.

Range : 25, 27, 28, 29, 30 .

Site: Well-drained, sun, shade.

Fruit: Winged capsule.

A large shrub to small or large tree; flowers March-April; rarely attacked by insect pests; easily storm-damaged; very ornamental and much cultivated; propagation is by seed stratified and sown in spring or sown as soon as ripe.

Halesia diptera Ell.

Mohrodendron dipterum Britt.

Two-wing silverbell.

Range: 29, 30.

Site: Well-drained, moist, sun, shade.

Fruit: Winged capsule.

A small to large tree; flowers March-April ; propagation as above. 
Halesia monticola (Rehd.) Sarg.

Mountain silverbell.

Range: 27, 29.

Site: Well-drained, sun.

Frult: Winged capsule.

A large tree; flowers in May; rapid growing in cultivation; more vigorous and upright than $\boldsymbol{H}$. carolina.

Halesia parvifiora Michx.

Mohrodendron parviflorum Britt.

Range: 29, 30.

Site: Well-drained, sun, shade.

Fruit: Winged capsule, avallable August-September.

A small to large tree; flowers March-April. Possibly only a variety of $H$. carolina. Propagation as above.

Halesia tetraptera, see Halesia carolina.

Halliophytum hallil (Brandeg.) Johnst.

Tetracoccus hallii Brandeg., Securingea fasciculata hallii (Brand.) Jeps. Range: 10.

Site: Dry, sun.

Fruit: Capsule.

A small to large, dloecious, spreading shrub; flowers April-May; spinescent; leares fascicled; intricately branched but scarcely bushy.

Hamamelis macrophylla Pursh.

Range: 29, 30.

Southern witch hazel.

Site: Well-drained, sun.

Fruit: Capsule, available September-November.

A small to large tree; flowers December-February; produces stolonfferous shoots around the trunk; propagation is by seed stratified and sown in spring or as soon as ripe.

Hamamelis vernalls Sarg.

Iittle witch hazel.

Range : 25, 29.

Site: Well-drained, moist, sun.

Frult: Capsule.

A small to large shrub; occurs only on gravel; flowers January-March; thicket forming by means of stolons.

Observations: White-tailed deer.

Hamamelis virginiana $L$.

Range: $21,22,23,24,25,26,27,28,29$.

Site: Dry, well-drained, moist, sun, shade.

Fruit: Capsule, available August-December.

A large shrub to small or large tree; occurs in sandy and other soila; flowers August-December ; free from insects and disease; slow growing; thicket forming; will withstand city smoke; propagation is by seed stratified and sown in spring or as soon as ripe; seeds ordinarily take 2 years to germinate.

Stomach records: Ruffed grouse, bobwhite, ring-necked pheasant; white-tailed deer. Observations: Ring-necked pheasant; cottontail rabbit, beaver, whitetailed deer.

Havardia brevifolia, see Pithecolobium brevifolium.

Havardia pallens, see Pithecolobium brevifolium.

Hazardia cana, see Aplopappus canus.

Hazardía detonsa, see Aplopappus canus.

Hazardia serrata, see Aplopappus canus.

Hazardia squarrosus, see Aplopappus squarrosus.

Hedeoma incana, see Poliomintha incana.

Helianthus cernuus, see Flourensia cernua.

Helletta parvifolia (Gray) Benth.

Ptelea parvifolia Gray.

Range: 17.

Site: Dry, well-drained, sun.

Fruit: Samara, avallable in October.

A large shrub to small or large tree; evergreen; thicket forming; flowers April-May; occurs on limestone and other solls. 
Heliomeris tenuifolia, see Viguiera stenoloba.

Herpothamnus crassifolius, see Vaccinium crassifolium.

Hesperodoria scopulorum, see Aplopappus scopulorum.

Hesperopeuce mertensiana, see Tsuga mertensiana.

Heteromeles arbutifolia, see Photinia arbutifolia.

Heteromeles salicifolia, see Photinia arbutifolia.

Heyderia decurrens, see Libocedrus decurrens.

Hicoria alba, see Carya alba.

Hicoria aquatica, see Carya aquatica.

Hicoria buckleyi, see Carya buckleyi.

Hicoria carolinae-septentrionalis, see Carya carolinae-septentrionalis.

Hicoria cordiformis, see Carya cordiformis.

Hicoria fernowiana, see Carya myristicaeformis.

Hicoria floridana, see Carya floridana.

Hicoria glabra, see Carya glabra.

Hicoria laciniosa, see Carya laciniosa.

Hicoria leiodermis, see Carya leiodermis.

Hicoria microcarpa, see Carya microcarpa.

Hicoria minima, see Carya cordiformis.

Hicoria myristicaeformis, see Carya myristicaeformis.

Hicoria ovalis, see Carya ovalis.

Hicoria ovata, see Carya ovata.

Hicoria pallida, see Carya pallida.

Hicoria pecan, see Carya pecan.

Hicoria sulcata, see Carya laciniosa.

Hicoria texana, see Carya texana.

Hicoria villosa, see Carya villosa.

Hoffmanseggia microphylla Torr.

Range: 10.

Site: Dry, well-drained, sun.

Fruit: Legume.

A small to large shrub; flowers in April; stems rushlike, forming a broad, rounded bush; commonly occurs in sandy soils.

Holacantha emoryi Gray.

Crucifixion thorn.

Range: 10, 11.

Site: Dry, sum.

Fruit; Nutlike drupe.

A large dioecious, thorny, rigid, much-branched, nearly leafless shrub; fruiting clusters very dense.

Holodiscus spp.

Propagation of all spccies is by seed sown in the fall.

observations (in addition to specific records): Relished by Olympic wapiti.

Holodiscus discolor (Pursh) Maxim.

0ceanspray.

Spiraea discolor Pursh, Sericotheca discolor (Pursh) Rydb. Schizonotus discolor (Pursh) Raf.

Range: $1,2,4,5,12$.

Site: Dry, well-drained, sun.

Fruit: Follicle.

A large bushy shrub; flowers May-July; often pioneers in burned-orer areas. Var. microphyllus (Rydb.) Jeps. ( $H$. microphyllus Rydb., Sericotheca microphylla $R y d b$.$) , occurring in regions 4,12$, and 13 , is a dwarf form. 
Var. glabrescens (Heller) Jeps. ( $H$. glabrescens Heller, Sericotheca glabrescens (Greenm.) Rydb., S. obovata Rydb.), occurring in reglons 4,12 , and 13 , is a more spreading type.

Observations: Black-tailed deer. Of minor importance as browse for livestock.

Holodiscus dumosus (Nutt.) Heller.

Sericotheca dumosa (Nutt.) Rydb., Spiraea dumosa Nutt.

Range: $9,10,11,13,14$.

Site: Dry, well-drained, sun.

Fruit: Follicle.

A small to large, compact shrub; often forms large clumps.

Observations: Yosemite cony.

Holodiscus glabrescens, see Holodiscus discolor.

Holodiscus microphyllus, see Holodiscus discolor.

Holodiscus schaffneri (Rydb.) Standl.

Sericotheca schaffneri Rydb.

Range: 9, 11.

Site: Dry, sun.

A small shrub.

Hopea tinctoria, see Symplocos tinctoria.

Horsfordia alata (Wats.) Gray.

Range: 10.

Site: Dry, well-drained, sun.

Fruit: Dry carpel.

A large shrub; flowers April-December.

Horsfordia newberryl (Wats.) Gray. Abutilon newberryi Wats.

Newberry falsemallow.

Range: 10.

Site: Dry, sun.

Fruit: Dry carpel.

A small to large shrub with virgate branches; flowers April-May. Apparently not palatable to livestock.

Hosackia balsamifera, see Lotus stipularis.

Hosackia macrophylla, see Lotus stipularis.

Hosackia stipularis, see Lotıs stipularis.

Houstonia fasciculata Gray.

Range: 11, 17.

Site: Dry, sun.

Fruit: Capsule.

A small, spreading shrub.

Hudsonia ericoides $L$.

Range: 26, 27, 28, 29.

Gold-heather.

Site: Dry, well-drained, sun.

Fruit: Capsule.

A small, bushy evergreen shrub, often occurs on sandy or rocky soil; flowers in May; occurs mainly along the coast.

Hudsonia montana Nutt.

Range: 27.

Site: Dry, sun.

Fruit: Capsule.

A small, bushy evergreen shrub; very local in occurrence but probably once more widely distributed.

Hudsonia tomentosa Nutt.

Range: $23,24,26,27,28,29$.

Beach-heather.

Site: Dry, well-drained, sun.

Fruit: Capsule.

A small evergreen shrub; flowers May-July; occurs in sand; intricately branched and matted. 
Hugeria erythrocarpa (Michx.) Small.

Vaecinium erythrocarpum Michx., Oxycoccus erythrocarpus (Michx.) Pers. Range: 27.

Site: Dry, well-drained, sun, shade.

Fruit: Berry, available August-October.

A small to large strub; flowers, June-July; ordinarily occurs in acid soil. Hydrangea arborescens $\mathrm{L}$.

Range: $22,24,25,27,28,29,30$.

Wild hydrangea.

Site: Dry, well-drained, moist, shade.

Fruit: Capsule, available October-December.

A small to large, somewhat straggling shrub; flowers June-July and sometimes again in September; propagation is by seed stratified and sown in spring.

Observations: Wild turkey; white-talled deer. Reputed polsonous to livestock.

Hydrangea cinerea Small.

Range: 25, 27.

Ashy hydrangea.

Site: Well-drained, shade.

Frult: Capsule, avallable September-November.

A small to large shrub; flowers June-July.

Hydrangea quercifolia Bartr.

Range: 28, 29, 30.

Oakleaf hydrangea.

Site: Dry, well-drained, sun, shade.

Frult: Capsule.

A small to large spreading shrub; flowers in June.

Hydrangea radiata Walt.

Range: 27, 28.

Site: Dry, well-dralned, moist, shade.

Fruit: Capsule.

A small to large shrub; flowers June-July.

Hymenoclea monogyra Torr. and Gray

Range: 5, 10, 11.

Site: Dry, well-drained, molst, sun.

Fruit: Achene.

A small to large shrub; occurs in sandy and other soils; thicket forming; rapld growing; aggressive; leafier than $H$. salsola. Little browsed by livestock.

Hymenoclea pentalepis Rydb.

Range: 10.

Site: Dry, sun.

Fruit: Achene.

A small to large shrub; very similar to $H$. monogyra.

Hymenoclea salsola Torr. and Gray

Range: $9,10$.

Site: Dry, well-drained, moist, sun.

Fruit: Achene.

A small, spreading shrub; occurs on sandy and alkallne solls.

Hypericum spp.

Stomach records (in addition to specific records): Eleven species of birds, including bobwhite, ruffed grouse, and ring-necked pheasant, but nearly all species in this country are herbaceous and the records of utilization by wildlife may apply mostly to them.

Hypericum microsepalum, see Crookea microsepala.

Hypericum prolificum L.

Range: 22, 23, 24, 25, 27, 28, 29.

Site: Dry, well-dralned, sun, shade.

Fruit: Achene, available September-October.

A small shrub; flowers July-September; occurs on sandy and other calcareous soils ; foliage dense; free from insects and diseases; commonly occurs on eroded slopes; propagation is by seed or cuttings.

Hyptis emoryi Torr.

Range: 10, 11.

Site: Dry, sun.

Fruit: Nutlet.

Shrubby St. Johnswort.

White burrobrush.

all to large, compact shrub. 
Observations: Much visited by hummingbirds. Considered a fair to fairly good livestock browse.

Ilex spp.

Stomach records (in addition to specific records): Thirty-two species of birds including ruffed grouse, bobwhite and wild turkey; white-talled deer.

Observations: Nine species of birds.

Ilex ambigua, see Ilex montana.

Ilex beadlei, see Ilex montana.

Ilex bronxensis, see Ilex verticillata.

Ilex caroliniana, see Ilex montana.

Ilex cassine $\mathrm{L}$.

I. dahoon Walt., I. myrtifolia Walt.

Dahoon holly.

Range: 29, 30 .

Site: Well-drained, moist, sun, shade.

Fruit: Berry, avallable September-March.

A large shrub to small tree or rarely a large tree; evergreen; flowers in May; occurs on sandy and often acid soils.

Stomach records: Six species of birds; raccoon. Observations: Fish crow, redejed vireo.

Ilex coriacea (Pursh) Chapm.

I. lucida Torr. and Gray, Prinos coriacea Pursh.

Tall inkberry.

Range: $28,29,30$.

Site: Well-drained, molst, sun.

Fruit: Berry, avallable September-October.

A small to large shrub, or rarely a small to large tree; evergreen; flowers April-May.

Ilex dahoon, see Ilex cassine.

Ilex decidua Walt.

Range: $16,17,20,25,28,29,30$.

Site: Dry, well-drained, moist, sun, shade.

Fruit: Berry, available September-March.

A large shrub to small or large tree; flowers April-May.

Stomach records: Nine species of birds, including bobwhite.

Ilex dubia, see Ilex montana.

Ilex glabra (L.) Gray.

Range : $26,27,28,29,30$.

Site: Dry, well-drained, moist, sun, shade.

Fruit: Berry, available July-June.

A small evergreen shrub; occurs on sandy and other soils; free from insects and diseases; will sprout after fire.

Stomach records: Flfteen species of birds, including bobwhite and wild turkey. Observations: Mockingbird, hermit thrush; capitive marsh rabbit. An important honey plant.

Ilex laevigata (Pursh) Gray.

Range: $26,27,28,29$.

Smooth winterberry.

Site: Moist, sun.

Fruit, Berry, available September-January.

A small to large shrub or rarely a large tree; flowers May-June; often occurs on acld soil.

Ilex longipes Chapm. (pl. 16, $A$ ).

Range: $20,27,28,29,30$.

Site: Dry, sun.

Fruit: Berry, available September-October.

A small to large shrub or small tree; branches widespreading, but not dense.

Ilex luclda, see Ilex coriacea.

Ilex montana Torr. and Gray.

Mountaln holly.

I. monticola, I. caroliniana (Walt.) Trel., not mill. Gray, I. ambigua (Michx.) Chapm., I. beadlei Ashe, I. dubia B. S. P.

Range: 25, 27, 28, 29.

Site: Dry, well-drained, moist, sun.

Fruit: Berry, available October-November.

$130186^{\circ}-39-10$ 
A small to large shrub or small to large tree; flowers in May; 1,375 berries per pound; germination of seed about 50 percent.

Stomach records: White-tailed deer.

Ilex monticola, see Ilex montana.

Ilex myrtifolia, see Ilex cassine.

Ilex opaca Alt. (pl. 16, $B$ ).

Range: $20,25,27,28,29,30$.

American holly.

Site: Dry, well-drained, moist, sun, shade.

Fruit: Berry, available August-June.

A small to large evergreen tree; occurs on sandy, loam, gravel, clay, and other soils; flowers April-June; taproot deep and well developed, especially with age; easy to transplant when young; slow growing, somewhat long-lived; free from insects and diseases; wood of importance commercially; fruits 5 to 8 years after planting; embryo of seed rudimentary, good germination obtained when seeds are treated with a normal solution of potassium hydroxide for 5 minutes, then a normal solution of hydrochloric acid, washed and sown, and watered as needed with a 5-percent solution of glucose; 31,000 seeds per pound, germination 20 percent, about 1,000 usable plants per pound of seed.

The berries are borne on pistillate trees or occasionally on trees which may be monoeclous. In growing hollies from seed, the proportion of pistillate to staminate trees produced is about 1 to 10 . The plants ordinarily flower from 5 to 12 years after planting, but until then the two kinds of plants cannot be distinguished. Wild seedlings ordinarily are not satisfactory for transplanting because of the extensive root system developed at an early age. Seed germination extends at the very least over 1 year, and nothing is to be gained by fall planting since seeds sown in spring germinate just as quickly as if sown 6 months earlier. Propagation by cuttings results in forms true to type. All staminate forms should not be destroyed since pollination is necessary for the formation of the fruit.

Stomach records: Eighteen species of birds, including bobwhite and wild turkey; white-tailed deer. Observations: Refused by captive marsh rabbit.

Ilex verticillata (L.) Gray.

Range : $23,24,25,26,27,28,29,30$.

Site: Dry, well-drained, moist, sun, shade.

Fruit: Berry ; available September-October, persistent or not.

A small to large shrub or rarely a small tree; flowers June-July; free from Insects and diseases; easily transplanted; 2,000 berries per pound. Several minor varieties have been described.

Val. tenuifolia Wats., ( $I$. bronxensis Britt.) has solitary fruit and occurs in the northeastern part of the species range.

Stomach records: Sixteen species of birds, including ruffed grouse, bobwhite, and sharp-talled grouse. Observations: Ten species of birds, including ringnecked pheasant.

Ilex vomitoria Ait. (pl. 16, $C$ ).

Yaupon.

Range: $20,28,29,30$.

Site: Dry, well-drained, sun.

Fruit: Berry; available September-October, persistent or not.

A large evergreen shrub; occurs in sandy and other soils; flowers in May.

Stomach records: Seven species of birds, including bobwhite.

Illicium floridanum Ell.

Range: 29, 30 .

Site: Well-drained, moist, sun.

Fruit: Drupelike.

A large evergreen shrub. Reputed to be poisonous to livestock.

Illicoides mucronata, see Nemopanthus mucronata.

Indigofera sphaerocarpa Gray.

Range: 10.

Site: Dry, sun.

Fruit: Legume.

A small shrub. 
Ingenhouzia triloba, see Thurberia triloba.

Inodes texana, see Sabal texana.

Ioxylon pomiferum, see Maclura pomifera.

Isocoma acradenius, see Aplopappus acradenius.

Isocoma scopulorum, see Aplopappus scopulorum.

Isomeris arborea Nutt.

Bladderpod.

Range: 5, 10.

Site: Dry, sun.

Fruit: Capsule.

A small shrub; flowers February-May; usually occurs on alkaline solls ; sometimes herbaceous.

Itea virginica $\mathrm{L}$.

Range: 25, 28, 29.

Sweetspire.

Site: Well-drained, moist, sun, shade.

Fruit: Capsule.

A large shrub; flowers May-June; usually occurs along the Coast; propagation is by seed sown under glass in spring.

Jamesia americana Torr. and Gray.

Cliffbush.

J. americana californica Jeps., Edwinia americana (Torr. and Gray) Heller, E. californica Small.

Range: $4,10,11,12,13,14$.

Site: Dry, well-drained, moist, sun.

Fruit: Capsule.

A small shrub; flowers May-July; commonly occurs on stream banks; in cultivation.

Janusia gracilis Gray.

Range: 10, 11, 16, 17.

Site: Dry, sun.

A vine.

Fruit: Samara.

Jatropha cardiophylla (Torr.) Muell.

Range: 10 .

Site: Dry, sun.

A small shrub.

Fruit: Capsule.

Jatropha carthaginensis, see Manihot carthaginensis.

Jatropha multifida $\mathbf{L}$.

Range: 17.

Site: Dry, well-drained, sun.

Fruit: Capsule.

A large shrub to small tree.

Jatropha spathulata (Orteg.) Muell.

Mozinna spathulata Orteg.

Sangre de drago.

Range: 11.

Site: Dry, Well-drained, sun.

Fruit: Capsule.

A small to large shrub; stems flexible and tough.

Juglans spp.

Walnuts.

Most species are commonly attacked by fungi and insects but none is very seriously damaged.

Stomach records (in addition to specific records): Four species of birds; Arizona gray squirrel, walnut rock squirrel. Observations: Two species of birds.

Juglans californica Wats.

Range : 3, 5, 10.

California walnut.

Site: Well-drained, moist, sun.

Fruit: Nut.

A large shrub; resistant to walnut yellows; 30 seeds per pound.

observations: California mule deer. 
Juglans cinerea $\mathrm{L}$.

Range: $18,19,21,22,23,24,25,26,27,28$.

Butternut.

Site: Well-drained, sun.

Frult: Nut, available September-November.

A large monoecious tree; root system deep with a deep taproot, but rather widespreading; rapid growing, especially when young; short lived; foliage much injured by defoliating insects ; very susceptible to fire damage; wind-firm, but easily storm damaged; ordinarily occurs on rich soils but will grow on somewhat poorer and drier soils than J. nigra; wood somewhat used commercially; heartwood durable; propagation is by seed stratified in the fall and sown in spring; $16-40$ seeds per pound, germination 80 percent; somewhat difficult to transplant; sugar may be produced from this species as in sugar maple.

Observations: White-tailed deer, cottontail rabbit, red squirrel, and other squirrels.

Juglans glabra, see Carya glabra.

Juglans hindsil Jeps.

J. californica hindsii Jeps.

Hinds walnut.

Range: 1, 3, 4 .

Site: Well-drained, sun.

Fruit: Nut.

A large tree; not resistant to walnut yellows; 30 seeds per pound.

Juglans major (Torr.) Heller.

$J$. rupestris major Torr.

Range: 11, 16, 17.

Site: Well-drained, sun.

Fruit: Nut.

A small or large shrub to large tree; taproot much developed, especially in early stages; at first rapid growing, later slower; long-lived; wood very durable in contact with soil; fruit borne abundantly every 2 or 3 years; 45 seeds per pound, germination $30-50$ percent; occurs in many kinds of soil.

Observations: Much eaten by squirrels and other rodents.

Juglans myristicaeformis, see Carya myristicaeformis.

Juglans nigra $\mathrm{L}$.

Range: $18,19,20,21,22,23,24,25,26,27,28,29,30$.

Arizona walnut.

Site: Well-drained, sun, shade.

Fruit: Nut, available October-November.

A large monoecious tree; root system deep, widespreading; will not grow on dry or poor soils; rapid growing, especially when young; long-lived; wind-firm; fire resistant; foliage much attacked by caterpillars; wood injured by borers; generally free from fungus attacks; wood of great commercial value, very durable; begins bearing at 10 to 15 years of age; propagation is by seeds stratified and sown in spring; about 25 seeds per pound, germination $90-95$ percent; much cultivated.

Observations: White-tailed deer, red squirrel, and other squirrels. Not palatable to cattle.

Juglans ovata, see Carya ovata.

Juglans rupestris Engelm.

J. whippleana Torr.

Range: 11, 14, 16, 17, 19, 20, 29.

Site: Dry, well-drained, moist, sun.

Fruit: Nut.

A small to large shrub to small or rarely a large tree; seedlings with a deepgrowing taproot, fairly rapid growing; occurs commonly on limestone soils; may often form thickets; often branched to the base; fruit generally borne in abundance every 2 or 3 years; 75 seeds per pound. What was formerly considered merely a western form of this species is here treated as $J$. major, although it is often given only varietal rank and intermediate forms exist.

Observations: Rock squirrel ; favorite food of Huachuca squirrel.

Juglans whippleana, see Juglans rupestris.

Juniperus spp.

Junipers.

Evergreen, commonly dioecious, or rarely monoecious trees or shrubs; fruit a berrylike cone maturing in 1 to 3 seasons. Some forms are of value commer- 
cially but all species are important because of their ability to grow on dry, barren slopes and exposed situations. Nearly all junipers are slow growing; propagation is by seed stratified at $32^{\circ}-50^{\circ} \mathrm{F}$., $30-60$ days before planting in spring. Most are secondary hosts for the cedar apple rust.

Stomach records (in addition to specific records) : Twenty-six species of birds, including bobwhite, ruffed grouse, and sharp-tailed grouse; armadillo, gray fox, Gila chipmunk, black-tailed deer, plains white-tailed deer. Observations (in addition to specific records: Twenty-four species of birds, including Merriam's turkey, Mearn's quail, northern, prairie, and Columbian sharp-tailed grouse; coyote, Oregon gray fox, cliff chipmunk, opossum, rock squirrel, Arizona gray fox, Texas plains coyote, San Juan coyote; much eaten by New Mexico black bear, Say chipmunk, Utah chipmunk, Couch rock squirrel; berries a staple food of mule deer; an emergency browse of mule deer.

Juniperus ashei, see Juniperus mexicana.

Juniperus barbadensis, see Juniperus lucayana.

Juniperus californica Carr.

Range: 1, 3, 4, 10 .

Californla juniper.

Site: Dry, sun.

Fruit: Berry, available all year round.

A large shrub.

Observations: California mule deer.

Juniperus communis $\mathbf{L}$.

Dwarf juniper.

Range: 1, 4, 8, 9, 11, 12, 13, 14, 15, 18, 19, 21, 22, 23, 24, 25, 26, 27.

Site: Dry, well-drained, molst, sun.

Fruit: Berry; available September; persistent all year round.

A small to large shrub, or even a small tree, very rarely a large tree; evergreen; occurs on sandy and other soils; usually monoecious, rarely dioeclous; thrives on almost any soils; very slow growing; long-lived; wood exceptionally durable, not used commercially; fruit maturing the third year, persistent 1 to 2 years after maturity, of some importance commercially; $17,000-30,000$ seeds per pound.

Var. depressa Pursh., occurring in the northeastern United States, rarely exceeds 3-4 feet in height. Var. montana Ait. (J. sibirica Burgsd.), is of more general distribution; a high mountain form usually less than 3 feet in height. Var. jackii Rehd. is a prostrate western form. A fourth form is known in the high mountains of Japan.

Stomach records: Nine species of birds, including ruffed grouse, bobwhite, sharp-tailed grouse, Hungarian partridge, and ring-necked pheasant; this and $J$. horizontalis composed 1.6 percent of winter food of northern sharp-tailed grouse in Quebec and Ontario. Observations: Twenty-two species of birds, including bobwhite and Hungarian partridge; many small mammals; white-tailed deer, moose.

\section{Juniperus erythrocarpa Cory.}

Range: 11.

Site: Dry, well-drained, sun.

Fruit: Berry, avallable in December.

A small evergreen tree.

Juniperus flaccida Schlecht.

Sabina faccida (Schlecht.) Lewis.

Drooping juniper.

Range: 11, 17.

Site: Dry, well-drained.

Fruit: Berry; mature in September of the second season; long persistent.

A small to large, dioecious, evergreen tree; occurs on sandy and other soils; slow growing, long-lived; wood very durable, somewhat used locally.

Juniperus gymnocarpa (Lemmon) Cory.

J. occidentalis gymnocarpa Lemmon.

Range: 11, 13, 14, 16.

Site: Dry, sun.

Fruit: Berry, available August-December.

A large evergreen tree.

Red-frulted junlper. 
Juniperus horizontalis Moench. (pl. 17, A).

Range : 12, 15, 18, 21, 23, 24, 26, 27.

Site: Dry, well-drained, moist, sun.

Fruit: Berry, available all year round.

A small evergreen shrub; occurs on sandy and other soils ; forms dense mats.

Stomach records: Sharp-tailed grouse; this and $J$. communis composed 1.6 percent of winter food of northern sharp-tailed grouse in Quebec and Ontario. Observations: Sparingly browsed by moose, northern white-talled deer.

Juniperus knightii, see Juniperus utahensis.

Juniperus lucayana Britt.

J. barbadensis L., Sabina barbadensis (L.) Small.

Southern red cedar.

Range: 29, 30.

Site: Moist, sun, shade.

Fruit: Berry, available all year round.

A small to large, nsually dioecious, evergreen tree; root system shallow; slow growing, long-lived; wood very durable, much used commercially; in cultivation.

Juniperus megalocarpa Sudw.

J. utahensis megalocarpa Sudw.

Big-berry juniper.

Range: 9, 11, 14.

Site: Dry, well-drained, sun.

Fruit: Berry, ripe September-October of the second season.

A large, dioecious, evergreen tree; occurs in sandy, loam, gravel, and other soils; slow growing, long-lived.

Juniperus mexicana Spreng.

J. sabinoides (H. B. K.) Nees, Sabina sabinoides Small.

Mountain cedar.

Range: 11, 16, 17, 20.

Site: Dry, well-drained, sun.

Fruit: Berry, available September of the first season.

A small to large evergreen tree; occurs on sandy and other poor soils, often limestone; wood very durable, much used locally.

$J$. ashei Buch., occurring along the White River in the Ozarks, in northwestern Arkansas, and southwestern Missouri, as well as in the Arbuckle Mountains of Oklahoma, has been said to be the same species as $J$. mexicana. There still seems to be considerable doubt whether the two are synonymous. The large break in the distribution of the two forms and the fact that $J$. ashei has been little studied make it impossible to state with definiteness whether the two forms are distinct or not.

Both forms are claimed to be resistant to the cedar apple rust; both fork near the base, thus possessing sereral boles. The fruits of $J$. ashei are much fleshier and twice as large as J.virginiana. J. ashei was in the fall of 1936 found to be much eaten by many songhirds, more notably robins. These birds succeeded in stripping almost the entire crop of seeds produced by these species throughout the Ozarks.

Juniperus monosperma (Engelm.) Sarg. (pl. 17, $B, C$ ). Cherrystone juniper.

J. mexicana monosperma Cory, J. occidentalis monosperma Engelm., Sabina monosperma (Engelm.) Rydb.

Range : $8,9,11,13,14,16,25$.

Site : Dry, well-drained, sun.

Fruit: Berry; available in September; persistent all year.

A large shrub to small tree; evergreen; dioecious, rapid growing for a juniper, long-lived; wood of value and much used locally for posts and fuel; usually several trunked.

Stomach records: Four species of birds. Observations: Four species of songbirds, Gambel quail; coyote, fox, raccoon, rock squirrel; extensively eaten by Hopi chipmunk; deer. Browsed to some extent by goats.

Juniperus occidentalis Hook. (pl. 18, A).

Western juniper.

Sabina occidentalis (Hook) Ant.

Range: $3,4,5,6,7,8,12$.

Site: Dry well-drained, sun.

Fruit: Berry ; available September of the second season; persistent all year round.

A small to large, dioecious, evergreen tree; slow growing and very long-lived; apparently unable to exist in close formation; grows on extremely sterile granite or gravels; regenerative powers remarkable. 

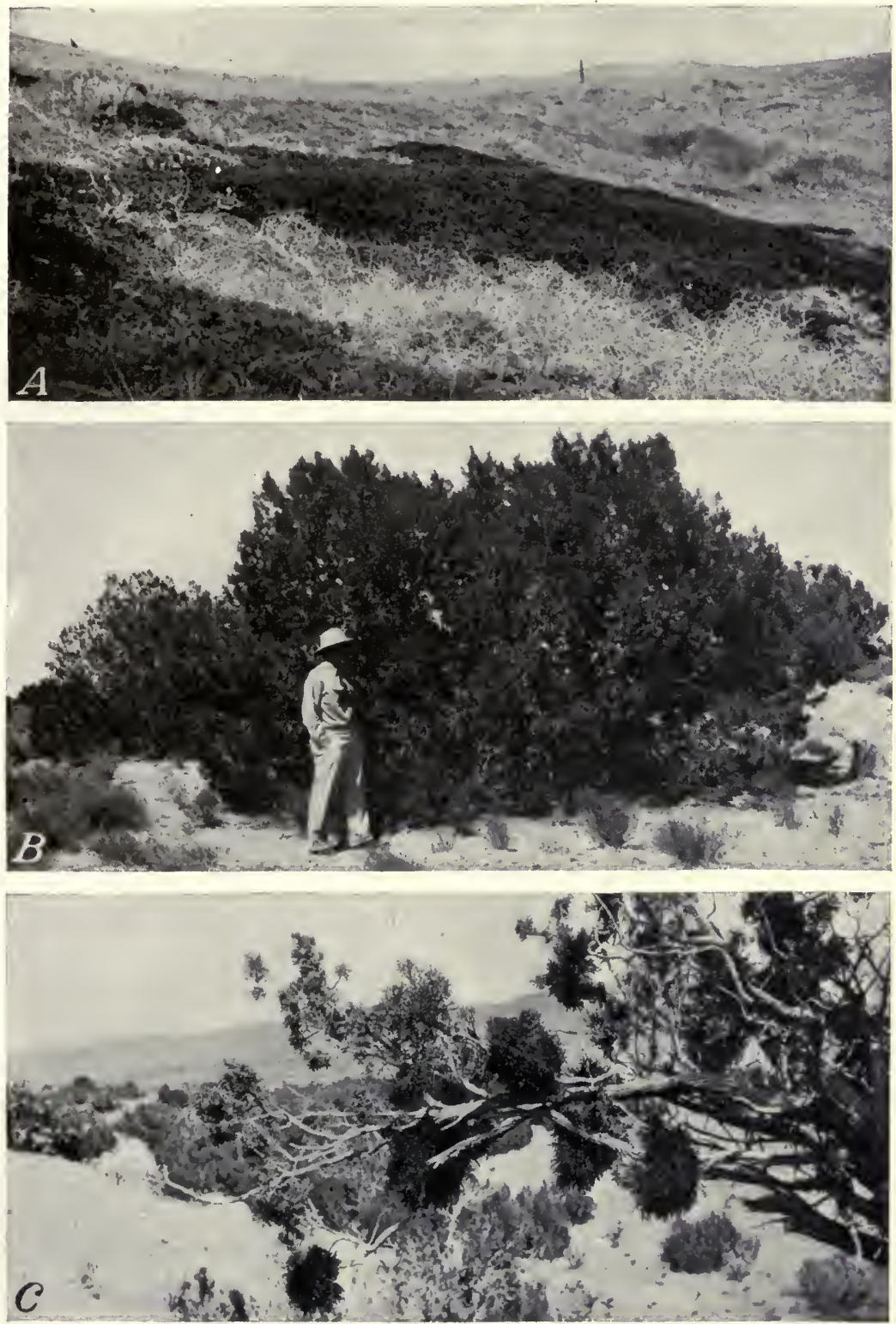

A, Juniperus horizontalis. Like other junipers, this species can grow on very difficult sites, but develops slowly. The mat-forming habit enhances its value as soil cover. $B, J$. monosperma. As with other southwestern junipers, this form provides excellent cover for soil and wildlife and an important food for birds and mammals. $C, J$. monosperma. The cherrystone juniper, besides itself producing valuable wildlife food, often serves as host to a mistletoe that bears a berry very attractive to small birds. 

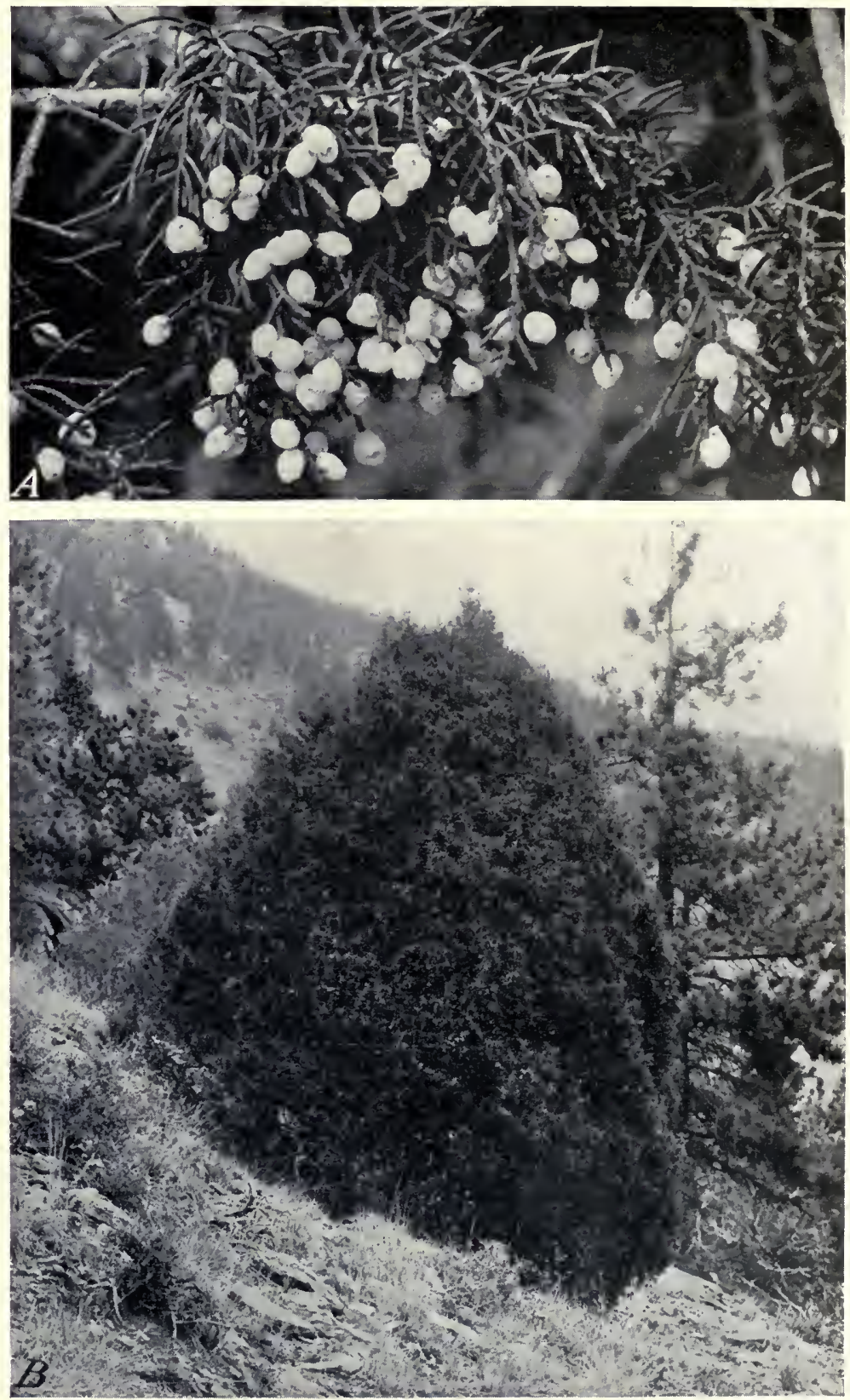

A. Juniperus occidentalis. The fruit of the western juniper is very similar in appearance to that of many others. The berries of all species appear to be much utilized by wildlife, although specific records are often lacking. $B, J$. scopulorum. Dense foliage and the ability to thrive in poor soils are valuable erosioncontrol characters common to most junipers. The fruits of all junipers are relished by many mammals as well as by a host of birds. (Photograph by Department of the Interior.) 
Observations: Pinyon jay, Townsend solitaire; of slight importance as browse for mule deer.

Juniperus pachyphloea Torr.

Alligator juniper.

$J$. mexicana pachyphloea Torr., Sabina pachyphloea (Torr.) Lewis.

Range: 11, 14, 17.

Site: Dry, well-drained, sun.

Fruit: Berry, available September-December.

A small to large, dioecious, evergreen tree; seasoned wood durable, used locally; slow growing, long-lived; fruit matures slowly and remains in good condition either on or off the tree for a considerable period.

observations: Wild turkey; New Mexico black bear, Couch rock squirrel; extensively eaten by gray fox; deer; considered of first importance as food for big game in New Mexico. Eaten by all classes of livestock.

Juniperus pinchotil Sudw.

Sabina pinchotii (Sudw.) Lewis.

Red-berry juniper.

Range: 11, 16, 20 .

Site : Dry, well-drained, sun.

Fruit: Berry, available all year round.

A large shrub to small or large tree; evergreen; coppices freely when cut; wood durable but soft; very local.

Juniperus sabinoides, see Juniperus mexicana.

Juniperus scopulorum Sarg. (pl. 18, $B$ ).

Rocky Mountain red cedar.

Sabina scopulorum (Sarg.) Lewis.

Range: $2,6,7,9,11,12,13,14,15,16$.

Site : Dry, well-drained, sun.

Fruit: Berry; ripening the second season, available all year round.

A large shrub to small or large tree; evergreen; dioecious, slow growing, long-lived; 20,000-30,000 seeds per pound.

Stomach records: Townsend's solitaire; bighorn.

Juniperus sibirica, see Juniperus communis.

Juniperus utahensis (Engelm.) Lemmon.

Utah juniper.

$J$. californica utahensis Engelm., J. knightii Nels., Sabina utahensis

(Engelm.) Rydb.

Range: 8, 9, 10, 11, 13, 14.

Site: Dry, well-drained, sun.

Fruit: Berry; available in September, persistent all year.

A small to large, evergreen tree; $6,000-7,000$ seeds per pound.

Stomach records: Avocet; Utah cliff chipmunk, black-tailed deer. Observations: Deer. Eaten to some extent by goats.

Juniperus virginiana $\mathrm{L}$.

Sabina virginiana (L.) Antoine.

Eastern red cedar.

Range : 18, 20, 21, 22, 23, 24, 25, 26, 27, 28, 29.

Site: Dry, well-drained, molst, sun.

Fruit: Berry ; available September-November, persistent all year round.

A large evergreen tree; at first deep rooted, but root system becomes more shallow with age; thrives in many kinds of soil, including limestone, dolomitic, and rarely granitic and siliceous soils; slow growing and long-lived; easily killed by fire; attacked by fungi; wood very durable, much used commercially; 18,000-30,000 seeds per pound, germination ordinarily 35-70 percent; from berries frozen in ice 21 days, seeds germinate in 35 days to 56 percent; resists grazing well; very drought resistant; notable secondary host to cedar apple rust; some 30 varieties distinguished in cultivation.

Stomach records: Twenty-nine species of birds including bobwhite; oppossum.

Observations: Fifty-two species of birds including bobwhite, prairie sharptailed grouse, ring-necked pheasant, and mourning dove; cottontail rabbit, moose.

Kalmia sp.

Observations (in addition to specific records) : Ruffed grouse.

Kalmia angustifolia $\mathrm{L}$.

Narrow-leaved laurel.

Range : 24, 26, 27, 28, 29 .

Site. Well-drained, moist, sun, shade.

Fruit: Capsule.

A small evergreen shrub; usually occurs on acid soil ; flowers June-July.

Stomach records: Ruffed grouse. Polsonous to sheep and cattle. 
Kalmia carolina Small.

Range: 27, 28, 29.

Wicky.

Site: Well-drained, moist, sun, shade.

Fruit: Capsule.

A small evergreen shrub; flowers June-July; occurs on acid soil.

Kalmia cuneata Michx.

Range: 29,30 .

White wicky.

Site : Moist, sun.

Fruit: Capsule.

A small evergreen shrub; flowers Aprll-May; occurs in acld swamps.

Kalmia glauca, see Kalmia polifolia.

Kalmia hirsuta Walt.

Kalmiella hirsuta (Walt.) Small.

Range: 29, 30.

Site: Well-drained, molst, sun, shade.

Fruit: Capsule.

A small evergreen shrub; flowers May-August; occurs in sandy and other acid soils.

Kalmia latifolia L. (pl, 19).

Range: $24,25,26,27,28,29,30$.

Mountain-laurel.

Site: Dry, well-drained, moist, sun, shade.

Fruit: Capsule, available in September.

Usually a small to large shrub, more rarely a small tree, or very uncommonly a large tree; evergreen; occurs in sandy and other acid soils; free from insects and diseases; many cultivated forms are known; nelther the specles nor the varieties thrive on clay or limestone soils:

Stomach recorls: Ruffed grouse; white-tailed deer. Observations: Ruffed grouse; an important winter food of white-tailed deer but toxic to them if taken in great quantities to the exclusion of other foods. Leaves poison sheep and cattle, which avoid it unless other forage is poor. Fatalities from honey made from this plant are on record.

Kalmia microphylia (Hook.) Heller.

$\bar{K}$. glauca microphylla Hook.

Range: 4, 12, 13 .

Site: Well-drained, sun.

Fruit. Capsule.

A small evergreen shrub; flowers June-August.

Kalmia polifolia Wang.

K. glauca Ait.

Pale-laurel.

Range: $4,12,23,24,26,27$.

Site: Moist, sun, shade.

Fruit: Capsule.

A small, straggling, evergreen shrub; flowers May-July; usually occurs on acid soils. Very poisonous to livestock.

Kalmiella hirsuta, see Kalmia hirsuta.

Karwinskia spp.

Stomach records (in addition to specific records): Antelope jack rabbit (?), gray-sided jack rabbit (?).

Karwinskia glandulosa, see Karwinskia humboldtiana.

Karwinskia humboldtiana (Roem. and Schult.) Zucc.

Coyotillo.

$K$. parvifolia Rose, $K$. glandulosa Zucc., Rhammus humboldtiana Roem. and

Schult., R. maculata Sesse.

Range: 11, 16, 17.

Site: Dry, sun.

Fruit: Berry ; available in October, commonly persistent.

A smali to large shrub; easily transpianted by root divisions. Seeds of this species are highly toxic to all domestic animais as well as children; leaves only slightly so; the flesh of the berry is apparently not as poisonous.

Karwinskia parvifolia, see Karwinskia humboldtiana. 
Koeberlinia spinosa Zucc.

Range : 11, 16, 17.

Allthorn.

Site: Dry, sun.

Fruit: Berry, avallable in September.

A small to large shrub, or rarely, a small to large tree; much branched, almost leafless; flowers May-June; extremely spiny; difficult to transplant; thicket forming.

Observations: Scaled quail, jack rabbit.

Krameria spp.

Observations (in addition to specific records): Mountain sheep.

Krameria canescens, see Krameria grayi.

Krameria glandulosa (MacBr.) Rose and Paint.

$K$. parvifolia glandulosa $\mathrm{MacBr}$.

Range ratany.

Range: 10, 11, 16.

Site: Dry, sun.

Fruit: Pod.

A small, much-branched, somewhat tralling shrub; flowers July-August and October-November; occurs in the hottest and driest parts of gravelly mesas; seed abundantly produced. A valuable forage for stock; grazing assists in spreading the burlike fruits.

Krameria grayi Rose and Paint.

$K$. canescens Gray, not Willd.

Chacate.

Range: $10,11,17$.

Site: Dry, sun.

Fruit: Pod.

A small, thorny, spreading shrub; densely and intricately branched; occurs on sandy and rocky soils; parasitic on roots of varlous associated woody plants. Krameria parvifolia Benth.

Range: 10, 11, 17.

Pima ratany.

Site: Dry, sun.

Fruit: Pod.

A small, rigid, often spinose shrub; parasitlc on the roots of Parkinsonia microphylla.

Krameria ramosissima (Gray) Wats.

K. parvifolia ramosissima Gray.

Range: 11, 17.

Site: Sun.

Fruit: Pod.

A small, spiny, rigid, much-branched shrub; flowers April-May.

Kraunhia frutescens, see Wisteria frutescens.

Kraunhia macrostachya, see Wisteria macrostachya.

Kunzia glandulosa, see Purshia glandulosa.

Kunzla tridentata, see Purshia tridentata.

Lantana aculeata, see Lantana camara.

Lantana camara $\mathbf{I}$.

L. aculeata $\mathrm{I}$.

Iantana.

Range: 10, 17, 20, 29, 30.

Site: Well-drained, sun.

Fruit: Drupe, available August-September.

A small to large, thorny shrub; occurs only on sandy soils; resistant to drought; apparently long-lived; the Arizona locality appears to be one where the plant was introduced not by man but by birds; very showy, much cultivated. Considered poisonous to sheep and cattle but shunned by them.

Lantana involucrata $\mathrm{L}$.

$L$. velutina Mart. and Gal., $\boldsymbol{L}$. odorata berlandieri Torr.

White-flowered lantana.

Range: 17,30 .

Site: Dry, well-drained, sun.

Fruit: Drupe.

A small to large, much-branched shrub with willowlike stems; occurs in sandy and other soils. 
Lantana lippioides, see Lippia geminata.

Lantana macropoda Torr.

Range: 11, 17, 20.

Site: Dry, well-drained, sun.

Fruit: Drupe.

A small shrub.

Lantana velutina, see Lantana involucrata.

Larix spp.

Larches.

Dioecious, deciduous trees, nine of which are known, three occurring in North America; propagation is by seed sown in spring.

Stomach records (in addition to specific records): Three species of birds, including ruffed gronse; plains white-tailed deer. Observations (in addition to specific records): Five species of birds, including Franklin grouse; Olympic black bear; rarely cut for building material, not food, by beaver.

Larix americana, see Larix laricina.

Larix laricina (Du Roi) Koch.

Tamarack.

L. americana Michx.

Range: $22,23,24,26,27$.

Site: Well-drained, moist, sun.

Fruit: Cone; mature the autumn of the first season, seeds shed during fall and winter, cones persistent 1 or 2 years longer.

A large tree; root system shallow and spreading on wet sites, deeper on drier sites; rapid growing until 35 to 45 years old, then slower on ordinary sites, or on poor sites generally slow growing; intolerant of shade; not fire resistant; susceptible to the attacks of the larch sawfiy; very old trees produce less seed and irregularly ; 90,000 seeds per pound ; wood hard, of importance commercially ; quite intolerant of drier soils.

Stomach records: Four species of birds, including ruffed grouse and northern sharp-tailed grouse. Observations: Eight species of birds, including sprnce grouse, northern sharp-tailed grouse, emergency food of prairie sharp-tailed grouse; snowshoe hare, porcupine, red squirrel; casually browsed by northern white-tailed deer.

Larix lyallii Parl.

Alpine larch.

Range: 4, 12.

Site: Dry, well-drained, sun.

Fruit: Cone; ripens in August of the first season; seeds shed at once, cones soon falling.

A large, long-lived tree; wood hard, tough, heavy, somewhat used commercially.

Stomach records: Plains white-tailed deer.

Larix occidentalis Nutt.

Range : 4, 12.

Site: Dry, well-drained, moist, sun.

Fruit: Cone; mature in August-September of the first season; seeds soon shed, cones soon falling.

A large tree; rapid growing only in juvenile stages; long-lired; grows best in well-drained soils; intolerant of shade, especially on dry soils ; resistant to fire after the pole stage; generally free from insects and diseases; rood rery heary, rery durable, and of value commercially; prolific seeder in good years, but sterile periods often occur for 1 or 2 seasons; has not been successful as an ornamental in the East; $100,000-150,000$ seeds per pound, germination 19-30 percent.

stomach records: Plains white-tailed deer.

Larrea, see Covillea.

Iasiococcus dumosus, see Gaylussacia dumosa.

Lasiococcus mosieri, see Gaylussacia dumosa.

Laurocerasus caroliniana, see Prunus caroliniana.

Laurus albida, see Sassafras albidum.

Lauris geniculata, see Glabraria geniculata. 
Lavatera assurgentiflora Kellogg.

Callfornea treemallow.

Sanviniona assurgentiflora Greene.

Range: 5.

Site : Well-drained, sun.

Fruit: Dry carpel.

A large shrub; has been much used in windbreak plantings; from seed reaches 6 feet in height, and blooms the first year.

Iedum buxifolium, see Leiophyllum ouxifolium.

Ledum columbianum Piper.

Range: 1 .

Site: Moist, sun.

Fruit: Capsule.

A small evergreen shrub; flowers in June; common in acid bogs.

Ledum glandulosum Nutt.

Smooth Labrador-tea.

Range: $4,12,13$.

Site : Moist, sun.

Fruit: Capsule, avallable August-September.

A small to large evergreen shrub; flowers May-June; common in acid bogs.

Observations: Mountain beaver. Only slightly toxic to livestock.

Ledum groenlandicum Oeder.

Range : 4, 12, 23, 24, 26, 27.

Labrador-tea.

Site: Well-drained, moist, sun, shade.

Fruit: Capsule, available in August.

A small evergreen shrub; flowers May-June; common in acid bogs.

Stomach records: Sharp-talled grouse; composed 1.8 pelcent of winter food of northern sharp-tailed grouse in Ontario and Quebec. Poisonous to cattle, although a liigh-ranking summer food for reindeer. Observations: Casually browsed by northern white-tailed deer.

Leiophyllum buxifolium (Berg.) Ell.

Ledum buxifolium Berg., Dendrium buxifolium (Berg.) Desv.

Box sandmyrtle.

Range : $28,29,30$.

Site: Well-drained, sun, shade.

Fruit: Capsule.

A small, widely-branched evergreen shrub; flowers May-June; occurs on sand.

Leiophyllum hugeri (Small) Sch.

Dendrium hugeri Small.

Range: 27, 28.

Site: Well-drained, sun.

Fruit: Capsule.

A small, much-branched evergreen shrub.

Lelophyllum iyonii Sweet.

Dendrium lyonii (Sweet) Small.

Range: 27.

Site: Dry, well-drained, sun.

Fruit: Capsule.

A small, copionsly-branched evergreen shrub; usually decumbent and with matted branches.

Leitneria floridana Chapm.

Range : $20,25,29,30$.

Corkwood.

Site: Well-drained, moist, sun.

Fruit: Leathery drupe, available May-September.

A small shrub to small tree; flowers March-Aprll; spreads by suckers; does well only on peaty soils; wood lighter than cork.

Lepargyrea argentea, see Shepherdia argentea.

Lepargyrea canadensis, see Shepherdia canadensis.

Lepargyrea rotundifolia, see Shepherdia rotundifolia.

Lepidanthus phyllantholdes, see Andrachne phyllanthoides. 
Iepisdospartum latisquamum Wats.

Broadscale broom.

L. striatum Cov.

Range: 10.

Site: Dry, sun.

Fruit: Achene.

A large shrub.

Lepidospartum squamatum Gray.

Linosyris squamata Gray, Tetradymia squamata Gray.

Scalebroom.

Range: $5,10$.

Site: Dry, sun.

Fruit: Achene.

A small to large, rigid, broomlike shrub.

Iepidospartum striatum, see Lepidospartum latisquamum.

Leucaena greggii Wats.

Ryncholeucaena greggii (Wats.) Britt. and Rose.

Gregg's lead tree.

Range: 11.

Site: Dry, well-drained, sun.

Fruit: Legume.

A large shrub to small tree.

Leucaena pulverulenta (Schlecht.) Benth.

Acacia pulverulenta Schlecht.

Range : 11, 17.

Site: Well-drained, sun.

Fruit: Legume.

A large tree or becoming a shrub northward; wood occasionally used locally, less commonly commercially; a rich soll species.

Ieucaena retusa Benth.

Caudoleucaena retusa (Benth.) Britt. and Rose.

Range: 11, 16, 17, 20.

Site: Dry, well-drained, sun.

Fruit: Legume, available in August.

A large shrub to small tree or rarely a large tree; flowers April-October; occurs on limestone and other soils. A favorite browse of cattle.

Leucophyllum frutescens (Berl.) Johnst.

L. texanum Benth.

Range: 11, 17, 20.

Site: Dry, sun.

Fruit: Capsule.

A small to large shrub; in cultivation.

Leucophyllum minor Gray.

Range: 11, 17.

Site: Dry, sun.

Fruit: Capsule.

A small, almost prostrate shrub.

Leucophyllum texanum, see Leucophyllum frutescens.

Leucothoë acuminata (Ait.) Don.

Andromeda acuminata Ait.

Range: 29, 30.

Site: Moist, sun.

Fruit: Capsule.

A small to large evergreen shrub, occurs on acid solls.

Leucothoë axillaris (Lam.) Don.

Andromeda axillaris Lam.

Range: 29, 30.

Site: Moist, sun, shade.

Fruit: Capsule. soils.

A small to large evergreen shrub; flowers February-April; occurs in acid 
Ieucothoë catesbaei (Walt.) Gray.

Andromeda catesbaei Walt.

Range : 27, 28 .

Site: Well-drained, moist, shade.

Fruit: Capsule.

A small to large evergreen shrub; flowers in April; branches long, spreading or recurved; occurs on acid solls ; used commercially.

Leucothoë davisiae Torr.

Oreocallis davisiae (Torr.) Small.

Blacklaurel.

Range: 1,4 .

Site: Moist, sun, shade.

Fruit: Capsule.

A small evergreen shrub; flowers in June; occurs on acid soils. 1 to 2 ounces of leaves will kill a sheep.

Leucothoë elongata Small.

Eubotrys elongata Small.

Range : $29,30$.

Site: Moist, sun.

Fruit: Capsule.

A large shrub; occurs in acid swamps.

Leucothoë racemosa (L.) Gray.

Eubotrys racemosa (L.) Nutt., Andromeda racemosa $L$.

Range: 27, 28, 29, 30 .

Site: Well-drained, moist, sun, shade.

Fruit: Capsule.

A small to large, widely-branching shrub; flowers May-June; occurs in acid swamps. Poisonous to livestock, especially calres.

Leucothoë recurva (Buckl.) Gray.

Eubotrys recurva (Buckl.) Britt., Andromeda recurva Buckl.

Range: 27 .

Site: Dry, well-drained, sun, shade.

Fruit: Capsule.

A small to large shrub; flowers April-May; occurs in acid soils.

Libocedrus decurrens Torr.

Heyderia decurrens (Torr.) Koch.

Incense cedar.

Range: $1,4,5$.

Site: Dry, well-drained, sun, shade.

Fruit: Cone; ripening August-September, seeds soon shed, cones persistent.

A large, evergreen, usually dioecious, rarely monoecious tree; root system compact, without a taproot; grows on any soil but adobe and boulder wash; high humidity is not essential for its growth; slow growing, long-lived; windfirm; somewhat susceptible to diseases and mistletoe; wood of great importance commercially, very durable; abundant seed crop produced every 3 years; 11,000 17,000 seeds per pound; germination $20-40$, percent; ornamental and in cultivation.

Observations: Of fair importance as browse for mule deer; mountain beaver.

Ligustrum spp.

Privets.

In addition to the species listed below, $L$. sinense Lour., the Chinese privet, and $L$. lucidum, the glossy prlvet, are sometimes spontaneous about towns in the South. Sereral species, notably those following, have been used successfully in erosion control in the Pledmont, Atlantlc, and Gulf Coastal Plains.

observations (in addition to speciflc records): Fourteen specles of birds, including bobwhite.

Ligustrum ovalifolium Hassk.

Range: 29,30 .

California privet.

Site: Dry, well-drained, sun.

Fruit: Berry, available in September, persistent.

A large shrub to small tree; nearly evergreen southward; a native of Japan but more or less naturallzed in the regions indicated; much cultivated. 
Ligustrum vulgare L.

Range : 26, 27, 28, 29.

Privet.

Site: Dry, well-drained, sun.

Fruit: Berry, available in September, long persistent.

A large shrub, nearly evergreen southward; introduced from Eurasia but more or less naturalized in the regions indicated; not hardy in North Dakota; 13,000 seeds per pound.

Stomach records: Robiu. Observations: Ring-necked pheasant in southern Michigan.

Linnaea boreails $\mathrm{L}$.

Linnaea borealis americana Rehd.

Twinflower.

Range: 1, 2, 4, 12, 13, 14, 23, 24, 26, 27.

Site: Dry, well-drained, moist, sun, shade.

Fruit: Capsule.

A prostrate, evergreen vine; flowers June-August ; often forms a good ground cover.

Stomach records: Ruffed grouse, plains white-tailed deer. Possibly poisonous to livestock.

Linosyris depressa, see Chrysothamnus depressus.

Linosyris parryi, see Chrysothamnus parryi.

Linosyris pulchelia, see Chrysothamnus pulchellus.

Linosyris squamata, see Lepidospartum squamatum.

Linosyris teretifolia, see Chrysothamnus teretifolius.

Lippia berlandieri Schauer.

Redbush.

Range: 17.

Site: Well-drained, sun.

Fruit: Nutiet.

A small shrub; root system shallow; easily transplanted.

Lippia geminata H. B. K.

L. lantanoides Coult, Lantana lippioides Hook.

Range: 17.

Site: Well-drained, sun.

Fruit: Nutiet.

A smali sbrub.

Lippia lantanoides, see Lippia geminata.

Lippia ligustrina Britt.

L. lycioides Steud., Aloysia ligustrina (Lag.) Small.

Whitebrush.

Range: 11, 16, 17, 20.

Site: Dry, sun.

Fruit: Nutlet.

A large, sometimes spinescent shrub; easily grown from seed, and easily transpianted. Palatable to livestock, and a good honey plant.

IIppia lycioldes, see Lippia ligustrina.

Lippia wrightii Gray.

Range: $9,10,11,14$.

Site: Dry, well-drained, sun.

Fruit: Nutlet.

A smail to large shrub; generally grows among rocks; under 3,000 feet elevation grows only on northern slopes; from 3,000 to 5,000 feet grows at any aspect; but over 6,000 feet it is limited to southern exposures.

Fair to fairly good local browse for livestock. A good honey plant.

Liquidambar styraciflua $\mathrm{L}$.

Range: $20,22,25,27,28,29,30$.

Sweetgum

Site: Dry, well-drained, moist, sun.

Fruit: Compound capsule, available September-November; seeds shed during the winter.

A large tree; ordinarily occurs on better soils but abie to grow on very poor ones; flowers April-May; very rapid growing, rather long-lived; seriousiy injured by fire; free from insects and diseases; coppices freely; wood of importance commercially; about 128,000 seeds per pound, germination 50-75 percent; somewhat difficuit to transplant; very ornamental and in cultivation. 
Stomach records: Twelve species of birds, including bobwhite and wild turkey. Observations: Thirteen species of birds, including bobwhite; ranks sixteenth in the list of quail food plants of the southeast; captive marsh rabbits, eastern chipmunk, gray squirrel.

Lirlodendron tulipifera $\mathrm{L}$.

Range : 21, 22, 23, 24, 25, 26, 27, 28, 29.

Tuliptree.

Site: Dry, well-drained, sun.

Fruit: Samara, available September-November.

A large tree; occurs on a variety of soils; flowers May-June; root system deep, wide spreading; not easily transplanted when young; rapid growing when young, later slower; comparatively long-lived; seriously injured by fire; free from insects and diseases; coppices freely; wood durable, of importance commercially; a pioneer in gullies, often forming thickets in rapidly gullying ravines; $12,000-14,000$ seeds per pound, germination 2-12 percent, slow.

Stomach records: Four species of birds, including bobwhite; white-tailed deer. Observations: Three species of birds ; cottontail rabbit, white-tailed deer, red squirrel.

Lithocarpus densiflora (Hook. and Arn.) Rehd.

Pasania densiflora Orst., Quercus densiflora Hook. and Arn.

Tan oak.

Range: 1,4 .

Site: Dry, well-drained, moist, sun, shade.

Fruit: Nut, mature at the end of the second season.

A large evergreen tree; slow growing; free from insects and fungi; windfirm; much damaged by fire; stump sprouts abundantly after injury; very aggressive; of great importance commercially for tannage; second season after the bark is stripped a heavy crop of acorns is produced, the tree then dies.

Var. echinoides Jeps. is a shrubbier form in region 4.

Observations: Redwood chipmunk; of slight importance as browse for mule deer. Usually avoided by livestock.

Iltsea geniculata, see Glabraria geniculata.

Lonicera spp.

Honeysuckles.

Stomach records (in addition to specific records) : Fourteen species of birds, including bobwhite, Gambel quail, sharp-tailed grouse, and ring-necked pheasant; Mono chipmunk, Coeur d'Alene chipmunk, buff-bellied chipmunk. Observations (in addition to specific records): Six specles of birds; moose. Most species are generally unpalatable to stock, although sometimes browsed.

Lonicera albiflora Torr. and Gray.

L. dumosa Gray.

Range: 11, 14, 16, 17, 20.

Site: Well-drained, moist, sun.

Fruit: Berry, available October-November.

A small to large, bushy shrub, or occasionally somewhat climbing.

Lonicera altissima, see Lonicera oblongifolia.

Lonicera arizonica Rehd.

Arizona honeysuckle.

Range: 11, 14.

Site: Well-drained, sun.

Fruit: Berry.

A vine.

Lonicera caerulea, see Lonicera cauriana and $L$. villosa.

Lonicera canadensis Marsh.

L. ciliata Muhl., Xylosteon ciliatum (Muhl.) Pursh.

American fly-honeysuckle.

Range: 23, 24, 26, 27.

Site: Moist, shade.

Fruit: Berry, available June-September.

A small, straggling shrub; flowers April-May.

Observations: White-tailed deer.

Lonicera caprifolium $\mathrm{L}$.

Range: 22, 24, 25, 27, 28, 29.

Sweet honeysuckle

Site: Well-drained, sun.

Fruit: Berry, available August-September.

A twining vine, or occasionally somewhat shrubby; introduced from Europe but more or less established in regions indicated; flowers May-June. 
Lonicera cauriana Fernald.

L. caerulea of auths., not $\mathrm{L}$.

Mountain fly-honeysuckle.

Range: 4, 12, 13.

Site: Well-drained, moist, sun.

Fruit: Berry, available June-July.

A small shrub; flowers April-May.

Lonicera cillata, see Lonicera canadensis.

Lonicera cillosa Poir.

Range: 4, 12, 13, 14.

Honeysuckle.

Site: Dry, well-drained, sun, shade.

Fruit: Berry, available July-September.

A twining or procumbent vine; flowers in June.

Stomach records: Catbird.

Lonicera conjugialis Kellogg.

Xylosteon conjugiale Howell.

Range: 1,4 .

Site: Dry, well-drained, sun.

Fruit: Berry, available Angust-September.

A small, much-branched shrub; flowers in June.

Stomach records: Sooty grouse. Observations: Blue grouse.

Lonicera dioica $\mathrm{I}$.

Mountain honeysuckle.

Range: 23, 24, 25, 27.

Site: Dry, well-drained, moist, sun, shade.

Fruit: Berry, available June-October.

A diffuse or twining vine; flowers May-June; attacked by green aphis.

Lonicera dumosa, see Lonicera albiflora.

Lonicera ebractulata, see Lonicera utahensis.

Lonicera flava Sims.

Range: 25, 27, 28, 29.

Yellow honeysuckle.

Site: Dry, well-dralned, sun, shade.

Fruit: Berry, available August-September.

A slightly twining vine; flowers April-May.

Lonicera flavida Cockerell.

Range: 25.

Site: Dry, well-drained, sun.

Fruit: Berry.

A trailing or climbing vine.

Lonicera glaucescens Rydb.

Douglas honeysuckle.

L. dioica glaucescens (Rydb.) Butters, L. hirsuta glaucescens Rydb.

Range: 18, 21, 22, 23, 24, 25, 26, 27.

Site: Dry, well-drained, moist, sun.

Fruit: Berry, available August-September.

A twining vine; very similar to $L$. hirsuta; intergrades with $L$. dioica.

Lonicera hirsuta Eaton.

Range: 23, 24, 26, 27.

Hairy honeysuckle.

Site: Dry, well-drained, sun.

Fruit: Berry, available July-October.

A high-climbing vine; flowers June-July.

Stomach records: Two species of birds.

Lonicera hispidula Dougl.

Range: $2,3,4,5$.

Pink honeysuckle.

Site: Dry, well-drained, sun.

Fruit: Berry, available July-February.

A climbing vine; evergreen; flowers July-August; several varletles have been described. Of some importance as a honey plant.

Lonicera interrupta Benth.

Range: $4,10,11,14$.

Site: Dry, sun.

Fruit: Berry, available June-December.

A bushy vine or small shrub; evergreen.

Chaparral honeysuckle. 
Observations: Wren-tit; of slight importance as browse for mule deer. Not browsed by stock; reported by stockmen as poisonous. Of some importance as a honey plant.

Lonicera involucrata (Richards) Banks.

Twinberry honeysuckle.

Xylosteon involucrata Richards, Distegia involucrata (Richards.) Raf.,

L. ledebouri Esch.

Range: 4, 5, 7, 12, 13, 14, 23, 24, 26.

Site: Well-drained, moist, shade.

Fruit: Berry, available August-September.

A large bushy shrub; flowers June-July; suckers very freely and may form patches of considerable size; root system flbrous, shallow, rootstocks also shallow ; 226,000 seeds per pound.

Stomach records: Four species of birds. Observations: Blue grouse, flowers much used by blue-throated and Rivoli hummingbirds. Only locally browsed by livestock.

Lonicera japonica Thunb.

Nintooa japonica Sweet.

Range: 5, 20, 22, 25, 27, 28, 29, 30 .

Site: Dry, well-drained, moist, sun, shade.

Fruit: Berry, available September-March.

A half-evergreen vine; flowers June-August; introduced from eastern Asia and well established in regions indicated; extremely aggressive in competition with native plants; known to have killed trees up 6 inches in diameter; not necessarily conflned to richer, moister woodlands, where it does best; often considered a troublesome weed, especially in the South; gradually becoming more widespread; many cultivated varieties known, of which var. halliana is most widely naturalized.

Stomach records: Five species of birds, Including bobwhite.

Lonicera ledebouri, see Lonicera involucrata.

Lonicera oblongifolia (Goldie) Hook.

L. altissima Jennings, Xylosteon oblongifolia Goldie.

Range : 23, 24, 26, 27.

Site: Molst, sun.

Fruit: Berry, available May-August.

A small to large, somewhat straggling shrub; flowers May-June.

Lonicera prolifera (Booth) Rehd.

L. sullivantii Gray, Caprifolium proliferum Booth.

Swamp fly-honeysuckle.

Range: $22,23,24,25$.

Site: Dry, well-drained, sun.

Fruit: Berry, available July-October.

A vine; flowers May-June; very similar to $L$. dioica; attacked by green aphis.

Lonicera sempervirens L.

Phenianthus sempervirens (L.) Raf.

Trumpet honeysuckle.

Range: $11,20,22,25,26,27,28,29,30$.

Site: Dry, well-drained, sun.

Fruit: Berry, available September-October.

A high-climbing vine; evergreen; flowers April-September; leaves declduous northward; in cultivation.

Observations: Purple finch.

Lonicera subspicata Hook. and Arn.

Range: 5.

Moronel.

Slte: Dry, well-drained, sun.

Fruit: Berry.

A climbing or trailing vine or small to large shrub; evergreen.

Observations: California mule deer.

Lonicera sullivantil, see Lonicera prolifera.

Lonicera utahensis Wats.

L. ebractulata Rydb. Xylosteon utahense (Wats.) Howell.

Utah honeysuckle.

Range: 4, 12, 13, 14 .

Site: Dry, well-drained, shade.

Fruit: Berry, available June-August.

A small to large shrub; forms clumps. Locally of some value as browse for livestock.

$130186^{\circ}-39-11$ 
Lonicera villosa (Michx.) Roem. and Schult.

L. caerulea of auths., not L., Xylosteon villosum Michx.

Mountain fly-honeysuckle.

Range: 23, 24, 26, 27.

Site: Well-drained, moist, sun.

Fruit: Berry, available in July.

A small, much-branched shrub with ascending branches; generally free from insects and diseases; may occur on limestone, peat, and other soils.

Lotus stipularis (Benth.) Greene.

Hosackia stipularis Benth., H. macrophylla Kellogg, H. balsamifera Kellogg.

Range: 1, 4 .

Site: Dry, well-drained, sun.

Fruit: Legume.

A small shrub; flowers April-July.

Lupinus spp.

These species are claimed to harbor the bean weavil in California.

Iupines.

Stomach records (in addition to specific records) : Richardson's grouse ; mountain sheep, black-tailed deer. Observations: Clark's nutcracker. These records apply to herbaceous species also.

Lupinus albifrons Benth.

Range: 4 , 5 .

Site: Well-drained, sun.

Fruit: Legume.

A small to large shrub or small tree; evergreen; flowers March-July; occurs on sandy or dry loam; often gregarious; several varieties known.

Lupinus arboreus Sims.

L. propinquus Greene.

Range: 1, 5 .

Site: Well-drained, sun.

Fruit: Legume.

A small to large evergreen shrub; occurs in sandy soil; flowers April-June; has been introduced Into New Zealand, where it is considered valuable as a cover for shifting sand, being used extensively in dune reclamation; it is not a sandbinder, but should be used where there is a well-controlled area to the windward; pod-bearing branches laid on bare dunes will prevent the movement of sand, and seeds later germinate to form a cover.

Lupinus austromontanus, see Lupinus excubitus.

Lupinus breweri Gray.

Mat lupine.

Range: $4,10$.

Site: Dry, well-drained, sun.

Fruit: Legume.

A small evergreen shrub; flowers June-July; ordinarily occurs in rocky soil ; forms dense, prostrate mats ; season's growth 1 to 6 inches ; several varieties with less seasonal growth are known.

Lupinus chamissonis Esch.

Range: 1, 5 .

Site: Well-drained, sun.

Fruit: Legume, available August-September.

A small evergreen shrub; flowers May-June; occurs in sandy soil; the species occurs on the most exposed areas in wind-swept blow-outs and often on the crest of sand dunes; withstands the severest winds, and becomes established where sand is not moving; root system extensive.

Lupinus excubitus Jones.

Guard lupine.

Range: 4, 5, 10.

Site: Well-drained, sun.

Fruit: Legume, available August-September.

A small evergreen shrub; occurs on gravelly and other soils; flowers May-June.

Var. hallii Sm. (L. hallii Abrams, L. paynei Dav.), is larger and coarser. Var. johnstonii Sm., is a lower, subalpine form of dry mountain tops. Var. austromontanus $\mathrm{Sm}$. (L. austromontanus Heller), is a herbaceous form.

Lupinus hallii, see Lupinus excubitus.

Lupinus paynei, see Lupinus excubitus. 


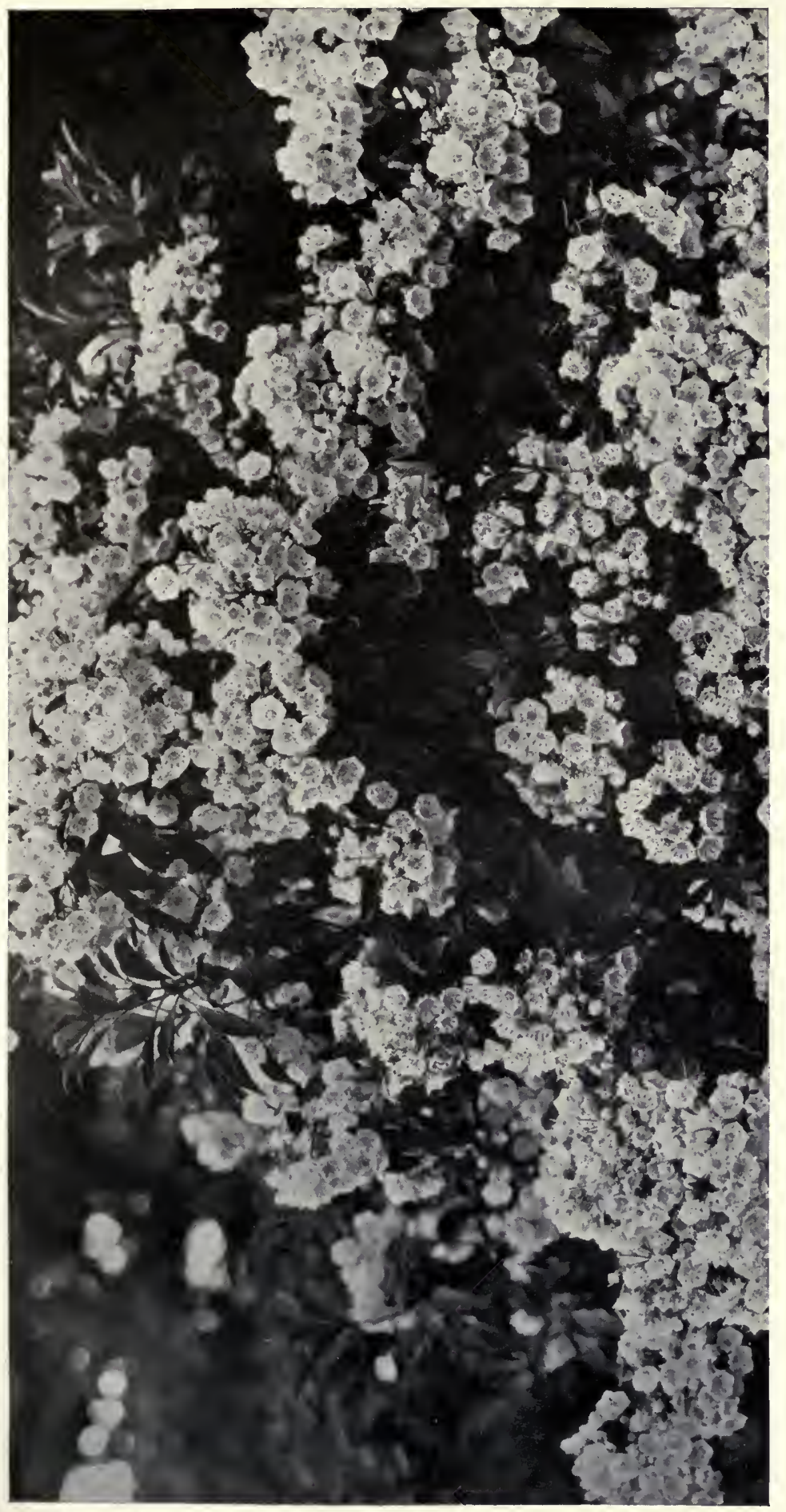



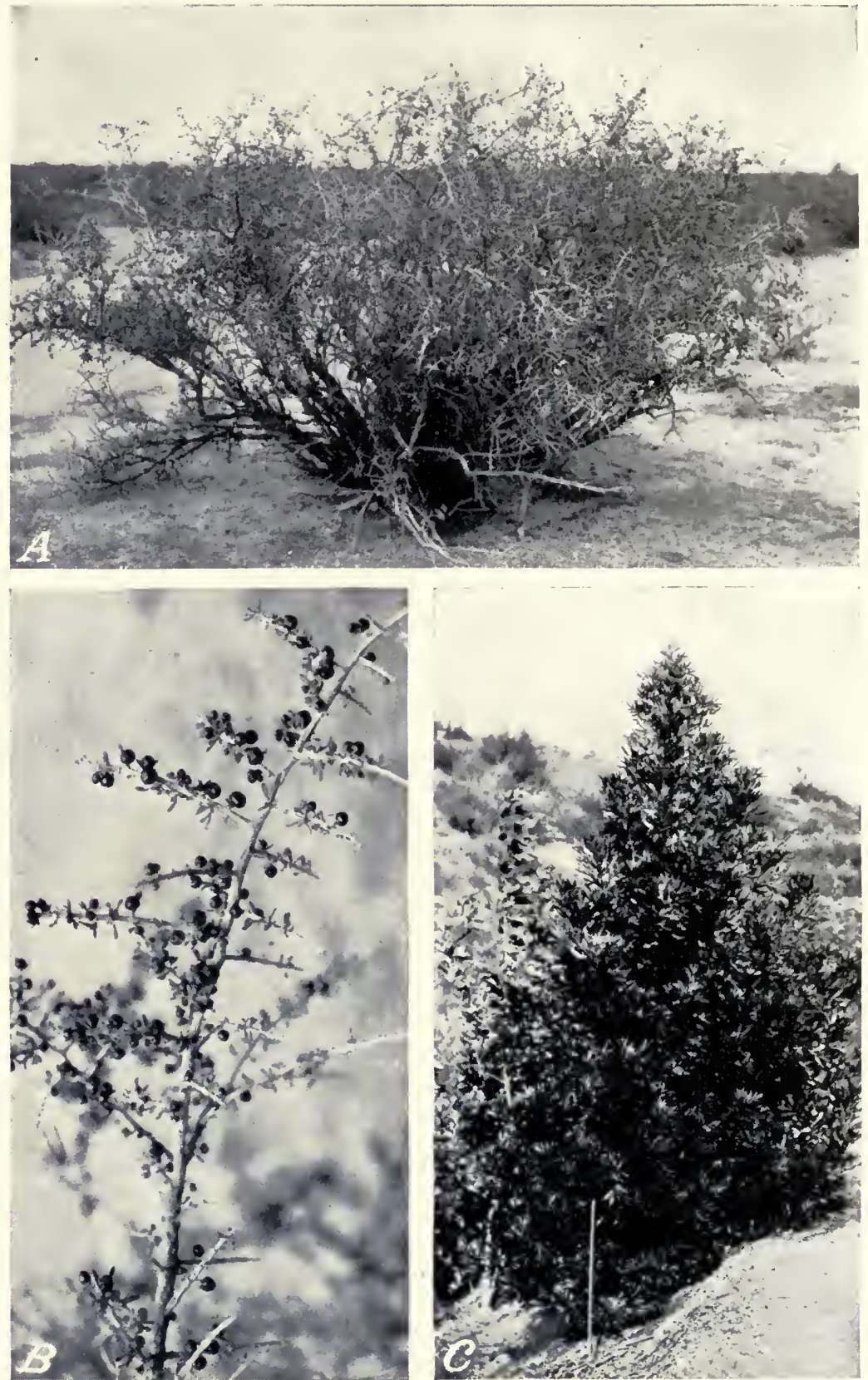

A, Lycium andersonii. The desert-thorns as a group show much promise for erosion control and wildlife plantings in the Southwest. B, L, andersonii. The fruits of most species of $L y c i u m$ are probably utilized by wildlife much more than available records indicate. $C$, Lyonothamnus fioribundus. A young specimen of the Catalina ironwood growing in a California garden. Although as yet not commonly planted, this native tree of bushy habit and rapid growth, when supplied with adequate water, may prove valuable. 
Lupinus propinquus, see Lupinus arboreus.

Lycium spp.

The root systems of the species are relatively extensive in comparison with the aerial portions, often extending 25-30 feet from the plants; roots tough and fibrous; propagation is by seed sown as soon as rlpe or by cuttings.

Stomach records (in addition to specific records): Three species of birds, including Gambel and scaled quall. Observations (in addition to specific records) : Verdin, Gila woodpecker; Mexican raccoon; important food for birds and desert rodents generally.

Lycium andersonii Gray. (pl. 20, $A, B$ ).

Anderson desert-thorn.

Range: $5,8,9,10,11,14$.

Site: Dry, sun.

Fruit: Berry, available April--May.

A small, spiny, scraggly shrub; flowers April-June; profusely branched; tolerant of alkali; occurs in sandy and other soils.

Stomach records: Gambel quail. Observations: Attractive to black-chinned hummingbird.

Lycium berlandieri Dunal.

Range: 10, 11, 14, 16, 17, 20.

Site: Dry, sun.

Fruit: Berry.

A small to large shrub; occurs in sandy and other soils.

Forma parviflorum (Gray) Hitchc., (L. parviflorum Gray) is more robust with numerous leaves and is generally found in the northwestern part of the range.

Lycium californicum Nutt.

California desert-thorn.

Range: 5, 10, 11.

Site: Well-drained, moist, sun.

Fruit: Berry, available April-October.

A small, densely-branched shrub; occurs on clay or sand; decumbent or spreading; spiny, and branches much intertwined.

Lycium carolinianum Walt.

Range: 17, 20, 29, 30 .

Christmasberry.

Site: Well-drained, moist, sun.

Fruit: Berry.

A small, trailing or somewhat climblng, spiny shrub; occurs on saline or alkaline soil, sand or limestone.

Var. quadrifidum (Moc. and Sesse) Hitchc., (L. quadrifium Moc. and Sesse), the large-fruited matrimony vine, is more widely distributed and spinier than the species, commoner westward; grows in sand; drought resistant; will grow in standing water; fruit attractive to waterfowl.

Iycium cooperi Gray.

Range: 9, 10.

Site: Dry, sun.

Fruit: Berry.

A small to large, compact shrub; flowers April-June; occurs in sandy and other soils; stout, spiny and densely branched.

Iycium exsertum Gray.

L. fremontii bigelovii Gras.

Range: 11 .

Site: Dry, sun.

Fruit: Berry.

A small to large, sparingly-branched, few-spined, rigid shrub; rapid growing; nearly evergreen; procumbent branches root; roots well from cuttings; seed produced abundantly.

Lycium fremontii Gray.

L. pallidum fremontii Terac., L. gracilipes Gray.

Fremont desert-thorn.

Range: $5,10,11$.

Site: Dry, sun.

Fruit: Berry.

A small to large, freely-branched, somewhat splny shrub; usually occurs in rather alkaline soil. Browsed by livestock in winter.

Lycium gracilipes, see Lycium fremontii. 
Iycium halimifolium Mill.

L. vulgare (Ait.) Dunal.

Matrimony-vine.

Range: $2,4,9,13,14,15,16,22,23,24,25,27,28,29,30$.

Site: Dry, well-drained, sun, shade.

Fruit: Berry, available August-May.

A vine or small to large shrub; sparingiy branched, spreading to recumbent; spiny or unarmed; introduced and more or less naturalized from Europe in the regions indicated; in the west sometimes considered a weed.

Iycium hassei, see Lycium richii.

Lycium macrodon Gray.

Range: 10, 11.

Site: Dry, sun.

Fruit: Berry, available March-May.

A small to large, much-branched, spreading, spiny shrub; flowers in February.

Iycium pallidum Miers.

Range: $9,10,11,13,14$.

Pale desert-thorn.

Site: Dry, sun.

Fruit: Berry, availabie July-August.

A small to large, widespreading, thorny shrub; flowers April-May; occurs in sandy and other soils; sprouts readily when eut or broken down; often forms thickets.

Locally important and valuable as browse for livestock, especially on winter range.

Lycinm palmeri, see Lycium richii.

Iycium parishii Gray.

Range: 10.

Site: Dry, sun.

Fruit: Berry.

A smail to large, much-branched, short-spined, rigid shrub.

Iycium parviflorum, see Lycium berlandieri.

Iycium pringlei, see Lycium richii.

Iycium puberulum Gray.

Range: 11, 17.

Site: Dry, sun.

Fruit: Berry, available in June.

A smail, spiny, sparingly branched shrub.

Iycinm quadrifidum, see Lycium carolinianum.

Iycium richii Gray.

L. palmeri Gray, L. pringlei Gray.

Range: 5, 10.

Site : Dry, sun.

Fruit: Berry.

A small to large, spiny shrub; erect or somewhat clambering; much branched; sometimes forms dense thickets; tolerant of saline conditions; drought resistant; tolerant of poor soil.

Var. hassei (Greene) Johnst., (L. hassei Greene) occurs in region 5 and is almost unarmed. The species calied $L$. verrucosum Eastw, of the San Nicholas Isiands is considered a freak originating from this species. It grows in eroded arroyos.

Iycium spencerae, see Prunus fasciculata.

Lycium torreyi Gray.

Range: $9,10,11,16,17$.

Site: Dry, well-drained, moist, sun.

Fruit: Berry, available June-September.

A smali to large thorny shrub; flowers March-June; much branched and spreading; with heavy spines or unarmed.

Lycium verrucosum, see Lycium richii.

Lycium vulgare, see Lycium halimifolium. 
Lymnobtrya lacustris, see Ribes lacustre.

Lymnobotrya montigena, see Ribes montigena.

Lymnobotrya parvula, see Ribes lacustre.

Lyonia ferruginea, see Xolisma fruticosa.

Iyonia frondosa, see Xolisma ligustrina.

Iyonia ligustrina, see Xolisma ligustrina.

Lyonia mariana, see Xolisma mariana.

Lyonida nitida, see Xolisma lucida.

Iyonia rigida, see Xolisma ferruginea.

Iyonothamnus asplenifolius, see Lyonothamnus floribundus.

Iyonothamnus floribundus Gray. (pl. 20, C).

Catalina ironwood.

L. asplenifolius Greene.

Range: 5.

Site: Dry well-drained, sun.

Fruit: Capsule, available August-September.

A small to large evergreen tree; fowers June-July; rapid growing, especially when well supplied with water; bushy; drought resistant; very ornamental and commonly cultivated.

Maclura aurantiacum, see Maclura pomifera.

Maclura pomifera (Raf.) Schneid.

Osage-orange.

M. aurantiacum Nutt., Toxylon pomiferum Raf., Ioxylon pomiferum Raf. Range: $20,22,25,27,28,29,30$.

Site: Dry, well-drained, sun.

Fruit: Syncarp, available in October.

A large, dioecious, much-branched, thorny tree; wood very strong and durable; much cultivated as a hedge plant and extensively planted throughout the country for that purpose; a host for the San Jose scale; not hardy in northern Iowa, Minnesota, and the Dakotas; a thorny variety is known in cultivation; propagation is by seed sown in spring after soaking 48 hours; about 12,000 seeds per pound.

Stomach records: Black-talled deer. Observations: Crossbill; fox squirrel ; particularly valuable cover plant for small forms of wild iffe.

Macrosiphonia berlandieri, see Macrosiphonia macrosiphon.

Macrosiphonia macrosiphon (Torr.) Heller.

M. berlandieri Gray, Echites macrosiphon Torr.

Range : 11, 17.

Site: Dry, sun.

Fruit: Pod.

A small shrub.

Magnolia spp.

Magnolias.

Most species are generally free from insects and diseases; most grow in acid soil; propagation is by seed stratified and sown in spring or sown at once; usually difficult to transplant.

Stomach records (in addition to speciflc records): Five species of birds, including bobwhite.

Magnolia acuminata $\mathrm{L}$.

Tulipastrum acuminatum (L.) Small.

Cucumber magnolia.

Range : 22, 24, 25, 27, 28, 29, 30 .

Site: Well-drained, moist, sun, shade.

Fruit: Drupe, available August-October.

A large tree; flowers May-June; occurs on fertile, not heavy soils, nor dry sand or shale; root system deep, wide spreading, taproot rarely developed; rapid growing, rather short-lived; severely injured by fire and cucumber scale; coppices freely; wood soft, weak, durable, used to some extent commercially; often used as grafting stock for named varietles; propagation is by seed stratified at $32^{\circ} \mathrm{F}$., 15 to 20 weeks, and sown in spring; about 3,000 seeds per pound; easy to transplant. 
Magnolia ashei Weath.

Ashe magnolia.

Range : 29, 30.

Site: Well-drained, sun.

Fruit: Drupe, a vailable September-October.

A large shrub to large tree; occurs in sandy and other solls.

Magnolia cordata Michx.

M. acuminata cordata Sarg., Tulipastrum cordatum Small.

Range: 27, 28, 29.

Site: Well-drained, sun.

Fruit: Drupe, arailable September-October.

A large shrub; or in cultivation, becoming a large tree.

Magnolia foetida, see Magnolia grandiflora.

Magnolia fraseri Walt.

Range : 27, 28.

Mountain magnolia.

Site: Well-drained, moist, sun.

Fruit: Drupe, available September-October.

A large tree; flowers May-June.

Magnolia glauca, see Magnolia virginiana.

Magnolia grandiflora L. (pl. 21, A).

M. foetida (L.) Sarg.

Range: $28,29,30$.

Site: Well-drained, moist, sun, shade.

Fruit: Drupe, available August-October.

A large evergreen tree; flowers April-August; wood weak, not durable, somewhat used commercially; about 2,000 seeds per pound; easily transplanted, much cultivated.

Stomach records: Five species of birds. Observations: Five species of birds, including wild turkey; gray squirrel, captive marsh rabbit.

Magnolia macrophylla Michx.

Range: 25, 27, 28, 29, 30.

Bigleaf magnolia.

Site: Well-drained, moist, shade.

Fruit: Drupe, available September-October.

A large tree; flowers May-June; leaves much wlnd-damaged; young trees will coppice.

Magnolia pyramidàta Pursh.

Pyramid magnolia.

Range: 29, 30.

Site: Well-drained, moist, sun.

Fruit: Drupe, available September-October.

A small to large tree; flowers in June.

Magnolia tripetala $\mathrm{L}$.

M. umbrella $\mathrm{L}$.

Range, 25, 27, 28, 29.

Site: Well-drained, moist, sun.

Fruit: Drupe, available September-October.

A large, rapid-growing tree; flowers May-June.

Magnolia umbrella, see Magnolia tripetala.

Magnolia virginiana $L$.

M. glauca $\mathrm{L}$.

Range: 27, 28, 29, 30.

Site: Well-drained, moist, sun.

Fruit: Drupe, available September-October.

A large shrub to small or large tree; evergreen; flowers May-June; generally occurs near the coast in the southern part of its range; often thicket forming; consistently found on mediacid soil ; cultivated to some extent.

Mahonia aquifolium, see Berberis aquifolium.

Mahonia fascicularis, see Berberis pinnata.

Mahonia fremontii, see Berberis fremontii.

Mahonia haematocarpa, see Berberis haematocarpa.

Mahonia nervosa, see Berberis nervosa. 
Mahonia nevinii, see Berberis nevinii.

Mahonia pinnata, see Berberis pinnata.

Mahonia pumila, see Berberis pumila.

Mahonia repens, see Berberis repens.

Mahonia swaseyi, see Berberis swaseyi.

Mahonla trifoliolata, see Berberis trifoliolata.

Malache lasiopetala, see Pavonia lasiopetala.

Malachodendron pentagyna, see Stuartia pentagyna.

Malacothamnus davidsonii, see Malvastrum davidsonii.

Malacothamnus fasciculatum, see Malvastrum fasciculatum.

Malacothamnus nuttalli, see Malvastrum nuttallii.

Malosma laurina, see Rhus laurina.

Malplghia glabra L.

Wild crapemyrtle.

Range: 17.

Site: Well-drained, sun.

Fruit: Drupe.

A small to large shrub; occurs on sandy soil; fruit edible.

Malus spp.

Propagation of all species is by seed stratified 85 days at $41^{\circ}-46^{\circ} \mathrm{F}$; most species grow in neutral soil.

Stomach records (in addition to specific records): Eighteen species of birds, including ruffed grouse, bobwhite, and ring-necked pheasant; composed 14.4 percent of winter food taken by ruffed grouse in the northeastern United States; opossum, dusky marmot, western skunk, gray fox, red fox; composed 0.03 percent of fruit food of eastern skunk in Michigan; found in 17.4 percent of 130 raccoon stomachs collected in winter in New York; found in 13 percent of 139 skunk stomachs examined in New York. Observations (in addition to specific records) : Three species of birds; emergency food of greater prairie chicken; woodchuck, red squirrel, snowshoe rabbit, cottontail rabbit, gray fox; staple food of red fox in times of scarcity; an important food of raccoon in times of scarcity.

Malus angustifolia Michx.

M. sempervirens Desf., Pyrus angustifolia Ait.

Range: $25,27,28,29,30$.

Site: Dry, well-drained, moist, sun.

Fruit: Pome, available September-October.

A large shrub to small or large tree; partially evergreen southward; considered by some to be a form of $\boldsymbol{M}$. coronaria (q. v.).

Stomach records: Blue jay.

Malus bracteata Rehd.

Pyrus bracteata Bailey.

Range: $25,27,28,29,30$.

Site: Well-drained, molst, sun.

Fruit: Pome, available September-October.

A large shrub to small or large tree.

Malus coronaria (L.) Mill.

Pyrus coronaria $\mathbf{L}$.

Narrowleaf crab apple.

Range: 16, 19, 22, 24, 25, 27, 28, 29, 30 .

Site: Dry, well-drained, moist, sun.

Fruit: Pome, available September-November.

A large shrub to small or large tree; blooms March-May, forms dense, spiny thickets.

Stomach records: Grosbeak, white-tailed deer. Observations: Ring-necked pheasant.

Malus diversifolla, see Malus fusca.

Malus fragrans, see Malus glaucescens. 
Malus fusca (Raf.) Schn. (pl. 21, B).

Oregon crab apple.

M. rivularis Roem., $\boldsymbol{M}$. diversifolia (Bong.) Roem., Pyrus fusca Raf., $\boldsymbol{P}$. diversifolia Bong., $P$. rivularis Dougl.

Range: 1, 2, 4 .

Site: Well-drained, moist, sun.

Fruit: Pome, available August-November.

A small to large tree; flowers April-May; thicket forming; specimens usually straggling when single.

Stomach records: Robin. Observations: Much eaten by Oregon ruffed grouse. Not a first-class browse plant because often inaccessible on account of thicketforming tendency but sometimes fair cattle forage.

Malus glabrata Rehd.

Pyrus glabrata Bailey.

Crab apple.

Range: 27.

Site: Well-drained, sun.

Fruit: Pome.

A small to large tree.

Malus glaucescens Rehd.

M. fragrans Rehd., Pyrus glaucescens Bailey.

Dunbar crab apple.

Range: 22, 24, 25, 27, 28, 29.

Site: Dry, well-drained, moist, sun.

Fruit: Pome, avallable in September.

A large shrub to small or large tree; flowers April-May; commonly clump forming and spiny.

Malus ioensis (Wood) Britt.

Pyrus coronaria ioensis Wood, $P$. ioensis Caruth.

Prairie crab apple.

Range: 20, 21, 22, 23, 25, 29.

Site : Dry, well-drained, sun.

Fruit: Pome, available September-October.

A large shrub to small tree; flowers April-May; several varieties, all occuring within the range of the species have been described.

Malus lancifolia Rehd.

Pyrus lancifolia Bailey.

Lanceleaf crab apple.

Range: 25, 27.

Site: Dry, well-drained, sun.

Fruit: Pome.

A large shrub to small, spiny tree.

Malus malus, see Malus pumila.

Malus platycarpa Rehd.

Pyrus platycarpa Bailey.

Range: 25, 27.

Site: Well-drained, moist, sun.

Fruit: Pome.

A large shrub to small tree.

Malus pumila Mill.

M. malus (L.) Britt., M. sylvestris Mill., Pyrus malus L.

Wild apple.

Range: 22, 23, 24, 25, 27, 28, 29.

Site: Well-drained, sun.

Fruit: Pome, available September-November.

A small to large tree, flowers April-May; introduced from Asia, but widely naturalized and easily escaping.

Stomach records: Three species of birds; gray fox, white-talled deer. Observations: Nine species of birds, including ring-necked pheasant and mourning dove; white-tailed deer. Without doubt of extreme importance as a foodproducing plant for wildlife.

Malus rivularis, see Malus fusca.

Malus sempervirens, see Malus angustifolia.

Malus soulardii (Bailey) Britt.

Soulard crab apple.

Pyrus soulardii Bailey.

Range: 19, 20, 21, 22, 23, 25.

Site: Well-drained, sun.

Fruit: Pome. 
A large shrub to small tree; presumably a cross between $\boldsymbol{M}$. ioensis and $\boldsymbol{M}$. pumila.

Malus sylvestris, see Malus pumila.

Malva fasciculata, see Malvastrum fasciculatum.

Malvastrum spp.

Stomach records (in addition to specific records) : Three species of birds, but many species are herbaceous.

Malvastrum davidsonii Robins.

Malacothammus davidsonii

(Robins.) Jeps.

Sphaeralcea davidsonii

Range: 5.

Site: Dry, well-drained, sun.

Fruit: Dry carpel.

A small to large shrub.

Malvastrum fasciculatum (Nutt.) Greene.

Bushmallow.

M. thurberi Gray, Malva fasciculata Nutt., Malacothamnus fasciculatum, Greene, Sphaeralcea fasciculata (Nutt.) Arthur.

Range: 5, 10.

Site: Dry, sun.

Fruit: Dry carpel.

A large shrub with wandlike branches.

Malvastrum gabrielense Munz and Johnst.

Range: 5.

Site: Dry, sun.

Fruit: Dry carpel.

A small to large shrub.

Malvastru'm nuttallii (Abrams) Dav. and Moxl.

Malacothamnus nuttallii Abrams.

Range: 5 .

Site: Dry, sun.

Fruit: Dry carpel.

A large shrub.

Malvastrum thurberi, see Malvastrum fasciculatum.

Malvaviscus drummondii Torr. and Gray.

Range: 17, 20; 30 .

Site: Well-drained, sun.

Fruit: Berrylike carpel, available August-September.

A large shrub to small tree; usually occurs in sand; fruit edible. Of some value as forage for livestock.

Manihot carthaginensis (Jacq.) Muell.

M. chlorostica Standl. and Goldm., Jatropha carthaginensis Jacq.

Range: 10.

Site: Dry, sun.

Fruit: Capsule.

A large shrub to small tree; roots fleshy.

Manlhot chlorostica, see Manihot carthaginensis.

Maytenus phyllanthoides Benth.

Range: 17, 30, 32.

Site: Dry, well-drained, sun.

Fruit: Capsule.

A large shrub to small tree; evergreen.

Melia azedarach L.

Range: 17, 20, 28, 29, 30.

Nuttall globemallow.

Site: Dry, well-drained, moist, sun.

Fruit: Drupe, avallable October, falling through the winter.

A small to large tree; foliage dense; introduced from India and China and apparently completely naturalized in the regions indicated; will not stand excessive drought; free from insects; rapid growing; somewhat tolerant of salinity ; much cultivated through the southern part of the country ; fruit pulp is a vermifuge and a repellant of insects.

Stomach records: Three species of birds. Observations: Robin; western chipmunk. Fermented fruit toxic to pigs. 
Melochia tomentosa L.

Range: 17.

Site: Dry, well-drained, sun.

A small shrub.

Fruit: Capsule.

Menispermum canadense $\mathrm{L}$.

Range: $21,22,24,25,26,27,28,29,30$.

Moonseed.

Site: Well-drained, moist, sun shade.

Fruit: Drupe, available September-October.

A twining or clambering vine; flowers June-July; exceptionally fast growing; spreads by means of suckers; berries poisonous to humans. Livestock seldom, if ever, eat the plant.

Menispermum lyonii, see Calycocarpum lyonii.

Menodora spinescens Gray.

Range: 4, 9, 10.

Menodora.

Site: Dry, sun.

Fruit: Capsule.

A small spinose shrub with small leaves.

Menziesia ferruginea Sm.

M. gabella Gray.

Range: 1, 4, 12, 23.

Site: Well-durained, moist, shade.

Fruit: Capsule, available August-September.

A small to large shrub; flowers May-June. Poisonous to livestock when eaten in large quantities.

Menziesia glabella, see Menziesia ferruginea.

Menziesia glanduliflora, see Phyllodoce glanduliflora.

Menziesia pilosa (Michx.) Pers.

Minnie-bush.

Aźalea pilosa Michx.

Range: 27.

Site: Well-drained, shade.

Fruit: Capsule.

A small to large shrub; flowers May-June.

Microrhamnus ericoides Gray.

Javelin brush.

Range: 11, 16, 17.

Site: Dry, sun.

Fruit: Drupe, avallable in May.

A small to large, spiny evergreen shrub with minute leaves.

Mimosa angustissima, see Acacia angustissima.

Mimosa berlandieri, see Mimosa pigra.

Mimosa biuncifera Benth.

Rustyleaf.

M. prolifica Wats., Mimosopsis biuncifera (Benth.) Britt. and Rose.

Range: 10, 11, 16, 20.

Site: Dry, sun.

Fruit: Legume, available in September.

A small, rarely large, thorny shrub.

Stomach records: Scaled quail. Observations: Gambel and scaled quail ; particularly palatable to captive deer. Falrly good browse for livestock.

Mimosa borealis Gray.

$M$. fragrans Gray, $M$. texana Small, $M$. borealis texana Gray.

Catclaw.

Range: $11,16,17,20$.

Site: Dry, sun.

Fruit: Legume.

A small to large, much-branched, spiny, rigid shrub. Browsed by livestock but brittle and apt to be braken down with overgrazing.

Mimosa dysocarpa Benth.

Velvetpod mimosa.

Range: 11.

Site: Dry, sun.

Fruit: Legume, available in August.

A small to large, spiny shrub.

Observations: Gambel and scaled quail. Considered fair browse for livestock. 
Mimosa emoryana Benth.

Range: 11, 17.

Site: Dry, sun.

Truit:Legume.

A small to large, spiny shrub.

Mimosa endlichii, see Mimosa lemmonii.

Mimosa farnesiana, see Acacia farnesiana.

Mimosa flliculoides, see Acacia angustissima.

Mimosa flexuosa Benth.

M. biuncifera flexuosa Robins., Mimosopsis flexuosa (Benth.) Britt. and Rose.

Range: 11.

Site: Dry, well-drained, sun.

Fruit: Legume.

A small, much-branched, spiny shrub.

Mimosa fragrans, see Mimosa borealis.

Mimosa grahamil Gray.

Mimosopsis grahamii (Gray) Britt. and Rose.

Range: 10.

Site: Dry, sun.

Fruit: Legume.

A small to large, spreading or decumbent shrub.

Mimosa laxiflora Benth.

Range: 11.

Slte: Dry, well-drained, sun.

Fruit: Legume.

A small to large, somewhat prickly shrub.

Mimosa lemmonil Gray.

$M$. endlichii Harms, Mimosopsis lemmonii (Gray) Britt. and Rose.

Range: 11.

Site: Dry, sun.

A small shrub.

Fruit: Legume.

Stomach records: Gambel quall.

Mimosa lindheimeri Gray.

M. biuncifera lindheimeri Robins., Mimosopsis lindheimeri (Gray) Britt. and Rose.

Range: 11, 16, 17, 20.

Site: Dry, sun.

Fruit: Legume.

A small, spiny shrub.

Mimosa malacophylla Benth.

Senegalia malacophylla (Benth.) Britt. and Rose.

Range: 11, 17.

Site: Dry, sun.

Fruit: Legume, available August-September.

A large, spiny, decumbent, or even climbing shrub.

Mimosa pigra I.

M. berlandieri Gray.

Range: 17.

Site: Well-drained, sun.

Fruit: Legume.

A small to large, prickly shrub.

Mimosa pringlei Wats.

Range: 11.

Site: Dry, sun.

Fruit: Legume.

A small to large, densely branched, spiny shrub.

Mimosa prolifica, see Mimosa biuncifera.

Mimosa texana, see Mimosa borealis. 
Mimosa wrightii Gray.

Range: 10.

Site: Dry, well-drained, sun.

Fruit: Legume.

A small to large, spiny shrub.

Mimosopsis biuncifera, see Mimosa biuncifera.

Mimosopsis flexuosa, see Mimosa flexuosa.

Mimosopsis grahamii, see Mimosa grahamii.

Mimosopsis lemmonii, see Mimosa lemmonii.

Mimosopsis lindheimeri, see Mimosa lindheimeri.

Mimulus aridns (Abrams) Grant.

Diplacus aridus Abrams.

Range: 5, 10.

Site: Dry, well-drained, sun.

Fruit: Capsule.

A small, decumbent, evergreen shrub.

Mimulus anrantiacus Curtis.

Diplacus aurantiacus (Curtis) Jeps.

Bush monkeyflower.

Range: 1, 4, 5 .

Site: Dry, well-drained, sun, shade.

Fruit: Capsule.

A small, sparingly branched, erergreen shrub; flowers April-September. Palatability to livestock low or negligible.

Mimulus flemingii Munz.

M. parviflorus (Greene) Grant, Diplacus parviflorus Greene.

Range: 5 .

Site: Dry, well-drained, sun.

Fruit: Capsule.

A smail, evergreen shrub; flowers January-August.

Mimulus longiflorus (Nutt.) Grant.

Diplacus arachnoides Greene, $D$. longiflorus Nutt.

Long monkeyflower.

Range: 5 .

Site: Dry, sun.

Fruit: Capsule.

A small, profusely branched shrub. Palatability to livestock low or negligible. Mimulus parviflorus, see Mimulus flemingii.

Mimulus puniceus (Nutt.) Steud.

Diplacus puniceus Nutt.

Range: 5 .

Site: Dry, sun.

Fruit : Capsule.

A small to large, freely branched shrub. Palatability to livestock low or negligible.

Mitchella repens. L.

Range: 23, 24, 25, 26, 27, 28, 29, 30 .

Site: Dry, well-drained, moist, shade.

Fruit: Berry, available July-October, often persistent throughout the year.

An evergreen vine with creeping, matted, rooting stems; flowers April-June and often again in autumn.

Stomach records: Nine species of birds including ruffed grouse, bobwhite, sharp-tailed grouse, and greater prairie chicken. Observations: Fire species of birds, including ruffed grouse, bobwhite, and Canadian spruce grouse; much eaten by raccoon; frequently eaten by red fox.

Mohrodendron carolinum, see Halesia carolina.

Mohrodendron dipterum, see Halesia diptera.

Mohrodendron parvifiorum, see Halesia parvifiora. 
Momisia aculeata, see Celtis iguanaea.

Momisia pallida, see Celtis pallida.

Morella cerifera, see Myrica cerifera.

Mortonia greggii Gray.

Range: 17.

Site: Dry, well-drained, sun.

Fruit: Capsule.

A very small, everygreen shrub; usually occurs on limestone soil.

Mortonia scabrella Gray.

Range: 11.

Site: Dry, sun.

Fruit: Capsule, available in September.

A small, densely branched shrub; usually occurs on limestone soil. Not browsed by lirestock.

Mortonia sempervirens Gray.

Range: 17.

Site: Well-drained, sun.

Fruit: Capsule.

A small, leafy shrub.

Mortonia utahensis (Cov.) Rydb.

Mortonia.

M. scabrella utahensis Cov.

Range: 10.

Site: Dry, sun.

Fruit: Capsule.

A small, intricately branched shrub. Not browsed by livestock.

Morus spp.

Members of this genus are attacked by the Texas root rot caused by

Phymatotrichum omnivorum.

Stomach records (in addition to specific records): Forty-five species of birds, including ruffed grouse and bobwhite; opossum, red fox; composed 19.54 percent of fruit food of eastern skunk in Michigan.

observations (in addition to specific records) : Twenty-eight species of birds including wild turkey; cottontail rabbit.

Morus alba $\mathbf{L}$.

Range: 17, 20, 22, 25, 27, 28, 29.

White mulberry.

Site: Dry, well-drained, moist, sun.

Fruit: Compound drupe, available May-July.

A small to large, rapid-growing tree; a very variable species introduced from China but more or less naturalized in the regions indicated; some 10 varieties are distinguished in cultivation; $300,000-350,000$ seeds per pound.

Stomach records: Four species of birds.

Morus celtidifolia, see Morus microphylla.

Morus microphylla Buckl.

M. celtidifolia of Sarg., not H. B. K.

Texan mulberry.

Range: $10,11,14,16,17,20$

Site: Dry, well-drained, moist, sun.

Fruit: Compound drupe, avallable May-June.

A large shrub to small or large tree; usually occurs on limestone soil; thicket-forming; usually dioecious; possibly not distinct from $M$. celtidifolia, a Mexican species.

Observationss Gambel, scaled, and Mearns quail ; many' songbirds; highly palatable the year round to captive deer.

Morus nigra $\mathbf{L}$.

Range: 17, 21, 22, 23, 24, 26, 27, 28, 29 .

Black mulberry.

Site: Dry, well-drained, sun.

Fruit: Compound drupe, available June-August.

A small to large tree introduced ultimately from Persia but more or less naturalized in the regions indicated; 200,000 seeds per pound. 
Morus rubra $\mathrm{L}$.

Range: 16, 17, 18, 19, 20, 21, 22, 23, 24, 25, 27, 28, 29, 30 .

Red mulberry.

Site: Dry, well-drained, moist, sun.

Fruit: Compound drupe, available May-August.

A small to large, rapid-growing tree; monoecious or dioecious; root system shallow; short-lived; much attacked by insects and fungi; wood used commercially to some extent; seed generally not very fertile; grows on various soils ; 200,000 seeds per pound; a large-fruited and everbearing varlety is known.

Stomach records: Twenty-one species of birds, including bobwhite.

Observations: Twenty-one species of birds; much eatell by Carolina fox squirrel; leaves refused by captive marsh rabbits. .

Mozinna spathulata, see Jatropha spathulata.

Muscadinia munsoniana, see Vitis munsoniana.

Muscadinia rotundifolia, see Vitis rotundifolia.

Myrica spp.

Propagation of all species is by seed stratified and sown in spring; propagation by cuttings is considered difficult; most species grow in acid soil.

Stomach records (in addition to specific records): Sixty species of birds, including ruffed grouse and bobwhite. Observations (in addition to specific records) : Hungarian partridge, ring-necked pheasant, white-tailed deer.

Myrica asplenifolia $\mathrm{L}$.

Comptonia peregrina (L.) Coult.

Sweetfern.

Range: 22, 23, 24, 25, 26, 27, 28.

Site: Dry, well-drained, sun.

Fruit: Nutlet, available September-October.

A small shrub; often forms very dense colonies, especially on poor, sterile soils, often to the exclusion of other growth; often a pasture weed; a pioneer in burned-over areas northward.

Observations: Ruffed grouse, prairie sharp-tailed grouse; white-tailed deer.

Myrica californica Cham. (pl. 21, C).

Pacific waxmyrtle.

Range: 1,5 .

Site: Dry, well-drained, moist, sun, shade.

Fruit: Waxy, nutllke, available July-June.

A large shrub to small or large tree; evergreen; occurs in sandy soil, salt marshes, or other situations; produces suckers; somewhat thicket forming.

Stomach records: Five species of birds, including California quail.

Myrica carolinensis Mill.

Cerothamnus carolinensis (Mill.) Tidest.

Bayberry.

Range: 20, 24, 26, 27, 28, 29, 30 .

Site: Dry, well-drained, moist, sun, shade.

Fruit: Waxy, nutlike, available June-April or longer.

A small to large, almost evergreen shrub; occurs in sandy, or dry, sterile soil ; 55,500 seeds per pound.

Stomach records: Thirty-eight species of birds, including ruffed grouse, bobwhite, and ring-necked pheasant. Observations: Sixteen species of birds, including bobwhite, ranks with $M$. cerifera as twentieth on the list of quail food plants of the Southeast. (Some of these observations may apply wholly or in part to $M$. cerifera).

Myrica cerifera L. (pl. 22, A).

Morella cerifera (L.) Small, Cerothamnus ceriferus (L.) Small.

Waxmyrtle.

Range: $20,24,28,29,30,31,32$.

Site: Well-drained, moist, sun, shade.

Fruit: Waxy, nutlike, avallable August-October.

A small to large shrub or rarely a small to large tree; evergreen; grows in sandy or sterile, often acid soil.

Stomach records: Forty-one species of birds including ruffed grouse, bobwhite, and wild turkey. Observations: Six species of birds including bobwhite; ranks with $M$. caroliniana as twentieth on the list of quail food plants of the Southeast; leaves refused by captive marsh rabbits. (See also $M$. carolinensis.) 

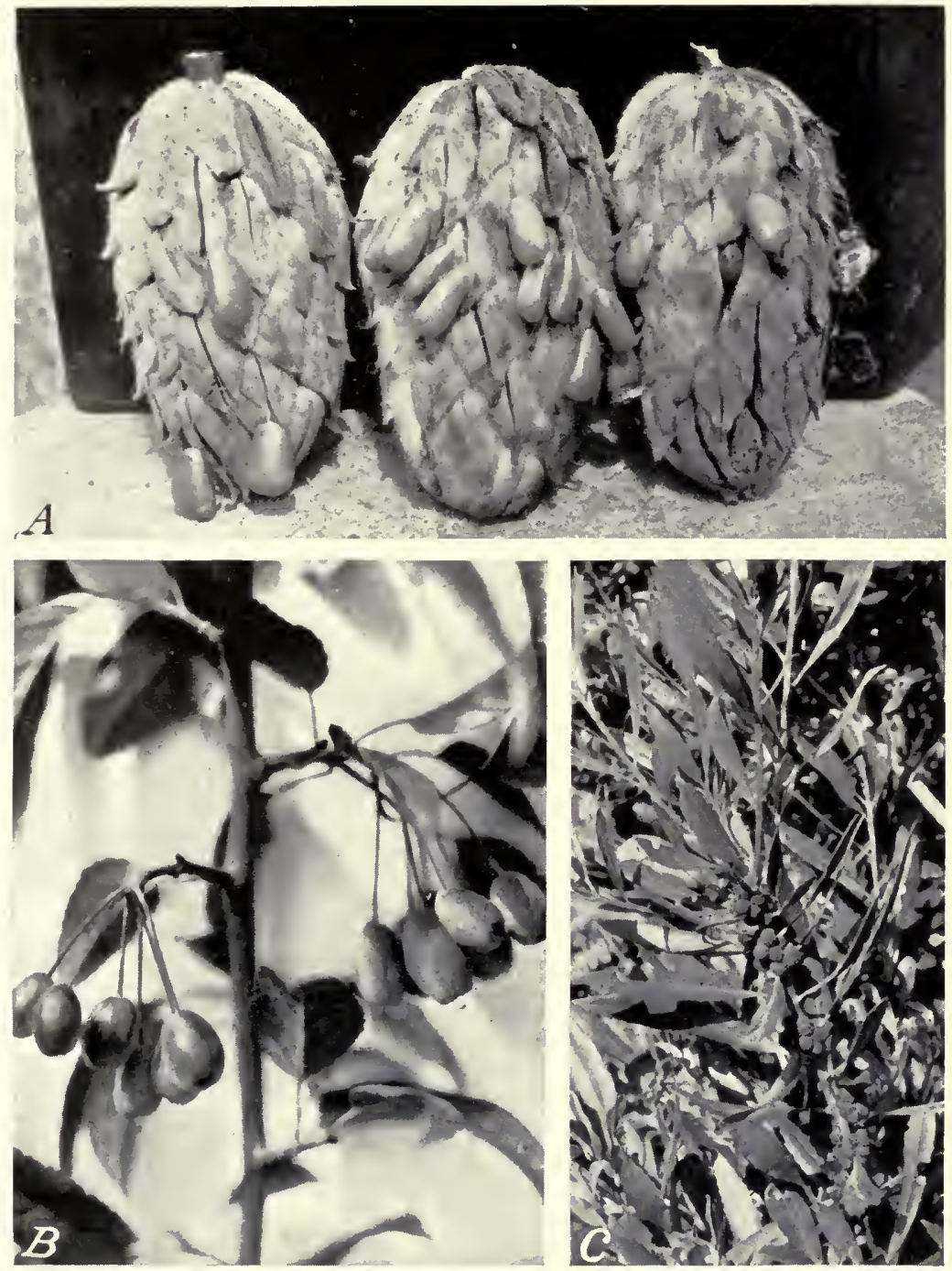

A, Magnolia grandiflora. The fruit of the evergreen magnolia is of particular appeal to wild turkey. The fleshy red drupes, extruded from the conelike structure, are characteristic of magnolias. B, Malus fusca. The Oregon crab apple, ordinarily found in moist soils, may prove of value in stream-bank control. The fruits, though much smaller than those of eastern species, are similarly used by man. $C$, Mfyrica californica. The fruit of the Pacific waxmyrtle will probably be found to occupy the same place in the diet of western birds that the fruits of eastern waxmyrtles do in the diet of eastern birds. 

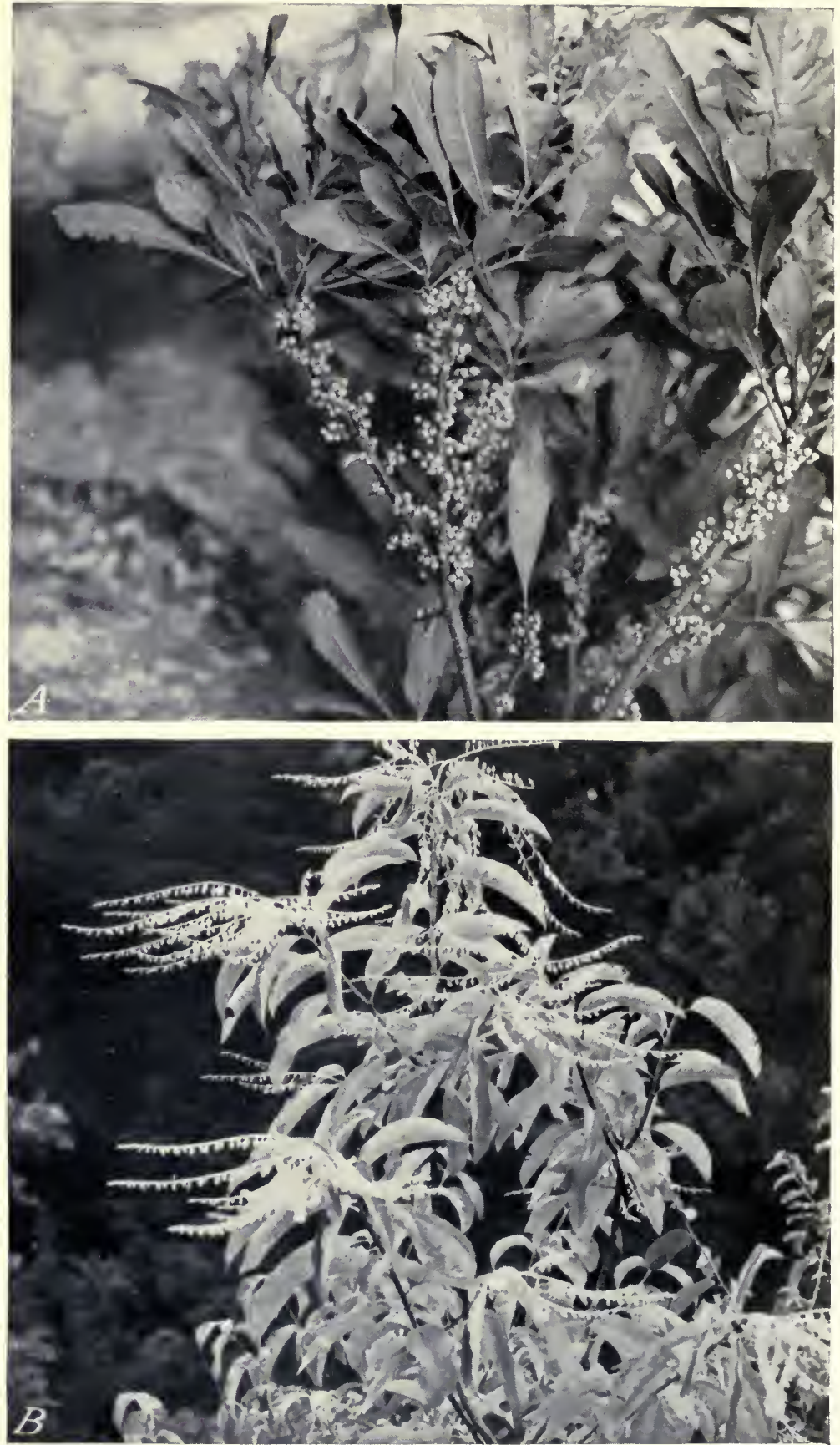

A, Myrica cerifera. The fruits of this sand-inhabiting shrub have been found in the stomachs of 41 kinds of birds. In sand-dune control, such wildlife use may considerably enhance the value of plantings of the species. B, Oxydendrum arboreum. The ornamental flowers of the sourwood, of use in honey production, entitle this species to consideration in erosion-control planting along roadsides. (Photograph by Department of the Interior.) 
Myrica gale L.

Range: $1,2,4,21,23,24,26,27$.

Sweetgale.

Site: Moist, sun.

Fruit: Waxy, nutlike, available August-September.

A small to large shrub; often occurs in acid soil.

Observations: Prairie sharp-tailed grouse; casually browsed by northeru white-tailed deer.

Myrica hartwegii Wats.

Sierra sweetbay.

Range: 4.

Site: Well-drained, sun.

Fruit: Waxy, nutlike.

A small to large shrub.

Myrica inodora Bartr.

Cerothamnus inodorus (Bartr.) Small.

Range: 29, 30 .

Site: Well-drained, moist, sun.

Fruit: Waxy, nutlike.

A large shrub to small or large tree; evergreen.

Myrica pumila (Michx.) Small.

Dwarf waxmyrtle.

M. cerifera pumila Michx., Cerothamnus pumilus (Michx.) Small.

Range: 29,30 .

Site: Dry, sun, shade.

Fruit: Waxy, nutlike, available May-October.

A small evergreen shrub; occurs in sandy or acid soils.

Observations: Bird stomach records for $M$. cerifera should be consulted for this species.

Negundo aceroides, see Acer negundo.

Negundo californicum, see Acer negundo.

Negundo interius, see Acer negundo.

Negundo negundo, see Acer negundo.

Negundo nuttallii, see Acer negundo.

Negundo texanum, see Acer negundo.

Neillia alternans, see Physocarpus alternans.

Neillia capitata, see Physocarpus capitatus.

Neillia malvacea, see Physocarpus malvaceus.

Neillia opulifolia, see Physocarpus opulifolius.

Neltuma glandulosa, see Prosopis chilensis.

Neltuma juliflora, see Prosopis chilensis.

Neltuma velutina, see Prosopis chilensis.

Nemopanthus mucronata (L.) Trel.

Mountain-holly.

Illicoides mucronata Britt.

Range: 21, 22, 23, 24, 26, 27.

Site: Well-drained, moist, sun.

Fruit: Drupe, available July-September.

A small to large shrub; usually occurs in bogs; about 1,600 berries per pound.

Stomach records: Ruffed grouse, robin.

Neopieris mariana, see Xolisma mariana.

Neopieris nitida, see Xolisma lucida.

Neostyphonia integrifolia, see Rhus integrifolia.

Neostyphonia ovata, see Rhus ovata.

Neowashingtonia robusta, see Washingtonia robusta. 
Nephropetalum pringlei Robins. and Greenm.

Range: 17.

Site: Dry, well-drained, sun.

A small shrub.

Fruit: Capsule.

Nicotiana glauca Graham.

Range: 1, 3, 5, 10, 11, 17, 20.

Tree tobacco.

Site: Dry, well-drained, molst, sun, shade.

Fruit: Capsule.

A large shrub to small tree; evergreen; introduced from South America, but naturalized in the regions indicated; foliage sparse, furnishing little soil cover; a pioneer in eroded areas; reputed to be poisonous.

Observations: Especially attractive to hummingbirds.

Nintooa japonica, see Lonicera japonica.

Nuttallia cerasiformis, see Osmaronia cerasiformis.

Nyssa sp.

Observations (in addition to specific records) : Red-headed woodpecker.

Nyssa aquatica Marsh.

Range: $25,29,30$.

Site: Moist, shade.

Fruit: Drupe, not available in October.

A large tree; wood not durable, used commercially to some extent.

Stomach records: Ten species of birds, including bobwhite and wild turkey.

Observations: Four species of birds.

Nyssa biflora Wait.

Range: 28, 29, 30.

Swamp black gum.

Site: Moist, sun, shade.

Fruit: Drupe, available August-September.

A large tree; wood of little importance commercially.

Stomach records: Four species of birds, including bobwhite and wild turkey.

Nyssa ogeche Marsh.

Range: 29, 30.

Site: Moist, sun.

Fruit: Drupe, available July-August, persistent until NovemberDecember.

A large shrub, or more commonly a small to large tree; very rare and local; fruits much larger than those of other species, and edible.

Siomach records: Opossum. An important source of honey.

Nyssa sylvatica Marsh.

Range: 20, 22, 24, 25, 26, 27, 28, 29, 30 .

Black gum.

Site: Well-drained, moist, sun, shade.

Fruit: Drupe; available September-October, persistent until May or falling at once.

A large tree; root system deep, widespreading, as well as superficiai ; resistr ant to fire; not wind-firm; coppices after cutting; wood not durable in soil, used commercially; without notable insect enemies; $3,000-4,000$ seeds per pound.

Stomach records: Thirty-two species of birds, including ruffed grouse, bobwhite, wild turkey, ring-necked pheasant, and greater prairie chicken; Louisiana white-talled deer. Observations: Twenty-four species of birds, including ruffed grouse; greatly preferred food of wild turkey; captive marsh rabbit; favorite food of black bear; white-tailed deer.

Obione confertifolia, see Atriplex confertifolia.

Obione hymenelytra, see Atriplex hymenelytra.

Obione lentiformis, see Atriplex lentiformis.

obione polycarpa, see Atriplex polycarpa.

Odostemon aquifolius, see Berberis aquifolium.

Odostemon dictyotus, see Berberis californicum.

Odostemon fascicularis, see Berberis californicum and B. pinnata. 
Odostemon fremontii, see Berberis fremontii.

Odostemon haematocarpus, see Berberis haematocarpa.

Odosteman nervosus, see Berberis nervosa.

odostemon nevinil, see Berberis nevinii.

odostemon nutkanus, see Berberis aquifolium.

Odostemon pumllus, see Berberis pumila.

Odostemon repens, see Berberis repens.

odostemon trifoliolatus, see Berberis trifoliolata.

Odostemon wilcoxil, see Berberis wilcoxii.

olneya tesota Gray.

Desert ironwood.

Range: 10, 11.

Site: Dry, well-drained, sun.

Fruit: Legume, avallable August-September.

A large shrub to small or large tree; flowers May-June; evergreen; somewhat spiny; foliage rather dense; 2,000 seeds per pound.

Observations: Hooded orioles; hummingbirds ; much used as roosts by Gambel quail ; bighorn.

The species is attacked by a mistletoe (Phoradendron californicum) which produces fruits attractive to many berry-eating birds. Of some value as a forage for livestock.

Oplopanax horridum (Small) Miquel.

Devilsclub.

Fatsia horrida (Small) B. and H., Echinopanax horridum Decne. and Planch., Ricinophyllum horridum (Small) Nels. and MacBr.

Range: 1, 2, 4, 12, 13, 24.

Site: Dry, well-drained, moist, shade.

Fruit: Drupe, available July-October.

A large, straggling, large-leafed, very thorny shrub; flowers May-June.

Observations: Preferred food of Olympic wapiti.

Opulaster alabamensis, see Physocarpus stellatus.

Opulaster alternans, see Physocarpus alternans.

Opulaster australis, see Physocarpus opulifolius.

Opulaster bracteatus, see Physocarpus bracteatus.

Opulaster capitatus, see Physocarpus capitatus.

Opulaster glabratus, see Physocarpus glabratus.

Opulaster intermedius, see Physocarpus stellatus and $P$. opulifolius.

Opulaster monogynus, see Physocarpus monogynus.

Opulaster opulifolius, see Physocarpus opulifolius.

Opulaster pauciflorus, see Physocarpus malvaceus.

Oreocallis davisiae, see Leucothoë davisiae.

Osmanthus americanus (L.) Benth. and Hook.

Amarolea americana (L.) Small.

Range: 29, 30.

Site: Well-drained, moist, sun, shade.

Fruit: Drupe, available in September.

Usually a large shrub to small tree or rarely a large tree; evergreen; often occurs in sandy soil ; flowers March-April.

Osmaronia cerasiformis (Torr. and Gray) Greene.

Nuttallii cerasiformis Torr. and Gray.

Range: 1, 2, 4.

Site: Well-drained, shade.

Fruit: Drupe, available July-August.

A small to large shrub; flowers March-April; fruit pulp bitter in some regions, sweet in others, but not poisonous.

Observations: Greedily eaten by many birds and mammals. Apparently of little value as forage for livestock. 
Ostrya baileyi Rose.

Bailey hophornbeam.

Range: 11, 16, 19.

Site: Dry, well-drained, sun.

A small tree.

Fruit: Nutlet.

0strya knowltonii Cov.

Range : 9, 11.

Western hophornbeam.

Site: Dry, well-drained, sun.

Fruit: Nutlet.

A large shrub to small tree.

Ostrya virginiana (Mill.) Koch.

Range: $15,18,20,21,22,23,24,25,27,28,29,30$.

Hophornbeam.

Site: Dry, well-drained, moist, sun, shade.

Fruit: Nutlet, available August-October.

A small, very slow-growing tree. Var. glandulosa (Spach) Sarg., the more northern form, has been noted to be possibly the same as $O$. baileyi.

Stomach records: Five species of birds including ruffed grouse, bobwhite, ptarmigan; white-tailed deer; composed 14.73 percent of winter food of ruffed grouse in New York. Observations: Five species of birds, including ruffed. grouse, ring-necked pheasant; staple food of northern sharp-tailed grouse in Quebec; white-tailed deer, cottontail rabbit.

Oxycoccus erythrocarpus, see Hugeria erythrocarpa.

Oxycoccus macrocarpus, see Vaccinium macrocarpon.

Oxycoccus oxycoccus, see Vaccinium oxycoccus.

Oxycoccus palustris, see Vaccinium oxycoccus.

oxydendrum arboreum (L.) DC. (pl. 22, B).

Sourwood.

Andromeda arboreum $\mathrm{L}$.

Range: $25,27,28,29,30$.

Site: Dry, well-drained, sun, shade.

Fruit: Capsule, available September-October.

A large tree; flowers June-August; rarely attacked by insects or diseases; wood sometimes used locally.

Stomach records: White-tailed deer. A good bee plant.

Oxytenia acerosa Nutt.

Range: 9, 10.

Site: Dry, sun.

Fruit: Achene.

A large shrub, leafless and rushlike, or with leaves; often occurs on alkaline soil. Not eaten by livestock and considered poisonous to cattle by stockmen. Pachistima canbyi Gray.

Cliffgreen.

Range: 27 .

Site: Dry, well-drained, sun, shade.

Fruit: Capsule, available August-September.

A small evergreen shrub; flowers April-May; occurs on limestone and other soils; creeping branches root.

Stomach records: White-tailed deer.

Pachistima myrsinites (Pursh) Raf.

Range: 1, 2, 4, 9, 12, 13, 14.

Site: Dry, well-drained, moist, sun, shade.

Fruit: Capsule, available July-September.

A small evergreen shrub; flowers May-July; densely branched, very leafy; sometimes nearly prostrate.

Stomach records: Richardson's grouse; mountain sheep, black-tailed deer, plains white-tailed deer. Occasionally browsed by livestock; rarely causes livestock poisoning.

Pachysandra procumbens Michx.

Range : $25,27,28,29,30$.

Pachysandra.

Site: Well-drained, sun, shade.

Fruit: Capsule.

A small evergreen shrub; flowers April-May; often occurs on calcareous soil ; forms large clumps by means of rootstocks. 
Padus alabamensis, see Prunus alabamensis.

Padus australis, see Prunus australis.

Padus caroliniana, see Prunus caroliniana.

Padus cuthbertii, see Prunus cuthbertii.

Padus nana, see Prunus virginiana.

Padus demissa, see Prunus demissa.

Padus eximia, see Prunus eximia.

Padus melanocarpa, see Prunus demissa.

Padus pumicea, see Prunus virginiana.

Padus rufula, see Prunus virens.

Padus valida, see Prunus valida.

Padus virens, see Prunus virens.

Padus virginiana, see Prunus virginiana.

Palmerocassia wislizenii, see Cassia wislizenii.

Papyrius papyrifera, see Broussonetia papyrifera.

Parkinsonia aculeata L.

Horsebean.

Range: $10,11,16,17,20,30$.

Site: Dry, well-drained, moist, sun.

Fruit: Legume.

A large shrub to small or large spiny tree; occurs in rich, sandy soils; introduced from tropical America; generally free from pests ; resistant to saline conditions; often grown for hedges. Of local importance as an emergency fodder for livestock.

Parkinsonia, see Oercidium.

Parosela arborescens (Torr.) Heller.

Mohave dalea.

$P$. neglecta Parish, Dalea arborescens Torr., Psorodendron arborescens (Torr.) Rydb.

Range: 10.

Site: Dry, sun.

Fruit : Legume.

A small, spiny shrub with slender branches; flowers April-May.

Parosela argyrea (Gray) Heller.

Dalea argyrea Gray.

Range: 11, 17.

Site: Dry, sun.

Fruit: Legume.

A small, stout shrub.

Parosela californica, see Parosela fremontii. .

Parosela emoryi (Gray) Heller.

Dalea emoryi Gray, Psorothamnus emoryi (Gray) Rydb.

White dalea.

Range: 5, 10.

Site: Dry, sun.

Fruit: Legume.

A small, densely branched shrub; flowers April-May; occurs on sandy and other soils.

Parosela formosa (Torr.) Vail.

Dalea formosa Torr.

Feather peabush.

Range: 9, 10, 11, 14, 16, 17, 20.

Site: Dry, sun.

Fruit: Legume.

A small, much-branched shrub; flowers April-October; very handsome in flower.

Observations: Particularly palatable to captive deer. Of little importance as forage for livestock. 
Parosela fremontii (Torr.) Vail.

Fremont dalea.

Dalea fremontii Torr., D. wheeleri Vail, Psorodendron fremontii (Torr.)

Rydb.

Range: 9, 10, 11 .

Site: Dry, sun.

Fruit: Legume.

A small shrub; flowers April-June.

Var. saundersii McB., (Dalea saundersii Parish, P. saundersii Abrams), occurs in region 10. Var. johnsonii (Wats.) Jeps., (Dalea johnsonii Wats., P. johnsonii Vall., Dalea amoena Wats., Psorodendron johnsonii Rydb.), is more leafy than the species. Var. californica (Wats.) Jeps., (Dalea californica Wats., $P$. californica (Wats.) Vail, Psorodendron californicum Rydb.), has also been described.

Parosela frutescens (Gray) Vail.

Dalea frutescens Gray.

Range: $11,14,16,17,20,30$.

Site: Dry, sun.

Fruit: Legume.

A small, very drought-resistant shrub. Somewhat browsed by livestock.

Parosela greggii (Gray) Heller.

Dalea greggii Gray.

Range: 10, 11.

Site: Dry, sun.

Fruit: Legume.

A small shrub. Much browsed by livestock.

Parosela johnsonii, see Parosela fremontii.

Parosela neglecta, see Parosela arborescens.

Parosela polyadenia (Torr.) Heller.

Dalea polydeni Torr., Psorothamnus polyadenius (Torr.) Rydb., Psorothamnus subnudus Rydb.

Range: 9, 10.

Site: Dry, sun.

Fruit: Legume.

A small to large, stout, intricately-branched, spiny shrub; flowers May-June; occurs in sandy and other soils.

Parosela sanctae-crucis Rydb.

Range: 11.

Site: Dry, sun.

Fruit: Legume.

A small shrub.

Parosela saundersii, see Parosela fremontii.

Parosela schottil (Torr.) Heller.

Mesa dalea.

Dalea schottii Torr., Psorodendron schottii (Torr.) Rydb., Psorodendron puberulum Rydb.

Range: 10.

Site: Dry, sun.

Fruit: One-seeded legume, available in June.

A small to large, slender, densely branched shrub; flowers in April; commonly occurs in gravelly soils; somewhat spinose.

Parosela scoparia (Gray) Heller (pl. 23, A).

Dalea scoparia Gray, Psorothamnus scoparius (Gray) Rydb.

Range: 11.

Site: Dry, sun.

Fruit: Legume.

A small, broomlike shrub with rigid, slender stems and minute leares; very drought resistant; occurs on sandy soil and has been recommended for use as a sand-binding plant.

Parosela sessilis (Gray) Rydb.

Dalea wislizenii sessilis Gray.

Range: 10, 11.

Site: Dry, sun.

Fruit: Legume.

A small shrub. 
Parosela spinosa (Gray) Heller.

Dalea spinosa Gray, Psorodendron spinosum (Gray) Rydb.

Smoketree.

Range: 10.

Site: Dry, sun.

Fruit: Legume.

A large shrub to small tree; flowers January-July; leaves few, early deciduous; very spiny; fruit produced rarely, very showy in flower. Not eaten by livestock.

Parosela thyrsiflora (Gray) Vail.

$P$. soralea humilis Mill., Dalea thyrsiflora Gray.

Range: 11, 17.

Site: Dry, sun.

Fruit: Legume.

A small shrub.

Parosela wheeleri, see Parosela fremontii.

Parryella fllifolia Torr. and Gray.

Range: 11.

Site: Dry, sun.

Fruit: One-seeded legume.

A small, much-branched shrub; grows in sandy soil.

Parthenium incanum H. B. K.

$P$. ramosissimum DC.

Mariola.

Range: 11, 17.

Site: Dry, sun.

Fruit: Achene.

A small shrub; furnishes a small amount of rubber. New shoots and flower heads sometimes nibbled by livestock.

Parthenium ramosissimum, see Parthenium incanum.

Parthenocissus spp.

Observations (in addition to specific records) : Frequently eaten by red fox; much eaten by raccoon in New York.

Partlienocissus heptaphylla (Buckl.) Small.

$P$. texana Rehder, Ampelopsis heptaphylla Buckl., Psedera heptaphylla

(Buckl.) Greene.

Range: 16, 17, 20.

Site: Dry, well-drained, sun.

Fruit: Berry.

A high-climbing vine; occurs on rocky or sandy soil; propagated by cuttings; easily transplanted.

Parthenocissus hirsuta, see Parthenocissus quinquefolia.

Parthenocissus laciniata, see Parthenocissus vitacea.

Parthenocissus quinquefolia (L.) Planch. (pl. 25, A).

Virginia creeper.

Psedera quinquefolia (L.) Greene, Ampelopsis quinquefolia Michx.

Range: 11, 15, 16, 17, 18, 19, 20, 21, 22, 23, 24, 25, 26, 27, 28, 29, 30.

Site: Well-drained, moist, sun, shade.

Fruit: Berry available August-February.

A high-climbing or trailing vine; occurs in sand, loam, clay, and other soils; claimed to remain on fence posts not following the wires when planted along fences; has been used as a cover on rocky roadsides; resists grazing well; 12,000-19,000 seeds per pound.

Var. hirsuta (Donn.) Rehder (P. hirsuta (Donn.) Small), is more hairy than the species.

Stomach records: Thirty-eight species of birds including ruffed grouse, bobwhite, wild turkey, ring-necked pheasant, and greater prairie chicken; skunk. observations: Eleven species of birds, including ruffed grouse, ring-necked pheasant, wild turkey; white-tailed deer, eastern chipmunk.

Parthenocissus texana, see Parthenocissus heptaphylla.

Parthenocissus vitacea (Knerr.) Hitche.

P. laciniata Small, Psedera vitacea Greene.

Virginia creeper.

Range: 9, 11, 14, 15, 16, 17, 20, 22, 25, 27, 28, 29.

Site: Well-drained, moist, sun, shade.

Fruit: Berry, available August-October. 
Usually a low and rambling, or rarely a high-climbing, vine; occurs in a variety of soils; very rapid growing and vigorous; growth increases with water, but comparatively drought resistant; claimed not to stay on fence posts but to follow the wires when planted along fences.

Observations: Birds especially fond of the berries.

Pasania densiflora, see Lithocarpus densiflora.

Pavonia lasiopetala Scheele.

$P$. wrightii Gray, Malache lasiopetala (Scheele) Kuntze.

Pavonia.

Range: 17, 20, 30 .

Site: Dry, sun.

Fruit : Capsule.

A small shrub; ornamental in cultivation. Apparently has little browse value.

Pavonia wrightil, see Pavonia lasiopetala.

Pectis taxifolia, see Chrysactinia mexicana.

Pentstemon antirrhinoides Benth.

Range : 5.

Snapdragon pentstemor.

Site: Dry, sun.

Fruit: Capsule.

A small to large, bushy evergreen shrub; flowers April-May.

Var. microphyllus (Gray) Munz and Johnst., occurring ill regions 10, 11, and 14, is considered fair browse for sheep and goats in times of scarcity.

Pentstemon breviflorus LindI.

Range: 4.

Site: Dry, sun.

Fruit: Capsule.

A small to large evergreen shrub; forms loose clumps. Locally useful as sheep browse.

Pentstemon cordifolius Benth.

Heartleaf pentstemon.

Range: 5 .

Slte: Dry, sun.

Fruit: Capsule.

A large, loosely branched shrub; flowers June-July.

Pentstemon lemmonii Gray.

Bush beardtongue.

Range: 4.

Site: Dry, well-drained, moist, sun.

Fruit: Capsule.

A small shrub; flowers July-August. Locally valuable as sheep browse.

Pentstemon rothrockil Gray.

Rothrock pentstemon.

Range: 4.

Site: Dry, well-drained, sun.

Fruit: Capsule.

A small, loosely branched shrub.

Peraphyllum ramosissimum Nutt.

Range : 4, 12, 13, 14.

Site: Dry, well-drained, sun.

Fruit: Pome, available July-September.

A small to large, intricately branched, rigid shrub; flowers April-May; fruit occasionally not formed owing to late frosts but very abundant when produced; rarely does well in cultivation.

Apparently of some value as sheep and cattle browse, although this is questioned by some authorities.

Persea borbonia (L.) Spreng.

Redbay.

Tamala borbonia (L.) Raf.

Range: $17,29,30$.

Site: Moist, sun.

Fruit: Drupe, available August-September.

A small to large evergreen tree; flowers April-June; wood formerly used commercially.

Stomach records: Two species of birds. 
Persea humilis Nash.

Tamala humilis (Nash) Small.

Silkbay.

Range: 17, 30.

Site: Well-drained, sun.

Fruit: Drupe.

A large shrub to small tree; evergreen; usually occurs in sandy soil.

Persea palustris, see Persea pubescens.

Persea pubescens (Pursh) Sarg.

Swampbay.

P. palustris Sarg., Laurus carolinensis pubescens Pursh, Tamala pubescens (Pursh) Small.

Range: 20, 28, 29, 30, 31.

Site: Moist, sun.

Fruit: Drupe, available in September, long persistent.

A small to large evergreen tree; flowers May-July.

Stomach records: Bobwhite, fish crow.

Petrophytum acuminatum, see Spiraea caespitosa.

Petrophytum caespitosum, see Spiraea caespitosa.

Peucephyllum schottil Gray.

Range : 10.

Site: Dry, sun.

Fruit: Achene.

A small to large, much-branched, small-leaved shrub.

Phenianthus sempervirens, see Lonicera, sempervirens.

Philadelphus spp.

Mockoranges. soil.

Most species are free from insects and diseases, and most occur in neutral

Stomach records (in addition to specific records): Mountain sheep.

Philadelphus argenteus, see Philadelphus microphyllus.

PhHladelphus argyrocalyx Woot.

P. ellipticus Rydb.

Mockorange,

Range: $9,11,14$.

Site: Dry, well-drained, sun.

Fruit: Capsule.

A large shrub.

Philadelphus californicus, see Philadelphus lewisii.

Philadelphus columbianus, see Philadelphus levisii.

Philadelphus confusus, see Philadelphus lewisii.

Philadelphus ellipticus, see Philadelphus argyrocalyx.

Philadelphus gloriosus, see Philadelphus inodorus.

Philadelphus gordonianus, see Philadelphus lewisii.

Philadelphus grandiflorus, see Philadelphus inodorus.

Philadelphus hirsutus Nutt.

II ockorange.

Range: 27, 28.

Site: Well-drained, moist, sun, shade.

Fruit: Capsule.

A large, straggling shrub; flowers May-June.

Philadelphus inodorus $\mathrm{I}$.

Range : 27, 28, 29.

Mockorange.

Site: Dry, well-drained, sun.

Fruit: Capsule.

A large shrub; flowers May-Jume.

Var. grandiflorus (Willd.) Gray, (P. grandiflorus Willd., P. gloriosus Beadle) has larger flowers and occurs within range of the species.

Philadelphus intectus, see Philadelphus pubescens. 
Philadelphus lewisil Pursh.

Mockorange.

$P$. confusus Piper.

Range: 4, 6, 7, 8, 12 .

Site: Well-drained, moist, sun.

Fruit: Capsule.

A large shrub; flowers May-August.

Var. californicus Gray, ( $P$. californicus Benth.) occurs in region 4, Var. gordonianus Jeps. ( $P$. gordonianus Lindl., $P$. columbianus Koehne.) occurs in regions 1,2 , and 4.

Observations: Foliage browsed by deer in California; seed eaten by quail and squirrels.

Philadelphus mearnsii Evans.

Range: 14.

Mockorange.

Site: Well-drained, sun.

A small shrub.

Fruit: Capsule.

Philadelphus microphyllus Gray.

$P$. argenteus $\mathbf{R y d b}$.

Mockorange.

Range: 4, 11, 13, 14 .

Site: Well-drained, sun.

Fruit: Capsule.

A large shrub; flowers June-A ugust.

Observations: Mexican bighorn.

Phlladelphus occidentalis Nels.

Range: 9, 11, 12, 13, 14.

Mockorange.

Site: Well-drained, sun.

Fruit: Capsule.

A small shrub; flowers July-August, very floriferous and fragant.

Philadelphus pubescens Loisel.

Mockorange.

Range: 25, 29.

Site: Well-drained, sun.

Fruit: Capsule.

A large shrub; flowers June-July.

Var. intectus Moore, ( $P$. intectus Beadle) occurs in region 25.

Philadelphus pumilus, see Philadelphus serpyllifolius.

Phlladelphus serpyllifolius Gray.

P. pumilus Rydb.

Range : 5, 9, 10, 11, 16, 20.

Site: Dry, sun.

Frult: Capsule.

A small, straggling shrub; branches commonly bent down at their ends.

Photinia arbutifolia Lindl. (pl. $23, B$ ).

Heteromeles arbutifolia Roem. H. salicifolia (Presl.) Abrams.

Christmasberry.

Range : 3, 4, 5 .

Site: Dry, well-drained, sun, shade.

Fruit: Berrylike pome, available October-February.

A large, bushy shrub to small or rarely large tree; evergreen; foliage dense; somewhat tolerant of saline conditions; not inflammable; crown sprouts vigorously after a fire or when cut; a pioneer on eroded land; extensively used for Christmas greens.

Stomach records: Four species of birds, including California quail; raccoon.

Observations: Seven species of birds, including band-tailed pigeon; of slight importance as browse for mule deer; much eaten by birds generally.

Phyllodoce spp.

Stomach records (in addition to specific records): Mountain sheep.

Phyllodoce breweri (Gray) Heller.

Red heather.

Range: 4.

Site: Well-drained, sun.

Fruit: Capsule.

A small evergreen shrub; flowers July-August. 

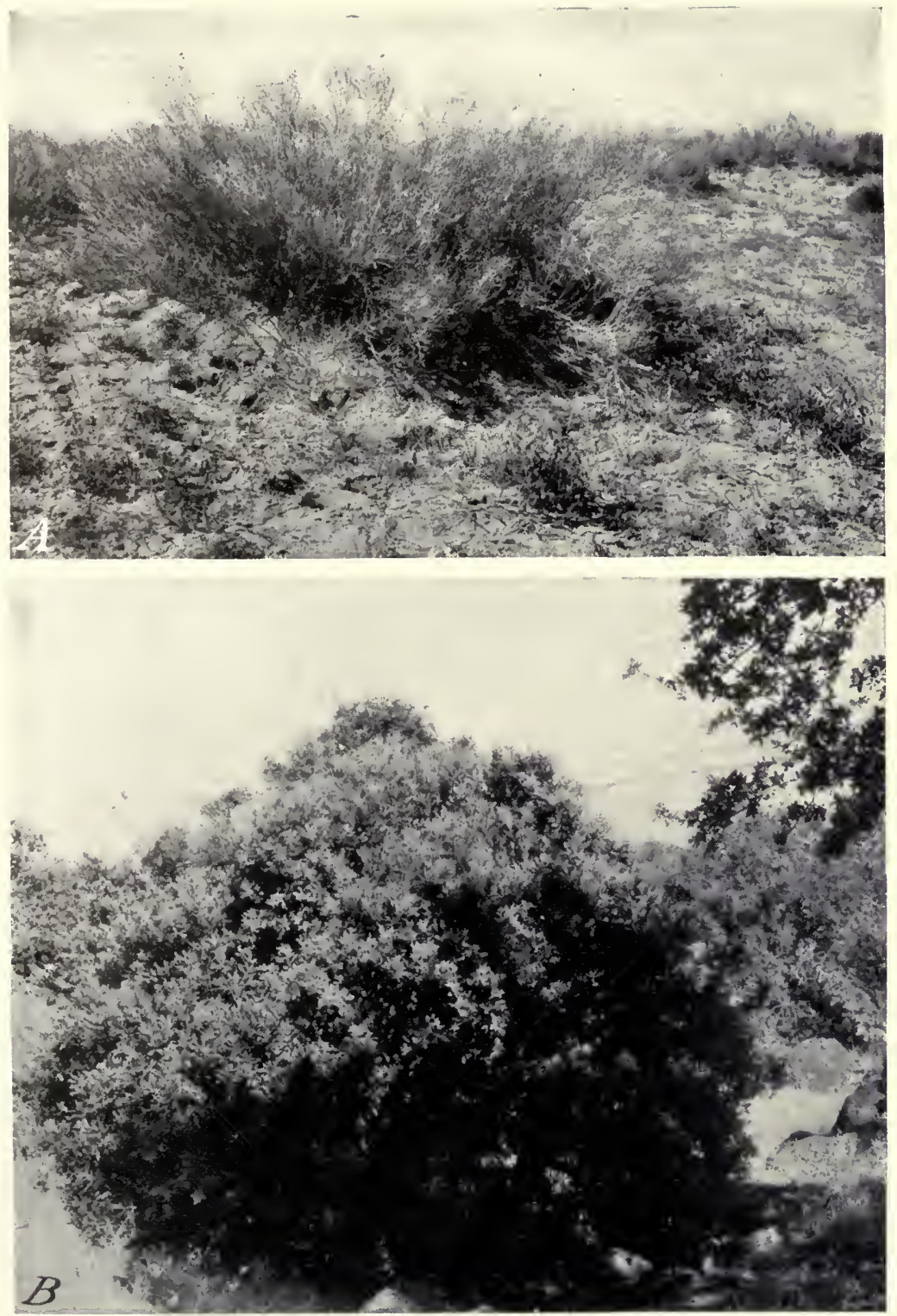

A, Parosela scoparia, a species which may prove of value on sandy soil. The foliage, such as it is, is fully developed in this specimen. $B$, Photinia arbutifolia. The toyon is one of the more important shrubs in California for soil- and wildlife-conservation plantings. 

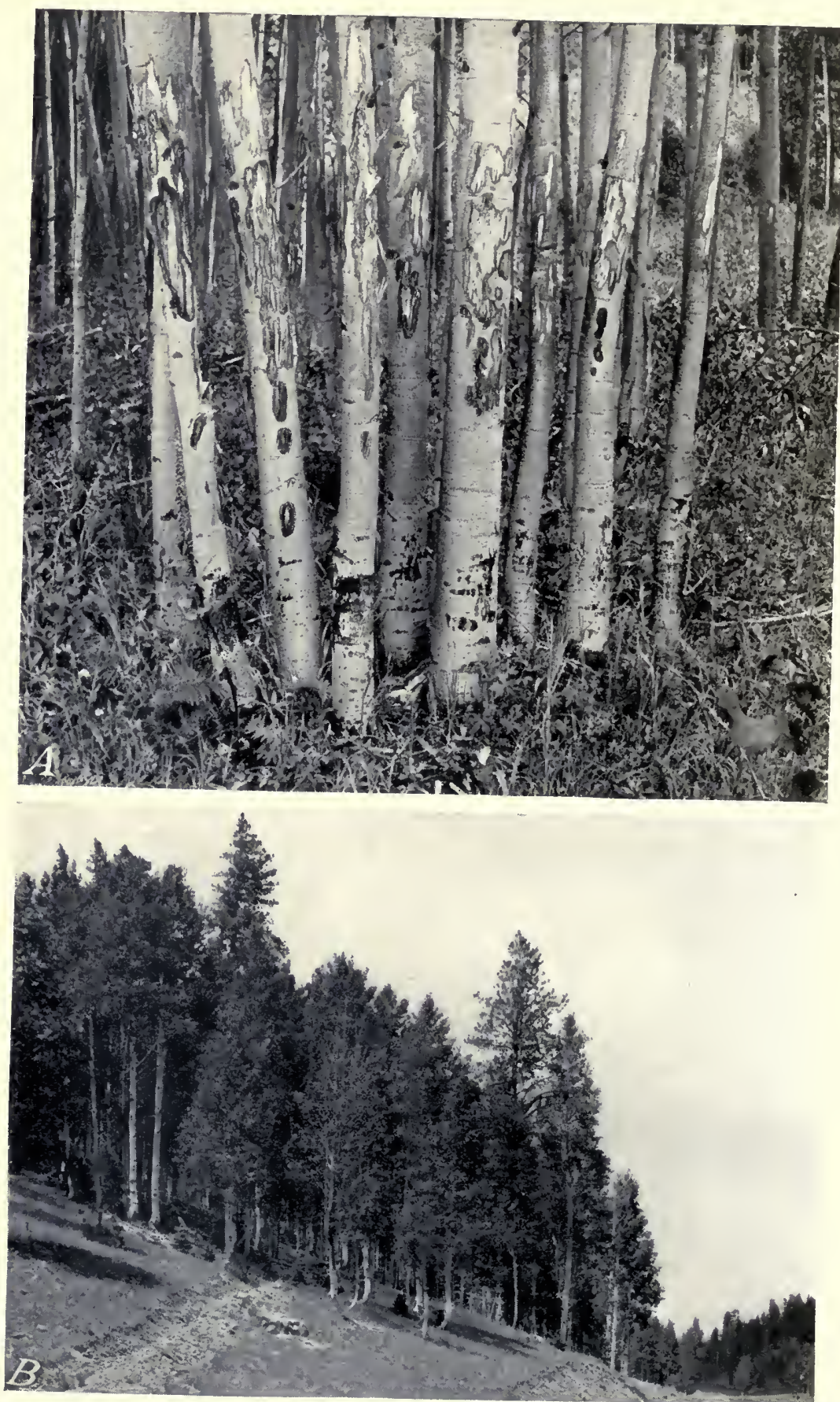

Populus tremuloides: $A$, Tooth marks indicate that quaking aspen is sometimes used as food by elk. It is species of great importance as soil cover and wildlife food. (Photographs ouaking aspen, a rapid-growing 
Phyllodoce caerulea (L.) Bab.

Andromeda caerulea L., Bryanthus taxifolius Gray.

Mountainheath. Range: 26.

Site: Dry, well-drained, sun.

Fruit: Capsule.

A small evergreen shrub; flowers July-August.

Phyllodoce empetriformis (Sm.) Don.

Red heather.

Range: 1, 4, 12, 13.

Site: Well-drained, sun.

Fruit: Capsule.

A small evergreen shrub; flowers July-August.

Stomach records: Mountain sheep.

Phyllodoce glanduliflora (Hook) Cov.

Menziesia glanduliflora Hook.

Range: 1, 4, 12.

Site: Well-drained, sun.

Fruit: Capsule.

A small, tufted, matted evergreen shrub.

Physocarpus spp.

Most species are free from insects and diseases; most occur in neutral soil; propagation of all species is much easier by cuttings than by seed.

Physocarpus alternans (Jones) Howell.

Neillia alternans Jones, Opulaster alternans (Jones) Heller.

Range: 10 (at high elevations), 13.

Site: Dry, well-drained, sun.

Fruit: Follicle.

A small to large, densely branched shrub; flowers June-August.

Physocarpus australis, see Physocarpus opulifolius.

Physocarpus bracteatus (Rydb.) Rehd.

Opulaster bracteatus Rybd.

Range: 13.

Site: Well-drained, sun.

Fruit: Follicle.

A small to large shrub; flowers June-July.

Physocarpus capitatus (Pursh) Kuntze.

opulaster capitatus (Pursh) Kuntze, Neillia capitata Greene.

Ninebark.

Range: 1, 2, 4.

Site: Well-drained, moist sun, shade.

Fruit: Follicle.

A large, often gregarious shrub; flowers April-July.

Physocarpus glabratus (Rydb.) Rehd.

Opulaster glabratus Rydb.

Range: 13.

Site: Well-drained, sun.

Fruit: Follicle.

A small, very floriferous shrub; flowers June-July.

Physocarpus intermedius, see Physocarpus opulifolius.

Physocarpus malvaceus Kuntze.

$P$. pauciflorus Piper, Spiraea pauciflora Nutt., Neillia malvacea Greene.

Range: 4, 7, 12, 13.

Site: Well-drained, sun.

Fruit: Follicle.

A small to large shrub; flowers May-July ; root system comparatively shallow; rhizomes long. Considered fairly good browse for sheep, goats, and occasionally cattle.

Physocarpus michiganensis, see Physocarpus opulifolius.

Physocarpus missouriensis, see Physocarpus opulifolius. 
Physocarpus monogynus (Torr.) Coult.

$P$. torreyi Maxim., Opulaster monogynus ('Torr.) Kuntze.

Range: 11, 12, 13, 14, 15 .

Site: Well-drained, sun.

Fruit: Follicle.

A small shrub; flowers May-July.

Physocarpus opulifolius (L.) Maxim.

Ninebark.

$P$. australis (Rydb.) Rehd., $P$. michiganensis Daniels, Spiraea opulifolia L., Opulaster opulifolius (L.) Kuntze, O. pauciflorus (Torr. and Gray) Heller, Neillia opulifolia Brew. and Wats.

Range: $22,23,24,25,26,27,28,29,30$.

Site: Well-drained, moist, sun, shade.

Fruit: Follicle, available September-October.

A large shrub; flowers June-July ; 1,600,000 seeds per pound.

Var. intermedius (Rydb.) Robins., (P. intermedius Schneid., O. intermedius Rydb., P. missouriensis Daniels) occurs also in regions 15, 16, 18, and 19.

Stomach records: Three species of birds

Physocarpus pauciflorus see Physocarpus malvaceus.

Physocarpus stellatus (Rydb.) Rehd.

Opulaster stellatus Rydb., Opulaster alabamensis Rydb., Opulaster intermedius Small, not Rydb.

Range: $28,29,30$.

Site: Well-drained, moist, sun.

Fruit: Follicle.

A small to large shrub; flowers May-June.

Physocarpus torreyi, see Physocarpus monogynus.

Picea spp.

Spruces.

Evergreen, monoecious trees with cones maturing in a single season ; important timber trees and unsurpassed as producers of paper pulp.

Stomach records (in addition to specific records): Twenty-eight species of birds, including ruffed grouse, Hungarian partridge, ring-necked pheasant ; porcupine, black-tailed deer. Observations (in addition to specific records): Fifteen species of birds, including spruce, ruffed, Franklin, and dusky grouse; much eaten by Cascade squirrel; Sierra chickaree, Richardson's squirrel, Townsend's chipmunk, Allen's chipmunk, Digger squirrel, Fremont pine. squirrel, spruce squirrel, Olympic black bear, Arizona porcupine ; rarely cut for building material, not food, by beaver.

Picea alba, see Picea australis and P. canadensis.

Picea albertiana Brown.

P. glauca albertiana (Brown) Rehd.

Western white spruce.

Range: 4, 12, 15 (Black Hills).

Site: Well-drained, sun.

Fruit: Cone.

A large evergreen tree.

Picea amabilis, see Abies amabilis.

Picea australis Small.

P. alba Chapm.

Range: 27.

Site: Dry, well-drained, sun.

Fruit: Cone.

A large evergreen tree.

Picea breweriana Wats.

Range: 4.

Site: Dry, well-drained, sun, shade.

Fruit: Cone; ripe in early fall, seed shed September-October, cones soon falling.

A large evergreen tree; slow growing; wood of no importance commercially; has proven unsatisfactory in cultivation; very local in distribution; good seed years every 2 or 3 years. 
Picea canadensis (Mill.) B. S. P.

P. glauca (Moench.) Voss., $P$. alba Link.

White spruce.

Range: 12, 15 (Black Hills), 21, 23, 24, 26, 27.

Site: Well-drained, sun, shade.

Fruit: Cone; seeds shed in September, cones soon falling.

A large evergreen tree; root system shallow and spreading; wood of great importance commercially; seed produced locally every year but heavy seed production occurs at intervals of 5 to 8 years; vitality of seed persistent; $130,000-$ 230,000 seeds per pound. Ten horticultural varieties are in cultivation; longlived.

Stomach records: Crossbill ; mountain sheep, plains white-tailed deer. Observations: Eight species of birds ; porcupine, red squirrel, moose; casually browsed by northern white-tailed deer.

Picea engelmannil (Parry) Engelm.

Engelmann spruce.

$P$. parryana Sarg.

Range: $4,9,11,12,13,14,15$.

Site: Dry, well-drained, moist, sun, shade.

Fruit: Cone; mature in August, seeds shed by October, cones falling by spring.

A large evergreen tree; root system shallow; growth fair on dry soil; longlived; wood much used commercially; 0.5 pound of seed per bushel of cones, $69,000-376,000$ seeds per pound; germination 34-68 percent; seeds produced in quantity locally about every 3 years; seed vitality persistent, as much as $30-50$ percent after 5 years when properly stored.

Stomach record: Three species of birds, including dusky grouse; black-tailed deer, plains white-tailed deer. Observations: Red squirrel, porcupine, bighorn.

Ficea glauca, see Picea canadensis.

Picea mariana (Mill.) B. S. P.

$P$. mariana brevifolia Rehd.

Black spruce.

Range : 23, 24, 26, 27.

Site: Well-drained, moist, sun, shade.

Fruit: Cone; mature in August, persistent many years.

A large evergreen tree; commonly most abundant on acid soils; root system shallow and widespreading; slow growing; somewhat damaged by insects and fungi; wood of little importance commercially; seeds produced abundantly at irregular intervals; 540,000 seeds per pound, vitality persistent; prostrate branches often root.

Stomach records: Blue heron, crossbill. Observations: Seven species of birds ; snowshoe hare, porcupine.

Picea parryana, see Picea engelmannii and $P$. pungens.

Picea pungens Engelm.

P. parryana (Andre) Parry.

Blue spruce.

Range: $9,12,13,14$.

Site: Well-drained, moist, sun.

Fruit: Cone; available in August, seeds shed in September, most cones persistent until the following autumn.

A large evergreen tree; root system shallow in wet soils; deeper in dry soils; long-lived; wood of least value commercially of the spruces; abundant seed crops produced every 2 or 3 years; $80,000-130,000$ seeds per pound, germination 48-77 percent, vitality long persistent; brilliant color of forms (as Koster spruce) gradually lost with age.

Stomach records: Black-tailed deer. Observations: Three species of birds.

Picea rubens, see Picea rubra.

Picea rubra Link.

$P$. rubens Sarg.

Red spruce.

Range: 27 .

Site: Well-drained, moist, sun, shade.

Fruit: Cone; available in September, most seeds falling by late fall, a few the following spring. 
A large evergreen tree; root system shaliow and superficial; slow growing, especially when young; often attacked by bark beetles, much wind and frost damaged; rarely injured by fire; wood of great importance commercially; $130,000-140,000$ seeds per pound, abundantly produced at intervals of 6 to 8 years, germination $50-75$ percent.

Observations: Much eaten by red squirrel.

Picea sitchensis (Bong.) Carr.

Range: 1 .

Site: Well-drained, moist, sun.

Fruit: Cone; available in September, seeds soon shed, cones soon falling.

A large evergreen tree; root system shaliow in moist soil, much deeper in drier ones; seedlings, but not mature trees, are tolerant of shade; wood much used commercially; about 260,000 seeds per pound, germination 40 percent; abundant seed crops every 2 or 3 years; seeds with persistent vitality; seedlings sensitive to frost.

Stomach records: Bufflehead; stone caribou. Observations: Much eaten by Douglas' squirrel.

Pickeringia montana Nutt.

Xylothermia montana (Nutt.) Greene.

Chaparral pea.

Range: 4,5 .

Site: Dry, sun.

Fruit: Legume.

A small to large, densely branched, spiny, evergreen shrub, flowering MayJune; fruits sparingiy produced; crown sprouts after fire; uncovered roots will sprout; nodules resembling those of Ceanothus occur on the roots in very large clusters. Var. tomentosa (Abrams) Johnst. is a hairy form.

Observations: California mule deer.

Picrothamnus desertorum, see Artemisia spinescens.

Pleris floribunda (Pursh) Benth.

Andromeda floribunda Pursh.

Range: 27.

Site: Weli-drained, moist, sun.

Fruit: Capsule.

A small evergreen shrub with dense foliage; usually occurs on acid soil; flowers April-June; $1,250,000$ seeds per pound.

Stomach records: White-tailed deer.

Pleris mariana, see Xolisma mariana.

Pieris nitida, see Xolisma lucida.

Pinckneya pubens Michx.

Fevertree.

Range: $29,30$.

Site : Moist, sun, shade.

Fruit: Capsuie, available September-October.

A large shrub to small or large tree; flowers May-June; very rare and local in occurrence.

Pinus spp.

Pines.

Probably the most important genus of timber trees in the world, and the largest of the coniferous group. All are evergreen trees. The cones produced may be from 1 to 24 inches long and the seeds are usually, but, not always, winged. Some seeds are shed at once, others require up to three seasons to mature. About 70 species are known in the world, 36 occurring in North America.

Stomach records (in addition to specific records): Forty-seven species of birds, including ruffed grouse, bobwhite, dusky grouse, ring-necked pheasant, Richardson's grouse, and sharp-tailed grouse; mountain sheep, opossum, blacktailed deer, spotted skunk, gray fox, white-tailed deer. Observations (in addition to specific records) : Thirty species of birds, including ruffed grouse, bandtailed pigeon, dusky grouse, mourning dove, ring-necked pheasant; ranks third in the list of quail food plants for southeastern United States; an emergency food of pinnated grouse; important food of porcupine; Siskiyou chipmunk, Allen's chipmunk, Merriam's chipmunk, Douglas' squirrel, Cascade squirrel, Richardson's squirrel, Digger squirrel, Arizona gray squirrel, red spruce squir- 
rel, rock squirrel, Fremont squirrel, many flying squirrels; Texas plains coyote, New Mexico black bear, Olympic black bear.

The five-needled pines are variously restricted by plant-quarantine measures, and movement or planting of stock should be preceded by conferences with State and/or Federal authorities. Certain species, because of their susceptibility to Woodgate rust, are prohlbited from interstate movement in the State of New York.

Pinus albicaulis Engelm.

Apinus albicaulis (Engelm.) Rydb.

Whitebark pine.

Range: 1, 4, 12, 13.

Site: Dry, well-drained, sun.

Fruit: Cone; matures in August-September of the second season, persistently closed; seeds only liberated through the rotting of the cones.

A large shrub to small or large tree; leaves five; often dwarfed and prostrate, especially in alpine situations; more tolerant of shade in moist than in dry situations; susceptible to blister rust; wood soft and brittle; 2,800 seeds per pound, germination 20 percent.

Observations: Clark's crow ; porcupine, bighorn, red squirrel ; seeds commonly extracted by squirrels and birds from the cones.

Pinus apacheca Lemmon.

Range : 11, 14.

Site: Well-drained, sun.

Fruit: Cone; available September-October of the second season, soon falling.

A large evergreen tree; leaves commonly three in a cluster; taproot well developed in seedling stages; at first rapid growing, later slower; intolerant of shade except when rery young; wood hard.

Observations: Seeds much eaten by birds and rodents.

Pinus aristata Engelm.

Range : $9,10,11,13,14$.

Site: Dry, well-drained, sun.

Fruit: Cone; mature in August of the second season, seeds shed September-October.

A large evergreen tree; five-needled; often stunted at high elevations; withstands prolonged drought in its native habitat; wood not used commerciaily; susceptible to blister rust; 16,000 seeds per pound, 0.88 pound of seed per bushel of cones; germination of seed 66 percent.

Observations: Seeds much eaten by rodents; porcupine.

Pinus arizonica Engelm.

$P$. ponderosa arizonica Shaw.

Arizona pine.

Range: 11, 14.

Site: Dry, well-drained, sun.

Fruit: Cone mature August-September of the second season, seeds soon shed, cones soon falling.

A large evergreen tree; commonly five-needled; intolerant of shade except in seedling stages; wood of limited use commercially.

Pinus attenuata Lemmon.

P. tuberculata Gord.

Knobcone pine.

Range: $4,10$.

Site: Dry, well-drained, sun.

Fruit: Cone; mature in September of the second season, persistent, closed as long as 30 years, opening when heated.

A small to large evergreen tree; three-needled; very resistant to drought in its native habitats; easily killed by fire; intolerant of shade; wood soft; seeds produced annually abundantly; seed vitality persistent.

Pinus australis Michx.

$P$. palustris Mill., in part.

Longleaf pine.

Range : 28, 29, 30.

Site: Dry, well-drained, sun.

Fruit: Cone; seeds shed October-November of the second season, cones soon falling.

A large evergreen tree; three-needled; often occurs in sandy soil; possesses a massive taproot; very intolerant of shade; does not form dense woods; fairly 
resistant to fire; susceptible to bark beetle damage as well as rot; difficult to transplant; a timber tree of the flrst importance, the principal source of rosin and turpentine in the United States.

Stomach records: Seven species of birds, including bobwhite. Observations: Crossbill; much eaten by Carolina fox squirrel and other squirrels.

Pinus balfouriana Murr.

Foxtail pine.

Range: 4.

Site: Dry, well-drained, sun.

Fruit: Cone; mature in August of the second season, seeds shed in September, cones soon falling.

A small to large evergreen tree; five-needled; endures extreme drought in its native habitat; intolerant of shade; wood soft, of little importance commercially; susceptible to blister rust.

Observations: Porcupine; much eaten by birds and rodents; of slight importance as browse for mule deer.

Pinus banksiana Lam.

$P$. divaricata (Ait.) Du Mont.

Range: $23,24,26,27$.

Site: Dry, well-drained, moist (rare), sun.

Fruit: Cone; mature in September of the second season, seeds shed irregularly over several years; cones persistent 12 to 25 years.

A large evergreen tree; two-needled; often occurs in sandy or rocky soil; at first rapid growing, later slower; intolerant of shade; except for the attacks of Peridermium cerebrum, generally free from most conifer diseases; has been successfully established in the sand-hill section of western Nebraska; wood decays rapidly in the soll, much used commercially; $105,000-164,000$ seeds per pound, germination 54 percent.

Stomach records: One species of bird. Observations: Porcupine.

Pinus brachyptera Engelm.

Rocky mountain yellow pine.

$P$. ponderosa scopulorum Engelm., $P$. scopulorum (Engelm.) Lemmon.

Range: $9,11,12,13,14,15$.

Site: Dry, well-drained, sun.

Fruit: Cone; mature in August of the second season, seeds shed in September, comes soon falling.

A very large evergreen tree; three-needled; forms a long taproot in seedling stages but laterals form later; grows on almost any kind of soil; rapid growing especially in juvenile stages; very intolerant of shade; resistant to fire; susceptible to red rot in pure stands and much attacked by insects; wood not durable in the soil, of great importance commercially; $10,000-20,000$ seeds per pound, germination 37-61 percent, about 5,000 usable plants per pound of seed.

Stomach records: Richardson's grouse, mountain sheep, plains white-tailed deer, black-tailed deer. Observations: Fire species of birds; white-tailed squirrel, Richardson's pine squirrel, Abert's squirrel, tassel-eared squirrel, spruce squirrel, Say's ground squirrel, chestnut-mantled ground squirrel. Records of utllization of $P$. ponderosa Douglas may apply partially to this species.

Pinus caribaea Morel.

$P$. heterophylla (Ell.) Sudw.

Range : $30,31,32$.

Site: Well-drained, moist, sun.

Fruit: Cone; mature in October, seeds shed the following spring.

A large evergreen tree; two- to three-needled; occurs in sandy and other soils; rapid growing; subject to red heart or red rot especially northward; wood hard, strong, tough, durable, of value commercially; susceptible to Woodgate rust; 15,500 seeds per pound, germination $36-85$ percent.

Pinus cembroides Zucc.

Mexican piñon.

Range: 11, 14, 16, 17.

Site: Dry, well-drained, sun.

Fruit: Cone; ripe in September, seeds shed by October, cones soon falling.

A small or rarely large, bushy, evergreen tree; commonly three-needled; slow growing; intolerant of shade; wood used for fuel; only the scales in the middle of the cone bear seeds; 1,500 seeds per pound, vitality transient.

observations: Thick-billed parrot; birds and rodents. 
Pinus chihuahuana, see Pinus leiophylla.

Pinus clausa (Engelm.) Vasey.

Sand pine.

Range: 30 .

Site: Dry, well-drained, sun.

Fruit: Cone; persistent, closed for 3 or 4 years.

A large evergreen tree; occurs commonly on poor sandy soil; wood of some importance locally for lumber; 74,000 seeds per pound.

Pinus contorta Loud.

Shore pine.

Range: 1 .

Site: Dry, well-drained, moist, sun.

Fruit: Cone; mature August-September of the second season; seeds shed at once or over a period of years; cones long, persistent.

A large shrub to commonly a small, or rarely, a large tree; two-needled; commonly occurs on sandy soil; close to the sea often forms dense, impenetrable thickets; $40,000-280,000$ seeds per pound. Var. bolanderi Vasey is a canelike dwarf 2 to 5 feet high, with very small cones.

Observations: Of slight importance as browse for mule deer.

Pinus coulteri Don.

Range: 4.

Site: Dry, well-drained, sun.

Fruit: Cone; mature in August of the second season; seeds shed from October onward; cones persistent 5 or 6 years.

A large evergreen tree; three-needled; slow growing; wood rarely used except for fuel; 1,250 seeds per pound; vitality transient.

Observations: Of slight importance as browse for mule deer.

Pinus divaricata, see Pinus banksiana.

Pinus echinata Mill.

P. mitis Michx.

Shortleaf pine.

Range: $20,25,27,28,29,30$.

Site: Dry, well-drained, sun.

Fruit: Cone; mature in September of the second season; persistent 2 or more years after ripening.

A large evergreen tree; commonly two-needled; occurs in sandy and other soils; forms a long taproot as a seedling and additional strong laterals later; grows poorly on lime or too rich soils; crowded out by loblolly pine on moist soils; growth rate at first rapid, later slower; fairly free from fungus and insect pests; fairly resistant to fire; stump sprouts but sprouts seldom develop merchantable trees; wood hard, resinous, much used commercially; 41,000-84,000 seeds per pound; germination 30-90 percent.

Stomach records: Three species of birds. Observations: Pine siskin, crossbill. Pinus edulis Engelm.

$P$. cembroides edulis Voss., Caryopitys edulis (Engelm.) Small.

Piñon.

Range: $9,11,13,14,16,17$.

Site: Dry, well-drained, sun.

Fruit: Cone; mature August-September ; seeds shed September-October, cones soon falling.

A small to large evergreen tree; two- or sometimes three-needled; very resistant to drought in its natural habitat; very slow growing; wood soft, decaying rapidly; locally used for fuel and fence posts; 1,700 seeds per pound.

Stomach records: Nine species of birds, including Mearn's quail. Observations: Seven species ${ }^{5}$ of birds, including Merriam turkey, thick-billed parrot; porcupine, Hopi chipmunk, ${ }^{5}$ Magdalena chipmunk, ${ }^{6}$ cliff chipmunk, ${ }^{6}$ rock squirrel, ${ }^{5}$ New Mexico black bear, antelope ground squirrel, ${ }^{5}$ mule deer; ${ }^{\circ}$ much eaten by birds and mammals. Seeds eaten by livestock, especially goats.

Pinus flexilis James.

Apinus flexilis (James) Rydb.

Limber pine.

Range: $4,5,11,12,13,14,15$.

Site: Dry, well-drained, sun.

Fruit: Cone; mature in September, seeds shed by the end of October, cones soon falling.

5 These records may refer to other species of piñon pines as well, since the animals wers stated merely to be eating piñon nuts. 
A large evergreen tree; five-needled; adapted to many kinds of soil ; seedlings form large taproots; difficult to transplant; very intolerant of shade; susceptible to blister rust; most seed is produced by trees in open stands at low altitudes; long-lived; wood soft, of value commercially; $5,400-5,600$ seeds per pound, germination 36 percent.

Stomach records: Two species of birds, including grouse. Observations: Porcupine, spruce squirrel, Fremont squirrel; much eaten by birds and squirrels generally.

Pinus glabra Walt.

Range: $29,30$.

Spruce pine.

Site: well-drained, moist, sun, shade.

Fruit: Cone.

A large evergreen tree; two-needled; growth remarkably rapid; wood soft, of some value commercially; 77,500 seeds per pound.

Stomach records: Bobwhite, squirrel.

Pinus heterophylla, see $P$. caribaea.

Pinus jeffreyi Murr.

$P$. ponderosa jeffreyi Vasey.

Range: 4.

Site: Well-drained, sun.

Fruit: Cone.

A large evergreen tree; three-needled; appears to intergrade with $P$. ponderosa; tolerant of shade in early stages, later intolerant; produces seed prolifically; wood of great commercial value; $3,100-3,300$ seeds per pound; seeds from large cones complete their germination 2 weeks before seeds from small cones.

Stomach records: Four species of birds, including quail and Mount Pinos grouse. Observations: Clark's nutcracker; Columbian gray squirrel, Sierra chickaree, Tahoe chipmunk, Allen's chipmunk; commonly much eaten by birds and rodents; of slight importance as browse for mule deer.

Pinus lambertiana Dougi.

Range: 1, 4, 10.

Sugar pine.

Site: Well-drained, sun.

Fruit: Cone; ripe in August of the second season, seeds shed in October, cones falling the following year.

A very large evergreen tree; largest of all pines; five-needled; susceptible to blister rust; very intolerant of shade except in the seedling stage; wood soft, of high commercial value; 2,300 seeds per pound, germination 65 percent.

Observations: Porcupine, Columbian gray fox, Sierra chickaree, Allen's chipmunk, long-eared chipmunk, California gray squirrel; of slight importance as browse for mule deer.

Pinus lasiocarpa, see Abies lasiocarpa.

Pinus leiophylla Schlecht. and Cham.

$P$. chihuahuana Engelm., $P$. leiophylla chihuahuana Shaw.

Chihuahua pine.

Range: 11, 14

Site: Dry, well-drained, moist, sun.

Fruit: Cone; mature in September of the third season, often persistent closed 5 or more years.

A large evergreen tree; commonly three-needled; intolerant of shade; wood of importance commercially but only a small supply is known.

Observations: Much eaten by thick-billed parrots.

Pinus mitis, see Pinus echinata.

Pinus monophylla Torr. and Frem.

Singleleaf piñon.

P. cembroides monophylla Voss., Caryopitys monophylla (Torr. and Frem.)

Rydb.

Range: $4,5,9,10,13,14$.

Site: Dry, weli-drained, sun.

Fruit: Cone; mature in August of the second season, seeds shed in September.

A small to large, flat-topped evergreen tree; commonly one-needled; very local in occurrence; endures extreme drought in its native habitat; very slow growing; intolerant of shade; wood much used for fuel locally; 1,200 seeds per pound. 
Stomach records: Black-tailed deer. Observations: Seeds of great value generally for wildlife; of slight importance as browse for mule deer. Seeds are much used as food by Indians, and commonly eaten by livestock.

Pinus monticola Dougl.

Strobus monticola (Dougl.) Rydb.

Western white pine.

Range: $1,4,12$.

Site: Dry, well-drained, moist, sun.

Fruit: Cone; mature in September of the second season, seeds soon shed, cones soon falling.

A large evergreen tree; five-needled; seedlings with a large taproot, difficult to transplant; somewhat tolerant of shade in early stages, later intolerant; susceptible to blister rust; wood of great commercial value; most seed is produced by the dominant and codominant crown classes of trees; 14,000-29,000 seeds per pound, germination 18-44 percent; largest cones produce the bestquality seeds; in pure stands $21 / 2$ to 5 pounds of viable seed is produced per acre, in moderately good seed years; trees 70 to 100 years old produce a larger quantity of viable seed than older trees; seeds first borne by trees from 40 to 60 years of age; long-lived.

Observations: Say's chipmunk, porcupine; of slight importance as browse for mule deer.

Pinus muricata Don.

Range: 1,5 .

Bishop pine.

Site: Dry, well-drained, moist, sun.

Fruit: Cone; mature in August of the second season, persistent closed for many years.

A large evergreen tree; two-needled; grows especially well in water-soaked sand but thrives also in dry soil ; fairly tolerant of shade; an aggressive species ; adaptable to many difficult positions; wood of value commercially ; $18,000-60,000$ seeds per pound.

Pinus murrayana Balf.

$P$. contorta murrayana (Balf.) Engelm., P. contorta latifolia Wats.

Lodgepole pine.

Range: $2,4,10,12,13,14,15$.

Site: Dry, well-drained, moist, sun.

Fruit: Cone; mature August-September of the second season, seeds shed at once or orer a period of years.

A small to large evergreen tree; two-needled; intolerant of shade; easily killed by fire; comparatively free from fungi; not wind-firm; root system shallow, or deep on well-drained, deep soil ; susceptible to sunscald; 76,000-110,000 seeds per pound, germination 63 percent.

Stomach records: Sierra grouse; plains white-tailed deer. Observations: Three species of birds, including Franklin grouse; porcupine, Sierra chickaree, Fremont pine squirrel, red squirrel, Yosemite cony; western chipmunk; an important browse of deer and elk in the northern Rocky Mountains.

Pinus palustris, see also Pinus australis.

Pinus palustris Mill.

Range : 29,30 .

Swamp pine.

Site: Moist, sun.

Fruit: Cone.

A large evergreen tree; two-needled; grows particularly well near the sea; $4,000-8,000$ seeds per pound, germination $46-87$ percent. See $P$. australis for what has heretofor been known as the longleaf pine.

Pinus parryana Engelm.

$P$. cembroides parryana Voss., $P$. quadrifolia Parry.

Parry piñon.

Range: 5, 10.

Site: Dry, well-drained, sun.

Fruit: Cone; ripe in August of the second season, seeds shed before the middle of September.

A small to large evergreen tree; commonly four-needled; slow growing; somewhat tolerant of shade in the early stages; wood without commercial value.

observations: Seeds much eaten by birds and squirrels.

Pinus ponderosa Laws.

Western yellow pine.

Range: 4.

Site: Dry, well-drained, sun.

Fruit: Cone; ripe August-September of the second season, seeds soon shed, cones soon falling.

$130186^{\circ}-39-13$ 
A large evergreen tree; three-needled; wood of great commercial value.

Stomach records: Seven species of birds including California quail. Observations: Four species of birds including sooty grouse; porcupine, Columbian gray squirrel, Sierra chickaree, California gray squirrel; of outstanding importance as browse for mule deer. (Records of utilization of this species may apply partially to $\mathbf{P}$. brachyptera.)

Pinus pungens Lam.

Mountain pine.

Range : 25, 27.

Site: Dry, well-drained, sun.

Fruit: Cone; seeds shed in autumn of the second season or within 2 or 3 years, cones persistent 18 to 20 years but seeds often sterile with age.

A large evergreen tree; two-needled; rather slow growing; intolerant of shade; bears seed when 5 years old; often occurs on dry, gravelly slopes but grows also in moist clay; aggressive in old fie'ds; 40,500 seeds per pound, germination $60-90$ percent.

Pinus quadrifolia, see Pinus parryana.

Pinus radiata Don.

Monterey pine.

Range: 1, 5 .

Site: Well-drained, sun.

Fruit: Cone; mature in August of the second season, persistent closed 6 to 10 years, opening when heated.

A large, often flat-topped evergreen tree; three-needled; occurs naturally in only a few scattered colonies; short-lived in arid situations; does not thrive in wet soils; rapid growing; somewhat tolerant of shade; prolific annual seeder; wood little used because scarce; humus from the species accumulates rapidly ; tolerant of saline conditions; 20,000 seeds per pound.

Stomach records: Two species of birds.

Pinus remorata Mason.

$P$. radiata binata Lemmon.

Range: 5 .

Site: Dry, well-drained, sun.

Fruit : Cone.

A large evergreen tree; two-needled.

Pinus resinosa Ait.

Range: 23, 24, 26, 27.

Site: Dry, well-drained, sun.

Fruit: Cone; ripe in September, seeds soon shed, cones falling the next spring.

A large evergreen tree; two-needled; rapid growing; intolerant of shade; withstands severe cold and drought; resistant to fire; much more resistant to insects and diseases than white pine; rarely seeds abundantly; typical of, but not restricted to sandy soils; prunes itself early in close stands; wood not durable in soil, much used commercially; 30,000-69,000 seeds per pound, germination 50-87 percent; easily transplanted.

Stomach records: One species of bird. Observations: Cottontail rabbit.

Pinus rigida Mill.

Range: 26, 27.

Site: Dry, well-drained, moist, sun.

Fruit: Cone; mature the second season, opening slowly, persistent several years.

A large evergreen tree; three-needled; grows in dry, rocky, sandy, and other sterile soils; coppices when cut; rapid growing when established; extremely resistant to fire; wood somewhat used commercially; 35,000-73,000 seeds per pound, germination 70 percent.

Stomach records: Three species of birds including ruffed grouse; white-tailed deer. Observations: Seven species of birds; a preferred food of red squirrels.

Pinus sabiniana Dougl.

Range: 4.

Digger pine.

Site: Dry, well-drained, moist, sun.

Fruit: Cone; mature in September of the second season, seeds sher during several years, cones persistent several years longer. 
A large evergreen tree; three-needled; rapid growing, especially in moist soil; extremely drought resistant; scarcely resistant to tire; seedlings, but not older trees, tolerant of shade; susceptible to fungus attack; wood of little commercial value, easily decaying; vitality of seeds transient.

Observations: California gray squirrel; of slight importance as browse for mule deer.

Pinus scopulcrum, see Pinus brachyptera.

Pinus serotina Michx.

$P$. rigida scrotina (Michx.) Loud.

Pond pine.

Range: $28,29,30$.

Site: Moist, sun.

Fruit: Cone; some open, some remain closed after maturity.

A large evergreen tree; commonly three-needled; rapid growing; intolerant of shade; wood heavy, resinous; 56,000 seeds per pound, germination 70-90 percent.

Stomach rccords: Bobwhite.

Pinus strobiformis Engelm.

Mexican white pine.

Range: 11, 14.

Site: Dry, well-drained, sun.

Fruit: Cone; mature in September, seeds completely shed by the middle of October.

A large evergreen tree; five-needled; susceptible to blister rust; seedlings endure moderate shade; wood little used commercially; most seed produced at middle elevations; 2,700 seeds per pound.

observations: Much eaten by birds and squirrels.

Pinus strobus L.

Strobus weymouthiana Opiz., S. strobus (L.) Small.

Northern white pine.

Range: $21,22,23,24,27$.

Site: Well-drained, moist, sun, shade.

Fruit: Cone; mature in July of the second season, seeds discharged in September.

A large evergreen tree; five-needled; root system small, shallow; successful on sandy soils; commonly attacked by white-pine weevil and blister rust; wood of great importance commercially; numerous varieties distinguished in cultivation; 25,000 seeds per pound, germination 67 percent.

Stomach records: Six species of birds, including bobwhite; white-tailed deer. Observations: Eight species of birds; a preferred food of red squirrel; moose, snowshoe hare, cottontail rabbit, casually browsed by northern white-tailed deer.

Pinus taeda $\mathrm{L}$.

Range: $19,20,22,25,28,29,30$.

Loblolly pine.

Site: Dry, well-drained, moist, sun.

Fruit: Cone; opens slowly, seeds shed in late fall and winter, cones persist a year longer.

A large evergreen tree; three-needled; seedlings with a long taproot, older trees with a spreading root system; not commonly found on heavy clay or highly siliceous soils; rapid growing; tolerant of shade in earlier stages, later much less so; susceptible to diseases and insects; wood not durable, valuable commercially; invades and reforests abandoned fields very rapidly; 13,000 55,000 seeds per pound, germination $25-80$ percent.

Stomach records: Eight species of birds, including bobwhite.

Pinus torreyana Carr.

Range: 5 .

Site: Well-drained, sun.

Frult: Cone; mature in August of the third season, some seed shed in September, the rest remaining in the cone for several years.

A small to large evergreen tree; five-needled; often low, crooked, and sprawling in exposed situations; apparently intolerant of shade; wood of no importance commercially because scarce; slow growing; 657 seeds.per pound, prolific annual seeder; the rarest and with the most restricted range of any American pine.

Pinus tuberculata, see Pinus attenuata. 
Pinus venusta, see Abies venuista.

Pinus virginiana Mill.

Range: $25,27,28,29$.

Virginia pine.

Site: Dry, well-drained, sun.

Fruit: Cone; mature in Angust of the second season, opening slowly, persistent up to 4 years.

A large evergreen tree; two-needled; may grow on poor, light, sandy soils, but thrives best on clay, loam, or sandy loam; slow growing; intolerant of shade; damage by insects slight; not subject to any fungus threatening widespread destruction; short-lived; abundant seeder; 62,000 seeds per pound, percentage of fertile seeds high; wood somewhat used commerclally.

Stomach records: Six species of birds, including bobwhite; white-triled deer. Observations: Six species of birds.

Piptolepis phlllyreoldes, see Forestiera phillyreoides.

Pistacia mexicana, see Pistacia texana.

Pistacia texana Swingle.

P. mexicana of auths., not H. B. K.

Range: 11, 17.

Site: Dry, well-drained, moist, sun.

Fruit: Dry drupe.

A large shrub to small or rarely large tree; dioecious; leaves semievergreen; commonly occurs on limestone soils; as old trunks die new ones sprout from the base; highly drought resistant; vigorously recuperative; highly intolerant of shade; root system deep-penetrating; largest trees often staminate, smaller ones pistillate; seed commonly without an embryo when fruit is ripe. Leaves commonly eaten by goats.

Pitavia dumosa, see Cneoridium dumosum.

Pithecolobium brevifolium Benth.

Huajillo.

Havardia brevifolia (Benth.) Small, H. pallens (Benth.) Britt. and Rose, Zygia brcvifolia Sudw.

Range: 17.

Site: Well-drained, sun.

Fruit: Legume, arailable July-August.

A small to large spiny evergreen tree; commonly occurs in rich soils; thicket forming.

Of some importance as winter browse for sheep and goats.

Pithecolobium flexicaule (Benth.) Conlt.

Texas-ebony.

Acacia flexicanlis Benth., Siderocarpos flexicaulis (Benth.) Small, Zygia flexicaulis Sudw., Ebenopsis flexicaulis (Benth.) Britt. and Rose, Samanea flexicaulis MacBr.

Range: 17.

Site: Dry, well-drained, sun.

Fruit: Legume; available in September, pods never shed.

A large shrub to large tree; evergreen; spiny; slow growing; wood very durable; locally used for fence posts; very ornamental in bloom; seeds eaten by natives.

Pityothamnus pygmaeus, see Asimina pygmaea.

Pityothamnus angustifolius, see Asimina incana.

Pityothamnus incanus, see Asimina incana.

Planera aquatica (Walt.) Gmel.

Range: $20,25,29,30$.

Site: Moist, sun, shade.

Fruit: Dry, drupe, available April-May.

A small to large tree; fairly rapid growing, short-lived; wood not used commereially; somewhat cultivated; grows on many soils.

Stomach records: Four species of birds; composed 45.5 percent of food of 175 mallard ducks collected October-December in central Louisiana. Observations: Black duck; ring-neck duck; considered an important duck food; squirrels.

Observations (in addition to specific records): goldfinch, band-tailed pigeon. 
Platanus occidentalis $\mathrm{L}$.

Range: $16,20,21,22,24,25,26,27,28,29,30$.

Sycamore.

Site: Moist, well-dralned, sun.

Fruit: Achene; available in October, persistent through the winter.

A very large, spreading tree; root system shallow, wide spreading; rapid growing, long-lived; much decayed with age; grows on coal-stripped lands in Illinois; wood of importance commercially; 100,000-170,000 secds per pound, germination 5-10 percent, slow.

Stomach records: Mallard. Observations: Four species of birds; whitetailed deer; somewhat eaten by muskrat.

Platanus racemosa Nutt.

California sycamore.

Range : 3, 4, 5 .

Site: Well-drained, moist, sun.

Fruit: Achene.

A large tree; somewhat tolerant of alkali; trunk commonly leaning, horizontal, or even prostrate; wood not durable.

Observations: Goldfinch; California mule deer.

Platanus wrightil Wats.

Arizona sycamore.

Range: 10, 11.

Site: Well-drained, moist, sun.

A large tree.

Fruit: Achene.

Pluchea borealis, see Pluchea sericea.

Pluchea sericea (Nutt.) Cov.

Arrowwood.

Polypappus sericeus Nutt., Tessaria borealis DC., Pluchea borealis Gray., Berthelotia sericea Rydb.

Range: 9, 10, 11.

Site: Well-drained, moist, sun.

Fruit: Achene.

A large, willowlike shrub; flowers November-June; often forms dense, pure stands.

Observations: California mule deer. Somewhat nibbled by cattle and horses.

Pollomintha incana (Torr.) Gray.

Hedeoma incana Torr.

Range: 9, 11.

Site : Dry, sun.

Fruit: Nutlet.

A small shrub; commonly occurs on sandy soil ; will grow on gypsum deposits.

Polycodium caesium, see Vaccinium caesium.

Polycodium floridanum, see Vaccinium caesium.

Polycodium melanocarpum, see Vaccinium melanocarpum.

Polycodium neglectum, see Vaccinium neglectum.

Polycodium stamineum, see Vaccinium stamineum.

Polygala acanthoclada Gray.

Range: $9,10$.

Thorn polygala.

Site : Dry, sun.

Fruit: Capsule.

A large, spiny, much-branched shrub; forms densely interwoven mounds. Not eaten by livestock.

Polypappus sericeus, see Pluchea sericea.

Poncirus trifoliata, see Citrus trifoliata.

Popanax, see Aeacia.

Popanax schaffnerl, see Acacia tortuosa.

Popanax tortuosa, see Acacia tortuosa.

Populus spp.

Commonly large dioecious trees; occur on neutral soils; ordinarily rapid growing and short-lived; most cottonwoods appear to be fairly tolerant of salinity, especially $P$. fremontii. Members of the genus are attacked by the Texas root rot caused by Phymatotrichum omnivorum.

Stomach records (in addition to specific records): Ten species of birds, including ruffed grouse, dusky grouse, California quail, valley quail, sharp-tailed 
grouse; composed 12.46 percent of winter food of eastern ruffed grouse in New York, and 8.8 percent of winter food for the entire northeastern United States; mountain sheep. Observations (in addition to specific records): Twelre species of birds including spruce gronse, Columbian sliarp-tailed grouse, staple winter food of prairic sharp-tailed gronse; staple food of greater prairie chicken, northern sharp-tailed grouse, pinnated, gray, and ruffed grouse; important food of white-tailed deer; preferred food of snowshoe hare; porcupine; important food of Pacific coast beaver; Sonora deer, moose; cottontail rabbit; broad-tailed beaver; staple food of mule deer; favorite food of beavers, few other trees being cut where these are present. A chief source of propolis. Nearly all western species are palatable to livestock.

Populus acuminata Rydb.

Range: 11, 12, 13, 14, 15, 16.

Lanceleaf cottonwood. •

Site: Well-drained, moist, sun.

Fruit: Capsule.

A large tree; commonly occurs in sandy or rocky soils; wood used locally.

Populus alba L.

Range: $6,8,9,11,22,25,27,28,29$.

White poplar.

Site: Dry, well-drained, sun.

Fruit: Capsule.

A large tree; introduced from Eurasia and more or less naturalized in the regions indicated; much attacked by scale and canker in Indiana; many varieties in cultivation.

Populus angulata, see Populus sargentii.

Populus angustifolia James.

Range: $6,8,9,11,12,13,14,15$ (Black Hills).

Narrowleaf cottonwood.

Site: Well-drained, moist, sm.

Fruit: Capsule.

A large, rapid-growing tree; wood used locally.

Populus arizonica Sarg.

P. mexicana of Amer. auths., not Westm.

Arizona cottonwood.

Range: 10, 11, 14.

Site: Well-drained, moist, sun.

Fruit: Capsule.

A large, rapid-growing, short-lived tree; wood much used locally.

Observations: Beaver.

Populus aurea, see Populus tremuloides.

Populus balsamifera $\mathrm{L}$.

$\boldsymbol{P}$. tacamahaca Mill., $P$. candicans Michx.

Balsam poplar.

Range: 12, 13, 15, 18, 21, 23, 24, 25, 26, 27 .

Site: Dry, well-drained, sun.

Fruit: Capsule, arailable May-June.

A large trec; commonly occurs in any wet soil ; root system deep, sureading; rapid growing, somewhat short-lived; wood used commercially ; vitality of seeds transient; germination percentage of seeds low. The much planted Carólina poplar is believed to be a hybrid between this and $P$. nigra $\mathrm{L}$.

Stomach records: Stone caribou. Observations: Ruffed grouse.

Populus besseyana Dode.

Range: $8,12,15$.

Site: Well-drained, sun.

A large tree.

Fruit: Capsule.

Populus candicans, see Populus balsamifora.

Populus cercidiphylla, see Populus tremuloides.

Populus deltoides Marsh.

P. virginiana Fourq.

Eastern cottonwood.

Range: $15,17,18,19,20,21,22,23,24,25,26,27,28,29,30$.

Site: Well-drained moist, sun.

Fruit: Capsule available May-June.

A large tree; commonly occurs in rich soil; root system shallow, widespreading; appears to thrive in any moist soil; very rapid growing, short- 
lived; easily damaged by fire when young, less so with age; much attacked by fungi; easily storm damaged; fairly wind-firm; 1,300,000 seeds per pound, germination 60-90 percent, vitality transient; stump sprouts and root sprouts produced; has been successfully used in checking erosion and in fixation of sand dunes; wood used commercially; grows on coal-stripped lands in Illinois.

Stomach records: Black-tailed deer. Observations: Evening, and rose-breasted grosbeak; cottontail rabbit. Much browsed by cattle.

Populus fremontil Wats.

Fremont cottonwood.

$P$. macdougalii Rose.

Range: 1, 3, 4, 5, 9, 10, 11, 13, 14.

Site: Well-drained, moist, sun.

Fruit: Capsule.

A large tree; commonly occurs in sandy soil; grows well in saline soils; rapid growing, short-lived; wood used locally; much attacked by mistletoc. Several varieties are described, all occurring within the range of the species.

Observations: California mule deer.

Populus grandidentata Michx.

Range: $21,22,23,25,26,27,28$.

Largetooth aspen.

Site: Dry, well-drained, moist, sun.

Fruit: Capsule, available in May.

A small to large tree; grows in sand, humus or loam; root system shallow; very rapid growing, short-lived; often severely injured by fungi, fire, wind, and insects; wood used commercially ; a pioneer in burned and cut-over land; germination percentage of seeds higb, vitality transient.

Observations: Cottontail rabbit, white-talled deer.

Populus heterophylla $\mathrm{L}$.

Range: $25,27,28,29,30$.

Swamp cottonwood.

Site: Moist, sun.

Fruit: Capsule, available in May.

A large tree; root system very shallow; rapid growing, short-lived; subject to heart rot at maturity; wood of importance commercially.

Populus macdougalii, see Populus fremontii.

Populus mexicana, see Populus arizonica.

Populus occidentalis, see Populus sargentii.

Populus palmeri Sarg.

Range: 16, 20.

Palmer cottonwood.

Site: Well-drained, moist, sun.

A large tree.

Fruit: Capsule.

Populus sargentii Dode.

Sargent cottonwood.

$P$. deltoides oeeidentalis Rydb., $P$. occidentalis (Rydb.) Britt., P. angulata

Port. and Coult.

Range: 12, 13, 14, 15, 16, 18, 19, 21.

Site: Well-drained, moist, sun.

Fruit: Capsule.

A large tree; rapid growing, short-lived; wood used to some extent locally.

Populus tacamahaca, see Populus balsamifera.

Populus texana Sarg.

Texas cottonwood.

Range: 16.

Site: Well-drained, moist, sun.

Fruit: Capsule.

A large, short-lived, rapid-growing tree.

Populus tremuloides Michx. (pl. 24, A, B, ).

$P$. aurea Tidest., $P$. vaneouveriana Trel., $P$. cercidiphylla Britt.

Range: 1, 2, 4, 6, 7, 8, 9, 11, 12, 13, 14, 15, 18, 21, 22, 23, 24, 25, 26, 27.

Site: Dry, well-drained, sun.

Fruit: Capsule, available May-June.

A small to large tree; occurs in many soils; apparently not satisfactory in pure plantations owing to insects and disease; root system shallow; will grow in many soils but apparently does best in sandy loam; very rapid growing, shortlived; easily and seriously damaged by fire, wind, fungi, and insects; wood 
of importance commercially ; root sprouts formed; seed vitality transient, much abortive; generally a transient species invading and quickly occupying burned and logged areas and soon giving way to otlier species; the shade of these trees is never dense in spite of the closeness of stands; frequently supports an understory of weeds.

Stomach records: Three species of birds, including ruffed grouse and sharptailed grouse; black-tailed deer, northern white-tailed deer, mountain sheep, plains white-tailed deer; composed 3.2 percent of winter food of northern sharptailed grouse in Quebec and Ontario. Observations: Highly palatable to captive deer; pika; mountain beaver; white-tailed deer; important food of snowshoe hare; important browse of moose; important food of Pacific coast and Shasta beaver; of outstanding importance as browse for mule deer; red squirrel; the principal food of beaver throughout its range; black bear, cottontall rabbit, porcupine. Frequently supports understories of weeds and browse highly esteemed by livestock. Very palatable to sheep and goats.

Populus trichocarpa Torr. and Gray.

Range: $1,2,3,4,5,6,7,8,12,13$.

Black cottonwood.

Site: Moist, sun.

Fruit: Capsule.

A large tree; commonly occurs in sandy humus or gravel; root system shallow; very rapid growing, longest-lived of the poplars although comparatively shortlived; storm-damaged, not wind-firm; wood of importance commercially, especially for pulp; seed with a high percentage germination, vitality transient.

Stomach records: Ruffed grouse.

Populus tweedyi Britt.

Tweedy cottonwood.

Range: 9.

Site: Well-drained, molst, sun.

Fruit: Capsule.

A small to large tree.

Populus vancouveriana, see Populus tremuloides.

Populus virginiana, see Populus deltoides.

Populus wislizenil (Wats.) Sarg.

$P$. fremontii wislizenii Wats.

Range: 11, 17.

Site: Well-drained, moist, sun.

Fruit: Capsule.

A large tree; commonly occurs in sandy soil ; rapid growing in moist situations, slow in intermittently moist situations; short-lived, muck cultivated throughout New Mexico; wood used locally, especially for fence posts. Eaten by cattle.

Porlieria angustifolia (Engelm.) Gray.

Guiacum angustifolium Engelm.

Range: 11, 17, 20.

Site: Dry, well-drained, sun.

Fruit: Capsule.

A large shrub to small tree; evergreen; brancles rigid, spreading or straggling; wood very durable, used locally for fence posts. An important honey plant.

Potentilla fruticosa L.

Dasiphora fruticosa (L.) Rydb.

Shrubby cinquefoil.

Range: 4, 12, 13, 14, 15, 18, 21, 22, 23, 24, 25, 26, 27, 28.

Site: Dry, well-drained, moist, sun, shade.

Frult: Achene.

A small evergreen shrub; flowers June-September; often sprawling; much branched; an aggressive species commonly invading pastures in New England, but plowing and close pasturing have successfully checked its spread; some 14 varieties are in cultivation.

Observations: Rarely browsed by moose; casually browsed by northern whitetailed deer. Considered inferior forage for cattle, but of importance for sheep and goats in the Southwest.

Prinos coriacea, see Ilex coriacea. 
Prosopis spp.

Mesquites.

Stomach records (in addition to specific records) : Scaled quail, antelope jack labbit, gray-sided jack rabbit; Texas jack rabbit, Arizona cottontail, Holzner cottontail. Observations (in addition to specific records) : Gambel quail, Mexican turkey, white-winged dove.

Prosopis articulata, see Prosopis chilensis.

Prosopis chilensis (Mol.) Stuntz.

Mesquite.

$P$. juliflora (Swartz) DC., $P$. velutina Woot., $P$. juliflora volutina (Woot.) Sarg., $P$. odorata Torr., $P$. articulata Wats., $P$. glandulosa Torr., $P$. juliflora glandulosa (Torr.) Cockerell, Neltuma juliflora (Swartz) Raf., $N$. glandulosa (Torr.) Britt. and Rose, N. velutina (Woot.) Britt. and Rose.

Range : 9, 11, 16, 17, 19, 20, 25, 29, 30 .

Site: Dry, well-drained, moist, sun.

Fruit: Legume; available September-October, rarely July.

A large, spiny shrub to a small or rarely large tree; adapted to a wide range of soil conditions; seedling with a taproot but mature plant with a generalized root system; roots penetrate as much as 60 feet below the surface and 30 feet is common; little damaged by insects or disease; much used locally for fuel; thicket forming; shrubby in dry areas, larger and treelike in moist places; wood very hard and durable, often used for fence posts; underground stems enormous, locally an important source of fuel; commonly attacked by mistletoe; aggressive, apparently taking possession of grasslands, particularly when they are overgrazed ; nearly impossible to kill by overgrazing; usually widespreading and lower when heavily grazed.

Standley (539) points out that in Mexico so many intergrading forms occur that separation of $P$. chilensis into tliree or more species is impossible. He notes that specimens from Peru and Argentina, if labeled from the United States, would be determined by a botanist as $P$. juliflora. (In an appendix he changes this name to $P$. chilensis). The rariability of the species permits of many different forms, but from studies made by Standley of specimens from many localities, it would seem most useful to consider all forms as one species.

Stomach records: Five species of birds including scaled quail and Gambel quail; Mearn's coyote, northern hooded skunk; composed $36^{\circ}$ percent of food of antelope jack rabhit, and 56 percent of food of Arizona jack rabbit throughout the year in Arizona.

Forage value for stock high; occaslonally poisonons to stock if eaten to the exclusion of other forage; seeds pass out of the digestive tract of livestock unharmed, and in this condition are often eaten by birds, especially Gambel quail. An exceptionally good honey plant. Observations: Scaled quail; western white-winged dore; captive porcuplne (pods only) ; Texas antelope squirrel ; gray-tailed antelope squirrel; Harris ground squirrel; gray-spotted ground squirrel; Rio Grande ground squirrel; Mexican raccoon; coyote; Texas whitetailed deer; mule deer; rock squirrel. Far surpasses any other species in both frequency of occurrence and quantity taken in the food of Gambel quail; the buds and flowers are taken in spring, and in fall and winter seeds are eaten; these quail often use the rachides of the leaves in nest-building.

A host for the mistletoe (Phoradendron californicum) which produces an abundant and almost continuous crop of berries. Phainopeplas, mockingbirds, sage thrashers, robins, and bluebirds depend almost wholly on these berries for food; they are also eaten by Gambel quail. The Abert towhee, Crissal thrasher, phainopepla, and Lucy warbler commonly breed in the mesquite association.

Prosopis clnerascens Gray.

Strombocarpa cinerascens Gray.

Screwbean.

Range: 11, 17.

Site: Dry, sum.

Fruit: Legume.

A small, spiny shrub.

Prosopis glandulosa, see Prosopis chilensis.

Prosopis juliflora, see Prosopis chilensis.

Prosopis odorata, see Prosopis chilensis. 
Prosopis pubescens Benth.

Range: $9,10,11,17$.

Screwpod mesquite.

Site: Dry, well-drained, moist, sun.

Fruit: Legume, available July-October.

A large shrub to small or large tree; spiny; occurs in sandy loam, gravel, and other soils; has a tendency to grow in thickets; wood very durable in contact with the soil, of importance locally.

Stomach records: Masked bobwhite, road runner, Gambel quail. Much browsed by livestock, and pods used for fodder.

Prosopis velutina, see Prosopis chilensis.

Prunus spp.

Cherries, plums.

Trees or shrubs commonly divided into two classes, the cherries and the plums; most species are in general rather easily damaged by fire; constant cropping of the twigs leads to much suckering in the plums, which in turn saps the vitality of the root system.

Considerable discussion, in print and out, has resulted in causing the genus to be regarded with suspicion, as far as the poisonous qualities of some species are concerned. The statement that leaves in a wilting condition are poisonous is common. This may be a fallacy in view of work done at the New Hampshire Agricultural Experiment Station (Dayton, 158). However, parts of the plants contain rarying quantities of amygdalin, a glucoside which, with the proper enzyme, yields hydrocyanic acid. The glucoside is present in leaves, bark, and especially in the seed, but never in the fruit pulp. In the eastern chokecherries the young vigorons leares and tenderest shoots develop most of the cyanogenetic materials, and therefore in that region cattle should not be permitted to graze too early in the season in pastures where cherry is growing and should never be permitted to gorge themselves upon it. Hungry sheep should never be driven along trails lined with cherries. The pits, which are most poisonous, are never eaten by livestock. Birds, rodents, and other mammals are fond of the fruits and are considered to be largely responsible for the dissemination of the species.

Stomach records (in addition to specific records) : Sixty-nine species of birds, including ruffed grouse, bobwhite, dusky grouse, sharp-tailed grouse, and ringnecked pheasant; composed 8.8 percent of winter food of ruffed grouse in New York, and 9.8 percent of winter food of ruffed grouse for the northeastern United States; red squirrel, gray eastern chipmunk, red fox, white-tailed deer; found in 71 skunk stomachs in New York; composed 6 percent of fruit food of eastern skunk in Michigan. Observations (in addition to specific records): Thirty-two species of birds, including band-tailed pigeon, Gambel quail, dusky, gray ruffed, and ruffed grouse, emergency food of northern sharp-tailed grouse; ranks nineteenth on the list of quail food plants of the Southeast; ring-necked pheasant; coyote, Say chipmunk, opossum, Douglas ground squirrel, raccoon, pica, and red fox, porcupine, Olympic wapiti, Wasatch chipmunk, Siskiyou chipmunk, rock squirrel; New Mexico black bear, Say's ground squirrel. Browse value on sheep and cattle range is considerable, although most species do not resist overgrazing well.

Prunus alabamensis Mohr.

Alabama cherry.

Padus alabamensis Small.

Range: 27.

Site: Well-drained, sun.

Fruit: Drupe, available September-October.

A large shrub to small or large tree; flowers in May.

Prunus alleghaniensis Porter.

Range: 27.

Site: Dry, well-drained, moist, sun.

Fruit: Drupe, available July-August.

A small to large shrub or small tree; flowers in April, commonly straggling; thicket forming; flowers and fruit borne profusely; sprouts readily from injured or exposed roots.

Prunus americana Marsh. (pl. 25, $B$ ).

Wild plum.

Range: $12,13,14,15,16,17,18,19,20,21,22,23,24,25,27,28,29,30$.

Site: Dry, well-drained, molst, sun, shade.

Fruit: Drupe, available July-October. 

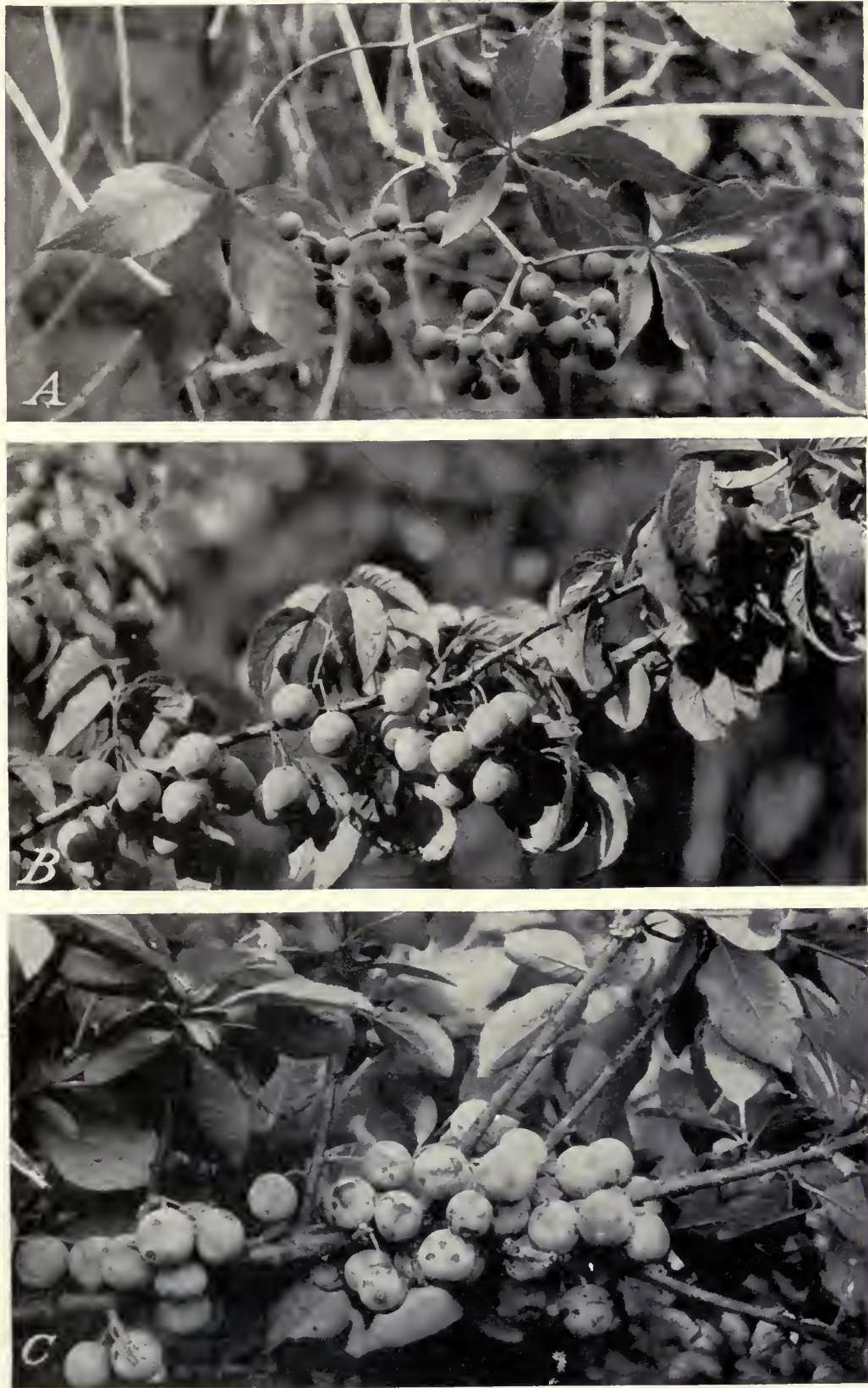

A, Parthenocissus quinquefolia. Along fence rows and as a cover for steep banks, the Virginia creeper should find much use. Its fruits are much sought after, especially by birds. B, Prunus americana. This plum and its close relatives are of outstanding merit in controlling erosion on poor sites. Its value as cover for wildlife is equally great. $C, P$. maritima. Although a native on sandy soil, the beach plum has been successfully used on poor clay soil. It forms an excellent cover both for soil and wildlife, and produces an abundant crop of fruit. 

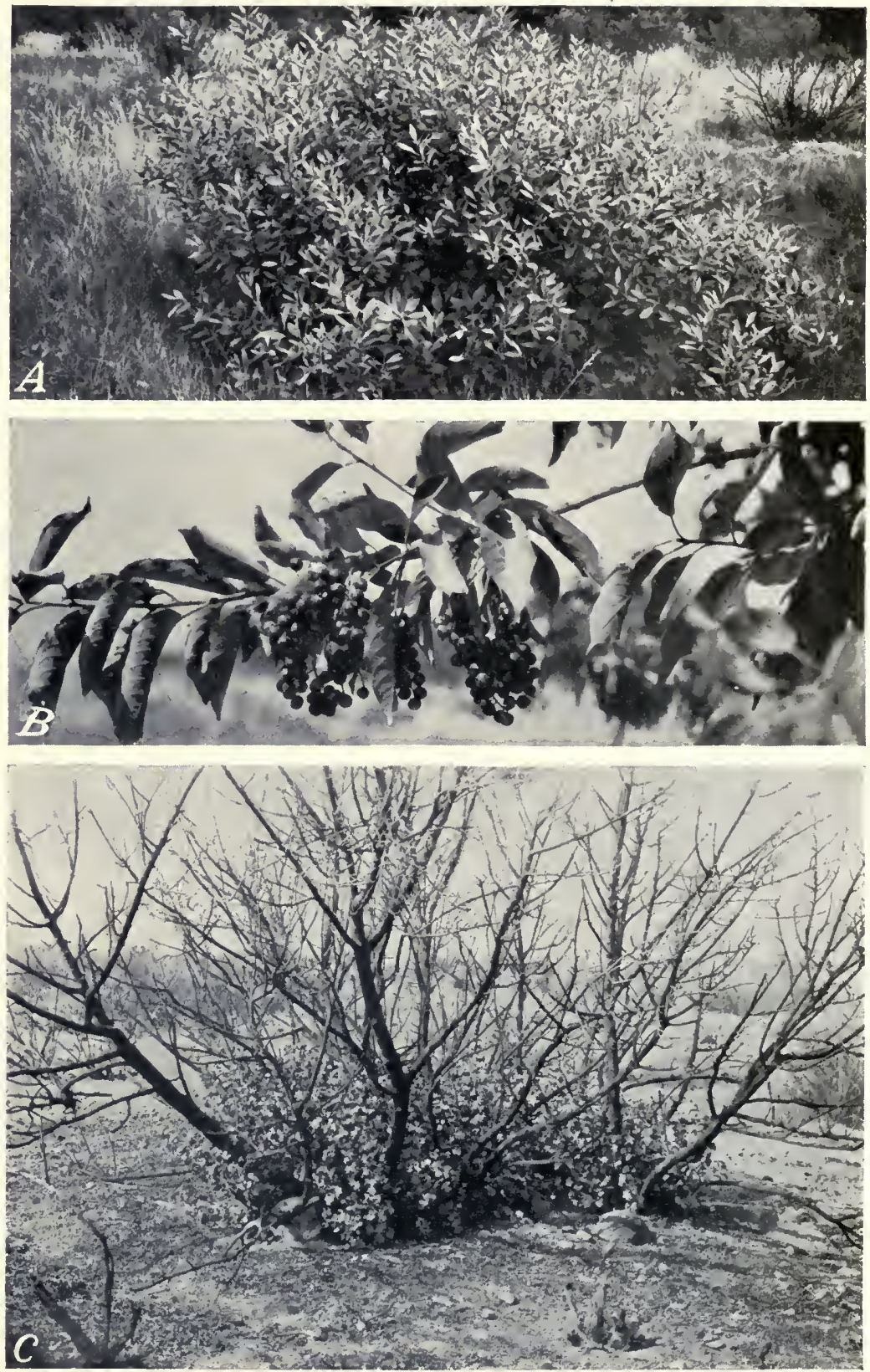

A, Prunus besseyi. A specimen in a garden where maximum development of the bushy habit indicates possibilities for soil and wildlife-cover planting. $B, P$. demissa. The fruit of the western chokecherry is of considerable value for wildlife. In planting it for erosion control care must be taken to guard against possible stock poisoning. $C, P$. ilicifolia. The ability of the hollyleaf cherry to coppice after killing of Its aerial portious enhances its erosion-control value. (Photograph by U. S. Forest Service.) 
A large, spiny shrub to small or rarely large tree; flowers April-May; thicket forming; about 316 named varieties are known, the best-fruited types occurring in the Middle West; commonly sprouts from the roots to form extensive colonies; 800-1,500 seeds per pound.

Stomach records: Pine grosbeak. Observations: Prairie sharp-tailed grouse, ring-necked pheasant; leaves refused by captive marsh rabbits; much eaten by many kinds of birds.

Prunus andersonii Gray.

Desert peach.

Emplectocladus andersonii (Gray) Nels. and Ken., Amygdalus andersonii (Gray) Greene.

Range: 4,9 .

Site: Dry, well-drained, sun.

Fruit. Drupe.

A small to large shrub or small tree; flowers in May; thorny, spreading; accurs on gravelly, sandy, or other soils; extremely drought resistant; taproot well developed; thicket forming.

Considered fair to good sheep and goat browse and only slightly inferior for cattle.

Prunu's angustlfolia Marsh.

P. chicasa Michx.

Chickasaw plum.

Range: $20,22,25,28,29,30$.

Site: Dry, well-drained, sun.

Fruit: Drupe, available May-August.

A large shrub to small or large tree; flowers March-April; somewhat thorny; densely thicket forming; commonly occurs in sandy soil ; 800-1,000 seeds per pound.

Var. watsonii (Sarg.) Waugh, (P. watsonii Sarg.) is a dwarf occurring in regions 17 and 19.

Prunus arkansana, see Prunus mexicana.

Prunus australis, see also Prunus mexicana.

Prunus australis Beadle.

Padus australis Small.

Southern wild cherry.

Range: 29.

Site: Well-drained, sun.

Fruit: Drupe, available July-August.

A small to large tree; flowers in April; occurs on clay soil.

Pronus avium L.

Range: 27, 28.

Site: Dry, well-drained, sun.

Fruit: Drupe, available in July.

A small to large tree; flowers April-May; introduced from Eurasia and more or less naturalized in the regions indicated; wood used commercially.

Stomach records: Nine species of birds; red squirrel.

Prunus besseyi Bailey (pl. 26, $A$ ).

$P$. prunella Daniels, $P$. pumila besseyi (Bailey) Waugh.

Range: 15, 16, 18, 19, 23.

Site: Well-drained, sun.

Fruit: Drupe.

A small, bushy shrub; flowers April-May; more or less prostrate; sprouting from roots but rarely forming thickets; occurs on sandy and other soils; 4,000 seeds per pound; fruit produced the second or third year from seed; largefruited varieties are known.

Observations: Ring-necked pheasant. Poisonous to livestock.

Prunus borealis, see Prunus nigra.

Prunus capollin, see Prunus serotina.

Prunus capuli, see Prunus serotina. 
Prunus caroliniana Ait.

Laurel cherry.

P. sempervirens Willd., Laurocerasus caroliniant (Mill.) Roem., Padus caroliniana Mill., Cerasus caroliniana Michx.

Range: 20, 29, 30.

Site: Well-drained, moist, sun.

Fruit: Drupe, persistent the year round.

A large shrub to small or large tree; evergreen; flowers February-April; rapld growing; thicket forming.

Observations: Three species of birds. Leaves poisonous to llvestock.

Prunus cerasus L.

Range: $22,25,27$.

Sour cherry.

Site: Dry, well-drained, sun.

Fruit: Drupe, available June-July.

A small to large tree; flowers April-May; introduced from southem Europe and more or less naturalized in the regions indicated.

Stomach records: Three species of birds, including bobwhite. Observations: Seven species of birds.

Prunus chicasa, see Prunus angustifolia.

Prunus corymbulosa Rydb.

Rocky Mountain red cherry.

P. pennsylvanica corymbulosa (Rydb.) Wight, Cerasus trichopetala Greene.

Range: 12.

Site: Dry, sun.

Fruit: Drupe.

A small to large shrub; flowers May-June; commonly occurs in stony places.

Prunus cuneata, see Prunus susquehanae.

Prunus cuthbertii Small.

Padus cuthbertii Small.

Range: 28.

Site: Well-drained, moist, sun.

Fruit: Drupe, available July-August.

A large shrub to small tree.

Prunus demissa' (Nutt.) Walp. (pl. 26, $B$ ).

Western chokecherry.

$P$. virginiana demissa Sarg., Cerasus demissa Nutt., Padus demissa Roem.

Range : 1, 2, 4, 6, 7, 9, 12, 13, 14, 15, 16, 18, 21.

Site : Dry. well-drained, moist, sun.

Fruit: Drupe, available July-October.

A large shrub to small tree; flowers April-May; thicket forming.

Var. melanocarpa. Nels. (Padus melanocarpa (Nels.) Shaf., Prunus mclanocarpa (Nels.) Rydb.), the black western chokecherry, occurs with the species; thicket forming; spreads by rhizomes; root system shallow with occasional deep-feeding roots; $3,000-5,000$ seeds per pound.

Stomach records: Six species of birds; black-tailed deer, plains white-tailed deer. Observations: Three species of birds, including ring-necked pheasant, sharp-tailed grouse; of outstanding importance as browse for mule deer; pica; eaten avidly by many birds. Commonly lightly to moderately browsed by stock; overgrazing of this species commonly leads to poisoning, notably in the spring; not harmful in the fall.

Prunus depressa, see Prunus pumila.

Prunus emarginata (Doug1.) Walp.

Bitter cherry.

Cerasus emarginata Dougl., C. glandulosa Kellogg., C. californica Greene,

C. crenulata Greene, O. arida Greene, C. rhamnoides Greene, C. kelloggiana Greene, $C$. padifolia Greene, $C$. obliqua Greene, $C$. parvifolia Greene, $C$. obtusata Greene.

Range: $1,2,4,6,8,9,10,11,12,13,14$.

Site : Dry, well-drained, moist, sun.

Fruit: Drupe, available May-September.

A large shrub to small or large tree; flowers April-Mas; densely thicket forming; flowers and fruit appear earliest near the Coast.

Var. villosa Sudw., ( $P$. mollis Walp., $P$. emarginata mollis Brew., Cerasus prunifolia Greene, $P$. prunifolia (Greene) Shaf.), the plumleaf cherry, occurs within the range of the species. 
Stomach records: Six species of birds, including ruffed grouse; Mono chipmunk. Observations: Of outstanding importance as browse for mule deer; much eaten by Allen's chipmunk; alpine chipmunk. Of most value as stock forage toward the end of the season; has been frequently claimed to be poisonous, but probably because it has been confused with the chokecherries.

Prunus eriogyna Mason.

P. fremontii Wats., Amygdalus fremontii (Wats.) Abrams.

Desert apricot.

Range: $5,10$.

Site: Dry, sun.

Fruit: Drupe, available in May.

A large, spiny shrub; flowers February-March; heat and drought resistant; germination of seed rapid, from 8 to 10 days after planting. Furnishes a small amount of forage for sheep and goats.

Pruinus eximia Small.

Padus eximia Small.

Range: 17.

Site: Well-drained, sun.

A large tree.

Fruit: Drupe.

Prunus fasciculata Gray.

Desert almond.

Emplectocladus fasciculatus Torr., Lycium spencerae MacBr., Amygdalus fasciculata Gray.

Range : $3,5,9,10,11,13$.

Site: Dry, sun.

Fruit: Drupe, arailable April-May.

A small to large shrub or small tree; dioecious, thorny; occurs in gravelly and sandy soil; densely branched; forms dense thickets. Furnishes some browse for sheep and goats.

Prunus fremontii, see Prunus eriogyna.

Prunus fultonensis, see Prunus mexicana.

Prunus glandulosa, see Prunus texana.

Prunus gracilis Engelm. and Gray.

oklahoma plum.

$P$. normalis Rydb., $P$. normalis Small, $P$. chicasa normalis Torr. and Gray.

Range: 16, 22, 25.

Site: Dry, sun.

Fruit: Drupe, available June-August.

A small, straggling shrub; commonly occurs in sandy soil; thicket forming; especially susceptible to the black knot fuugus.

Prunus havardii (Wight) Mason.

Range: 11.

Site: Dry, well-drained, sun.

Fruit: Drupe, available in July.

A large, rigidly-branched, spinescent shrub.

Prunus hookeri, see Prunus texana.

Prunus hortulana, see also Prunus munsoniana.

Prunus hortulana Bailey.

Range: 22, 25, 27, 29.

Site: Dry, well-drained, moist.

Fruit: Drupe, available July-October.

A large shrub to small or large tree; flowers April-May; commonly occurs in ricl soils; does not produce suckers but often occurs in groves; fruit produced abundantly ; 34 named varieties are known.

Prunus ilicifolia (Nutt.) Walp. (pl. 26, C).

Hollyleaf cherry.

Range: $1,3,4,5$.

Site: Dry, well-drained, moist, sun.

Fruit: Drupe, avallable October-December.

A large shrub to small or large tree; evergreen; foliage dense and compact; flowers March-May; occurs in sand, loam, clay, and other solls; clump forming; 
casts a heavy shade; coppices vigoronsly after fire; tolerant of alkali; drought resistant; will withstand considerable abuse in handling; 240 seeds per pound.

Observations: Hairy woodpecker; eaten by songbirds; California mule deer.

Prunus incana, see Prunus pumila.

Prunus injucunda, see Prunus mitis.

Pruinus integrifolia, see Prunus lyonii.

Prunus lanata (Sudw.) Mack and Bush.

Wild plum.

$P$. americana lanata Sudw., $P$. palmeri Sarg.

Range: $22,25,29,30$.

Site: Dry, well-drained, sun.

Fruit: Drupe, available July-October.

A large shrub to small tree; thicket forming, suckering; 16 named varieties known.

Prunus lyonii (Eastw.) Sarg. (pl. 27, A).

Catalina cherry.

$P$. ilicifolia integrifolia Sudw., $P$. integrifolia Sarg., not Walp., $P$. ilicifolic occidentalis Brandeg.

Range: 5 .

Site: Dry, well-drained, sun.

Fruit: Drupe, available August-September.

A large shrub to small or large tree; evergreen; flowers Marcl--June; more robust and rapid growing than $P$. ilieifolia, even when planted on the mainland; drought resistant.

Observations: Fruit much sought after by birds which commonly eat off the flesh and leave the seed hanging on the bush.

Prunus mahaleb L.

Cerasus mahaleb (L.) Mill.

Range: 22, 25, 27, 28.

Site: Dry, well-drained, sun.

Fruit: Drupe, available in July.

A large shrub to small tree; flowers April-May; introduced from Europe and more or less naturalized in the regions indicated.

Prunus maritima Wang. (pl. 25, C).

Beach plum.

$P$. pygmaea Willd., $P$. sphaerocarpa Michx., $P$. acuminata Michx., $P$. sphaerica Willd., P. pubescens Pursh, P. littoralis Bigel., P. pubigera Steud.

Range: 26, 27, 28, 29.

Site: Dry, well-drained, sun.

Fruit: Drupe, available August-March.

A small to large, straggling shrub; flowers April-May; lower branches often decumbent or prostrate; more or less thorny; occurs only on sandy soils but will grow on clay.

Stomach records: Starling.

Prunus melanocarpa, see Prunus demissa.

Prunus mexicana Wats.

Mezican plum.

$P$. australis Muns., $P$. reticulata Sarg., $P$. tenuifolia Sarg., $P$. polyandra Sarg., P. arkansana Sarg.

Range: $19,20,22,25,29,30$.

Site: Dry, well-drained, moist, sun.

Fruit: Drupe, available September-November.

A small to large tree; flowers in March; does not sucker or form thickets; somewhat drought resistant; occasionally injured by frost; has been successfully used as grafting stock; numerous varieties occur within the range of the species.

Var. fultonensis Sarg. (P. fultonensis Sarg.), has fruits which ripen in June. Prunus minutiflora Engelm.

Cerasus minutiflora (Engelm.) Gray, Amygdalus minutiflora (Fngelm.) Wight.

Range: 11, 16, 17, 20.

Site: Dry, sun.

Fruit: Drupe. 
A small to large, intricately-branched, dioecious shrub; forms dense thickets; staminate plants much more numerous than pistillate plants in the field; probably occurs most commonly on limestone soil. Furnishes a small amount of browse for sheep and goats.

Prunus mitis Beadle.

$P$. injucunda Small, $P$. umbellata injucunda (Small) Sarg.

Georgia sloe.

Range: $28,29,30$.

Site: Dry, well-drained, sum.

Fruit: Drupe, available June-August.

A large shrub to small tree; occurs in sandy and other soils.

Prunus mollis, see Prunus emarginata and P. nigra.

Prunus munsoniana Wight and Hedr.

$P$. hortulana Bailey in part, $P$. hortulana Waugh, not Bailey.

Range: $20,22,25,29$.

Site: Well-drained, moist, sun.

Fruit: Drupe, available July-September.

A large shrub to small or large tree; flowers March-May; forms dense thickets; about 67 named varieties are known.

Prunus nana, see Prunus virginiana.

Prunus nigra Ait.

Canada plum.

P. mollis Torr., P. borealis Poir., P. amerieana nigra Waugh, Cerasus borealis Michx., $\dot{C}$. nigra Loisel.

Range : 21, 23, 24, 26, 27.

Site: Dry, well-drained, moist, sun, shade.

Fruit: Drupe, available August-October.

A large shrub to small tree; flowers in May; forms root sprouts; thicket forming; branches often spinescent; mas occur on limestone soils; does not break or damage in severe snow and storms; about 20 named varieties are known.

Prunus normalis, see Prunus gracilis.

Prunus palmeri, see Prunus lanata.

Prunus pennsylvanica L.f.

P. perscifolia Desf., $\dot{P}$. montana Marsh., $P$. lanceolata Willd.

Pin cherry.

Range: 13, 15, 18, 21, 23, 24, 26, 27.

Site: Dry, well-drained, sun.

Fruit: Drupe, available August-October.

A small to large tree; flowers April-June; root system shallow; rapid growing, short-lived; particularly bushy northward; thicket forming; occasionally seriously damaged by the cherry-leaf beetle; commonly a shrub on poor soils; occurs on many kinds of soil including sand; has been used as grafting stock for sour cherry; 8,000 seeds per pound.

Stomach records: Twenty-three species of birds, including ruffed grouse, bobwhite, ptarmigan, sharp-tailed grouse, ring-necked pheasant and greater prairie chicken; this and $P$. serotina composed 2.3 percent of winter food of northern sharp-tailed gromse in Quebec and Ontario; composed 0.64 percent of fall food of prairie chicken in Wisconsin; Lyster chipmunk, white-tailed deer; chipmunk. Observations: Five species of birds; an emergency food of prairie sharp-tailed grouse; cottontail rabbit, moose; of importance as food for beaver where Populus is lacking. Poisonous to livestock.

Prunus prunella, see Prunus besseyi.

Prunus prunifolia, see Prunus emarginata.

Prunus pumila $\mathbf{L}$.

Sand cherry.

P. depressa Pursh, P. incana Schwein., Cerasus canadensis Mill. C. glauca Moench.

Range: 15, 18, 21, 23, 24, 26, 27, 28.

Site: Dry, well-drained, moist, sun.

Fruit: Drupe, available June-August.

A small shrub; flowers April-May; spreading and creeping; commonly prostrate with growing branches erect; suckers abundantly produced where stems touch the ground; occurs commonly in sandy soil; 4,000 seeds per pound.

Observations: Three species of birds; casually browsed by northern whitetailed deer. 
Prunus pygma, see Prunus reverchonii.

Prunus reverchonil Sarg.

\section{P. pygma Muns.}

Range: 16, 20.

Hog plum.

Site: Well-drained, moist, sun.

Fruit: Drupe, available July-September.

A small to large shrub; flowers March-April; forms dense thickets; witlstands severe drought; will grow on limestone soils.

Prunns rivularis Scheelc.

$P$. texana Scheele, not Dietr.

Creek plum.

Range: 17, 25, 29, 30 .

Site: Well-drained, moist, sun.

Fruit: Drupe, available in June.

A large shrub.

Prunus rufula, see Prunus virens.

Prunus salietfolia, see Prunus serotina.

Prunus sempervirens, see Prunus caroliniana.

Prunus serotina ${ }^{6}$ Ehrh.

Range: 11, 18, 19, 20,21, 22, 23, 24, 25, 26, 27, 28, 29, 30.

Black cherry.

Site: Dry, well-drained, moist, sun.

Fruit: Drupe, available June-November.

A small to large tree; root system deep; wind-firm; much attacked by insects and fungi; easily injured by fire; wood of importance commercially ; $4,000-5,000$ seeds per pound, germination 70-90 percent.

Stomach records: Thirty-three species of birds, including ruffed grouse, bobwhite, and sharp-tailed grouse; composed 0.47 percent of fall food of prairie chicken in Wisconsin; this and $P$. pennsylvanica composed 2.3 percent of winter food of northern sharp-tailed grouse in Quebec and Ontario; white-tailed deer. observations: Twenty-one species of birds including bobwhite, ring-necked pheasant; an important food of red fox; sixth most important preferred food of white-tailed deer in Massachusetts; raccoon; cottontail rabbit; squirrel; black bear.

The most poisonous species to livestock of all cherries.

Prunus subcordata Benth.

$P$. subcordata kelloggii Lemmon.

Range : 2, 3, 4, 12.

Site: Dry, well-drained, sun.

Fruit: Drupe, available August-September.

A large shrub or rarely a small tree; flowers March-May; thicket forming; leaves commonly shed just before fruit is ripe; fruit commonly borne only every 2 years; in the central portion of its range the fruit often develops into a bladdery structure caused by a fungus; propagates not only by seed but by buds formed on the roots; occurs in sand, gravel, loam, and other soils.

Observations: Of fair importance as browse for mule deer. Heavily browsed by sheep; often killed by overgrazing.

Prunus susquehanae Willd.

$P$. cuneata Raf., $P$. pumila cuneata (Raf.) Bailey.

Appalachian cherry.

Range: 23, 24, 26, 27, 28.

Site: Dry, well-drained, moist, sum.

Fruit: Drupe, available July-August.

A small shrub; occurs in sandy and rocky barrens; roots long and stocky.

Stomach records: Prairie chicken.

Prunus tarda Sarg.

P. umbellata tarda (Sarg.) Wight.

Texan sloe.

Range: 16, 17, 20, 29.

Site: Dry, well-drained, sun.

Fruit: Drupe, available October-November.

A small to large tree; flowers in April; often more or less thorny; flowers abundantly produced.

- Var. salicifolia (H. B. K.) Koehne, (P. salicifolia II. B. K., P. capuli Cav, P. capollin Koehne), is a Mexican species apparently outside the United States. 

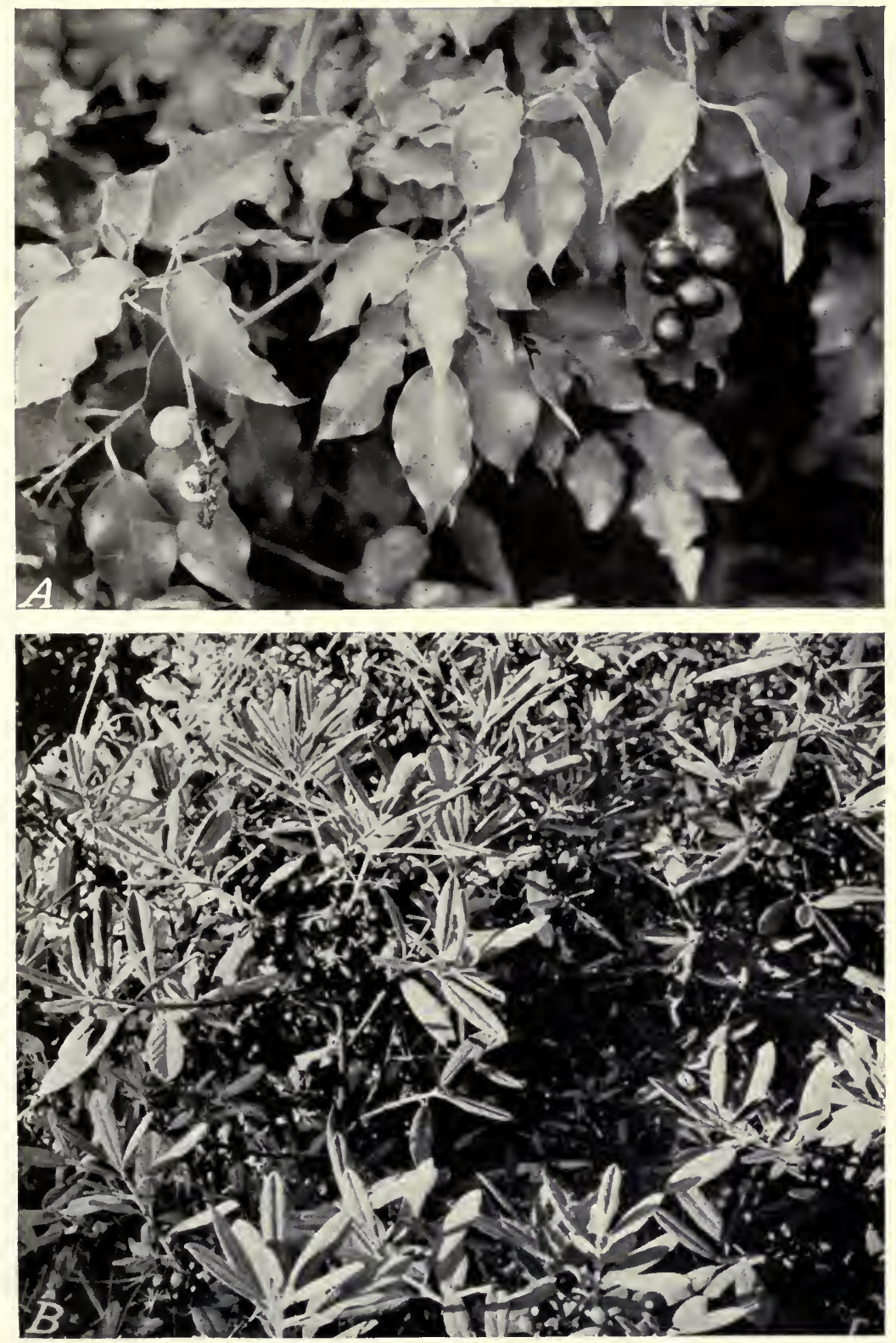

A, Prunus lyonii. The naked pits at the left have been stripped of their flesh by songbirds. The species is an excellent soil cover and should prove of great value in conservation plantings. B, Rhamnus californica var, tomentella. More robust and bushier than the species, this vas iety affords better cover for soil and wildife. In the records of considerable utilization as wildlife food no distinction is made between the frults of the variety and of the species. 


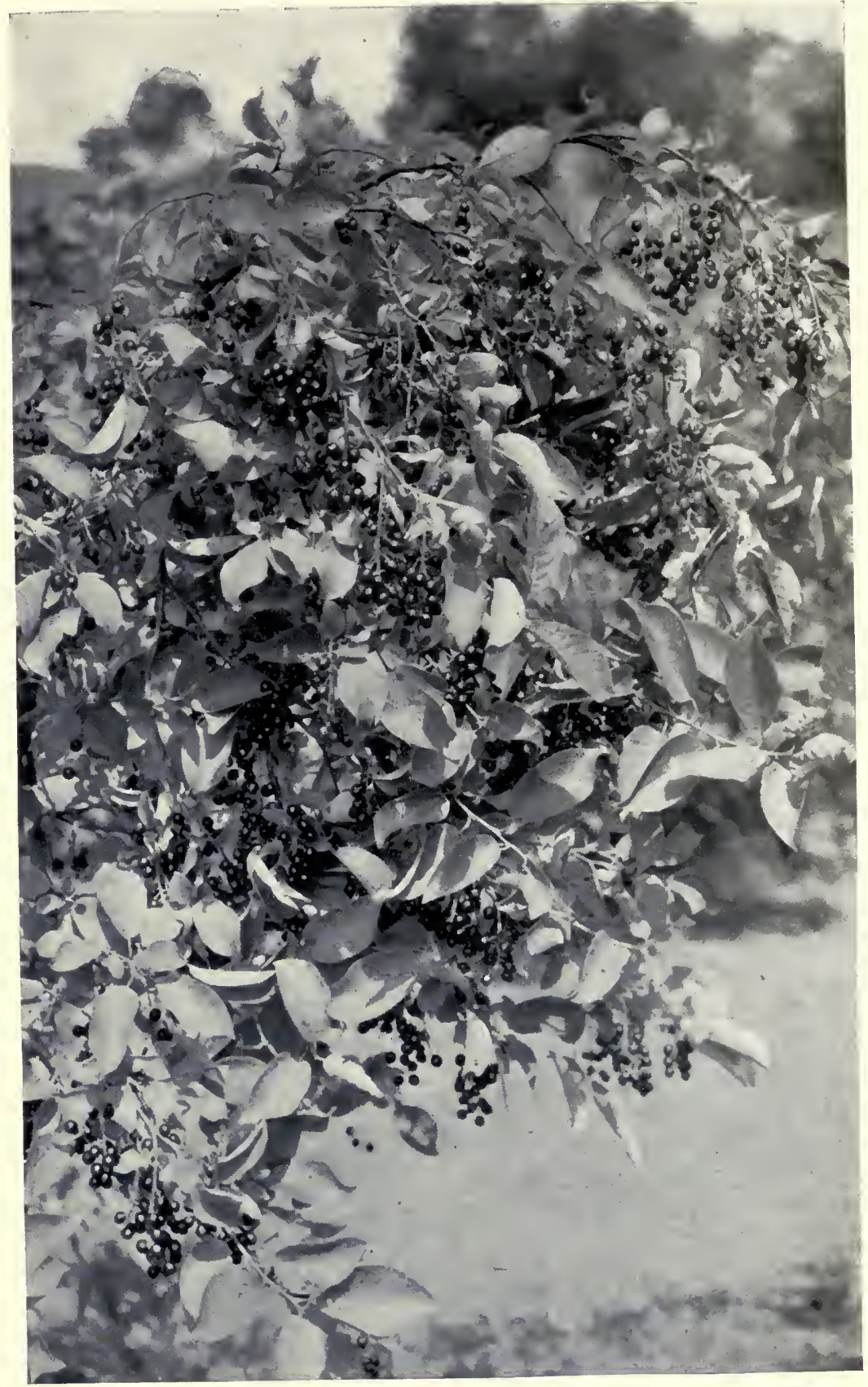

Prunus virginiana. This thicket-forming, profusely fruiting cherry appears to have great value in a program involving soil and wildlife conservation. Its stock-poisoning character prevents any use of it except in fenced areas. 
Prunus tenuffolia, see Prunus mexicana.

Prunus texana, see also Prunus rivularis.

Prunus texana Dietr.

Wild peach.

P. glandulosa (Hook.) Torr. and Gray, P. hookeri Schneid., Amygdalus glandulosa Hook., A. texana (Dietr.) Wight.

Range: 17, 20, 29, 30.

Site: Well-drained, sun.

Fruit: Drupe, available April-May.

A small to large almost evergreen shrub; somewhat thorny; fonnd on sand or sandy loam; apparently does not occur on limestone; root system deep; drought resistant. Furnishes a small amount of forage for sheep and goats.

Prunus umbellata Elliott.

Black sloe.

Range: 28, 29, 30 .

Site: Dry, well-drained, moist, sun.

Fruit: Drupe, available July-September.

A small tree; occurs in sandy and other soils.

Prunus valida (Woot. and Standl.) Rydb.

Padus valida Woot. and Standl.

Range: 9,14 .

Site: Well-drained, sun.

Fruit: Drupe.

A small tree; flowers in June.

Prunus virens Shreve.

Padus vircns Woot. and Standl.

Southwestern black cherry.

Range: $10,11,14$

Site: Moist, sun.

Fruit: Drupe, arailable Angust-September.

A large shrub to small or large tree; more or less evergreen; flowers in May; fruit sometimes borne in great profusion; attempts to use this as grafting stock have been unsuccessful.

Var. rufula Sarg. (P. rufula Tidest., Padus rufula Woot. and Standl.) is more pubescent than the species.

Observations: Eagerly eaten by bears and other wild animals. Fair to good winter browse for livestock.

Prunus virginiana L. (pl. 28).

P. nana (Du Roi) Roem., Padus nana Du Roi, P. virginiana

Range : $21,22,23,24,25,26,27,28,29,30$.

Site: Dry, well-drained, moist, sun, shade.

Fruit: Drupe, available July-September.

A large shrub to small tree; forms dense thickets by sending out long roots which sprout at intervals; fruit abundantly produced; 3,000-5,000 seeds per pound.

Var. pumicea (Woot. and Standl.) Palmer, (Padus pumicea Woot. and Standl.) occurs in regions 11 and 14.

Stomach records: 31 species of birds including ruffed grouse, bob-white, ring-necked pheasant, sharp-tailed grouse, and greater prairie chicken. $\mathrm{Ob}$ servations: Fourteen species of birds including bobwhite, ring-necked pheasant, cottontail rabbit, black bear.

Prunus watsonii, see Prunus angustifolia.

Psedera heptaphylla, see Parthenocissus heptaphylla.

Psedera quinquefolia, see Parthenocissus quinquefolia.

Pseđera vitacea, see Parthenocissus vitacea.

Pseudotsuga spp.

Douglas fir.

Evergreen, monoecious trees of the greatest importance as timber.

Stomach records (in addition to specific records): Black-tailed deer. $O b$ servations (in addition to specific records) : Spruce squirrel.

$130186^{\circ}-39-14$ 
Pseudotsuga douglasii, see Pseudotsuga taxifolia.

Pseudotsuga glauca Mayr.

$P$. douglasii glauca Mayr.

Colorado Douglas fir.

Range: 9, 11, 13, 14, 16.

Site: Well-drained, stm.

Fruit: Cone, available September-October.

A large evergreen tree; resistant to winter cold; susceptible to spring frost; grows well on dry, sandy soil and moist loamy soil but not clay, gravel or poorly drained sites; slow growing; wood much less valuable commercially than that of $P$. taxifolia; does not pioneer in burns; shorter lived than $P$. taxifolia.

Stomach records: Richardson's grouse; plains white-tailed deer, black-tailed deer, mountain sheep. Observations: Captive sharp-tailed grouse, dusky grouse; red squirrel, chestnut-mantled ground squirrel, porcupine, bighorn.

Pseudotsuga macrocarpa (Torr.) Mayr.

Bigcone spruce.

Range: 4, 5, 10.

Site: Dry, well-drained, sun.

Fruit: Cone; mature in August, seeds shed August-September, some cones persistent the year round.

A large evergreen tree; slow growing; wood not used commercially; seed vitality low but persistent.

Observations: Seeds eaten by rodents and birds.

Pseu'dotsuga mucronata, see Pseudotsuga taxifolia.

Pseudotsuga taxifolia (Lam.) Britt.

$\boldsymbol{P}$. douglasii Carr., P. mucronata (Raf.) Sudw., $\boldsymbol{P}$. douglasii caesia Schwerin.

Range: 1, 2, 3, 4, 5, 6 .

Site: Well-drained, sun.

Fruit: Cone; mature September-October, seeds shed at once.

A very large evergreen tree; demands high relative humidity for best growth; cannot withstand severe cold or drying winds; grows best on well-drained, sandy loam; absent from poorly drained areas; growtl rate rapid; an extremely important timber tree; often a pioneer in burns; much larger and longer lived tree than $P$. glauca. (See footnote under $P$. glauca.)

Var. caesia Schweriu is a form more or less intermediate between this speeies and $P$. glauca; it occurs in regions 6,7 , and $12 ;$ makes no summer growth and is slower growing than the species.

Observations: Dusky and Frauklin grouse; browsed as a last resort by Olympic wapiti; porcupine; much eaten by Douglas squirrel, Sierra chickaree, red spruce squirrel, and Magdalena chipmunk; of slight importance as browse for mule deer.

\section{Psilostrophe cooperi (Gray) Greene.}

Riddelia cooperi Gray.

Range: 9, 10, 11 .

Site: Dry, well-drained, sun.

Fruit: Achene.

A small, clump-forming shrub.

\footnotetext{
7 The separation of the Rocky Mountain from the western form of the Douglas fir has not commonly been made in this country, but there appears to be such a good basis for this separation, not only ecologically but taxononically, that it is here made. Reference to Henry and Flood (27) and Frothingham (204) will show the following characteristics to separate the two species: $P$. taxifolia-(1) Rapid growing; (2) wide crown; (3) produces a second leading shoot in summer and this late growth makes it susceptible to injury by late frosts; (4) foliage more regularly disposed in two ranks, soft to touch; (5) leaves thin, under surface flat, no idioblasts present: (6) leaves contain geraniol, and, consequently, smell like pineapple; (7) young cones green to pink, bracts erect: (8) cones 3 to 4 inches long; (9) wood straight, light, durable, excellent timber; (10) torus of bordered pits centrally placed, wood readily permeated by creosote; (11) germination of seed poor; (12) attacked by Chermes; (13) growth rate twice that of the other species, timber yield 4 to 10 times that of the other; (14) will grow in England but not New England. $P$. glauca-(1) Less rapid growing; (2) crown narrow, compact, pyramidal; (3) does not produce a second leading shoot, growth completed early in the season, and, consequently, not susceptible to frost; (4) foliage less regularIy disposed in two ranks; (5) leaves thick, under surface convex, idioblasts present: (6) leaves contain bornyl acetate and, consequently, smell llke turpentine; (7) young cones brilliant red, bracts spreading and reflexed; (8) cones 2 to 3 inches long; (9) wood irregular in structure, strong and durable, rough timber: (10) torus of bordered pits pressed to one side, wood not readily permeated by creosote; (11) germination of seed much better and sooner than the other species; (12) not attacked by Chermes; (13) growth rate about half that of the other species, timber yield much less than that of the other species; (14) will not grow in England, but will grow in New England.
} 
Psorodendron arborescens, see Parosela arborescens.

Psorodendron californicum, see Parosela fremontii.

Psorodendron fremontii, see Parosela fremontii.

Psorodendron johnsonti, see Parosela fremontii.

Psorodendron puberulum, see Parosela schottii.

Psorodendron schottii, see Parosela schottii.

Psorodendron spinosum, see Parosela spinosa.

Psorothamnus emoryi, see Parosela emoryi.

Psorothamnus polyadenia, see Parosela polyadenia.

Psorothamnus scoparius, see Parosela scoparia.

Psorothamnus subnudus, see Parosela polyadenia.

Ptelea spp.

The species of this genus are apparently not well understood at present. The reduction of all to two species is without doubt open to question but since authorities do not agree on what is to be done with the $P$. trifoliata complex, it is offered here as one species. None is eaten by livestock.

Ptelea angustifolia, see Ptelea baldwinii.

Ptelea baldwinii Torr. and Gray.

California hoptree.

$P$. baldwinii crenulata Jeps., $P$. crenulata Greene, $P$. angustifolia Benth.

Range: 3, 5, 9, 17 .

Site: Dry, well-drained, sun.

Fruit: Samara.

A large shrub to small tree; flowers April-May; about 7,000 seeds per pound. Ptelea crenulata, see Ptelea baldwinii.

Ptelea microcarpa, see Ptelea trifoliata.

Ptelea parvifolia, see Helietta parvifolia.

Ptelea rhombifolia, see Ptelea trifoliata.

Ptelea serrata, see Ptelea trifoliata.

Ptelea tomentosa, see Ptelea trifoliata.

Ptelea trifoliata $\mathrm{L}$.

Hoptree.

$P$. microcarpa Small, $P$. tomentosa Raf., $P$. serrata Small, $P$. rhombifolia

Heller.

Range: 11, 16, 17, 20, 22, 23, 24, 25, 27, 28, 29.

Site: Dry, well-drained, sun.

Fruit: Samara; available in September, persistent until spring.

A large shrub to small or very rarely a large tree; flowers in June; 18,350 seeds per pound.

Ptilocalyx greggii Torr.

Coldenia greggii Gray.

Range: 11.

Site: Dry, sun.

Frnit: Nutlet.

A small, much-branched shrub.

Purshia glandulosa Curran.

Kunzia glandulosa Greene, $P$. tridentata glandulosa Jones.

Range: 10.

Site: Dry, sun.

Fruit: Achene, available August-September.

A small to large evergieen shrub; flowers April-July.

Observations: Eagerly eaten by California mule deer.

Purshia tridentata (Pursh) DC.

Kunzia tridentata Spreng.

Antelope brush.

Range: $4,6,7,8,9,11,12,13,14,16$.

Site: Dry, well-drained, sun.

Fruit: Achene, available in August.

Antelope brusl. 
A small to large shrub; flowers May-August.

Intricately branched, often many-stemmed; occurs in clay, sand, and other soils; root system fairly deep, scarcely spreading.

Stomach records: Columbian chipmunk, black-tailed deer. Observations: of ontstanding importance as browse for mule deer; pica, painted chipmunk, sage brush chipmunk; one of the chief browse plants for deer and antelope.

A very important browse plant seldom touched by horses but extensively cropped by goats, cattle, and especially sheep; palatability appears greatest in spring, winter, and late fall.

Pyracantha coccinea, see Cotoneaster pyracantha.

Pyrus americana, see Sorbus americana.

Pyrus angustifolia, see Malus angustifolia.

Pyrns arbutifolia, see Aronia arbutifolia.

Pyrus bracteata, see Malus bracteata.

Pyrus coronaria, see Malus coronaria.

Pyrns diversifolia, see Malus fusca.

Pyrus Pusca, sce Malus fusca.

Pyrus glabrata, see Malus glabrata.

Pyrus glaucescens, see Malus glaucescens.

Pyrus ioensis, see Malus ioensis.

Pyrus lancifolia, see Malus lancifolia.

Pyrus malus, see Malus pumila.

Pyrus melanocarpa, see Aronia melanocarpa.

Pyrus nigra, see Aronia melanocarpa.

Pyrus occidentalis, see Sorbus occidentalis.

Pyrus platycarpa, see Malus platycarpa.

Pyrus rivularis, see Malus fusca.

Pyrus sambucifolia, see Sorbus anericana.

Pyrus sitchensis, see Sorbus americana and S. sitchensis.

Pyrus soulardii, see Malus soulardii.

Quercus spp.

Oaks.

There are two classes of oaks; the black oak group and the white oak group. The acorns of the white oaks mature in a single season. Those of the black oaks ordinarily take 2 years to mature. It seems possible to insure a consistent crop of acorns by planting oaks of the two groups in mixtures when a consistent food supply is assured to wildlife. Where one type may fail to produce seed, the other may supplement. White and black oaks occur in about equal numbers in the eastern United States and in the Mexican Sierras, Cordillera, and tableland. The total number of species of white oaks in the United States amounts to about 54 ; of black oaks 26 , and of an intermediate class 4 , making a total of approximately 84 species. The timber produced by the white oaks is heavier, harder and more durable than that of the black oaks. Together they produce about half the hardwood lumber of the United States.

As a class the oaks are slow growing, long-lived, disease-resistant, very little subject to insect attacks. One thinks immediately of oak galls or oak apples, but these malformations are seldom of sufficient importance to make much difference to the general vigor and health of the species involved.

The poisonous properties of oaks should be considered in making any extensive plantings of them. It is known that concentrated feeding of stock on oak forage may result in tannic acid poisoning. This is true especially in the spring. However, cattle losses are apt to occur when other forage is scarce, as in the spring, in dry years, and on overgrazed range. Proper management of livestock should preclude any serious effects from the oaks. The best practices would include grazing cattle in summer and fall on oak, not grazing them before grass has had a chance to become lush, and in general, seeing to 
it that there is variety in forage. Chemical analyses show that the leaves are not a balanced ration for livestock and accordingly, they must be supplemented by grass or other feed. The deciduous species are more nutritive than the evergreen, and are more readily eaten by livestock.

While most tree oaks are recognized as having timber value, there are many shrubby species that may be profitably utilized for erosion-control planting and wildlife food and cover. These are the species ordinarily classed as scrub oaks. Certain of these are always shrubby, no matter in what site they may be growing. The tree oaks, however, may gradually become reduced in size in mountainous or arid regions. So far as known, there are no oaks which can be classed as weeds, although they are occasionally considered to be so in certain localities. Eradication, however, is not difficult.

Many of the species of scrub oaks are thicket forming and some reproduce by stolons. Their growth is generally vigorous, many are evergreen, and as a group are comparatively fast growing. The ability on the part of scrub oaks to form a dense cover rapidly is one which is well known. Altogether there would appear to be ferw plants that are more admirably adapted for erosion control, coupled with value to livestock, wild mammals, and birds, than the oaks.

Stomach records (in addition to specific records) : Sixty-three species of birds including ruffed grouse ( 1 stomach with parts of 24 acorns and many with 10 to 20 ), bobwhite ( 36 parts of acorns in 1 stomach), Mearn's quail, California quall, Gambel quail, wild turkey, plumed quail, sharp-talled grouse, ring-necked pheasant, greater prairie chicken, lesser prairie chicken (50 parts of acorus in 1 stomach), and mourning dove; ground squirrel, armadillo, opossum, black-tailed deer; Louisiana white-tailed deer, muskrat, raccoon, gray squirrel, eastern chipmunk, black bear, gray fox, white-tailed deer, ring-tailed cat, eastern skunk. Composed 4.5 percent of the entire fall food eaten by prairie chicken in Wisconsin; composed 5.0 percent of the winter food of ruffed grouse in the northeastern United States; composed 2.3 percent of food of 1,725 mallards. It may be noted here that stomach records show such birds as wrens and sparrows to have taken at least one complete acorn and that the comparatively large size of acorns apparently does not prevent even small birds from eating them.

Observations (in addition to specific records): Forty-nine species of birds including turkeys, ruffed grouse, sharp-tailed grouse, doves; acorns heavily utilized by lesser prairie chicken in the fall, and oak flowers an important food of the same bird in spring in Oklahoma, ranks sixth on the list of quail food plants of the Sontheast; Merriam turkey; preferred fall food of prairie sharptailed grouse, ruffed grouse, and pinnated grouse; Mearn's quall ; an important food of band-tailed pigeons; constituted a larger percentage of food of mule deer in the Kaibab National Forest than any other food; Columbian blacktailed deer; Texas white-tailed deer; red fox; raccoon, porcupine, Mexican raccoon, peccary, Virginia opossum, snowshoe hare, New Mexico black bear, Olympic black bear, Townsend's chipmunk, Siskiyou chipmunk, Allen's chipmunk, larger Colorado chipmunk, Arizona chipmunk, gray-footed chipmunk, cliff chipmunk, golden-mantled ground squirrel, chestnut-mantled ground squirrel, Douglas ground squirrel, southwestern chipmunk, little northern chipmunk, pale chipmunk, gray chipmunk; cut for food and building material in times of scarcity by beaver; Merriam's chipmunk; Douglas' squirrel, Sierra chickaree, digger squirrel, Abert's squirrel, Arizona gray squirre̊l, rock squirrel, gray squirrel, Carolina fox squirrel, Couch rock squirrel, black-backed rock squirrel, fiying squirrels, California gray squirrel.

Without doubt there is a much greater number of animals, particularly squirrels and chlpmunks, than here listed that feed on acorns. That they have not been recorded in the literature is evidence that acorns are so generally accepted as being food for squirrels and chipmunks that many workers have felt it unnecessary to record utilization.

Quercus acuminata, see Quercus muhlenbergii.

Quercus agrifolia Née.

California live oak.

Range: 1, 5.

Site: Dry, well-drained, sun.

Fruit: Acorn, annual.

A large shrub to large tree; evergreen; occurs in sand, loam, gravel, and other soils; attacked by tent caterpillars; wood of some value as fuel; a shrub in dry hills (Var. frutescens Engelm.).

Observations: California quail ; California mule deer. 
Quercus alba $\mathbf{L}$.

Range: $20,22,23,24,25,26,27,28,29,30$.

White oak.

Site: Dry, well-drained, sun.

Fruit: Acorn; annual, available September-October.

A large tree, or rarely a low shrub with altitude; root system deep, taproot well developed; slow growing, rery long-lived; not seriously injured by insects or fungi; not very fire resistant; difficult to transplant even as seedling; wood durable, of great inmortance commercially ; bark a source of tannin ; fruit borne when trees are 20 to 40 years old; full crops bolne at intervals of 8 to 10 years, but some seed produced almost annually; 100-150 seeds per pound, germination 75-95 percent; coppice shorter lived and more tolerant of shade than seed-grown stock. Several varieties liave been described, all of which occur within the range of the species.

Stomach records: Ruffed grouse. Observations: Ring-necked pheasant, bol-white, ruffed grouse, wild turkey ; an important food of white-tailed deer ; cottontail rabbit; forms a considerable proportion of the food of the red squirrel.

Quercus alvordiana, see Quercus dumosa.

Quercus andromeda, see Quercus virginiana.

Quercus annulata, see Quercus breviloba.

Quercus aquatica, see Quercus nigra.

Quercus arizonica Sarg.

Arizona white oak.

Range: $10,11$.

Site: Dry, well-drained, sun.

Fruit: Acorn; annual, available September-November.

A small to large shrub or small tree; fruit ripens very irregnlarly; a small shrub at higher elevations.

Observations: Thick-billed parrots; highly palatable to captive deer.

Quercus arkansana Sarg.

Arkansas oak.

Range: 29.

Site: Well-drained, sun.

Fruit: Acorn; biennial.

A large tree; occurs in sandy and other soils; has been considered a hybrid between $Q$. nigra and $Q$. marilandica.

Quercus austrina, see Quercus durandii.

Quercus bicolor Willd.

Q. platanoides (La Marck) Sudw.

Swamp white oak.

Range: 21, 22, 23, 24, 25, 26, 27, 28.

Site: Well-drained, moist, sun.

Fruit: Acorn; annual, available September-October.

A large tree; root system somewhat shallow; free from insects and diseases, fire-damaged especially when young; produces stump sprouts; wood durable, of commercial value; $90-125$ seeds per pound, germination 80 percent.

Quercus borealis Michx. f.

Q. rubra of auths., not L.

Northern red oak.

Range: 21, 22, 23, 24, 25, 26, 27.

Site: Well-drained, sun, shade.

Fruit: Acorn; biennial, available October-November.

A very large tree; rapid growing when young, long-lived; taproot deen; nroduces a denser shade than most oaks; severely injured by fire; much attacked by borers and subject to fungus attack, especially heart rot; apparently not drought resistant; coppices freely when young; wood of great importance commercially ; 80-100 seeds per pound, germination 80-95 percent.

Var. borealis maxima (Marsh.) Ashe, (Q. maxima Ashe) is a large-fruited form occurring within the range of the species.

Stomach records: White-tailed deer. Observations: Ruffed grouse; tenth most important food of white-tailed deer in Massachusetts; forms a considerable portion of the food of red squirrels; cottontail rabbit; heavily browsed by moose on Isle Royal. Observations: Bobwhite; eaten by white-tailed deer in Missouri, and northern white-tailed deer in Michigan. 
Quercus boyntonii Beadle.

Q. stellata boyntonii (Beadle) Sarg.

Boynton oak.

Range: 27.

Site: Dry, sun.

Fruit: Acorn, annual.

A large, thicket-forming shrub.

Quercus brayi Small.

Q. muhlenbergii brayi (Snall) Sarg.

Bray's oak.

Range: 11, 16.

Site: Dry, well-drained, sun.

Fruit: Acorn, annual.

A large tree. Acorns much sought after by livestock, including domesticated turkeys.

Quercus brevifolia, see Quercus cinerea.

Quercus breviloba, see also Quercus durandii.

Quercus breviloba (Torr.) Sarg.

Q. obtusifolia breviloba Torr., Q. annulata Buckl.

Range: 11, 16, 20.

Site: Dry, well-drained, suu.

Fruit: Acorn, annual.

Commonly a Iarge shrub, or a small to large tree; thicket forming; occurs on limestone and other soils.

Var. laceyi (Small) Trel., (Q. laceyi Small), the Lacey oak, is a particularly rapid-growing form.

A valuable browse for liyestock.

Quercus breweri, see Quereus garryana.

Quercus californica, see Quercus kelloggii.

Quercus canbyi Trel.

Range: 11.

Site : Dry, well-drained, sun.

Fruit: Acorn, annual.

A small to large tree.

Quercus catesbaei, see Quercus laevis.

Quercus chapmanil Sarg.

Chapman white oak.

Range: 29, 30.

Site: Well-drained, sun.

Fruit: Acorn, annual.

Commonly a small shrub or a large shrub to large tree; semievergreen; occurs in sandy and other soils.

Quercus chisosensis, see Quercus gravesii.

Quercus chrysolepis Liebm.

Canyon live oak.

Range: 1, 4, 10, 11, 14.

Site : Dry, well-drained, sun.

Fruit: Acorn, biennial.

A small to large shrub, or small to large tree; evergreen; commonly shrubby on exposed sites; occurs in sand, loam, and other soils; forms a dense ground cover; long lived; stump sprouts abundantly produced, somewhat spiny; wood of some value commercially; the most ancient existing American oak; acorns much attacked by grubs.

Observations: California woodpecker; of slight importance as browse for mule deer.

Quercus cinerea Mlchx.

Q. brevifolia (Lam.) Sarg.

Bluejack oak.

Range: 16, 20, 25, 28, 29, 30.

Site: Dry, well-drained, sun.

Fruit: Acorn, biennial, available in November.

A small to large tree; occurs in sand, loam, and other soils; frult produced in great profusion.

Quercus coccinea Muench.

Range: 21, 22, 23, 24, 25, 26, 27, 28 .

Scarlet oak.

Site: Dry, well-drained, sun.

Fruit: Acorn, biennial, available September-October. 
A large tree; root system shallow; rapid growing, short-lived; much attacked by dry rot; coppices produced by young trees only; wood of importance commercially; much cultivated; apparently not dronght resistant; $156-400$ seeds per pound, germination 75 percent. Var. tuberculata Sarg. has larger acorns and oceurs withln the range of the species sonthward.

Observations: Bluejay, sharp-tailed grouse; white-tailed deer.

Quercus confusa Woot. and Standl.

Range: 11, 14.

Site: Well-drained, sun.

Fruit: Acorn, annual.

A small, somewhat evergreen tree.

Quercus densiflora, see Lithocarpus densiflora.

Quercus digitata, see Quercus rubra.

Quercus diversicolor Trel.

Q. reticulata of auths., not H. B. K.

Netleaf oak.

Range : 10, 11, 14.

Site: Dry, well-dralned, sun.

Fruit: Acorn, annual.

A small to large shrub or small to large tree; erergreen.

Observations: Thick-billed parrot. Fair summer browse for stock.

Quercus douglasii Hook. and Arn.

California blue oak.

Range: $1,3,4,5,10$.

Site: Dry, well-drained, sum.

Fruit: Acorn, annual.

A small to large tree; slow growing; stump sprouts produced; subject to dry rot; wood much used locally for fuel; seed produced abundantly.

Observations: Of slight importance as browse for mule deer. Acorns much used for livestock feeding.

Quercus dumosa Nutt.

Range: 1, 3, 4, 5, 10.

California scrub oak.

Site: Dry, well-drained, sun.

Fruit: Acorn, annual.

A large shrub to small, or rarely large tree; evergreen; root system deep, taproot well developed, especially in seedling stages; commonly occurs in sterile soils; branches numerous, closely tangled, starting near from the ground; acorn crop ordinarily light and very uncertain; grows on all kinds of soils; killed by severe fires, but if not too sererely burned, coppices and within 3 years again produces good cover; a small tree only on the California islands.

Var. macdonaldii (Greene) Jeps., (Q. macdonaldii Greene), the MacDonald oak, is in region 5 , and has been claimed to be a hybrid between $Q$. dumosa and Q. engelmannii. Var. bullata Engelm. (Q. durata Jeps.), the leather oak, is a spreading, thicket-forming shrub occurring in regions 1 and 5. Var. alvordiana (Eastw.) Jeps. (Q. alvordiana Eastw.) occurs in region 5. Var. turbinella (Greene) Jeps. (Q. turbinella Greene), occurring in regions 5, 9, 11 and 14, is a small to large shrub considered a valuable winter browse plant for livestock. It has been observed to be eaten by Mearns, Gambel, and sealed quail.

Observations: Of outstanding importance as browse for mule deer. Important as a sheep and goat browse but distinctly inferior for cattle. The high tannin content of the plant necessitates careful handling of lambs where it occurs.

Quercus durandii Buckl.

Durand white oak.

Q. breviloba (Torr.) Sarg., in part., Q. sinuata Walt., Q. austrina Small.

Range: 20, 29, 30.

Site: Dry, well-drained, sun.

Fruit: Acorn, annual.

A large shrub to large tree; thicket forming and shrubby westward; occurs on limestone and other soils.

Quercus durata, see Quercus dumosa.

Quercus eastwoodiae Rydb.

Range: 11, 13 .

Site: Dry, well-drained, sun.

Fruit: Acorn, annual.

A large shrub; not thicket forming. 
Quercus ellipsoidalis Hill.

Range: 21, 22, 23, 24.

Jack oak.

Site: Well-drained, sun.

Fruit: Acorn, biennial.

A small to large shrub or small to large trec; often occurs on clay soils.

Quercus emoryi Torr.

Q. hastata Liebm.

Emors oak.

Range: 10, 11.

Site: Dry, well-drained, sun.

Fruit: Acorn; annual, available July-August, or ripening irregularly from June-September.

A small to large shrub or small to large tree; evergreen; wood somewhat used commercially.

Observations: Mearn's Gambel, and scaled quall ; Mexican mule deer; Couch rock squirrel; much eaten by Gila chipmunk; highly palatable the year round to captive deer.

Quercus engelmannii Greene.

Range: 5.

Site: Dry, well-drained, sun.

Fruit: Acorn, annual.

A large evergreen tree; occurs on loam, sand, gravel, and other soils; wood useful only for fuel.

Observations: California mule deer.

Quercus falcata, see Quercus rubra.

Quercus fendleri Llebm.

Q. Undulata pedunculata DC.

Evergreen white oak.

Range: 11, 13, 14, 16.

Site: Dry, sun.

Fruit: Acorn, annual.

A large shrub; not thicket forming. Considered fair browse for cattle.

Quercus fusiformis, sec Quercus virginiana.

Quercus gambelii, see also Quercus leptophylla.

Quercus gambelii Nutt.

Q. douglasii gambelii DC., Q. Undulata gambelii Engelm.

Fendler oak.

Range: 9, 11, 13, 14.

Site: Dry, well-drained, sun.

Fruit: Acorn, annual.

A large shrub to small tree; resistant to heavy grazing.

Observations: Turkey. When associated with more palatable species, lightly grazed by cattle, sheep and horses; acorns sweet, relished by swine and other stock and with high fattening qualities; of moderately high palatability to goats; shoots contain 4-10 percent of tannic acid.

Quercus garryana Dougl.

Range: 1, 2.

Oregon white oak.

Site: Dry, well-drained, sun.

Fruit: Acorn, annual.

A large shrub to large tree; wood durable, valuable commerclally.

Var. breweri (Engelm.) Jeps. (Q. breweri Engelm., Q. oerstediana Brown), the Brewer oak, is a small to large, spreading shrub occurring in region 4 . It is much browsed by Rocky Mountain mule deer and much eaten by stock, the protein content of the foliage being almost equal to that of alfalfa hay. Var. semota Jeps., the Kaweah oak, is a shrub occurring in region 4. bear.

observations: Band-tailed plgeon, Lewis' woodpecker, ring-necked pheasant;

Quercus geminata, see Quercus virginiana.

Quercus georgiana Curtis.

Range: 27, 28.

Site: Dry, well-drained, sun.

A large, rare tree.

Georgia oak.

Fruit: Acorn, biennial. 
Quercus gravesii Sudw.

Q. texana chisosensis Sarg., Q. chisosensis Sarg.

Grave's oak.

Range: 11

Site : Dry, well-drained, sun.

Fruit: Acorn, biennial.

A small to large tree.

Quercus grisea Liebm.

Range: 11, 14, 16, 17.

Gray oak.

Site: Dry, well-drained, sun.

Fruit: Acorn, annual.

A large shrub or rarely a small tree; partially evergreen; clump forming, bears great quantities of nut galls; wood useful only for fuel; very resistant to drought.

Observations: Viosca's pigeon, thick-billed parrot; Sonora deer, Arizona poreupine. An important local browse for livestock.

Quercus gunnisonii (Torr.) Rydb.

Q. alba gunnisonii Torr., Q. gambelii gunnisonii Wenz.

Range: 11, 13, 14.

Site: Dry, well-drained, sun.

Fruit: Acorn, amnual.

A small to large shrub or small tree.

Quercus hastata, see Quereus emoryi.

Quercus havardii Rydb.

Range: 11, 16.

Shinnery oak.

Site: Dry, sun.

Fruit: Acorn, annual.

A small shrub; thicket forming; grows in sandy soil ; spreads by underground stems, the bulk of the species being underground; propagation is by separation of the root stocks as well as by acorns.

Observations: Bobwhite, prairie chicken; peccary. The large and sweet acorns are relished by livestock but this species has caused much poisoning.

Quercus humilis, see Quercus pumila.

Quercus hypoleuca Engelm.

Range: 11, 14.

Site: Dry, well-drained, sun.

Fruit: Acorn, annual, although often maturing the second season.

A large shrub to small or large tree; semievergreen; wood used locally.

Observations: Thick-billed parrot; favorite food of the Apache squirrel.

Quercus ilicifolia Wang.

Q. pumila (Marsh) Sudw., Q. nana Sarg.

Bear oak.

Range: 22, 25, 26, 27, 28.

Site: Dry, well-drained, sun.

Fruit: Acorn biennial, available September-October.

A large shrub to small tree; thicket forming; often forms a nearly complete ground cover; fruit produced very prolifically; suckers freely; not evergreell, but dead leaves often persistent through the winter; often occurs in extremely sterile soils. deer.

Stomach records: Ruffed grouse. Observations: Wild turkey; white-tailed

Quercus imbricaria Michx.

Range: 22, 23, 24, 25, 27, 28.

Site: Well-drained, moist, sun.

Fruit: Acorn; biennial, arailable September-October.

A large tree; wood used commercially; somewhat cultivated; 450-800 seeds per pound.

observations: Red-headed woodpecker's.

Quercus intricata Trel.

Range: 11.

Site: Dry, well-drained, sun.

Fruit: Acorn, annual.

A small, intricately branched shrub. 
Quercus kelloggii Newb.

Q. californica (Torr.) Cooper.

California black oak.

Range: $1,3,4,5,10$.

Site: Dry, well-drained, sun.

Fruit: Acorn, biennial.

A small sliub to large tree; occurs in sandy and other soils; root system deep; slow growing, long-lived; shrubbier at higher elevations; wood much used for fuel; stump sprouts freely produced, of rapid growth, often prostrate; subject to mistletoe.

Observations: Of outstanding importance as browse for mule deer.

Quercus laceyi, see Quercus breviloba.

Quercus laevis Walt.

Q. catesbaei Michx.

Turkey oak.

Range: 29,30 .

Site: Dry, well-drained, sun.

Fruit: Acorn, biennial.

A large tree; commonly oceurs in sandy soil ; root system deep; rather rapid growing, generally short-lived; free from insects and disease.

Quercus laurifolia Michx.

Range : 20, 28, 29, 30 .

Laurel oak.

Site: Well-drained, moist, sun.

Fruit: Acorn; biennial, available September-October.

A large tree; occurs in sand, loam, and other soils; somewhat cultivated; $540-690$ seeds per pound.

Var. rhombica (Sarg.) Trel., (Q. rhombica Sarg., Q. obtusa Ashe) occurs within the range of the species.

Quercus leiodermis, see Quercus velutina.

Quercus leptophylla Rydb.

Q. gambelii Nutt., in part.

Range: 13, 14.

Site: Well-drained, sun.

Fruit: Acorn, annual.

A large tree; commonly occurs in groups; wood hard, strong, used for fuel. Quercus lobata Née.

Range: $3,4,5$.

Site: Well-drained, sun, shade.

Fruit: Acorn, ammual.

A large tree; ordinarily occurs in richer soils; rapid growing; wood of some value commercially; taproot well developed; long-lived; produces very abundant crops of acorns; weeping trees confined to fertile loam soils.

Obscrvations: Of slight importance as browse for mule deer.

Quercus lyrata Walt.

Range: 20, 22, 25, 28, 29, 30.

Site: Well-drained, moist, sun.

Fruit: Acorn; annual, available September-October.

A small to large tree; commonly does not oceur on poor soils; root system deep, taproots and deep-seated laterals well-developed; slow growing, long-lived; generally free from insects and disease; resistant to fire; wood durable, of importance commercially; 150 seeds per pound, commonly produced abundantly every 3 or 4 years. Young plants browsed by cattle.

Quercus macdonaldii, see Quercus dumosa.

Quercus macrocarpa Michx.

Range: $15,16,18,19,20,21,22,23,24,25,26,27,28,29,30$.

Site: Dry, well-drained, sun.

Frult: Acorn; annual, available September-October.

Rarely a large shrub to small tree, or more commonly a large tree; root system deep, especially on dry sites; commonly oceurs on rich, not poor solls, although often found in sand; slow growing, long-lived; not seriously injured by fungi or insects, except rarely Jume beetles; more resistant to smoke than most oaks ; wood durable, much used commercially; 380-400 seeds per pound, germination $60-75$ percent, vitality 6 to 12 months.

Observations: Wood duck; acorns form a considerable portion of food of red squirrel; white-tailed deer, Young plants browsed by stock. 
Quercus margaretta Ashe.

Q. Stellata margaretta Sarg.

Small post oak.

Rauge : $20,29,30$.

Site: Dry, well-drained, sun.

Fruit: Acorn, annual.

A large shrub to small tree; occurs on sandy and other soils.

Var. stolonifera Ashe forms dense thickets by means of stolons.

Querous marilandica Muench.

Range: $16,19,20,22,24,25,27,28,29,30$.

Blackjack oak.

Site : Dry, well-drained, sun.

Fruit: Acorn; biennial, available in October.

In the north, a large shrub; in the south, a large tree; commonly occurs on sand, clay, loam, and other soils; wood rarely used commercially. Var. ashei Sudw. occurs in regions 19, 20, and 29.

Stomach records: Wild turkey; white-tailed deer. Observations: A greatly preferred food of wild turkey, white-tailed deer.

Quercus maxima, see Quercus borealis.

Quercus media Woot. and Standl.

Range: 11, 14.

Site: Dry, well-drained, sun.

Fruit: Acorn, annual.

A large shrub to small tree; thicket forming.

Quercus michauxii, see Quercus prinus.

Quercus microcarya, see Quercus nigra.

Quercus minima, see Quercus virginiana.

Quercus minor, see Quercus stellata.

Quercus mohriana Buckl.

Shin oak.

Range: 11, 16, 17, 19, 20.

Site: Dry, well-drained, sun.

Fruit: Acorn, annual.

Usually a small shrub, more rarely a small tree; thicket forming; occurs on limestone, sandy, and other soils; becomes a tree only in deep ravines and on steep hillsides where protected.

Quercus montana Willd.

Q. prinus of auths., not $\mathrm{L}$.

Chestnut oak.

Range: $22,24,25,26,27,28,29$.

Site: Dry, well-drained, sun.

Fruit: Acorn; anmul, available October-November.

A large tree; root system deep; occurs on rich or poor soils; fairly rapid growing, long-lived; seedlings tolerant of shade; very fire resistant; coppices freely when young; wood durable, much used commercially; bark contains more tannin than any other eastern oak; 60-150 seeds per pound.

Quercus muhlenbergii Engelin.

Q. acuminata Sarg.

Chinquapin oak.

Range: $11,16,20,21,22,23,24,25,26,27,28,29,30$.

Site : Dry, well-drained, sull.

Fruit: Acorn; annual, available October-November.

Commonly a small, or more rarely, a large tree; may occur on limestone soil ; taproot well developed; rather rapid growing; becomes more intolerant of shade with age; free from insects and disease; young growth easily damaged by fire; stump sprouts produced; wood durable, used commercially; 520 seeds per pound.

Quercus myrtifolia Willd.

Myrtle oak.

Range: $17,29,30$.

Site: Dry, well-drained, sun.

Fruit: Acorn, blennial.

A small to large shrub or small tree; thicket forming; commonly occurs on sandy soil.

Quercus nana, see Quercus ilicifolia. 
Quercus nigra L.

Q. aquatica Walt.

Water oak.

Range : 17, 20, 25, 28, 29, 30.

Site: Well-drained, moist, sum.

Fruit: Acorn; biennial, available October-November.

A large tree; rapid growing in good soils; occurs in sand, loam and other soils; wood somewhat used commercially; much cultivated; very susceptible to mistletoe; 400-600 seeds per pound. A form described as Q. microcarya Small occurs on Stone Mountain, Ga.

Quercus nitescens, see Quercus novomexicana.

Quercus novomexicana (DC.) Rydb.

Q. douglasii novomexicana DC., Q. nitescens $\mathrm{Rydb}$.

New Mexican shinnery.

Range: $11,13,14,16$.

Site: Dry, well-drained, sun.

Fruit: Acorn, annual.

A large shrub to small or large tree.

Quercus oblongifolia Torr.

Range: $10,11,17$.

Mexican blue oak.

Site: dry, well-drained, sun.

Fruit: Acorn, annual.

A large shrub to small or large trees; evergreen; often thicket forming, especially at the heads of canyons; produces fruit even as a shrub.

Observations: Highly palatable to captive deer.

Quercus obtusa, see Quercus laurifolia.

Quercus obtusifolia (DC.) Rydb.

Q. undulata obtusifolia $\mathrm{DC}$.

Range: 14, 29.

Site: Dry, well-drained, sun.

Fruit: Acorn, annual.

A large shrub to small tree.

Quercus oerstediana, see Quercus garryana.

Quercus pagoda, see Quercus rubra.

Quercus pagodaefolia, see Quercus rubra.

Quercus palmeri Engelm.

Q. chrysolepis palmeri Engelm.

Palmer oak.

Range: 5, 10, 11.

Site: Dry, suu.

Fruit: Acoru, biennial.

A large, divaricately-branched, evergreen shrub.

Quercus palustris Muench.

Range: 21, 22, 23, 24, 25, 27, 29.

Site: Well-drained, sum.

Fruit: Acoru; biennial, available September-October.

A large tree; root system well developed laterally; rather rapid growing and short-lived; resistant to dust and smoke; freé from insects and disease; coppices fairly well; much cultivated; wood used commercially; 600 seeds per pound.

Observations: Bobwhite, mourning dove; cottontail rabbit.

Quercus pauciloba Rydb.

MacDougal oak.

Range: 13, 14.

Site: Dry, well-drained, sun.

Fruit: Acorn, annual.

A large shrub, or more commonly a small to large tree.

Quercus phellos L.

Range : $20,25,27,28,29,30$.

Pin oak.

Site: Well-drained, sun.

Fruit: Acorn; biennlal, available in October.

A large tree; occurs in sandy and other soils; wood used commercially ; much cultivated; 600 seeds per pound.

Stomach records: Gray fox. Observations: Wild turkey, mourning dove, bobwhlte. 
Quercus platanoides, see Quercus bicolor.

Quercus pricei Sudw.

Coast live oak.

Range: 5 .

Site: Dry, well-drained, sun.

Fruit: Acorn, biennial.

A small to large evergreen tree; occurs in gravelly and other soils. Hardly separable from $Q$. agrifolia.

Quercus prinoides Willd.

Range : 21, 22, 23, 24, 25, 27, 28, 29, 30.

Dwarf chinquapin oak.

Site: Dry, sun.

Fruit: Acorn; annual, available September-October.

A large shrub to small tree; thicket forming; occurs on sandy, limestone and other soils; 400 seeds per pound.

Observations: Ruffed grouse, cottontail rabbit.

Quercus prinus, see also Quercus montana.

Quercus prinus $\mathbf{L}$.

Q. michauxii Nutt.

Swamp chestnut oak.

Range: $20,25,28,29,30$.

Site: Well-drained, moist, sun.

Fruit: Acorn; annual, available September-October.

A large tree; taproot and deep laterals well developed; long-lived; generally free from insects and diseases; easily fire-damaged when young; stump sprouts never large; wood durable, much used commercially; a fertile-soil species; 70-150 seeds per pound, germination 86 percent.

Stomach records: Mourning dove; white-tailed deer. Observations: Cottontail rabbit.

Quercus pumila, see also Quercus ilicifolia.

Quercus pumila Walt.

Q. humilis Walt.

Range: 29,30 .

Site: Dry, well-drained, sun, shade.

Fruit: Acorn, annual.

A small evergreen shrub; often forms small sparse thickets by means of root stocks; not a pioneer species.

Stomach records: Bobwhite.

Quercus pungens, see Quercus undulata.

Quercus reticulata, see Quercus diversicolor.

Quercus rhombica, see Quercus laurifolia.

Quercus rubra, see also Quercus borealis.

Quercus rubra $\mathbf{L}$.

Southern red oak.

Q. falcata (Michx.) of Amer. auths., Q. digitata (Marsh.) Sudw.

Range : $20,25,27,28,29,30$.

Site : Dry, well-drained, sun.

Fruit: Acorn; biennial, available September-October.

A large tree; root system deep as well as shallow on the same tree; occurs on sandy or heavy soils; rapid growing, rather short-lived; very sensitive to late frosts; much attacked by heart rot; coppices freely, especially when young; much cultivated; wood not durable, somewhat used commercially.

Var. pogodaefolia (Ell.) Ashe, (Q. pogodaefolia (Ell.) Ashe, Q. pagoda Raf.), and var. leucophylla Ashe, both occur within the range of the species.

Quercus rydbergiana Cockercll.

Q. undulata rydbergiana Cockerell.

Rydberg oak.

Range: 13, 14.

Site: Dry, sun.

Fruit: Acorn, anrual.

A small evergreen shrub.

Quercus sadleriana Brown.

Range: 4.

Sadler oak.

Site: Dry, well-drained, sun, shade.

Fruit: Acorn, annual.

A small to large evergreen shrub; forms dense thickets; occurs at altitudes of from 5,000-7,000 feet. 
Observations: Acorns relished by deer and bear. Poor to fair browse for livestock, but acorns relished.

Quercus schneckii, see Quercus shumardii.

Quercus shumardii Buckl.

Shumard red oak.

Q. texana Sarg.

Range: $16,20,22,24,25,27,28,29$.

Site: Dry, well-drained, moist.

Fruit: Acorn; biennial, available in October.

A very large tree; occurs on limestone and other soils; root system shallow; free from insects and diseases; wood of value commercially.

Var. schnecliii (Britt.) Sarg., (Q. schneckii Britt.), the Schneck red oak, occurs also in region 17.

Quercus sinuata, see Quercus durandii.

Quercus stellata Wang.

Q. minor (Marsh.) Sarg.

Post oak.

Range : $19,20,22,25,27,28,29,30$.

Site: Dry, well-drained, sun.

Fruit: Acorn; annual, available September-October.

A large tree; commonly occurs in poor soll such as sand and gravel; root system deep; slow growing; long-lived; tolerant of shade only when young; fruit produced abundantly every 2 or 3 years; wood durable, difficult to season, much used commercially ; 35-636 seeds per pound.

Stomach records: Wild turkey. Observations: A preferred food of wild turkey; white-tailed deer.

Quercus submolis Rydb.

Q. utahensis submollis (Rydb.) Sarg.

Range: 9, 10, 11, 13, 14.

Site: Dry, well-drained, sun.

Fruit: Acorn, annual.

A large shrub to small tree.

Quercus subturbinella Trel.

Range: 11, 14.

Site: Dry, well-drained, sun.

Fruit: Acorn, annual.

A large shrub to small tree.

Quercus texana Buckl.

Range: 11, 16, 17, 20, 29.

Texas red oak.

Site: Dry, well-drained, sun.

Fruit: Acorn, biennial.

A small to large tree; occurs on limestone and other soils. Var. stellapila Sarg., occurs within the range of the species; by some it is considered specifically distinct.

Quercus texana, see Quercus shumardii.

Quercus tomentella Engelm.

Range: 5 .

Island live oak.

Site: Dry, well-drained, sun.

Fruit: Acorn, biennial.

A large evergreell tree; moderately long-lived; occurs in gravelly and other soils. Possibly only a variety of $Q$. chrypolepis.

Quercus toumeyi Sarg.

Range: 11 .

Toumey oak.

Site: Dry, well-drained, sun.

Fruit: Acorn, annual.

A large shrub to large tree; more or less evergreen.

Quercus turbinella, see Quercus dumosa.

Quercus undulata Torr.

Q. vaseyana Rydb., Q. vaseyana Buckl., Q. undulata vaseyana Rydb.

Range: 9, 11, 13, 14, 16, 17, 20.

Site: Dry, sun.

Fruit: Acorn, annual. 
A small to large shrub or small to large tree; somewhat evergreen; forms thickets of vast extent; bears great quantities of nut galls.

Var. pungens Engelm. (Q. pungens Liebm.), the holly oak, occurs in regions 9 and 11.

Stomach records: Prairie chicken. Fair to fairly good cattle feed in winter and spring; good goat feed, especially in spring.

Quercus utahensis (DC.) Rydb.

Q. stellata utahensis DC.

Rocky Mountain white oak.

Range: $9,11,13,14$.

Site: Dry, well-drained, sun.

Fruit: Acorn, annual.

A large tree; root system shallow with occasional deep-feeding branches, or sometimes altogether deep; wood used to some extent for fuel.

stomach records: Porcupine, black-tailed deer.

Quercus vaccinifolia Kellogg.

Q. chrysolepis vaccinifolia (Kellogg) Engelm.

Huckleberry oak.

Range: 4.

Site: Dry, sun.

Fruit: Acorn, biennial.

A small, thicket-forming evergreen shrub.

Stomach records: Sooty grouse. Observations: Of outstanding importance as browse for mule decr. Acorns readily eaten by livestock, but foliage of low palatability.

Quercns vaseyana, see Quercus undulata.

Quercus velutina Lam.

Range: $20,22,23,24,25,26,27,29,29,30$.

Black oak.

Site: Dry, well-drained, sun.

Fruit: Acorn; biennial, available October-November.

A large tree; commonly occurs on poor soil; taproot at first well developed, later superficial; scedlings slow growing; long-lived; coppice freely produced, rapid growing, short-lived; wind-firm; rarely injured by insects, except when fire-damaged; susceptible to drought injury; easily fire-damaged; wood used commercially; usually attacked by heart rot; $130-300$ seeds per pound, germination 80 percent or more.

Var. missouriensis Sarg., (Q. lciodermis Ashe), the smooth-bark oak, occurs with the specles westward.

Observations: Cottontail rabbit, white-tailed deer.

Quercus venustnla Greene.

Range: 13, 14.

Site: Dry, sun.

Fruit: Acorn, annual.

A small to large shrub; acorns commonly produced abrundantly.

Quercus virginiana Mill.

Range: 11, 16, 17, 20, 25, 29, 30, 31 .

Live oak.

Site: Dry, well-drained, sun.

Fruit: Acorn; annual, available September-October.

A small to large slurrib or small to large, evergreen tree; occurs on sand, clay, and alluvial soils; root system deep, spreading; fruit often produced by plants 12 inches in height; able to grow very close to the sea, where roots may be covered with salt water at high tide; rapid growing at first, later slower; long-lived; free from insects and diseases; produces stump sprouts; branches very wide-spreading; wood durable, of little importance commercially.

Var. geminata. (Small) Sarg., (Q. geminata Small) occurs in regions 29 and 30. Var. virescens Sarg. occnrs in Florida. Var. macrophylla Sarg., with larger leaves, occurs in southeastern Texas. Var, eximea Sarg., (Q. andromeda Ridd.) of eastern Louisiana, has smaller leaves and acorns. Var. fusiformis (Small) Sarg., (Q. fusiformis Small) occurs in regions 16 and 20 and is generally shrubby. Var. minima (Small) Sarg., (Q. minima Small, Q. virginiana dentata Chapm.) occurs in region 30 , is usually less than 3 feet high, and has underground stems. Var. maritima (Michx.) Small occurs in regions 29 and 30 and is shrubby. Var. pygmaea Sarg. has smaller acorns, is a shrub, and occurs in region 30 . 
Quercus vreelandii Rydb.

Range: 11, 13, 14.

Site: Dry, well-drained, sun.

Fruit: Acorn, annual.

A small to large shrub.

Quexcus wilcoxii Rydb.

Wilcox oak.

Range: $9,11,14$.

Site: Dry, sun.

Fruit: Acorn, biennial.

A small to large shrub or rarely a small tree; evergreen; thicket forming. Not eaten to any extent by cattle.

Quercus wislizenii DC.

Range: 4, 5, 10.

Highland live oak.

Site: Dry, well-drained, sun.

Fruit: Acorn, biennial.

A large shrub to small or large tree; evergreen; not as tolerant of shade as formerly supposed; coppices quickly after flres, but such growth is slow; attacked by mistletoe; makes good soil cover; acorns not produced in very great quantities; wood not durable, locally valuable as fuel; occurs in loam, gravel, and other soils; near the coast and on the California islands generally shrubby.

Observations: Of fair importance as browse for mule deer.

Ramona incana, see Salvia carnosa.

Ramona polystachya, see Salvia apiana.

Ramona stachyoides, see Salvia mellifera.

Raphis acaulis, see Sabal minor.

Rhamnus spp.

Buckthorns.

Most species occur on neutral soil ; some specles are secondary hosts for the crown rust of oats; propagation is by seeds stratifled and sown in spring or by soft or hardwood cuttings made at the nodes.

Observations (in addition to specific records): Three species of birds; generally relished by birds. Evergreen species have a limited value as browse for livestock in winter.

Rhamnus alnifolia L'Her.

Range: $4,12,18,21,22,23,24,26,27$.

Alder-leaved buckthorn.

Site: Well-drained, moist, shade.

Fruit: Drupe, available July-September.

A small shrub; flowers May-June; branches decumbent, rooting; thicket forming. Of no valne as browse for cattle; poor to fair browse for sheep.

Rhamnus betulaefolia Greene.

$\boldsymbol{R}$. californica betulaefolia (Greene) Trel., $R$. confinis Greene, $R$. ellipsoidea Greene, $R$. revoluta Rose.

Range: 9, 11, 14.

Site: Well-drained, moist, sun, shade.

Fruit: Drupe, available, September-October.

A small to large shrub; flowers May-June; not a secondary host for oat crown rust.

Rhamnus californica Esch.

Range: $1,3,4,5,10$.

California buckthorn.

Site : Dry, well-drained, sun.

Fruit: Drupe, available August-September.

A large evergreen shrub; flower's March-April; a secondary host for the rust of relvet grass but not oats.

Var. tomentella (Benth.) Brewer and Wats. ( $R$. tomentella Benth., $R$. ursina Greene) (pl. 27, $B$ ), commonly more compact, bushy, and robust than the species, occurs in regions $3,4,5,10$, and 11. Var. viridis Jeps. ( $R$. cuspidata Greene) occurs in reglons 4, 5, 9, and 10. Var. obtusissima (Greene) Jeps., ( $R$. obtusissima Greene) occurs in region 4. Var. occidcntalis (Howell) Jeps. ( $R$. occidentalis Howell), occurs in region 1.

Stomach records: Seven species of birds. Observations: Four species of birds, including band-tailed pigeon; California mule deer, black bear. Of some im- 
portance as a honey plant. Of no value as forage for cattle; poor to fair for sheep.

Rhamnus caroliniana Walt.

Range: 17, 20, 22, 25, 28, 29, 30.

Yellow bickthorn.

Site: Well-drained, moist, sun, shade.

Fruit: Drupe, available September-November.

A large shrub to small or large tree; flowers May-June: occurs on limestonc, loam, and other solls; susceptible to the crown rust of oats.

Stomach records: Catbird.

Rhamuus catalinae, see Rhamnus crocea.

Rhamnus confinis, see Rhamnus betulaefolia.

Rhamnus crocea Nutt. (pl. 29, $A, B$ ).

Range: $3,5,11$.

Site: Dry, well-drained, sun.

Fruit: Drupe, available August-September.

A small to large shrub, or rarely a small to large tree; partially evergreen; flowers February-May; densely branched; experimentally susceptible to the crown rust of oats.

Var. insularis Sarg. ( $R$. insularis Greene, $R$. pirifolia Greene, $R$. catalinae, Davids.) has larger berries, and occurs in region 5. Var. ilicifolia (Kellogg) Greene ( $R$. iticifolia Kellogg) has spiny leaves, is more commonly treelike, and occurs in regions 4, 5, and 10. Var. pilosa Trel. (R. pilosa Abrams) occurs in region 5.

Stomach records: Mountain sheep. Observations: California mule deer.

Rhamnus cuspidata, see Rhamnus californica.

Rhamnus ellipsoidea, see Rhamnus betulaefolia.

Rhamnus fasciculata, see Rhamnus smithii.

Rhamnus humboldtiana, see Karvinskia humboldtiana.

Rhamnus ilicifolia, see Rhamnus crocea.

Rhamnus insularis, see Rhamnus crocea.

Rhamnus lanceolata Pursh.

Range: 22, 25, 27, 29.

Lance-leaved buckthorn.

Site: Well-drained, moist, sun, shade.

Fruit: Drupe, available August-September.

A small to large shrub; flowers in May; commonly occurs on calcareous soils: susceptible to crown rust of oats.

Stomach records: Three species of birds.

Rhamnus maculata, see Karwinstia humboldtiana.

Rhamnus obtusifolia, see Condalia obtusifolia.

Rhamnus obtusissima, see Rhamnus californica.

Rhamnus occidentalis, see Rhamnus californica.

Rhamnus pilosa, see Rhamnus crocea.

Rhamnus pirifolia, see Rhamnus crocea.

Rhamnus purshiana DC. (pl. $30, A, B$ ).

Cascara.

Range: $1,2,3,4,6,7,9,11,12$.

Site: Dry, well-drained, moist, sun, shade.

Fruit: Drupe, available July-September.

A small to large shrub or a small to large tree; occurs on sand, gravel, loam, and other soils; experimentally susceptible to the crown rust of oats; coppices freely after cutting; bark of importance commercially; commonly smaller southward ; 4,735 seeds per pound.

Stomach records: Seven species of birds. Observations: Five species of birds, including Oregon ruffed grouse, band-tailed pigeon; New Mexico black bear; of fair importance as browse for mule deer; Olympic black bear, Oregon gray fox, raccoon, ring-tailed cat. Without forage value for livestock.

Rhamnus revoluta, see Rhamnus betulaefolia. 

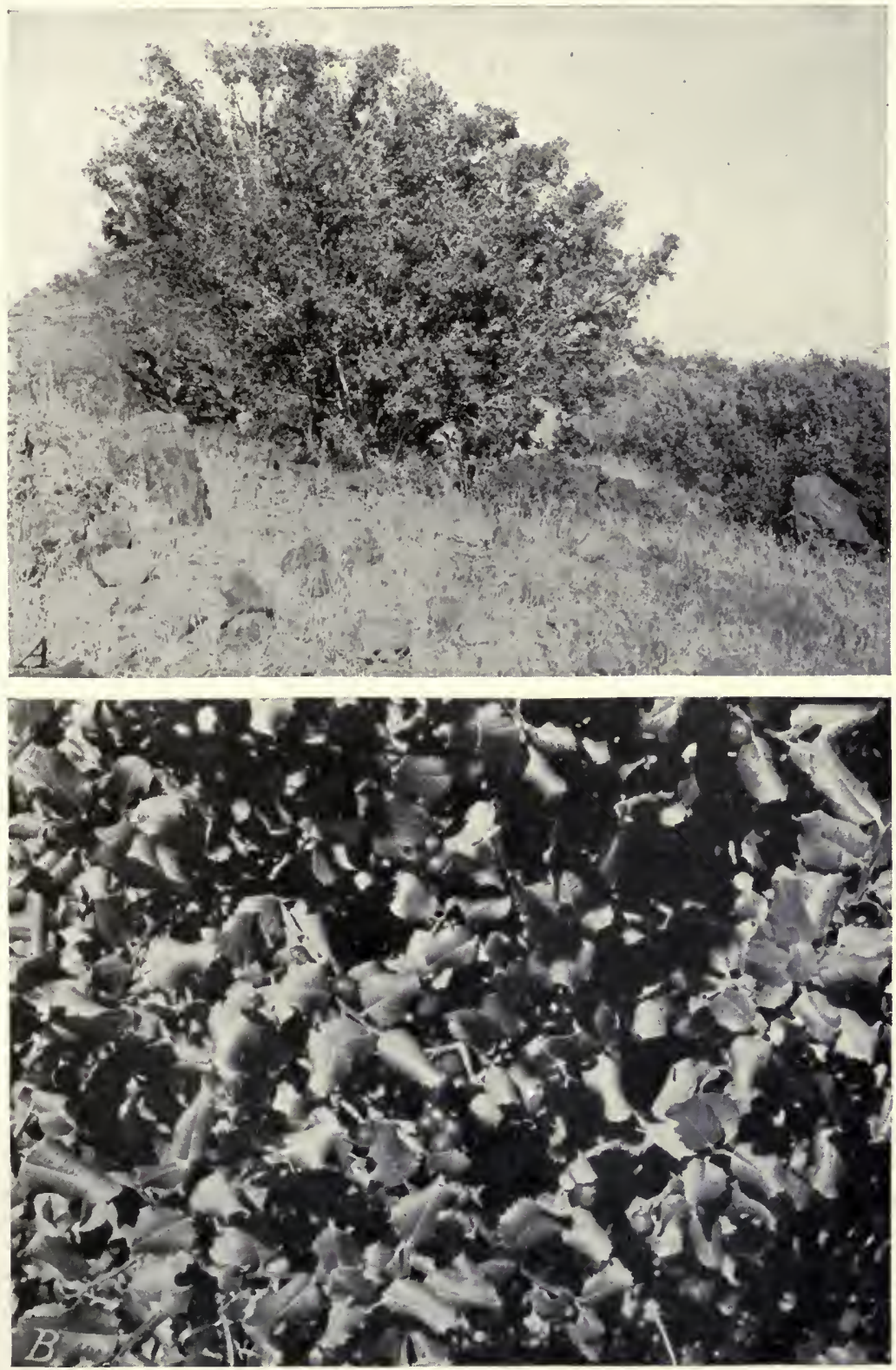

Rhamnus crocea: $A$, A large specimen of hollyleaf buckthorn forming an effective cover on poor soil; $B$, a close view of the dense foliage and fruit. 

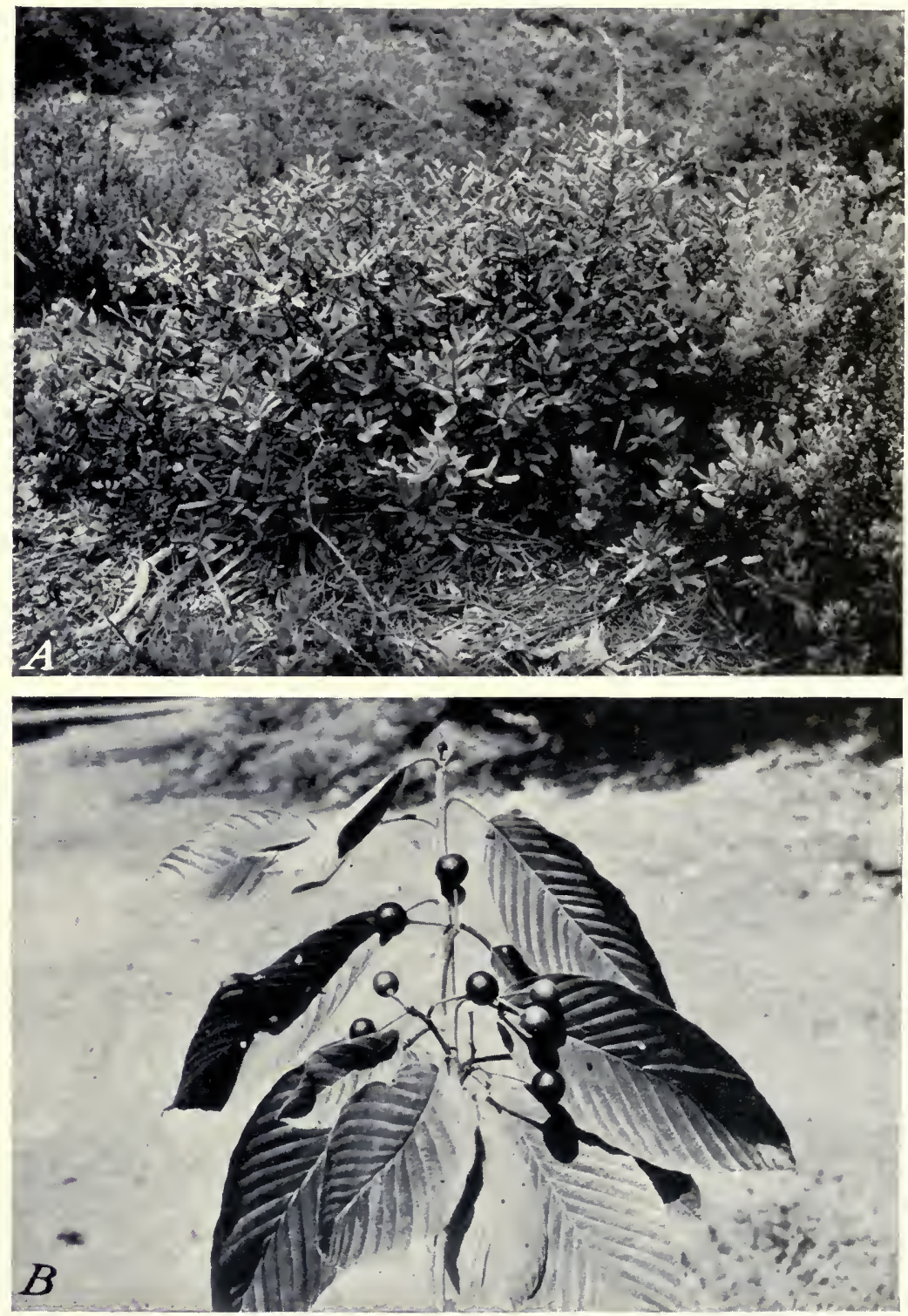

Rhamnus purshiana: $A$, The shrubby southern form of cascara may prove a more valuable cover plant than the treelike northern form. $B$, The drupes are cathartic to man. Their physiologic effect on wildlife species is not known. 
Rhamnus rubra Greene.

Redstem buckthorn.

Range: 4.

Site: Well-drained, sun.

Fruit: Drupe, available August-September.

A small shrub; flowers ill June; susceptibllity to crown rust of oats not known.

Rhannus smithii Greene.

Smith buckthorn.

$R$. fasciculata Greene.

Range: 11, 13, 14.

Site: Well-drained, moist, sun.

Fruit : Drupe.

A small to large, dioecious, densely leafy shrub; susceptible to the crown rust of oats.

Rhamnus texensis, see Colubrina texensis.

Rhamnus tomentella, see Rhamnus californica.

Rhamnus ursina, see Rhamnus ealifornica.

Rhapidophyllum hystrix (Fraser) Wendl. and Drude.

Needle palm. Chamacrops hystrix Fraser, Corypha hystrix (Fraser) Desf., Sabal hystrix Desf.

Range: 29,30 .

Site: Dry, well-drained, sun.

Fruit: Drupe.

A small to large evergreen shrub; rootstoeks ereeping and rooting.

Rhododendron spp.

This genus has often been divided into several separate genera or genus sections. The most notable for the United States are rhododendron and azalea. It is generally agreed among botanists that these two cannot be maintained as separate genera although they may well appear to be separable as far as the species in this country are concerned. They are here treated as one. The species popularly known as azaleas are largely deciduous, at least in North Ameriea. Those known as rhododenärons are mostly evergreen. The azaleas are generally to be found growing in the sun; the rhododendrons make their best growth in the shade. Nevertheless, there are no constant botanical eharacters to separate them.

Rhododendron alabamense Rehd.

Azalea alabamense (Rehd.) Small.

Alabama azalea.

Range : $28,29,30$.

Site: Dry, well-drained, sun.

Fruit: Capsule.

A small shrub; flowers April-May.

Rhododendron albiflorum Hook.

White-flowered azalea.

Azaleastrum albiflorum (Hook.) Rydb., Azalea albiflora Kuntze., Cladothamnus campanulatus Greene.

Range: 4, 12.

Site: Well-drained, shade.

Fruit: Capsule.

A small to large shrub; flowers June-July. While under normal range conditions it is not palatable to livestock, it is nevertheless poisonous.

Rhododendron arborescens (Pursh) Torr.

Smooth azalea.

Azalea arborescens Pursh.

Range: 27.

Site: Well-drained, moist, sun, shade.

Frult: Capsule.

A small to large shrub or rarely a small tree; flowers June-July.

Rhododendron atlanticnm (Ashe) Rehd.

Azalea atlantica Ashe.

Range: 28, 29, 30 .

Site: Dry, well-drained, sun, half shade.

Fruit: Capsule.

A small shrub; flowers April-May; mat forming; aggressive; spreads by means of stolons; many often invade fields. 
Rhododendron austrinum (Small) Rehd.

Azalea austrina. Small.

Range: 30 .

Site: Well-drained, molst, shade.

Fruit: Capsule.

A large shrub; flowers April-May; commonly occurs on sandy soil.

Rhododendron calendulaceum (Michx.) Torr.

Azalea calendulacea Michx., A. lutea L.

Flame azalea.

Range: 27, 28.

Site: Well-drained, sun, shade.

Fruit: Capsule.

A small to large shrub; flowers May-June; branches erect or spreading; very ornamental.

Rhododendron californicum Hook.

California rose-bay.

R. macrophyllum Don.

Range: 1, 2.

Site: Well-drained, sun.

Fruit: Capsule.

A small to large shrub or rarely a small tree; evergreen; flowers May-June; considered poisonous to sheep.

Rhododendron canadense (L.) B. S. P.

$R$. canadense Torr., $R$. rhodora Gmel., Rhodora canadensis L.

Rhodora.

Range: 26, 27.

Site: Well-drained, moist, sun.

Fruit: Capsule.

A small, much-branched shrub; flowers in May.

Rhododendron canescens (Michx.) Sweet.

Azalea canescens Michx, not Small.

Range: 26, 27, 28, 29, 30 .

Site: Well-drained, moist, sun, shade.

Fruit: Capsule.

A large sparingly-branched shrub, flowers April-May; occurs in sandy and other soils.

Rhododendron carolinianum Rehd.

Carolina rhododendron.

Range: 27.

Site: Well-drained, sun.

Fruit : Capsule.

A large, much-branched evergreen shrub; flowers April-May.

Rhododendron catawbiense Michx. (pl. 31).

Range: 27, 28.

Site: Dry, well-drained, moist, sun.

Fruit : Capsule.

A large evergreen shrub; flowers May-June; often forms thickets covering extensive tracts of land; poisonons to livestock either fresh or dry.

Rhododendron cuthbertil, see Rhododendron minus.

Rhododendron lapponicum (L.) Wahl.

Azalea lapponica $\mathbf{L}$.

Lapland rose-bay.

Range: 26.

Site: Dry, well-drained, sun.

Fruit: Capsule.

A small, prostrate evergreen shrub, commonly occurring on alpine summits.

Rhododendron macrophyllum, see Rhododendron californicum.

Rhododendron maximum $\mathrm{L}$.

Range: 24, 26, 27.

Site: Well-drained, molst, sun, shade.

Fruit: Capsule.

A large shrub to small tree; evergreen; flowers June-July; thicket forming; much cultivated.

Stomach records: Sharp-tailed grouse; white-tailed deer. Observations: Eaten by deer but poisonous to them if taken in large quantities. Poisonous to stock, which avoid it unless very hungry. 
Rhododendron minus Michx.

$\boldsymbol{R}$. cuthbertii Small., $\boldsymbol{R}$. punctatum Ander.

Piedmont rhododendron.

Range: 28, 29.

Site: Well-drained, sun, shade.

Fruit: Capsule.

A small to large, straggling evergreen shrub; commonly occurs on sandy soil.

Rhododendron nudiflorum (L.) Torr.

Azalea nudiflora $\mathrm{L}$.

Pinxter flower.

Range: $25,26,27,28,29,30$.

Site: Dry, well-drained, moist, sun, shade.

Fruit: Capsule.

A small to large shrub; flowers April-May; commonly occurs in sandy soll.

Rhododendron oblongifolium (Smali) Mill.

Azalea oblongifolia Small.

Range: 25, 29.

Site: Dry, well-drained, moist, sun, shade.

Fruit: Capsule.

A small to large shrub; commonly occurs in sand or limestone soils.

Rhododendron occidentale (Torr. and Gray) Gray.

Azalea occidentalis Torr. and Gray, 4 . californica Torr. and Gray.

Range: 4.

Site: Well-drained, moist, sun, shade.

Fruit: Capsule.

A large shrub; flowers June-July; rarely occurs in sunny positions.

Observations: Much used by mountain beaver. An important livestock-poisoning plant.

Rhododendron prinophyllum, see Rhododendron roseum.

Rhododendron prunifolium (Small) Mill.

Azalea prunifolia Small.

Range : 29.

Site: Well-drained, moist, shade.

A large shrub.

Fruit: Capsule.

Rhododendron punctatum, see Rhododendron minus.

Rhododendron rhodora, see Rhododendron canadense.

Rhododendron roseum (Loisel.) Rehd.

R. prinophyllum (Small) Mill., Azalea rosea Loisel., A. prinophylla Small,

A. canescens Porter, not Torr., and of Small, not Michx.

Range: 25, 27, 28, 29.

Site: Dry, well-drained, sun.

Fruit: Capsule.

A large shrub; often dominant and thicket forming in old clearings; very ornamental.

Rhododendron serrulatum (Small) Mill.

Azalea serrulata Small.

Range: 30 .

Site: Moist, well-drained, sun.

Fruit: Capsule.

A large shrub.

Rhododendron speciosum (Wilid.) Sweet.

Azalea speciosa Willd.

Range: $27,28,29$.

Site: Well-drained, sun.

Fruit: Capsule.

A small to large shrub; flowers April-May; thicket forming; commonly occurs on sandy soll.

Rhododendron vaseyi Gray.

Azalea vaseyi (Gray) Rehd., Biltia vaseyi (Gray) Small.

Pinkshell azalea.

Range: 27.

Site: Well-drained, moist, sun, shade.

Fruit: Capsule.

A small to iarge shrub; occurs in sandy and other soils; in cultivation. 
Rhododendron viscosum (L.) Torr.

Swamp azalea.

Azalea viscosa $\mathrm{L}$.

Range: $25,26,27,28,29,30$.

Site: Moist, sun, shade.

Fruit: Capsule.

A large shrub; flower's June-July; stoloniferous forms are often found.

Rhodora canadensis, see Rhododendron canadense.

Rhoetdium cinereum, see Rhus microphylla.

Rhoeldium microphyllum, see Rhus microphylla.

Rhoeidium potosinum, see Rhus microphylla.

Rhus spp.

This genus has been variously divided. One section in particular, (Lobadium (Raf.) DC.), has been much separated as Schmaltzia. The group Venenatae Engelm. has been much separated as Toxicodendron.

Most species grow on nentral soil; nearly all species are comparatively free from insects and diseases; propagation is by stem or root cuttings, or by seed sown as soon as ripe or stratified and sown in spling.

Stomach rccords (in addition to specific records): Seventy-one species of birds inciuding ruffed grouse, sharp-tailed grouse, lesser prairie chickens, bobwhite, California quail, plumed quail, wild turkey, and mourning dove; composed 3.17 percent of winter food of ruffed grouse in New York, and 3.8 percent of winter food of the same bird for the northeastern United States; opossum. Observations (in addition to specific records): Thirty-three species of birds, including ruffed grouse. An important food of bobwhite in Oklahoma; ranks tenth in the list of quail food plants in the Sontheast; Mearn's quail; rock squirrel, cedarbelt cottontail; preferred food of cottontail rabbit.

Rhus albida, see Rhus glabra.

Rhus angustiarum, see Rhus glabra.

Rhus arbuscula, see Rhus glabra.

Rhus arguta, see Rhus glabra.

Rhus aromatica Ait. (pls. 32 A, B: 33 ).

Fragrant sumac.

$R$. canadensis Marsh., R. crenata (Mill.) Rybd., R. nortonii (Greene) Rydb., Schmaltzia aromatica Desv., S. arenaria Greene, S. illinoensis Greene.

Range: 20, 22, 23, 24, 25, 26, 27, 28, 29.

Site: Dry, well-drained, sun, shade.

Fruit: Drupe; available July-August, persistent the year round.

A small to large shrub; adapted to many kinds of soil including limestone; thicket forming.

Stomach records: Western flicker, ruffed grouse. Obscrvations: Preferred food of wild turkey; white-tailed deer.

Rhus ashei (Small) Greene.

$R$. caroliniana Ashe, not Mill., Schmalizia ashei Small.

Range : 28.

Site: Well-drained, sun.

Fruit: Drupe.

A small shrub; commonly occurs in sandy soil.

Rhus asplenifolia, see Rhus glabra.

Rhus canadensis, see Rhus aromatica.

Rhus choriophylla Woot. and Standl.

Range: 11, 14.

Site: Dry, well-drained, sun.

Fruit: Drupe, available through winter.

A small to large evergreen shrub.

Rhus cismontana, see Rhus glabra.

Rhus copallina $\mathrm{L}$.

Schmaltzia copallina (L.) Small.

Dwarf sumac.

Range: $20,21,22,23,24,25,27,28,29,30,32$.

Site: Dry, well-drained, sun, shade.

Fruit: Drupe; available September-October, persistent the year round. 


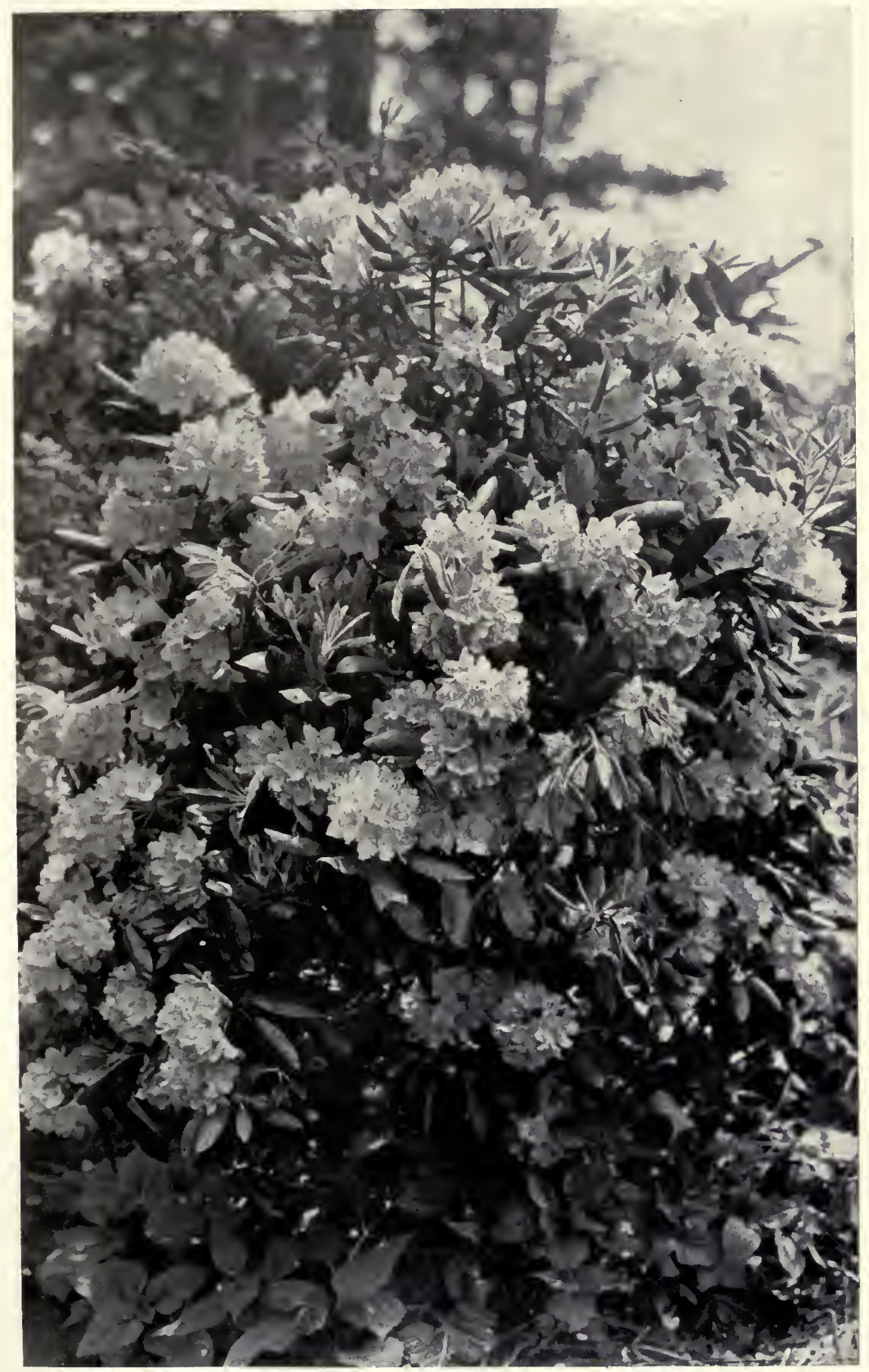

Rhododendron catawbiense. The ornamental value of the catawba rhododendron, its thicket-forming tendency, and the cover it provides for soil, combine to make it of value in highway plantings. (Photograph by U. S. Forest Service.) 

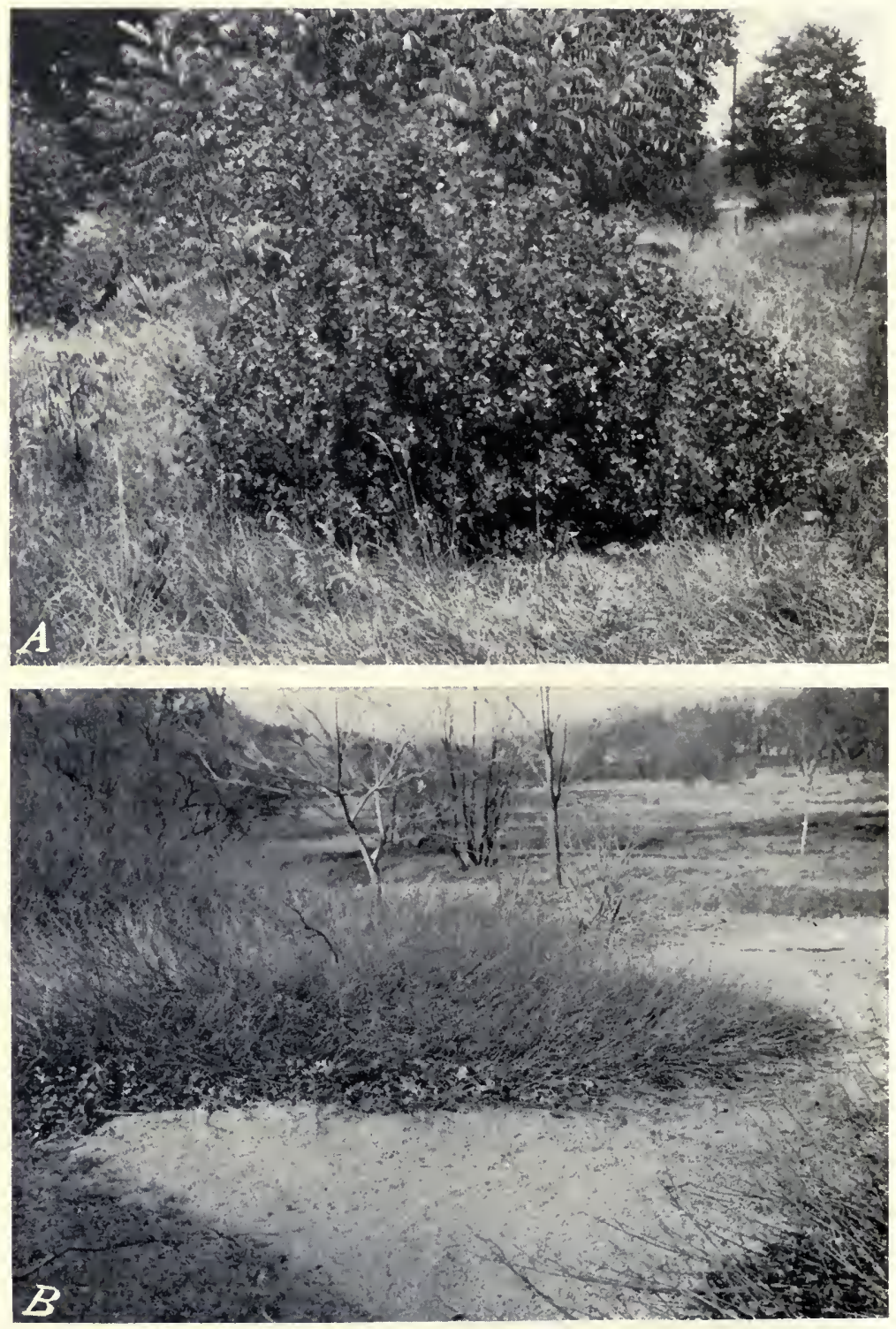

Rhus aromatica: $A$, The fragrant sumac in summer. The dense foliage provides excellent cover for soil and wildlife. $B$., The winter aspect of fragrant sumac, showing the spreading, semiprostrate habit, and indicating the cover afforded the soil even when leaves are gone. 


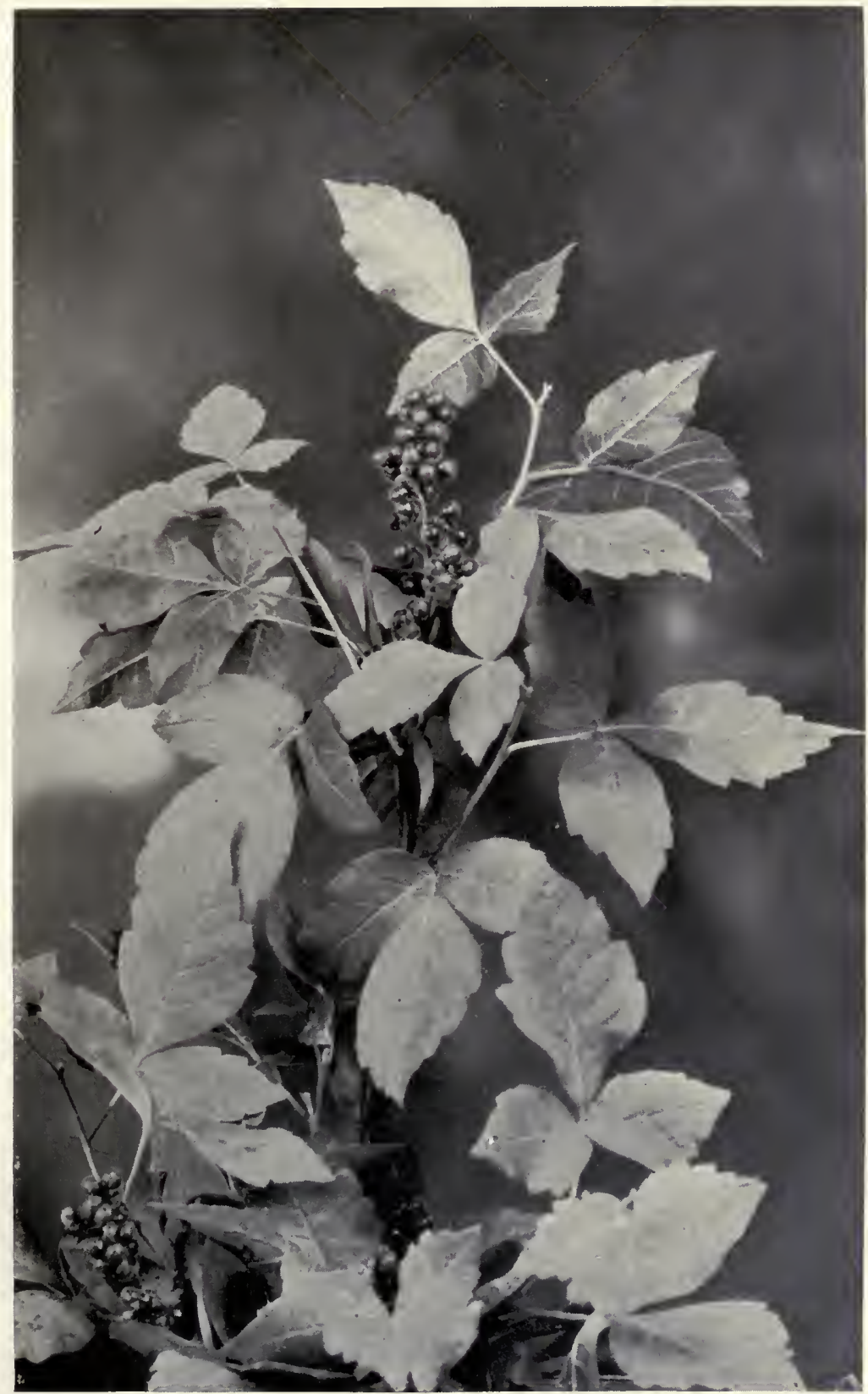

Rhus aromatica. The ornamental fruit, useful for wildlife, enhances the value of fragrant sumac plantings in the control of erosion. 

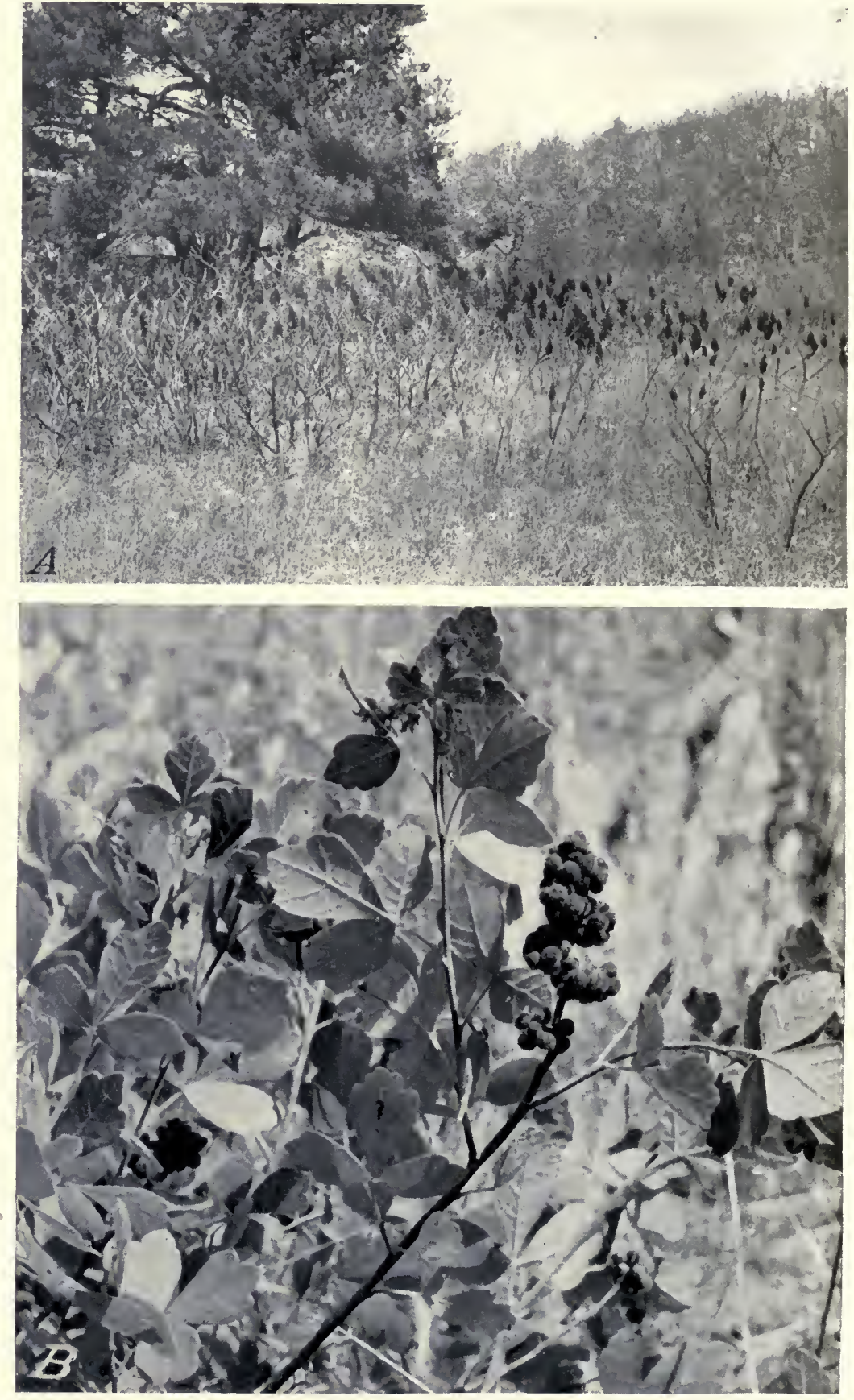

$A$, Rhus glabra. A typical sumac thicket furnishing food the year round for wildlife. Adaptable to poor soils, this plant may well aid in the control of erosion. $B, A$ fruiting branch of $R$. trilobata, a species with great possibilities for planting in the arid parts of the country. 
A small to large shrub or small to large tree; commonly forms thickets; occurs in slightly acid soils; trunks sometimes used for fence posts ; $13,000-70,000$ seeds per pound.

Var. lanceolata Gray, (Rhus lanceolata Gray, Schmaltzia lanceolata Small) occurs in region 11 where it commonly grows on dry, limestone soil.

Stomach records: Twenty species of birds, including ruffed grouse, bobwhite, sharp-tailed grouse, and lesser prairie chicken: Observations: Ring-necked pheasant; white-tailed deer.

Rhus cotinoldes, see Cotinus americanus.

Rhus crenata, see Rhus aromatica.

Rhus arenatifolla, see Rhus trilobata.

Rhus desertorum, see Rhus toxicodendron.

Rhus diversiloba Torr. and Gray.

Poison oak.

R. diversiloba radicans (Torr. and Gray) McNair, $R$. lobata Hook., Toxicodendron diversilobum (Torr. and Gray) Greene, T. comarophyllum Greene, T. isophyllum Greene.

Range: $1,2,3,4,5$.

Site: Dry, well-drained, sun, shade.

Fruit: Drupe; available September-October, commonly persistent.

A small to large shrub or occasionally a vine; often forms extensive thickets ; somewhat aggressive; poisonous.

Stomach records: Thirty-three species of birds, including California quail. observations: Three species of birds; of slight importance as browse for mule deer; black bear. Of importance as a honey plant. Not poisonous to livestock, fair cattle feed, especially in dry seasons.

Rhus emoryi, see Rhus trilobata.

Rhus cximia, see Rhus toxicodendron.

Rhus glabra L. (pl. 34, A).

Smooth sumac.

$\boldsymbol{R}$. albida Greene, $\boldsymbol{R}$. angustiarum Lunell, $\boldsymbol{R}$. arbuscula Greene, $\boldsymbol{R}$. arguta Greenc, $R$. asplenifolia Greene, $R$. cismontana Greene, $R$. media Greene, $R$. nitens Greene, $R$. occidentalis (Torr.) Blankenship, $R$. sambucina Greene, $R$. sandbergii (Vasey and Holz.) Greene, $R$. tesselata Greene, Schmaltzia glabra (L.) Small.

Range : $6,7,8,9,11,14,15,17,18,19,20,21,22,23,24,25,26,27,28$, $29,30,31$.

Site: Dry, well-drained, moist, sun.

Fruit: Drupe; available September-October persistent the year round. A small to large straggling shrub; little branclied; commonly thicket forming; grows on coal-stripped land in Illinois; commonly occurs in slightly acld soil; 27,000-32,000 seeds (with coats) per ponnd.

Stomach records: Thirty-two species of birds, including ruffed grouse, bobwhite, prairie chicken, mourning dove, and wild turkey. Observations: Seren species of birds including bobwhite, Hungarian partridge, ring-necked pheasant; a preferred food of wild turkey; white-tailed deer; a preferred food of cotton-tail rabblt.

Rhus hirta, see Rhus typhina.

Rhus integrifolia (Nutt.) Benth. and Hook.

Neostyphonia integrifolia Shaf., Styphonia integrifolia Nutt.

Mahogany sumac. Range: 5, 10.

Site: Dry, well-drained, sun.

Fruit: Drupe; available August-September.

A small to large evergreen shrub; forms remarkably dense thickets; tolerant of saline conditions; very drought resistant; will grow on extremely poor soils Including sand and clay; lower procumbent branches root where they touch the ground; taproot and secondaries well developed and often extending 10 feet beyond the periphery of aerial portions; 6,800 seeds per pound.

Stomach records: Five specles of birds; composed 8.4 percent of food of 84 road runners, being found in 31 percent of stomachs examined. Observations: California mulc deer. Poor or worthless forage for livestock except occasionally goats. 
Rhus kearneyi Barkl.

Range: 10.

Site: Dry, well-drained, sun.

Fruit: Drupe.

A small evergreen tree.

Rhus lanceolata, see Rhus copallina.

Rhus laurina Nutt.

Malosma laurina (Nutt.) Nutt.

Range: 5 .

Laurel sumac.

Site: Dry, well-drained, sun.

Fruit: Drupe, available in September, persistent.

A large evergreen shrub; root system spreading; produces a very dense shade; endures extreme heat and drought; seeds produced abundantly; coppices vigorously after fire; extremely sensitive to frost; 129,600 seeds per pound.

Stomach records: Six species of birds, Including quail. Otservations: Pallid. wren tit; California mule deer.

Rhus lobata, see Rhus diversiloba.

Rhus longipes, see Rhus toxicodendron.

Rhus media, see Rhus glabra.

Rhus michauxil Sarg.

R. pumila Michx. Schmaltzia michauxii (Sarg.) Small.

Michaux sumac.

Range: 28.

Site: Well-drained, sun.

Fruit: Drupe, available August-September.

A small stolonlferous shrub; commonly occurs on sandy soil; has been considered poisonous but recent manuals do not list it as such.

Rhus microcarpa, see Rhus toxicodendron.

Rhus microphylla Engelm.

Rhoeidium microphyllum Greene, $R h$. cinereum Greene, Rh. potosinum Greene.

Range: 11, 16, 17, 20.

Site: Dry, well-drained, sun.

Fruit: Drupe, available May-July.

A small or rarely a large shrub; densely branched; somewhat spinescent.

Stomach records: Cliff chipmunk. Observations: Sonora deer. Palatabllity to livestock low.

Rhus nitens, see Rhus glabra.

Rhus nortonil, see Rhus aromatica.

Rhus occidentalis, see Rhus glabra.

Rhus osterhoutli, see Rhus trilobata.

Rhus ovata Wats. (pl. 35).

Neostyphonia ovata (Wats.) Abrams.

sugar sumac.

Range: 5, 10, 11.

Site: Dry, well-drained, sun.

Fruit: Drupe, available August-September, persistent.

A large evergreen shrub; casts a dense shade; coppices rapidly after burning; thicket forming; 18,700 seeds per pound.

Observations: California mule deer. Worthless or poor browse for livestoch, except occaslonally for goats.

Rhus oxyacanthoides, see Rhus trilobata.

Rhus pulvinata, see Rhus typhina.

Rhus pumlla, see Rhus michauxii.

Rhus quercifolia (Michx.) Steud.

$\boldsymbol{R}$. toxicodendron quercifolia. Michx., Toxicodendron queroifolium (Michx.) Greene.

Range: 20, 25, 28, 29, 30 .

Site: Dry, well-drained, sun, shade.

Fruit: Drupe.

A small poisonous shrub. 


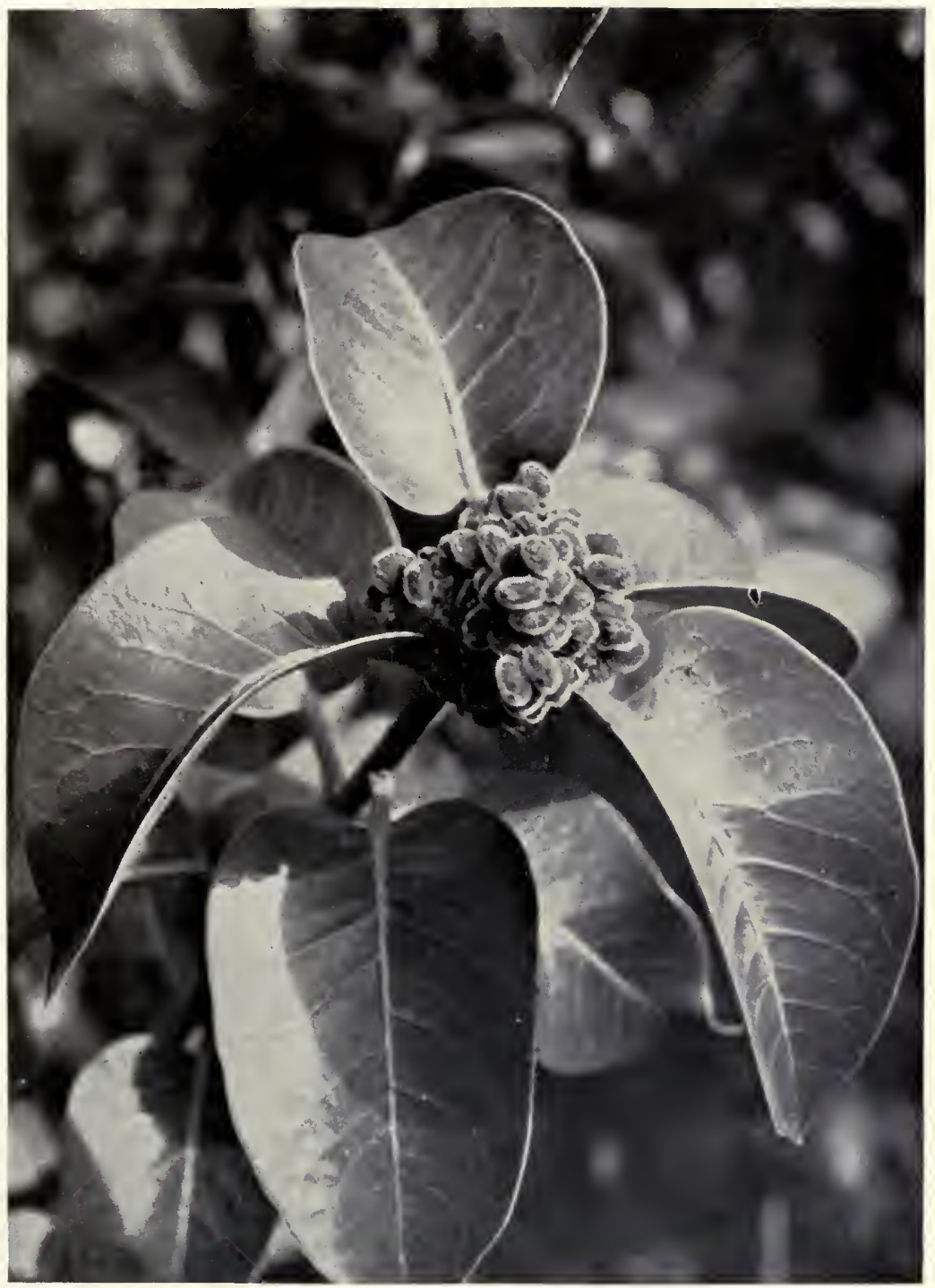

Rhus ovata, a species of great importance as protection for soll and cover for wildlife. The utilization of the fruit is as yet unrecorded. 

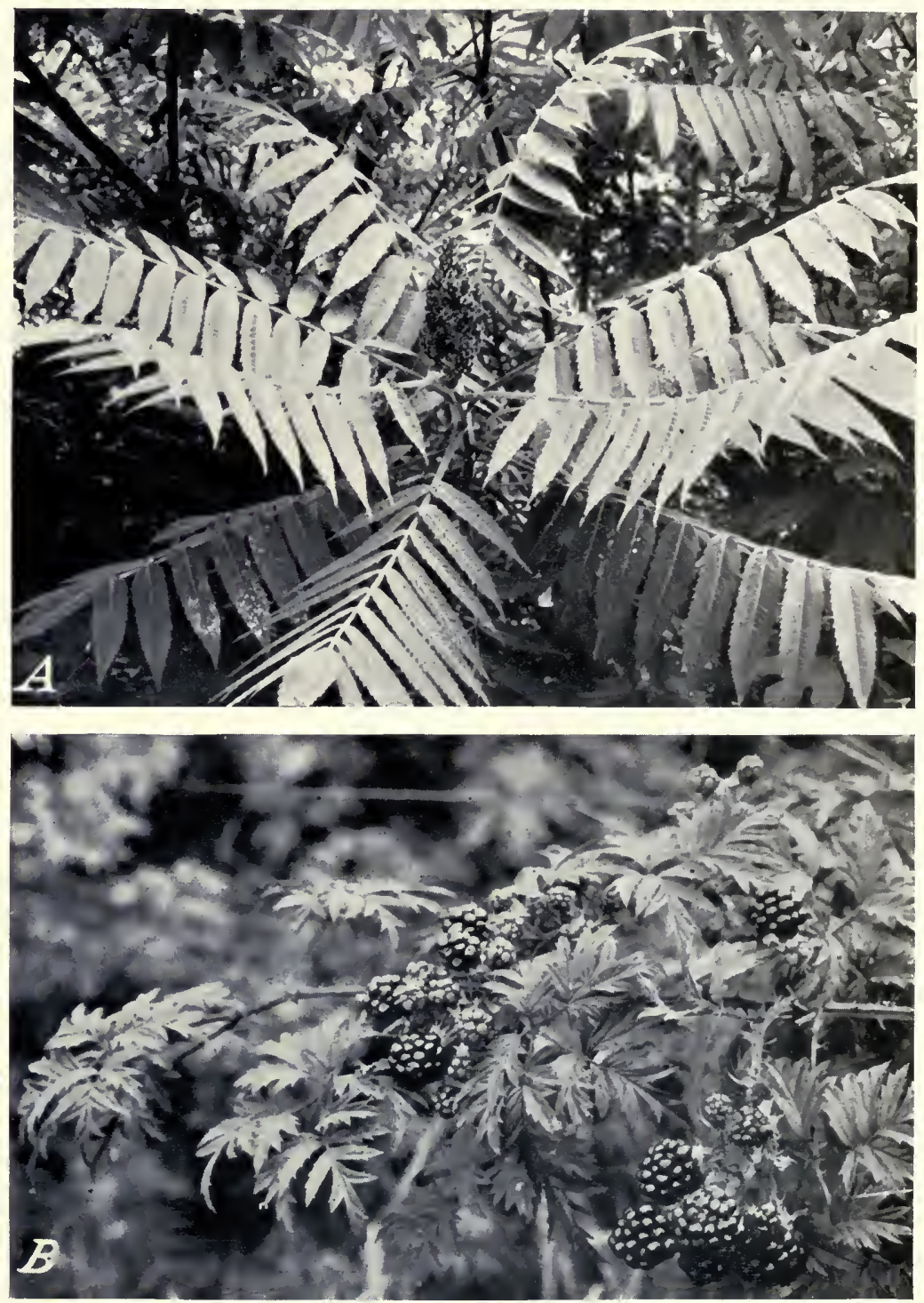

A, Rhus typhina. The staghorn sumac fruit, while eaten by numerous birds, is probably a last resort. The thickets it forms recommend it for erosion-control planting. B, Rubus laciniatus. The large, thorny hummocks formed by this species are of outstanding value as wildlife cover. In the Northwest its relative freedom from disease will permit its use in erosion-control planting. 
Rhus radicans, see Rhus toxicodendron.

Rhus rydbergil, see Rhus toxicodendron.

Rhus sambucina, see Rhus glabra.

Rhus sandbergii, see Rhus glabra.

Rhus tesselata, see Rhus glabra.

Rhus toxicodendron $I$.

Poison-ivy

$R$. desertorum Lunell, $R$. eximia Standl., $R$. longipes Greene, $R$. microcarpa Steud., $R$. radicans L., $R$. rydbergii Small, $R$, toxicodendron radicans Dippel, Toxicodendron radicans (L.) Kuntze, T. biternatum Greene, $T$. eximium Greene, $T$. fothergilloides Lunell, $T$. hesperinum Greene, $T$. macrocarpum Greene, T. negundo Greene, T. punctatum Greene, T. rufescens Greene, $T$. rydbergii (Small) Greene.

Range: $2,6,7,8,9,11,12,13,15,16,17,18,19,20,21,22,23,24$, $25,27,28,29,30$.

Site: Dry, well-dralned, sun, shade.

Fruit: Drupe, available September-November.

A small to large poisonous shrub or vine; very variable in habit, from a small, nearly herbaceous shrub to a vigorous, high-climbing vine. This species has been much broken up as the synonomy indicates, but good botanical characters separating the forms as specles do not appear to be satisfactory. A study of the forms in Indiana by Dream (162) showed that the low, erect forms are branches of underground stems; that the thick-leaved forms are always found in places exposed to heavy winds and direct sunlight; and that the hairy-fruited forms are rare, distributed throughout the area, and without other characters to distinguish them.

Stomach records: Sixty species of birds including ruffed grouse, bobwhite, wild turkey, sharp-tailed grouse, ring-necked pheasant, and greater prairie chicken; composed 0.8 percent of fall food of prairie chicken in Wisconsin. Observations: Nineteen species of birds including ring-necked pheasant; whitetailed deer; leaves refused by captive marsh rabbits.

Rhus trilobata Nutt. (pl. 34, B).

Lemonade sumac.

$\boldsymbol{R}$. canadensis trilobata (Nutt.) Gray, $\boldsymbol{R}$. crenatifolia Schlecht., $\boldsymbol{R}$. emoryi Woot., $\boldsymbol{R}$. osterhoutii Rydb., $\boldsymbol{R}$. oxyacanthoides (Greene) Rydb., $\boldsymbol{R}$. trilobata mollis Greene, $R$. utahensis Good., Schmaltzia trilobata (Nutt.) Small, S. affinis Greene, S. anisophylla Greene, 8. bakeri Greene, \&. cognata Greene, S. cruciata Greene, S. emoryi Greene, S. glabrata Greene, S. glauca Greene, S. glomerata Greene, S. leiocarpa Greene, S. malacophylla Greene, S. oxyacanthoides Greene, S. pulchella Greene, S. quercifolia Greene, S. ribifolia Greene, S. scaberula Greene, S. simplicifolia Greene, S. straminea Greene, S. subpinnata Greene.

Range: $1,3,4,5,8,9,10,11,12,13,14,15,16,19,20,22,24,25$. Site: Dry, well-drained, sun, shade.

Fruit: Drupe, avallable the year round.

A small shrub; roots very long; sometimes thicket forming; under natural conditions endures extreme drought; $10,000-25,0000$ seeds per pound. This species has been much broken up, and the segregates recombined as the synonomy indicates.

Stomach records: Nineteen specles of birds, including ruffed grouse, bobwhite, valley, Gambel and western quail, greater prairie chicken and lesser prairie chicken. Observations: Ring-neck pheasant, sage hen, scaled quail; mountain sheep; of slight importance as browse for mule deer. Worthless to good forage for stock; of most value in Arizona and Colorado, less so in Utah.

Rhus typhina Torner (pl. 36, A).

R. hirta (L.) Sudw., Datisca hirta L., Schmaltzia hirta (L.) Small.

Range: $18,19,20,21,22,23,24,25,26,27,28$.

Site: Dry, well-drained, sun, shade.

Fruit: Drupe; available in September, persistent the year round.

A large shrub to small tree; sprouts persistently from the roots after cutting or injury; forms loose thickets; 50,000 seeds per pound.

A plant more or less intermediate between this and $\boldsymbol{R}$. glabra has been de. scribed as $R$. pulvinata Greene. 
Stomach records: Fourteen species of birds, including ruffed grouse, bobwhite, ring-necked pheasant and mourning dove; eastern skunk. Observations: Four species of birds including sharp-tailed grouse; important food of ringnecked pheasant in southern Michigan ; closely browsed by moose on Isle Royale; white-tailed deer, cottontail rabhit; nintl most important preferred winter foud of deer in Massachusetts. Resistant to grazing.

Rhus utahensis, see Rhus trilobata.

Rhus venenata, see Rhus vernix.

Rhus vernix $\mathrm{L}$.

Poison sumac.

$R$. venenata DC., Toxicodendron vernix (L.) Kuntze, T. pinnatusn Mill.

Range: 22, 23, 24, 25, 26, 27, 28, 29, 30.

Site: Moist, sun.

Fruit: Drupe; available in September, persistent.

A large shrub to small or large tree; foliage not dense; rather loosely branched; poisonous.

Stomach records: Sixteel species of birds, including ruffed grouse and ringnecked pheasant. Observations: Five species of birds; an important food of ring-necked pheasant and bobwhite; cottontail rabbit.

Rhus virens Lindh.

Schmaltzia virens (Lindh.) Small.

Evergreen sumac.

Range: 11, 16, 17, 20.

Site: Dry, sun.

Fruit: Drupe, available in September.

A small to large shrub or small tree; evergreen; commonly occurs on limestone soils; grows in extremely difficult positions; may often be prostrate.

Ribes spp.

Gooseberry, culrant.

These species are alternate hosts of the white-pine blister rust. Various State and Federal laws restrict or prohibit the movement of Ribes as well as the fiveleaved pines, and any operators interested in planting these should get in touch with the United States Bureau of Entomology and Plant Quarantine, as well as with the officers in their particular State who are concerned with the movement of the shrubs and trees (State entomologists, plant-quarantine officers, and horticulturists).

At the present time, while all species have not been tested, no native species is known to be resistant to the blister rust. Nine hundred feet is a safe distance to plant Ribes (except the cultivated black currant) away from the pines. The spores of the rust have been known to infect cultivated black currant 150 miles or more from the pines, and the statement has been made (154) that if there were no cultivated black currants, the disease would not be as widespread as it is. Reference to Pinus will show which of those species have five needles.

The genus is often divided into two, Ribes and Grossularia, currants and gooseberrles, respectively. There appears yet to be considerable difference of opinion as to whether the two should be combined or separated.

Stomach records (in addition to specific records): Thirty-three species of birds, including dusky grouse, mourning dove, and Richardson's grouse; mountain sheep, black-tailed deer, coyote, northern chipmunk, pale chipmunk, and rufous-tailed chipmunk. Observations (in addition to spccific records) : Seven species of birds including dusky grouse, prairie sharp-tailed grouse, Gambel quail ; Say chipmunk, painted chipmunk, gray-footed chipmunk, lesser Colorado chlpmunk, Arizona chipmunk, cliff squirrel, golden-mantled ground squirrel, alpine chipmunk, eastern chipmunk, western chipmunk, Allen's chipmunk, Siskiyou chipmunk, pica, and porcupine; formed a prominent share of the midsummer food of skunks in New York. Fairly to moderately palatable to livestock, except goats, and of considerable forage significance on some ranges.

Ribes acerifolium Howell

R. howellii Greene.

Range: 4.

Site: Well-drained, sun.

Fruit: Berry.

A small shrub.

Ribes affne, see Ribes laxiflorum. 
Ribes amarum McClatch.

Grossularia amara (McClatch.) Cov. and Britt.

Bitter gooseberry.

Range: 4.

Site: Dry, well-drained, shade.

Fruit: Berry.

A small to large, spiny shrub; flowers March-April.

Ribes americanum, see also Ribes laxiflorum.

Ribes americanum Mill.

R. floridum L'Her.

Range: $12,13,14,15,18,21,22,23,24,25,27,28$.

Site: Dry, well-drained, moist, sun, shade.

Fruit: Berry, available July-August.

A small, unarmed shrub; flowers April-May; closely related to $R$. nigrum of Europe, the most dangerous host of the white-pine blister rust.

Observations: Ring-necked pheasant; eagerly eaten by songbirds.

Ribes ascendens, see Ribes nevadense.

Ribes aureum Pursh.

Chrysobotrya aurea (Pursh) Rydb.

Golden currant.

Range: $1,2,3,4,6,7,8,9,11,12,13,14,15,22,23$.

Site: Dry, well-drained, moist, sun, shade.

Fruit: Berry, available June-July.

A small to large shrub; flowers April-May.

Observations: Ring-necked pheasant; of fair importance as browse for mule deer. Poor to fair browse for livestock.

Ribes binominatum Heller.

Grossularia binominata (Heller) Cor. and Britt.

Ground gooseberry.

Range: 4.

Site: Well-drained, sun.

Fruit: Berry.

A small, trailing, spiny shrub; flowers in June.

Ribes bracteosum Dougl.

Range: 1, 2, 4 .

Site: Moist, shade.

Fruit: Berry.

A small to large shrub; flowers May-June.

Ribes californicum Hook. and Arr.

Grossularia californica (Hook. and Arn.) Cov. and Britt.

Range: $1,4,5,10$.

Site: Dry, sun.

Fruit: Berry.

Commonly a small shrub, rarely a large shrub; spiny and compact; flowers January-April; berry small and usually single.

Ribes cereum Dougl.

$\boldsymbol{R}$. inebrians LindI., $R$. pumilum Nutt., $\boldsymbol{R}$. churchii Nels.

Wax currant.

Range: $4,6,8,9,10,11,12,13,14,15,16$.

Site: Dry, sun.

Fruit: Berry, available June-August.

A small to large, unarmed, much-branched shrub; flowers June-August.

Observations: Blue, spruce, and Richardson's grouse, chickadee; eaten by many songbirds; an important food of chipmunks in California; California mule deer. Of some importance as forage for livestock.

Ribes churchii, see Ribes cereum.

Ribes ciliosum, see Ribes triste.

Ribes cognatum Greene.

Grossularia cognata (Greene) Cov. and Britt.

Range: 7, 8, 9.

Site: Moist, sun.

Fruit: Berry.

A large, spiny shrub. 
Ribes coloradense Cov.

Colorado currant.

Range: 13, 14.

Site: Well-drained, sun.

Fruit: Berry.

A small, unarmed shrub; branches decumbent or prostrate.

Ribes curvatum Small.

Grossularia curvata (Small) Cov. and Britt.

Georgia gooseberry.

Range: 28, 29.

Site: Dry, well-drained, sun.

Fruit: Berry, available in July.

A small, spiny shrub.

Ribes cynosbatii $I$.

R. gracile Michx., Grossularia cynosbatii (L.) Mill.

Pasture gooseberry.

Range: 21, 22, 23, 24, 25, 27, 28, 29.

Site: Dry, well-drained, moist, sun, shade.

Fruit: Berry, available April-August.

A small, spiny shrub; flowers April-June.

Observations: Red squirrel, cottontail rabbit.

Ribes divaricatum Dougl.

R. sucksdorfi Heller, Grossularia divaricata (Dongl.) Straggly gooseberry. parishii Cov. and Britt.

Range: 1, 2, 4, 5 .

Site: Well-drained, moist, sun.

Fruit: Berry.

A large, spiny, straggling shrub; flowers in April.

Ribes erythrocarpum Cov. and Leiberg.

Range: 4.

Site: Well-drained, sun.

Fruit: Berry.

A small, unarmed shrub; branches trailing and rooting.

Ribes floridum, see Ribes americanum.

Ribes glandulosum Grauer.

Skunk currant.

R. prostratum L'Her.

Range: 23, 24, 26, 27.

Site: Moist, sun, shade.

Fruit: Berry.

A small shrub; flower's May-June; decumbent or spreading; spiny or unarmed.

Ribes glaucescens, see Ribes nevadense.

Ribes gracile, see Ribes cynosbatii.

Ribes grantil, see Ribes nevadense.

Ribes halli, see Ribes viscosissimum.

Ribes hesperium McClatch.

Grossularia hesperia (McClatch.) Cov, and Britt.

Range: 5.

Site: Dry, well-drained, sun.

Fruit : Berry.

A small to large spreading, spiny shrub.

Ribes hirtellum Michx.

R. saxosum Hook., Grossularia hirtclla (Michx.) Spach.

Range: 15, 18, 21, 23, 24, 26, 27.

Site: Moist, shade.

Fruit: Berry, available in July.

A small, spiny shrub.

Ribes hittellianum, see Ribes nevadense.

Ribes howelli, see Ribes acerifolium.

Ribes hudsonianum Rich.

Range: 23, 24.

Site: Moist, shade.

Fruit: Berry, available July-August.

A small to large, unarmed shrub; flowers May-June.

Hudson Bay currant.

Low wild gooseberry. 
Ribes indecorum Eastw.

Range: 5.

Site: Well-drained, sun.

Fruit: Berry.

A large, loosely-branched, unarmed shrub.

Ribes inebrians, see Ribes cereum.

Ribes inerme Rydb.

Grossularia inermis (Rydb.) Cov. and Britt.

Whitestem gooseberry.

Range: $4,6,7,8,9,11,12,13,14$.

Site: Dry, well-drained, moist, sun.

Fruit: Berry, available August-September.

A small to large shrub; flowers in May; spiny or unarmed. Forage value for sheep, fair.

Rikes irriguum Dougl.

Arossularia irrigua (Dougl.) Cov. and Britt.

Range: 6, 7, 12.

Site: Moist, sun, shade.

Fruit: Berry.

A small to large, spiny shrub.

Ribes lacustre (Pers.) Poir.

Swamp currant. Rydb.

Range: $4,12,13,14,23,24,26,27$.

Site: Moist, sun, shade.

Fruit: Berry, available in August.

A small, spiny shrub; flowers May-Jine; stems prostrate or ascending.

Ribes lasiantha, see Ribes leptanthus.

Ribes laxiflorum, see also Ribes odoratum.

Ribes laxiflorum Pursh.

Western black currant.

R. americanum Pall., not Mill., R. affine Dougl.

Range: 1, 4, 12, 13.

Site: Moist, shade.

Fruit: Berry.

A small, unarmed shrub; flowers in April; often decumbent and covering large areas.

Ribes lentum, see Ribes montigenum.

Ribes leptanthum Gray.

Grossularia leptantha (Gray) Cov. and Britt.

Alpine gooseberry.

Range: 9, 11, 13, 14 .

Site: Dry, well-drained, sun, shade.

Fruit: Berry.

A small to large spiny shrub.

Var. lasiantha (Greene) Jeps. (R. lasiantha Greene, Grossularia lasianthum (Greene) Cov. and Britt.) occurs in region 4 and is smaller than the species.

stomach records: Black-tailed deer.

Ribes lobbil Gray.

Grossularia lobbii (Gray) Cov. and Britt.

Gummy gooseberry.

Range: 1, 2.

Site: Well-drained, sun.

Fruit: Berry.

A large, spiny shrub; flowers in June.

Stomach records: Lewis woodpecker (?)

Rikes longiflorum, see Ribes odoratum.

Ribes malvaceum Smith.

California black currant.

R. purpurascens Heller.

Range: 3, 4, 5 .

Site: Dry, well-drained, sun, shade.

Fruit: Berry.

A large unarmed, many-stemmed shrub; flowers December-April.

Observations: California mule deer. 
Ribes marshallii Greene.

Grossularia marshallii (Greene) Cov. and Britt.

Hupa gooseberry.

Range: 4 .

Site: Well-drained, sun.

Fruit: Berry.

A small, spiny shrub; flowers in July; low and spreading; forms matlike colonies.

Ribes menzlesii Pursh.

Grossularia menziesii (Pursh) Cov. and Britt.

Menzies gooseberry.

Range: 1.

Site: Well-drained, sun, shade.

Fruit: Berry.

A large, spiny, loosely branched shrub; flowers Feluruary-April.

Stomach records: Sooty grouse. Obscrvations: Blue grouse.

Ribes mescaleriun Cov.

Range: 11, 14.

Site: Dry, well-drained, sum.

Fruit: Berry.

A small to large, unarmed shrub, with insipid fruit.

Ribes missouriense Nutt.

Grossularia missouriensis (Nutt.) Cov. and Britt.

Missouri gooseberry.

Range: 21, 22, 23, 25.

Site: Dry, well-drained, moist, sun, shade.

Fruit: Berry, available July-September.

A small to large, spiny shrub; flowers in May; berries very large.

Ribes mogollonieum, see Ribes wolfii.

Ribes molle, see Ribes montigenum.

Ribes montigenum MeClatch.

Mountain gooseberry.

$\boldsymbol{R}$. lentum (Jones) C. and R., $\boldsymbol{R}$. molle Howell, not Poepp., Lymnobotrya montigena (McClatch.) Rydb.

Range: $4,10,11,12,13,14$.

Site: Dry, well-drained, sun.

Fruit: Berry.

A small, spiny shrub; flowers in July; straggling and much-branched. Of more than average palatability to livestock.

Rlbes nevadense Kellogg.

Nevada eurrant.

$\boldsymbol{R}$. variegatum Nels., $R$. ascendens Eastw., $R$. hittellianum Eastw., $R$. glaucescens Eastw., $\boldsymbol{R}$. grantii Heller.

Range: 4, 10, 12, 13 .

Site: Well-drained, moist, sun, shade.

Fruit: Berry.

A small to large, diffusely branched, unarmed shrub; flowers May-July.

Observations: Of outstanding importance as browse for mule deer; mountain beaver. Somewhat browsed by sheep in California.

Ribes niveum Lindl.

Grossularia nivea (Lindl.) Cov. and Britt.

Snow gooseberry.

Range: 7, 8, 9, 12, 13.

Site: Dry, sun.

Fruit: Berry.

A small to large, spiny shrub.

Ribes odoratum Wendl.

Golden currant.

R. laxiflorum Nutt., R. longiflorum Nutt., Chrysobotrya odorata (Wendl.)

Rydb.

Range: $15,16,18,19,20,22,23,25$.

Site: Dry, well-drained, sun, shade.

Fruit: Berry.

A small to large, unarmed shrub; flowers April-May.

Ribes oxyacanthoides $\mathrm{L}$.

Grossularia oxyacanthoides (L.) Mill.

Northern gooseberry.

Range: 4, 12, 15, 18, 21, 23, 24, 26, 27.

Site: Moist, sun.

Fruit: Berry, available in August.

A small, spiny shrub.

Stomach records: Bobwhite. 
Ribes parvulum, see Ribes lacustre.

Ribes petiolare Dougl.

Range: 4, 12, 13.

Site: Well-drained, sum.

Frult: Berry.

A small to large, unarmed shrub.

Ribes pinetorum Greene.

Grossularia pinctorum (Greene) Cov. and Britt.

Orange gooseberry.

Range: 10, 14.

Site: Well-drained, sun, shade.

Fruit: Berry.

A small to large, spiny shrub; very ornamental in bloom.

Ribes prostratus, see also Ribes glandulosum.

Ribes prostratum L'Her.

Range: $23,24,26,27$.

Skunk currant.

Site: Moist, shade.

Fruit: Berry, available in July.

A small shrub with reclining stems.

Ribes pumilum, see Ribes cereum.

Ribes purpurascens, see Ribes malvaceum.

Ribes quercetorum Greene.

Grossularia quercetorum (Greene) Cov. and Britt.

Rock gooseberry.

Range: 3, 4, 5, 14 .

Site: Dry, well-drained, sun.

Fruit: Berry.

A small, spiny shrub; flowers February-March.

Ribes reniforme Nutt.

Range: 12.

Site: Well-drained, sun.

Fruit: Berry.

A small or, more generally, a large shrub.

Ribes roezlii Regel.

R. wilsonianuum Greene, Grossularia roezlii (Regel) Cov. and Britt.

Range: $4,5,10$.

Site: Dry, well-drained, sun.

Fruit: Berry.

A small, spiny shrub; flowers May-July; loosely branched; fruit produced abundantly.

Observations: Of outstanding importance as browse for mule deer. A fair sheep and cattle browse.

Ribes rotundifolium Michx.

Grossularia rotundifolia (Michx.) Cov. and Brltt.

Roundleaf gooseberry.

Range: 27.

Site: Dry, well-drained, sun.

Fruit: Berry, available June-August. •

A small shrub; flowers May-July; spiny or unarmed.

Ribes sanguineum Pursh.

Red-flowered currant.

Range: 1, 2, 4.

Site: Dry, well-drained, sun, shade.

Fruit: Berry, available July-August.

A large, unarmed shrub; flowers April-June; several varieties are in cultivation.

Stomach records: Sooty grouse. Observations: Three specles of birds, includIng blue grouse. Good sheep and fair cattle browse.

Ribes saxosum, see Ribes hirtellum.

Ribes sericeum Eastw.

Grossularia sericea (Eastw.) Cov. and Britt.

Lucia gooseberry.

Range: 1.

Site: Well-drained, sun.

Fruit: Berry.

A small, prickly shrub; flowers February-March; berries large. 
Ribes setosum Lindl. (pl. 37, A).

Grossularia setosa (Lindl.) Cov. and Britt.

Missouri gooseberry.

Range: 12, 15, 18.

Site: Dry, well-drained, sun.

Fruit: Berry, available June-August.

A small, spiny shrub; flowers in May.

Observations: Moose.

Ribes speciosum Pursh.

Grossularia speciosa (Pursh) Cov. and Britt.

Garnet gooseberry.

Range: 1, 5 .

Site: Well-drained, shade.

Fruit: Berry.

A large, spiny shrub; flowers April-May; nearly or quite evergreen; very ornamental in bloom.

observations: California mule deer.

Ribes stanfordil, see Ribes velutinum.

Ribes suksdorfii, see Ribes divaricatum.

Ribes triste Pall.

R. ciliosum Howell.

American red currant.

Range: $4,12,15,18,21,23,24,26,27,28$.

Site: Moist, sun, shade.

Fruit: Berry.

A small unarmed shrub; flowers June-July; the prostrate or ascending branches root.

Ribes variegatum, see Ribes nevadense.

Ribes velutinum Greene.

R. stanfordii Elmer, Grossularia velutina (Greene) Cov, and Britt.

Range: $4,9,10,13,14$.

Site: Dry, well-drained, sun, shade.

Fruit: Berry.

A small to large shrub; flowers May-June; spiny or unarmed.

Observations: Of slight importance as browse for mule deer.

Ribes viburnifolium Gray.

Range: 5 .

Island gooseberry.

Site: Dry, well-drained, sun.

Fruit: Berry.

A small, evergreen, straggling shrub; flowers in January.

Ribes victoris Greene.

Grossularia victoris (Greene) Cov. and Britt.

Victor gooseberry

Range: 1,3 .

Site: Well-drained, shade.

Fruit: Berry.

A small to large, spiny shrub; flowers in March.

Ribes viscosissimum Pursh.

R. hallii Jancz.

Range: $4,9,11,12,13,14$.

Site: Well-drained, sun, shade.

Fruit: Berry.

A small, unarmed shrub; flowers June-July; root system as much as 4 feet deep, not fibrous.

Stomach records: Ruffed grouse, Richardson's grouse. Observations: of slight importance as browse for mule deer; mountain beaver. Palatability good, as browse for livestock.

Ribes watsonianum Koehne.

Grossularia watsoniana. (Koehne) Cov. and Britt.

Watson gooseberry.

Range: 4 .

Site: Well-drained, sun.

Fruit: Berry.

A small to large, spiny shrub. Highly palatable to livestock.

Ribes wilsonlanum, see Ribes roeztii. 
Rlbes wolfii Rothr.

Rothrock currant.

$R$. mogollonicum Greene.

Range: 13, 14.

Site: Well-drained, moist, sun.

Fruit: Berry, available in August.

A small to large shrub. Fairly good cattle browse in Utah.

Ricinella vaseyi (Coult.) Coult. and Fish.

Adelia vaseyi Coult.

Range: 17.

Site: Dry, sun.

Fruit: Capsule.

A small to large dioecious shrub; sometines spiny; leaves few.

Ricinophyllum horridum, see Oplopanax horridum.

Ricinus communis $\mathbf{L}$.

Range: $3,5,10,17,20,30$.

Castor-bean,

Site: Well-drained, sun.

Fruit: Capsule, available August-September.

A large shrub or rarely a small tree; probably introduced from Africa, but more or less naturalized in the regions indicated; herbaceous, and not escaping northwards.

Stomach records: Bobwhite, mourning dove.

Riddelia cooperi, see Psilostrophe cooperi.

Robinia spp.

Locusts.

Stomach records (in addition to specific records): Seven species of birds including ruffed grouse, bobwhite, western quail, and mourning dove.

Robinia boyntonii Ashe.

R. hispida rosea Hort.

Range: 27.

Site: Well-drained, sun.

Frult: Legume.

A large shrub or rarely a large tree; flowers May-June; probably does not produce fruit; very handsome when in flower.

Robinia elliottii (Chapm.) Ashe.

$R$. hispida elliottii Chapm.

Range: $28,29,30$.

Site: Dry, well-drained, sun.

Fruit: Legume.

A large, spiny shrub; flowers May-June; occurs on sandy and other soils.

Robinia fertilis Ashe.

Range: 27.

Site: Well-drained, sun.

Fruit: Legume.

A small to large, stoloniferous shrub; fruit freely produced; spiny or unarmed.

Robinia grandiflora Ashe.

Range: 27.

Site: Well-drained, sun.

Fruit: Legume, available in July.

A small to large shrub; flowers April-May ; rarely spiny; easily propagated by root suckers which are extensively produced; occurs in sandy and other soils.

Robinia hartwigil Koehne.

R. viscosa hartwigii (Koehne) Ashe.

Range : 27, 28,

Site: Well-drained, sun.

Fruit: Legume.

A large, spiny shrub; flowers in June.

Robinia hispida L.

Range : 25, 27, 28 .

Rose-acacia.

Site: Dry, well-drained, moist, sun, shade.

Fruit: Legume, available in September.

A small to large, stoloniferous shrub; spiny, or more commonly unarmed; foliage not deuse; tolerant of arld conditions; commonly produces little fruit; propagates extensively by suckering. 
Robinia kelseyi Cowell.

Range: 27.

Site: Well-drained, sun.

Fruit: Legume.

A small to large, spreading, spiny shrub; flowers May-June; 80,640 seeds per pound.

Robinia longiloba Ashe.

Range: 27, 28 .

Site: Dry, well-drained, sun.

Fruit: Legume.

A small shrub; flowers in May; spiny or unarmed; seldom produces fruit, propagates extensively by suckering, but never forms extensive thickets. Possibly a hybrid between $R$. boyntonii and $R$. grandiflora.

Robinia luxurians, see Robinia neomexicana.

Robinia nana Ell.

R. hispida nana (Ell.) Torr. aud Gray.

Range: $28,29,30$.

Site: Dry, well-drained, sun.

Fruit: Legume.

A small shrub; occurs in sandy and other soils; spiny or unarmed; usually little branched.

Robinia neomexicana Gray.

Range: $9,10,11,14$.

New Mexican locust.

Site: Dry, well-drained, moist, sun.

Fruit: Legume, available September-October.

A small to large, spiny shrub; thicket forming on drier, rockier slopes; hardy as far northward as New England; in cultivation in the Eastern States and western Europe; 21,800 seeds per pound.

Var. luxurians Dieck, ( $R$. luxurians (Dieck) Rydb.) is a small tree occurring withln the range of the species.

Stomach records: Gambel quail (?) ; mountain sheep, porcupine, black-tailed deer; Coeur d'Alene chipmunk. Observations: Porcupine, mule deer. An important goat browse; somewhat cropped by horses and cąttle without harmful effects.

Robinta pallida Ashe.

Range: 27.

Site: Well-drained, sun.

Fruit: Legume.

More commonly a small, or sometimes a large shrub; reproduces by suckers.

Robinia pedunculata Ashe.

Range: 27.

Site: Dry, well-drained, sun.

Fruit: Legume.

A large shrub; spiny or unarmed. Possibly a hybrid between $R$. hispida and R. boyntonii.

Robinia pseudoacacia L.

Black locust.

Range: $1,2,3,4,5,6,7,8,12,15,16,20,21,22,23,25,26,27,28,29$.

Site: Dry, well-drained, moist, sun.

Fruit: Legume, available September-April.

A large, short-lived tree; somewhat tolerant of alkali ; much attacked by locust borer, but apparently the greater the growth rate the less borer tronble; wood of importance commercially, particularly for fence posts; root system extremely shallow; easily transplanted when young; makes its best growth on fertile soil; on very poor soils makes poor growth and does not reach large size; rapid growing on good soils, slow growing on poor soils; serionsly injured by fungi; not resistant to fire; coppices freely; 20,000-26,000 seeds per pound. Range much extended by cultivation; orlginal range not clear.

Var. rectissima Raber, the shipmast locust, is a tree to 100 feet, occurring on the richer soils of the northern and western parts of Long Island, and locally in New York and Massachusetts. The trunk is columnar, very straight and yields a wood which is harder and more durable than that of the species. It is longer lived than the species, produces almost no seed, and propagation is by root cuttings and root sprouts. May possibly be more resistant to the attacks of the 
borer, and the damage is confined to branches rather than trunks. Some 16 other varieties are known in cultivation.

Stomach records: Five species of birds, including bobwhite, and mourning dove; gray fox, opossum, white-tailed deer. Observations: Four species of birds; ranks thirteenth on the list of quail food plants in the Southeast; an important food of the bobwhite in Oklahoma ; ring-necked pheasant; cottontail rabbit, snowshoe hare, white-tailed deer. Young shoots and bark poisonous to all livestock; leaves not poisonous; poisoning cases not infrequent.

Robinia rusbyi Woot. and Standl.

Range: 14.

Site: Well-drained, sun.

Fruit: Legume.

A large shrub to small tree.

Robinia speciosa Ashe.

Range: 27.

Site: Well-drained, sm.

Fruit: Legume.

Commonly a small shrub, rarely a large one; much branched; unarmed; propagates by root suckers.

Robinia subvelutina Rydb.

Rauge: 11.

Site: Dry, well-drained, sun.

Fruit : Legume.

A small spiny shrub.

Robinia viscosa Vent.

Range: $27,28,29$.

Clammy locust.

Site : Well-drained, sun.

Fruit: Legume, available in September, persistent through the winter. A small to large, spreading tree; extensively uaturalized in the eastern United States.

Rosa spp.

Wild roses.

Because of the difficulty of identifying the various species and the fact that at present there appears to be considerable confusion in the taxonomy of roses, the species are here omitted except for the general characterization of the genus.

Their erosion-control value lies in the fact that many are climbing, sprawling, or thicket-forming species, often making a rather dense cover on the surface of the soil, with the branches usually rooting where they touch the ground. Nonclimbing species may produce suckers at various distances from the crown. Some species have dense foliage, but others have open foliage. Some may eften be weedy in fields. The best procedure, in working with roses, as with the hawthorns and blackberries, is to choose for planting those species in any given region which seem to be doing the best job of erosion control under natural conditions.

Among the thicket-forming species may be mentioned $\boldsymbol{R}$. californica $\mathbf{C}$. and $\mathbf{S}$., $\boldsymbol{R}$. carolina L., $\boldsymbol{R}$. laevigata (the Cherokee rose), $\boldsymbol{R}$. nutkana Presl, and $\boldsymbol{R}$. pisocarpa Gray.

Species with more or less outstanding livestock browse records include $R$. acicularis Lindl., $R$. californica C. and S., $R$. eglanteria L. ( $R$. rubiginosa L.), $R$. fendleri Crep. (probably the most important browse species of the genus), $R$. gymnocarpa Nutt., $R$. macounii Greene, $R$. macrantha Greene, $R$. manca Greene, $R$. melina Greene, $R$. nutkana Presl, $R$. pisocarpa Gray, $R$. sayi Schwein., $R$. spaldingii Crep., $R$. spithamea Wats., and $R$. woodsii Lindl.

Stomach records (summary) : Thirty-eight species of birds, including ruffed grouse, bobwhite, sharp-tailed grouse, and prairie chicken; composed 1.7 percent of fall food of prairie chicken in Wisconsin; composed 5.6 percent of fall food of sharp-tailed grouse in Wisconsin; composed 3.0 percent of winter food of northern sharp-tailed grouse in Quebec and Ontario; composed 1.5 percent of winter food of ruffed grouse in the northeastern United States; mountain sheep, pale chipmunk, black-tailed deer; plains white-talled deer, opossum, white-tailed deer, coyote. Observations (summary): Sixteen species of birds; of considerable importance as food for greater prairie chicken, sharp-tailed grouse and ring-necked pheasant; a greatly preferred food of wild turkey; furnishes grit for prairie sharp-tailed grouse, northern sharp-tailed grouse, pir- 
nated grouse, and ruffed grouse; Merriam's turkey; red squirrel, pale chipmunk, mule deer, porcupine; relished by Olympic wapiti. Rocky Mountain mule deer, Columbian black-tailed deer, Rocky Mountain snowshoe rabbit, New Mexico black bear, moose, snowshoe hare, cottontail rabbit, nica.

In view of the involved synonomy of the species it is quite certain that identifications and reports of utilization by wildlife are probably very often in error, and that some of the species names listed above may be misunderstood by users of this list. Perhaps the safest statement to make would be that since most of the roses hold their fruit the year round and have been fairly well demonstrated to act either as a reserve food or grit or both, that utilization of the wild roses in planting for wildlife may often be of value.

\section{Rubus spp.}

Blackberries, dewberries.

Because of the difficulty of identifying species of Rubus, which are in the same general taxonomic confusion as Crataegus, they are treated only as a genus.

The erosion-control value of the blackberries or dewberries lies in the fact that many species form dense thickets comparatively rapidly, and that many form dense mats on the ground. The branches of most species are either prostrate or with the tips bent down, and wherever they touch the ground they take root. Most species will grow satisfactorily in very barren and infertile soils and most of them require sunlight for their best growth and for fruit production. Many are considered troublesome weeds in fields. The greater number ordlnarily invade and rapidly occupy burns, eroded areas, old fields, and logged areas. Many produce biennial canes which fruit and perish.

Numerous species harbor rusts which also attack cultivated blackberries and raspberries. They are subject as well to anthracnose leaf spot, mosaic, and double blossom, all diseases which affect cultivated species of Rubus. For this reason considerable care needs to be exercised in planting them. Among those most free of disease should be listed the Himalaya blackberry (R. procerus Muell., $R$. thyrsanthus of Am. Auths.) which is susceptible to orange rust, but fairly free from other diseases and safe to plant. The second species is the evergreen blackberry ( $R$. laciniatus Willd.) (Pl. 36, B) which, outside of the Northwest, is generally subject to double blossom but otherwise is comparatively free from disease. Both of these introduced species are more or less naturalized in various parts of the country.

Mowing brambles usually results in an increase in the number of shoots and enhanced vigor of growth. If this is practiced two to three time a season for 2 years or longer, eradication may be accomplished. Burning generally favors brambles unless additional brush is piled on them to make a hotter fire.

Stomach records (summary): One hundred and forty-six species of bird's, including bobwhite, ruffed grouse, dusky grouse, sharp-tailed grouse, Ricliardson's grouse, California quail, ring-necked pheasant, and greater prairie chicken; composed 3.1 percent of fall food of prairie chicken in Wisconsin; composed 8.1 percent of fall food of sharp-tailed grouse in Wisconsin; mountain sheep, coyote, opossum, Townsend's chipmunk, chipmunk, dusky marmot, Florida skunk, black-tailed deer, red fox, gray fox, plains white-tailed deer, whitetalled deer; composed 10.8 percent of fruit food of the eastern skunk in Michigan.

Observations (summary) : Sixty-three species of birds; ranks eighteenth on the list of quail food plants of the Southeast; an important food of ringnecked pheasants; blue grouse, ruffed grouse, Hungarian partridge, relished by scaled quail, band-tailed pigeon; form a prominent share of midsummer food of skunks in New York; of considerable importance as food and cover for rabbits ; pica, red squirrel, black bear, bearer; second most preferred winter food of deer in Massachusetts (especially $R$. hispidus); $R$. parviflorus is of outstanding importance as browse for mule deer, $R$. leucodermis of slight importance; red fox, captive marsh rabbit, porcupine; relished by Olympic wapiti: an important food of Roosevelt elk; Columbian black-tailed deer, Rocky Mountain mule deer, ring-tailed cat, Townsend's chipmunk, Allen's chipmunk, goldenmantled ground squirrel, brown mountain beaver, Pacific mountain beaver, olympic black bear, snowshoe hare; squirrels, moose.

of some small value as forage for livestock; as a whole the group is of secondary palatability to livestock.

Rufacer rubrum, see Acer rubrum.

Rulac californicum, see Acer negundo. 
Rulac interior, see Acer negundo.

Rulac negundo, see Acer negundo.

Rulac nuttalii, see Acer negundo.

Rulac texana, see Acer negundo.

Ryncholeucaena greggii, see Leucaena greggii.

Sabal spp.

Stomach records (in addition to specific records): Two species of birds. Sabal adansonii, see Sabal louisiana, and S. minor.

Sabal caroliniana, see Sabal minor.

Sabal dceringiana, see Sabal louisiana.

Sabal glabra, see Sabal minor.

Sabal hystrix, see Rhapidophyllum hystrix.

Sabal louisiana (Darby) Bomhard.

Delta palmetto.

S. adansonii IRaf., not Guers., S. decringiana Small, Chamaerops louisiana Darby.

Range: 30 .

Site: Well-drained, sun.

Fruit: Drupe.

A small to large evergreen tree.

Sabal mexicana, see Sabal texana.

Sabal minima, see Sabal minor.

Sabal minor (Jacq.) Pers.

Dwarf palmetto.

S. adansonii Guers., not Raf., S. caroliniana Schult., S. glabra (Mull.) Sarg., S. minima (Nutt.) Wendl., S. nitida Hart., S. pumila (Walt.) Ell., S. taurina Lodd., Brahea minima (Nutt.) Wendl., Chamaerops glabra Mill., C. acaulis Michx., Corypha minor Jacq., C. pumila Walt., Raphis acaulis Walt.

Range: 20, 29, 30 .

Site: Well-drained, moist.

Fruit: Drupe, persistent.

A large evergreen shrub; stems subterranean; oftell considered a troublesome plant in cultivated fields. Much browsed by cattle.

Sabal nitida, see Sabal minor.

Sabal palmetto (Walt.) Lodd.

S. schwarzii (Cook) Becc., Corypha palmetto Walt.

Cabbage palmetto.

Range: 30 .

Site: Dry, well-drained, sun, moist.

Fruit: Drupe, available October-November.

A large evergreen tree.

Stomach records: Four species of birds. Observations: Five species of birds including bobwhite.

Sabal pumila, see Sabal minor.

Sabal schwarzii, see Sabal palmetto.

Sabal taurina, see Sabal minor.

Sabal texana (Cook) Becc.

S. mexicana Wats., not Mart., Inodes texana Cook.

Texas palm.

Range: 11, 17.

Site: Well-drained, sun.

Fruit: Drupe.

A large evergreen tree; commonly occurs in sand; grows readily from seed; slow growing; difficult to transplant.

Sabina barbadensis, see Juniperus lucayana.

Sabina flaccida, see Juniperus flaccida.

Sabina monosperma, see Juniperus monosperma.

Sabina oocidentalis, see Juniperus occidentalis. 
Sabina pachyphloea, see Juniperus pachyphloea.

Sabina pinchotii, see Juniperus pinchotii.

Sabina sabinoides, see Juniperus mexicana.

Sabina scopulorum, see Juniperus scopulorum.

Sabina utahensis, see Juniperus utahensis.

Sabina virginiana, see Juniperus virginiana.

Saccharodendron barbatum, see Acer saccharum.

Saccharodendron floridanum, see Acer floridanum.

Saccharodendron leucoderme, see Acer leucoderme.

Saccharodendron nigrum, see Accr nigrum.

Sageretia minutlfora (Michx.) Trel.

Buckthorn.

Range: 29, 30.

Site: Dry, well-drained, sun, shade.

Fruit: Drupe.

A small or large, trailing or straggling shrub, or occasionally a vine; spinescent; flowers April-May; commonly occurs on calcareous soil.

Sageretia wrightii Wats.

Range: 10, 11.

Site: Dry, sun.

Fruit: Drupe.

A small to large, spiny shrub. Without forage value for livestock as far as known.

Salazaria mexicana Torr.

Range: 9, 10.

Site: Dry, sun.

Fruit: Nutlet.

A small or rarely a large shrub; intricately branched and spinescent.

Salix spp.

Willows.

The willows are generally rapid growing; tolerant of moisture; adaptable to a great variety of soils and situations; gregarious because of the ease with which they grow from suckers and their vitality and free formation of shoots and seeds; most willows commonly produce root shoots and shoot roots; generally intolerant of shade and hence usually replaced by other trees in forests; relatively short-lived; seed vitality transient; often much winddamaged; many of the species are very difficult of separation.

Attention should be called to the willow scab. This disease, caused by the attacks of two fungi (Fusicladium saliciperdium and Physalospora miyabeana), occurs through most of New England and in New York and Pennsylvania. It has recently been found in the mountains of North Carolina. Willows of the Salix alba, S. nigra, and S. cordala types seem most susceptible. In the susceptible region at least, willows used for extensive planting should be grown from cuttings taken fiom resistant trees.

Stomach records (in addition to specific records): Twenty-three species of birds, including ptarnigan, ruffed grouse, dusky grouse, California quail, sharptailed grouse, and Richardson's grouse; composed 3.9 percent of winter food of northern sharp-tailed grouse in Ontario and Quebec; mountain shcep, moose, northern white-tailed deer, brush rabbit, grizzly, plains white-tailed deer, blacktailed deer. Observations (in addition to specific records) : Thirteen species of birds, mostly upland game birds, as ptarmigan, ruffed grouse, Gambel quail, sharp-tailed grouse; willow, rock and white-tailed ptarmigan; staple winter food of prairie sharp-tailed grouse in Wisconsin; emergency food of greater prairie chicken in Wisconsin and Iowa; somewhat eaten by muskrats in times of scarcity; much eaten by beaver; much eaten in the spring by rock squirrels in the Southeast; principal food of golden beaver; important food of snowshoe rabbits in northern Minnesota; Olympic wapiti; important food of moose; porcupine, Columbian black-tailed deer; important food of Pacific coast beaver, Shasta beaver and brown mountain beavel; Rocky Mountain snowshoe rabbit, broad-tailed beaver, Rio Grande beaver, bighorn.

The majority of species have value as browse for livestock. 
Salix adenophylla Hook.

S. syrticola Fern.

Range : 23, 24, 26.

Site: Well-drained, moist, sun.

Fruit: Capsule.

A large, straggling shrub.

Salix alba $\mathrm{L}$.

Range: 9, 15, 16, 19, 22, 25, 27, 28, 29.

European white willow.

Site: Well-drained, moist, sun.

Fruit: Capsule.

A large tree introduced from Europe and more or less naturalized in the regions indicated.

Salix ambigua, see Salix longipes.

Salix amygdaloides Anders.

Peachleaf willow.

Range: $4,6,7,8,9,11,12,13,14,15,16,18,19,20,21,22,23,24,25$, $26,27$.

Site: Moist, sun.

Fruit: Capsule. lived.

A large shrub to small or large tree; dioecious; rapid growing; short-

Salix argophylla Nutt.

S1lverleaf willow.

S. maerostachya Nutt.

Range: $4,6,7,8,9,12,13,14$.

Site: Moist, sun.

Fruit: Capsule.

A large shrub to small tree.

Observations: Of slight importance as browse for mule deer. Of value as browse for cattle and sheep.

Salix argyrocarpa Anders.

Range : 26, 27.

Site: Well-drained, moist, sun.

A small shrub.

Fruit: Capsule.

Salix austinae, see Salix lemmonii.

Salix bakeri, see Salix lasiolepis.

Salix balsamifera (Hook.) Barr.

S. pyrifolia Anders.

Range: 23, 24, 26.

Site: Moist, sun.

Fruit: Capsule.

A large shrub or rarely a small tree.

Salix barclayi Anders.

S. conjuncta Bebb.

Range : 4, 12, 13.

Site: Well-drained, sun.

Fruit: Capsule.

A small to large, thicket-forming shrub.

Stomach records: Mountatin sheep. An especially good browse for sheep.

Salix bebbiana Sarg.

S. perrostrata Rydb., S. rostrata Rich.

Range: $6,7,8,9,11,12,13,14,15,18,19,21,22,23,24,26,27$.

Site: Dry, well-drained, moist, sun.

Fruit: Capsule.

A large shrub to small or large tree; does not form suckers.

Observations: Cottontail rabbit. Relished by livestock in the West.

Salix bella Piper.

Range: $7,12$.

Site: Well-drained, sun.

A large shrub.

Balsam willow.

Barclay willow.

Bebb willow.

Fruit: Capsule. 
Salix bigelovii, see Salix lasiolepis.

Salix boiseana, see Salix Zasiolepis.

Salix bolanderiana, see Salix molanopsis.

Salix bonplandiana H. B. K.

S. pallida H. B. K., S. bonplandiana toumeyi Schneid.

Range: 10, 11.

Site: Well-drained, sun.

Fruit: Capsule.

A large tree. Eaten by livestock when young.

Salix brachycarpa Nutt.

S. stricta (Anders.) Rydb.

Range: 4, 12, 13.

Site: Moist, sun.

A small shrub.

Fruit: Capsule.

Salix brachystachys, see Salix scouleriana.

Salix breweri Bebb.

Range: 4.

Brewer willow.

Site: Moist, sun.

Fruit: Capsule.

A small, spreading shrub.

Salix caespitosa, see Salix petrophila.

Salix californica, see Salix castiooodiae.

Salix candida Fluegge.

Range : 12, 13, 15, 18, 21, 22, 23, 24, 26, 27.

Sage willow.

Site: Moist, sun.

A small shrub.

Fruit: Capsule.

Salix capreoides, see Salix scouleriana.

Salix cascadensis Cockerell.

S. tenera Anders.

Range: 4, 12, 13, 14 .

Site: Well-drained, sun.

Fruit: Capsule.

A small, prostrate shrub.

Stomach records: Mountain sheep. Observations: Of slight importance as browse for mule deer. Eaten by sheep.

Salix caudata (Nutt.) Heller.

S. lasiandra caudata (Nutt.) Sudw.

Caudate willow.

Range: 4, 6, 8, 11, 12, 13, 14, 15 (Black Hills).

Site: Well-drained, moist, sun.

A large shrub.

Fruit: Capsule.

Salix chapmanif, see Salix longipes.

Salix chlorophylla, see Salix planifolia.

Salix coactilis Fern.

Range: 26.

Site: Well-drained, sun.

A large shrub.

Fruit: Capsule.

Salix columbiae, see Salix pseudomyrsinites.

Salix commutata Bebb.

Range: 4, 12 .

Site: Moist, sun.

Fruit: Capsule.

A small to large shrub.

Observations: Of slight importance as browse for mule deer. An important, hrowse for livestock. 
Salix conjuncta, see Salix barclayi.

Salix cordata Muhl.

Range: 18, 21, 22, 23, 24, 25, 26, 27, 28.

Heartleaf willow.

Site: Well-drained, moist, sun.

Fruit: Capsule.

A large shrub to large tree.

Salix coulteri Anders.

Range: $1,2$.

Site: Well-drained, sun.

Fruit: Capsule.

A large shrub.

Salix covillei, see Salix subcoerulea.

Salix cuneata, see Salix sitchensis.

Salis discolor Muhl.

S. eriocephala Michx., S. prinoides Pursh.

Pussy willow.

Range: 15, 18, 21, 22, 24, 25, 26, 27, 28.

Site: Well-drained, moist, sun.

Fruit: Capsule.

A large shrub to small tree.

Observations: Cottontall rabbit.

Salix dodgeana Rydb.

Range : 12.

Site: Well-drained, sun.

Fruit: Capsule.

A prostrate, tiny shrub of mountain peaks.

Salix eastwoodiae Cockerell.

S. californica Bebb, not Lesq.

Range: 4,12 .

Site: Well-drained, moist, sun.

A small shrub.

Fruit: Capsule.

Salix eriocephala, see Salix discolor.

Salix exigua Nutt.

Sandbar willow.

S. fluviatilis exigua (Nutt.) Sarg., S. lutosericea Rydb., S. nevadensis Wats., S. stenophylla Rydb.

Range : 4, 5, 6, 7, 8, 9, 10, 11, 12, 13, 14, 15, 16.

Site: Well-drained, moist, sun.

Fruit: Capsule.

A large shrub to small tree; commonly occurs in sand and other soils.

Observations: Of slight importance as browśe for mule deer. Relished by livestock.

Salix farrae Ball.

Range: 12.

Farr willow.

Site: Well-drained, sun.

Fruit: Capsule.

A small, alpine shrub.

Sallx fendleriana, see Salix lasiandra.

Salix fernaldii, see Salix vestita.

Salix flava, see Salix lutea.

Sallx flavescens, see Salix scouleriana.

Sallx fluviatilis, see also Salix interior.

Salix fluviatilis Nutt.

S. longifolia of auths, not Muhl., S. sessifolia of auths., not Nutt.

Range: 1, 2, 6.

Site: Well-drained, moist, sun.

Fruit: Capsule.

A large shrub to small tree. 
Salix fragilis $\mathbf{L}$.

Range: 21, 22, 24, 25, 26, 27, 28, 29.

Crack willow.

- Site: Dry, well-drained, moist, sun.

Fruit: Cansule.

A small to large tree; twigs very brittle at base (abcission layer), easily breaking off and rooting.

Observations: Cottontail rabbit.

Salix franciscana, see Salix lasiolepis.

Sallx geyeriana Anders.

S. macrocarpa Nutt.

Geyer wlllow.

Range : $2,4,12,13,14,15$.

Site: Well-drained, sun.

Fruit: Capsule.

A small to large shrub. Relished by livestock.

Salix glauccphylla Bebb.

Range : 22, 23, 24, 26.

Site: Well-drained, moist, sun.

Fruit: Capsule.

A small to large shrub; forms extensive thickets; occurs in sand.

Salix glaucops Anders.

S. glauca glabrescens of auths., S. mudescens Rydb., S. pseudolapponum v.

Seem., S. seemanii Rydb., S. wyomingensis Rydb.

Range: $4,12,13,14,15$ (Black Hills).

Site: Well-drained, sim.

Fruit: Capsule.

A small shrub. An especially important stock-browse plant of the highest summer ranges.

Salix gooddingii Ball.

S. nigra of Jeps., not Marsl., S. vallicola (Dudl.) Britt.

Range: $3,4,5,9,10,11,14$.

Site: Well-drained, sun.

Fruit: Capsule.

A small shrub to large tree; apparently not tolerant of alkaline conditions; commonly occurs in patches or clumps.

observations of fair importance as browse for mule deer.

Sallx gracills, sce Salix petiolaris.

Salix harbisonii Schneid.

Harbison willow.

Range: 28, 29, 30 .

Site: Well-drained, moist, sun.

Fruit: Capsule.

A small to large tree.

Salix herbacea $\mathrm{L}$.

Range: 26.

Site: Well-drained, sun.

Fruit: Capsule.

A creeping plant of mountain peaks.

Salix hindsiana Benth.

S. parishiana Rowl., S. sessilifolia of Calif. auths.

Valley willow.

Range: $1,3,4,5,10$.

Site: Well-drained, moist, sun.

Fruit: Capsule.

A large shrub to large tree.

Sallx hookeriana Barr.

Coast willow.

Range: 1.

Site: Dry, well-drained, moist, sun.

Fruit: Capsule.

A large, bushy shrub to small or large tree; may occur on or near salt marshes; commonly occurs in sand, gravel, or muck; may be buried by sand although often continuing to grow. 
Salix humilis Marsh.

Prairie willow.

Range: $15,18,19,20,21,22,23,24,25,26,27,28,29$.

Site: Dry, well-drained, moist, sun.

Fruit: Capsule.

A small to large shrub; thicket forming.

Salix interior Rowl.

Sandbar willow.

S. fluviatilis of anths., not Nutt., in part, S. linearifolia Rydb., in part,

S. longifolia Muhl., S. thurberi Rowl., S. wheeleri (Rowl.) Rydb.

Range: 15, 16, 17, 18, 20, 21, 22, 23, 24, 25, 26, 27, 28, 29, 30.

Site: Well-drained, moist, sun.

Fruit: Capsule, available in April.

A large shrub to small or rarely a large tree; forms thickets by stolons.

Observations: White-tailed deer.

Salix irrorata Anders.

Bluestem willow.

Range: 11, 13, 14.

Site: Well-drained, sun.

Fruit: Capsule.

Commonly a small shrub, more rarely a large shrub to small tree.

Salix laevigata Bebb.

Range: $1,3,4,5,9,10,11$.

Red willow.

Site: Well-drained, moist, sun.

Fruit: Capsule.

A large shrub to large tree; rapid growing when young; short lived; commonly occurs in sandy or gravelly soil.

observations: Of fair importance as browse for mule deer.

Salix lancifolia, see Salix lasiandra.

Salix lasiandra Benth.

S. fendleriana Anders., S. lancifolia Anāers., S. lyallii (Sarg.) Heller.

Range: $1,2,3,4,5,11,13,14$.

Site: Well-drained, moist, sun.

Fruit: Capsule.

A large shrub to small or large tree; commonly occurs in sandy and other soils.

Observations: Of fair importance as browse for mule deer.

Salix lasiolepis Benth.

S. bakeri v. Seem., S. boiseana Nels., S. sandbergii Rydb.

Arroyo willow.

Range: $1,3,4,5,6,7,8,10,11,12,13,14$.

Site: Dry, well-drained, moist, sun.

Fruit: Capsule.

A large shrub to small or large tree.

Var. bigelovii (Torr.) Bebb, (S. bigelovii Torr., S. franciscana v. Seem.) occurs in the central northern portions of the range. The form described as S. sandbergii is perhaps better considered a variety of the species. It occurs in regions 8 and 12 , and is able to grow in dry sites.

observations: Of fair importance as browse for mule deer.

Salix lemmonii Bebb.

S. austinae Bebb.

Range : 4, 10 .

Site: Well-drained, moist, sun.

Fruit: Capsule.

A small to large shrub.

Observations: Of slight importance as browse for mule deer.

Salix ligulifolia Ball.

Range: 4, 13, 14.

Site : Moist, sun.

Fruit: Capsule.

A small or large shrub to small trec.

Salix linearifolia, see Salix interior.

Salix longifolia, see Salix fuviatilis, S. interior, and S. melanopsis. 
Sallx longipes Shuttlew.

S. ambigua Small, S. chapmanii Small, S. occidentalis Koch, S. wardii Bebb. Range: $19,20,22,25,27,28,29,30,31,32$.

Site: Well-drained, moist, sun.

Fruit: Capsule.

A small to large tree.

Observations: Captive marsh rabbit.

Salix lucida Muhl.

Range: 18, 21, 22, 23, 24, 25, 26, 27.

Shining willow.

Site: Well-drained, moist, sun.

Fruit: Capsule.

A large slirub to small or rarely a large tree.

Observations: Cottontail rabbit.

Salix Iutea Nutt.

S. flava Rydb., S. watsonii (Bebb) Rydb.

Yellow willow.

Range: $4,6,8,9,10,12,13,14,15,18$.

Site: Moist, sun.

Fruit: Capsule.

A small or large shrub to small tree, universally browsed by livestock.

Salix lutosericea, see Salix exigua.

Salix lyallii, see Salix lasiandra.

Sallx mackenziana (Hook.) Barr.

S. cordata mackenziana Hook.

Mackenzie willow.

Range: 1, 2, 4, 6, 7, 8, 12, 13.

Site: Moist, sun.

Fruit: Capsule.

A large shrub to small or rarely a large tree; occurs in rocky and gravelly soil.

Salix macrocarpa, see Salix geyeriana.

Salix macrostachya, see Salix argophylla.

Salix marginata, see Salix nigra.

Salix melanopsis Nutt.

Range: $3,4,5,7,8,9,10,12,13$.

Dusky willow.

Site: Moist, sun.

Fruit: Capsule.

A large shrub to small or large tree.

Var. bolanderiana (Rowl.) Schneid. (S. bolanderiana Rowl., S. longifolia Jeps.) occurs within the range of the species.

observations: Of slight importance as browse for mule deer.

Salix microphylla, see Salis taxifolia.

Salix missouriensis Bebb.

Range: 15, 18, 21, 22, 25.

Site: Well-drained, sun.

Fruit: Capsule.

A large shrub to small tree.

Salix monochroma Ball.

S. pyrifolia Anders., as used by Ball.

Range: 6, 8, 12.

Site: Well-drained, moist, sun.

Fruit: Capsule.

A small to large shrub; rellshed by livestock, especially in the fall.

Salix monticola Bebb.

S. padophylla Rydb.

Range: $9,12,13,14$.

Site: Moist, sun.

Fruit: Capsule.

A small to large shrub.

Salix myrtilloides, see Salix pedicellaris.

Salix nelsonii, see Salix planifolia. 
Salix nevadensis, see Salix exigua.

Salix nigra, see also Salix gooddingii.

Salix nigra Marsh.

S. marginata Wimm.

Black willow.

Range: $16,17,19,20,21,22,23,24,25,26,27,28,29,30$.

Site: Dry, well-drained, moist, sun.

Fruit: Capsule, available April-June.

A large shrub to small or large tree; root system spreading; rapid growing, especially when young; short-lived; much injured by fire, wind, and fungi; seed germination percentage high, vitality transient; wood used to some extent commercially.

Observations: White-tailed deer, cottontail rabbit.

Salix nivalis Hook.

Range: $4,12,13,14$.

Site: Well-drained, sun.

Fruit: Capsule.

A small, prostrate shrub.

Salix nudescens, see Salix glaucops.

Salix nuttallii, see Salix scouleriana.

Salix occidentalis, see Salix longipes.

Salix orestera Schneid.

S. glauca orestera Jeps., S. glauca villosa Bebb (Jeps. et al.).

Range: 4.

Site: Moist, sun.

Fruit: Capsule.

A small to large, spreading shrub.

Salix pachnophora, see Salix subcoerulea.

Salix padophylla, see Salix monticola.

Salix pallida, see Salix bonplandiana.

Salix parishiana, see Salix hindsiana.

Salix parksiana Ball.

Range: 1 .

Site: Well-drained, moist, sun.

Fruit: Capsule.

A small to large shrub.

Salix pedicellaris Pursh.

S. myrtilloides of auths., not $\mathrm{L}$.

Bog willow.

Range: 26, 27.

Site: Moist, sun.

Fruit: Capsule.

A small shrub. Var. hypoglauca Fern., is in regions 1, 2, 4, 12, 21, 23, and 24. Salix pellita Anders.

Range: 26, 27.

Site: Well-drained, moist, sun.

Fruit: Capsule.

A large shrub to small tree.

Salix pennata Ball.

Range: $4,12$.

Site: Well-drained, sun.

Fruit: Capsule, available in August.

A small, spreading shrub.

Salis perrostrata, see Salix bebbiana.

Salix petiolaris Smith.

S. gracilis Anders.

Range : 13, 15 (Black Hills), 18, 21, 22, 23, 24, 25, 26, 27.

Site: Well-drained, moist, sun.

Fruit: Capsule.

A small to large shrub. 
Salix petrophila Rydb.

S. caespitosa Kem.

Range: 4, 12, 13, 14.

Site: Well-drained, sun.

Fruit: Capsule.

A small shrub with creeping stems; occurs on alpine summits.

Salix phylicifolia, see Salix planifolia.

Salix piperi Bebb.

Range: 1, 2.

Piper willow.

Site: Dry, well-drained, moist, sun.

Fruit: Capsule.

A large shrub to small tree, commonly occurs in sand.

Salix planifolia Pursh.

S. chlorophylla Anders., S. monica Bebb, S. nclsonii Ball, s. phylicifolia of Amer. auths., not $\mathrm{L}$.

Range: 4, 12, 13, 14, 15 (Black Hills), 23, 26, 27.

Site: Well-drained, sun.

Fruit: Capsule.

A small to large shrub.

Observations: Of slight importanee as browse for mule deer.

Salix prinoides, see Salix discolor.

Salix pseudolapponum, see Salix glaucops.

Salix pseudomonticola Ball.

Range: 4, 12, 15 (Black Hills).

Site: Well-drained, sun.

Fruit: Capsule.

A small to large shrub.

Salix pseudomyrsinites Anders.

Salix columbiae Mac $\mathrm{Br}$ and Nels.

Range: $4,8,9,12,13,14$.

Site: Well-drained, sun.

Fruit: Capsule.

A small to large shrub.

Salix purpurea $\mathrm{L}$.

Range: 22, 25, 27, 28, 29.

Basket willow.

Site: Well-drained, moist, sun.

Fruit: Capsule.

A large shrub to small tree.

Salix pyrifolia, see Salix balsamifera, and S. monochroma.

Salix rostrata, see Salix bibbiana.

Salix sandbergii, see Salix lasiolepis.

Salix saximontana Rydb.

Range: 12, 13, 14.

Site: Moist, sum.

Fruit: Capsule.

A prostrate shrub; branches oceasionally rooting.

Salix scouleriana Barr.

Fire willow.

S. brachystachys Nutt., S. capreoides Anders., S. flavescens Nutt., S. nuttallii Sarg., S. scouleriana crassijulis Anders.

Range: 2, 3, 4, 6, 7, 8, 9, 10, 12, 13, 14, 15 .

Site: Dry, well-drained, molst, sun.

Fruit: Capsule.

A large shrub to small or large tree; rapid growing; easily recovers from grazing; thieket forming; a pioneer in burned-over areas.

observations: Of fair importance as browse for mule deer. One of the best species of native western range willows as browse for livestock.

Salix seemanii, see Salix glaucops. 
Salix sericea Marsh.

Range: 21, 22, 23, 24, 25, 26, 27, 28.

Silky willow.

Site: Moist, well-drained, sun.

Fruit: Capsule.

A large shrub.

Observations: Cottontall rabbit.

Salix serissima (Bail.) Fern.

Autumn willow.

S. pallescens hirtisquama Anders.

Range : $12,13,15,18,21,23,24,26,27$.

Site: Moist, sun.

Fruit: Capsule.

A large shrub; commonly occurs on calcareous soil.

Salix sessilifolia, see also Salix fluviatilis and S. Hindsiana.

Salix sessilifolia Nutt.

Sandbar willow.

Range: 1, 2, 4 .

Site: Well-drained, moist, sun.

Fruit: Capsule.

A large shrub to small tree, of some importance as a honey plant in California.

Salix sitchensis Sans.

S. cuneata Nutt.

Range: 1, 2, 4, 7, 12 .

Site: Well-drained, moist, sun.

Fruit: Capsule.

A large shrub to small or large tree.

Salix stenophylla, see Salix exigua.

Salix stricta, see Salix brachycarpa.

Salix subcoerulea Piper.

S. covillei Eastw., S. pachnophora Rydb.

Blue willow.

Range: 4, 12, 13, 14.

Site: Well-drained, moist, sun.

Fruit: Capsule.

A small to large shrub; relished by livestock.

Salix syrticola, see Salix adenophylla.

Salix taxifolia H. B. K.

S. microphylla Schlecht. and Cham.

Yewleaf willow.

Range: 9, 11.

Site: Well-drained, sun.

Fruit: Capsule.

A large shrub to large tree.

Salix tenera, see Salix cascadensis.

Salix thurberi, see Salix interior.

Sallx tracyi Ball.

Range: 1, 4 .

Site: Well-drained, moist, sun.

Fruit: Capsule.

A large shrub to small tree.

Salix tristis Ait.

Range: 21, 22, 23, 24, 25, 27, 28, 29.

Dwarf gray willow.

Site: Dry, well-dralned, sun.

Fruit: Capsule.

A small shrub; commonly occurs in sandy soil.

Salix tweedyl (Bebb) Ball.

S. barrattiana tueedyi Bcbb.

Range: 12.

Site: Moist, sun.

Fruit: Capsule.

A large shrub. 
Salix uva-ursi Pursh.

Range: $26,27$.

Bearberry willow.

Site: Well-drained, sun.

Fruit: Capsule.

A small, prostrate, mat-forming, alpine shrub, with a central root.

Salix vallicola, see Salix gooddingii.

Salix vestita Pursh.

S. fernaldii Blankinship.

Range: 12, 26.

Site: Well-drained, sun.

Fruit: Capsule.

Sallx wardii, see Salix longipes.

Salix watsonii, see Salix lutea.

Salix wheeleri, see Salix interior.

Saliz wolfii Bebb.

Range: 12, 13.

Site: Well-drained, sun.

Fruit: Capsule.

A small shrub. Var. idahoensis Ball, is considered a very good sheep browse in Idaho.

Salix wrightii Anders.

S. amygdaloides vorightii Anders.

Wright willow.

Range: 11, 14, 16.

Site: Moist, sun.

Fruit: Capsule.

A large shrub to large tree, eaten by livestock when young.

Salix wyomingensis, see Salix glaucops.

Salvia spp.

Sage.

Stomach records (in addition to specific records): Gambel and scaled quail.

These records may apply to herbaceous as well as woody species. In general, the species rival clover and linden as honey plants.

Salvia apiana Jeps.

Audibertia polystachya Benth., Ramona polystachya (Benth.) Greene.

Range: $5,10$.

Site : Dry, sun.

Fruit: Nutlet.

A large shrub. An apparent hybrid between this and $P$. clevelandii is called S. palmeri (Gray) Greene.

Furnishes some winter browse for livestock. An important honey plant.

Salvia ballotaeflora Benth.

Range: 11, 16, 17, 20.

Site: Dry, sun.

Fruit: Capsule.

A small shrub; flowers throughout the summer; drops its leares in times of drought, regains them with rain.

Salvia carnosa Dougl.

Audibertia incana Benth., Audibertiella incana Briq., Ramona incana

(Benth.) Dougl.

Range: 4, 7, 8, 9, 10.

Site: Dry, well-drained, sun.

Fruit: Nutlet.

A small, compact, much-branched shrub; flowers May-June; a variety which is woody at the base only occurs in region 5. Generally of low palatability but somewhat useful as browse for livestock.

Salvia clevelandil Gray.

Range: 5 .

Site: Dry, sun.

Fruit: Nutlet.

A small shrub; flowers May-August. 
Salvia confinis Fern.

Range: 10, 11 .

Site: Dry, well-drained, sun.

Fruit: Nutlet.

A small shrub.

Salvia eremostachya Jeps.

Range: 10 .

Site: Dry, sun.

Fruit: Nutlet.

A small shrub.

Salvia funerea Jones.

Range : 10.

Site: Dry, sun.

Fruit: Nutlet.

A small, densely branched, compact, densely leafy shrub; flowers April-May. Salvia greatae Brandeg.

Range : 10 .

Site: Dry, sun.

Fruit: Nutlet.

A small shrub; flowers in April.

Salvia greggii Gray.

Range: 11, 17.

Site: Dry, sun.

Fruit : Nutlet.

Antumn sage.

A small shrub; flowers throughout the summer.

Salvia mellifera Greene.

Audibertia stachyoides Benth., Ramona stachyoides (Benth.) Briq.

Range: 5, 10.

Site: Dry, sun.

Fruit: Nutlet.

A small to large, openly branched shrub; flowers April-May; inflammable; somewhat loosely branched.

More or less browsed by sheep and goats. Has been said to be the best honey plant of the Pacific coast.

Salvia mohavensis Greene.

Audibertia capitata Gray.

Range: 10.

Site: Dry, sun.

Fruit: Nutlet.

A small, much-branched, compact shrub; flowers May-June.

Salvia pachyphylla Epling.

Audibertia pachystachya Gray.

Range: 10.

Site: Dry, sun.

A small shrub.

Fruit: Nutlet.

Salvia palmeri, see Salvia apiana.

Salvia pinguifolia (Fern.) Woot, and Standl.

Range: 11.

Site: Dry, sun.

A small shrub.

Fruit: Nutlet.

Salvia vaseyi (Porter) Parish.

S. vaseyi (Porter) Jeps.

Range: 10.

Site: Dry, sun.

Fruit: Nutlet.

A small shrub.

Samanea flexicaulis, see Pithecolobium flexicaule.

$130186^{\circ}-39-17$ 
Sambucus spp.

Elders.

The blue- or black-fruited species are edible at least when cooked; some red berries have poisoned human beings; most species grow on slightly acid soil.

Stomach records (in addition to specific records) : One hundred and eleven species of birds, including ruffed grouse, dusky grouse, California quail, and Gambel quail ; opossum. Observations (in addition to specific records) : Thirtyfour species of birds, including band-tailed pigeon, porcupine, Olympic black bear.

Sambucus caerulea Raf. (pl. 37, B).

S. glauca Nutt., S. neomexicana Woot.

Blueberry elder.

Range: $1,2,4,5,6,7,8,9,11,12,13,14$

Site: Dry, well-drained, moist, sun.

Fruit: Berry; available August-October, or rarely to December.

Usually a large shrub, more rarely a small to large tree; flowers April-July; not gregarious; coppices freely, the sprouts growing as much as 15 feet in a single year; berries produced abundantly; wood durable in contact with the soil.

Var. velutina (Dur.) Schwer., (S. velutina Dur.), the velvet-leaf elder, occurs in regions 4, 5, and 10. It has a limited value as browse for livestock and is of outstanding importance as browse for mule deer. A form of the species occurring in region 14 has been described as S. vestita Woot. and Standl.

Stomach records: Nine species of birds, including ruffed grouse, Callfornia quail, valley quail, and Gambel quail. Observations: Ring-necked pheasant; much eaten by birds generally; Rocky Mountain mule deer; California mule deer. Worthless to poor forage for sheep; worthless for cattle in the spring and summer, but in the fall good to excellent.

Sambucus callicarpa Greene.

Range: 1, 2, 4 .

Site: Dry, well-drained, moist, sun.

December.

Fruit: Berry ; avallable June-September, occasionally persistent until

Commonly a large shrub or rarely a small to large tree; flowers April-May; somewhat loosely-branched; coppices freely; sprouts may grow as much as 13 feet in one season; clump forming.

Stomach records: Three species of birds, including sooty grouse. Observations: Sooty grouse, band-tailed pigeon. Good sheep and fairly good cattle browse in the fall.

Sambucus canadensis L. (pl. 38).

Range: $15,16,17,18,20,21,22,23,24,25,26.27,28,29,30$.

Site: Well-drained, moist, sun, shade.

Fruit: Berry, arailable August-October.

A large stoloniferous shrub; flowers June-July; produces seed 4 years after sowing; the fresh leaves, berries, flowers, and roots yield hydrocyanic acid; cooking breaks up the cyanogenetic glucosides; grows on coal-stripped lands in Illinois: $175,000-468,000$ seeds per pound.

Stomach records: Forty-three species of birds, including ruffed grouse, bobwhite, and ring-necked pheasant; composed 0.2 percent of total annual food, and 2.8 percent of fruit food of ring-necked pheasant in Michigan. Observations: Sixteen species of birds, including mourning dove, wild turkey; an important food of ring-necked pheasant in Michigan; red squirrel, captive marsh rabbit, white-tailed deer. Highly palatable in the fall to livestock.

Sambucus glauca, see Sambucus caerulea.

Sambucus melanocarpa Gray.

Black elder.

Range : $4,9,10,12,13,14$.

Site : Moist, sun, shade.

Fruit: Berry, available July-September.

A large shrub with comparatively thick foliage; flowers May-June; may occur on rocky sites. Locally valuable as a fall forage for livestock.

Sambucus mexicana Presl.

S. caerulea arizonica Sarg.

Range: 5, 10, 11, 16, 17 .

Site: Moist, sun.

Fruit: Berry, sald to be available the year around.

A large shrub to small tree, said to be evergreen; fruit rarely matures in New Mexico. 

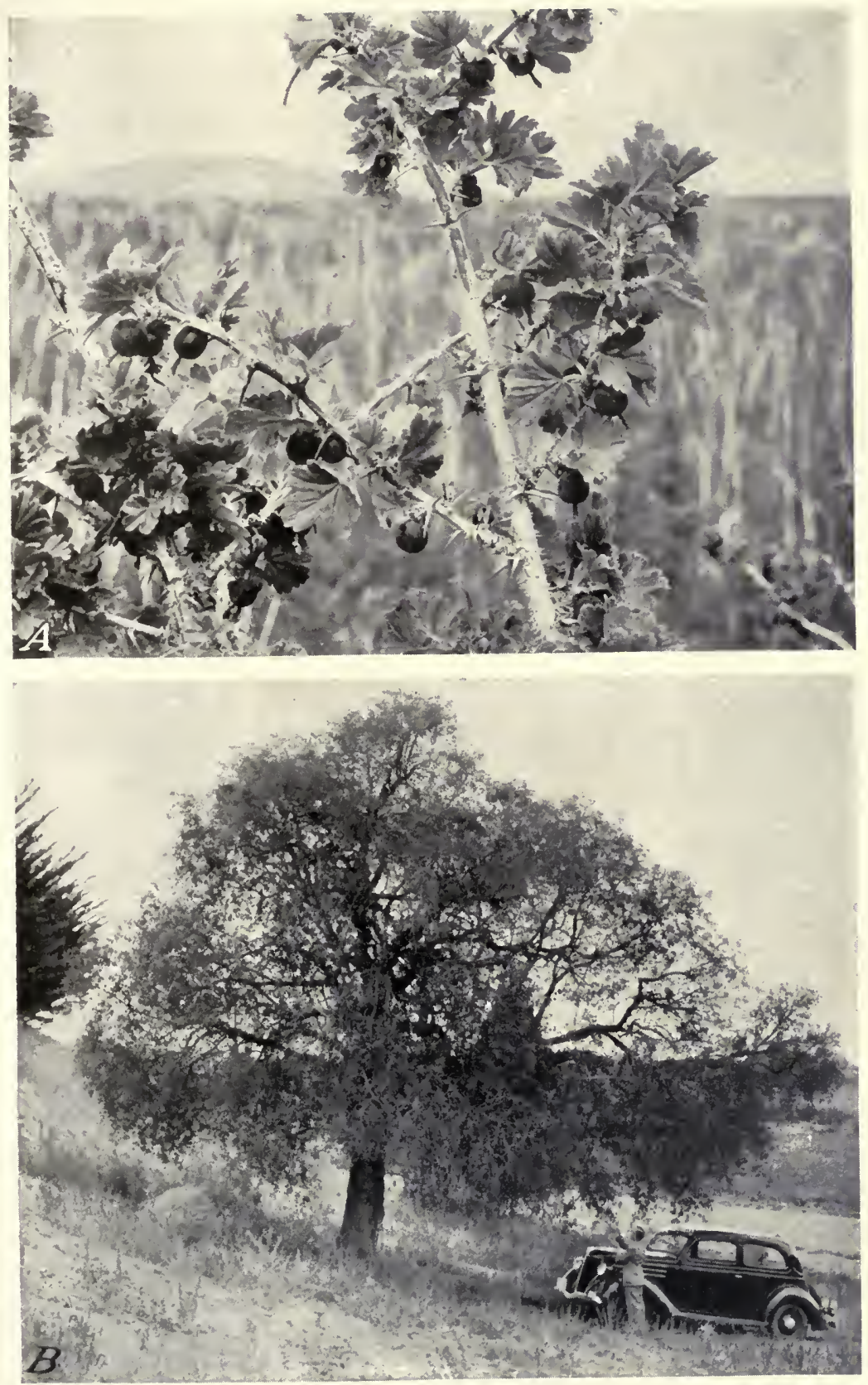

A, Ribes setosum. A typical wild gooseberry, susceptible to whitepine blister rust, but valuable for soiland wildlife-conservation plantings in regions where five-needled pines are not grown. $B$, Sambucus caerulea. A very large specimen of an elder that more commonly attains only shrub stature. A noteworthy species for erosion-control and wildlife plantings. 


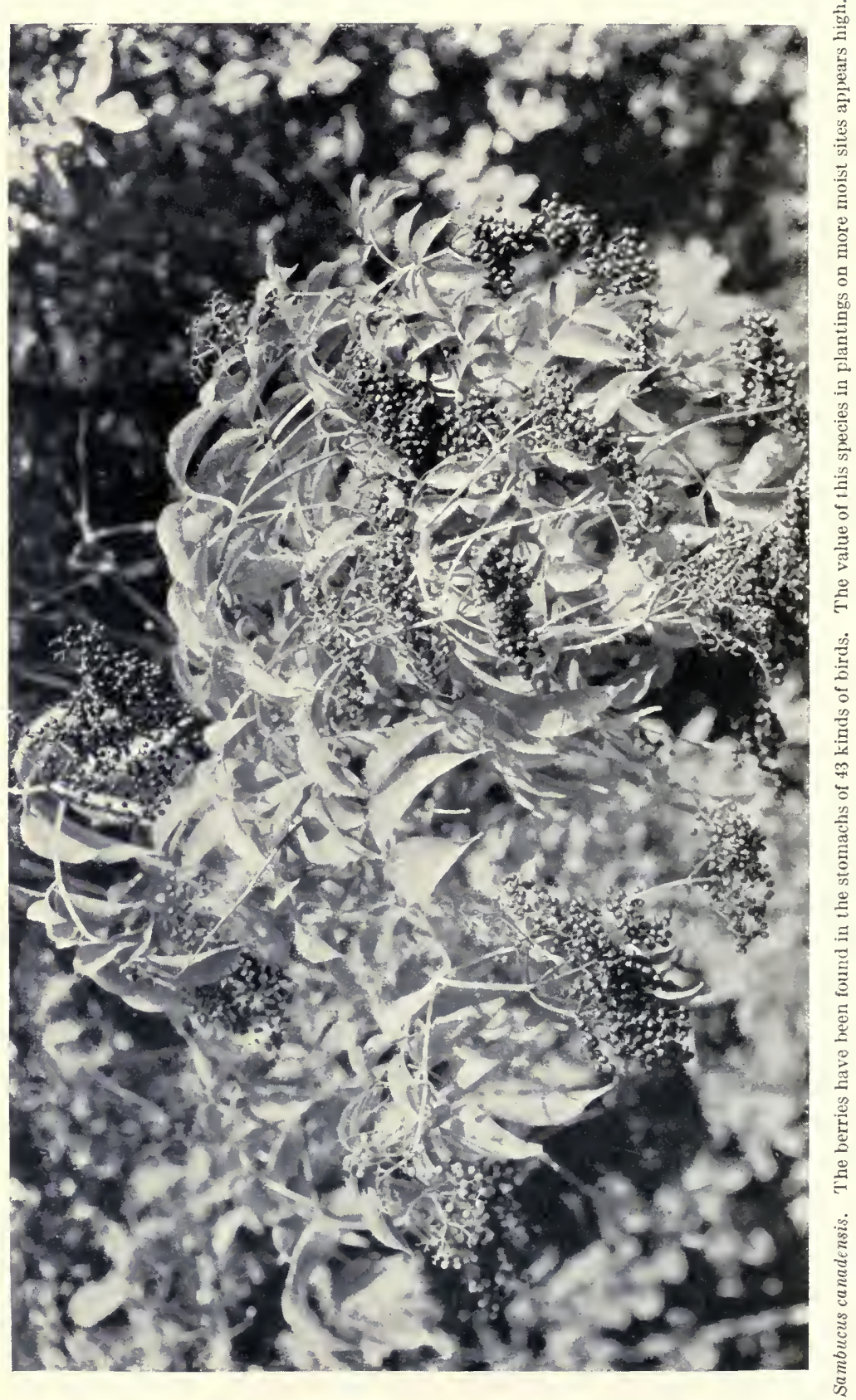


Sambucus microbotrys Rydb.

Range: 9, 13, 14, 15 (Black Hills).

Bunchberry elder.

Site: Well-drained, moist, sun, shade.

Fruit: Berry, available July-September.

A small shrub or rarely a large shrub; flowers May-July.

Stomach records: Richardson's grouse. Observations: Dusky grouse. Extensively browsed in summer, even more in the fall, by livestock.

Sambucus neomexicana, see Sambucus caerulea.

Sambucus pubens Michx.

Red elder.

S. racemosa of auths., not $\mathbf{L}$.

Range: 15 (Black Hills), 21, 22, 23, 24, 26, 27, 28.

Site: Dry, well-drained, sun, shade.

Fruit: Berry, available June-November, sometimes persistent until January.

A large shrub; flowers April-May; 48,300 seeds per pound. Records of this species on the West Coast probably refer to S. callicarpa (q. ₹.).

Stomach records: 'Twenty-three species of birds, including ruffed grouse, bobwhite, and ring-necked pheasant. Observations: Moose, red squirrel, whlte-tailed deer.

Sambucus racemosa, see Sambucus pubens.

Sambucus simpsonii Rehd.

Range: $29,30,31$.

Site: Well-drained, moist, sun.

Fruit: Berry.

A large shrub to small tree; flowers throughout the year; forms vast thickets.

Sambucus velutina, see Sambucus caerulea.

Sambucus vestita, see Sambucus caerulea.

Sanviniona assurgentiflora, see Lavatera assurgentifolia.

Sapindus drummondii Hook, and Arn.

Range: $11,16,17,19,20,22,25,29,30$.

Site: Dry, well-drained, moist, sun.

Fruit: Berry ; available September-October, commonly persistent until spring.

A large shrub or small to large tree with dense follage; flowers May-June; occurs on clay, limestone and other soils; wood used to some extent commercially; 1,500-1,700 seeds per pound; contains large quantities of saponin, a severe poison which is objectionable to the taste. Not browsed by livestock.

Sapindus manatensis, see Sapindus marginatus.

Sapindus marginatus Willd.

S. manatensis Radek.

Florida soapberry.

Range: 29, 30 .

Site: Well-drained, moist, sun.

Fruit: Berry; available in October.

A small to large tree; flowers in May; commonly occurs in sand.

Sapium biloculare (Wats.) Pax.

S. bilocularis amplum Johnst., Sebastiania bilocularis Wats.

Range: 10.

Site: Dry, weli-drained, sun.

Fruit: Capsule.

A large shrub to small tree; a fish poison; produces jumping beans.

Sarcobatus balleyi Cov.

Range: 10.

Site: Dry, sun.

Fruit: Achene.

A small shrub.

Sarcobatus vermiculatus (Hook.) Torr.

Range: $6,7,8,9,10,11,12,15$.

Greasewood.

Site: Dry, sun.

Fruit: Achene.

A small to large, spiny shrub; occurs in alkaline soil, withstanding a hydrogenion concentration to $\mathrm{pH} 8.0$. 
Observations: Porcupine, fack rabbit, Zuni prairie dog, painted chipmunk; Cary San Luis chipmunk, western chipmunk. A valuable fall and winter browse for livestock provided it is eaten with other forage in ordinary amounts; young stems and fresh leaves in the spring have caused livestock poisoning.

Sassafras albidum (Nutt.) Nees.

Sassafras.

S. variifolium (Sallsb.) Kuntze., S. sassafras (L) Karst., S. offcinale Nees and Eberm., Laurus albida Nutt.

Range: $20,22,23,24,25,26,27,28,29,30$.

Site: Dry, well-drained, sun.

Fruit: Drupe; a vailable August-October.

Usually a large shrub, less commonly a small to large tree; occurs on many kinds of soils including sand; reproduces extensively by means of root stocks; densely thicket forming; dioecious; coppices freely after cutting; wood very durable, somewhat used commercially; a pioneer species in old fields; often a troublesome weed.

Stomach records: Eighteen species of birds including bobwhite; woodchuck. observations: Ten species of birds; ranks twenty-sixth on the list of quail food plants in the Southeast; marsh rabbit, woodchuck, wild turkey; black bear, white-tailed deer.

Sassafras offlinale, see Sassafras albidum.

Sassafras sassafras, see Sassafras albidum.

Sassafras variifolium, see Sassafras albidum.

Savia phyllanthoides, see Andrachne phyllanthoides.

Schaefferia cuneifolia Gray.

Range: 11, 17, 20.

Desert yaupon.

Site : Dry, swn.

Fruit: Dry drupe; available in May.

A small, densely-branched, spinose shrub; slow growing; easily transplanted.

Schinus fagara, see Xanthoxylum fagara.

Schizonotus discolor, see Holodiscus discolor.

Schmaltzia affnis, see Rhus trilobata.

Schmaltzia anisophylla, see Rhus trilobata.

Schmaltzia arenaria, see Rhus aromatica.

Schmaltzia aromatica, see Rhus aromatica.

Schmaltzia ashei, see Rhus ashei.

Scinmaltzia bakeri, see Rhus trilobata.

Schmaltzia cognata, see Rhus trilobata.

Schmaltzia copallina, see Rhus copallina.

Schmaltzia cruciata, see Rhus trilobata.

Schmaltzia emoryi, see Rhus trilobata.

Schmaltzia glabra, see Rhus glabra.

Schmaltzia glabrata, see Rhus trilobata.

Schmaltzia glauca, see Rhus trilobata.

Schmaltzia glomerata, see Rhus trilobata.

Schmaltzia hirta, see Rhus typhina.

Schmaltzia illinoensis, see Rhus aromatica.

Schmaltzia lanceolata, see Rhus copallina.

Schmaltzia leiocarpa, see Rhus trilobata.

Schmaltzia malacophylla, see Rhus trilobata.

Schmaltzia michauxii, see Rhus michauxii. 
Schmaltzia oxyacanthoides, see Rhus trilobata.

Schmaltzia pulchella, see Rhus trilobata.

Schmaltzia quercifolia, see Rhus trilobata.

Schmaltzia ribifolia, see Rhus trilobata.

Sclimaltzia scaberula, see Rhus trilobata.

Schmaltzia simplicifolia, see Rhus trilobata.

Schmaltzia straminea, see Rhus trilobata.

Schmaltzia subpinnata, see Rhus trilabata.

Schmaltzia trilobata, see Rhus trilobata.

Schmaltzia virens, sec Rhus virens.

Sebastiania bilocularis, see Sapium bilorulare.

Securingea fasciculata, see Halliophytum hallii.

Senegalia berlandieri, see Acacia berlandieri.

Senegalia emoryana, see Acacia emoryana.

Senegalia greggli, see Acacia greggii.

Senegalia malacophylla, see Mimosa malacophylla.

Senegalia roemeriana, see Acacia roemeriana.

Senegalia wrightil, see Acacia wrightii.

Sequoia spp.

Two species of trees attaining tremendous size and age, and producing fine timber; wood very resistant to decay. The tallest, most massive, and oldest of United States forest trees; bark very thick; range of both species very restricted; finest specimens often protected; reproduce freely and abundantly.

observations (in addition to specific records): Crossbill; much eaten by squirrels.

Sequoia gigantea, see Sequoia washingtoniana.

Sequola sempervirens (Lamb.) Endl.

Range: 1.

Site: Well-drained, sun.

Fruit: Cone; ripe in September, seeds shed at once, cones persistent a few months.

A very large, evergreen tree; root system deep or shallow; rapid growing when young, later slower; extremely long-lived; forms very dense forests; reproduces commonly by root and stump sprouts which grow faster than seedlings; wood of great importance commercially; $82,000-115,000$ seeds per pound.

Observations: Sierra chickaree.

Sequoia washingtoniana (Winsl.) Sudw.

S. gigantea Decne., S. wellingtoniana v. Seem.

Bigtree.

Range: 4.

Site: Dry, well-drained, sun.

Fruit: Cone; mature at the end of the second summer, seeds shed slowly, cones soon falling.

A very large, evergreen tree; extremely long-lived; at first rapid growing, later slower; resistant to fire, insects, and fungi; wood of great importance commercially ; 93,300 seeds per pound, germination 24 percent, vitality persistent.

Observations: Much eaten by the California pine squirrel.

Sequola wellingtoniana, see Sequoia washingtoniana.

Serenoa repens (Bart.) Small.

S. serrulata (Michx.) Hook. f., Corypha repens Bart.

Saw palmetto.

Range: $29,30$.

Site: Dry, well-drained, moist, sun.

Fruit: Drupe; arailable June-Norember. 
A small to large shrub or small tree; evergreen; stems erect, or often creeping and rooting, or subterranean ; forms extensive, dense colonies.

Stomach records: Five species of birds, including bobwhite. Observations: Captive marsh rabbit; gray squirrel. An important source of honey.

Serenoa serrulata, see Serenoa repens.

Sericotheca discolor, see Holodiscus discolor.

Sericotheca dumosa, see Holodiscus dumosus.

Sericotheca glabrescens, see Holodiscus discolor.

Sericotheca microphylla, see Holodisous discolor.

Sericotheca obovata, see Holodiscus discolor.

Serlcotheca schaffneri, see Holodiscus schaffneri.

Serjania brachycarpa Gray.

Range: 17 .

Site: Dry, sun.

A vine. Fruit: Samara.

Serjania incisa Torr.

Range: 17.

Site: Well-drained, sun.

Fruit: Samara.

A vine.

Shepherdia spp.

Stomach records (in addition to specific records): 7 species of birds, including ruffed grouse; buff-bellied chipmunk, black-tailed deer. Observations (in addition to specific records): Three species of birds, including prairie chicken; much eaten by pale chipmunk; porcupine, western chipmunk.

Shepherdia argentea Nutt. (pl. 40, $B$ ).

Lepargyrea argentea (Nutt.) Greene, Elaeagnus utilis Nelson.

Silver buffaloberry.

Range: $4,9,11,12,13,15,16,18,19,21,22,23$.

Site: Dry, well-drained, moist, sun, shade.

Fruit: Berry, available July-August.

A large, somewhat thorny, dioecious shrub; flowers April-May; edible fruit borne in great profusion; difficult to transplant from the wild; staminate plants in winter have dense clusters of rounded flower buds, while the fruit-bearing, pistillate plants have smaller, flattened, fewer, more slender buds ; $36,000-43,000$ seeds per pound.

Stomach records: Twelve species of birds; pale chipmunk. Observations: Western robin, sharp-tailed grouse. Of slight importance as browse for mule deer; porcupine, Wasatch chipmunk. Worthless as browse for livestock.

Shepherdia canadensis (L.) Nutt.

Lepargyrea canadensis (L.) Greene, Elaeagnus canadensis (L.) Nelson.

Range: 2, 12, 13, 14, 15 (Black Hills), 18, 21, 23, 24, 26, 27.

Site: Dry, well-drained, moist, sun, shade.

Fruit: Berry, available July-September.

A small to large, dioecious shrub; flowers April-June; typical of moist, open, wooded slopes; root system compact, fibrous, rather shallow; commonly occurs on calcareous soil.

Stomach records: Seven species of birds, including dusky grouse. Observations: Bohemian and cedar waxwings, sharp-tailed grouse; Alpine chipmunk; casually browsed by northern white-tailed deer. Without browse value for cattle; of limited value for sheep before frost.

Shepherdia rotundifolia Parry.

Lepargyrea rotundifolia (Parry) Greene, Elaeagnus rotundifolia (Parry) Nelson.

Range: 9, 11.

Site: Dry, sun.

Fruit: Berry.

A small, densely branched evergreen shrub; flowers in March; commonly sprawling; often occurs in clay soil. Considered a valuable winter food for livestock in southeastern Utah. 


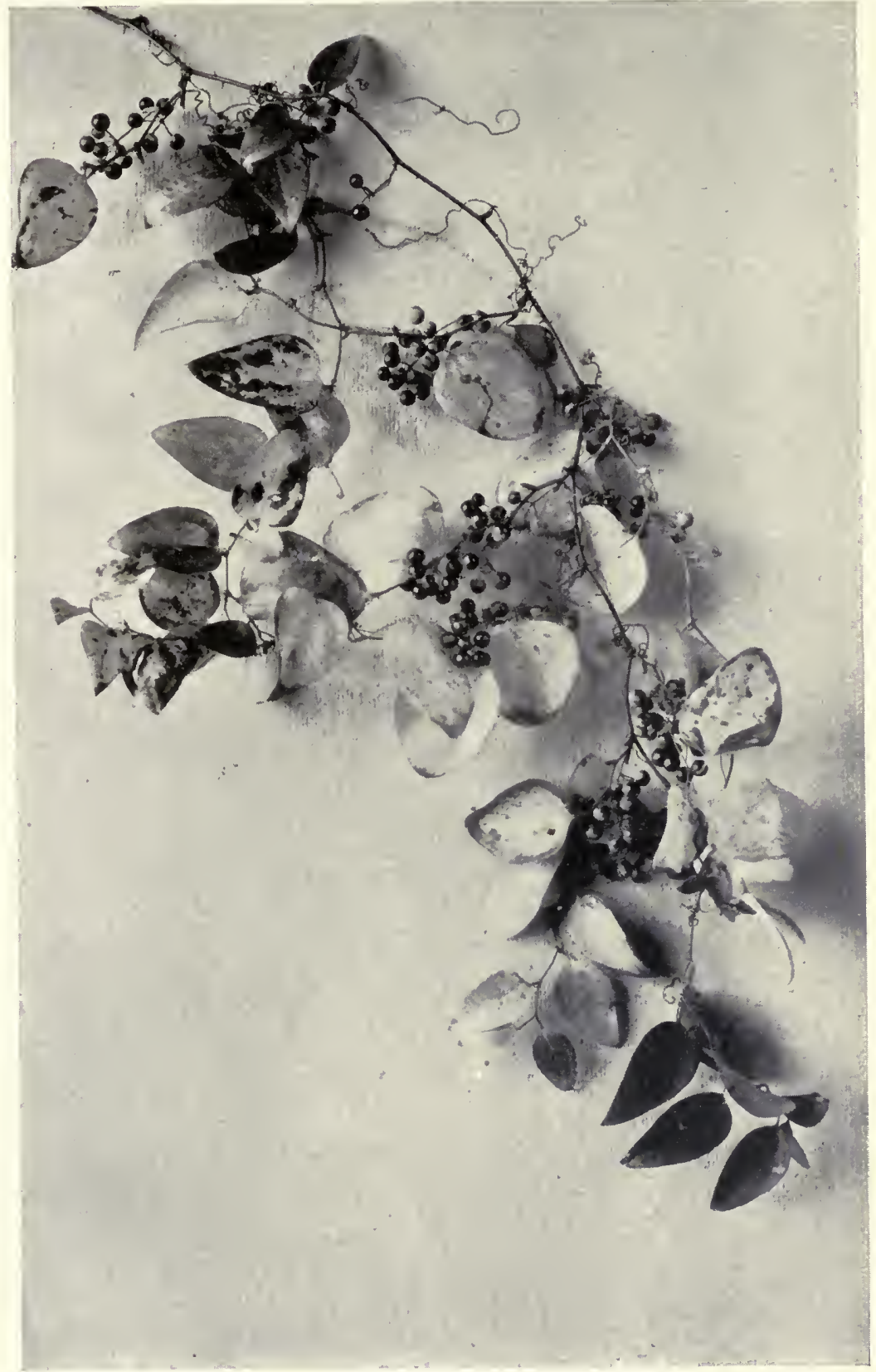

smilax glauca. A fruiting branch collected in midwinter in Maryland. The thicket-forming tendency of this and other species of Smilax make them valuable erosion-control plants on submarginal land where they provide food and cover for wildlife as well as cover for soil. 

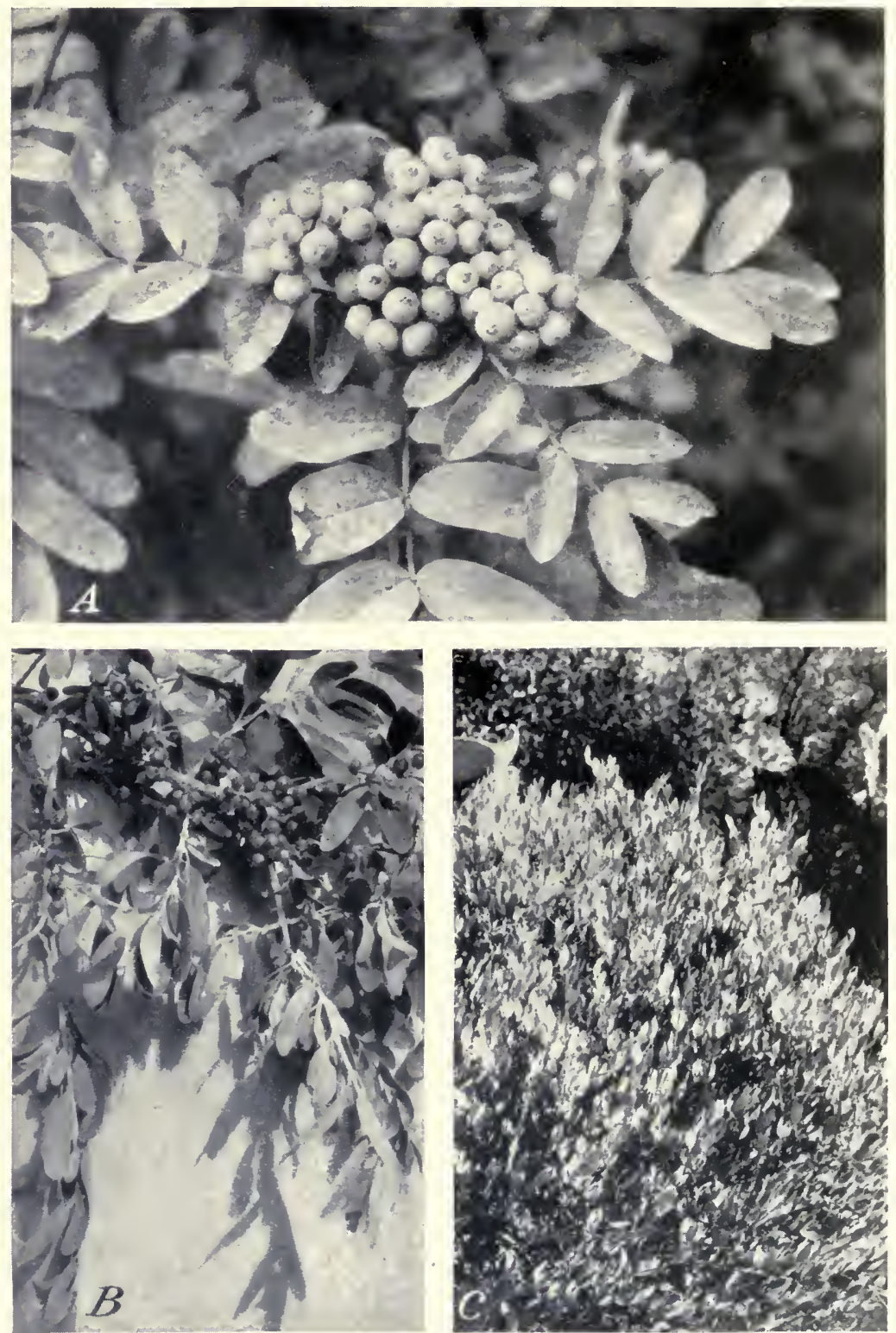

A, Sorbus sitchensis. A species with promise for erosion-control and wildlife plantings at higher elevations in the West. $B$, Shepherdia argentea, a fruit-bearing shrub of value to wildlife and of great potential use in erosion-control plantıng. C, Simmondsia chinensis. The goat nut provides a thick cover in the desert region where cover is at a premium. Its nutlike seed is utilized by wildlife. 
Siderocarpos flexicaulis, see Pithecolobium flexicaule.

Sideroxylon lanuginosa, see Bumelia lanuginosa.

Simmondsia californica, see Simmondsia chinensis.

Simmondsia chinensis (Link) Schneid. (pl. 40, $C$ ).

S. californica Nutt., S. pabulosa Kellogg, Buxus chinensis Link.

Goat-nut.

Range: 5,10 .

Site: Dry, sun.

Fruit: Capsule, available August-September.

A small to large, bushy monoecious or dioecious shrub; slow growing, fruit often produced in great quantities; flowers in April; seed germination 80-100 percent; seedlings slow-growing.

Observations: Much eaten by squirrels; mule deer; white-winged doves. An important browse for livestock.

Simmondsia pabulosa, see Simmondsia chinensis.

Smilax spp.

Stomach records (in addition to specific records: Forty-four species of birds, including ruffed grouse, bobwhite, wild turkey, sharp-tailed grouse, ring-necked pheasant, and greater prairie chicken; composed 3.6 percent of the fall food of prairie chicken in Wisconsin; composed 1.0 percent of fall food of sharp-tailed grouse in Wisconsin; gray fox, white-tailed deer. Observations (in addition to specific records) : Twelve species of birds, considerably eaten by marsh rabbit; cottontail rabbit.

Smilax auriculata Walt.

Range: 29, 30.

Site: Dry, well-drained, moist, sun, shade.

Fruit: Berry.

An evergreen vine; unarmed, or with small prickles, rootstocks bearing large tubers; occurs in sandy and other soils.

Observations: Captive marsh rabbit.

Smilax bona-nox L.

Range: $11,16,17,20,25,27,28,29,30$.

Fringed greenbrier.

Site: Dry, well-drained, sun, shade.

Fruit: Berry, available October-November.

A spiny vine, partially evergreen; flowers in June; root-stocks bearing large tubers. (See also S. pseudochina.)

Stomach records: Thirteen species of birds, including ruffed grouse. Observations: Captive marsh rabbit.

Smilax californica Gray.

Range: 4.

Site: Well-drained, moist, sun, shade.

Fruit: Berry, available July-November.

A smooth or prickly vine; commonly spreads by rootstocks.

Smilax cinnamomifolia, see Smilax lanceolata.

Smilax glauca Walt. (pl. 39).

Range: $20,21,22,25,27,28,29,30$.

Site: Dry, well-drained, sun.

Fruit: Berry, available September-October, often persistent until spring.

A partially evergreen vine; flowers in June; occurs on sand, clay, and other soils; underground stems deep, bearing large tubers; often troublesome in clearings and meadows; comparatively difficult to eradicate; thicket forming; very tolerant of fire.

Stomach records: Seven species of birds, including ruffed grouse. Observations: Captive marsh rabbit.

Smilax hispida Muhl.

Range : $20,21,22,23,24,25,26,27,28,29,30$.

Bristly greenbrier.

Site: Dry, well-drained, moist, sun.

Fruit: Berry; available October-November, commonly persistent until spring. 
A high-climbing vine; grows well on poor soils including sand; does not spread by stolons.

Observations: Wild turkey.

\section{Smilax lanceolata $\mathrm{L}$.}

S. cinnamomifolia Small.

Coral greenbrier.

Range: $20,28,29,30$.

Site: Dry, well-drained, sun.

Fruit: Berry, available in September.

A vigorous, evergreen vine; prickly or unarmed; rootstocks commonly fleshy ; production of fruit uncertain.

Observations: Captive marsh rabbit. Browsed by cattle.

Smilax laurifolia $\mathrm{L}$.

Range: $20,28,29,30$.

Laurel greenbrier.

Site: Dry, well-drained, moist, sun, shade.

Fruit: Berry, available August-September of the second season.

A very vigorous, high-climbing evergreen vine; not thorny; commonly forms large entanglements; fruit very abundantly produced; rootstocks commonly bearing very large tubers which may be used for propagation purposes.

Stomach records: Three species of birds. Observations: Refused by captice marsh rabbits.

Smilax pseudochina L.

Range: 16, 20, 22, 23, 24, 25, 27, 28, 29, 30.

Chinabrier.

Site: Dry, well-drained, sun.

Fruit: Berry.

An evergreen vine; commonly occurs in sandy and other soils; rootstocks often bear large tubers. By some authorities considered identical with $S$. bona-nox.

Stomach records: Mockingbird.

Smilax pumila Walt.

Range : 20, 29, 30.

Sarsparilla vine.

Site: Well-drained, moist, sun, shade.

Fruit: Berry, available in spring, persistent the year round.

A trailing or low-climbing, unarmed vine; flowers in the fall.

Observations: Captive marsh rabbit.

Smilax renifolia Small.

Range: 17, 30.

Site: Well-drained, moist, sun.

Fruit: Berry.

A high-climbing dioecious vine.

Smilax rotundifolia $\mathrm{L}$.

Range: $20,22,23,24,25,26,27,28,29,30$.

Catbrier.

Site: Well-drained, moist, sun.

Fruit: Berry, available in October, persistent throughout the winter.

A thicket-forming, evergreen, spiny vine; rootstocks tuberous, very long.

Stomach records: Ten species of birds, including ruffed grouse. Obscrvations: Pileated woodpecker; captive marsh rabbit, opossum.

Smilax walteri Pursh.

Range: $28,29,30$.

Site: Dry, well-drained, moist, sun, shade.

Fruit: Berry, available September-October, persistent all winter, especially southward.

An unarmed, or rarely somewhat prickly vine; flowers in June.

Stomach records: Two species of birds. Observations: Captive marsh rabbit.

Solanum dulcamara $\mathrm{L}$.

Bitter nightshade.

Range: 2, 6, 22, 23, 24, 25, 27, 28, 29, 30.

Site: Dry, well-drained, moist, sun, shade.

Fruit: Berry, available August-May.

A thicket-forming vine; flowers May-September; introduced from Eurasia and more or less naturalized in the regions indicated; often only herbaceous; rot a dermatitic poison; berries not poisonous when cooked; often considered a weed. Species of Solanum commonly harbor the potato and tomato mosaic as well as potato stalk borer, Colorado potato beetle, onion thrip, and green- 
house red spider mite. For this reason the species should be used with considerable caution.

Stomach records: Eight species of birds, including ruffed grouse, bobwhite, and ring-necked pheasant; composed 0.3 percent of total annual food, and 3.9 percent of fruit food of ring-necked pheasant in Michigan. Observations: Redeyed vireo; an important food of pheasants in southern Michigan; black duck, white-tailed deer, cottontail rabbit.

Sophora affinis Torr. and Gray.

Range: $10,16,20,25,29$.

Site: Dry, well-drained, moist, sun.

Fruit: Legume; available September-October, persistent through the winter.

A large shrub to small tree; flowers in June; occurs in limestone and other soils.

Sophora arizonica Wats.

Range: 10, 11 .

Site: Dry, well-drained, sun.

Fruit: Legume, arailable in May.

A large, handsome, shrub; flowers in March.

Sophora secundiflora (Cav.) DC.

Broussonetia secundifiora Orteg.

Frigolito.

Range: $11,16,17,20,30$.

Site: Dry, well-drained, moist, sun.

Fruit: Legume, available in September.

A large shrub, or rarely a small to large tree; evergreen; often occurs on limestone soil; seeds contain sophorin and are extremely poisonous; thicket forming; propagation is by seeds sown at once; growth of seedlings very slow. Poisonous to livestock as well as human beings.

Sophora tomentosa $\mathbf{L}$.

Range: $17,32$.

Site: Well-drained, sun.

Fruit: Legume.

A small to large, evergreen shrub; flowers the year round; commonly occurs in sandy soils.

Sorbus spp.

Mountain-ashes.

Propagation of all species is by seeds stratified 90 days at $32^{\circ}-41^{\circ} \mathrm{F}$. and sown in spring.

Stomach records (in addition to specific records): Nine species of birds, including ruffed, sooty, and sharp-tailed grouse. Observations (in addition to specific records) : Eleven species of birds, including ruffed grouse, ring-necked pheasant, sharp-tailed grouse; a favorite food of moose.

Sorbus americana Marsh.

American mountain-ash.

Pyrus americana (Marsh) DC., P. sambucifolia of auths., not Cham. and Schlecht.

Range : 23, 24, 26, 27.

Site: Dry, well-drained, moist, sun.

Fruit: Pome, available August-March.

A small to large tree; flowers May-June; fruit commonly bearing very few seeds; very susceptible to San José scale; 83,000-100,000 seeds per pound.

Var. decora (Schneid.) Sarg. (Pyrus sitchensis of Gray's Man., not Piper, S. decora Schneid.), occurs in regions 24 and 27.

Stomach records: Eight species of birds including ruffed grouse, ptarmigan, and sharp-tailed grouse; composed 17.9 percent of winter food of sharp-tailed grouse in Ontario and Quebec. Observations: Thirteen species of birds; preferred winter food of ruffed grouse in Wisconsin; blue grouse; fruits claimed preferred by birds to that of $\mathbf{S}$. aucuparia when the two species are available together; white-talled deer; of importance as browse for moose; much eaten by fisher; a staple food of marten.

Sorbus angustifolia, see Sorbus sitchensis.

Sorbus aucuparia $\mathbf{L}$.

Range : 21, 22, 27.

European mountain-ash.

Site: Dry, well-drained, moist, sun, shade.

Fruit: Pome, available August-September. 
A large shrub or more commonly a small tree; introduced from Europe and more or less naturalized in the regions indicated; commonly produces more viable seeds than $S$. americana; 104,700 seeds per pound.

Observations: Three species of birds, including sharp-tailed grouse; songbirds generally; claimed to be a second choice of birds where this and S. americana grow together.

Sorbus californica, see Sorbus sitchensis.

Sorbus decora, see Sorbus americana.

Sorbus dumosa, see Sorbus scopulina.

Sorbus occidentalis (Wats.) Greene.

S. pumila Raf., Pryus occidentalis Wats.,

Alpine mountain-ash.

Range: 4, 12.

Site: Well-drained, sun.

Fruit: Pome, available Angust-December.

A large shrub; flowers June-August.

Observations: Oregon jay; Clark's crow. Important locally as browse for livestock, although susceptibility to rust lessens the browse value.

Sorbus pumila, see Sorbus occidentalis.

Sorbus scopulina Greene.

Greene mountain-ash.

S. dumosa Greene.

Range: $4,9,10,12,13,14$.

Site: Well-drained, moist, sun, shade.

Fruit: Pome, available July-December.

A large shrub to small tree; flowers in June; commonly occurs in sandy or gravelly soil.

Stomach records: Dusky grouse. Where in association with highly palatable species is little cropped by livestock; elsewhere excellent browse for sheep.

Sorbus sitchensis Roem. (pl. 40, A).

Pacific mountain-ash.

S. angustifolia Rydb. (?), S. californica Greene, Pyrus sitchensis (Roem.) Piper.

Range: 4, 12.

Site: Dry, well-drained, moist.

Fruit: Pome, available August-November.

A large shrub to small tree; flowers in June; thicket forming; occurs in sandy loam and other soils.

Stomach records: Three species of birds, including Richardson's grouse. Fair browse for sheep, less so for cattle.

Sphaeralcea davidsonii, see Malvastrum davidsonii.

Sphaeralcea fasciculata, see Malvastrum fasciculatum.

Spiraea spp.

Spiraeas. soil.

Nearly all species are free from insects and diseases; most occur in neutral

Stomach records (in addition to specific records): Ruffed grouse, sharptailed grouse; mountain sheep. Observations (in addition to specific records): Pica, cottontail rabbit. Palatability of the western specles to livestock is low.

Spiraea albla Du Roi.

Range : 15 (Black Hills), 21, 22, 25, 26, 27, 28.

Meadow spiraea.

Site: Well-drained, moist, sun.

Fruit: Follicle.

A small shrub: flowers June-August.

A possible hybrid between this and $S$. tomentosa has been described as S. subcanescens Rydb. It occurs in region 28.

Spiraea arbuscula, see Spiraea densiflora.

Spiraea caespitosa Nutt.

Petrophytum caespitosum (Nutt.) Rydb., P. acuminatum Rydb.

Dwarf spiraea.

Range: $4,9,10,11,13,15$.

Site: Dry, sun.

Fruit: Follicle.

A small, mat-forming shrub; flowers in May; occurs on limestone and other soils; will grow over dry bare rocks. 
Spiraea californica, see Vauquelinia californica.

Spiraea corymbosa Raf.

Dwarf spiraea.

Range: 27, 28.

Site: Well-drained, sun.

Fruit: Follicle.

A small, sparsely-branched shrub; flowers May-June.

Spiraea densiflora Nutt.

S. arbuscula Greene, S. helleri Rydb., S. splendens Koch.

Range: 1, 4, 12, 13, 15 (Black Hills).

Site: Dry, well-drained, sun.

Fruit: Follicle.

A small shrub, flowers July-August; forms dense mats.

spiraea discolor, see Holodiscus discolor.

Spiraea douglasii Hook.

Range: $1,2,3,4$.

Douglas spiraea.

Site: Well-drained, moist, sun.

Fruit: Follicle, available September-October.

A small to large shrub; flowers July-August; thicket forming by means of suckers.

Spiraea dumosa, see Holodiscus dumosus.

Spiraea glutinosa, see Chamaebatiaria millefolium.

Spiraea helleri, see Spiraea densiflora.

Spiraea latifolia (Ait.) Borkh.

Meadowsweet.

Range: 26, 27.

Site: Well-drained, moist, sun.

Fruit: Follicle.

A large, thicket-forming shrub; flowers June-August.

Stomach records: Ruffed grouse. Observations: Ignored by deer in Massachusetts; casually browsed by northern white-tailed deer in northern Michigan.

Spiraea lucida Dougl.

Range: 2, 4, 6, 7, 12, 13, 15 (Black Hills).

Site: Well-drained, sun.

Fruit: Follicle.

A small, sparsely branched shrub; flowers May-July; possesses creeping rootstocks; erect branches often die back annually too near the base. A possible hybrid between this and $S$. menziesii has been described as $S$. pyramidata Greene. It occurs in regions 1, 2, 4, and 12 .

Spiraea menziesii Hook.

Range: 2, 4, 7, 8, 12.

Menzies spiraea.

Site: Moist, sun.

Fruit: Follicle.

A small shrub; flowers June-August. Fair to good forage in the fall for sheep and cattle.

Spiraea millefolium, see Chamaebatiaria millefolium.

Spiraea opulifolia, see Physocarpus opulifolius.

Spiraea pauctlora, see Physocarpus malvaceus.

Spiraea pyramidata, see Spiraea Lucida.

Spiraea salicifolia $\mathbf{L}$.

Range: 25, 27.

Site: Well-drained, moist, sun.

Fruit: Follicie.

A small to large shrub; introduced from Siberia and eastern $\cdot$ Russia and more or less escaped and naturalized in the regions indicated.

observations: Ring-necked pheasant; cottontail rabbit.

Spiraea splendens, see Spiraea densiflora.

Spiraea subcanescens, see Spiraea alba. 
Spiraea tomentosa $\mathbf{L}$.

Range: $21,22,23,24,25,26,27$.

Hardhack.

Site: Well-drained, moist, sun.

Fruit: Follicle, available August-December.

A small shrub; flowers July-September; possesses underground stems; long considered an aggressive weed in New England pastures.

observations: Ignored by white-tailed deer in Massachusetts.

Spiraea virginiana Britt.

Virginia spiraea.

Range: 27.

Site: Dry, sun.

Fruit: Follicle, available in September.

A small, straggling shrub; flowers in June.

Spirostachys occidentalis, see Allenrolfea occidentalis.

Staphylea bolanderi Gray.

Range: 4.

Site: Dry, well-drained, sun.

Frult: Capsule, available August-September.

A large shrub to large tree; flowers April-May.

\section{Staphylea trifolia L.}

Range: 22, 23, 24, 25, 26, 27, 28, 29.

American bladdernut.

Site: Moist, sun, shade.

Fruit: Capsule, available in September.

A large shrub to small tree; flowers in May.

Observations: Cottontail rabbit.

Stenolobium incisum, see Tecoma stans.

Stenoloblum stans, see Tecoma stans.

Stenotopsis interior, Aplopappus linearifolius.

Stenotopsis linearifolius, see Aplopappus linearifolius.

Stenotus linearifolius, see Aplopappus linearifolius.

Stewartia, see Stuartia.

Stillingia aquatica Chapm.

Range: 29,30 .

Corkwood.

Site: Moist, sun, shade.

Fruit: Capsule.

A small to large shrub; often grows in standing water.

Stomach records: Bobwhite.

Strobu's monticola, see Pinus monticola.

Strobus strobus, see Pinus strobus.

Strobus weymouthiana, see Pinus strobus.

Strombocarpa cinerascens, see Prosopis cinerascens.

Stuartia malachodendron L.

Silky-camellia.

Range: 28, 29, 30.

Site: Well-drained, sun.

Fruit: Woody capsule.

A large shrub; flowers June-August.

Stuartia pentagyna L'Her.

Malachodendron pentagynum (L'Her.) Small.

California bladdernut.

Range: 27, 28.

Site: Well-drained, moist, sun, shade.

Fruit: Woody capsule.

A large shrub; flowers July-August.

Styphonia integrifolia, see Rhus integrifolia.

Styrax americana $\mathbf{L}$.

Range: 25, 27, 28, 29, 30.

American snowbell.

Site: Moist, sun, shade.

Fruit: Drupe, available September-October.

Mountain-camellia. 
A large shrub; flowers March-April.

Stomach records: Maliard.

Styrax fulvescens, see Styrax officinalis.

Styrax grandifolia Ait.

Range: $29,30$.

Snowbell.

Site: Dry, well-drained, moist, sun, shade.

Fruit: Dry drupe, available in October.

A large shrub to small or large tree; flowers March-May; occurs in sandy and other soils.

Stomach records: Wood duck.

Styrax officinalis $\mathbf{L}$.

A Mediterranean species represented in California by var. californica Mumz and Johnst., a large shrub; in regions 4 and 10; flowering May-July. Var. fulvescens (Eastw.) Munz and Johnst. (Styrax fulvescens Eastw.) is a similar plant in regions 5 and 10.

The fruit of both is a capsule, and both occur in sunny sites which are dry or well-drained.

Styrax platanifolia Engelm.

Range: 20, 29.

Site: Moist, sun.

Fruit: Stony capsule.

A large, handsome shrub.

Styrax pulverulenta Michx.

Range: 27, 28, 29, 30.

Powdery storax.

Site: Moist, sun.

Fruit: Capsule.

A small to large shrub; flowers March-April. Very similar to S. americana. Stomach rccords: Mallard.

Svida alternifolia, see Cornus alternifolia.

Svida amomum, see Cornus amomum.

Svida asperifolia, see Cornus asperifolia.

Svida baileyi, see Cornus baileyi.

Svida californica, see Cornus californica.

svida catalinensis, see Cornus glabrata.

Svida foemina, see Cornus foemina.

Svida interior, see Cornus interior.

Svida microcarpa, see Cornus microcarpa.

Svida priceae, see Cornus priceae.

Svida pubescens, see Cornus occidentalis.

Svida rugosa, see Cornus circinata.

Svida stricta, see Cornus foemina.

Svida stolonifera, see Cornus stolonifera.

symphoricarpos spp.

All species may be propagated by soft or hardwood cuttings cut below the node and treated with potassium permanganate, or they may be propagated by seed. Many species contain small amounts of saponin, but such large quantities are necessary to cause acute poisoning that cases of livestock poisoning are rare.

Stomach records (in addition to specific records): Twenty-six species of birds, including ruffed grouse, dusky grouse, sharp-tailed grouse, ring-necked pheasant, and California quail; black-tailed deer, plains white-tailed deer. Observations (in addition to specific records): Six species of birds; much eaten by ringnecked pheasant; Hungarian partridge; pica, Columbiàn black-tailed deer. Extremely important browse for livestock in Utah, Nevada, and southern Idaho; cases of livestock sickness charged to this genus appear to be extremely rare.

Symphoricarpos acutus, see Symphoricarpos albus. 
Symphoricarpos albus (L.) Blake. (pl. 41, A).

Snowberry.

S. racemosus Michx., S. mollis Nutt., S. acutus (Gray) Howell, S. albus nollis (Nutt.) Keck.

Range: $1,2,3,4,5,6,7,8,9,10,11,13,14,15,18,21,22,23,24,25$, $26,27,28$.

Site: Dry, well-drained, moist, sun, shade.

Fruit: Berry, available year round.

A small, thicket-forming shrub; flowers June-September; occurs on limestone and other soils; declined branches root; killed by excessive grazing; 72,000 95,000 seeds per pound.

Var. laevigatus (Fern.) Blake, is taller, has larger leaves, larger clusters of fruit, and larger fruit than the species. It occurs within the range of the species. Var. pauciflorus Blake, (S. pauciflorus Britt.), is a dwarf occurring within the range of the species.

Stomach records: Nineteen species of birds, including ruffed grouse, California quail, ring-necked pheasant, Hungarian partridge, sharp-tailed grouse, and Richardson's grouse; plains white-tailed deer. Observations: Hungarian partridge, sharp-tailed grouse, prairie sharp-tailed grouse, ring-necked pheasant, bobwhite; of slight importance as browse for mule deer. A very important browse for livestock.

Symphoricarpos fragrans, see Symphoricarpos longiflorus.

Symphoricarpos glabratus, see Symphoricarpos oreophilus.

Symphoricarpos glau'cus, see Symphoricarpos rotundifolius.

Symphoricarpos longiflorus Gray.

S. fragrans Nels.

Range: 9, 10, 11, 13.

Site: Dry, sun.

Fruit: Berry.

A small shrub, with somewhat declining branches.

Symphoricarpos mollis, see Symphoricarpos albus.

Symphoricarpos occidentalis Hook.

Range: 15, 18, 21, 22, 23, 24.

Site: Dry, well-drained, sun.

Fruit: Berry, avallable September-January.

A small shrub; flowers June-July; commonly reproduces by rootstocks; very similar to $S$. albus, but generally stouter.

Stomach records: Five species of birds, including greater prairie chicken. Observations: Five species of birds; a fairly important food of ring-necked pheasant. An important and nonpoisonous browse for livestock. A good honey plant.

Symphoricarpos orbiculatus Moench.

S. vulgaris Michx., S. symphoricarpos (L.) MacM.

Coralberry.

Range: $18,20,21,22,23,24,25,27,28,29,30$.

Site: Dry, well-drained, moist, sun, shade.

Fruit: Berry, available September-June.

A small shrub, or very rarely, a large shrub; flowers in July; thicket forming by means of stolons which are freely produced; grows on coal-stripped land in Illinois; has demonstrated great adaptability to rigorous conditions and high value for erosion control of the most barren and sterile soils in the Piedmont; has been effectively used as living check dams and water spreaders; commonly bears fruit soon after planting; often weedy in pastures; 407,000 seeds per pound.

Stomach records: Nine specles of birds, including ruffed grouse, bobwhite, sharp-tailed grouse, ring-necked pheasant, greater prairie chicken, and wild turkey. Observations: Ring-necked pheasant, white-tailed deer.

Symphorlcarpos oreophilus Gray.

Mountain snowberry.

S. rotundifolius oreophilus Jones, S. glabratus Eastw., S. parishii Rydb.

Range: $4,9,10,11,12,13,14$.

Site: Dry, well-drained, moist, sun.

Fruit: Berry, a vailable August--September.

A small, stoloniferous shrub ; flowers June-July; root system fibrous, generalized; often trailing or with procumbent branches.

Stomach records: Black-tailed deer. Observations: Wasatch chipmunk, deer. A valuable forage for livestock. 
Symphoricarpos parishii, see Symphoricarpos oreophilus.

Symphoricarpos parvifolius, see Symphoricarpos rotundifolius.

Symphoricarpos pauciflorus, see Symphoricarpos albus.

Symphoricarpos racemosus, see Symphoricarpos albus.

Symphoricarpos rotundifolius, Gray.

Roundleaf snowberry.

S. glaucus Eastw., S. parvifolius Eastw., S. vaccinioides Rydb., S. tetonensis Nels.

Range: $4,9,10,11,12,13,14$.

Site: Dry, well-drained, sun.

Fruit: Berry, available July-September.

A small, straggling shrub; flowers May-June.

Stomach records: Varied thrush, California quail. Observations: Chipmunk, California mule deer. Fair to good sheep and goat browse.

Symphoricarpos symphoricarpos, see Symphoricarpos orbiculatus.

Symphoricarpos tetonensis, see Symphoricarpos rotundifolius.

Symphoricarpos utahensis Rydb.

Etah snowberry.

Range: $\mathbf{9}, 12,13$.

Site: Dry, well-drained, sun.

Fruit: Berry.

A small shrub.

Symphoricarpos vaccinioides, see Symphoricarpos rotundifolius.

Symphoricarpos vulgaris, see Symphoricarpos orbiculatus.

Symplocos tinctoria (L.) L'Her.

Hopea tinctoria $\mathrm{L}$.

Sweetleaf.

Range: $27,28,29,30$.

Site: Dry, well-drained, moist, sun, shade.

Fruit: Drupe, available August-September.

A large shrub to small or large tree; semievergreen; fowers March-May, the two forms occurring along the coast and in the mountains respectively are by some considered specifically distinct.

Stomach records: Phoebe. Relished by cattle.

Tallnopsis frutescens Gray.

Range: 11.

Site: Dry, sun.

Fruit: Capsule.

A small shrub.

Tamala borbonia, see Persea borbonia.

Tamala humilis, see Persea humilis.

Tamala pubescens, see Persea pubescens.

Tamarix gallica $\boldsymbol{L}$.

Range: $3,4,9,10,11,13,16,19,22,25,29,30$.

Tamarisk.

Site: Dry, well-drained, moist, sun.

Fruit: Capsule.

A large shrub to small tree; follage comparatively sparse; introduced from Europe but more or less naturalized in the regions indicated; withstands continued drought well; not easily hurt by alkall in the soil; generally free from insects and disease; thicket forming; grows rapidly from cuttings.

Taxodium spp.

Baldcypress.

Stomach records (in addition to specific records): Eleven species of birds, including wild turkey. Observations (in addition to specific records): Texas fox squirrel.

Taxodium ascendens Brongn.

T. imbricarium (Nutt.) Harp.

Pondcypress.

Range: 29, 30.

Site: Well-drained, moist, sun.

A large tree.

Fruit: Cone.

Stomach records: Little brown crane. 
Taxodium distichum (L.) Rich.

Range: $17,20,25,28,29,30,31,32$.

Southern cypress.

Site: Dry, well-dralned, moist, sun.

Fruit: Cone.

A large tree; root system shallow, with "knees" in wet situations; at first rapld growing, later slower; somewhat attacked by fungi; wood of great importance commercially, especially durable; heavy seed years frequent; 3,000 seeds per pound 15-25 percent viable, vitality transient (1 year or less).

Stomach records: Six species of birds.

Taxodium imbricarium, see Taxodium ascendens.

Taxus brevifolla Nutt.

Range: 1, 2, 4, 12.

Site: Well-drained, moist, sun, shade.

Fruit: Drupelike, available in September, falling in October.

A small to large, evergreen tree with very dense follage; extremely slow growing, very long-lived; attacked at maturity by heart rot; wood rery durable, little used commercially; germination of seeds $50-60$ percent, vitality persistent.

observations: Much eaten by birds; ring-tailed cat. Poisonous to cattle.

Taxus oanadensis Marsh.

Range: $21,22,23,24,26,27$.

Site: Well-drained, moist, sun (rare), shade.

Fruit: Drupellke, avallable August-September of the second season.

A small evergreen shrub with dense foliage; commonly forms a continuous ground cover; prostrate branches root where covered by detritus ; fruit produced sporadically.

Stomach records: 'Three species of birds, including ruffed grouse. Observations: Third most important preferred winter food of white-tailed deer in Massachusetts; highly palatable winter and summer food for moose on Isle Royale; favorite food of northern white-tailed deer in Michlgan. Polsonous to livestock, although the pulp of the fruit is harmless.

Taxus floridana Nutt.

Range : 29,30 .

Site: Dry; well-drained, sun, shade.

Fruit: Drupelike, avallable in fall.

A small evergreen tree; very local in distribution; wood not used commercially because scarce.

Tecoma radicans, see Campsis radicans.

Tecoma stans (L.) H. B. K.

Trumpetflower.

Bignonia stans L., Stenolobium stans v. Seem., S. incisum Rose and Standl.

Range: $10,11,17,20,29,30$.

Site: Dry, sun.

Fruit: Capsule.

A small shrub to small tree; much cultivated.

Stomach records: Mountain sheep. Without browse value for livestock.

Tessaria borealis, see Pluchea sericea.

Tetracoccus dioicus Parry.

Range: 5.

Site: Dry, sun.

Fruit: Capsule, available July-November.

A small much-branched dioecious shrub.

Tetracocous hallii, see Halliophytum hallii.

Tetracoccus ilicifolius Cov. and Gilm.

Range: 10.

Site: Dry, well-drained, sun.

Fruit: Capsule, available August-September.

A small evergreen shrub; growth open and spreading; very rare.

Tetradymia spp.

Observations (in addition to specific records): Pigmy rabbit; Oregon jack rabbit in dry seasons.

Tetradymia axillaris, see Tetradymia spinosa. 
Tetradymia canescens DC.

T. linearis Rydb.

Gray horsebrush.

Range: $4,6,7,8,9,10,13,14$.

Site : Dry, sun.

Fruit: Achene.

A small, freely-branched shrub; flowers July-August; occurs in sandy and rocky soils.

Var. inermis (Nutt.) Gray, ( $T$. inermis Nutt.) the spineless horsebrush, occurs with the species, often on alkaline soil. Considered worthless or poor winter feed for stock; possibly poisonous to sheep.

Tetradymia comosa Gray.

Range: 10.

Hairy horsebrush.

Site: Dry, sun.

Fruit: Achene.

A small, many-stemmed shrub.

Tetradymia glabrata Gray.

Range: 8, 9, 10.

Site: Dry, sun.

Fruit: Achene.

A small shrub; flowers June-August; commonly without leaves from about June 15. Generally not palatable to livestock; sheep poisoned by it, especially when taken in large quantitles in the spring; poisonous effect cumulative; apparently not poisonous to cattle.

Tetradymia inermis, see Tetradymia canescens.

Tetradymia linearis, see Tetradymia canescens.

Tetradymia longispina, see Tetradymia spinosa.

Tetradymia nuttallii Torr. and Gray.

Nuttall horsebrush.

Range: 9, 13.

Site: Dry, sun.

Fruit: Achene.

A small prickly shrub; flowers May-August; of local browse value for sheep. Tetradymia spinosa Hook. and Arn.

Range: $8,9,10$.

Site: Dry, sun.

Fruit: Achene.

A small, rigid, divaricately-branched shrub; flowers May-August; somewhat spiny. Var. longispina Jones, ( $T$. longispina (Jones) Rydb., T. axillaris Nels.) occurs in the southern part of the range.

Observations: A valuable forage for antelope. Locally valuable as a forage for sheep.

Tetradymia squamata, see Lepidospartum squamatum.

Tetradymia stenolepis Greene.

Range: 4, 10.

Site: Dry, sun.

Fruit: Achene.

A small, much-branched shrub.

Thamnosma montana Torr. and Frem.

Range : 9, 10, 11.

Shortspine horsebrush.

Site: Dry, sun.

Fruit: Capsule.

A small shrub; flowers April-May; branches broomlike; leaves early deciduous. Not palatable to livestock.

Thuja spp.

Stomach records (in addition to specific including ruffed grouse.

Thuja occidentalis L.

Range: 22, 23, 24, 26, 27.

Mohave horsebrush.

Site: Dry, well-drained, sun, shade.

Fruit: Cone; mature in early autumn, persistent through the winter.

A small to large, evergreen tree; root system usually shallow, or deeper on dry sites; slow growing, long-lived; very easily damaged by fire and wind; mature trees often decay at the base; wood durable, important commercially; 
some 50 varieties are known in cultivation; $184,000-412,000$ seedr per pound, germination 44 percent.

Stomach records: Armadillo. Observations: Redpoll, pine siskin; staple food of white-tailed deer; eaten extensively by red squirrel; winter food of moose, but not relished, on Isle Royale; snowshoe hare; cottontail rabbit.

Thuja plicata Don.

Range: 1, 2, 4, 6, 7, 12 .

Western red cedar.

Site: Well-drained, moist, sun, shade.

Fruit: Cone; mature in August, opening in September, persistent until the following summer.

A large evergreen tree; root system shallow; wind-firm, except on wet solls; develops best in a humid climate; slow growing, long-lived; easily fire-damaged ; without notable insect enemies, or fungi, until mature; heavy seed crop produced every 2 or 3 years; wood durable, of great importance commercially; 203,000-504,000 seeds per pound, germination 52-73 percent, vitality transient, some 13 varieties distinguished in cultivation.

Stomach records: Plains white-tailed deer. Observations: Bark commonly used by Richardson's pine squirrel for nest material; an important browse for deer in the northern Rockv Mountains.

Thurberia thespesioides, see Thurberia triloba.

Thurberia triloba (DC.) Tidest.

T. thespesioides of auths, not Gray, Ingenhouzia triloba DC.

Arizona wild ootton.

Range: 10, 11, 14 .

Site: Dry, well-drained, sun.

Fruit: Capsule, available August-September.

A large, sparsely-branched shrub; flowers May-July; growth more vigorous on moist areas protected from wind; distribution extremely local; will not grow where soil is too dry; a native host plant of the wild cotton boll weevil, which also feeds on cultivated cotton, and for this reason restricted by plant quarantine.

Scarcely palatable to cattle but somewhat nibbled by sheep and goats.

Tilia spp.

Basswoods.

The taxonomy of this group is much confused, owing in great part to the fact that the species vary considerably and that hybrids are apparently easily formed. Propagation of all species is by seed stratified as soon as ripe and planted in spring; dried seed may require 2 years for germination. Many species attacked by Texas root rot disease caused by Phymatotrichum omnivorum.

Stomach records (in addition to specific records): English sparrow, bobwhite; Franklin ground squirrel, white-tailed deer. Observations (in addition to specific records) : Redpoll; porcupine, fox squirrel, white-tailed deer; staple food of cottontail rabbit; eastern chipmunk.

Tilia alabamensis, see Tilia floridana.

Tilia americana, see Tilia, glabra.

Tilia apposita, see Tilia caroliniana.

Tilia australis Small.

Range : 27.

Site: Well-drained, sun.

Fruit: Nutlike.

A large tree.

Tilia caroliniana Mill.

T. apposita Ashe, T. lata Ashe, T. pubescens Ait.

Range: $20,29,30$.

Site: Well-drained, sun.

Fruit: Nutlike, available in July.

A large tree; flowers in May.

Var. rhoophila Sarg. occurs in regions 17, 20, 29, and 30.

Tilia cinerea, see Tilia truncata.

Tilia cocksii Sarg.

Range: 29.

Basswood.

Site: Well-drained, moist, sun.

Fruit: Nutlike, available in July.

A small tree; flowers in May. 
Tilia crenoserrata, see Tilia fioridana.

Tilia eburnea, see Tilia lasioclada.

Tilia floridana Small.

T. alabamensis Ashe, T. crenoserrata Sarg.

Range: 17, 20, 25, 27, 29, 30.

Site: Well-drained, sun.

Fruit: Nutlike, available August-September.

A large tree; flowers in May.

Var. alabamcnsis Ashe, (T. alabamensis Ashe, var. oblongifolia Sarg., $T$. oblongifolia Sarg.) occurs in region 29. Var. hypoleuca Sarg. (T. hypoleuca Ashe) occurs in region 25 and has been also considered a variety of T. glabra. Tilia fulva, see Tilia glabra.

Tilia georgiana Sarg.

Basswood.

T. pubescens Vent., not Ait.

Range: 29,30 .

Site: Well-drained, sun.

Fruit: Nutlike, available in September.

A small to large tree.

Tilia glabra Vent.

T. americana L., in part, T. fulva Raf., T. venulosa Sarg.

Basswood.

Range: 20, 21, 22, 23, 24, 25, 26, 27.

Site: Dry, well-drained, moist, sun.

Fruit: Nutlike, available August-October, sometimes persistent.

A large tree; flowers May-July; root system deep, wide spreading; rapid growing, rather short-lived; attacked by rots and insects; resistant to fire when older; coppices freely; wood not durable, of importance commercially; $3,500-6,500$ seeds per pound, germination 10-15 percent.

Stomach records: Four species of birds, including ruffed grouse and bobwhite; gray eastern chipmunk. Observations: Pinnated grouse; cottontail rabbit, white-tailed deer. A valuable honey plant.

Tilia heterophylla Vent.

$T$. tenera Ashe.

Range: 20, 25, 27, 28, 29, 30.

Site: Dry, well-drained, sun.

Fruit: Nutlike, arailable August-September.

A large tree; flowers May-July; root system deep; wide spreading; rapid growing, short-lived; coppices freely; wood used commercially.

Var. michauxii (Nutt.) Sarg., (T. michauxii Nutt.), occurs in regions 22, 25, 27,28 , and 29 .

Tilia hypoleuca, see Tilia foridana.

Tilia lasioclada Sarg.

Basswood.

T. eburnea Ashe.

Range: 27, 28, 29, 30 .

Site: Well-drained, sun.

Fruit: Nutlike, available in September. .

A large tree; flowers in May; commonly occurs on rich soils.

Tilla lata, see Tilia caroliniana.

Tilia leucocarpa Ashe.

T. nuda Sarg.

Basswood.

Range: 20, 29.

Site: Well-drained, moist, sun.

Fruit: Nutlike, avatlable July-September.

A small or large tree.

Tilia littoralis Sarg.

Range: 29,30 .

Site: Well-drained, sun.

Fruit: Nutlike.

A large tree; flowers in June; very locally distributed.

Tilia michauxil, see Tilia heterophylla and $T$. neglecta.

Tilia monticola, see Tilia truncata. 
Tilla neglecta Spach.

T. michauxii Sarg., not Nutt., T. pubescens Sarg., not Ait.

Range: 22, 23, 24, 26, 27.

Site: Well-drained, sun.

Fruit: Nutlike, available in September.

A large tree; flowers June-July.

Tilia nuda, see Tilia leucocarpa.

Tilia oblongifolia, see Tilia floridana.

Tilia phanera Sarg.

Range: 17, 20.

Site: Well-drained, sun.

Fruit: Nutlike, available in September.

A small to large tree; flowers in June; rare and local. Var. scabrida Sarg., occurs in regions 11,20 , and 30.

Tilia pubescens, see Tilia caroliniana, $T$. georgiana, and $T$. neglecta.

Tilia tenera, see Tilia heterophylla.

Tilia texana Sarg.

Basswood.

Range: 17, 20, 29, 30 .

Site: Well-drained, sun.

Fruit: Nutlike.

A small tree; flowers in June.

Tilia truncata Spach.

T. cinerea Raf., T. monticola Sarg.

Range: 27.

Site: Well-drained, sun.

Fruit: Nutlike, available in September.

A large tree; flowers in July.

Tilia venulosa, see Tilia glabra.

Torreya californica, see Tumion californicum.

Torreya taxifolia, see T'umion taxifolium.

Toxicodendron biternatum, see Rhus toxicodendron.

Toxicodendron comarophyllum, see Rhus diversiloba.

Toxicodendron diversilobum, see Rhus diversiloba.

Toxicodendron eximium, see Rhus toxicodendron.

Toxicodendron fothergilloides, see Rhus toxicodendron.

Toxicodendron hesperinum, see Rinus toxicodendron.

Toxicodendron isophyllum, see Rhus diversiloba.

Toxicodendron macrocarpum, see Rhus toxicodendron.

Toxicodendron negundo, see Rhus toxicodendron.

Toxicodendron pinnatum, see Rhus vernix.

Toxicodendron punctatum, see Rhus toxicodendron.

Toxicodendron quercifolium, see Rhus quercifolia.

Toxicodendron radicans, see Rhus toxicodendron.

Toxicodendron rufescens, see Rhus toxicodendron.

Toxicodendron rydbergii, see Rhus toxicodendron.

Toxicodendron vernix, see Rhus vernix.

Toxylon pomiferum, see Maclura pomifera.

Trichostema arizonicum Gray.

Range: 11.

Site: Dry, sun.

A small shrub. 
Trichostema lanatum Benth.

T. parishii Vasey.

Range: 5.

Site: Dry, sun.

Fruit: Nutlike.

A small to large, leafy shrub; flowers May-June.

Trichostema parishii, see Trichostema lanatum.

Trixis californica Kellogg.

American trixis.

Range: 10, 11.

Site: Dry, sun.

Fruit: Achene.

A small, bushy shrub. Lightly browsed by cattle in winter and early spring.

Tsuga spp.

Hemlocks.

Stomach records (in addition to specific records) : Nine species of birds, including ruffed grouse. Observations (in addition to specific records) : Pine siskin; porcupine; Douglas' squirrel, Cascade squirrel, Sierra chickaree, Richardson's squirrel, Townsend's chipmunk, Cooper's chipmunk, Allen's chipmunk, Pacific mountain beaver, Olympic black bear ; rarely cut for building material, not food, by beaver.

Tsuga canadensis (L.) Carr.

Range: 22, 23, 24, 25, 27, 28.

Eastern hemlock.

Site: Well-drained, sun, shade.

Fruit: Cone, mature in October, seeds shed during winter, cones falling

in the spring of the second year.

A large, evergreen tree; root system very shallow except in deep soils; generally free from fungi; easily killed by humus fires; attacked by eastern hemlock borer; easily wind damaged; wood of importance commercially; bark a valuable source of tannin; seed produced abundantly at intervals of 2 or 3 years; $144,000-279,000$ seeds per pound, germination 30-60 percent; some 16 varieties in cultivation.

Stomach records: Eight species of birds, including ruffed grouse and sharptailed grouse; white-tailed deer. Observations: Nine species of birds; seventh most important preferred winter food of white-tailed deer in Massachusetts; browsed to some extent by northern white-tailed deer in Michigan; red squirrel, snowshoe hare, cottontail rabbit.

Tsuga caroliniana Engelm.

Carolina hemlock.

Range: 27.

Site: Well-drained, sun, shade.

Fruit: Cone, mature September-October.

A large evergreen tree; root system shallow and spreading; wood of some importance commercially.

Tsuiga heterophylla (Raf.) Sarg.

Range: $1,2,4,6,12$.

Site: Well-drained, sun, shade.

Fruit: Cone; mature in August, seeds shed September-October, cones falling by spring.

A large evergreen tree; root system shallow and spreading except on deep soils; slow growing, long-lived; easily injured by fire; susceptible to insect damage; wood of considerable importance commercially; 274,000-324,000 seeds per pound, produced abundantly at intervals of 2 or 3 years.

Stomach records: Two species of birds; plains white-tailed deer, blacktailed deer. Observations: Browsed as a last resort by Olympic wapiti.

Tsuga mertensiana (Bong.) Sarg.

Mountain hemlock.

Hesperopeuce mertensiana (Bong.) Rydb.

Range: 4, 12.

Site: Well-drained, sun.

Fruit: Cone; seeds shed September-October, cones falling by spring.

A large evergreen tree; slow growing, probably long-lived; wood not used commercially; seed produced abundantly every several years; 102,000-207,000 seeds per pound, vitality transient.

Stomach records: Crow, sooty grouse.

Tulipastrum acuminatum, see Magnolia acuminata.

Tulipastrum cordatum, see Magnolia cordata. 
Tumion californicum (Torr.) Greene.

Torreya californica Torr.

California-nutmeg.

Range: $1,4$.

Site: Well-drained, moist, sun, shade.

Fruit: Drupelike, available September-October.

A large, dioecious, evergreen tree; wood durable, locally used for fence posts. Tumion taxifolium (Arn.) Greene.

Torreya taxifolia Arn.

Range: 30 .

Site: Dry, well-drained, sun.

Fruit: Drupelike.

A large evergreen tree; commonly occurs on limestone soils; wood used locally for fence posts.

Tumionella monactis, see Aplopappus cooperi.

Tyria myricaefolia, see Bernardia myricaefolia.

Ulex europaeus L.

Range : 1, 2, 27.

Site: Dry, well-drained, sun.

Fruit: Legume, available August-October.

A small to large, very spiny evergreen shrub; flowers May-July; foliage extremely dense; occurs on sand, loam, clay, and other soils; forms impenetrable thickets; introduced from Europe and locally established in the regions indicated; able to survive burial in sand; almost explosively inflammable; tolerant of saline conditions; aggressively spreading in regions 1 and 2.

Not grazed by livestock. Of some value as a honey plant.

Ulmus spp.

Elms.

Stomach records (in addition to specific records): Seven species of birds, including ruffed grouse; white-tailed deer. Observations (in addition to specific records) : Nine specles of birds; an emergency food of pinnated grouse in Wisconsin and Iowa; greater prairie chicken; fox squirrel, red squirrel; a favorite food of muskrat.

All native species of elm are susceptible to the Dutch elm disease, caused by the fungus Ceratostomella $u$ lmi. The virulence of the disease is very great and every effort should be made to prevent its further spread. Interstate movement of some species from certain States is prohibited because of the disease. The principal resistant species is the Asiatic U. pumila. Members of this genus are also seriously subject to the attacks of the Texas root rot caused by Phymatotrichum omnivorum.

Ulmus alata Michx.

Range: 17, 20, 25, 28, 29, 30 .

Site: Dry, well-drained, sun.

Fruit: Samara, available in March.

A large tree; occurs in gravel, loam, and other soils; wood used commercially ; easily transplanted; much cultivated.

Observations: White-tailed deer.

Ulmus americana $\mathbf{L}$.

Range: $15,16,18,19,20,21,22,23,25,26,27,28,29,30$.

Site: Dry, well-drained, sun.

Fruit: Samara, available March-May.

A large tree; root system very shallow; rapid growing, long-lired; much subject to defoliating insects and borers; not wind-firm; comparatively fire resistant; wood of this species is the most important commercially of the elms; 53,000-100,000 seeds per pound, germination as much as 95 percent; much cultivated; resistant to drought; grows on coal-stripped lands in Illinois.

Stomach records: Ruffed grouse, bobwhite, Hungarian partridge; opossum. Observations: Five species of birds including Hungarian partridge, pinnated grouse; cottontail rabbit, snowshoe hare; heavily browsed by white-tailed deer.

Ulmus crassifolia Nutt.

Cedar elm.

Range: 17, 20, 29, 30.

Site: Dry, well-drained, sun.

Fruit: Samara, available September-November.

A large shrub or more commonly a large tree; may occur on alluvial soil or dry limestone; a shrub in dry situations; wood used commercially to a limited extent; somewhat cultivated. 
Ulmus fulva Michx.

Range: $15,16,18,19,20,21,22,23,24,25,26,29,30$.

Slippery elm.

Site: Dry, well-drained, sun.

Fruit: Samara, available May-June.

A large tree; root system deep and spreading; rapid growing, short-lived; severely injured by defoliating insects; wood durable, used commercially to some extent; $35,000-75,000$ seeds per pound.

Observations: Purple finch; porcupine, cottontail rabbit, white-talled deer.

Ulmus racemosa Thomas.

Rock elm.

U. thomasii Sarg.

Range : 18, 19, 21, 22, 23, 24, 25, 26, 27.

Site: Dry, well-drained, sun.

Fruit: Samara, available in May.

A large tree; root system deep when mature; slow growing, rather longlived; severely injured by defoliating insects; wind-firm; fairly free from fungi; easy to transplant; wood used commercially, the most durable of any of the elms.

observations: Cottontail rabbit.

Ulmus serotina Sarg.

Range: 25, 27, 29.

Red elm.

Site: Dry, well-drained, sun.

Fruit: Samara, available in November.

A large tree; wood hard, tough; somewhat cultivated; occurs on limestone and other soils; 149,000 seeds per pound.

Ulmus thomasil, see Ulmus racemosa.

Umbellularia californica (Hook. and Arn.) Nutt. (pl. 41, B).

Oregon myrtle.

Range: $1,4,5,10$.

Site: Well-drained, moist, sun, shade.

Fruit: Drupe, avallable in October, somewhat persistent.

A small to large shrub or small to large tree; the typical form is a large tree occurring along streams and valley floors; may be gregarious on north slopes of canyons, forming a very solid cover; dwarf forms, which fruit heavily and form very dense cover, are known to occur in dry chaparral ; prostrate forms, occurring on ocean bluffs and hillsides, form low, thick, compact, dense mats; sprouts freely after injury ; fruits abundantly produced; wood very valuable commercially.

Stomach records: Steller jay. Observations: Much eaten by Columbian gray squirrels. Of slight importance as browse for mule deer. Roots eaten by hogs.

Ungnadia speciosa Endl.

Range: 11, 16, 17, 20, 29, 30.

Spanish buckeye.

Site: Dry, well-drained, moist, sun.

Fruit: Capsule; available August-October, persistent unopened for a considerable period.

A large shrub or rarely a small to large tree; occurs on limestone and other solls; not resistant to extremely hot weather; occasionally cultivated. Probably has caused some livestock poisoning, but not commonly taken by livestock except in time of food scarcity. Seeds poisonous to human belngs. A source of early honey.

Urvillea mexicana, see Urvillea ulmacea.

Urvillea ulmacea H. B. K.

U. mexicana Gray.

Range: 17.

Site: Well-drained, sun.

Fruit: Samara.

A large vine

Uva-ursi, see Arctostaphylos.

Vaccinium spp.

Blueberries, huckleberries.

With one exception, none of these specles can be grown on soil containing calclum even in small quantities; all occur naturally on acid soils.

Stomach records (in addition to specific records): Eighty-seven species of birds, including ruffed grouse, sharp-tailed grouse, dusky grouse, southern 
white-tailed ptarmigan, Richardson's grouse; composed 2.4 percent of fall food of prairfe chicken in Wisconsin; composed $\mathbf{7 . 6}$ percent of winter food of northern sharp-tailed grouse in Ontario and Quebec; Coeur d'Alene chipmunls, red fox, plains white-tailed deer, opossum, white-tailed deer; composed 0.56 percent of fruit food of eastern skunk in Michigan. Observations (in addition to specific records): Thirty-five species of birds including ruffed, and spruce grouse, ptarmigan, an important food of ring-necked plieasant; ranked with Gaylussacia as twenty-ninth on the list of quail food plants of the Southeast; emergency food of prairie sharp-tailed grouse, Hungarian partridge; southern white-tailed deer, ptarmigan; skunk; much browsed by moose; much eaten by red fox; rarely eaten by coyote; relished by Olympic wapiti, Columbian black-tailed deer, Douglas squirrel, Allen's chipmunk, Pacific mountain beaver, Oregon gray fox, California skunk, Olympic black bear, Virginia opossum; heavily browsed by Rocky Mountain snowshoe rabbit; lesser Colorado chipmunk, Virginia opossum; heavily browsed by white-tailed deer, cottontail rabbit; much eaten by raccoon; alpine chipmunk, ring-tailed cat.

Vaccinium amoenum, see Vaccinium corymbosum.

Vaccinium angustifolium Ait.

Lowbush blueberry.

$V$. dobbinii Burn., V. nigrum Britt., V. pennsylvanicum Lam., not Miller, Cyanococcus pennsylvanicus (Lam.) Rydb., O. angustifolius (Alt.) Rydb. Range: 22, 23, 24, 26, 27.

Site: Dry, well-drained, sun, shade.

Fruit: Berry, available July-September.

A small shrub, flowers April-June; occurs in sandy and other soils; spreads by underground stems; commonly the earliest ripening blueberry.

Stomach records: Six species of birds, including ruffed grouse, bobwhite, and greater prairie chicken. Observations: Ruffed grouse, bobwhite. Without forage significance for livestock.

Vaccinium arboreum Marsh.

Batodendron arboreum (Marsh.) Nutt.

Tree huckleberry.

Range: $17,20,25,27,28,29,30$.

Site: Dry, well-drained, sun, shade.

Fruit: Berry, available, September-November.

A large shrub to small or large tree; evergreen southward; flowers MayAugust; occurs in sandy and other soils; the only species of the genus and one of the two in the heath family supposedly capable of growing in neutral or slightly alkaline soil.

Stomach records: Bobwhite. Observations: Mockingbird.

Vaccinium atrococcum (Gray) Heller.

Black blueberry.

V. corymbosum atrococcum Gray, Oyanococcus atrococcus (Gray) Small.

Range: 24, 26, 27, 29.

Site: Dry, well-drained, moist, sun, shade.

Fruit: Berry, available July-August.

A small to large, spreading shrub; flowers May-June.

Vaccinium brachycerum, see Gaylussacia brachycera.

Vaccinium, caesarlense Mack.

Range: 28.

Site: Well-drained, moist, sun.

Fruit: Berry.

A small to large shrub; flowers in May.

Vaccininm caesium Greene.

Polycodium caesium Greene, $\boldsymbol{P}$. floridanum (Nutt.) Greene.

Range : 29, 30 .

Site: Well-dralned, sun.

Fruit: Berry.

A small, irregularly branched shrub.

Vaccinium caespitosnm Michx.

Range: 4, 7, 12, 13, 23, 24, 26, 27.

New Jersey blueberry.

Site: Dry, well-drained, sun.

Fruit: Berry, avallable June-September.

A small shrub: flowers June-July. Without value as forage for livestock. 
Vaccinium canadense Kalm.

Range: 22, 23, 24, 26, 27.

Canada blueberry.

Site: Dry, well-drained, moist, sun, shade.

Fruit: Berry, available July-September.

A small, much-branched shrub; flowers May-June.

stomach records: Ruffed grouse, sharp-tailed grouse. Of mediocre forage value for livestock.

Vaccinium corýmbosum L.

Highbush blueberry.

V. amoenum Ait., Cyanococcus amoenus (Ait.) Small, C. corymbosus (L.) Rydb.

Range: 22, 23, 24, 26, 27, 28, 29.

Site: Dry (rare), well-drained (rare), moist, sun, shade.

Fruit: Berry, available June-August.

A small to large shrub; flowers May-June; suckers freely and transplants well; fruit of value commercially.

Var. pallidum (Ait.) Gray, (V. pallidum Ait., Cyanococcus pallidus (Ait.) Small), has superior fruit.

Observations: Mourning dove, ruffed grouse, ring-necked pheasant ; cottontail rabbit.

Vaccinium crassifolium Andr.

Herpothamnus crassifolius (Andr.) Small.

Creeping blneberry.

Range: 29, 30.

Site: Well-drained, sun.

Fruit: Berry.

A small evergreen shrub; possibly maintains itself mainly by vegetative reproduction.

Vaccinium deliciosum Piper.

Range: 1, 4 .

Site: Well-drained, sun.

Fruit: Berry.

A small shrub.

Vaccinium dobbinii, see Vaccinium angustifolium.

Vaccinium dumosum, see Gaylussacia dumosa.

Vaccinium elliotti Chapm.

Cyanococcus elliottii (Chapm.) Small.

Range: 28, 29, 30.

Site: Well-drained, moist, sun.

Fruit: Berry, available May-June.

A small to large shrub; flowers March-May.

Vaccinium erythrocarpum, see Hugeria erythrocarpa.

Vaccinium erythrococcum, see Vaccinium scoparium.

Vaccinium frondosum, see Gaylussacia frondosa.

Vaccinium globulare, see Vaccinium membranaceum.

Vaccinium hirsutum Buckl.

Cyanococcus hirsutus (Buckl.) Small.

Range: 27.

Site: Well-drained, sun.

Fruit: Berry, available in August.

A small shrub; flowers May-June; fruit hairy.

Vaccinium hispidulum, see Chiogenes hispidula.

Vaccinium humifusum, see Gaultheria humifusa.

Vaccinyum macrocarpon Ait.

Oxycoccus macrocarpus (Ait.) Pursh.

Elliott blueberry

Range: 22, 23, 24, 25, 26, 27.

Site: Well-drained, moist, sun.

Fruit: Berry, available August-March.

A creeping, evergreen, mat-forming vine; flowers June-August; this species includes varieties furnishing the commercial cranberry; 500 berries per pound, about 25 seeds per berry.

Stomach records: Six species of birds, including ruffed grouse.

observations: Crow, mourning dove, bobwhite, prairie sharp-tailed grouse. 
Vaccinium macrophyllum, see Vaccinium membranaceum.

Vaccinium melanocarpum Mohr.

Polycodium melanocarpum (Mohr) Small.

Southern gooseberry.

Range: 25, 27, 28, 29, 30.

Site: Dry, well-drained, sun, shade.

Fruit: Berry, available in July.

A small shrub; occurs in sandy and other soils; fruit commonly produced in great quantities.

Vaccinium membranaceum Dougl.

$V$. globulare Rydb., V. macrophyllum Piper, V. myrtilloides Hook.

Thinleaf huckleberry.

Range : 1, 4, 12, 13, 15 (Black Hills), 23, 24.

Site: Dry, well-drained, moist, sun, shade.

Fruit: Berry, avallable July-September.

A small shrub; flowers June-July. Poor to worthless to fairly good or gooi browse for sheep; poor to worthless forage for cattle and horses.

Vaccintum microphyllum, see Vaccinium scoparium.

Vaccinium myrsinites Lam.

Cyanococcus myrsinites (Lam.) Small.

Evergreen blueberry.

Range: 28, 29, 30.

Site: Dry, well-drained, sun.

Fruit: Berry, available in May.

A small evergreen shrub; flowers April-May decumbent or upright; occurs in sandy and other soils. Var. glaucum Gray, in the southern part of the range, is taller than the species.

Vaccinium myrtilloides, see Vaccinium membranaceum.

Vaccinium neglectum (Small) Fern.

Polycodium neglectum Small.

Range: $22,25,28,29,30$.

Site: Dry, sun.

Fruit : Berry.

A small shrub with inedible fruit.

Vaccinium nigrum, see Vaocinium angustifolium.

Vaccinium occidentale Gray.

Range: 4, 12, 13.

Site: Well-drained, moist, sun.

Fruit: Berry, available July-August.

A small shrub.

Stomach records: Sooty grouse. Observations: Blue grouse. Fair to falrly good sheep and goat feed; cropped locally by cattle.

Vaccinium oreophilum Rydb.

Rocky Mountain whortleberry.

Range: 12, 13, 14.

Site: Well-drained, sun.

Fruit: Berry, available July-October.

A small shrub; flowers in June.

Stomach records: Richardson's grouse. Worthless as forage for cattle; sometimes falr sheep feed.

Vaccinium ovallfolium Smith.

Range: 2, 4, 12, 23, 24.

Site: Dry, well-drained, sun, shade.

Fruit: Berry, available July-August.

A large, straggling shrub; flowers June-July. Locally useful as browse for sheep and goats.

Observations: Spruce grouse.

Vaccinium ovatum Pursh.

Range: 1, 2, 5 .

Evergreen huckleberry.

Site: Well-drained, moist, sun, shade.

Fruit: Berry, available July-September, or rarely longer.

A small to large evergreen shrub; most commonly occurs in sandy soil ; forms a dense cover when growing close together.

Var. saporosum Jeps., in region 1, has fruit which rlpens earlier with a better flavor. 
Stomach records: Ruffed grouse (?). Observations: Listed with V. parvifolium as second in importance as browse for Olympic wapiti in Washington; California mule deer; an important food of Roosevelt elk.

Vaccinium oxycoccus $\mathrm{L}$.

Oxycoccus palustris Pers., O. oxycoccus (L.) MacBr.

Small cranberry.

Range: 23, 24, 26, 27.

Site: Moist, sun.

Fruit: Berry, available August-September, often persistent.

A low, creeping, evergeen vine, occurring only in peat; flowers May-July.

Var. intermedium Gray occurs in regions 1,2 , and 12.

Stomach records: Coeur d'Alene chipmunk. Observations: Prairie sharptailed grouse, ring-necked pheasant.

Vaccinium pallidum, sce Vaccinium corymbosum.

Vaccinium parvifolium Smith. (pl. 41, C).

Range: $1,2,4,12$.

Site: Dry, well-drained, moist, sun, shade.

Fruit: Berry, arailable June-September.

A suall to large shrub.

Observations: Sooty grouse; listed with $V$. ovatum as second in importance as browse for Olympic wapiti in Washington; an important food of Roosevelt elk. Locally of value as browse for sheep and occasionaily cattle.

Vaccinium pennsylvanicum, see Vaccinium angustifolium.

Vaccinium scoparium Leiberg.

V. erythrococcum Rydb., V. microphyllum Rydb.

Grouseberry.

Range: $4,12,13,14,15$ (Black Hills).

Site: Dry, well-drained, moist, shade.

Fruit: Berry, available July-September.

A smail shrub.

Observations: An important food of wildlife. Inferior browse for livestock.

Vaccinium simulatum Small.

Cyanococcus simulatus Small.

Range: 27.

Site: Well-drained, sun.

Fruit: Berry.

A smail to large shrub.

Vaccinium stamineum $L$.

Polycodium stamineum (L.) Greene.

Deerberry.

Range: $23,24,25,26,27,28,29$.

Site: Dry, well-drained, sun, shade.

Fruit: Berry; available July-September, soon dropping.

A small, profusely-branched shrub; somewhat thicket forming.

Stomach records: Ruffed grouse; gray fox. Observations: Eight species of birds, including bobwhite and ruffed grouse; white-tailed deer.

Vaccinium tenellum, see Vaccinium virgatum.

Vaccininm uliginosum $\mathbf{L}$.

Range: $1,4,12,13,14,23,24,26,27$.

Bog bilberry.

Site: Dry, well-drained, sun.

Fruit: Berry, available July-September.

A small shrub; flowers June-July.

Stomach records: Spruce grouse, ptarmigan, Harris' sparrow; mountain sheep. Obscrvations: Three species of birds.

Vaccinium vacilians Kalm.

Cyanococcus vacillans (Kalm.) Rydb.

Dryland blueberry.

Range: 22, 23, 24, 25, 26, 27, 28, 29.

Site: Dry, well-drained, sun, shade.

Fruit: Berry, available July-September.

A small, loosely-branched shrub; flowers May-June; occurs in sandy and other soils.

Stomach records: Gray fox. Observations: Ruffed grouse; preferred food of wild turkey; cottontail rabbit, white-tailed deer. 
Vaccinium virgatum Ait.

Cyanococcus virgatus (Ait.) Small.

Rabbiteye blueberry.

Range: 27, 28, 29, 30.

Site : Dry, well-drained, moist, sun.

Fruit: Berry, available July-August.

A small to large shrub; flowers April-May.

Var. tenellum (Ait.) Gray, ( $V$. tenellum Ait., Cyanococcus tenellus (Ait.) Small), possesses underground stems, and occurs in regions 25, 27, and 29.

Stomach records: Cardinal.

Vaccinlum vitis-idaea $L$.

Vitis-idaea vitis-idaea (L.) Britt., Vitis-idaea punctata Moench.

Cowberry.

Range : 23, 26.

Site: Dry, well-drained, sun.

Fruit: Berry, available August-October.

A small shrub or mat-forming vine; evergreen; flowers June-July; reproduces by creeping rootstocks.

Var. minus Lodd., a dwarf variety, is claimed by some to be the only representative of the species in the United States.

Vachellia farnesiana, see Acacia farnesiana.

Vauquelinia angustifolia Rydb.

Range: 11.

Site: Dry, sun.

Fruit: Capsule.

A large shrub to small tree; evergreen.

Vauquelinia californica (Torr.) Sarg.

V. corymbosa Corr., V. torreyi Wats., Spiraea californica Torr.

Vauquelinia.

Range: 5, 10, 11.

Site: Dry, well-drained, sun.

Fruit: Capsule, available in August.

A large shrub to small tree; evergreen; flowers in June.

Vauquelinia corymbosa, see Vauquelinia californica.

Vauquelinia torreyi, see Vauquelinia californica.

Viborquia polystachya, see Eysenhardtia, polystachya.

Viburnum spp.

Viburnums.

Most species occur on nearly neutral soil; most are free from insects and disease; propagation is by seed stratified and sown in spring or by soft or hardwood cuttings, cut below the node, and if propagated in sand and peat, treated with potassium permanganate.

Stomach records (in addition to specific records): Twenty-seven species of birds, including ruffed grouse, sharp-tailed grouse, and greater prairie chickell; coyote; white-tailed deer. Observations (in addition to specific records): Ten species of birds, including bobwhite and ruffed grouse; porcupine; eastern chipmunk. Of comparatively little value as browse for livestock.

Viburnum acerifolium $\mathrm{L}$.

Range : 23, 24, 25, 26, 27, 28, 29.

Mapleleaf viburnum.

Site: Dry, well-drained, sun, shade.

Fruit: Drupe; available September-October, often persistent until July.

A small shrub; flowers May-June; slow growing; endures city smoke; occasionally thicket forming; about 4,500 fresh berries per pound.

Stomach records: Four species of birds, including ruffed grouse; white-tailed deer. Observations: Sparingly eaten by cottontail rabbit.

Viburnum affine Bush.

Missouri viburnum.

$V$. pubescens affine Rehd.

Range: 22, 25.

Site: Dry, well-drained, moist (rare), sun, shade.

Fruit: Drupe, available August-September.

A small shrub; flowers May-June. Var. hypomalucum Blake extends the range to regions $23,24,26,27$, and 28 , and is more floriferous. 

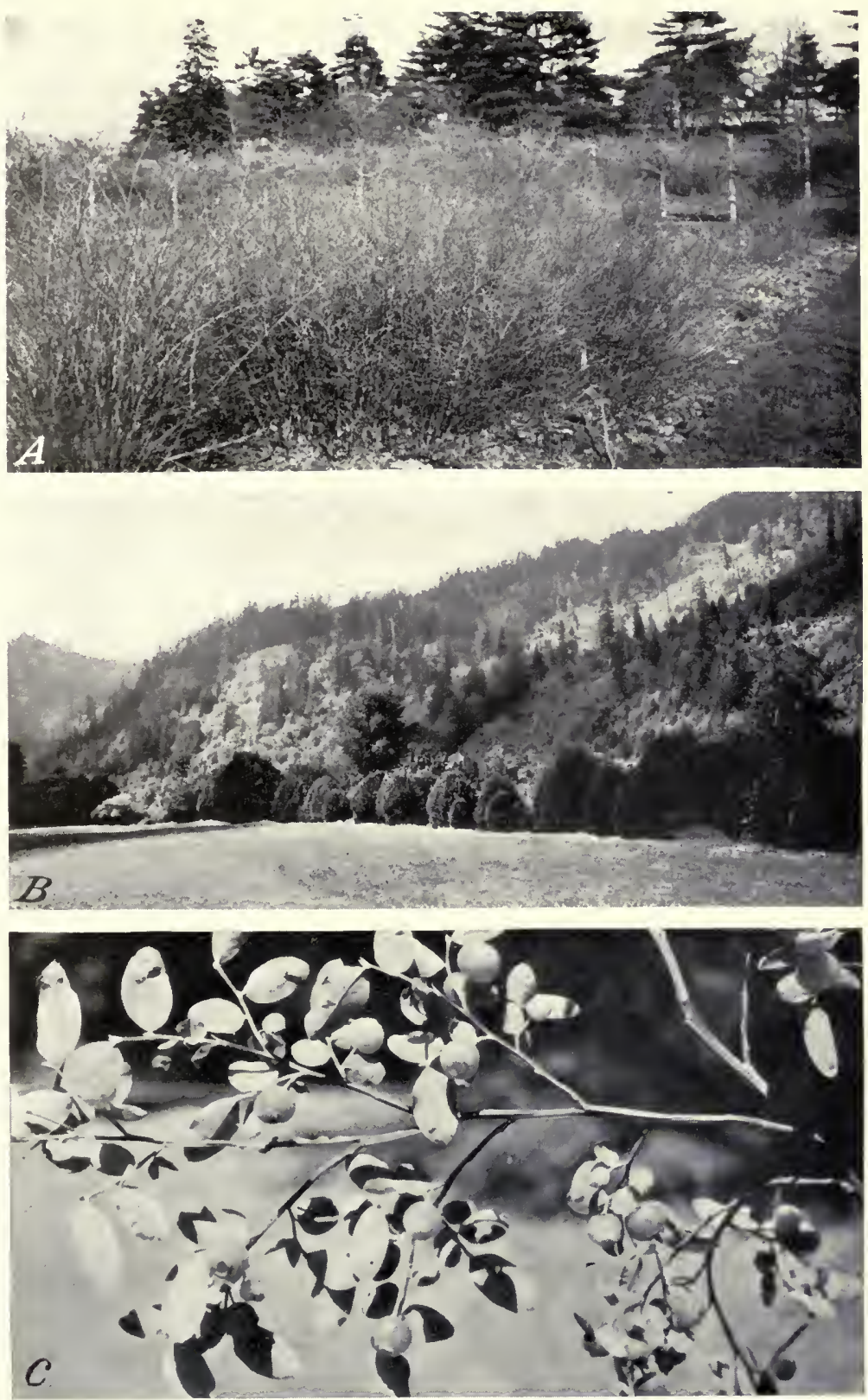

A, Symphoricarpos albus. The dense thickets formed by the snowberry, coupled with its ability to grow on poor sites, make it a valuable plant in erosion control. B, Umbellularia californica. Oregon myrtle, shown here growing along a stream in the northern part of its range, may find a place in stream-bank plantings. Its value as wildlife cover is great; its value as food is possibly greater than actual records would indicate. C, Vaccinium parvifolium. The juicy, red fruit of this species is probably of great value for wildlife despite the paucity of actual stomach records. 


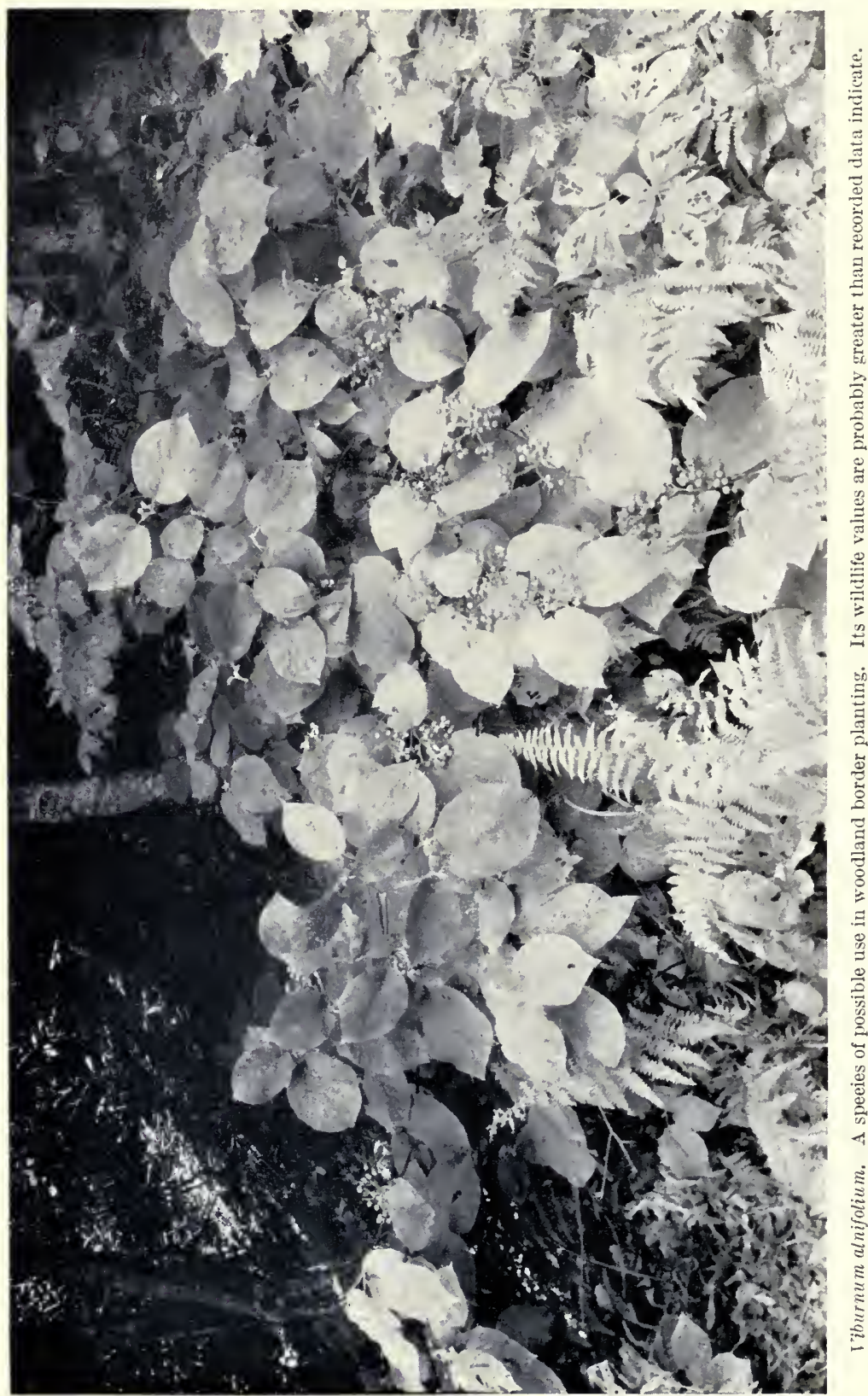


Viburnum alnifolium Marsh. (pl. 42).

Hobblebush.

Range: $23,24,26,27$.

Site: Well-drained, moist, shade.

Fruit: Drupe, available August-September.

A small to large shrub; flowers May-June; commonly occurs in acld soils; thicket forming; reclining branches often root at the nodes or at the tip.

Stomach records: Ruffed grouse. Observations: Cottontail rabblt; preferred food of white-tailed deer in New York.

Viburnum americanum, see Viburnum trilobum.

Viburnum bracteatum Rehd.

Range: 27.

Site: Well-drained, sun.

Frult: Drupe.

A large shrub.

Viburnum cassinoldes $\mathrm{L}$.

Range: $23,24,25,26,27,28,29$.

Withe rod.

Site: Dry, well-drained, moist, sun, shade.

Fruit: Drupe, available September-October, falling at once.

A small or more commonly a large shrub; flowers June-July; occasionally thicket forming; 3,000 dry berries per pound.

Stomach records: Ruffed grouse, sharp-tailed grouse, ring-necked pheasant. observations: Hungarian partridge; an important food of white-tailed deer; cottontail rabbit.

Viburnum densiflorum Chapm.

Range: 30 .

Site: Well-drained, sun.

Fruit: Drupe.

A small shrub; flowers April-May.

Viburnum dentatum $\mathrm{L}$.

Arrowwood.

Range: 22, 23, 24, 25, 26, 27.

Site: Well-drained, moist, sun, shade.

Fruit: Drupe, available October-December.

A large shrub; flowers May-June; thlcket forming; endures city smoke; easily propagated by cuttings; 17,900 seeds per pound.

Stomach records: Seven species of birds, including ruffed grouse. Observations: Three species of birds; eastern chipmunk.

Viburnum ellipticum Hook.

Range: $1,4$.

Site: Dry, well-drained, moist, sun.

Fruit: Drupe, available July-September.

A small to large shrub; flowers April-June.

Stomach records: Magpie.

\section{Viburnum ferragineum, see Viburnum rufidulum.}

Viburnum lentago $\mathrm{L}$.

Range: 13, 15 (Black Hills), 18, 21, 22, 23, 24, 25, 26, 27, 28, 29.

Site: Dry, well-drained, moist, sun, shade.

Fruit: Drupe; available August-September, commonly persistent.

Usually a large shrub, more rarely a small or large tree; multiplies freely by suckers; will endure city smoke; easily propagated by cuttings; 3,000-5,000 berries per pound, 4,300 seeds per pound.

Stomach records: Four species of birds, including ruffed grouse. Observations: Ten species of birds, including ring-necked pheasant; much eaten by ruffed grouse; much eaten by raccoon; skunk, cottontail rabbit; gray squirrel. Fruit eaten to some extent by sheep and goats.

Viburnum molle Michx.

Soft arrowwood.

Range: 22, 25, 29.

Site: Dry, well-drained, sun, shade.

Fruit: Drupe, avallable September-October.

A large shrub; flowers in June; commonly occurs in calcareous soil. Stomach records: Two species of birds. 
Viburnum nitidum Ait.

V. nudum angustifolium Torr. and Gray.

Shining withe rod.

Range: 28, 29.

Slte: Moist, sun, shade.

Fruit: Drupe, available September-October.

A large shrub with reclining branches.

Viburnum nudum L.

Possumhaw.

Range: 20, 25, 27, 28, 29, 30 .

Site: Moist, sun, shade.

Fruit: Drupe, available September-March.

Usually a large shrub or rarely a small tree; flowers May-June or occasionally in autumn.

Stomach records: Bobwhite.

Viburnum obovatum Walt.

Range : 29, 30.

Small viburnum.

Site: Moist, sun, shade.

Fruit: Drupe.

A large shrub to small tree.

Viburnum opulus, see Viburnum trilobum.

Viburnum pauciflorum Raf.

Range : 4, 12, 13, 23, 24, 26, 27.

Squashberry.

Site: Moist, sun, shade.

Fruit: Drupe, available July-September, more or less persistent.

A small to large, straggling shrub; flowers June-July.

Stomach records: Three species of birds, Including ruffed grouse. Observations: Moose, red squirrel. Foliage of low palatabllity to livestock.

Viburnum prunifolium L.

Range: $20,22,23,24,25,27,28,29,30$.

Blackliaw.

Site: Dry, well-drained, moist, sun, shade.

Fruit: Drupe, available August-March.

Usually a small or large shrub or rarely a small tree; flowers April-June; 4,200 seeds per pound.

Stomach records: Eight species of birds including bobwhite; gray fox, whitetailed deer. Observations: Three species of birds.

Viburnum pubescens (Ait.) Pursh.

$V$. dentatum pubescens Ait., $V$. rafinesquianum Schult.

Hairy nannyberry.

Range: 15, 21, 22, 24, 25, 27.

Site: Dry, well-drained, sun, shade.

Fruit: Drupe, available August-October. soil.

A small, straggling shrub; flowers June-July; commonly occurs on calcareous

Stomach records: Thrush.

Viburnum rafinesquianum, see Viburnum pubescens.

Viburnum rufidulum Raf.

$V$. ferrugineum Small, V. rufotomentosum Small.

Sonthern blackhaw.

Range: $17,19,20,25,27,28,29,30$.

Site: Dry, well-drained, sun.

Fruit: Drupe; available October-November, often persistent until March.

A large shrub to small tree; flowers April-May; slow-growing, long-lived; occurs in sand, loam, and other soils.

Viburnum rufotomentosum, see Viburnum rufidulum.

Viburnum scabrellum (Torr. and Gray) Chapm.

Rough arrowwood.

$V$. dentatum semitomentosum Michx., $\nabla$. semitomentosum (Michx.) Rehd.

Range: 27, 28, 29, 30.

Site: Well-drained, moist.

Fruit: Drupe; available September-October.

A small to large shrub; flowers in June. Very simllar to V. dentatum.

Viburnum semitomentosum, see Viburnum scabrellum. 
Viburnum trilobum Marsh. (pl. 43).

$V$. opulus americanum of amer. auths., not Mill.

Highbush eranberry.

Range: 4, 12, 15 (Black Hilis), 18, 21, 22, 23, 24, 26, 27.

Site: Well-drained, moist, sun, shade.

Fruit: Drupe; available September-October, often persistent until May. A large shrub; flowers June-July; 16,000 seeds per pound.

Stomach records: Three species of birds, including ruffed grouse and sharptailed grouse. Observations: Six species of birds, including Canada ruffed. grouse and ring-necked pheasant. Without significance as browse for livestock.

Viburnum venosum Britt.

V. venosum canbyi Rehd.

Veiny viburnum.

Range : 27.

Site: Dry, sun.

Fruit: Drupe.

Usually a small shrub, rarely a large shrub; flowers June-July.

Viguiera deltoidea Gray.

Range: 5, 9, 10 .

Site: Dry, sun.

Fruit: Achene.

A small, much-branched shrub represented in the United States by var. parishii (Greene). Browse value for livestock limited.

Viguiera parishii, see Viguiera deltoidea.

Viguiera reticulata Wats.

Range: 10.

Site: Dry, sun.

Fruit: Achene.

A small, loosely branched shrub with limited browse value for livestock.

Viguiera stenoloba Blake.

Gymnolomia tenuifolia Benth. and Hook., Heliomeris tenuifolia Gray.

Range: 11, 16, 17.

Site: Dry, sun.

Fruit: Achene.

A small, much-branched shrub with limited value, as browse for livestock.

Viorna addisonii, see Clematis addisonii.

Viorna arizonica, see Clematis arizonica.

Viorna bigelovii, see Clematis bigelovii.

Viorna coccinea, see Clematis texensis.

Viorna crispa, see Clematis crispa.

Viorna filifera, see Clematis pitcheri.

Viorna gattingeri, see Clematis gattingeri.

Viorna obliqua, see Clematis obliqua.

Viorna pitcheri, see Clematis pitcheri.

Viorna reticulata, see Clematis reticulata.

Viorna versicolor, see Clematis versicolor.

Viorna viorna, see Clematis viorna.

Vitis spp.

Grapes.

The species vary greatly in many characters including resistance to disease; species native to high arid regions where the air is too dry to permit growth of mildews and rots are attacked quickly when transplanted to low, moist climates; species growing in Phylloxera-free regions are usually much attacked. when transplanted to regions infested with the pest; the species are nearly dioecious, but staminate flowers are often borne on pistillate vines; propagated by stratified seed or soft or hardwood cuttings.

Stomach records (in addition to specific records): Eighty-two species of birds, including ruffed grouse, sharp-tailed grouse, bobwhite, California quall, wild turkey, ring-necked pheasant, and mourning dove; western skunk, striped skunk, gray fox, red squirrel, raccoon, eastern skunk, opossum; composed 2.36 
percent of fruit food of eastern skunk in Michigan. Observations (in addition to specific records) : Forty-five species of birds, inciuding Gambel quail, bandtailed pigeon, ruffed grouse; ranks seventeenth on the list of quail food plants of the Southeast; ring-necked pheasant, Hungarian partridge, pinnated grouse; heavily browsed by white-tailed deer; important food of raccoon, gray fox, red fox, coyote, cottontail rabbit, skunk, rock squirrel.

Vitis acerifolia, see Vitis longii.

Vitis aestivalis Michx.

Range: 22, 23, 24, 25, 27, 28, 29.

Summer grape.

Site: Dry, weil-drained, moist, sun.

Fruit: Berry, available August-September, often persistent.

A vigorous, high-climbing vine; flowers May-June; grows on sand, clay, loam, and other soils, but does best on warm, gravelly, well-drained ones; roots large, hard, penetrating; falrly resistant to cold and drought; resistant to mildew and rot, about 75 percent to Phylloxera; has given rise to numerous cultivated forms ; about 50 percent of cuttings root.

Stomach records: Eight species of birds, including ruffed grouse and bobwhite. Observations: Cardinal, cowbird; a greatly preferred food of wild turkey; white-tailed deer.

Vitis andersonil, see Vitis vulpina.

Vitis argentifolia Muns.

Blueleaf grape.

$\nabla$. aestivalis bicolor Deam, $V$. bicolor LeConte, V. caerulea Munson, V. lecontiana House.

Range: 22, 23, 24, 25, 26, 27, 28.

Site: Dry, weli-drained, moist, sun, shade.

Fruit: Berry, available September-October, often persistent.

A vigorous, high-climbing vine; flowers May-June; resistant to very low temperatures; somewhat attacked by mildew; grows in sand, sandy clay, and other soils; resistant to cold and drought; roots hard, fibrous, large; about 40 percent of cuttings root although propagation by cuttings is often difficult; fruit borne prolifically.

Stomach records: Ruffed grouse.

Vitis arizonica Engelm.

Range: $9,10,11,16,17$.

Site: Well-drained, moist, sun.

Fruit: Berry; available July-August, often persistent until October.

A weak, much-branched vine or small to large shrub with abortive tendrils; scarcely climbing; endures cold and drought well; where grown with excessive moisture commonly attacked by mildew and rots; grows better in sandy than heavy solis; easily grown from cuttings; apparently formerly cultivated by the Pueblo Indians.

Observations: Eaten by numerous birds including Gambel, scaled, and Mearns quail; prized food of skunks, foxes, coyotes, bears; much eaten by captive deer. Vitis austrina, see Vitis simpsonii.

Vitis baileyana Muns.

V. virginiana Muns., not Poir.

Possum grape.

Range : 25, 27, 28, 29.

Site: Weli-drained, sun.

Fruit: Berry, availabie Augușt-September.

A slender, climbing, much-branched vine; roots fleshy, sparingiy branched, not deep-penetrating; fairly resistant to Phylloxera; commonly occurs on calcerous soils.

Vitis berlandieri Planch.

Winter grape.

Range: 11, 17, 20, 30.

Site: Dry, well-drained, molst, sun.

Fruit: Berry, available August-October.

A stocky vine; high climbing in favorable situations; commoniy occurs on limestone soils; roots hard, little-branched, penetrating deeply; resistant to black rot and Phylloxera; susceptible to mildew; long-lived; will endure cold and drought; commonly occurs on calcareous soil; seed germination slow; about 40 percent of cuttings root.

Vitis bicolor, see Vitis argentifolia.

Vitis boulderensis, see Vitis vulpina. 


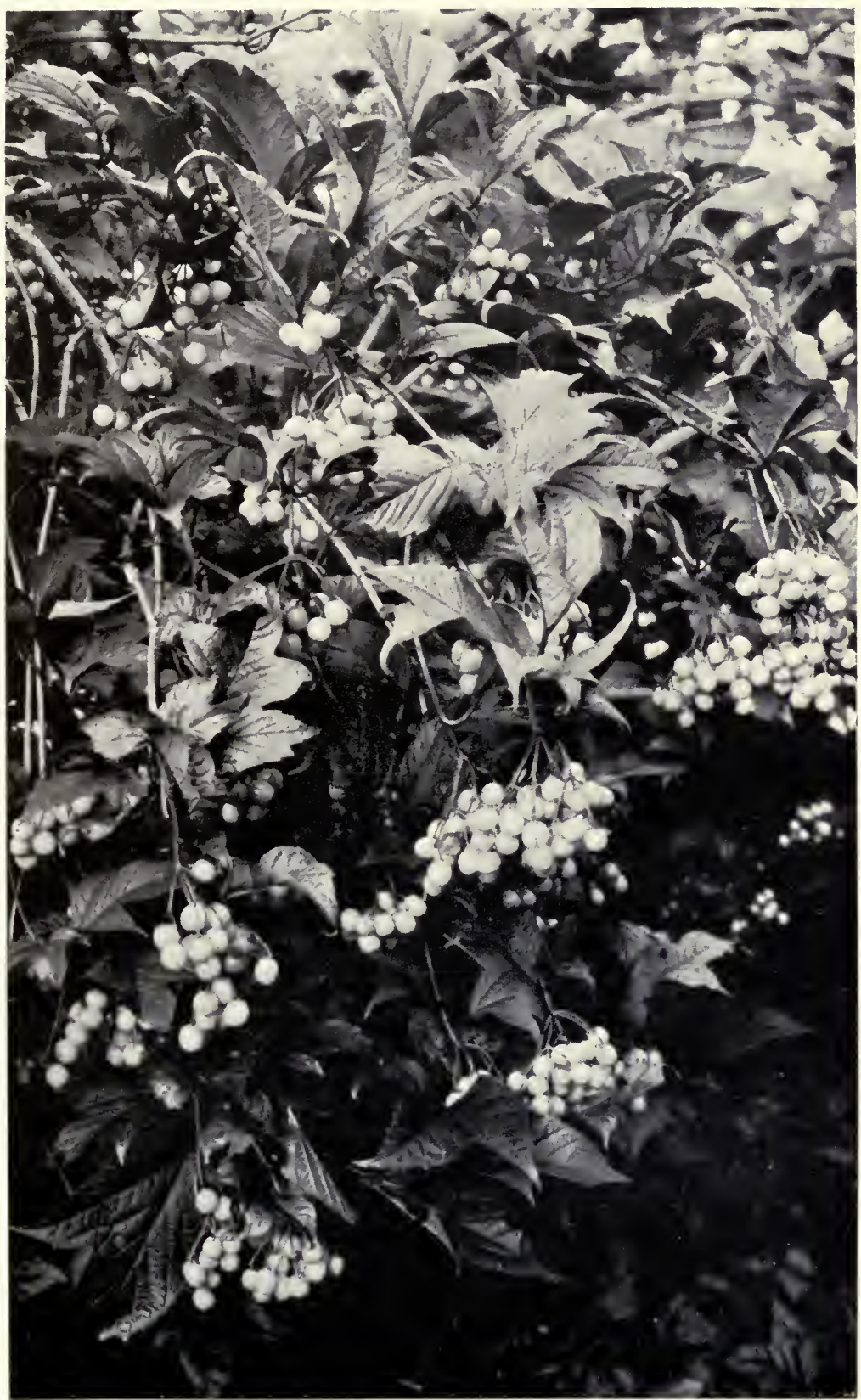

Viburnum trilobum. Highbush cranberry ranks high for erosion-control and wildlife plantings. Its ornamental character recommends its use on lighway cuts. 


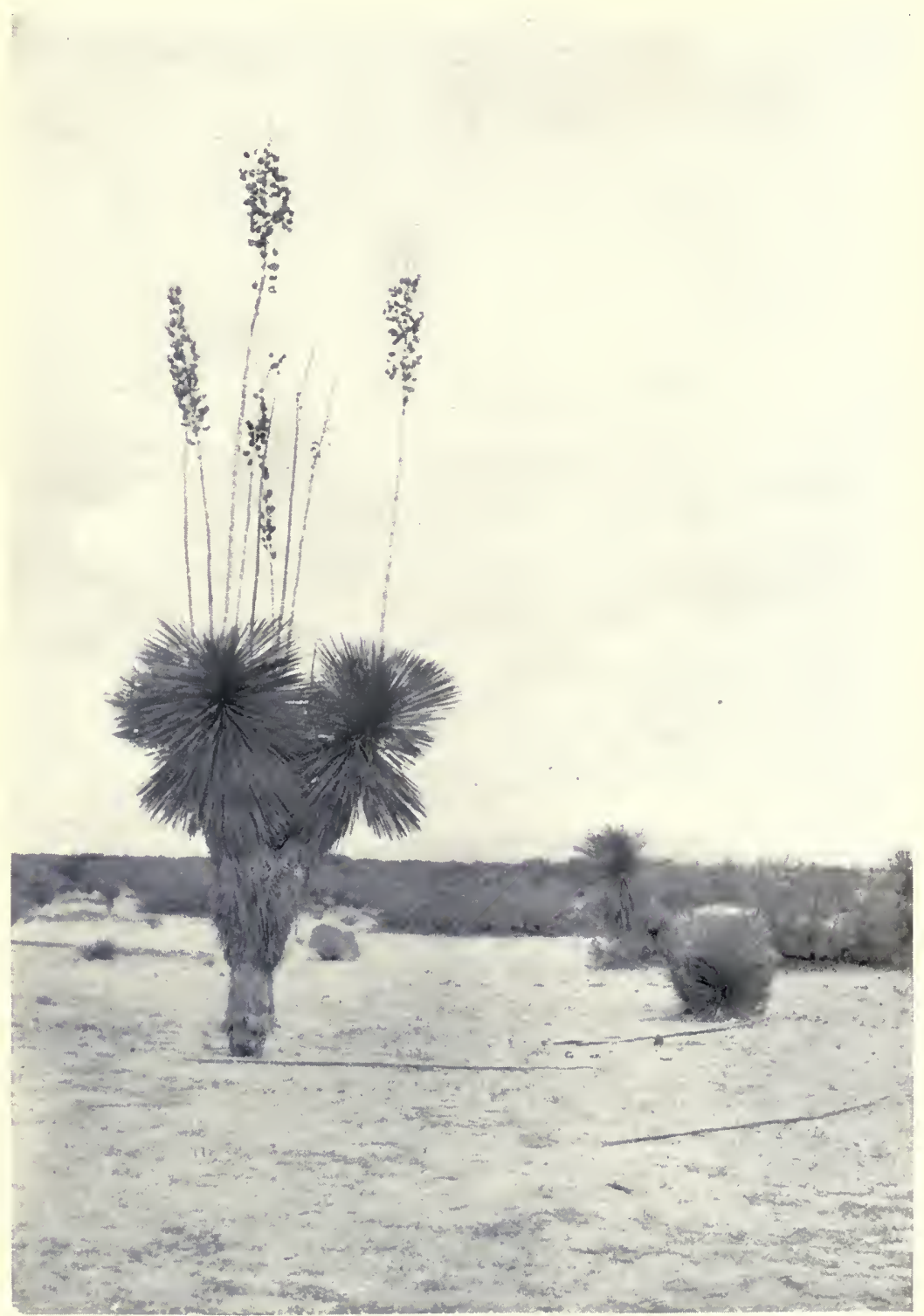

Yucca elata. Yuccas appear to have little value either for wildlife or soil conservation. More information on their possible usefulness is needed. 
Vitis caerulea, see Vitis argentifolia.

Vitis californica Benth.

Range: 1, 2, 3, 4, 10, 11.

California grape.

Site: Well-drained, moist, sun.

Fruit: Berry, available July-August, commonly persistent.

A vigorous, high-climbing or traillng vine, or frequently a shrub; roots oft; very susceptible to downy mildew; more or less resistant to Phylloxera; very resistant to fire.

Stomach records: Robin, valley quail. Observations: Mountain quail.

Vitis candicans Engelm.

Range: 11, 16, 17, 20, 29, 30.

Mustang grape.

Site: Well-drained, moist, sun, shade.

Fruit: Berry; available June-August, often persistent until well into winter.

A vigorous, climbing vine; roots vigorous, tender, penetrating more deeply than any other species of grape; endures great drought and heat; free from disease; long-lived; foliage thick; difficult to grow from cuttings; about 75 percent resistant to Phylloxera; commonly occurs on limestone soil although thriving in nearly any soil; seedlings at first feeble, later very vigorous.

Var. coriacea Bailey has smaller and more edible fruit and occurs within the range of the species.

Vitis caribaea, see Vitis sola.

Vitis champinil Planch.

Range: 11, 16, 17, 20, 25.

Site: Dry, well-drained, sun.

Fruit: Berry; available June-August, commonly persistent.

A robust, climbing vine; roots deep-penetrating, large, much-branched; often occurs on limestone soil but will grow on a variety of soils; about 60-percent resistant to Phylloxera; resistant to Anaheim disease; resistant to cold and drought; staminate vines commonly fewer in its native habitats than the pistillate ones; 80 percent of cuttings root; often forms dense thickets. Has heen considered a possible hybrid between $V$. rupestris or $V$. berlandieri, and V. candicans.

Vitis cinerea Engelm.

Range: $11,17,20,22,23,25,29,30$.

Sweet winter grape.

Site: Well-drained, moist, sun, shade.

Fruit: Berry ; available August-November, long persistent.

A vigorous, high-climbing vine; flowers May-June; commonly occurs on deep, rich, riverbank soils; roots large, fleshy, deep-penetrating, scarcely fibrous; very long-lived, resistant to great extremes of drought and moisture; free from disease; 75 percent resistant to Phylloxera; resistant to cold; about 25 percent of cuttings root; often difficult to reproduce by cuttings.

Vitls cordifolia Michx.

Range: 17, 20, 22, 25, 27, 28, 29, 30 .

Site: Well-drained, moist, sun.

Fruit: Berry, available August-October, often persistent.

A large, vigorous, high climbing vine; flowers May-June; roots strong, hard, fairly deep-penetrating; nearly completely resistant to Phylloxera; resistant to mildew, rot, and drought; very resistant to cold; cuttings grow with difficulty, approximately 25 percent bcing successful; occurs on calcareous, sandy, and other soils. Var. sempervirens Muns., occurring within the range of the species, has more persistent foliage, is more sensitive to cold, and has fruit which ripens later than that of the species.

Stomach records: Twenty-eight species of birds, including ruffed grouse, bobwhite, and wild turkey. Observations: Cardinal, gray-cheeked thrush.

Vitis doaniana Muns.

Range: 16, 19, 20.

Site: Well-drained, sun.

Fruit: Berry, available July-October, persistent.

A rapid-growing, vigorous vine, remaining bushy if failing to find support; commonly occurs on sandy, calcareous soils; roots fibrous, hard, spreading, and penetrating; resistant to drought, cold, and disease; 60 percent resistant to Phylloxera; 60 percent of cuttings take. 
Vitis girdiana Muns.

Range: $5,10$.

Valley grape.

Site: Dry (rare), well-drained, moist, sun.

Fruit: Berry, avallable August-September, persistent.

A robust, high-climbing vine; roots soft, not completely resistant to Phylloxera; sensitive to cold; subject to mildew, rot, and Anaheim disease; often occurs on sandy soil.

Vitis helleri (Bailey) Small.

$V$. cordifolia helleri Bailey.

Roundleaf grape.

Range: 17, 20.

Site: Well-drained, sun.

A vine.

Fruit: Berry, available in July.

Vitis incisa, see Cissus incisa.

Vitis labrusca $\mathrm{L}$.

Range: 22, 23, 24, 25, 26, 27.

Fox grape.

Site: Dry, well-drained, moist, sun, shade.

Fruit: Berry ; available August-October, dropping at once.

A vigorous, high-climbing, bushy vine; roots large and fleshy, spreading, not deeply penetrating; growth of 1-year-old plants feeble, rigorous when established; does best ill well-drained, alluvial soil but occurs in many, including sand; withstands cold well, heat and drought rather poorly; not affected by downy mildew; berries falling singly when ripe; easily grown from cuttings; susceptible to Phylloxera; seeds rarely produce plants true to type.

Stomach records: Six species of birds, including ruffed grouse and ringnecked pheasant. Observations: Much eaten by skunk, fox, raccoon, and opossum.

Vitis lecontiana, see Vitis argentifolia.

Vitis lincecumii Buckl.

Range: 20, 25, 29.

Site: Dry, well-drained, sun, shade.

Fruit: Berry; available Jume-September, falling at once or persistent.

$\Lambda$ vigorous, moderately-climbing vine, or a shrub if without support; occurs in sand, clay, loam, and other soils; roots, long, hard, fleshy, penetrating deeply; fairly resistant to cold; extremely resistant to drought; susceptible to mildew and rot; 75-percent resistant to Phylloxera; about 50 percent of cuttings take; reproduction by cuttings often difficult; fruit-bearing vines generally do not self-fertilize; seed germination prompt. Fruit often eaten by domestic turkeys before ripening.

Vitis longii Prince.

$\nabla$. acerifolia Raf., $\nabla$. nova-mexicana Muns., $\nabla$. solonis Hort.

Long's grape.

Range: 11, 16, 17, 19, 20, 25.

Site: Dry, well-drained, sun.

Fruit: Berry, available July-August, long persistent.

A vine or more commonly a small to large, stocky, erect, much-branched shrub; climbs vigorously in cultivation; roots large, much-branched, hard, deeppenetrating; occurs in sand and calcareous soils; drought and cold-resistant; about 75-percent resistant to Phylloxera; not resistant to mildew or anthracnose; 60 percent of cuttings root; self-pollination rare.

Var. microsperma Balley, a vigorous, small-seeded form very resistant to drought, occurs along the Red River in Texas.

Vitis montana, see Vitis monticola.

Vitis monticola Buckl.

$V$. montana of Auths. not Buckl.

Sweet mountain grape.

Range: 11, 17, 20.

Site: Dry, well-drained, sun.

Fruit: Berry, available August-October.

A slender, small-leaved vine with open foliage; roots little-branched; resistant to cold, drought, mildew, rot and nearly completely resistant to Phylloxera; slender when wild, stocky in cultivation; commonly occurs on limestone soils, but grows moderately well on sand; 65 percent of cuttings root. 
Vitis munsoniana Simpson.

Muscadinia munsoniana Small.

Little muscadine grape.

Range: 30, 31.

Site: Dry, well-drained, sun, shade.

Fruit: Berry, available August-November.

A slender, trailing vine; blooms nearly continuously; usually not high-climbing.

Vitls muscadina, see Vitis rotundifolia.

Vitis nova-mexicana, see Vitis longii.

Vitls novae-angliae Fern.

Pilgrim grape.

Range : 26, 27.

Site: Well-drained, sun.

Fruit: Berry, available in September.

A vigorous, climbing vine; often forms thickets of great profusion.

Vitis palmata Vahl.

V. rubra Michx.

Cat grape.

Range: 22, 25, 29.

Site: Well-dratned, sun.

Fruit: Berry, available September-October, persistent.

A slender, high-climbing vine; flowers May-June; roots fibrous at the surface, hard and penetrating; resistant to drought and cold when established ; resistant to Phylloxera; free from disease; seed germination very slow.

Vitis riparia, see Vitis vulpina.

Vitis rotundifolia Michx.

V. muscadina Raf., Muscadinia rotundifolia (Michx.) Small.

Muscadine grape.

Range : $20,22,25,28,29,30$.

Site: Well-drained, moist, sun, shade.

Fruit: Berry, available August-September.

A very vigorous, high-climbing vine; flowers in May; occurs in sandy and other soils; roots thick, little-branched; berries drop singly as soon as ripe; free from diseases; cuttings root with diffeulty, but layers of wood twisted withelike at one point when covered root easily; the original of the Scuppernong grape.

Stomach records: Cardinal, bobwhite; opossum. Observations: Cardinal.

Vitis rubra, see Vitis palmata.

Vitis rufotomentosa Small.

Range: 29,30 .

Site: Well-drained, sun.

Fruit: Berry, avallable August-September.

A strong, high-climbing vine.

Vitis rupestris Scheele.

Range: 11, 16, 17, 20, 25, 27, 28, 29.

Sand grape.

Site: Well-drained, sun.

Fruit: Berry, available July-August. .

A vigorous, much-branched vine, or more commoniy a low, bushy shrub; occasionally prostrate and trailing; succeeds in poor, calcareous and sandy soils; roots slender, long; almost entirely resistant to Phylloxera; more or less resistant to drought; resistant to cold; not resistant to anthracnose; resistant to other diseases and insects; easily propagated by cuttings; 80 percent of cuttings root; pistillate plants rarely produce fruit alone; seed germination rapid.

Observations: Deer. Browsed by cattle and sheep.

Vitis simpsonii Munson.

$V$. cincerea floridana Munson, V. austrina Small.

Currant grape.

Range : 29, 30 .

Site: Well-drained, sun.

Fruit: Berry, available in August.

A strong, high-climbing vine.

Vitis slavinii, see Vitis vulpina. 
Vitis sola Bailey.

Curtiss grape.

V. caribaca Am. auth., not DC.

Range: 30 .

Site: Well-drained, moist, sun.

Fruit: Berry; available August-September, persistent.

A vigorous vine.

Vitis solonis, see Vitis longii.

Vitis treleasei Munson.

Gulch grape.

Range: 11.

Site: Dry, well-drained, sun.

Fruit: Berry, available September-November.

A vine or shrub; much branched; scarcely climbing; tendrills deciduous the first year unless they find support; seeds small; drought resistant; comparatively susceptible to mildew and rot.

Vitis virginiana, see Vitis baileyana.

Vitis vulpina L.

V. boulderensis Daniels, $\nabla$. riparia Michx.

Riverbank grape.

Range: $15,16,18,19,21,22,23,24,25,26,27,28,29$.

Site: Well-drained, suu.

Fruit: Berry; available June-November, persistent.

A vigorous, moderately-branching and climbing vine; commonly occurs on well-drained, loose, sandy soils; grows poorly in lime or clay soil ; roots long, thin, hard, flbrous; almost entirely resistant to Phylloxera; very resistant to cold; not resistant to heat and drought; germination of seed quick and vigorous; easily grown from cuttings, 85 percent of cuttings root; easily grafted; commonly used in Europe as grafting stock for $V$. vinifera; 14,500 seeds per pound.

Var. syrticola Fern. and Wieg., the dune grape, commonly occurs on sand dunes in region 24 and apparently withstands partial burial in sand. $V$. slavinii Rehd. is a supposed hybrid between $\nabla$. vulpina and $\nabla$. argentifolia, $\nabla$. andersonii is a supposed hybrid between $\nabla$. vulpina and $\nabla$. kacmpferi glabrescens, a Japanese species.

Stomach records: Six species of birds, including ruffed grouse, bobwhite, wild turkey, and mourning dove; composed 4.1 percent of total annual food and 54.3 percent of total fruit food of ring-necked pheasant in Michigan; whitetailed deer. Observations: Ring-necked pheasant, cedar waxwing; red fox, skunk, white-talled deer, cottontail rabbit.

Vitis-idaea punctata, see Vacinium vitis-idaea.

Vitis-idaea vitis-idaea, see Vaccinium vitis-idaea.

Washingtonla robusta Wendl.

Fan palm.

W. filifera robusta (Wendl.) Parish, Neowashingtonia robusta (Wendl.) Heller.

Range: 10.

Site: Well-drained, moist, sun.

Fruit: Berry.

A large evergreen tree; occurs in alkaline soll.

Whipplea modesta Torr.

Range: 1, 4 .

Site: Moist, sun, shade.

Fruit: Capsule.

A small trailing shrub; flowers April-June; prostrate branches root freely at the nodes.

Whipplea utahensis, see Fendlerella utahensis.

Wisteria frutescens (L.) Poir.

W. speciosa Nutt., Kraunhia frutescens (L.) Greene.

American wisteria.

Range: $17,20,22,25,28,29,30$.

Site: Well-drained, moist, sun.

Fruit: Legume, available September-November.

A vine.

Yerba de selva. 
Wisteria macrostachya Torr. and Gray.

Kraunhia macrostachya (Torr. and Gray) Small.

Kentucky wisteria.

Range: $25,27,28,29,30$.

Site : Well-drained, moist, sun.

Fruit: Legume; available in October, often persistent until March.

A robust and vigorous vine; flowers May-July.

Wisteria speciosa, see Wisteria frutescens.

Xanthorhiza aplifolia, see Xanthorhiza simplicissima.

Xanthorhiza simplicissima Marsh.

Yellowroot.

$X$. apiifolia L'Her.

Range : 27, 28, 29, 30 .

Site: Dry, well-drained, sun.

Fruit: Follicle.

A small creeping and rooting shrub; flowers April-May; free from insects and diseases; may form a dense ground cover.

Xanthoxylum spp.

Observations (in addition to specific records) : Extensively used by kingbird.

Xanthoxylum americanum Mill.

Range : 22, 23, 24, 25, 26, 27, 29, 30.

Northern prickly-ash.

Site: Dry (rare), well-drained, moist, sun, shade.

Fruit: Follicle.

A large shrub to small tree; flowers April-May; spiny.

Stomach records: Red-eyed vireo, bobwhite. Observations: Important food of pheasants in southern Michigan; cottontail rabbit; eastern chipmunk.

Xanthoxylum clava-herculis L.

Fagara clava-herculis (L.) Small.

Hercules-club.

Range: $20,22,25,28,29,30$.

Site: Dry, well-drained, moist, sun.

Fruit: Follicle, available May-June.

A large shrub to small tree; thorny; occurs in sandy or gravelly soils.

Xanthoxylum fagara (I.) Sarg.

$X$. pterota H. B. K., Schinus fagara L., Fagara pterota L., $F$. fagara Small.

Range: 11, 17, 32.

Site: Well-drained, sun.

Fruit: Follicle, available March-September.

A large shrub to large tree; evergreen, thorny, and dioecious; shrubby westward.

Observations: Cottontall rabbit.

Xanthoxylum texanum, see Amyris texana.

Xerocassia armata, see Cassia armata.

Xolisma ferruginea (Walt.) Heller.

Lyonia rigida Nutt.

Range : 29, 30.

Site: Well-drained, sun.

Fruit: Capsule.

A large shrub to small tree, or very rarely a large tree; erergreen; widelybranched; occurs in sandy and other soils; flowers February-April.

Xolisma follosiflora, see Xolisma ligustrina.

Xolisma fruticosa (Michx.) Nash.

Lyonia ferruginea Nutt.

Range : 29, 30.

Site: Well-drained, sun.

Fruit: Capsule.

A small to large evergreen shrub.

Xolisma ligustrina (L.) Britt.

Lyonia ligustrina (L.) DC., Arsenococcus ligustrinus (L.) Small, Andromeda

ligustrina Muhl.

Range: 27, 28, 29, 30 .

Site: Moist, sun, shade.

Fruit: Capsule.

A large shrub; flowers May-July. 
Var. foliosiflora (Michx.) Fern., (Arscnococcus frondosus (Pursh) Small, Xolisma foliosiflora Small, Lyonia frondosa Pursh) is commoner southward.

Observations: Ignored by white-tailed deer in Massachusetts.

Xolisma lucida (Bartr.) Rehd.

Fetter bush.

Lyonia nitida (Bartr.) Fern., Pieris nitida Benth. and Hook., Desmothamnus lucidus (Lam.) Small, Neopieris nitida (Bartr.) Britt.

Range: 29, 30.

Site: Well-drained, moist, sun, shade.

Fruit: Capsule.

A small to large evergreen shrub; flowers April-May.

Xolisma mariana' (L.) Rehd.

Staggerbush.

Lyonia mariana (L.) Don., Neopieris mariana (L.) Britt., Pieris mariana

(L.) Benth. and Hook.

Range: $20,27,28,29,30$.

Site: Well-drained, moist.

Fruit: Capsule.

A small shrub; flowers May-July; occurs in sandy soil. Follage said to be poisonous to lambs and calves.

Xylococcus bicolor, see Arctostaphylos bicolor.

Xylosteon ciliatum, see Lonicera canadensis.

Xylosteon conjugiale, see Lonicera conjugialis.

Xylosteon involucrata, see Lonicera involucrata.

Xylosteon utahensis, see Lonicera utahensis.

Xylosteon villosum, see Lonicera villosa.

Xylosteon oblongifolia, see Lonicera oblongifolia.

Xylothermia montana, see Pickeringia montana.

Yucca spp. (pl. 44).

Generally slow-growing, simple-stemmed, treelike species often with very long roots; commonly occur in dry, sterile soils; stems commonly grow to keep pace with shifting sands; trunks occasionally used in construction; pollination rarely occurs unless a small white moth gathers the pollen and pushes it into the stigmatic tube, the larvae feeding exclusively on maturing seeds of the plant. Propagation is by seed, offsets, stems, or rhizome cuttings.

Stomach records (in addition to specific records): Band-tailed pigeon; wild turkey. Observations (in addition to specific records) : Baccate fruit commonly eaten by birds and mammals; jack rabbit, rusty antelope squirrel, gray-tailed antelope squirrel, black-backed rock squirrel, mexican mule deer. Nearly all species are eaten by livestock if the tender parts are within reach. Some are of importance as honey plants.

Zanthoxylum, see Xanthoxylum.

Zenobia cassinefolia (Vent.) Poll.

Andromeda cassinefolia Vent.

Range : 29, 30.

Site: Well-drained, sun, shade.

Fruit: Capsule.

A small to large shrub.

Zenobia pulverulenta (Partr.) Poll.

Andromeda pulverulenta Bartr.

Range: 29, 30 .

Site: Well-drained, sun, shade.

Fruit: Capsule.

A small to large shrub; occurs on sandy and other soils.

Zizyphus lycioides, see Condalia lycioides.

Zizyphus obtu'sifolia, see Condalia obtusifolia.

Zizyphus parryi, see Condalia parryi.

Zygia brevifolia, see Pithecolobium brevifolium.

Zygia flexicaulis, see Pithecolobium flexicaule. 


\section{BIBLIOGRAPHY ${ }^{8}$}

(1) ANonymous.

1936. SEVEN HUNDRED MILES OF ROADSIDE PLANTINGS ALONG STATE HIGH-

(2) ABRAMS, L. WAYS. Outdoor Ind. 3 (11, December) : 21, 26.

(3) 1904. FLORA OF LOS ANGELES AND VICINITY. $474 \mathrm{pp.}$ Stanford University. 1910. A PHYTOGEORAPHIC AND TAXONOMIC STUDY OF THE SOUTHERN CALIFORNIA TREES AND SHRU'BS. N. Y. Bot. Gard. Bull. 6: 300-485.

1923. AN ILUUSTRATED FLORA OF THE PACIFIC stATES, WAgHiNGTON, OREGON, AND CALIFORNIA. v. 1, illus. Stanford University. and SMILEY, F. J.

1915. TaxoNomy and distribution of eniodictyon. Bot. Gaz. 60: 115133 , illus.

(6) Afanasiev, M.

1936. Dormancy in seed of Magnolia aCuminata L. Amer. Jour. Bot. $23: 692$.

(7) AIKMAN, J. M.

1930. SECONDARY PLANT SUCCESSION ON MUSCATINe IgLAND, IOWA. Ecelogy 11: 577-588, illus.

(8)

1935. THE RETATTON OF THE STAGES OF PIANT SUCCESBION TO SOIL EROSION. Iowa State Col. Jour. Sci. 9: 379-389, illus.

(9) Aldous, A. E., and Shantz, H. L.

1924. TXPES OF VEGETATION IN THE SEMIARID PORTION OF THE UNITED STATES AND THEIR eCONOMIC sIgNuFicance. Jour. Agr. Research 28: 99128 , illus.

(10) Aldous, C. M.

1936. Food habits of LePUS americanus PHAEANotus. Jour. Mammal. $17: 175-176$.

(11) Allen, J. A.

1864. CATALOGUE OF THE BIRDS FOUND AT SPRINGFIELD, MASGACHUSETTS, With notes on their migrations, habits, etc. Essex Inst. Proc.

(12) 4: $48-98$.

(13) Allen, O. N., and AlleN, E. K.

1936. PLANTS IN THE SUB-FAMILY CAESALPINIOIDEAE OBSERVED TO BE LACKING NODUTES. Soil Sci. 42: 87-91.

(14) Aluison, A.

1904. THE BIRDS OF WEST Baton ROUGe PARISH, LOUISIATA. Auk 21:472484.

(15) American Joint Committee on Horticultural Nomenclature.

1924. STANDARDized PLANT Names. Prepared by F. L. Olmstead, F. V. Coville, and H. P. Kelsey. 564 pp. Salem, Mass.

(16) american Railway Engineering Assoctation.

1929. VEgETAtion FOR PROTECTION OF SLOPES FROM EROSION. Engin. and Contract. 68: 526.

(17) AMFrican Rose Societr.

1920. THF AMERICAN ROSE ANNUAL 5; THE 1920 YEAR-BOOK OF ROSE PROGRESS. 188 pp., illus. Harrisburg, Pa.

(18) Anderson, P. O.

1936. TREeS AND TREe PLANTING TOGETHER WITH A DESCRTPTIVE CATALOG OF COMMON FOREST TRFES OF MINNESOTA AND THE LAKE STATES. 95 pp., illus. St. Paul, Minn.

(19) ANDREWs, E. F.

1919. THE JAPANESE HONEYSUCKLE IN THE EASTERN UNITED STATES. Tor-

(20) AsHE, W. W. reya $19: 37-43$, illus.

(21) 1897. ROBINIA BOYNTONII SP. NOV. CONTRIBUTION FROM MY HERBARIUM NO. II. Elisha Mitchell Sci. Soc. Jour. 14: 51-55.

1918. Notes on trees AND shrúrs. Charleston Mus. Bull. 14 : 29-32.

8 See also mimeographed and unpublished references on page 321 . 
(22) AsHe, W. W.-Continued.

1922. THE EASTERN SHBUBBY SPECIES OF ROBINIA. Elisha Mitchell Sci. Soc. Jour. $37:$ 175-177.

(23)

1923. NOTES ON TREES AND SHRUBS OF THE SOUTHEAפTERN UNITED STATES. Rhodora 25: 179-183.

(24)

1923. NOTES ON SHRUBS OF THE SOUTHEA STERN STATES. Elisha Mitchell Sci. Soc. Jour. 39 : 110-111, illus.

(25) Ashton, R. E.

1933. Plants of rocky mountain national Park. U. S. Natl. Park Serv. 157 pp., illus. Washington, [D. C.]

(26) Atwood, A. C.

1930. state ANd local floras . . . Wild Flower Preservation Soc. Bull. $1,16 \mathrm{pp}$.

(27) Audubon, J. J.

1831-39. ORNITHOLOGICAL BIOGRAPFY, OR AN ACCOUNT OF THE HABITS OF THE BIRDS OF THE UNITED STATES OF AMERICA. 5 v., illus. Edinburgh.

(28) AYRes, Q. C.

1936. SOIL EROSION AND ITS CONTROL. 365 pp., illus. New York.

(29) BaILEX, F. M.

1917. BIRDS OF THE HUMID COAST. Condor 19: 95-101, illus.

1928. BIRDS OF NEW Mexico . . 807 pp., illus. [Santa Fe, N. Mex.]

(31) BAILEY, L. H.

1925. MANUAL OF CULTIVATED PLANTS; A FLORA FOR THE IDENTIFICATION OF THE MOST COMMON OR SIGNIFICANT SPECIES OF PLANTS GROWN IN THE CONTINENTAL UNITED STATES AND CANADA ... $851 \mathrm{pp}$, illus. New York and London.

(32)

1932. THE BLACKBERRIES OF NOBTH AMERICA.- His Gentes Herbarum $2: 271-423$, illus.

(33) 1933. BLACKBERRIES OF THE LOWER soUTH. His Gentes Herbarum 3: 119-148, illus.

(34) 1934. THE speCies OF GRAPES PECULIAR TO NORTH AMERICA. His Gentes Herbarum 3: 151-244, illus.

(35) 1934. american Palme'toes. His Gentes Herbarum 3: 275-339, illus.

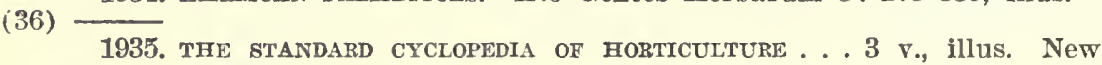

(37) BAILEY, V. York.

1905. BIOLOGICAL SURVEY OF TEXAS: LIFE ZONES WITH CHARACTERISTIC SPECIES OF MAMMALS, BIRDS, REPTILES, AND PLANTS. U. S. Dept. Agr. North Amer. Fauna 25, 222 pp., illus.

(38) 1922. BEAVER HABITS, BEAVER CONTROL, AND POSSIBIIITTES IN REAVER FARMING. U. S. Dept. Agr. Bull. 1078, 31 pp., illus.

(39) 1923. SOURCE OF WATER SUPPLY FOR DESERT ANIMALs. Sci. Monthly 17 : $66-86$, illus.

(40) 1926. BIOLOGICAL SURVEY OF NORTH DAKOTA. I, PHYSIOGRAPHY AND LIFE zones. I, тhe mamimals. U. S. Dept. Agr. North Amer. Fauna 49,226 pp., illus.

(41)

1931. mammals of New Mexico. U. S. Dept. Agr. North Amer. Fauna 53,412 pp., illus.

(42)

1936. the mammals and life zones of oregon. U. S. Dept. Agr. North Amer. Fauna 55, 416 pp., illus.

(43) BAIRd, S. F., BREWER, T. M., and RIDGeWAy, R.

1874. A HISTORY OF NORTH AMERICAN BIRDS. v. 2, Land Birds, 590 pp., illus. Boston. 
(44) Baker, F. S., and Konstian, C. F.

1931. SUITABILITY OF BRUSH LANDS IN THE INTERMOUNTAIN REGION FOR THE GROWTH OF NATURAL OR PLANTED WESTERN YELLOW PINE FORESTS. U. S. Dept. Agr. Tech. Bull. 256, 83 pp., illus.

(45) BAKER, O. E.

1936. ATLAS OF AMERICAN AGRICULTURE. PHYSICAL BASIS, INCLUDING LAND RETIFF, CLIMATE, SOILS, AND NATURAL VEGETATION OF THE UNITED STATES. 4 v., illus. Washington, D. C.

(46) BALL, C. R.

1905-15. NOTES ON NORTH AMERICAN WILLOWS. I-III. Bot. Gaz. 40: 376380 illus. $1905 ; 60: 45-54,391-399$, illus. 1915.

1921. Undescribed Whlows of the section condatae. Bot. Gaz. 71: $426-437$, illus.

(49) BaRKLEY, F. A.

1921. Notes on wimlows of sections pentandrae and nigrae. Bot. Gaz. 72: 220-236, illus.

1935. POISON IVY AND POISON SUMAC AS AN ETTOLOGIC FACTOR IN CONTACT dermatitis in the central states. Okla. Acad. Sci. Proc. 15: $22-30$, illus.

(50)

1937. A MONOGRAPHIC STUDY OF RHUS AND ITS IMMEDIATE ALLIES IN NORTH aNd CENTRAL aMerica, inCluding the West indies. Ann. Mo. Bot. Gard. $24: 256-498$.

(51) and BARKLEY, E. A.

1933. EPHEDRA ANTISIPHILITICA MEYTER, ESTABLISHING ANOTHER ORDER OF plaNts for oklahoma. Okla. Acad. Sci. Proc. 13: 11-12.

(52) Barnes, C. T.

1927. Utah Mammals. Utah Univ. Bull. v. 17, no. 12, 183 pp., illus.

(53) Barnes, W. C.

1935. ARIzona Place Names. Ariz. Univ. Gen. Bull, 2, 503 pp., illus.

(54) BaRnhaRT, J. H.

1910. KOEBERIJNIACEAE. North Amer. Flora 25: 101-102.

(55) BARRETT, M. F.

1931. A FIELD KEY TO THE GENERA OF THE WILD AND CUITIVATED HARDY TREES OF THE NORTHEASTERN UNITED STATES AND CANADA. 40 pp., illus. Bloomfield, N. J.

(56) BarRows, W. B.

1912. MICHIGAN BIRD LIFe. Mich. Agr. Coll., Dept. Zool. and Physiol.

(57) BEAL, W. J. Spec. Bull., 822 pp., illus.

1904. MICHIGAN FLORA; A LIST OF THE FERN AND SEED PLANTS ¥ROWING without cultrvation. $147 \mathrm{pp}$. Lansing, Mich.

(58) Beath, O. A., Draize, J. H., and Gilbert, C. S.

1934. Plants porsonous to LIVEstock. Wyo. Agr. Expt. Sta. Bill. 200,

(59) Bending, L. 84 pp., illus.

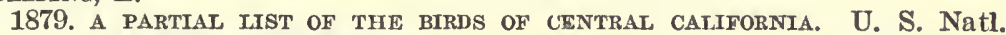
Mus. Proc. 1: 388-449.

(60)

1890. LAND birds of the Pacific District. Calif. Acad. Sci. Occas. Papers 2, 274 pp.

(61)

1892. FOOD OF THE GROUSE AND MOUNTAIN QUAIL OF CENTRAL CALIFORNIA. Zoe 3: 232-234.

(62)

1904. explanatory. Condor 6: 74-76.

(63) BENDIRE, C. E.

1877. NOTES ON SOME OF THE BMDS FOUND IN SOUTHEASTERN OREGON, ETC. Boston Soclety Nat. Hist. Proc. 19: 109-149.

(64)

1892. LIFE HISTORIES OF NORTH AMERICAN BIRDs. Smithsn. Inst. Pub. 840, v. 1, 446 pp., illus. 
(65) Brindre, C. E.-Continued.

1895. LIFE HISTORIES OF NORTH AMERICAN BIRDS FROM THE PARROTS TO THE GRACKLES, WITH SPECIAL REFERENCE TO THEIR BREEDING HABITS AND EGGS. Smithsn. Inst. Contrib. 985, 518 pp., illus.

(66) Benson, G. T.

1930. THE TREES AND SHRUBS OF WESTERN OREGON. $170 \mathrm{pp}$., illus. Stanford

(67) Bent, A. C. Univ. (Dudley Herbarium Stanford Univ. Contrib. v, 2).

1932. LIFE HISTORIES OF NORTH AMERICAN GALLINACEOUS BIRDS. ORDERS GaLlTFormes and ColUmbiformes. U. S. Natl. Mus. Buli. 162, 490 pp., lllus.

(68) Berguan, H. F.

1912. flora of NORTH DAkota. N. Dak. Soil and Geol. Survey Bien. Rept. $6: 147-387$, illus.

(69) BERRY, E. W.

1917. NOTES ON THE HISTORY OF THE WILlows AND POPLARS. Plant World $20: 16-28$, illus.

(70) Bidwelt, G. L., and Wooton, E. O.

1925. Saltbushes aNd thetr allies IN THE UNited states. U. S. Dept. Agr. Bull. 1345, 40 pp., illus.

(71) BrRd, L. G., and Bird, R. D.

1931. WINTER FOOD OF OKLAHOMA QUAT,. Wilsou Bull. 43: 293-305.

(72) BLAIR, W. F.

1936. THE FLORIDA MARSh rabrit. Jour. Mammal. 17: 197-207.

(73)

1937. THE BURROWS AND FOOD OF THE PRAIRIE POCKET MOUSE. Jour. Mammal. 18: 188-191.

(74) BLAKE, S. F.

1914. THE EARliest NAME OF THE sNowberRy. Rhodora 16: [117]-119.

(75) BLAKISTON.

1863. ON THE BIRDS OF THE INTERIOR OF BRITISH NORTH AMERICA. Ibis 5: 39-87, 121-155.

(76) BLUMER, J. C.

1908. DISTRIBUTTONAL FEATURES OF SOME southWESTERN sHRUBS. Plant World 11: [117]-123.

(77) BODE, I. T.

[n. d.] A HANDBook of the Native trees of Iowa. 95 pp., illus. Ames, Iowa.

(78) BOGUE, E. E.

1900. AN ANNOTATED CATALOG OF THE FERNS AND FLOWERING PLANTS OF oklahoma. Okla. Agr. Expt. Sta. Bull. 45, 48 pp.

(79) Branner, J. C., and Coville, F. V.

1891. A tist of THE Plants of arkansas. Ark. Geol. Survey Ann. Rept. 1888: $155-242$.

(80) BrauN, E. L.

1936. NOTES ON ROON BEHAVIOR OF CERTAIN TREES AND SHRUBS OF THE ILLINOIAN TILL PLAIN OF SOUTHWESTERN OHIO. Ohio Jour. Scl. 36: 141-146, illus.

(81) Bray, W. L.

1904. FoREst RegOURCES OF Thixas. U. S. Bur. Forestry Bull. 47, 71 pp., illus.

(82) Brayton, A. M.

1882. RePORT ON THe mammals of ohio. Rept. Geol. Survey Ohio 4, pt. 1, Zool. sec. 1, $185 \mathrm{pp}$.

(83) Brew stwR, W.

1895. A REMARKabLe FLight OF PINE gROSBEAKS (PINICOLA ENUCleator). Auk 12:245-256.

(84)

1902. BIRDS OF THE CAPE RDGION OF LOWER CALIFORNIA. Bull. Mus. Compar. Zool. 41, 241 pp.

(85)

1906. BIRDS OF THE CAMBRIDGE REgion of MassachusetTs. Mem. Nuttall Ornithol. Club 4, 426 pp., illus.

(86) Britton, N. L.

1905. cunoniaceae, iteaceae, hamamelddaceae. North Amer. Flora 22 : $179-180,181,185-187$. 
(87) Britton, N. L.-Continued.

1914. Clethrackae. North Amer. Flora 29: 3-9.

1930. krameriaceae. North Amer. Flora 23: 195-200.

(89) — and Brown, $A$.

1913. AN ILLUSTRATED FLORA OF THE NORTHERN UNITED STATES, CANADA, AND THE BRITISH POSSESSIONS . . E. Ed. 2, rev. and enl., 3 v. illus. New York.

(90) and Rose, J. N.

1928. MIMOSACEAE. North Amer. Flora 23: 1-194.

(91) — and Rose, J. N.

1930. CAESALPINIACEAE. North Amer. Flora 23: 201-349.

(92) - and Shafer, J. A.

1908. NORTH AMERICAN TREES . . . 894.pp., illus. New York.

(93) Bromley, S. W.

1935. ORIGINAL FOREST TYPes OF SOUTHERN NEW RNGLAND. Ecol. Monog. 5: $63-89$, illus.

(94) Bвоокs, A. B.

1920. West vibginia tries. W. Va. Agr. Expt. Sta. Bull. 175, 242 pp., illus.

(95)

1936. A New Holly For west virginia. South. Appalachian Bot. Club. Jour. 1 : 83-85, illus.

(96) Brooks, E. A.

1920. WHITE-WINGED CROSSBILL (LOXIA LEUCOPTERA) IN WEST VIRGINIA. Auk 37: 457.

(97) Brows, C. A.

[1937]. FERNs ANd Flowering PLANTs of isle royale, michigan. U. S. Natl. Park. Serv., 90 pp. lllus.

(98) Brown, H. P.

1922. TREeS OF NEW YORK STATh, NATIVE AND NATURALIzED. N. Y. State

(99) Brush, W. D.

Col. Forestry, Syracuse Univ., Tech. Pub. 15, 433 pp., illus.

1918. Utilization of FLm. U. S. Dept. Agr. Bull. 683, 43 pp., illus.

(100) Buch holz J. T., and Matroon, W. R.

1924. COMMON FOREST TREES OF ARKANSAS; HOW TO KNOW THEM ; A POCKET mandal. Ark. Agr. Col. Ext. Cir. 180, 84 pp., illus.

(101) Burns, G. P., and OTts, C. H.

1916. THe trees of VermoNt. Vt. Agr. Expt. Sta. Bull. 194, 244 pp., illus.

(102) BRyaNT, H. C.

1911. THE RELATION OF BIRDS TO AN INSECT OUTBREAK IN NORTHERN CALIFORNIA DURING THE SPRING AND SUMMER OF 1911. Condor 13: 195-208, illus.

(103)

1914. A DETERMINATION OF THE ECONOMIC STATUS OF THE WESTERN MEADOW-LARK (STURNELLA NEGLECTA) IN CALIFORNIA. Calif. Unlv. Pubs., Zool., 11: 377-510, illus.

(104)

1916. HABITS AND FOOD OF THE ROAD-BUNNER IN CALIFORNIA. Calff. Univ. Pubs., Zool. 17 : 21-58, lllus.

(105) BRYaNt, W. E.

1893-94. NOTES ON THE FOOD OF BIRDS. Zoe 4: 54-58.

(106) BUtler, A. W.

1891. A catalogue of the birds of indiana. Ind. Hort. Soc. Trans. 1890, App. C, 135 pp., illus.

(107)

1893. FURTHER NOTES ON THE EVENiNg GROSBEAK. Auk 10: 155-157.

(109) Cameron, E. S.

1897. The BIRds of INDiana. Ind. Dept. Geol. and Nat. Resources Ann. Rept. 22: 515-1187, illus.

1908. THE BIRDS OF CUSTER ANE DAWSON COUNTIEs, MONTANa. Auk 25: $39-56$.

(110) Campbel, E. G.

1925. PLANT RELATIONS IN BRAZOS COUNTY, TEXAS, WITH SPECIAL REFERENCE TO EASTERN AND WESTERN TYPES. Ecology 6: 163-170, illus. 
(111) Campbeil, R. S.

1929. VEGETATIVE SUCCESSION IN THE PROSOPIS SAND DUNES OF SOUTHERN NEW MEXICo. Ecology 10:392-398, illus.

(112) and KetLER, J. G.

(113) Cannon, W. A.

1932. GROWTH AND REPRODUCTION OF YUCCA ELATA. Ecology 13: 364374 , illus.

1911. the root habits of Desert plants. Carnegie Inst. Wash. Pub. 131, 96 pp., illus.

(114) Cary, C. A., Miller, E. R., and Johnstone, G. R.

1924. Polsonous plants of aladbama. 42 pp. illus. Auburn, Ala. (Ala. State Bd. Agr., Livestock Sanit. Dept. Bull., also issued as

(115) CARY, M. Ala. Ext. Serv. Cir. 71).

1911. Btological survey of Colorado. U. S. Dept. Agr. North Amer. Fauna 33, 256 pp., illus.

(116) Castetter, E. F.

1935. Uncutitivated Native Plants USed AS sounces of Food. N. Mex. Univ. Bull. 266, Biol. Ser. v. 4, no. 1, 62 pp., illus.

(117) Chapman, A. G.

1936. A BASIS FOR SELECTION OF SPECIES FOR REFORESTATION IN THE CENtral hardwood Region. Cent. States Forest Serv. Expt. Sta. Note $29,6 \mathrm{pp}$.

(118) Chapman, A. W.

1897. FLORA OF THE SOUTHERN UNited states. Ed. 3, 655 pp. Cambridge, Mass.

(119) Chesnut, V. K., and Wilcox, E. V.

1901. THE STOCK-POISONING PLANTS OF MONTANA : A PRELIMINARY REPORT. U. S. Dept. Agr., Div. Bot. Bull. 26, 150 pp., illus.

(120) Clements, F. E.

1916. CLIMAX Formations of NORTH AMERICA. Carnegie Inst. Wash. Pub. 242: 184-237.

(121) 1935. eXPERIMENTAL ECOLOG IN THE PUBLIC SERVICE. Écology 16: 342363.

(122) Clepper, H. E.

1931. THE DEER Problem in the Forests of PENnsyluania. Pa. Dept. Forest and Waters Bull. 50, 45 pp., illus.

(123) Clover, E. U.

1937. VEgETATIONAL SURVEY OF THE LOWER RIO GRANDE VALLEY, TEXas.

(124) COAD, B. R. III. COASTAL CLIMAX associations. Madroño 4:77-100, illus.

1916. STUDIES ON THE BIOLOGY OF THE ARIZONA IVILD COTTON WEEVIL. U. S. Dept. Agr. Bull. 344, 23 pp. illus.

(125) Cocks, R. S.

1921. A IIST OF THE TREes of IOUISIANA. Arnold Arboretum Jour. 2: 204-216.

(126) 1922. A IIST OT THE shrubs OF LoUisiana. Arnold Arboretum Jour. $3:[174]-182$.

(127) CoKER, W. C.

1915. our modntain shrubs. Elisha Mitchell Sci. Soc. Jour. 31: 91-112.

(128) 1920. AZALEA ATLANTICA ASHE AND ITS VARIETY LUTES-ALBA N. VAR. Elisha Mitchell Sci. Soc. Jour. 36: 97-99, illus.

(129) and TOTTEN, H. R.

1934. TREES OF THE SOUTHEASTERN STATES, INCLUDING VIRGINIA, NORTH CAROLTNA, SOUTH CAROLINA, GEORGIA, AND NORTHERN FLORIDA. 399 pp., illus. Chapel Hill, N. C.

(130) Conkun, W. G., and MorTon, J. N.

1935. MORJ Foon For UPIAND GAME. Pa. Game Comn. Bull. 11, rev., 37

(131) Coor, A. J. pp., illus.

(132) CooLey, L. M.

1936. Wild Rramble eradication. N. Y. State Agr. Expt. Sta. Bull. 674, 32 pp., illus. 
(133) CoOPER, J. G.

1870. LAND RIRDS. Geol. Survey, Calif., Ornith., v. 1, 592 pp., illus. Cambridge.

(134) COOPER, W. S.

1922. THE BROAD SCLEROPHYLL VEGETATION OF CALIFORNIA; AN ECOLOGICAL STUDY OF THE CHAPARRAL AND ITS RETATED COMMUNITIES. 124

(135) CoRY, V. L. pp., illus. Washington, D. C. (Carnegie Inst. Wash., Pub. 319).

1936. THREE JUNIPERS OF WESTERN TEXAS. Rhodora 38: 182-187.

(137) CotTalf, C.

1936. NEW NAMES AND NEW Combinations For TEXas Plants. Rhodora 38: $404-408$.

1929. THe statug of the RING-NECKed pheasant in Utah. Condor 31 : $117-123$.

(139) Сотти, H. J.

1936. THE PLACE OF FOOD HABITS RESEARCH IN WLLDIFE MANAGEMENT. Utah Juniper, July 1936, pp. 16-19.

(140) Coues, E.

1932. VEGETATION ON NORTH AND SOUTH SLOPES OF MOUNTAINA IN SOUTHWESTERN TEXAS. Ecology 13: 121-134, illus.

1866. FIHLD NOTES ON LOPHORTYX GAMBEII. Ibis 5: 46-55.

1874. BIRDS OF THE NORTHWEST: A HANDBOOK OF THE ORNITHOLOGY OF THE RBGION DRAINED BY THE MISSOURI AND ITS TRIBUTARIES. U. S. Dept. Int. Misc. Pub. 3, 791 pp.

(142)

(143) Coulter, J. M.

1878. birds of the colorado valley. U. S. Dept. Int. Misc. Pub. 11, 807 pp., illus.

1891-94. BOTANY OF WESTERN THXAS; MANUAL OF THE PHANEROGAMS AND PTERIDOPHYTES OF WESTERN texas. U. S. Dept. Agr., Herbarium Div. Bot. Contrib. U. S. Natl. Herbarium 2, 588 pp., illus.

(144) - and NelsoN, A.

1909. NEW MANUAT OF BOTANY OF THE CENTRAI ROCKY MOUNTAINS (VAScular Plants). Rev. by A. Nelson. $646 \mathrm{pp}$. New York and Cincinnati.

(145) Covilua, H. V.

1897. THE AUGUST VBgetation of moUnt MAZAMA, OREgon. Mazama 1: 170-203, illus.

(146) - and BRITTON, N. L.

1908. grossutadiacelate North Amer. Flora $22:$ 193-225.

(147) and GIMAN, M. F.

1936. THTRACOCCUS ILICIFOLIUS, A NEW SHRUB FROM DEATH VALLEY, CALIFORINIA. Wash. Acad. Sci. Jour. 26: 530-535.

(148) Critty, R. I.

1933. THE IOWA FLorA . . . Iowa State Col. Jour. Sci. 7 : 177-252.

(149) Croxton, W. C.

1928. REVEGETATION OF IILINOIS COAL STRIPPED LANDS. Ecology 9: 155175 , illus.

(150) Dahlgren, B. E., and Not, A. C.

1936. INDEx of AMERICAN PALM. Fleld Mus. Nat. Hist. [Chlcago] Pub.,

(151) DatKR, P. D. Bot. Ser. 14, $456 \mathrm{pp}$.

1935. CARRYING CAPACTTY OF PHEASANT RANGL Amer. Game 3 pp., illus.,

(152) March-April.

1935. DROPPING ANALYSES AS AN INDICATION OF PHEASANT FOOD HABITS. Amer. Game Conf. Trans. 21:387-391.

(153)

1987. FOOD HABITS OF ADULT PHEASANTS IN MICHIGAN BASED ON CROP ANALXSIS METHOD. Ecology 18: 199-213, illus. 
(154) Darrow, G. M., and Detwiller, S. B.

1933. CURRANTS AND GOOSEBERRIES ; THETR CULTURE AND RELATION TO WHITEPINE BLISTER RUST. U. S. Dept. Agr. Farmer's Bull. 1398, 43 pp.,

(155) Dawson, W. L. illus. (revised).

1923. THE bIrios of CAliforinia. 4 v., illus. San Diego.

(156) - and BowLEs, J. H.

1909. THE BIRDS OF WASHINGTON, 2 v., illus. Seattle.

(157) - and JoNEs, L.

1903. THE BIRDS OF OHIO. 671 pp., illus. Columbus, Ohio.

(158) Dayton, W. A.

1931. important westeirn browse Puants. U. S, Dept. Agr. Misc. Pub. 101, 214 pp., illus.

(159)

1937. FERNOW HICRORY (HICORIA FERNOWIANA SUDW.). Jour. Forestry 35 : 859-864, illus.

(160) - and others.

1937. Range Plant handbook. Illus. U. S. Dept. Agr.

(161) DUAM, C. C.

1931. TREes of Indiana. Ind. Dept. Conserv., Div. Forestry Pub. 13, rev. 1, 326 pp., illus. Fort Wayne, Ind.

(162)

1932. shrubs of indiana. Ind. Dept. Conserv. Pub. 44, rev. ed., 380 pp., illus.

(163) Delarborn, $\mathrm{N}$.

1932. FOODS OF SOME PREDATORY FUR-BEARING ANIMALS IN MICHIGAN. Mich. Univ. School Forestry and Conserv. Bull. 1, 52 pp., illus.

(164) DEKAY, J. E.

1844. ZOOLOGY OF NEW YORK, OR THE NEW YORK FAUNA. In Natural History of New York, pt. II, Birds, 380 pp., illus. Albany, N. Y.

(165) DETWLER, S. B.

1937. THE HISTORY OF SHIPMAST LOCUST. Jour. Forestry 35: 709-712, illus.

(166) Dice, L. R.

1918. THE BIRDS OF WALLA WALLA AND COLUMBTA COUNTIES, SOUTHEASTERN WASHINGTON. Auk 35: 148-161.

(167) DieTz, S. M.

1923. THE RÔLE OF THE GENUS RHAMNUS IN THE DISSEMINATION OF CROWN RUst. U. S. Dept. Agr. Bull. 1162, 19 pp., illus.

(169) DixoN, H.

1926. THE ALTERNATE Hosts OF CROWN RUST, PUCCINIA CORONATA CORDA. Jour. Agr. Research 33: 953-970, illus.

1935. hCological studies on the high PLATEAUs of UTAH. Bot. Gaz. 97 : $272-320$.

(170) Dixon, J. S.

1934. A STUDY OF THE LIFE HISTORY AND FOOD HABITS OF MULE DEER IN CALIFORNIA. . . 146 pp., illus. Sacramento, Calif. (Reprint from Calif. Fish and Game, v. 20, nos. 3-4.)

(171) DOAN, W. D.

1888. birds of West virainia. W. Va. Agr. Expt. Sta., Bull. 3, pp. 44-88.

(172) DODGE, N. N.

1936. TREes OF GRAND Canyon Nattonal Park. Grand Canyon Natl. Hist. Assoc. Nat. Hist. Bull. 3, 69 pp., illus.

(173) Dresser, H. E.

1866. NOTES ON THE BIRDS OF SOUTHERN TEXAS. Ibis $5: 23-46$.

(174) EAsTWOOD, A.

1891. THE COMMON SHRUBS OF SOUTHEASTERN COLORADO. Zoe 2 : 102-104.

(175) $\overline{1934}$. A REVISION OF ARCTOSTAPHYLOS WITH KEY AND DESCRIPTIONS. Leaflet West. Bot. 1: 105-127.

(176) EDGE, E. R.

1935. A STUDY OF THE RETAATION OF THE DOUGLAS GROUND SQUIRREL TO THO VEGETATION AND OTHER ECOLOGICAL FACTORS IN' WESTERN OREGON. Amer. Midland Nat. 16: 949-959. 
(177) EuLiotT, C. N.

1931. KeY to aborain trees. Ga. Forest Serv. Bull. 13: 54 pp., illus.

(178) Enders, R. K.

1932. FoOD GF THe MUSkrat IN SUMMER. Ohio Jour. Sci. 32: 21-30.

(179) ERrington, P. L.

1931. THE NORTHERN BOBWHITE's WINTER FOOD. part i-ii. Amer. Game July-August, September-October.

(180) 1936. DIFTERENCES IN NUTRITIVE VALUES OF WINTER GAME FOODS. Amer. Wildlife Conf. Proc. 1936: 356-360.

(181) and HAMERSTROM, F. N., JR.

1956. THE NORTHERN BOBWHITE'S WINTER TERRITORY. IOWa Agr. Expt. Sta. Bull. 201, pp. 301-443, illus.

(182) EWAN, J.

1936. Bibliography of THE Botany of aRizona. Amer. Midland Nat. 17 : $430-454$.

(183) Farweit, O. A.

1915. RANGe EXTENStoN OF CEANOTHUS SANGUINEUS. Rhodora 17 : [229]230.

(184) Fent, E. P., and RaNkin, W. H.

1932. INSECTS AND DISEASES OF ORNAMENTAL TREES AND SHRUBS. 507 pp., illus. New York.

(185) FerNaLd, M. L.

1923. THE IDENTITIES OF THE SAND CHERRIES OF EASTERN AMERIOA. Rhodora 25: [69]-74.

(186) 1924. NEW OR RECENTLY RESTUDIED PLANTS OF EASTERN AMERIOA. Rhodora $26: 122-127$.

(187) 1925. AMFRTCAN REPRESENTATIVES OF IONICERA CAERULFA. Rhodora 27 : $1-11$.

(188) Finlay, M. C.

1934. OUR AMERTCAN MAPLES AND SOME OTHERS. $19 \mathrm{pp}$., illus. New York.

(189) FISKE, J. G.

1932. SOME poisonous plants of New JeRser. N. J. Agr. Expt. Sta. Cir. 261, 30 pp., illus.

(190) Fleming, C. E., Miller, M. R., and Vawter, L. R.

1922. THE SPRING RABBIT-BRUSH (TETRADYMIA GLABRATA), A RANGE PLANT PoIsonous to sheep. Nev. Agr. Expt. Sta. Bull. 104, 29 pp., illus.

(191) MILLER, M. R., and VAwTER, L. R.

1928. THE GREASEWOOD (SARCOBATUS VERMIOULATUS), A RANGE PLANT PoIsonous to sheep. Nev. Agr. Expt. Sta. Bull. 115, 23 pp., illus.

(192) and SCHAPELLE, B. F.

1918. range plants potsonous to sheEP and cattrle in Nevada. Nev. Agr. Expt. Sta. Bull. 95, 51 pp., lllus.

(193) FLETCHER, W. F.

1915. THE NATIVE PERsimmon. U. S. Dept. Agr. Farmers Bull. 685, 22 pp., illus (Revised 1935).

(194) FLOWERS, S.

1934. vegetation of the great SAlt LAKE REgion. Bot. Gaz. 95: 353418 , illus.

(195) Forbes, E. B., and Beorder, S. I.

1931. MOUNTAIN LAUREL AND RHODODENDRON AS FOODS FOR THE WHITE TAILED DEER. Ecology 12: 323-333, illus.

(196) Forres, R. H.

1895. The mesquite trez; its products and usfi. Ariz. Agr. Expt. Sta. Bull. 13, pp. [15]-26, illus.

(197) Forbush, E. H

1925-29. BIRDS OF MASSACHUSETTS AND OTHER NEW ENÒLAND STATES. $3 \mathrm{v}$.,

(198) Ford, R. E. illus. Norwood, Mass.

1933. trea windbreaks for colorado. Colo. Agr. Col. Ext. Serv. Bull. 326-A, 23 pp., illus. 
(199) Forsung, C. L., and Storm, E. V.

1929. THE UTILIZATION OF BROWSE FORAGE AS SUMMET RANGE FOR CATTLEE IN gOUTHWESTERN UTAH. U. S. Dept. Agr. Cir. 62, 30 pp., illus.

(200) Foster, J. H.

1931. TREES AND SHRUBS OF NEW HAMPSHIRE. With N. H. Forestry Comn. Biell. Rept. 1929-30, 131 pp., illus.

(201) - KraUsz, H. B., and Lempigh, A. H.

1917. GENERAL SURVEY OF TRXAS WOODLANDS, INCLUDING A STUDY OF TIIE COMMERctal possibilities of mesquite. Tex. Agr. Col. Dept. Forestry Bull. 3, 47 pp., illus.

(202) Fox, A. C.

1937. PRAIRIE SHARP-TATHED GROUSE BUdDING ON WILD PLUM. Auk 54: $534-535$.

(203) Fred, E. B., Baldwin, I. L., and McCoy, E.

1932. rOOT NODULE BACTERIA AND LEGUMINOUS PLANTS. Wis. Univ. Studies in Sci. 5, 343 pp., illus.

(204) FrothinghaM, H. H.

1909. DOUGLAS FIR: A STUDY OF THE PACIFIC COAST AND ROCKY MOUNTAIN Forms. U. S. Forest Serv. Cir. 150, 38 pp., illus.

1915. THE EASTERN HEMLOCK. TSUgA CANADENSIS (LINN. CARR.) U. S. Dept. Agr. Bull. 152, 43 pp., illus.

(206) FrYe, T. C., and RIGG, G. B.

1912. NORTHWEST FLORA. $453 \mathrm{pp}$. Seattle.

(207)

1914. ELLMENTAIY FLORA OF THE NORTHWFST. $256 \mathrm{pp.} \mathrm{New} \mathrm{York} \mathrm{and}$ Cincinnati.

(208) FYLES, F.

1920. Principal Poisonovs Plants of canada. Cauada Dept. Agr. Expt. Farms. Bull. 39, ser. 2, 112 pp., illus.

(209) Gabristion, I. N.

1928. NOTES ON THE HABITS AND BEHAVIOR OF THE PORCUPINE IN OREGON. Jour. Mammal. 9: 33-38, illus.

(210) GaNDER, F. F.

1928. OBSERVATIONS ON THE FEEDING HARITS OF SOME COMMON BIRDS. Condor 30: 362-363.

(211) Garman, H.

1914. SOME KENTUCKY WEFDS AND POISONOUS I'LANTS, Ky. Agr. Expt. Sta. Bull. 183, [253]-339, illus.

(212) Gates, F. C.

1912. THE VEgETATION OF THE BEACH AREA IN NORTHEASTERN ILLINOIS AND southeastern wisconsin. Bull. Ill. State Lab. Nat. Hist. $9: 255-372$, illus.

(213)

1928. HandBook of Kansas trees. Kansas State Bd. Agr. Rept. 47: 148-372, illus.

(214)

1930. princtpal poisonous plants of Kansas. Kans. Agr. Expt. Sta. Tech. Bull. 25, 67 pp., illus.

(215) Gentry, T. G.

1876-77. LIFE HISTORIES OF BIRDS OF EASTERN PENNSYLVANIA. 2 V., Philadelphla and Salem.

(216) Grorae E. J.

1936. GROWTH AND SURVIVAL OF DECIDUOUS TREES IN SHELTER-BELT EXPERIMinnts at Mandan, N. DAK., 1915-34. U. S. Dept. Agr. Tech. Bull. 496, 48 pp., illus.

(217) Gigstead, G.

1937. HABITS OF WISCONBIN PHEASANTS. Wilson Bull. 49 : 28-34.

(218) GilkeY, H. M.

1936. HANDBook of NoRthWEst Flowering PLANTs. 407 pp., illus. Portland, Oreg.

(219) Gruman, M. F.

1915. WOODPECKERS OF THE ARIZONA LOWLANDS. Conđor 17: 151-163, illus.

(220) GrRaUd, J. P.

1844. BIRDS OF LONG ISLAND. 397 pp. New York. 
(221) Gleason, H. A.

1908. Platanaceael. North Amer. Flora 22: 227-229.

(222)

1910. THE VEGETATION OF THE INLAND SAND DEPOSITS OF ILIINOIS. Bull. Ill, State Lab. Nat. Hist. 9: 23-174, illus.

(223) Grock, W. S.

1937. OBSERtATIONS ON THE WESTERN JUNIPER. Madroño 4: 21-28, illus,

(224) Glover, G. H., and Robisns, W. W.

1915. colorado plants injurious to livistock. Colo. Agr. Expt. Sta. Bull. 211, 71 pp., illus.

(225) Goldman, E. A.

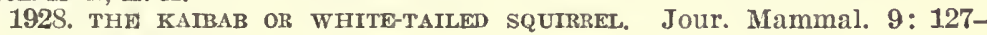
129, lllus.

(226) Gorsuch, D. M.

1934. LIFE HISTORY OF THE GAMBEL QUAIL IN ARIZONA. Ariz. Univ. Biol. Scl. Bull. 2,89 pp., illus.

(227) Goutd, C. N.

1903. NOTES ON TREES, SHRUBS, AND VINES IN THE CHEROKEE NATION. Kans. Acad. Sci. Trans. $18: 145-146$.

(228) Grange, W. B.

1932. OBSERVATIONS ON THE SNOESHOE HARE, LEPUS AMERICANUS PHAENNATUS ALLEN. Jour. Mammal 13: 1-19, lllus.

(229)

1936. SOME OBSERVATIONS ON THE RUFFED GROUSE IN WISCONSIN. WIIsOn Bull. 48: 104-110, illus.

(230) — and MCATEE, W. L.

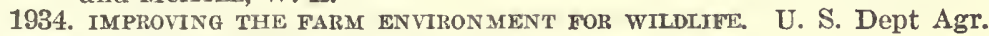
Farmers' Bull, 1719, 62 pp., illus.

(231) Grant, A. L.

1924. A monograph of the gends mimulus. Mo. Bot. Gard. Ann. 11: $99-388$, illus.

(232) GraY, A

1852-53. PLANTAE WRightiana TEXano-Neo Mexicanae. 2 v., illus. [Washington]. (Smithsn. Contrb. Knowledge v. 3, art. 5; v. 5, art. 6).

(233) Green, G. R.

1933-34. TREES OF NORTH AMERIOA• (EXCLUSTVE OF MEXICO). v 1. 1-2, illus. Ann Arbor, Mich.

(234) Grin NeUL, J.

1898. BIRDS OF THE PACTHIC SLOPE OF LOS ANGEUAS COUNTY. Pasadena Acad. Scl. Pub. 2, 55 pp.

(235)

(237) Grinnel, J

1905. SUMMRE BIRDS OF MOUNT PINOS, CALIFORNIA. Auk 22: 378-391.

1909. a biblography of caltrornia obnithology. Pacific Coast Avifauna No. 5, $166 \mathrm{pp}$.

1914. AN ACCOUNT OF THE MAMMALS AND BIRDS OF THE LOWER CGLORADO VALIEY, WITH ESPECIAL REFERENCE TO THE DISTRIBUTIONAL PROBLEMS PRESENTED. Calif. Univ. Yubs., Zool. 12: 51-294, illus.

(238) --, Bryant, H. C., and Storer, T. I.

1918. THE GAME BIRDS OF CALIFORNIA. 642 pp., illus. Berkeley, Calif.

(239) - - Dixon, J. S., and Linspale, J. M.

1937. FUR-BEARING MAMMALS OF CALIFORNIA, THETP NATURAL HISTORY, SYSTEMatic STATUS, aNd RELATions to MaN. 2 v., illus., Berkeley, Calif.

(240) and STORER, T. I.

1924. ANIMAI, LIFE IN THE YOSEMTTE; $\triangle N$ ACCOUNT OF THE MAMMALS, BIRDS, REPTILES, AND AMPHIBIANS IN A CROSB-SECTION OF THE SIERRA nevada. 752 pp., illus. Berkeley, Calif.

(241) and SwARTH, H. S.

1913. AN ACCOUNT OF BIRDS AND MAMMALS OF THE SAN JACINTO AREA OF" southrern CALIFORNIA. Calif. Univ. Pubs., Zool. 10: 197-406, illus. 
(242) Gross, A. O.

1926. FOOD OF RUFFED GRoUSE. Game Breeder 32 : 327-329.

(243)

1930. PROGRESS REPORT OF THE WISCONSIN PRAIRIE CHICKEN INVESTIGATION. Wis. State Conserv. Comn. 112 pp., illus. Madison, Wis.

(244) HaLe, E. M.

1891. ILEX CASSINE, THE ABORIGINAL NORTH AMERICAN TEA. ITS HISTORY, DISTRIBUTION, AND USE AMONG THE NATIVE NORTH AMERICAN indians. U. S. Dept. Agr., Div. Bot. Bull. 14, 22 pp., illus.

(245) HaLt, E. R.

1923. WINTER VISITORS AT LAWRENCE, KANSAS. Auk 40: 701-702.

(246) HAtL, H. M.

1907. compositae of southern california. Calif. Univ. Pubs., Bot. 3: 1-302, tllus.

(247) and Clements, F. E.

1923. THE PHYLOGENETIC METHOD IN TAXONOMY. THE NORTH AMERICAN SPECIES OF ARTEMISIA, CHRYSOTHAMNUS, AND ATRIPLEX. $355 \mathrm{pp}$., illus. Washington. (Carnegie Inst. Wash. Pub. 326.)

(248) - and YATES, H. S.

1915. stock Poisoning plants of california, Calif. Agr. Expt. Sta. Bull. 249, pp. [217]-247, illus.

(249) Hatr, R. C.

1937. GROWTH AND YIELD IN SHIPMAST LOCUST ON LONG ISLAND AND ITS RELATIVE RESISTANCE TO LONUST BORER INJURY. Jour. Forestry $35: 721-727$, illus.

(250) HaMblin, S. F.

1923. LISTS OF PLANT TYPES FOR LANDSCAPE PLANTING; THE MATERIALS OF PLANTING FOR ORNAMENT LISTED ACCORDING TO THEIR VARIOUS uses. $163 \mathrm{pp}$. Cambridge, Mass.

(251) Hamilton, W. J., Jr.

1929. Winter FOOD of the EAstekn SkUNK. Amer. Fur Breeder 2: 4.

(252) 1935 . NOTES ON FOOD OF RED FOXES IN NEW YORK AND NEW ENGLAND. JOur. Mammal. 16: 16-21.

(253) 1936. THE Food AND FEEDING HABITS of THE RACCON. Ohio Jour. Sci. $36: 131-140$.

(254) 1936. SEASONAL FOOD OF SKUNKS IN NEW YORK. Jour. Mammal. 17: 240-246.

(255) HaNSEN, N. E.

1930. THE SHADE, WINDBREAK, AND TIMBER TREES OF SOUTH DAKOTA. S. Dak. Agr. Expt. Sta. Bull. 246, 48 pp., illus.

(256) 1931. THE SHrubs AND climbing vines of south dakota. S. Dak. Agr.

(257) Hanson, H. C. Expt. Sta. Bull. 263, 135 pp., illus.

1924. A STUDY OF THE VEgETATION OF NORTHEASTERN ARIZONA. 94 pp., illus. Lincoln, Nebr. (Nebr. Unlv. Studles 24 : nos. 3-4.)

(258) HARPER, R. M.

1916. AN OVIRLOOKED ENVIRONMENTAL FACTOR FOR SPECIES OF PRUNUS. Rhodora 18: 201-203.

(259) 1928. economic botany of alabama. Ala. Geol. Survey Mono. 9, pt. 2, 357 pp., illus.

(260) HARRIS, H.

1919. BIRDS of the kansas CITY Region. Acad. Sci. St. Louis, Trans. 23: $213-371$.

(261) Harshberger, J. W.

1911. PHYTOGEOGRAPHIC SURVEY OF NORTH AMERICA. In Engler, A., and

(262) Hartian, C. Drude, O., Die Vegetation der Erde, v. 13, illus., New York.

1913. A LIST OF TREES AND SHRUBS OCCURRINA IN THE VICINITY OF HUNTSvILlE, texas. Tex. Acad. Sci. Trans. (1910-12) 12: [66]-90. 
(263) HatT, R. T.

1929. THE RED SQUIRREL: ITS LIFE HISTORY AND HABITS WITH SPECIAL REFERENCE TO THE ADIRONDACKS OF NEW YORK AND THE HARVARD FOREST. Roosevelt Wildlife Ann. 2: 11-146, illus.

(264) Hausman, L. A.

1927. ON THE WINTER FOOD OF THE TREE SWALLOW (IRIDOPROCNE BICOLOR) AND THE MYRTLE WARBLER (DENDROICA CORONATA). Amer. Nat. 61 : 379-382, illus.

(265)

1928. WOODPECKERS, NUTHATCHES, AND CREEPERS OF NEW JERSEY. N. J. Agr. Expt. Sta. Bull. 470, 48 pp., illus.

(266) 1931. THE sylvids AND FLycatchers of New Jersex. N. J. Agr. Expt. Sta. Bull. 531, 32 pp., illus.

(267) 1932. THE viREOS, CUCKOOS, AND SHRIKES OF NEW JERSEY. N. J. Agr. Expt. Sta. Bull. 544, 32 pp., illus.

(268) 1935. the sparrows of New Jersey. N. J. Agr. Expt. Sta. Bull. 580, $32 \mathrm{pp}$., illus.

(269) 1936. THE BUNTINGS, FINCHES, AND THEIR ALLIES OF NEW JERSEY. N. J. Agr. Expt. Sta. Bull. 602, 32 pp., illus.

(270) 1937. THE thrushes ANd MIMIDS of New Jersey. N. J. Agr. Expt. Sta.

(271) HAVARD, V. Bull. 618, 32 pp., illus.

1885. REPORT ON THE FLORA OF WESTERN AND SOUTHERN TEXAS. U. S. Natl. Mus. Proc. 8: 449-533, illus.

(272) HAWKINS, A. S.

1937. Winter FEeding AT FAville GROVe, 1935-36. Amer. Midland Nat. 18: $417-425$.

(273) 1937. WINTER FEEDING AT FAVILLE GROVE, 1985-37. Jour. Wildlife Management 1: 62-69, illus.

(274) Hawkins, P. H.

1924. THE TREES AND SHRUBS OF YeLLOWSTONE NATIONAL PARK . . 125 pp., illus. Menasha, Wis.

(275) HeaLd, F. D.

1933. mandal of Plant diseases. Ed. 2, 953 pp., illus. New York.

(276) HENDERSon, J.

1934. THE PRACTICAL VALUE OF BIRDS. 342 pp. New York.

(277) - and CraIG, E. L.

1932. Economic Mammatogy. 397 pp., illus. Springfield, Ill., and Baltimore.

(278) Henki, A., and Flood, M. C.

1920. THE DOUGLAS FIRS: A BOTANICAL AND SILVTCULTURAL DESCRIPTION OF the various species of pseudotsuga. Roy. Irish Acad. Proc. 35 (sec. B, no. 5) : 67-92, illus. .

(279) Henry, J. K.

1915. FLORA OF SOUTHERN BRITISH COLUMBIA AND VANCOUVER ISLAND, WITH MANY REFERENCES TO ALASKA AND NORTHEBN SPECIES. $363 \mathrm{pp}$. Toronto.

(280) Henshaw, H. W.

1886. IIST OF BIRDS OBSERVED IN SUMMER AND FALL ON THE UPPER PECOS RIVER, NEW MEXICO. Auk 3: 73-80.

(281)

1913. FIFTY COMMON BIRDS OF FARM AND orchard. U. S. Dept. Agr. Farmers' Bull. 513, 31 pp. illus.

(282) HERRICK, G. W.

1935. INSECT ENEMIES OF SHADE-TREes. $417 \mathrm{pp}$., illus. - Ithaca, N. Y.

(283) Hershex, J. W.

1936. balancing a wiLdiffe program. Amer. Wildlife 25: 71, 78, illus.

(284) HITCHCOCK, C. L.

1932. A MONOGRAPHIC STUDY OF THE GENUS IYCIUM OF THE WESTERN HEMISPHERE. Mo. Bot. Gard. Ann. 19: 179-374, illus. 
(285) HoFFMaN, R.

1927. BIRDS OF THE PACIFIC states. 353 pp., illus. New York.

(286) HoFrman, W. J.

1881. anNotated List of the birds of nevada. U. S. Geol. and Geogr. Survey of the Territories Bull. 6: 203-256.

(287) HoLBRooK, S. H.

1936. THE TRAGEDY OF BANDON. Amer. Forests 42: 494-497, illus.

(288) Holt, E. G.

1918. BIRDS AND MULBERRIES. Auk $35: 359-360$.

(289) Hoslet, N. W.

1928. KED SQUTRREL DAMAGE TO CONIFEROUS PLANTATIONS AND ITS RELATION TO CHANGING FOOD HABITS. Écology $9: 43-48$, illus.

(290) 1936. FOOD AND COVER FOR WIIDLIFE. Amer. Wildlife 25: 36, 44-46, illus.

(291) $\frac{1}{1936 .}$ PERMANENT FOOD AND COVER FOR WILDLIFE IN THE NORTHEASTERN UNITED STATES. North Amer. Wildlife Conf. Proc. 1936: 576583.

(292) - and ZikBaRTH, R. K.

1935. SOME WINTER RELATTONS OF THE WHITE-TAILED DEER TO THE FORESTS IN NORTH CENTRAL MASSACHUSETTS. Ecology 16: 535-553.

(293) Howard, W. J.

1936. Restoration of ROADSIDE COVER BY THE c. c. C. Wilson Bull. 48: 101-103, illus.

(294) 1937. NOTES ON WINTER FOODS OF MICHIGAN DEER. Jour. Mammal. 18: $77-80$.

(295) Howel, A. H.

1918. REvision of the aMerican Flying squirRels. U. S. Dept. Agr. North Amer. Fauna 44, 64 pp., illus.

(296) 1921. a riological survey of alabama. U. S. Dept. Agr. North Amer. Fauna 45, 88 pp., illus.

(297) 1924. REVISION OF THE AMERICAN PIKAs (GENUs ochotona). U. S. Dept. Agr. North Amer. Fauna 47, 57 pp., illus.

(298) 1928. BIRDs of Alabama. Ed. 2, 384 pp., illus. Birmingham, Ala.

(299) 1929. REVISION OF THE AMERICAN CHIPMUNKS (GENERA TAMIAS AND eUtamias). U. S. Dept. Agr. North Amer. Fauna 52, 157 pp., illus.

(300) 1932. FLORIDA BIRD LIFE. 579 pp., illus. New York.

(301) HOWELL, T.

1897. A FlORA of NORThWEST AMERICA . . 792 pp. Portland, Oreg.

(302) HOYT, R. S.

1933. PLANTING LIETS FOR SOUTHERN CALIFORNIA, A HANDBOOK OF ORINAMENTAL plants. 289 pp. Los Angeles.

(303) HubFarT, E. E.

1981. AN OUTLINE OF FOREST PATHOLOGX. 543 pp., illus. New York and London.

(304) HuNNEWELt, F. W.

1921. AN EXTENDED RANGE FOR AMELANCHIER AMABILIs. Rhodora 23: $71-72$.

(305) HURSh, C. R., and HaAsis, F. W.

1931. EFFEOTS OF 1925 SUMMER DROUGHT ON SOUTHERN APPALACHIAN HARDWOODS. Ecology $12: 380-386$, illus.

(306) Husmann, G. C.

1915. TESTING GRAPE VARIETIES IN THE VINIFERA REGIONS OF THE UTITED

(307) HYDE, J. STATES. U. S. Dept. Agr. Bull. 209, 157 pp., illus.

(308) ILtIOK, J. S

1898. VARIATIONS IN THE RATE OF AGRICULITURAL PRODUCTTON AND ONE OF THEIR cAUSES. Science (n. s.) 8: 575-576.

1925. Penngylvanta Treis. Pa. Dept. Forests and Waters Bull. 11, ed. 5, $237 \mathrm{pp}$., illus. 
(309) INGRAM, D. C.

1931. VEgETATIVE CHANGES AND GRAZING USE ON DOUGLAS FIR CUT-OVER IAND. Jour. Agr. Research 43: 387-417, illus.

(310) JeFFs, R. E., and LITTLE, E. L., JR.

1930. A PREIIMINARY LIST OF THE FERNS AND GEEUS PLANTS OF OKLAHOMA. Okla. Univ. Pubs. Biol. Survey, v. 2, no. 2, pp. [39]-101.

(311) JELLEY, M. E.

1937. KASTERN RED CEDAR.' Jour. Forestry 35 : 865-867.

(312) JENKS, J. W. P.

1860. THE RoBIN. Jour. Proc. Mass. Hort. Soc. 1859 : 150-154.

(313) JePsoN, W. L.

1909-36. A FLORA OF CALIFORNIA. 2 v., illus. Berkeley, Calif.

(314) 1910. THF simva of CALIFornia. Calif. Univ. Mem. 2, 480 pp., illus.

1916. REgeneration IN MANZanita. Madroño 1:3-11, illus.

1917. THE NATive WALNuts of CALIFornia. Mađ̊roño $1: 55-57$, illus.

1922. A NEW SPECIES OF CYPRESS. Madroño 1: 75.

1922. REVIRION OF THE CALIFORNIAN SPECIES OF ARCTOSTAPHYLOS. Madroño 1: 76-96, illus.

(319)

1925. MANUAL OF THE FlOWERING PLANTS OF CALIFORNIA. 1238 pp., illus. Berkeley, Calif.

(320) Johnson, R. A.

1928. THE FALL FOOD HABITS OF THE BUFFED GROUSE IN THE SYRACUSE AREA OF NEW YORK. Auk 45: 330-333.

(321) JoNEs, G. N.

1935. THE WASHINGTON SPECIES AND VARIETIES OF rosa. Madroño 3: 120-135, illus.

(322) JoNes, L. R., and RAND, F. V.

1909. vermont shrubs and woody vines. Vt. Agr. Expt. Sta. Bull. 145 , pp. [49]-199, illus.

(323) JosEPI', H. C.

1929. GERMiNation, AND vitality OF BIRCH sereos. Bot. Gaz. 87 : 127-151, illus.

(324) JUDD, S. D.

1902. BIRDs of a maryland farm. U. S. Bur. Biol. Survey Bull. 17, 116 pp., illus.

(325)

1905. THE BOBWHITE AND OTHER QUAILS OF THE UNITED STATES IN THEIR eConomic Retations. U. S. Bur. Biol. Survey Bull. 21, 66 pp., illus.

(326)

1905. THE GROUSE AND WILD TURKEYS OF THE UNITTE STATES, AND THEIR mConomic value. U. S. Bur. Biol. Survey Bull. 24, 55 pp., illus.

(327) KAMMERER, E. I.

1934. What DECTDUOUS SHRUBS WILL ENDURE shade? Morton Arboretum Bull. Pop. Inform. 9: 9-12.

(328) Kearney, T. H.

1931. PLANTS NEW TO ARIZONA. (AN ANNOTATED LIST OF SPECIES ADDED TO THF RECORDED FLORA OF THE STATE OR OTHERIVISE INTERESTING.)

(329) Wash. Acad. Sci. Jour. 21: 63-80.

1937. INGENHOUZIA AND THURBERIA. Amer. Jour. Bot. $24: 298-300$.

(330) and Harrison, G. J.

1932. ARIZONA PLANTS. (FURTHER ADDITIONS TO THE RECORDED FLORA OF THE STATE, WITH NOTES ON THE CHARACTERS AND GEOGRAPHICAL DISTRIBUTTON OF THESE AND OTHER SPECIES.). Wash. Acad. Sci. Jour. 22: 224-231.

(331) and SCOFIELD, C. S.

1936. THE CHOICe of Crops for saline land. U. S. Dept. Agr. Cir. 404, 24 pp. 
(332) - KECK, D. D.

1926. LONICERA AND SYMPHORICARPOS IN SOUTHERN CALIFORNIA. South. Calif. Acad. Sci. Bull. 25 : 66-73.

(333) Kellebman, W. A., Gleason, H. A., and Schaffner, J. H.

1914. SPRING FLORA FOR BEGINNERS AND AMATEURS ... Ed. 3, 205 pp. Columbus.

(334) KeLso, L.

1932. A NOTE ON THE FOOD OF THE HUNGARIAN PARTRIDGE. Auk 49: 204-207.

(335) Kennedy, P. B., and Doten, S. B.

1901. A PRELIMINARY REPORT ON THE SUMMER RANGES OF WESTERN NEVADA SHEEP. Nev. Agr. Expt. Sta. Bull. 51, 57 pp., illus.

(336) King, F. H.

1883. ECONOMIC RELATIONs of wisconsin RIRDs. Geol. Wis. Survey

(337) KING, R. T, $1873-79,1: 441-610$, illus.

(338) KIRKEGAARD, J.

1912. A PRACTICAL HANDBOOK OF TREES, SHRUBS, VINES, AND HERBACEOUS PERENNIALs. 407 pp., illus. Boston.

(339) KIRKwood, J. E.

1930. NORTHERN ROCKY MOUNTAIN TREES AND SHRUBS. 340 pp., illus. Stanford Univ.

(340) KLugH, A. B.

1927. ECOLOGY OF THE RED SQUTRREL. Jour. Mammal. 8 : 1-32, illus.

(341) KNIGHT, O. W.

1908. THE BIRDS OF MAINE. 693 pp., illus. Bangor, Maine.

(342) KоввE, W. H.

1900. THE BIRDS OF CAPE DISAPPOINTMENT, WASHINGTON. Auk 17:349 358.

(343) Korstian, C. F.

1917. THE INDICATOR SIGNIFTCANCE OF NATIVE VEGETATION IN THE DETERMINATION OF FOREST sITES. Plant World 20: 267-287.

(344)

1931. southern white cedar. U. S. Dept. Agr. Tech. Bull. 251, 75 pp., illus.

(345) Kraebet, C. J.

1936. Erosion control on mountain roads. U. S. Dept. Agr. Cir. 380, 45 pp., illus.

(346) Kramer, J., and Weater, J. E.

1936. RELATIVE EFFICIENCY OF ROOTA AND TOPS OF PLANTS IN PROTEOTING THE soIl FROM ERosion. Nebr. Univ. Conserv. Dept. Bull. 12,

(347) KUMLIEN, L. 94 pp., illus.

1879. CONTRIBUTIONS TO THE NATURAL HISTORY OF ARCTIC AMERICA MADE IN CONNECTION WITH THE HOWGATE POLAR EXPEDITION, 1877-78. U. S. Natl. Mus. Bull. 15: 69-105.

(348) LANGDON, F. W.

1879. A REVISEd LIST OF CINCINNATI BIRDS. Jour. Cincinnati Soc. Nat. Hist. 1: 167-193.

(349) LaNTz, D. E.

1905. COYOTES IN THEIR ECONOMIO RFuattons. U. S. Bur. Biol. Survey Bull. 20, $28 \mathrm{pp}$.

(350) Larsen, J. A.

1935. NATURAL REVEGETATION ON ERODED SOILS IN SOUTHEASTERN OHIO. Iowa State Col. Jour. Sci. 9: 365-376, illus.

(351) Laurie, A., and Chadwick, L. C.

1931. THE MODERN NURSERY, A GUIDE TO PLANT PROPAGATION, CULTURE, AND HANDLING. 494 pp., illus. New York.

(352) LAWRENCE, W. E.

1922. THE PRINCIPAL STOCK-POISONING PLANTS OF OREGON. Oreg. Agr.

(353) LeE, O. S. Expt. Sta. Bull. 187, 42 pp., illus.

1936. THE IIFE HISTORY OF THE COLUMBIAN SHARP-TAILED GROUSE (PEDIOECETES PHASIANELLUS COLUMBIANUS (ORD.)) IN UTAH. 86 pp., illus. (M. S. Thesis, Utah State Agr. Col.) 
(354) Leffingwet, A. M.

1931. FOOD HABITS OF SOME GAME BIRDS OF THE PACTFIC NORTHWEST. Northwest Sci. 5: 7-9.

(355) Lefringweil, D. J.

1928. THE RING-NECKed PHEASANT: its History aNd habits. C. R. Conner Mus. Occas. Papers 1, 35 pp., illus. Pullman, Wash.

(356) Leopold, A.

1933. game management. 481 pp., illus. New York and London.

(357) LewIS, I. M.

1915. THE TREES OF TEXAS: AN ILLUSTRATEd MANUAL OF THE NATIVE AND introduced trees of the state. Tex. Univ. Bull. 22, 169 pp., illus.

(358) Lrgon, J. S.

1927. WILDLIFE OF NEW MEXICO: ITS CONSERVATION AND MANAGEMENT, BEING A REPORT ON THE GAME SURVEY OF THE STATF, 1926 AND 1927. 212 pp., illus. Santa Fe.

(359) Lincoln, F. C.

1920. BIRDS OF THE CLEAR CREEK DISTRICT. Auk $37: 60-77$.

(360)

1923. A NOTE ON THE FOOD HABITS OF THE SHARP-TAILED GROUSE (PEDIoecetes P. CAMPESTRIS). Biol. Soc. Wash. Proc. 36: 200.

(361) LINDSEY, A. J.

1932. THE TREES OF INDIANA IN THE LOCAL AND GENERAL DISTRIBUTION ACCORDING To PHYSIOGRAPHIC DIvisions, Butler Univ. Bot. Studies 2: 93-124.

(362) Linsdale, J. M.

1936. CAIIFORNIA QUAIL FEEDING UPON ACORNS. Condor 38: 126.

(363) Livinoston, B. E., and Shreve, F.

1921. THE DISTRIBUTION OF VEGETATION IN THE UNITED STATEG, AS RELATED to climatic conditions. Carnegie Inst. Wash. Pub. 284, 590 pp., illus.

(364) LoNe, B.

1916. DISCOVERY OF PRUNUS CUNEATA IN SOUTHERN NEW JERSEY. Rhodora $18: 66-70$, ilius.

(365) LoNgrear, B. O.

1927. TREES AND SHRUBS OF THE ROCKY MOUNTAIN REGION, WTTH KEYS AND DESCRIPTIONS FOR THEIR IDENTIFICATION. 244 pp., illus, New York and London.

(366) LowE, E. N.

1921. PI.ANTS OF MISSISSIPPI; A LIST OF FLOWERING PLANTS AND FERNS. Miss. State Geol. Survey Bull. 17, 292 pp.

(367) Lyon, M. W., JR.

1936. MAMMALS of INDIANA. Amer. Midland Nat. $17: 1-384$, illus.

(368) МАBBOTT, D. C.

1920. FOOD HABTTS OF SEVEN SPECIES OF AMERICAN SHOAL-WATER DUCKS. U. S. Dept. Agr. Bull. 862, 67 pp., illus.

(369) MCATEE, W. L.

1912. METHODS OF Estidating THE CONTENTS OF BIRD stOMACHS. Auk 29: $449-464$.

(370)

1913. INDEX to PAPERS RELATING TO THE FOOD OF BTRDS ... U. S. Bur. Biol. Survey Bull. 43, 69 pp.

(371)

1915. eleven important wild-Duck Foods. U. S. Dept. Agr. Bull. 205, 25 pp., illus.

(372)

1917. HOW TO ATTRACT BIRDS IN THE MIDDLE ATLANTIC ITATES. U. S. Dept. Agr. Farmers' Bull. 844, 16 pp., illus.

(373)

1918. FOOD HARITS OF THE MALLARD DUCKS OF THE UNITED STATES. U. S. Dept. Agr. Bull. 720, 36 pp., illus.

(374)

1918. How to ATtract Btrds in the EAST Central states. U. S. Dept. Agr. Farmers' Bull. 912, 15 pp., illus.

1924. HOW TO ATTRACT BIRDS IN NORTHWESTERN UNITRD GTATES. U. S. Dept. Agr. Farmers' Bull. 760, 12 pp., illus. 
(376) McATLes, W. L.-Continued.

1931. HOW TO ATTRAOT BIRDS IN NOTTHEASTERN UNITED STATES. U. S. Dept. Agr. Farmers' Bull. 621, 16 pp., illus.

(377)

1936. GRoups of PLANTS VALUARLE For WILDLITE UTILIZATION AND EROSION CONTROL. U. S. Dept. Agr. Cir. 412, 12 pp., illus.

(378) MacDougal, D.T.

1908. BotANical FEATURES OF NORTH AMERICAN DESERTs. Carnegie Inst. Wash. Pub. 99, 111 pp., illus.

(379)

1921. THE REACTIONS OF PLANTS TO NEW HABITATS. Ecology 2: 1-20, illus.

(380) and CANNON, W. A.

1910. THE CONDITION OF PARASITISM IN PLANTs. Carnegie Inst. Wash. Pub. 129, 60 pp., illus.

(381) McDougald, W. B., and Bageley, H. A.

1936. Plants of Yeilowstone NATIONAL Park. U. S. Natil. Park Serv. 160 pp., illus. Washington.

(382) MaCKTE, W. W.

1903. THE value of oAK LEAVES For FORAGE. Calif. Agr. Expt. Sta. Bull. 150, 21 pp., illus.

(383) MCKINLEY, O.

1937. BOHEMIAN WAXWING IN LUCE COUNTT, MiCHIGAN. Auk 54:541-542.

(384) MCLEAN, D. D.

1930. THe bURro DeER in california. Calif. Fish and Game 16: 119-120.

(385)

1930. THe Quail of california. Calif. Fish and Game Comn. Game Bull. 2, 47 pp., illus.

(386) MoMinn, H. E.

1930. A GEOGRAPHIC AND TAXONOMIC STUDY OF THE CALIFORNIA SPECIES of THE GENUS CEANothus. Stanford Univ., Dudley Herbarium Contrib. 1: 121-154, illus.

1937. CEANOTHUS ON THE PACHFTC COASt. MOUNTAIN LITACS. Gard. Quart. San. Francisco 4: 34-35, 46, illus.

(3S8) and FORDERHASE, B.

1935. NOTES ON WESTERN IEATHERWOOD. DIRCA ACCIDENTALIS GRAY. Madroño 3: 117-120, illus.

(389) - and MaINo, E.

1935. AN ILLUSTRATEd MANUAL OF PACIFIC COAST TREeS. 409 pp., illus. Berkeley, Calif.

(390) MCNAIR, J. B.

1925. THE TAXONOMY OF POISON IVY, WITH A NOTE ON THE ORIGIN OF THE GENERIO NAME. Field Mus. Nat. Hist. (Chicago), Bot. Ser. 4: 5576 , illus.

(391) MATIITARD, J.

1918. EARLY AUTUMN BIRDS IN YOSEMTTE VALLEY. Condor 20: 11-19.

(392) MARSh, C. D.

1924. Stocik-Poisoning PLANTS of the RANGe. U. S. Dept, Agr. Bull. 1245, 36 pp., illus. (Revised, 1929).

(393) - Clawson, A. B., and Marsh, H.

1919. OAK-LEAF POIBONING OF DoMestic animals. U. S. Dept. Agr. Bull. 767, 36 pp., illus.

(394) Marsh, G. P.

1898. THE EARTH AS MODIFTED BY HUMAN ACTION. 629 pp. NeW York.

(395) Marshall, W. H., and Jensen, M. S.

1937. WINTER AND SPRING STUDIES OF THE SHARP-TAILED GROUSE IN UTAH. Jour. Wildlife Management 1: 87-99, illus.

(396) Mattin, A. C.

1935. QUaIl-food plants of the southern states. U. S. Dept. Agr. Cir. 348, 16 pp., illus.

(397) MLAson, D. T.

1915. THE LIFE HISTORY OF LODGEPOLE PINE IN THE FOCKY MOUNTAINB.

(398) MASON, H. L. U. S. Dept. Agr. Bull. 154, 35 pp., 1llus.

1930. THE SANTA CRUZ ISLAND PINE. Madroño 2: 8-10. 
(399) Mason, S. C.

1913. THE PUBESCENT-FRUTTED SPECIES OF PRUNUS OF THE SOUTHWESTERN states. Jour. Agr. Research 1: 147-178, illus.

(400) Maynard, C. T.

1881. THE BIRDS OF EASTERN NORTH AMERICA . . 532 pp., illus. Newtonville, Mass.

(401) Maynard, L.-A., Bump, G., Dariow, R., and Woodward, J. C.

1935. FOOD PREFERENCES AND REQUTREMENTS OF THE WHITE-TATLED DEER IN NEW YORK STATE. N. Y. State Conserv. Dept. Bull. 1, 35̃ pp., illus. •

(402) MEARHS, E. A.

1878-80. A LIST OF THE BIRDS OF THE HUDSON HIGHLANDS, WITH ANNotations. Essex Inst. Bull. $10: 166-179 ; 11: 43-52,154$ $168,189-204 ; 12$ : 11-25, 109-128.

(403)

1907. MAMMALS OF THE MEXICAN bOUNDARY OF THE UNITED STATES . . Part 1, FAMILIES DIDELPHIIDAE to MURIDAe. U. S. Natl. Mus. Bull. 56, 530 pp., illus.

(404) MEISEL, M.

1924-29. A BIBLIOGRAPII OF AMERICAN NATURAL HISTORY . . . 3 v. New York.

(405) Merriam, C. H.

1892. THE GEOGRAPHIC DISTRIBUTION OF IIFE IN NORTH AMERICA, WITH SPECI.IL REFERENCE TO THE MAMMALIA. Biol. Soc. Washington Proc. 7: 1-64, illus.

(406) Metcalf, C. L., and Flint, W. P.

1928. DESTRUCTIVE AND USEFUL INSECTS; THEIR HABITS AND CONTROL. 918 pp., illus. New York.

(407) MEtz, Sister M. C.

1934. A FLORA OF Bexar countr, texas. Catholic Univ. American Contrib. Biol. Lab. 16, 214 pp., illus.

(408) MILLER, R. B., and TehoN, L. R.

1929. THE NATIVE AND NATURALIzEd TREES OF ILIINoIs. Ill. Nat. Hist. Survey Bull. 18, art. 1, 339 pp., illus. Urbana, Ill.

(409) MuLs, H. B. PARK. Jour. Mammal. 18: 205-212.
(410) Minot, H. D.

1937. A PRELIMINARY STUDY OF THE BIGHORN OF YELLOWSTONE NATIONAL

(411) Mirov, N. T.

1877. THE LAND BIRDS AND GAME BIRDS OF NEW ENGLAND. $456 \mathrm{pp}$., illus. Boston.

(412) MoHr, C.

1936. GLRMINATION BEHAVIOR OF sOME CALIFORNia PLANTS. Ecology 17: $667-672$.

1901. PLANT LIFE OF ALABAMA, AN ACCOUNT OF THE DISTRIBUTION, MODLS OF ASSOCLATION, AND ADAPTATIONS OF THE FLORA OF ALABAMA, TOGETHER WITH A SYSTEMATIC CATALOGUE OF THE PLANTS GROWIN THE STATE. U. S. Natl. Mus. Herbarium Contrib. 6, 921 pp., illus. Washington, D. C.

(413) MorTon, C. V.

1930. A NeW spectes of essenbeckia from texas. Wash. Acad. Sci. Jour. 20: 135-136.

(414)

1935. THREE NEW PLANTS From deAtH VALLEY, CALIFornia. Wash. Acad. Sci. Jour. 25: 307-311.

(415) MuenschiR, W. C. L.

1930. Keys to woody Plants. Ed. 3, rev., 96 pp. Ithaca, N. Y.

(416) 1935. WEEDS. 577 pp., illus. New York.

(417) MuLFond, F. L.

1920. street treas. U. S. Dept. Agr. Bull. 816, 58 pp., illus. (Revised, 1929).

(418) 1922. TREes For TOWN AND CITY strekets. U. S. Dept. Agr. Farmers' Bull. 1208, 40 pp., illus. (Revised 1927).

(419)

1926. TREes for roAdSide Planting. U. S. Dept. Agr. Farmers' Bull. 1482, 50 pp., illus. 
(420) Munns, E. N.

1920. CHAPARRAL COVER, SUN-OFT AND EROSION. Jour. Forestry $18: 806-814$.

(421)

1921. EFFECT OF LOCATION OF SEed UPON Germination. Bot. Gaz. 72 : 256-260.

(422) MUnson, T. V.

1909. FOUNDATIONS OF AMERICAN GRAPE CULTURE. 252 pp., illus. Denison, Tex.

(423) MUNz, P. A.

1935. A MANUAL OF SOUTHERN CALIFOFNIA BOTANY. 642 pp., illus. Claremont, Calif.

(424) MURIE, A.

1934. THe moose of isle royale. Mich. Univ. Mus. Zool. Misc. Pub. 25,44 pp., illus.

(425) NasH, C. W.

1901. THE BIRDS OF ONTARIO IN BELATION TO AGRICULTURE. Ed. 2, 79 pp., illus..

(426) NehrLing, H.

1893-96. OUR NATIVE BIRDS OF SONG AND BEAUTY. 2 v., illus. Milwaukee.

(427) Net.son, A.

1920. FLoRA OF the NAVAJo Regervation. I. Amer. Bot. $26: 48-56,87-89$.

(428)

1922. FLORA OF THE NAVAJO INDIAN RESERVATION. II. Amer. Bot. 28: $20-25$.

(429) 1934. ROCIs MOUNTAin HERBarium studies. II. Amer. Jour. Bot. 21 : $573-582$.

(430) 1935. ROCKY MOUNTAIN HERBARIUM studies. III. THE ELAEAgNACEAEA MONO-GENERIC FAMILY. Amer. Jour. Bot. 22: 681-683.

(431) Netson, A. L.

1933. A PRELIMINARY REPORT ON THE WINTER FOOD OF VIRGINIA FOXES. Jour. Mammal. 14: 40-43.

(432) NeLson, E.

1902. The shrubs of wroming. Wyo. Agr. Expt. Sta. Bull. 54, 47 pp., illus.

(433) Nelson, E. W.

1857. NOTES ON BIRDS OBSERVED IN PORTIONS OF UTAH, NEVADA, AND CALIFORNIA. Boston Soc. Nat. Hist. Proc. 17 : 338-365.

(434) NeWHALL, C. S.

1893. THE SHRUBS OF NORTHEASTERN AMERICA. 249 pp., lllus. New York and London.

(435) Newsom, W. M.

1926. WhitetaILed DezR. 288 pp., illus. New York.

(436) Nice, M. M.

1931. THE BIRDs oF okLAhoma. Okla. Univ. Pub. 3, 224 pp., lllus. (Revised).

(437) Nichols, A. A.

1936. THE EXPERIMENTAL FEEDING OF DEER. North Amer. Wildlife Conf. Proc. 1936: 403-410.

(438) Nichols, G. E.

1923. CERCIS CANADENSIS IN CONNECTICUT. Rhodora 25: 203-204.

(439) Niecsen, E. L.

1937. THE IDENTITY OF AMELANOHIER FLORIDA LINDLEY. Madroño 4 : 17-21, illus.

(440) ObeRholser, H. C.

1925. RELATIONS OF Vegatation to BIRD IIFE IN tExas. Amer. Midland

(441) ORR, R. T. Nat. 9: 564-661.

(442) OVER, W. H.

1937. NOTES ON THE LIFE HISTORY OF THE ROOSEVELT ELK IN CAINFORNIA. Jour. Mammal. 18: 62-66.

1932. FLORA OF SOUTH DAKOTA: AN ILLUSTRATED CHBCR-LIST OF FLOWERING PLANTS, SHRUBS AND TREFS OF SOUTH DAKOTA. 161 pp., illus. Vermillion, S. Dak. 
(443) Palmer, E. J.

1921. FOREST FLORA OF THE OZARK REGION. Aruold Arboretum Jour. 2: 216-232

(444) 1927. ON NUTTALL's TRAIL THROUGH ARKANSAS. Jour. Arnold Arboretum $8: 24-55$.

(445)

1929. THE ligneous flora of the Davis modntains, texas. Arnold Arboretum Jour. $10: 8-45$.

(446)

1937. NOTES ON NORTH AMERICAN TREeS AND sHRUBS. Jour. Arnold Arboretum 18: 133-140.

(447) - and STeYermarK, J. A.

1935. AN ANNOTATED CATALOGUE OF THE FlOWERING PLANTS OF MisSOURI. Mo. Bot. Gard. Ann. 22 : 375-758, llius.

(448) Pammet, L. H.

1915. NATIVE SHRUBS of IowA. Iowa State Hort. Soc. Trans. (1914) $49: 34-43$.

(449) - MacDonatd, G. B., and Clark, H. B.

1916. THE NATTVE AND CULTIVATED FOREST TREES AND SHRURS OF THE MISSOURI RIVER BASIN. Iowa Acad. Sci. Proc. (1915) 22: 23-56, illus.

(450) Patraw, P. M.

1936. CHECK-LIST OF PLANTS OF GRAND CANYON NATIONAL PARK. Revised by A. C. Hawbecker, Grand Canyon Nat. Hist. Assoc. Bull. 6, $75 \mathrm{pp}$.

(451) Pearse, C. K., and Woolley, S. B.

1936. THE INFLUENCE OF RANGE PLANT COVER ON THE RATE OF ABSORPTION OF SURFACE WATER BY sOILS. Jour. Forestry 34: 844-847.

(452) Pellett, F. C.

1913. Food Habits of THE SkUNk. Iowa Acad. Sci. Proc. 20 : 307-309.

(453)

1930. AMERICAN HONEY PLANTS, TOGETHER WITH THOSE WHICH ARE OF SPECIAL VALUE TO THE BEEKEEPER AS sOURCES OF POLIEN. Ed. 3, rev. and enl., 419 pp., illus. Hamilton, Ill.

(454) Perry, G. S.

1932. THE COMMON TREES AND SHRUBS OF PENNSYLVANIA, NATIVE AND YNTroducEd. Pa. Dept. Forests and Waters Bull. 33, rev., 127 pp., illus.

(455) Petersen, N. F.

1923. FLORA OF NEBRASKA; A LIST OF THE FERNS, CONIFERS, AND FLOWERING PLANTS OF THE STATE, WITH KEYS FOR THEIR DETERMINATION. Ed. 3, $220 \mathrm{pp.}$ [Lincoln, Nebr.]

(456) Piper, C. V.

1906. flora of the state of washington. U. S. Natl. Mus. Contrib. U. S. Natl. Herbarium 11, 637 pp., illus.

(457) and BEATTIE, R. K.

1914. FLORA OF SOUTHEASTERN WASHINGTON AND ADJACENT IDAHO. 296 pp., illus., Lancaster, Pa.

(458) and BeAtTIE, R. K.

1915. FLORA OF THE NORTHWEST COAST, INCLUDING THE AREA WEST OF THE SUMMIT OF THE CASCADE MOUNTAINS, FROM THE FORTY-NINTH PARALLEL SOUTH TO THE CALAPOOIA MOUNTAINS ON THE SOUTH BORDER

(459) PIRNTE, M. D. OF LANE COUNTY, OREgON. $418 \mathrm{pp}$. Lancaster, Pa.

1935. MiOHIGAN WATERFOWL MANAgEMENT. 328 pp., illus. Lansing, Mich.

(460) Plummer, F. G.

1911. Chaparral. U. S. Forest Serv. Bull. 85,48 pp., illus.

(461) Pollard, C. L.

1908. Calycanthaceae. North Amer. Flora 22: 237-238.

(462) Powers, W. H.

1927. Flora of THe upper missouri valley. S. Dak. Acad. Sci. Proc. 11: $85-100$. 
(463) PURER, E. A.

1936. STUDIES OF CERTAIN COASTAL SAND DUNE PLANTS OF SOUTHERIN CALI-

(464) QUICK, C. R. FORNIA, Ecol. Monog. 6:1-87.

(465) RABER, 0 .

1928. PRINCIPLES OF PLANT PHYSTOLOgY. 377 pp., illus. New York.

(466) RAMSEY, F. T.

1921. THE SWAZEY BARBERRY. Jour. Heredity 12: 426-427, illus.

(467) RATHBUN, S. F.

1920. BOHEMIAN WAXWING AT SEATTLE, WASHINGTON, DURING THE WINTER 1919-20. Auk. 37: 458-460.

(468) RAY, M. S.

1912. THE DISCOVERY OF THE NEST AND EGGS OF THE CALIFORNIA PINE GROSBEAK. Condor 14: 157-187, illus.

(469) REED, E. L.

1935. A NEW SPECIES OF EPHEDRA FROM WESTERN TEXAS. Torrey Bot. Club Bull. 62: 43.

(470)

1936. EPHEDRA CORYr. Torrey Bot. Club Bull. 63: 351-353, illus.

(471) REHDER, A.

1917. THE GENUS Fraxinus IN NEW MExico AND ARIzona. Amer. Acad. Proc. 53: [197]-212.

(472)

1934. MANUAL OF CULTIVATED TREES AND SHRUBS HARDY IN NORTH AMERICA, EXCLUSIVE OF THE SUBTROPICAL AND WARMER TEMPERATE rearons. 930 pp., illus., New York.

(473) RiDley, H. N.

1930. THE dispersat OF PLANTS THRoughout THE WORLD. 744 p., illus., Ashford, Kent, England.

(474) RIDOEWAT, R.

1877. oвnitholooy. U. S. Geol. Survey, 40th Parallel 4, pt. 3, pp. 305669.

(475) - 1889-95. THE ORNITHOLOGY OF ILJINoIs. In Natural History Survey of Illinois, 2 v., illus. Springfield, Ill.

(476) Robingon, B. L., and Fernald, M. L.

1908. GRAY'S NEW MANUAL OF BOTANY . . Ed. 7, rearranged and eXtensively rev., 926 pp., illus. New York and Cincinnati.

(477) Robinson, C. S.

1931. FEEDINO HABITS AND FORAGE REQUIREMENTS OF ROCKY MOUNTAIN MULE DEER IN THE SIERRA NEVADA MOUNTAINS. Jour. Forestry 29 : $557-564$.

(478)

1937. PLANTS EATEN BY CALIFORNIA MULE DEER ON THE LOS PADRES NATIONAT FOREST. Jour. Forestry 35: 285-292.

(479) Rose, J. N.

1911. BURSERACEAE. North Amer. Flora 25: 241-261.

(480) Rosendahl, C. O., and ButTers, F. K.

1928. TREES AND SHRUBS OF MINNESOTA. 385 pp., illus. Minneapolis.

(481) RYDBERG, P. A.

1906. Flora of Colorado. Colo. Agr. Expt. Sta. Bull. 100, 448 pp.

1908. ROSACEAE. North Amer. Flora 22: 239-533.

(483) $\frac{1919}{19}$. FABACEAE. North Amer. Flora 24: 1-462.

(484) 1922 FLORA OF THE ROCKY MOUNTAINS AND ADJACENT PLAINS, COLORADO, UTAH, WYOMING, IDAHO, MONTANA, SASKATCHEWAN, ALBERTA, AND NETGHBORING PARTS OF NEBRASKA, SOUTH DAKOTA, NORTH DAKOTA, AND BRTTSH COLUMBiA. Ed. 2, $1144 \mathrm{pp.} \mathrm{New} \mathrm{York.}$

(485)

1932. FLORA OF THH PRAIRIES AND PLAINS OF CENTRAL NORTH AMERICA. 969 pp., illus. New York. 
(486) St. Clatr-Thompson, C. W.

1928. THE PROTECTION OF WOODLAND, BY NATURAL AS OPPOSED TO ARTIFICTAL METHODs. $223 \mathrm{pp}$, illus. London.

(487) ST. JoHN, H., and Jones, G. N.

1928. AN ANNOTATED CATALOGUE OF THE VASCULAR PLANTS OF BENTON COUNTY, WASHINGTON. Northwest Sci. 2: 73-93.

(488) SAMPBON, A. W.

1924. NATtve Amemican forage PLANTs. 435 pp., illus. New York.

(489) - and MALMsten, H. E.

1935. stock-Poisoning Plants of California. Calif. Agr. Expt. Sta. Bull. 593, 90 pp., illus.

(490) Samuets, E. A.

1883. OUR NORTHERN AND EASTERN BIRDS. 600 pp., ilius. New York.

(491) SARgent, C. S.

1916. THE NAME OF THE RED OAK. Rhodora 18: 45-48.

(492) 1920 . NOTES ON NORTH AMERICAN TREES. Vr. Arnold Arboretum Jour. 1: $245-254$.

(493) - 1922. MANOAL OF THE TREES OF NORTH AMERIOA (EXCLUSIVE OF MEXICO). 910 pp., illus. Boston and New York.

(494) SAUNDERS, A. A.

1911. A PRELIMINARY LIST OF BIRDS OF gallatin COUNTY, MONTANA. Auk $28: 26-49$.

(495) 1911. A STUDY OF THE NESTING OF THE CEDAR WAXwiNa. Auk 28:323329.

(496) 1912. THE PRoBable Brheding OF THE BOHEMTAN WAXWING IN MONTATA. Condor 14 : '224.

(497) SCLATTR, W. L.

1912. A HISTORY OF THE BIRDS OF COLORADO., 576 pp., illus. London.

(498) SELKS, L. F.

1937. FOOD HABITS OF IOWA SKUNKS IN THE FALL OF 1936. Jour. Wildlife Management 1: 70-76, illus.

(499) SenNetT, G. B.

1880. FURTHER NOTES ON THE ORNITHOLOGY OF THE LOWER RIO GRANDE OF TEXAS FROM OBSERVATIONS MADE DURING THE SPRING OF 1878. Bull. U. S. Geol. and Geogr. Survey of the Territorles, 1879-80, $5: 371-440$.

(500) SETON, E. T.

1929. luves of game antmals . . 4 v. in 8, illus. Garden City, N. Y.

(501) Sонмтт, F. J. W.

1936. WINTER FOOD OF THE SHARP-TAILED GROUSE AND PINNATED GROUSE IN wisconsis. Wilson Bull. $43: 186-203$, illus.

(502) SCHNHDER, C.

1921. NOTLS ON AMERICAN WILLOW8. XII. Arnold Arboretum Jour. 3: [61]-125.

(503) Shannon, C. W.

1913. the trees and shrubs of oklahoma. Okla. Geol. Survey Cir. 4, 41 pp., lllus.

(504) SHANTZ, H. L.

1935. challenge of erosion to botanigts. Iowa State Col. Jour. Sci. 9: 353-363.

(505) SHaw, G. R.

1914. THE GENUS PINU8. Arnold Arboretum Pub. 5, 96 pp., illus.

(506) SHAW, W. T.

1936. MOISTURE AND ITS RELATTON TO THE CONE-STORING HABIT OF THE WESTERN PINE SQUTRREL. Jour. Mammal. 17: 337-349, illus.

(507) SHEJTORD, V. E.

1926. NATURALists GUIDE TO THE amerioas . . 761 pp., illus. Balti-

(508) SHIMEK, $\mathrm{B}$. more.

1935. THE IMPoRta NCE OF OUTDOOR Ptant studies. Iowa State Col. Jour. Sci. 9 : 325-327. 
(509) SHREVE, F.

1917. A Map OF vegetation of the United states. Geogr. Rev. 3: 119 125 , illus.

(510) Chry - C. A., Blodgett, F. H., and Besley, F. W.

(511) Steglak, H. R.

1910. THe Plant LIFE of MaRYLAND. Md. Weather Serv. Spec. Pub. 3, 533 pp., illus. Baltimore, Md.

1937. Winter RODENT DAMAge TO GAME OOVER. Jour. Mammal. 18: 57-61.

(512) SImMONS, G. F.

1925. BIRDS OF THE AUSTIN Ragion. 387 pp., illus. Austin, Tex.

(513) Simonson, W. H.

1936. ROADSIDE PLANTING. Landscape Arch. 26: 167-174.

(514) Sitgreaves, L.

1854. REPORT OF AN EXPEDITION DOWN THE ZUNI AND COLORADO RIVERS. 330 Cong., 1st sess., S. Ex. [Doc.] 198 pp., illus. See pp. 37, 171.

(515) Skinner, M. P.

1936. BROWSING OF THE OLYMPIC PENINSULA FH.K IN EARLY WINTER. Jour. Mammal. 17 : 253-256.

(516) and AcHoRN, J. W.

1928. A GUTDE TO THE WINTER BIRDS OF THE NORTH CAROIJNA SANDHTLLS. 301 pp., illus. Albany, N. Y.

(517) Skutch, A. F.

1929. EARLY STAGES OF PLANT SUCCESSION FOLLOWING FOREST FIRES. Ecology 10: 177-190, illus.

(518) SMall, J. K.

1903-13. FLORA OF THE SOUTHEASTERN UNITED STATES . . . Ed. 1-2. NeW

1910. MaLPIGHIACEAE. North Amer. Flora 25: 117-171.

1911. simaroubadeae. North Amer. Flora 25: 227-239.

1914. ERICACFAE. North Amer. Flora 29: 33-102.

1927. the palmetto-palm-Sa'bai texana. N. Y. Bot. Gard. Jour. 28: 132-143.

(524)

1930. Vigetation AND EROSION ON THE EVERGLAdE KEYs. Sci. Monthly $30: 33-49$, illus.

1933. MANUAL OF THE SOUTHEASTERN FLORA; BEING DESCRIPTIONS OF THE SEED PLANTS GROWING NATURALLY IN FLORIDA, ALABAMA, MISSISSIPPI, EASTERN LOUISIANA, TENNESSEE, NORTI CAROLINA, SOUTH CAROLINA, AND GEORGIA. 1554 pp., illus. New York.

(526) - and RYDBerg, P. A

1905. SAXIFRAGACEAE, HYDRANGEACEAE. North Amer. Flora 22: 81-178.

(527) SMILEY, F. J.

1921. A REPORT UPON THE BORHAL FLORA OF THE SIERRA NEVADA OF CALIFORnIA. Calif. Univ. Pubs., Bot. 9, 423 pp., illus.

(528) Sмith, A. C.

1936. NOTES ON NORTH AMERICAN ARALIACTAE. Brittonia 2: 247-261.

(529) SMTTH, A. P.

1907. THE THICK-BILLED PARBOT IN ARIZONA. Condor 9: 104, illus.

1912. BIRDS OF THE Boston MoUntains, ARKangas. Condor 17: 41-57.

(531) SмITH, J. R.

1929. TREE CROPS ; A PERMANENT AGRTCULTURE. 333 pp., illus. New York.

(532) SNYDER, L. L.

1935. A STUDY OF THE SHARP-TAILEd GROUSE. Roy. Ontario Mus. Zool.

(533) SPenot, L. E. Contrib. Ser. 40 , no. 6,66 pp., illus.

1937. ROOT STUDIES OF IMPORTANT RANGE PLANTS OF THE BOISE RIVER WATERSHED. Jour. Forestry 35: 747-754, illus. 
(534) SPERRY, C. C.

1933. AUTUMN FOOD HABTTS OF COYOTES: A REPORT OF PROGRESS, 1932. Jour. Mammal. 14: 216-220, illus.

$(535)$

1934. WINTER FOOD HABITS OF COYOTES: A REPORT OF PROGRESS, 1933. Jour. Mammal. 15: 286-290, illus.

(536) SPIKER, C. J.

1935. SOME LATE WINTER AND EARLY SPRING OBSERVATIONS ON THE WHITETAILED DEER OF THE AdroNdACKs. Roosevelt Wildlife Bull. 6: $327-385$, illus.

(537) SPRATT, E. R.

1919. A COMPARATIVE ACCOUNT OF THE ROOT-NODULES OF THE LBGUMINOSAE. Ann. Bot. [London] 33: [189]-199, illus.

(538) Staltakd, H.

1929. SECONDARY SUCCESSION IN THE CLIMAX FOREST FORMATION OF NORTHERN MINNESOTA. Ecology 10: 476-547, illus.

(539) Standlex, P. C.

1920-26. Trees AND strubs of Mexico. U. S. Natl. Mus. Contrib. U. S. Natl. Herbarium 23, 1721 pp.

(540) Stearns, R. E. C.

1882. THE ACORN-STORING HABIT OF THE CALTFORNIA WOODPECKER. Amer. Nat. $16: 353-357$.

(541) STEMEN, T. R., and MYERs, W. S.

1937. OKLAHOMA FLORA. 706 pp., illus. Oklahoma City.

(542) STEPHeNs, F.

1919. AN ANNOTATED LIST OF THE BIRDS OF SAN DIEGO COUNTY, CALIFORNIA. San Diego Soc. Nat. Hist. Trans. 3: 142-180.

(543) STEPHENS, T. C.

1917. BIRD RECORDS DURING THE PAST WINTER, 1916-1917, IN NORTHWESTERN IOWA. 'Iowa Acad. Sci. Proc. 24: 245-258.

(544) StexermarK, J. A.

1932. a revision of the genda menodora. Mo. Bot. Gard. Ann. 19 : 87176 , illus.

(545) Stoddard, H. L.

1932. THE BOBWHITE QUAIL, ITS HABITA, PRESERVATION, AND INCREASE. 559 pp., illus. New York.

(546) STOKES, S. G.

1936. THE GENUS ERIOGONUM ; A PREIIMINARY STUDY BASED ON GEOGRAPHIC DISTRIRUTION. $124 \mathrm{pp}$. San Francisco.

(547) Stone, W., and Cram, W. E.

1905. AMERICAN ANIMALS; A POPULAR GUIDE TO THE MAMMALS OF NORTH AMERICA NORTH OF MEXICO, WITH INTIMATE BIOGRAPHIES OF THE MORE FAMILIAR SPECIES. 318 pp., illus. New York.

(548) Strausbaugh, P. D., Core, E. L., and AMmons, N.

1931. COMMON SEED PLANTS OF THE MID-APPALACHIAN REGION. $305 \mathrm{pp}$., illus. Morgantown, W. Va.

(549) SUDWoRTH, G. B.

1908. Forest trees of the Pacifio slope. U. S. Dept. Agr. 441 pp., illus. Washington, D. C.

(550) 1915. THE CYPRESS AND JU'NIPER TREES OF THE ROCKY MOUNTAIN REGION. U. S. Dept. Agr. Bull. 207, 36 pp., illus.

(551) 1916. THE GPRUCE AND BALSAM FIR TREES OF THE ROCKY MOUNTAIN REGION. U. S. Dept. Agr. Bull. 327, 43 pp., illus.

(552) 1917. the PINe trees of the Rocky modntain Region. U. S. Dept. Agr. Bull. 460, 47 pp., illus.

(553) 1918. MISCELLANEOUS CONIFERS OF THE ROOKT MOUNTAIN REGION. U. S. Dept. Agr. Bull. 680, 45 pp., illus.

(554) 1927. CHECK LIBT OT THE FOREST TREES OF THE UNITED STATES: THEIR Names AND ranges. U. S. Dept. Agr. Misc. Cir. 92, 295 pp.

(555) 1934. POPLARS, PRINCIPAL TREE WILLOWS, AND WALNUTS OF THE ROCKX mountain Region. U. S. Dept. Agr. Tech. Bull. 420, 112 pp., illus. 
(556) SUMNer, E. L.

1935. A LIFE HISTORY STUDY OF THE CALIFORNIA QUAIL, WITH RECOMMENDATIONS FOR CONSERVATTON AND MANAGEMENT. Calif. Flsh and Game 21: [167]-256, 277-342, illus.

(557) SwarTH, H. S.

1914. Distributional list of the birns of arazona. Pacific Coast Avifauna No. 10, 133 pp., illus.

(558) SWENK, M. H.

1930. THE FOOD HABITS OF THE RING-NECKED PHEASANT IN CENTRAL NEBRaska. Nebr. Agr. Expt. Sta. Research Bull. 50, 33 pp., illus.

(559) SwINGLE, C. F.

1937. EXPERIMENTS IN PROPAGATING SHIPMAST IOCUST. Jour. Forestry 35: 713-720, illus.

(560) Swingle, D. B., and WeLCH, H.

1916. POISONOUS PLANTS AND STOOK POISONING ON THE RANGES OF MONTANA. Mont. Agr. Expt. Sta. Cir. 51, pp. [73]-95, illus.

(561) Swingle, W. T.

1916. THE EARLY EUROPEAN HISTORY AND THE BOTANICAL NAME OF THE TRE of HEAVEN, ATlanthus Altissima. Wash. Acad. Sci. Jour. 6: $490-498$.

(562)

1920. A NEW SPECEES OF PISTACTA NATTVE TO SOUTHWESTERN TEXAS, P. TEXANA. Arnold Arboretum Jour. 2: 105-110.

(563) Tanslet, A. G.

1923. PRACTICAL PLANT ECOLOGY; A GUIDE FOH BEGINNERS IN FIELD STUDY OF PLANT COMMUNITIES. 228 pp., illus. London and New York.

(564) TATE, R. C.

1924. FAVORITE FOODS OF SOME OKLAHOMA BIRDS. Okla. Univ. Bull. 322 : 33-35.

(565) TAYLOR, W.'P.

1935. ECOLOGY AND LIFE HISTORY OF THE PORCUPINE (ERFTHIZON EPLXANTHUM) AS RELATED TO THE FORESTS OF ARIZONA AND THE SOUTHWESTERN UNITED StATES. Ariz. Univ. Bull. v. 6, no. 15, Biol. Sci. Bull. 3, 177 pp., illus.

(566) THARP, B. C.

1926. STRUCTURE OF TEXAS VEgETATION EAST OF THE 98TH MERIDIAN. Tex. Univ. Bull. 2606, 97 pp., illus.

(567) Thомpson, E. E.

1891. тHE BRDDS of manitoza. U. S. Natl. Mus. Proc. 13: 457-643, illus.

(568) Thoreau, H. D.

1910. FOTES ON NEW ENGLAND BIRDS. 441 pp., illus.

(569) Thorne, P. M.

1895. LIST OF BIRDS OBSERVED IN THE VICINITY OF FORT KDOGH, MONTANA, FROM JULY 1888 TO SEPTEMDER 1892. Auk 12:211-219.

(570) ThonNthWaITE, C. W.

1931. THE CIIMATES OF NORTH AMERICA ACCORDING TO A NEW CLASSTFTCATION. Geogr. Rev, 21: 633-655, illus.

(571) Tidestrom, I.

1925. Flora of utah and Nevada. U. S. Natl. Mus. Contrib. U. S. Natl. Herbarium 25, 665 pp., illus.

(572) Topp, J. B.

1927. WINTER FOOD OF COTTONTAI, RABBITS. Jour. Mammal. 8: 222-228.

(573) Toumey, J. W., and Korstian, C. F.

1931. SEEDING AND PLANTINO IN THE PRACTICE OF FORESTRY; A MANUAL FOR THE GUTDANCE OF FORESTRY STUDENTS, FORESTERS, NURSETIY MEN, FOREST OWNERS, AND FARMERS. Ed, 2, rev. and ell. by C. F. Korstian, 507 pp; illus. New York and London.

(574) Townsend, C. W.

1905. THE BIRDS OF ESSEX COUNTY, MASSACHUSETTS. Nuttall Ornithol. Club. Mem. 3, 352 pp., illus.

(575) 1918. IN AUDUBoN's LABRADOR. 354 pp., illus. Boston and New York.

(576) 1920 . SUPPLEMENT TO THE BIRDS OF ESSEX COUNTX, MASSACHUSETTS. Nuttall Ornithol. Club Mem. 5, 196 pp., illus. 
(577) Townsend, M. T., and Smith, M. W.

1933. THE WHTTE-TALLD DEER OF THE ADIRONDACTs. Roosevelt Wildlife Bull. 6 : 161-325, illus.

(578) Trgethase, W.

1924. THE AMERICAN oAKs. Natl. Acad. Sci. Mem. 20, 255 pp., illus.

(579) United States Forest Experiment Station, Lake States.

1935. POSSIBILITIES OF SHELTERBELT PLANTING IN THE PLAINS RHGION. . . 201 pp., illus. Washington [D. C.].

(580) VAIL, A. M., and RYDBerg, P. A.

1910. ZYGOPHYLLACEAE. North Amer. Flora 25 : 103-116.

(581) Vermont Botanical Club.

1915. FLORA OF VERMONT. LIST OF FERNS AND SEED PLANTS GROWING WITHovt coltivation. Vt. Agr. Expt. Sta. Bull. 187, pp. [139]-258.

(581A) VIEHMEYER, G.

1937. TREES AND SHRUBS OF VALUE AS A SOURCE OF FOOD FOR BIRDS IN THE SANDHILI REGION OF CENTRAL NEBRASkA. Nebr. Bird Rev. 5: 3-5.

(582) VISCHER, S. S.

1911. AN NOTATED LIST OF THE BIRDS OF HARDING COUNTY, NORTHWESTERN SOUTH DAKOTA. Auk 28: 5-16.

(583) Vorhies, C. 'T., and TAYLoR, W. P.

1933. THE LIFE HISTORIES AND ECOLOGY OF JACK RABBITS LEPUS ALLENI AND IEPUS CALIFORNICUS SSP., IN RETATION TO GRAZING IN ARIZONA. Ariz. Agr. Expt. Sta. Tech. Bull. 49, pp. 471-587, illus.

(584) WALKER, R. S.

1917. WILD Frutts of TENNESSEe. Tenn. Acad. Sci. Trans. 2: 69-77.

(585) WARE, L. M.

1935. the black locust in alabama. Ala. Agr. Expt. Sta. Cir. 73, 15 pp., illus.

(586) WARReN, B. H.

1890. REPORT ON THE BIRDS OF PENNSYLVANIA. Ed. 2, 434 pp., illus., Harrisburg.

(587) WARren, J. A.

1910. ADDITIONAL NOTES ON THE NUMBER AND DISTRIBUTION OF NATIVE I.EGUMES in NEBRAstra aNd kANSAS. U. S. Bur. Plant Indus Cir. $70,8 \mathrm{pp}$.

(588) WAYNE, A. T.

1906. A CONTRLBUTION TO THE ORNITHOLOGY OF BOUTH CAROLINA, CHIEFLY THE COAST REGION. Auk $23: 56-68$.

(589)

1910. BIRDS OF south CARoLINA. $255 \mathrm{pp.}$ Charleston, S. C.

(590) Weaver, J. E., and Clementa, F. E.

1929. Plant ECOLOGY. 520 pp., illus. New York.

(591) - and Fitzpatrick, T. J.

1934. THE PRATRIE. Ecol. Monog. 4: 113-295, illus.

(592) Weed, C. M., and Dearborn, N.

1901. A StUdy OF the AUTUMN FOOD OF THE MYRTLe Warbler. N. H. Agr. Expt. Sta. Tech. Bull. 3: 117-128, illus.

(593) - and DEARBORN, N.

1916. BIRDS IN their recations to man. 390 pp., illus. Philadelphia and London.

(594) WERTHNER, W. B.

1935. SOME AMERICAN TREES; AN INTIMATE STUDY OF NATIVE OHIO TREES. 398 pp., illus. New York.

(595) Westuerd, R. H.

1936. SOIL CHARACTERISTICS IN RELATTON TO THE OCCURRENCE AND GROWTH OF BLACK SPRUCE. Amer. Soil Survey Assoc. Bull. 17 (Rept. Ann. Meeting 16) : 45-47.

(596) - and BENNETT, R.

1936. IMPROVING FOOD AND COVER FOR WILDUIFE ON MISSOURI FARMS. Mo. Agr. Col. Ext. Cir. 348, 8 pp., illus.

(597) WetMoRe, A.

1935. THE THICK-BILLED PARBOT IN SOUTHERN ARIZONA. Condor 37: 18-21. 
(598) WheAToN, J. M.

1875. THE FOOD OF BIRDS AS RELATEd to Agriculture. Ohio State Bd. Agr. Ann. Rept. (1874) 29: 561--578.

(599)

1879. BEPORT ON THE BIRDS OF OHIO. Ohio Geol. Survey 4 (sec. 2) : 189-612.

(600) WHEELER, L. C.

1937. BERBERIS AMPLECTANS (EASTW). COMB. Nov. Rhodorn 39: 376.

(601) WHERRY, E. T.

1937. Clematis ADDISONII BRITTON. Claytonia 3: 42-43.

(602) Wregand, K. M.

1912. THE GENUS AMELANCHIER IN EASTERN NORTH AMERICA. Rhodora 14: 117-161, illus.

(603) 1920. ADDitTonar, Notes oN AMELANCHIER. Rhodora $22: 146-151$.

(604) Wтонт, H. M.

1933. sUgeESTIONS for PHEASANT MANAGEMENT IN SOUTHERN MiCHIGAN. Mich. Dept. Conservation. 25 pp., illus. Lansing, Mich.

(605) WreHt, W. F.

1915. THE VARIETIES OF PLUMS DERIVED FROM NATIVE AMERICAN SPECIES. U. S. Dept. Agr. Bull. 172, 44 pp.

(606)

1915. Native american spectes of prunus. U. S. Dept. Agr. Bull. 179, 75 pp., illus.

(607) WHLETT, G.

1912. BIRDS of the PACTFIC slope of southern califorinia. Pacific Coast Avifauna No. 7, $122 \mathrm{pp}$.

(608) WrLliams, R. W.

1904. A PREIIMINARY LIST OF THE BIRDS OF LEON COUNTY, FLORIDA. Auk. 21: 449-462.

(609) Wilson, A., and Bonaparte, C. L.

1831. AMERICAN ORNITHOLOGY. 4 v., illus. Edinburgh.

(610) WILson, C. P.

1931. the artiftctal reseeding of New mexico ranges. N. Mex. Agr. Exp. Sta. Bull. 189, 37 pp., illus.

(611) WIrson, E. H., and REHDER, A.

1921. A MIONOGRAPH OF AZALEAS; RHODODENDRON SUBGENUS ANTERODENDRON. Arnold Arboretum Pub. 9, 219 pp.

(612) Wilgon, F. G.

1928. FOREST TREES OF WISCONSIN; HOW TO KNOW THEM. A POCKET

(613) Wrison, $\mathbf{P}$. manual. Wis. Conserv. Comn. 64 pp., illus.

1905. altingiaceaE. North Amer. Flora 22: 189.

(614) - 1911 RUTACEAE, North Amer. Flora 25:173-204

(615) 1924 . MEIIACEAE. North Amer. Flora $25: 263-296$.

(616) WOODCOCK, A. R.

1902. ANNOTATED LIST OF THE BIRDS of oregon. Oreg. Agr. Expt. Sta.

(617) Wooton, E. O. Bull. 68, 118 pp., illus.

1913. Trees and shrubs of new Mexico. N. Mex. Agr. Expt. Sta. Bull. 87,159 pp., illus.

(618) 1915 . FLORA OF NEW MEXICo. U. S. Natl. Mus., Contrib. U. S. Natl.
19. C.

(619) WrMAN, D. Herbarium 19, 794 pp.

1936. WOody plants with ornamental frutts. Arnold Arboretum Bull.

(620) WrMAN, L. Pop. Inform. 4: 71-82.

1920. tree planting in texas towns and ctties. Tex. Agr. Col. Bull. 11,37 pp., illus.

(621) Yeagkr, A. F., Yatzke, F., and Berrigan, D.

1935. THE NATTVE FRUTS OF NORTh DAKota AND THEIr USE. N. Dak. Agr. Expt. Sta. Bull. 281, 26 pp., illus. 
(622) Yeatter, R. E.

1934. TIIE hungarian Partridge in the great lakes region. Mich.

Univ. School Forestry and Conserv. Bull. 5, 92 pp., illus.

(623) Young, M. S.

1925. THE SEED PLANTS, FERNS, AND FERN ALLIES OF TIIE AUSTIN REgION.

Tex. Univ. Bull. 2065, $98 \mathrm{pp}$.

\section{MIMEOGRAPHED AND UNPUBLISHED REFERENCES}

(624) Atwoon, E. L., and Steyermark, J. A.

1937. THE WHITE-TAILED DEER IN MISSOURI. (PREUIMINARY REPOITT). Clark Natl. Forest, U. S. Dept. Agr., 34 pp., illus. St. Louis, Mo. [Mimeographed.]

(625) BLAKEY, H. L.

1937. THE WILD TURKEY ON THE MISSOURI OZARK RANGE. (PRELUMINARY REPORT). U. S. Bur. Biol. Survey Wildlife Research and Management Leaflet $\mathbf{B S}-77,31 \mathrm{pp}$. [Mimeographed.]

(626) DaLke, P. D.

1934. FOOD HABITS OF THE PHFASANT iN SOUTHERN MICHIGAN. Ph. D. Thesis, Univ. Mich. [Pub. in part.]

(627)

(n.d.) FrUit-bearing shrubs VAluable as FOOD FOR GAME, SONG, AND INSECTIVOROUS BIRDS WITH PARTICULAR REFERENCE TO WINTER FooD. Conn. State Bd. Fish and Game. Game Management Cir. 1, 4 pp. [Mimeographed.]

(628) Davison, V.

1935. THE DAVISON RANCH, FLLIS COUNTY, OKLAHOMA, GAME BIRD PROJECT FROM FEBRUARY 1, 1932, TO JUNE 1, 1935. Unpub. Report.

(629)

1936. REPORT ON THE ARNETT, OKLAHOMA, EXPERIMENTAL QUAIL AND PRAIRIE CHICKEN MANAGEMENT PROJECT. U. S. Bux. Biol. Survey Wildlife and Management Leaflet BS-39, 6 pp. [Mimeographed.]

(630) Fisher, P. L., Briggs, A. H., Elikins, W. A., Roe, E. I., and Aldous, C. M. 1935. Propagation OF GAME FOOD AND COVER PLANTS OF THE LAKE STATES. Lake States Forest Expt. Sta. $81 \mathrm{pp.} \mathrm{[Mimeographed.]}$

(631) Gtrakd, G. L.

1935. IIFE HISTORY, HABITS AND FOOD OF THE SAGE GROLSE, CENTROCLRCUS URophasianus. Ulupublished M. A. Thesis, Univ. Wyo. Laramie, Wyo.

(632) Hagge, H. P.

1929. FLORA OF NORTHEASTERN IOWA AND SOUTHWESTERN WISCONSIN. 337

(633) Hershex, J. W. pp. Unpublished M. S. Thesis, Iowa State College.

1933. SUPPLEMENT TO FOREST TREE CROPS AND THETR PART IN THE TENNESSEe valley. TVA Div. Forestry Tree Crop Research. 9 pp. Knoxville, Tenn. [Mimeographed.]

(634) Hosley, N. W.

1935. A PRELIMINARY REPORT ON 104 SPECIES OF WOODY PLANTS GIVING PROMISE OF USE BY WILDLIFE. 87 pp. Unpublished report.

(635) KELSO, L, H.

1933. WINTER FOOD OF THE RUFFED GROUSE IN THE NORTHEAST. U. S. Bur. Biol. Survey Bull. Bi-1297, 2 pp. [Mimeographed.]

(636) 1935. WINTER FOOD OF RUFFED GROUSE IN NEW YORK. U. S. Biol. Survey Bull. BS-1, 3 pp. [Mimeographed.]

(637) - 1936. QUANTITY AND KINDS OF RABBIT, SQUIRREL, AND PRATRIE DOG FOODS. U. S. Bnr. Biol. Survey, unpublished report.

(638) 1937. Food of the scaled QUAIL. PReliminary REPoRT. U. S. Bur. Biol. Survey Wildlife Research and Management Leaflet BS-84, 9 pp. [Mimeographed.]

(639) Lefringweul, D. J.

1926. A STUDY OF THE PHeASANT, PHASIANUS COICHICUS L., WITH NOTES oN ITS ARTIFTCIAL pROPAgatron. 389 pp., illus. (Unpublished Ph. D. Thesis, Cornell Univ.). 
(640) Locise, S. B.

1931. STUDIES OF FOOD HABITS OF MULE DEER IN THE INTERMOUNTALN REGION. Intermountain Forest and Range Expt. Sta. unpublished report.

(641) MCATEE, W. L.

1935. PLANTS VALUABLE FOR WLLDLIFE UTILIZATION AND FOR EROSION Controu. U. S. Bur. Biol. Surrey Wildlife Research and Management Leaflet BS-19, 11 pp. [Minleographed.]

(642)

(643) MORRIS, N. A.

1936. Fruits AtTractive to BIRDs. U. S. Bur. Biol. Survey Wildlife Research and Management Leaflet BS-41-50. [Mimeographed.]

1933. Native shrús common to wisconsin. Wis. Agr. Col. Ext. Serv. Stencil Cir. 138, 17 pp., illus. [Mimeographed.]

(644) Ostrom, C. E.

1937. DEER AND RABBIT INJURY TO NORTHERN HARDWOOD REPRODUCTION. Allegheny Forest Expt. Sta. Tech. Notes 15, 2 pp. [Mimeographed.]

(645) SмIтH, C. F.

1936. food habits of kangaroo Rats. U. S. Bur. Biol. Survey, unpublished report.

(646) United States Forest Experiment Station, Lake States.

1936. WOODY FOOI PREFERENCES OF THE SNOWSHOE RABBTT IN THE LAKE states. U. S. Lake States Forest Expt. Sta. Tech. Notes 109, 1 p. [Mimeographed.]

(647)

1937. DAMAGE FROM RABBITS-A CONSIDERATION IN SHELTERBELT PLANTING. U. S. Forest Expt. Sta. Tech. Notes 121. 2 pp. [Mimeographed.]

(648) Wisconsin Conservation Department.

1935. PHEASANT CROP CONTENT REPORT. Unpublished report.

(649) WYKOFF, S. N.

1937. ANNUAL REPORT FOR 1936 AND PROGRAM FOR FISCAL YEAR $193 \mathrm{~S}$. Northern Rocky Mountain Forest and Range Expt. Sta. 77 pp. Missoula, Mont. [Mimeographed.]

\section{LIST OF COMMON NAMES OF WOODY PLANTS}

Acacia, (Albizzia julibrissin).

Dwarf (Robinia nana).

False- (Robinia pseudoacacia).

Fernleaf (Acacia angustissima).

Green-barked (Cercidium floriaum

Oercidium torreyanum).

Lemmon (Acacia lemmonii).

Mescat (Acacia constricta).

Netrein (Acacia reticulata).

Prairie (Acacia angustissima).

Rose- (Robinia hispida).

Sweet (Acacia farnesiana).

Acequia willow (Salix exigua).

Adelia (Forestiera acuminata).

Adobe-land grape (Vitis champinii).

Agarita (Berberis trifoliolata).

Agrito (Berberis trifoliolata).

Ailanthus (Ailanthus altissima).

Alabama,

azalea (Rhododendron alabamense).

cherry (Prunus alabamensis).

chinquapin (Castanea alabamensis).

croton (Croton alabamensis).

ninebark (Physocarpus alabamensis).

Alaska,

cedar (Chamaecyparis nootkatensis). cypress (Chamaecyparis nootkatensis).
Albaricoque (Prumus texana).

Alberta spruce (Picea albertiana).

Alder,

Black (Ilex verticillata).

California (Alnus rhombifolia).

European black (Alnus glutinosa).

Green (Alnus crispa).

Hazel (Alnus rugosa).

Hoary (Alnus incana).

Lanceleaf (Alnus oblongifolia).

Mexican (Alnus oblongifolia).

Mountain (Alnus crispa,

Alnus rhombifolia,

Alnus sinuata,

Alnus tenuifolia).

Northern (Alnus sinuata).

Oregon (Alnus rubra).

Paperleaf (Alnus tenuifolia).

Red (Alnus rubra).

Russet (Alnus crispa).

Seaside (Alnus maritima).

Sitka (Alnus sinuata).

Smooth (Alnus rugosa).

Speckled (Alnus incana).

Tag (Alnus tenuifolia).

Thinleaf (Alnus sinuata, Alnus tenuifolia).

Western (Alnus rubra). 
Alder-Continued.

White (Alnus rhombifolia, Clethra acuminata, Clethra alnifolia).

Alder buckthorn (Rhamnus caroliniana).

Alderleaf mountain-mahogang (Cercocarpus alnifolius).

Alder-leaved buckthorn (Rhamnus alnifolia).

Algaroba (Prosopis glandulosa).

Algerita (Berberis haematocarpa).

Allegheny,

barberry (Berberis canadensis). mountain-spurge (Pachysandra procumbens).

plum (Prunus allegheniensis).

Alligator,

juniper (Juniperus pachyphloca).

wood (Liquidambar styraciflua).

Allscale (Atriplex polycarpa).

Allthorn (Koeberlinia spinosa).

Almond, Texas (Prunus minutiflora).

Alpine,

fir (Abies lasiocarpa).

gooseberry (Ribes lepthanthum).

larch (larix lyallii).

mountain-ash (Sorbus occidentalis).

Ambrosia bur-sage (Franseria ambrosioides).

American,

arborvitae (Thuja occidentalis).

aspen (Populus tremuloides).

barberry (Berberis canadensis).

bladdernut (Staphylea trifolia).

chestnut (Castanea dentata).

china-root (Smilax pseudo-china).

crab apple (Malus coronaria).

cranberry-bush (Virburnum trilobum).

dogberry (Cornus stolonifera).

elder (Sambucus canadensis).

elm (Ulmus americana).

fly honeysuckle (Lonicera, canadensis).

hazelnut (Corylus americana).

holly (Ilex opaca).

ivy (Parthenocissus quinquefolia).

larch (Larix laricina).

linden (Tilia glabra).

mountafn-ash (Sorbus americana).

olive (Osmanthus americana).

red currant (Ribes triste).

snowbell (Styrax americana).

storax (Styrax americana).

trixis (Trixis californica).

wisteria (Wisteria frutescens).

Anacahuita (Cordia boissieri).

Anacua (Ehretia anacua).

Anderson,

desert-thorn (Iycium andersonii).

manzanita (Arctostaphylos andersonii).

Angelica tree (Aralia spinosa).

Anise, purple (Illicium floridanum).
Antelope-brush (Purshia glandulosa,

Apache,

pine (Pinus apacheca).

plume (Fallugia paradoxa).

Appalachian cherry (Prunus pumila, Prunus susque-

Apple, hanae).

Squaw (Peraphyllum ramosissimum).

Wild (Peraphyllum ramosissimum).

Arborvitae (Thuja occidentalis, Thuja plicata).

American (Thuja occidentalis).

Arizona,

ash (Fraxinus velutina).

buckthorn (Bumelia lanuginosa).

cottonwood (Populus arizonica).

cypress (Cupressus arizonica).

fir (Abies arizonica).

grape (Vitis arizonica).

honeysuckle (Lonicera arizonica).

madrone (Arbutus arizonica).

mesquite (Prosopis chilensis).

mountain-mahogany (Cerococarpus arizonicus).

pine (Pinus arizonica).

sycamore (Platanus wrightii).

walnut (Juglans major).

white oak (Quercus arizonica).

wild cotton (Thurberia triloba).

Arrowwood (Pluchea sericea,

Viburnum acerifolium,

Viburnum dentatum).

Mapleleaf (Viburnum acerifolium).

Rough (Viburnum scabrellum).

Soft (Viburnum molle).

Soft-leaved (Viburnum molle).

Veiny (Viburnum venosum).

Arroyo,

grape (Vitis vulpina).

willow (Salix lasiolepis). Ash,

Alpine mountain (Sorbus occidentalis).

American mountain (Sorbus americana).

Arizona (Fraxinus velutina).

Biltmore white (Fraxinus biltmoreana).

Black (Fraxinus nigra).

Blue (Fraxinus quadrangulata).

Brown (Fraxinus nigra).

Carolina (Fraxinus caroliniana).

Desert (Fraxinus velutina).

Dwarf (Fraxinus anomala).

European mountain (Sorbus aucuparia).

Flowering (Fraxinus cuspidata, Fraxinus dipetala).

Foothill (Fraxinus dipetala).

Fragrant (Fraxinus cuspidata).

Greene mountain (Sorbus scopulina).

Hoop (Fraximus nigra) 
Ash-Continued.

Leatherleaf (Fraxinus velutina).

Littleleaf (Fraxinus greggii).

Mexican (Fraxinus berlandieriana).

Mountain (Fraxinus texensis, Sorbus americana).

Oregon (Fraxinus oregona).

Paciflc mountain (Sorbus sitchensis).

Prickley (Xanthoxylum spp.).

Pumpkin (Fraxinus profunda).

Red (Fraxinus pennsylvanica).

Swamp (Fraxinus caroliniana).

Texas (Fraxinus texensis).

Thorny (Aralia spinosa).

Velvet (Fraxinus velutina).

Water (Fraxinus caroliniana, Fraxinus pauciflora).

Western mountain (Sorbus sitchensis).

White (Franxinus americana).

Yellow (Cladrastis lutea).

Ashe magnolia (Magnolia ashei).

Ashes (Fraxinus spp.)

Ash-leaved maple (Acer negundo).

Ashy,

grape (Vitis cinerea).

hydrangea (Hydrangea cinerea).

Asimina, Low (Asimina pygmaea).

Aspen (Populus tremuloides).

American (Populus tremuloides).

Largetooth (Populus grandidentata).

Quaking (Populus tremuloides).

Trembling (Populus tremuloides).

Autumn,

sage (Salvia greggii).

willow (Salix serissina).

Azalea,

Alabama ( $R$ hododcndron alabamense).

California (Rhododendron occidentale).

Early (Rhododendron canescens).

False (Rhododendron albiflorum).

Flame (Rhododendron calendulaceum).

Hoary (Rhododendron canescens).

Pinkshell (Rhododendron vaseyi).

Purple (Rhododendron nudiflorum).

Smooth (Rhododendron arborescens).

Swamp (Rhododendron viscosum).

Sweet (Rhododendron arborescens).

Western (Rhododendron occidentale).

White (Rhododendron viscosum).

White-flowered (Rhododendron albiflorum).

Yellow (Rhododendron calendulaceum).

Bailey,

cornel (Cornus baileyi).

grape (Vitis baileyana).

hop-hornbeam (Ostrya baileyi).

osier (Cornus baileyi).

Baldcypress (Taxodium distichum).
Balloon bush, California (Staphylea bolanderi).

Balm-of-gileạd (Populus bulsamifera). fir (Abies balsamea).

Balsam, (Abies balsamica,

Abies concolor,

Abies fraseri,

Abies lasiocarpa).

Single spruce (Abies balsamea).

Balsam,

cottonwood (Populus trichocarpa).

fir (Abies balsamea, Abies concolor).

poplar (Populus balsamifera).

willow (Salix balsamifera).

Bamboo, (Smilax bona-nox).

Red-berry (Smilax walteri).

Wild (Smilas aurioulata).

Bamboo vine (Smilax laurifolia).

Banks pine (Pinus banksiana).

Barbados cherry (Malpighia glabra).

Barberry,

Allegheny (Berberis canadensis).

American (Berberis canadensis).

California (Berberis californicum, Berberis pinnata).

Cliff (Berberis canadensis).

Common (Berberis vulgaris).

Creeping (Berberis repens).

Desert (Berberis fremontii).

Dwarf (Berberis pumila).

European (Berberis vulgaris).

Fendler (Berberis fendleri).

Fremont (Berberis fremontii).

Thunberg (Berberis thunbergii).

Barclay willow (Salix barclayi).

Baretta (Helietta parvifolia).

Barranca bush (Ceanothus verrucosus).

Barren oak (Quercus ilicifolia.

Quercus marilandica).

Bartram serviceberry (Amelanchier bartramiana).

Basin sagebrush (Artemisia tridentata)

Basket,

oak (Quercus durandii,

Quercus prinus).

willow (Salix purpurea) .

Basswood, (Tilia spp.)

White (Tilia heterophylla).

Bastard,

cedar (Libocedrus decurrens).

oak (Quercus coccinea, Quercus durandii).

Bay,

Lapland rose (Rhododendron lapponicum).

Loblolly (Gordonia lasianthus).

Mountain rose (Rhododendron catawbiense).

Poison (Illicium floridanum).

Red (Gordonia lasianthus, (Persea borbonia).

Silk (Persea humilis).

Smooth red (Persea borbonia).

Swamp (Persea pubescens).

Swamp red (Persea pubescens). 
Bay-Continued.

Sweet (Persea borbonia). Tan (Gordonia lasianthus).

Bay,

laurel (Umbellularia californica). tree (Umbellularia californica).

Bayberry (Myrica carolinensis).

Beach,

heather (Hudsonia tomentosa). plum (Prunus maritima).

Beadtree (Melia azedarach).

Beaked,

hazelnut (Corylus rostrata). willow (Salix bebbiana).

Bean,

Coral (Sophora affinis).

Evergreen coral (Sophora secundiflora).

Mescal (Sophora secundiflora).

Bear

brush (Garrya fremontii).

huckleberry (Gaylussacia ursina).

oak (Quercus ilicifolia,

Quercus sadlerina).

Bearberry (Arctostaphylos uva-ursi). holly (Ilex decidua).

honeysuckle (Lonicera involucrata). willow (Salix uva-ursi).

Bearmat (Chamaebatia foliolosa).

Beaver tree (Magnolia virginiana).

Beaverwood (Celtis occidentalis).

Bebb willow (Salix bebbiana).

Bee-sage (Hyptis emoryi).

White (Salvia apiana).

Beech (Fagus grandifolia).

Blue (Carpinus caroliniana).

Water (Carpinus caroliniana).

Bell-rue (Clematis verticillaris).

Belltree (Halesia carolina).

Benjamin bush (Benzoin aestivale).

Bennie bush (Ccanothus papillosus).

Bessey cherry (Prunus besseyi).

Big

buckeye (Aesculus octandra).

laurel (Magnolia grandiflora).

sagebrush (Artemisia tridentata).

saltbush (Atriplex lentiformis).

shellbark bickory (Carya laciniosa).

summer grape (Vitis lincecumii).

whortleberry (Vaccinium membra. naceum).

Bigberry juniper (Juniperus megalocarpa).

Bigbud hickory (Carya alba).

Bigcone

pine (Pinus coulteri).

spruce (Pseudotsuga macrocarpa).

Bigelow sagebrush (Artemisia bigelovii).

Bigleaf

magnolia (Magnolia macrophylla). maple (Acer macrophyllum).

mountain mahogany (Cercocarpus traskiae).

shagbark hickory (Carya laciniosa).

Bigpod ceanothus (Ceanothus macroсагpus).
Bigtooth maple (Acer grandidentatum).

Bigtree (Sequoia washingtoniana). plum (Prunus mexicana).

Bilberry,

Bog (Vaccinium uliginosum).

Dwarf (Vaccinium caespitosum).

Red (Vaccinium parvifolium).

Tall (Vaccinium ovalifolium).

Biltmore white ash (Fraxinus biltmo. reana).

Birch,

Black (Betula fontinalis,

Betula lenta,

Betula nigra).

Blue (Betula nigra).

Blueleaf (Betula coerulea).

Bog (Betula glandulosa).

Canoe (Betula papyrifera).

Cherry (Betula lenta).

Dwarf (Betula gtandulosa).

Gray (Betula lutea,

Betula populifolia).

Low (Betula pumila).

Mountain (Betula fontinatis).

old field (Betula poputifolia).

Paper (Betula papyrifera,

Betula populifolia).

Poverty (Betula populifolia).

Red (Betula fontinalis,

Betula nigra).

River (Betula nigra).

Scrub (Betula glandulosa).

Silver (Betula lutea).

Swamp (Betula fontinalis,

Betula pumila).

Sweet (Betula lenta).

Water (Betula fontinalis, Betula nigra).

Western paper (Betula papyrifera).

White (Betula papyrifera, Betula populifolia).

Yellow (Betula lutea).

Birchleaf,

buckthorn (Rhamnus betulaefolia). mahogany (Cercocarpus montanus).

mountaiu-mahogany (Cercocarpus betuloides).

Bird cherry (Osmaronia cerasiformis, Prunus avium, Prunus pennsylvanica).

Bishop pine (Pinus muricata).

Bitter

buffaloberry (Shepherdia canadensis).

cherry (Prunus emarginata).

gooseberry (Ribes amarum).

nightshade (Solanum dulcamara).

orange (Citrus trifoliata).

pecan (Carya aquatica,

Carya cordiformis,

Carya texana).

Bitter-bark (Rhamnus purshiuna).

Bitterbrush (Purshia tridentata).

Bitterbush (Cowania stansburiana).

Bitternut hickory (Carya cordiformis, Carya glabra). 
Bittersweet (Solanum dulcamara). Climbing (Celastrus scandens). False (Celastrus scandens).

Black,

alder (Ilex verticillata).

ash (Fraxinus nigra).

birch (Betula fontinalis, Betula lenta, Betula nigra).

blueberry (Vaccinium atrococcum). cherry (Prunus serotina).

cherry, southwestern (Prunus virens).

chokeberry (Aronia melanocarpa).

chokeberry, western (Prunus demissa).

cottonwood (Populus trichocarpa). currant (Ribes americanum). cypress (Taxodium distichum). elder (Sambucus melanocarpa). gum (Nyssa sylvatica).

gum, highland (Nyssa sylvatica).

gum, southern (Nyssa biflora).

gum, swamp (Nyssa biflora).

haw, southern (Viburnum rufidulum).

hickory (Carya alba, Carya glabra).

highbush blueberry (Vaccinium atrococcum).

huckleberry (Gaylussacia baccata).

laurel (Gordonia lasianthus, Leucothoè davisiae).

locust (Gleditsia triacanthos, Robinia pseudoacacia).

maple (Acer saccharum). mulberry (Morus nigra).

oak (Quercus coccinea, Quercus emoryi.

Quercus velutina).

persimmon (Diospyros texana).

pine (Pinus serotina,

Pinus taeda).

sage (Artemisia arbuscula,

Salvia mellifera).

scrub oak (Quercus ilicifolia).

sloe (Prunus umbellata).

spruce (Picea mariana).

sugar maple (Acer nigrum).

titi (Cliftonia monophylla, Cyrilla racemiflora).

walnut (Juglans nigra).

walnut, California (Juglans hindsii).

walnut, Southern California (Juglans californica).

western chokecherry (Prunus demissa).

willow (Salix nigra).

willow, western (Salix lasiandra).

Blackbead elder (Sambucus melanocarpa).

Blackberries (Rubus spp.).

Blackbruch (Acacia amentacea).

(Coleogyne ramosissima,

Flourensia cernua).

Blackbush (Ooleogyne ramosissima).
Blackhaw (Bumelia lanuginosa, Bumelia tenax,

Viburnum prunifolium).

Rusty (Viburnum rufidulum).

Blackjack oak (Quercus marilandica).

Blackthorn (Viburnum lentago).

Bladder,

bush (Salazaria mexicana).

saga (Salazaria mexicana).

Bladdernut,

American (Staphylea trifolia).

California (Staphylea bolanderi).

Sierra (Staphylea bolanderi).

Bladderpod (Isomeris arborea).

Blaspheme-vine (Smilax laurifolia).

Blood currant (Ribes sanguineum).

Bloomer goldenbush (Aplopappus bloomeri).

Blue,

agarita (Berberis swaseyi).

ash (Fraximus quadrangulata).

beech (Carpinus caroliniana).

birch (Bctula nigra).

blossom (Ceanothus thyrsiflones). cornel (Cornus alternifolia).

dogwood (Cornus alternifolia).

elder (Sambucus coerulea).

fly-honeysuckle (Lonicera villosa).

jasmine (Clematis crispa).

myrtle (Oeanothus thyrsiflorus).

oak (Quercus douglasii).

palmetto (Rhapidophyllum hystrix). poplar (Liriodendron tulipifera).

sage, shrubby (Salvia ballotacflora). spruce (Picea pungens).

tangle (Gayhussacia frondosa).

whortleberry (Vaccinium ovaltfolium).

willow (Satio subcoerulea).

Blueback willow (Salix glaucops).

Blueberry,

Black (Vaccinium atrococcum).

Black highbush (Vaccinium atro. coccum).

Bog (Vaccinium uliginosum).

Box (Vaccinium ovatum).

Canada (Vaccinium canadense).

Common (Vaccinium corymbosum).

Creeping (Vaccinium crassifolium).

Downy swamp (Vaccinium atrod coccum).

Dryland (Vaccinium vacillans).

Dwarf (Vaccinium angustifolium).

Elliott (Vaccinium elliottii).

Evergreen (Vaccinium myrsinites).

Highbush (Vacoinium corymbosum).

Low (Vaccinium vacillans).

Low sweet (Vaccinium angustifoTium).

Lowbush (Vaccinium angustifolium).

Rabbiteye (Vaccinium virgatum).

Sour-top (Vaccinium canadense).

Sugar (Vaccinium angustifolium).

Swamp (Vaccinium corymbosum).

Velvetleaf (Vaccinium canadense). 
Blueberry-Continued.

Western (Vaccinium occidentale).

Western bog (Vaccinium occidentale).

Blueberry elder (Sambucus caerulea). Blueblossom (Ceanothus thyrsiflorus). Bluebrush (Ceanothus integerrimus, Ccanothus thyrsiflorus).

Bluecurls (Trichostema arizonicum). Bluejack oak (Quercus cinerea).

Blueleaf,

birch (Betula coerulea). grape (Vitis argentifolia). willow (Salix glaucophylla).

Bluestem willow (Salix irrorata).

Bluewood (Condalia obovata). Mexicall (Condalia mexicana).

Bog, bilberry (Vaccinium uliginosum). birch (Betula glandulosa). blueberry (Vaccinium uliginosum). rosemary (Andromeda polifolia). rosemary, downy (Andromeda glaucophylla).

spruce (Picea mariana).

wortleberry (Vaccinium uliginosum). Bois willow (Salix pedicellaris).

d'arc (Maclura pomifera).

inconnu (Celtis mississippiensis).

Bottlebrush buckeye (Aesculus parviflora).

Bottom hickory (Carya carolinae-sep-

Box tentrionalis).

blueberry (Vaccinium ovatum).

huckleberry (Gaylussacia brachycera).

sandmyrtle (Leiophyllum buxifolium).

thorn (Lycium halimifolium).

thorn, California (Lycium californicum).

white oak (Quercus stellata).

Boxelder (Acer negundo).

Boxwood (Cornus florida).

false (Gyminda latifolia).

Boynton oak (Quercus boyntonii).

Brasil (Condalia obovata).

Bray oak (Quercus brayi).

Brewer

oak (Quercus garryana).

saltbush (Atriplex breweri).

spruce (Picea breweriana).

willow (Salix breweri).

Brickellbush,

Desert (Brickellia desertorum).

Littleleaf (Brickellia microphylla).

Rigid (Brickellia frutescens).

Bristlecone,

fir (Abies venusta).

pine (Pinus aristanta).

Bristly.

greenbrier (Smilax auriculata, Smilax hispida).

locust (Robinia hispida).
Broadleaf maple (Acer macrophyllum).

Broadscale broom (Lepidospartum latisquamum).

Brook feather (Xanthorhiza simplicis$\operatorname{sima)}$.

Broom,

Broadscale (Lepidospartum latisquamum ).

Scotch (Cytisus scoparius).

Broom,

brush (Symphoricarpos orbiculatus). crowberry (Corema conradii).

hickory (Carya glabra).

Brown,

ash (Fraxinus nigra).

crowberry (Corema conradii).

dogwood (Cornus glabrata).

Brown's hickory (Carya pecan).

Brush,

Black (Acacia amentacea).

Blue (Ceanothus thyrsiflorus).

Buck (Ceanothus cuneatus, Ceanothus sanguineus).

Coyote (Baccharis pilularis).

Deer (Ceanothus crassifolius,

Ceanothus fendleri,

Ceanothus integerrimus,

Ceanothus leucodermis,

Ceanothus tomentosus).

Douglas rabbit (Chrysothamnus viscidiflorus).

Javelin (Microrhamnus evicoides).

Jim (Ceanothus sorediatus).

Musk (Ceanothus jepsonii).

Red (Lippia berlandieri).

Rosin (Baccharis sarothroides).

Rubber rabbit (Chrysothamnus nauseosus).

Snow (Ceanothus cordulatus,

Ceanothus velutinus).

Tobacco (Ceanothus velutinus).

Varnish (Ceanothus velutinus).

White (Lippia ligustrina).

Bubby-blossoms (Calycanthus floridus).

Buck,

oak (Quercus coccinea).

vine (Brunnichia cirrhosa).

Buckberry (Gaylussacia ursina).

Buckbrush (Ceanothus cuneatus,

Ceanothus fendleri,

Ceanothus sanguineus,

Symphoricarpos orbicula tus).

Buckeye,

Big (Aesculus octandra).

Bottlebrush (Aesculus parviflora).

California (Aesculus californica).

Fetid (Aesculus glabra).

Georgia (Aesculus neglecta).

Large (Aesculus octandra).

Mexican (Ungnadia speciosa).

New Mexico (Ungnadia speciosa).

Ohio (Aesculus glabra).

Red (Aesculus pavia).

Scarlet (Aesculus discolor,

Aesculus pavia). 
Buckeye-Continued.

Shrubby (Aesculus glabra).

Spanish (Ungnadia speciosa).

Sweet (Aesculus octandra).

Western (Aesculus glabra).

Woolly (Aesculus discolor).

Yellow (Aesculus octandra).

Buckthorn (Bumelia cassinifolia, Rhamnus smithii, Sageretia minutaeflora).

Alder (Rhamnus caroliniana).

Alder-leaved (Rhamnus alnifolia).

Arizona (Bumelia lanuginosa).

Birchleaf (Rhamnus betulaefolia).

California (Rhamnus califormica).

Carolina (Bumelia lycioides,

Rhamnus caroliniana).

Cascara (Rhamnus purshiana).

Dwarf (Rhamnus alnifolia).

False (Bumelia lanuginosa).

Hollyleaf (Rhamnus crocea).

Lance-leaved (Rhamnus lanceolata).

Mountain (Bumelia monticola).

Narrow-leaved (Rhamnus lanceolata).

Redstem (Rhamnus rubra).

Smith (Rhamnus smithii).

Southern (Bumelia lycioides).

Tough (Bumelia tenas).

Woolly (Bumelia lanuginosa).

Yellow (Rhamnus caroliniana).

Buckthorn bumelia (Bumelia lycioides).

Buckwheat, California (Eriogonum fasciculatum).

Buckwheat vine (Brunnichia cirrhosa).

Buckwheatbrush,

Slender (Eriogonum microthecum).

Wright's (Eriogonum wrightii).

Bud sagebrush (Artemisia spinescens).

Budbrush (Artemisia spinescens).

Buffaloberry (Shepherdia argentea).

Bitter (Shepherdia canadensis).

Canadian (Shepherdia canadensis).

Russet (Shepherdia canadensis).

Sour (Shepherdia argentea).

Buffalo currant (Ribes odoratum).

Bull,

bay (Magnolia grandiflora).

grape ( itis rotundifolia).

pine (Pinus ponderosa).

Bullace,

grape (Vitis rotundifolia).

plum (Prunus umbellata).

Bullbrier (Smilax bona-nox).

Bullet grape (Vitis rotundifolia).

Bullnut hickory (Carya alba).

Bumelia, buckthorn (Bumelia lycioides).

Bunchberry elder (Sambucus microbotrys).

Bur oak (Quercus macrocarpa).

Bur, sand (Franseria dumosa).

Barningbush (Evonymus atropurpureus).

Western (Evonymus occidentalis).
Burrobrush (Hymenoclea monogyra). White (Hymenoclea salsola).

Burro-fat (Isomeris arborea).

Burro-weed (Allenrolfea occidentalis, Franseria dumosa).

Bur-sage,

Ambrosia (Franseria ambrosioides).

Hollyleaf (Franseria ilicifolia).

White (Franseria dumosa).

Woolly (Franseria eriocentra).

Bush,

Barranca (Ceanothus verrucosus).

Benjamin (Benzoin aestivale).

Bennie (Oeanothus papillosus).

Buttonball (Cephalanthus occidentalis).

Cattle (Ceanothus parvifolius).

Creosote (Covillea tridentata).

Cuyamaca (Ceanothus palmeri).

Explorers (Ceanothus oliganthus).

Fern (Chamaebatia foliolosa, Chamaebatiaria millefolium).

Fetter (Xolisma lucida).

Ferer (Benzoin aestivale).

Iodine (Allenrolfea occidentalis).

Ione (Ceanothus tomentosus).

Pine (Aplopappus pinifolius).

Quinine (Covania stansburiana).

Ramona (Ceanothus tomentosus).

Stagger (Xolisma mariana).

Tansy (Chamaebatiaria milefolium).

Tar (Chamaebatia foliolosa).

Bush,

beardtoungue (Pentstemon lemmonii.)

chinquapin (Castanopsis sempervirens).

cinquefoil (Potentilla fruticosa). grape (Vitis longii).

honeysuckle (Diervilla lonicera).

monkey flower (Mimulus aurantiacus).

paint-brush (Castilleja hololeuca). poppy (Dendromecon rigida).

wintergreen (Gaultheria ovatifolia).

Bushmallow (Malvastrum fasciculatum).

San Gabriel (Malvastrum gabrielense).

Bushmint, Emory (Hyptis emoryi).

Bushy samphire (Allenrolfea occidentalis).

Butternut (Juglans cinerea).

Button,

alder (Fothergilla major).

hazel (Fothergilla major).

Buttonball (Platanus occidentatis).

bush (Cephalanthus occidentalis).

tree (Platanus occidentalis).

Buttonwood (Platanus occidentalis).

Cabbage palmetto (Sabal palmetto).

Cabradora (Lippia ligustrina).

Cachanilla (Pluchea sericea).

Calcaire grape (Vitis champinii).

Calico-bush (Kalmia latifolia).

Calico-wood (Halesia carolina). 
California,

alder (Alnus rhombifolia). azalea (Rhodendron occidentale). balloon bush (Staphylea bolanderi). barberry (Berberis californicum, Berberis pinnata). bayberry (Myrica californica). black currant (Ribes malvaceum). black oak (Quercus kellogii). black walnut (Juglans californica, Juglans hindsii).

bladdernut (Staphylea bolanderi). blue oak (Quercus douglasii). box thorn (Lycium californicum). buckese (Aesculus californica). buckthorn (Rhamnus californica). buckwheat (Eriogonum fasciculatum).

chestnut (Castanopsis chrysophylla). chinquapin (Castanopsis sempervirens).

coffee berry (Rhamnus californica). desert-thorn (Lycium californicum). dutchman's pipe-vine (Aristolochia californica).

fremontia (Fremontia californica). grape (Vitis californica). greenbrier (Smilax californica). hardtack (Cercocarpus betuloides). hazelnut (Corylus californica). holly (Photinia arbutifolia).

hollygrape (Berberis californicum). hoptree (Ptelea baldwinii).

huckleberry (Vaccinium ovatum). indigobush (Amorpha californica). jointfir (Ephedra californica). juniper (Juniperus californica). laurel (Umbellularia californica). lilac (Ceanothus integerrimus, Ceanothus thyrsiflorus).

live oak (Quercus agrifolia). mahogany (Rhus integrifolia). nutmeg (Tumion californicum). redbud (Cercis occidentalis). red fir (Abies magnifica).

redwood (Sequoia sempervirens). rose bay (Rhododendron californicum ).

sagebrush (Artemisia californica). scrub oak (Quercus dumosa). slippery eln (Fremontia californica). spicebush (Calycanthus occidentalis). sweetshrub (Calycanthus occidentalis).

sycamore (Platanus racemosa). tanbark oak (Quercus densiflora). treemallow (Lavatera assurgentifolia).

walnut (Juglans californica). white oak (Quercus lobata). wild grape (Vitis californica). Jerba santa (Eriodictyon californicum).

Camellia,

Mountain (Stuartia pentagyna).

Silky (Stuartia malachodendron).
Camelthorn (Alhagi camelorum).

Canada,

hemlock (Tsuga canadensis).

plum (Prunus nigra).

serviceberry (Amelanchier canadensis).

yew (Taxus brevifolia).

Canadian buffaloberry (Shepherdia canadensis).

Canatilla (Ephedra antisyphilitica).

Candleberry, (Myrica carolinensis, Myrica cerifera).

Dwarf (Myrica pumila).

Swamp (Myrica carolinensis).

Candlewood (Fouquieria splendens).

Can-hoop (Ilex laevigata).

Canoe,

birch (Betula papyrifera).

cedar (Thuja plicata).

Canyatilla (Ephedra trifurca).

Canyon,

gooseberry (Ribes menziesii).

grape (Vitis arizonica).

live oak (Quercus chrysolepis, Quercus wislizenii).

tassel bush (Garrya veatchii).

Capillaire (Chiogenes hispidula).

Capul (Schaefferia cuneifolia, Celtis pallida).

negro (Oondalia obovata).

Carolina,

allspice (Calycanthus floridus).

ash (Fraxinus caroliniana).

buckthorn (Bumelia lycioides,

Rhamnus caroliniana).

cherry (Prunus caroliniana).

cherry-laurel (Prunus caroliniana).

hemlock (Tsuga caroliniana).

moonseed (Cebatha carolina).

rhododendron (Rhododendron caro-

linianum).

Carribean pine (Pinus caribaea).

Cascara (Rhamnus purshiana).

Cascara buckthorn (Rhamnus purshiana).

Cassandra (Chamaedaphne calyculata).

Cassena (Ilex vomitoria).

Cassie (Acacia farnesiana).

Cassioberry bush (Ilex vomitoria).

Castor-bean (Ricinus communis).

Cat,

grape (Vitis palmata).

spruce (Picea canadensis).

Catalina.

cherry (Prunus lyonii).

hard-tack (Cercocarpus trasiciae).

ironwood (Lyonothamnus floribun$d u s)$.

Catawba rhododendron (Rhododendron catawbiense).

Catbird grape (Vitis palmata).

Catbrier (Smilax rotundifolia).

Catclaw (Acacia emoryana,

Acacia tortuosa,

Iimosa borealis,

Mimosa biuncifera). 
Catclaw-Continued.

Long-flowered (Acacia greggii). Round-flowered (Acacia roemeriana). Texas (Acacia wrightii). Tree (Acacia wrightii).

Cattle,

bush (Ceanothus parvifolius). spinach (Atriplex polyoarpa).

Caudate willow (Salio caudata).

Ceanothus,

Bigpod (Ceanothus macrocarpus).

Fendler (Ceanothus fendleri).

Greenbark (Ceanothus spinosus).

Gregg (Ceanothus greggii).

Hairy (Ceanothus oliganthus).

Hoary-leaf (Ccanothus crassifolius).

Hollyleaf (Ceanothus jepsonii).

Jepson (Ceanothus jepsonii).

Littleleaf (Ceanothus parvifolius).

Martin (Ceanothus martinii).

Redstem (Ceanothus sanguineus).

Rigid (Ceanothus rigidus).

Trailing (Ceanothus diversifolius).

Wartystem (Ceanothus verrucosus).

Wavyleaf (Ceanothus foliosus).

Wedgeleaf (Ccanothus cuncatus).

Woolyleaf (Ceanothus tomentosus).

Cedar (Libocedrus decurrens,

Thuja occidentatis,

Thuja plicata).

Alaska (Chamaecyparis nootkatensis).

Bastard (Libocedrus decurrens).

Canoe (Thuja plicata).

Wastern red (Juniperus virginiana).

Incense (Libocedrus decurrens).

Mountain (Juniperus mexicana).

Mountain red (Juniperus scopulorum).

Northern white (Thuja occidentalis).

Port Orford (Ohamaecyparis Tawsoniana).

Post (Libocedrus decurrems).

Red (Juniperus scopulorum,

Juniperus viriginana, Thuja plicata).

Southern red (Juniperus lucayana).

Southern white (Chamaecyparis thyoides).

Stinking (Tumion taxifolium).

Western, red (Thuja plicata).

White (Chamaecyparis Tawsoniana, Libocedrus decurrens, Thuja occidentalis).

elm (Ulmus crassifolia).

plne (Pinus glabra).

Cenizo (Leucophyllum frutescens).

Chacate (Krameria grayi).

Chalk maple (Acer leucoderme).

Chalky leucaena (Leucaena putveru. lenta).

Chamis (Atriplex canescens).

Chamise (Adenostoma fasciculatum, Atriplex cancscens).

Chamiso (Adenostoma fassiculatum, Atriplex canescens).
Chamisso lupine (Lupinus chamissonis).

Chamiza (Atriplex canescens).

Chaparral (Ceanothus cuncatus). broom (Baccharis pilularis). goldenbush (Aplopappus propinquus).

honeysuckle (Loniccra interrupta). pea (Pickeringia montana).

whitethorn (Ceanothus leucodermis).

Champin grape (Vitis champinii).

Chapman,

oak (Quercus champanii).

white oak (Quercus chapmanii).

Chapotillo (Amyris texana).

Chayote (Diospyros texana).

Checkerberry (Gaultheria procumbens).

Cherry,

Alabama (Prunus alabamensis).

Appalachian (Prunus susquehanac, Prunus pumila).

Barbados (Malpighia glabra).

Bessey (Prunus besseyi).

Bird (Prunus avium,

Prunus pennsylvanica).

Bitter (Prunus emarginata).

Black (Prunus scrotina).

Carolina (Prunus caroliniana).

Catalina (Prunus lyonii).

Crab (Prunus avium).

Cuthbert's (Prunus cuthbertii).

Dwarf (Prunus pumila).

Evergreen (Prunus ilicifolia).

Fire (Prunus pennsylvanica).

Island (Prunus Tyonii).

Laurel (Prumus caroliniana).

Littleleaf (Prunus minutiflora).

Mahaleb (Prunus mahaleb).

May (Amelanchier canadensis).

Morello (Prunus cerasus).

Mountain (Prunus angustifolia).

Munson (Prunus munsoniana).

Perfumed (Prunus mahaleb).

Pigeon (Prunus pennsylvanica).

Pin (Prunus pennsylvanica).

Plumleaf (Prunus emarginata).

Quinine (Prunus emarginata).

Rocky Mountain red (Prunus corymbulosa).

Rum (Prunus serotina).

Sand (Prunus pumila).

Sour (Prunus cerasus).

Southern wild (Prunus australis).

Southwestern black (Prunus virens).

Sweet (Prunus avium).

Western cholse (Prunus demissa).

Western sand (Prunus besseyi).

Wild (Prunus emarginata, Prunus serotina).

Wild black (Prunus serotina).

Wild red (Prunus pennsylvanica).

Cherry,

birch (Betula lenta).

willow (Salio monticola). 
Cherry-laurel, Carolina (Prunus caroliniana).

Cherrystone juniper (Juniperus monosperma).

Chestnut oak (Quercus montana).

Chickasaw plum (Prunus angustifolia, Prunus umbellata).

Chicken grape (Vitis cordifolia).

Chico (Sarcobatus vermiculatus). bush (Sarcobatus vermiculatus). Clihuahua pine (Pinus leiophylla).

China-tree (Melia asedarach).

Chinaberry (Melia azedarach).

Chinabrier (Smilax pseudo-china, Snilax bona-nox).

Chinquapin (Castanea pumila, Castanopsis chrysophylla).

Alabama (Castanca alabamensis).

Bush (Castanopsis sempervirens).

California (Castanopsis sempervirens).

Coastal (Castanea ashei).

Dwarf (Castanea alnifolia).

Goldleaf (Castanopsis chrysophylla, Castanopsis sempervirens).

Giant (Castanopsis chrysophylla).

Ozark (Castanca ozarkensis).

Chinquapin oak (Quercus $m u$ ehlenbergii).

Chisos red oak (Quercus gravesii).

Chittim-bark (Rhamnus purshiana).

Chokeberry,

Black (Aronia melanocarpa).

Purple (Aronia arbutifolia).

Red (Aronia arbutifolia).

Cholsecherry (Prunus virginiana).

Western black (Prunus demissa).

Christmas holly (Ilex opaca).

Christmasberry (Lycium californicum, Lycium carolinianum, Photinia arbutifolia).

Chuperosa (Beloperone californica).

Cinnamon wood (Sassafras albidum).

Clammy locust (Robinia viscosa).

Clematis,

Curly (Clematis crispa).

Drummond (Clematis drummondii).

Mountain (Clematis verticillaris).

New Mexico (Clematis neomexicana).

Red-flowered (Clematis pitcheri).

Smooth (Clematis addisonii).

Virginia (Clematis virginiana).

Cliff,

barberry (Berberis canadensis).

elm (Ulmus racemosa).

Cliffbush (Jamesia americana).

Cliff-green (Pachistima canbyi).

Cliffrose (Cowania stansburiana).

Climbing,

bittersweet (Celastrus scandens). hydrangea (Decumaria barbara). nightshade (Solanum dulcamara).

Cloud-cap gooseberry (Ribes montigenum).
Cluster serviceberry (Amelanchier polycarpa).

Coachwhip (Fouquieria splendens).

Coast,

ceanothus (Ccanothus rigidus).

goldenbush (Aplopappus squarrosus).

juniper (Juniperus lucayana).

live oak (Quercus agrifolia,

Quercus pricei).

rhododendron (Rhododendron californicum).

silktassel (Garrya elliptica).

whitethorn (Ceanothus incanus).

willow (Salix hookeriana).

Coastal,

chinquapin (Castanea ashei).

sagebrush (Artcmisia californica).

Coffeeberry (Rhamnus californica).

Coffeetree (Rhamnus purshiana).

Kentucky (Gymnocladus dioica).

Colima (Xanthoxylum fagara).

Colorado,

blue spruce (Picea pungens).

currant (Ribes coloradense).

Douglas fir (Preudotsuga glauca).

juniper (Juniperus scopulorum).

sage (Artemisia tridentata).

white fir (Abies concolor).

white oak (Quercus leptophylla).

Coma (Bumelia lanuginosa).

Common,

barberry (Berberis vulgaris).

blueberry (Vaccinium corymbosum).

greenbrier (Smilax rotundifolia).

manzanita (Arctostaphylos manzanita).

papaw (Asimina triloba).

Cooper,

desert-thorn (Lycium cooperi) .

goldenbush (Aplopappus cooperi).

Coral,

greenbrier (Similar lanceolata, Smilax walteri).

honeysuckle (Loni cera sempervirens).

Coralbeads (Cebatha carolina).

Coralbean (Erythrina fabelliformis, Sophora affinis).

Evergreen (Sophora secundiflora).

Coralberry (Symphoricarpos orbiculatus).

Cork elm (Ulmus alata, Ulmus racemosa).

Corkbark fir (Abies arizonica).

Corkwood (Stillingia aquatica, Leitneria floridana).

Cornel,

Bailey (Cornus baileyi).

Rough-leaved (Cornus asperifolia, Cornus circinata).

Silky (Cornus amomum).

Stiff (Cornus foemina).

White (Cornus foemina).

Corona del Cristo (Dalea spinosa). 
Correosa (Rhus microphylla, Xanthoxylum fagara).

Cotton, Arizona wild (T'hurberia triloba).

Cotton,

gum (Nyssa aquatica).

thorn (Tetradymia spinosa).

Cottonwood (Populus deltoides, Populus trichocarpa).

Arizona (Populus arizonica).

Balsam (Populus trichocarpa).

Black (Populus trichocarpa).

Fastern (Populus deltoides).

Fremont (Populus fremontii).

Lanceleaf (Populus acuminata).

Narrowleaf (Populus angustifolia).

Palmer (Populus palmeri).

River (Populus sargentii).

Sargent (Populus sargentii).

Smooth (Populıs acuminata).

Smoothbark (Populus acuminata).

Swamp (Populus heterophylla).

Texas (Populus texana).

Tweedy's (Populus tweedyi).

Valley (Populus wislizenii).

Western (Populus sargentii).

Willow (Populus angustifolia).

Wislizenius (Populus wislizenii).

Coulter pine (Pinus coulteri).

Cow oak (Quercus prinus).

Cow-itch (Campsis radicans, Cissus arborea).

vine (Decumaria barbara).

Cowlicks (Halesia diptera).

Coyote,

brush (Baccharis pilularis).

willow (Salix exigua).

Coyotillo (Karwinskia humboldtiana).

Crab apple (Malus glabrata, Malus glancescens, Malus platycarpa).

American (Malus coronaria).

Iowa (Malus ioensis).

Lanceleaf (Malus lancifolia).

Narrowleaf (Malus angustifolia).

Oregon (Malus fusca).

Prairie (Malus ioensis).

Soulard (Malus soulardii).

Sweet (Malus coronaria).

Western (Malus fusca,

Malus ioensis).

Crab cherry (Prunus avium).

Crack willow (Salix fragilis).

Cranberry (Vaccinium macrocarpon).

Highbush (Viburnum trilobum).

Mountain (Hugeria erythrocarpa,

Vaccinium vitis-idaea).

Small (Vaccinium oxycoccus).

Cranberrybush

American (Viburnum trilobum).

Cream bush (Holodiscus discolor).

Creosote bush (Covillea tridentata).

Creek,

dogwood (Cornus californica).

plum (Prunus rivularis).
Creeping,

barberry (Berberis repens).

blueberry (Vaccinium crassifolium). hollygrape (Berberis repens). shadbush (Amelanchier stolonifera). snowberry (Chiogenes hispidula).

witch alder (Fothergilla parvifolia).

Crimson monkeyflower (Mimulus puniceus).

Crooked bush (Forestiera acuminata).

Crossvine (Bignonia capreolata).

Croton,

Alabama (Croton alabamensis).

Shrubby (Croton fruticulosus).

Crowberry, (Empetrum nigrum).

Broom (Corcma conradii).

Brown (Corema convadii).

Plymouth (Corcma conradii).

Crown-of-thorns (Koeberlinia spinosa).

Crucifixion thorn (Canotia holacantha, Holacantha emoryi).

Cucumber magnolia (Magnolia acuminata).

Cucumbertree (Magnolia acuminata).

Large-leaved (Magnolia macrophylla).

Long-leaved (Magnolia fraseri).

Yellow (Magnolia cordata).

Cupseed (Calycocarpum lyonii).

Curly clematis (Clematis erispa).

Curl-flower (Clematis crispa).

Curlleaf mountain-mahogany (Cercocarpus ledifolius).

Currant,

American red (Ribes triste).

Black (Ribes americanum).

Blood (Ribes sanguineum).

Buffalo (Ribes odoratum).

California black (Ribes malvaceum).

Colorado (Ribes coloradense).

Fetid (Ribes glandulosum).

Golden (Ribes aureum,

Ribes odoratum).

Gooseberry (Ribes montigenum).

Hudson Bay (Ribes hudsonianum).

Missouri (Ribes odoratum).

Mountain (Ribes viscosissimum).

Nevada (Ribcs nevadense).

Red-flowered (Ribes sanguineum).

Rothrock (Ribes wolfii).

Sheep (Ribes cereum).

Sierra (Ribes nevadense).

Skunk (Ribes bracteosum,

Ribes glandulosum,

Ribes prostratum).

Squaw (Ribes cereum).

Sticky (Ribes viscosissimum).

Stink (Ribes bracteosnm).

Swamp (Ribes lacustre).

Viscid (Ribes viscosissimum).

Wax (Ribes cereum).

Western black (Ribes laxiflorum).

Winter (Ribes sanguineum).

Wolf (Ribes wolfi).

Currant grape (Vitis simpsonii).

Curtiss grape (Vitis sola). 


\section{Cusick serviceberry (Amelanchier cusickii).}

Custard-apple (Asimina triloba).

Cuthbert's cherry (Prunus cuthbertii).

Cuyamaca bush (Ceanothus palmeri).

Cypress, (Taxodium distichum).

Alaska (Chamaecyparis nootkatensis).

Arizona (Cupressus arizonica).

Bald (Taxodium distichum).

Black (Taxodium distichum).

F'orbe's (Cupressus gaudeloupensis).

Gowen (Cupressus goveniana).

Guadeloupe (Cupressus guadeloupensis).

Lawson (Chamaecyparis lawsoniana).

Macnab (Cupressus macnabiana).

Monterey (Cupressus macrocarpa).

Pond (Taxodium ascendens).

Red (Taxodium distichum.).

Sargent (Cupressus sargentii).

Sitka (Chamaecyparis nootkatensis).

Smooth (Cupressus glabra).

Southern (T'axodium distichum).

Tecate (Cupressus guadeloupensis).

White (Taxodium distichum).

Dahoon holly (Ilex cassine).

Dalea,

Fremont (Dalea fremontii).

Mesa (Dalea schottii).

Mohave (Dalea arborescens).

Nevada (Dalea polyadenia).

White (Dalea emoryi).

Damianita (Chrysactinia mexicana).

Dangleberry (Gaylussacia frondosa).

D a vi d s o n globemallow (Malvastrum davidsonii).

Deciduous holly (Ilex decidua).

Deer,

brush (Ceanothus crassifolius, Ceanothus fendleri,

Caenothus integerrimus,

Ceanothus leucodermis,

Ceanothus tomentosus).

oak (Quercus sadleriana).

plum (Chrysobalanus oblongifolius).

Deerberry (Vaccinium stamineum).

Deerweed (Ceanothus papillosus).

Delta palmetto (Sabal louisiana).

Desert,

almond (Prunus fasciculata).

apricot (Prunus eriogyna).

ash (Fraxinus velutina).

barberry (Berberis fremontii).

brickellbush (Brickellia desertorum). ceanothus (Ceanothus greggii).

grape (Vitis girdiana).

hackberry (Celtis pallida).

holly (Atriplex hymenelytra).

ironwood (Olneya tesota).

lavender (Hyptis emoryi).

mahogany (Cercocarpus ledifolius). peach (Prunus andersonii).

polygala (Polygala acanthoclada).

sage (Salvia carnosa).
Desert-Continued.
silver-bush (Shepherdia rotundifolia).

walnut (Juglans rupestris).

willow (Chilopsis linearis).

yaupon (Schaefferia cuneifolia).

Desert-rue, Mohave (Thamnosna mon$\tan a)$

Desert-sweet (Chamaebatiaria millefolium).

Desert-thorn,

Anderson (Lycium andersonii).

California (Lycium californicum).

Cooper (Lycium cooperi).

Fremont (Lycium fremontii).

Pale (Lycium pallidum).

Parish (Lycium parishii).

Squaw (Lycium torreyi).

Desertwillow (Chilopsis linearis).

Devil's claw (Acacia greggii).

Devilsclub (Oplopanax horridum).

Devils-walking stick (Aralia spinosa).

Devilwood (Osmanthus armericana).

Dewberries (Rubus spp.).

Diamond willow (Salis mackenziana).

Digger pine (Pinus sabiniana).

Doan grape (Vitis doaniana).

Dockmackie (Viburnum acerifolium).

Dogberry (Ribes cynosbatii).

Dog-hobble (Leucothoë catesbaci).

Dogwood,

Blue (Cornus alternifolia).

Brown (Cornus glabrata).

Creek (Cornus californica).

Florida (Cornus florida).

Flowering (Cornus florida,

Cornus nuttallii).

Gray (Cornus paniculata).

Gray-stemmed (Cornus paniculata).

Miner's (Cornus sessilis).

Mountain (Cornus nuttallii).

Pale (Cornus obliqua).

Panicled (Cornus paniculata).

Purple (Cornus alternifolia).

Rough-leaved (Cornus asperifolia).

Stiff (Cornus foemina).

Western (Cornus nuttallii).

Double spruce (Picea mariana).

Douglas,

fir, Colorado (Pseudotsuga glauca).

fir, Oregon (Pseudotsuga taxifolia).

hackberry (Celtis douglasii).

honeysuckle (Lonicera glaucescens).

rabbitbrush (Chrysothamnus viscidi-florus).

spiraea (Spiraea douglasii).

spruce (Pseudotsuga glauca, Pseudotsuga taxifolia).

Downward plum (Bumelia spiniflora).

Downy,

bog rosemary (Andromeda glaucophylla.)

grape (Vitis cinerea).

poplar (Populus heterophylla).

serviceberry (Amelanchier canadensis). 
Downy-Continued.

storax (Styrax pulverulenta). swamp blueberry (Vaccinium atrococcum).

viburnum (Viburnum pubescens).

Drago, sangre de (Jatropha spathulata).

Drooping juniper (Juniperus flaccida).

Drummond

clematis (Clematis drummondii). soapberry (Sapindus drummondii). waxmallow ( $M$ a $l v$ a $v$ is $c$ us drummondii).

Dryland blueberry (Vaccinium vacillans).

Duck oak (Quercus nigra).

Dudley willow (Salix goodingii).

Dunbar crab (Malus glaucescens).

Dune,

lupine (Lupinus chamissonis). willow (Salix piperi).

Durand, oak (Quercus durandii). white oak (Quercus durandii).

Durasnillo (Prumus texana).

Dusky willow (Salix melanopsis).

Dutchmans pipe (Aristolochia durior).

Dutchman's pipe-vine (Aristolochia durior).

Dwarf, acacia (Robinia nana). ash (Fraxinus anomala). barberry (Berberis pumila). bilberry (Vaccinium caespitosum). birch (Betula glandulosa). blueberry (Vaccinium angustifolium). buckthorn (Rhamnus alnifolia). candleberry (Myrica pumila). cherry (Prunus pumila). chinquapin (Castanea alnifolia). chinquapin oak (Quercus prinoides). goldenbush (Aplopappus nanus). gray willow (Salix tristis). greasebush (Forsellesia pungens). hollygrape (Berberis pumila). huckleberry (Gaylussacia dumosa). indigobush (Amorpha microphylla). juniper (Juniperus communis). maple (Acer glabrum). mesquite (Acacia reticulata). ninebark (Physocarpus alternans). papaw (Asimina parviflora). palmetto (Sabal minor). pussy willow (Salix tristis). red huckleberry (Vacinium scoparium).

serviceberry (Amelanchier oblongifolia).

spiraea (Spiraea corymbosa, Spirea caespitosa).

sumac (Rhus copallina).

tassel bush (Garrya flavescens).

wax myrtle (Myrica pumila).

witch-alder (Fothergilla gardenii).

whortleberry (Vaccinium caespito-
Dwarf-acacia (Robinia nana).

Dyer's

greenweed (Genista tinctoria). oak (Quercius velutina).

Eardrop (Brunnichia cirrhosa).

Ear-leaved umbrella tree (Magnolia fraseri).

Early azalea (Rhododendron canescens).

Eastern, cottonwood (Populus deltoides). hemlock (T'suga canadensis). redcedar (Juniperus virginiana).

Eastwood manzanita (Aretostaphylos glandulosa).

Elbow bush (Forestiera pubescens).

Elder (Sambucus canadensis).

American (Sambucus canadensis).

Black (Sambucus melanocarpa).

Blackbead (Sambucus melanocarpa).

BIue (Sambucus coerulea).

Blueberry (Sambuous coerulea).

Box (Acer negundo).

Bunchberry (Sambucus microbotrys).

Mexican (Sambucus mexicana).

Mountain (Sambucus coerulea).

Red (Sambucus callicarpa,

Sambucus pubens).

Redberry (Sambucus callicarpa).

Velvetleaf (Sambucus caerulea).

Yellow (Tecoma stans).

Elderberry, pale (Sambucus coerulea). Elephant tree (Bursera microphylla).

Elliott's blueberry (Vaccinium elliottii). Elm,

American (Ulmus americana).

California slippery (Fremontia californica)

Cedar (Ulmus crassifolia).

Cliff (Ulmus racemosa).

Cork (Ulmus alata,

Ulmus racemosa).

Gray (Ulmus americana).

Red (Ulmus alata,

Ulmus fulva,

Ulmus serotina).

Rock (Ulmus racemosa).

September (Ulmus serotina).

Slippery (Ulmus fulva).

Texas ( Ulmus crassifolia).

Water (Ulmus americana).

White (Ulmus americana).

Winged (Ulmus alata).

Fimory,

bushmint (Hyptis emoryi).

oak (Quercus emoryi).

Encina (Quercus agrifolia).

Engelmann spruce (Picea engelmannii).

Estafiata (Artemisia frigida).

European,

barberry (Berberis vulgaris).

black alder (Alnus glutinosa).

mountain-ash (Sorbus ancuparia).

white willow (Salio alha). 
Evergreen,

blueberry (Vaccinium myrsinites). cherry (Prunus ilicifolia).

coralbean (Sophora secundiflora). huckleberry (Vaccinium ovatum). magnolia (Magnolia grandifiora). oak (Quercus engelmannii). sumac (Rhus virens). white oak (Quercus engelmannii). winterberry (Ilex glabra).

Explorers' bush (Ceanothus oliganthus).

Fall grape (Vitis berlandieri).

False

acacia (Robinia psendoacacia). bittersweet (Celastrus scandens). boxwood (Gyminda latifolia). buckthorn (Bumelia lanuginosa). greasewood (Amorpha canescens). jessamine (Gelsemium sempervirens). mountain willow (Salix pseudomonticola).

willow (Baccharis angustifolia).

False-azalea (Rhododendron albiflorum).

False-indigo (Amorpha californica, Amorpha fruticosa).

Falsemallow, newberry (Horsfordia newberryi).

False-mesquite (Calliandrá eriophylla).

Fan palm (Washingtonia robusta).

Farkleberry (Vaccinium arboreum).

Farr willow (Salix farrae).

Fat pine (Pinus australis).

Feather peabush (Dalea formosa).

Fendler,

barberry (Berberis fendleri).

ceanothus (Ceanothus fendleri). cak (Quercus fendleri).

soapbloom (Ceanothus fendleri).

Fern-bush (Chamaebatia foliolosa, Chamaebatriaria millefolium).

Fernleaf acacia (Acacia angustissima). Fetid,

buckeye (Aesculus glabra).

currant (Ribcs glandulosim).

Fetter-bush (Leucothoë catesbaei, Xolisma lucida).

Feverbush (Benzion aestivale, Ilex verticillata.)

Fever-tree (Pinckneya pubens).

Fiddlewood (Citharexylum fruticosum). Fir,

Alpine (Abies lasiocarpa).

Arizona (Abics arizonica).

Balm-of-gilead (Abies balsamea).

Balsam (Abies balsamea, Abies concolor).

Bristlecone (Abies venusta).

California (Abies magnifica) .

Colorado D o ug las (Pseudotsuga glauca).

Colorado white (Abies concolor).

Corkbark (Abies arizonica).

Lovely (Abies amabiis).
Fir-Continued.

Lowland white (Abies grandis).

Noble (Abies nobilis).

Oregon Douglas (Pseudotsuga taxifolia).

Red (Abies magnifica,

Abies nobilis,

Pseudotsuga glauca.

Pseudotsuga taxifolia).

Santa Lucia (Abies venusta).

Shasta red (Abies magnifica).

Silver (Abies ambilis,

Abies concolor,

Abies grandis).

Southern balsam (Abies fraseri).

Stinking (Abies grandis).

White (Abies grandis, Abies lasiocarpa).

Yellow (Abies grandis, Pseudotsuga glauca, Pseudotsuga taxifolia).

Fire,

cherry (Prunus pennsylvanica).

willow (Salio scouleriana).

Firecracker plant (Aesculus pavia).

Firethorn (Cotoneaster pyracantha).

Firmleaf willow (Salix pseudomyrsinites).

Flag papaw (Asimina incana).

Flame azalea (Rhododendron calendulaceum).

Flannelbush (Fremontia californica).

Flat sagebrush (Artemisia bigelovii).

Flat-top (Eriogonum fasciculatum).

Florida,

mahogany (Persea borbonia).

maple (Acer floridanum).

soapberry (Sapindus marginatus).

yew (Taxus fioridana).

Flowering,

ash (Chionanthus virginica, Fraxinus cuspidata, Fraxinus dipetala).

dogwood (Cornus florida, Cornus nuttallii).

Flycatcher (Befaria racemosa).

Fly honeysuckle, (Lonicera ciliosa).

Swamp (Lonicera oblongifolia).

Foothill ash (Fraxinus dipetala).

Forbes' cypress (Cupressus guadeloupensis).

Fox grape (Vitis labrusca).

Northern (Vitis labrusca).

Southern (Vitis rotundifolia).

Foxtail pine (Pinus aristata,

Pinus balfouriana).

Fragile willow (Salix fragilis).

Fragrant, ash (Fraxinus cuspidata). sumac (Rhus aromatica).

Frangipani (Acacia farnesiana).

Fraser magnolia (Magnolia fraseri).

Fremont,

barberry (Berberis fremontii).

chaffbush (Amphipappus fremontii). cottonwood (Populus fremontii). 
Fremont-Continued.

dalea (Dalea fremontii).

desert-thorn (Lycium fremontii).

hollygrape (Berberis fremontii).

silktassel (Garrya fremontii).

wolfberry (Lycium fremonti).

Fremontia, California (Fremontia californica).

French mulberry (Callicarpa americana).

Frijolillo (Sophora secundiflora).

Fringetree (Ohionanthus virginica).

Fringed,

greenbrier (Smilax bona-nox). wormwood (Artemisia frigida).

Frost grape (Vitis cordifolia, Vitis vulpina).

Frutilla (Lycium richii).

Fuchsia-flowered gooseberry (Ribes speciosum).

Gallberry (Ilex glabra).

Gambel oak (Quercus gainbelii).

Gander vine (Clematis virginiana).

Garden wild plum (Prunus hortulana).

Garland tree (Malus coronaria).

Garnet gooseberry (Ribes speciosum).

Garrumbullo (Lycium torreyi).

Garry oak (Quercus garryana).

Georgia,

bark (Pinckneya pubens).

buckeye (Aesculus neglecta).

gooseberry (Ribes curvatum).

hackberry (Celtis georgiana).

oak (Quercus georgiana).

pine (Pinus australis).

sloe (Prunus mitis).

Geyer willow (Salix geyeriana).

Giant chinquapin (Castanopsis chrysophylla).

Gigante (Nicotiana glauca).

Glaucous willow (Salix discolor).

Globemallow,

Davidson (Malvastrum davidsonii).

Nuttall (Malvastrum nuttallii).

Goat-nut (Simmondsia chinensis).

Goatbrush (Pachistima myrsinites).

Goatbush (Castela nicholsonii,

Golden, Castela texana).

currant (Ribes aureum, Ribes odoratum).

hardhack (Potentilla fruticosa).

Goldenbush (Aplopappus acradenius). Bloomer (Aplopappus bloomeri).

Chaparral (Aplopappus propinquus). Coast (Aplopappus squarrosus).

Cooper (Aplopappus cooperi).

Dwarf (Aplopappus nanus).

Heatherleaf (Aplopappus ericoides).

Narrowleaf (Aplopappus linearifolius).

Palmer (Aplopappus palmeri).

Parish (Aplopappus parishii).

Pineleaf (Aplopappus pinifolius).

Wedgeleaf (Aplopappus cuneatus).
Goldenfleece (Aplopappus arborescens).

Goldenhead (Acamptopappus sphaeroccphalus).

Goldleaf chinquapin (Castanopsis chrysophylla,

Castanopsis sempervirens).

Gold heather (Hudsonia ericoides).

Goldman serviceberry (Amelanchier goldmanii).

Goodding willow (Salix gooddingii).

Gooseberry,

Alpine (Ribes lepthanthum).

Canyon (Ribes monziesii).

Cloud-cap (Ribes montigenum).

Fuchsia-fiowered (Ribes speciosum).

Garnet (Ribes speciosum).

Georgia (Ribes curvatum).

Granite (Ribes curvatum).

Gummy (Ribes lobbii).

Hawthorn (Ribes oxyacanthoides).

Hill (Ribes californicum).

Hupa (Ribes marshallii).

Island (Ribes viburnifolium).

Low wild (Ribes hirtellum).

Lucia (Ribes sericeum).

Menzies (Ribes menziesii).

Missouri (Ribes missouriense, Ribes setosum).

Mountain (Ribes montigenum, Ribes rotundifolium).

Northern (Ribes oxyacanthoides).

Orange (Ribes pinetorum).

Oregon (Ribes lobbii).

Pasture (Ribes cynosbatii).

Prickly (Ribes cynosbatii).

Rock (Ribes quercetorum).

Round (Ribes rotundifolium).

Sierra (Ribes roealii).

Smooth (Ribes oxyacanthoides, Ribes rotundifolium).

Southern (Vaccinium melanocarpum).

Straggly (Ribes divaricatum).

Swamp (Ribes lacustre).

Watson (Ribes watsonianum).

White (Ribes inerme).

Whitestem (Ribes inerme).

Wine (Ribes inerme).

Gooseberry currant (Ribes monitgenum).

Gopher berry (Gaylussacia dumosa).

Gopher-wood (Cladrastis lutea).

Gorse (Ulex europaeus).

Gowen cypress (Cupressus goveniana).

Granite-gooseberry (Ribes curvatum).

Granjeno (Celtis pallida).

Grape,

Adobe-land (Vitis champinii).

Arizona (Vitis arizonica).

Arroyo (Vitis vulpina).

Ashy (Vitis cinerea).

Bailey (Vitis baileyana).

Big summer (Vitis lincecumii).

Blueleaf (Vitis argentifolia).

Bull (Vitis rotundifolia). 
Grape-Continued.

Bullace (Vitis rotundifolia).

Bullet (Vitis rotundifolia).

Bush (Vitis longii).

Calcaire (Vitis champinii).

California (Vitis californica).

California wild (Vitis californica).

Canyon (Vitis arizonica).

Cat ( itis palmata).

Catbird (Vitis palmata).

Champin (Vitis champinii).

Chicken (Vitis cordifolia).

Currant (Vitis simpsonii).

Curtiss (Vitis sola).

Desert (Vitis girdiana).

Doan (Vitis doaniana).

Downy (Vitis cinerea).

Fall (Vitis berlandieri).

Fox (Vitis labrusca).

Frost (Vitis cordifolia, Vitis vulpina).

Gulch (Vitis longii,

Vitis treleasei).

Little mountain (Vitis berlandieri).

Little muscadine (Vitis munsoniana).

Missouri (Vitis palmata).

Mountain (Berberis aquifolium, $\checkmark$ itis berlandieri, Vitis rupestris).

Muscadine (Vitis rotundifolia).

Mustang (Vitis candicans).

Northern fox (Vitis labrusca).

Oregon (Berberis aquifolium, Berberis nervosa,

Berberis repens).

Pacific (Vitis californica).

Panhandle (Vitis doaniana).

Pilgrim (Vitis novae-angliae).

Plum (Vitis labrusca).

Possum (Vitis baileyana).

Post-oak (Vitis lincecumii).

Red (Vitis palmata).

Redshank (Vitis rufotomentosa).

Riverbank (Vitis vulpina).

Rock (Vitis rupestris).

Roundleaf (Vitis helleri).

Sand (Vitis lincecumii, Vitis rupestris).

Solonis (Vitis longii).

Southern fox (Vitis rotundifolia).

Spanish (Vitis berlandieri).

Sugar (Vitis monticola, Vitis rupestris).

Summer (Vitis argentifolia).

Sweet mountain (Vitis monticola).

Sweet winter (Vitis cinerea).

Turkey (Vitis lincecumii).

Western wild (Vitis californica).

Wild (Vitis girdiana).

Winter (Vitis cordifolia,

$\nabla$ itis berlandieri).

Grape honeysuckle (Lonicera prolifera).

Grave's oak (Quercus gravesii).

Gray,

beard ( $B$ ydrangea quercifolia).
Gray-Continued.

birch (Betula lutea,

Betula populifolia).

dogwood (Cornus paniculata).

elm (Ulmus americana).

horsebrush (Tetradymia canescens). oak (Quercus grisea).

pine (Pinus banksiana).

willow, dwarf (Salix tristis).

Gray-stemmed dogwood (Cornus paniculata).

Greasebush (Forsellesia spinescens).

Dwarf (Forsellesia pungens).

Spiny (Forsellesia spinescens).

Grease-thorn (Forsellesia spinescens).

Greasewood (Adenostoma fasciculatum, Ceanothus velutinus, Covillea tridentata,

Sarcobatus vermiculatus).

Great,

laurel (Rhododendron maximum).

whortleberry (Vaccinium corymbosum).

Great-berried manzanita (Arctostaphylos glauca).

Great-leaved magnolia (Magnolia macrophylla).

Green,

alder (Alnus crispa).

locust (Robinia pseudoacacia).

osier (Cornus alternifolia).

Greenbark ceanothus (Ceanothus spinosus).

Green-barked acacia (Ocrcidium floridum,

Cercidium torreyanum).

Greenbrier,

Bristly (Smilax auriculata,

Smilax hispida).

California (Smilax californica).

Common (Smilas rotundifolia).

Coral (Smilax lanceolata, Smilax walteri).

Fringed (Smilax bona-nox).

Laurel (Smilax laurifolia).

Long-stalked (Smilas pseudo-china).

Greene mountain-ash (Sorbus scopu$\operatorname{lin} a$ ).

Greenleaf manzanita (Arctostaphylos patula).

Greensides willow (Salixo monochroma).

Greenweed, dyers (Genista tinctoria).

Gregg,

ceanothus (Ceanothus greggii).

hornbrush (Ceanothus greggii).

lead tree (Leucacna greggii).

sage (Salvia greggii).

Ground,

hemlock (Taxus canadensis).

gooseberry (Ribes binominatum).

Groundsel tree (Baccharis halimifolia).

Grouse whortleberry (Vaccinium scoparium). 
Grouseberry (Gaultheria procumbens, Hawthorn (Crataegus spp.)

$\nabla$ accinium scoparium).

Guadeloupe cypress (Cupressus guadeloupensis).

Guajillo (Acacia berlandieri).

Guard lupine (Lupinus excubitus).

Guayacan (Porlieria angustifolia).

Gulf, guajillo (Pithecolobium brevifolium). Gum,

Black (Nyssa sylvatica).

Cotton (Nyssa aquatica).

Highland black (Nyssa sylvatica).

- Large tupelo (Nyssa aquatica).

Sour (Nyssa sylvatica).

Sour tupelo (Nyssa ogeche).

Southern black (Nyssa biflora).

Swamp black (Nyssa biflora).

Tupelo (Nyssa aquatica).

Water (Nyssa biflora).

Gum elastic (Bumelia lanuginosa).

Gummy gooseberry (Ribes lobbii).

Hackberry (Celtis occidentalis).

Desert (Celtis pallida).

Douglas (Celtis douglasii).

Georgia (Celtis georgiana).

Small's (Celtis smallii).

Southern (Celtis mississippiensis).

Spiny (Celtis pallida).

Thick-leaved (Celtis reticulata).

Western (Celtis reticulata).

Hāekmatack (Larix laricina).

Hagbrier (Smilax hispida).

Hairy,

ceanothus (Ceanothus oliganthus).

honeysuckle (Lonicera hirsuta).

horsebrush (Tetradymia comosa).

huckleberry (Vaccinium hirsutum).

manzanita (Arctostaphylos colum-

biana).

nanny-berry (Viburnum pubescens).

Harbison willow (Salix harbisonii).

Hardhack (Spiraea douglasii, Spiraea tomentosa).

Hard maple (Acer saccharum).

Hardtack, (Cercocarpus betuloides). California (Cercocarpus betuloides). Catalina (Cercocarpus traskiae).

Mesa (Cercocarpus minutiflorus).

Havard shinnery oak (Quercus havardii).

Haw (Viburnum prunifolium).

Black (Bumelia lanuginosa,

Bumelia tenax,

Viburnum prunifolium).

Possum (Ilex deciàua,

Viburnum nudum).

Purple (Condalia obovata).

Southern black (Viburnum rufidulum).

Swamp (Viburnum cassinoides,

Viburnum nudum).

Sweet (Viburnum prunifolium).

Western black (Viburnum ellipticum.) gooseberry (Ribes oxyacanthoides).

Hazel, wild (Simmondsia chinensis).

Hazel alder (Alnus rugosa).

Hazelnut,

American (Corylus americana).

Beaked (Corylus rostrata).

Heartleaf,

ampelopsis (Cissus ampelopsis).

manzanita (Arctostaphylos andersonii).

pentstemon (Pentstemon cordifolius).

willow (Salix cordata).

Heartnut (Krameria glandulosa).

Heath cliffrose (Cowania ericaefolia).

Heather,

Beach (Hudsonia tomentosa).

Gold (Hudsonia ericoides).

Mountain (Phyllodoce caerulea).

Red (Phyllodoce breweri, Phyllodoce empetriformis).

Yellow (Phyllodoce glanduliflora).

Heatherleaf goldenbush (Aplopappus ericoides).

Hedge (Maclura pomifera).

Hedgehog oak (Lithocarpus densiflora).

Hediondilla (Covillea tridentata).

Hediondo (Covillea tridentata).

He-huckleberry (Cyrilla racemiflora).

Hellefetter (Smilax hispida).

Hell-vine (Campsis radicans).

Hemlock (Tsuga canadensis).

Canada (Tsuga canadensis).

Carolina (Tsuga caroliniana).

Eastern (Tsuga canadensis).

Ground (Taxus canadensis).

Mountain (Tsuga mertensiana).

Western (Tsuga hcterophylla).

Hemlock spruce ( $T s u g a$ canadensis).

Hercules-club (Aralia spinosa,

Xanthoxylum clava. herculis).

Hickory,

Big-bud (Carya alba).

Big shellbark (Carya laciniosa).

Bigleaf shagbark (Carya laciniosa).

Bitternut (Carya cordiformis,

Black (Carya alba, Carya glabra).

Carya glabra).

Bottom (Carya carolinae-septentrionalis).

Bullnut (Carya alba).

Hognut (Carya alba).

King nut (Carya laciniosa).

Little shagbark (Carya microcarpa).

Littlenut shagbark (Carya microcarpa).

Lowland (Carya aquatica).

Mockernut (Carya alba).

Nutmeg (Carya myristicaeformis).

Pignut (Carya cordiformis,

Carya glabra,

Carya leiodermis, 
Hickory-Continued.

Pignut-Continued.

$$
\text { Carya pallida, }
$$$$
\text { Carya villosa). }
$$

Scrub (Carya floridana).

Shagbark (Carya ovata).

Shellbark (Carya ovata).

Small-frulted (Carya microcarpa).

Small pignut (Carya ovalis).

Southern shagbark (Carya carolinaeseptentrionalis).

Swamp (Carya cordiformis).

Texas (Carya buckleyi).

Water (Carya aquatica).

White (Carya alba).

Whiteheart (Carya alba).

Hickory,

pine (Pinus aristata).

poplar (Liriodendron tulipifera).

Highbush,

blueberry (Vaacinium corymbosum). cranberry (Viburnum trilobum).

Highland,

black gum (Nyssa sylvatica).

live oak (Quercus wislizenii).

Hill,

gooseberry (Ribes californicum). oak (Quercus douglasii).

Hillside gooseberry (Ribes californicum).

Hinds walnut (Juglans hindsii).

Hoary,

alder (Alnus incana).

azalea (Rhododendron canescens).

sagebrush (Artemisia cana).

willow (Salix candida).

Hoary-leaf ceanothus (Ceanothus crassifolius).

Hobblebush (Viburnum alnifolium).

Hog plum (Prunus reverchonii, Colubrina texensis, Prunus umbellata).

Hognut hickory (Carya alba).

Holly,

American (Iles opaca).

Bearberry (Ilex decidua).

Christmas (1lex opaca).

Deciđuous (Ilex decidua).

Largeleaf (Ilex longipes).

Large-leaved (Nemopanthus mucronata).

Michigan (Ilex verticillata).

Mountain (Ilex montana,

Nemopanthus mucronata).

Holly oak (Quercus undulata).

Hollybush (Tetracoccus ilicifolius).

Hollygrape,

California (Berberis californicum).

Creeping (Berberis repens).

Dwarf (Berberis repens).

Fremont (Berberis fremontii).

Netleaf (Berberis californicum).

Nevin (Berberis nevinii).

Oregon (Berberis aquifolium, Berberis nervosa).
Hollygrape-Continued.

Red (Berberis haematocarpa).

Veinyleaf (Berberis nervosa).

Wavyleaf (Berberis pinnata).

Hollyleaf,

buckthorn (Rhamnus crocea).

bur-sage (Franseria ilicifolia). ceanothus (Ceanothus jepsonii). cherry (Prunus ilicifolia).

Hollyscale (Atriplex hymenelytra).

Honey,

mesquite (Prosopis chilensis).

shucks (Gleditsia triacanthos).

IIoneylocust (Gleditsia triacanthos,

Prosopis glandulosa,

Prosopis chilensis,

Robini pseudoacacia).

Honeysuckle (Lonicera ciliosa,

Rhododendron canescens).

American fly (Lonicera canadensis).

Arizona (Lonicera arizonica).

Bearberry (Lonicera involucrata).

Blue fly (Lonicera villosa).

Bush (Diervilla lonicera).

Chaparral (Lonicera interrupta).

Coral (Lonicera sempervirens).

Douglas (Lonicera glaucescens).

Fly (Lonicera ciliosa).

Grape (Lomicera prolifera).

Hairy (Lonicera hirsuta).

Japanese (Lonicera japonica).

Mountain (Lonicera dioica).

Mountain fly (Lonicera cauriana,

Orange (Lonicera ciliosa).

$$
\text { Lonicera villosa). }
$$

Pink (Lonicera hispidula).

Swamp fly (Lonicera oblongifolia).

Trumpet (Lonicera sempervirens).

Twinberry (Lonicera involucrata).

Utah (Lonicera utahensis).

Yellow (Lonicera flava).

Hoop ash (Fraxinus nigra).

Hopbush (Dodonaea arizonica).

Hophornbeam, (Ostrya virginiana).

Bailey (Ostrya baileyi).

Western (Ostrya knowltonii).

Hop-sage,

Spirieless (Grayia brandegei).

Spiny (Grayia spinosa).

Hoptree (Ptelea trifoliata).

Hornbeam, (Carpinus caroliniana).

Bailey hop (Ostrya baileyi) .

Western hop (Ostrya knowltonii).

Horse,

plum (Prunus americana, Prunus nigra).

sugar (Symplocos tinctoria).

Horsebean, (Parkinsonian aculeata).

Little-leaf (Parkinsonia microphylla).

Small-leaved (Parkinsonia microphylla).

Horsebrier (Smilax rotundifolia). 
Horsebrush (Partheneium incanum). Gray (Tetradymia canescens).

Halry (Tetradymia comosa).

Littleleaf (Tetradymia glabrata).

Longspine (Tetradymia spinosa).

Mohave (Tetradymia stenolepis).

Nuttall (Tetradymia nuttallii).

Shortspine (Tetradymia spinosa).

Hortulan plum (Prunus hortulana).

Huajillo (Pithecolobium brevifolium).

Huckleberry,

Bear (Gaylussacia ursina).

Black (Gaylussacia baccata).

Box (Gaylussacia brachycera).

California (Vaccinium ovatum).

Dwarf (Gaylussacia dumosa).

Dwarf red (Vaccinium scoparium).

Evergreen (Vaccinium ovatum).

Hairy (Vaccinium hirsutum).

Lowbush (Vaccinium vacillans).

Red (Vaccinium parvifolium).

Squaw (Vaccinium stamineum).

Tall red (Vaccinium parvifolium).

Thinleaf (Vaccinium membranacenm).

Tree (Vaccinium arboreum).

Western (Vaccinium occidentale).

Huckleberry oak (Quercus vaccinifolia).

Hudson Bay currant (Ribes hudsonianum).

Huisache (Acacia farnesiana).

Huisachillo (Acacia tortuosa).

Hupa gooseberry (Ribes marshallii).

Hydrangea,

Ashy (Hydrangea cinerea).

Climbing (Decumaria barbara).

Mountain (Hydrangea arborescens).

Oakleaf (Hydrangear quercifolia).

Silverleaf (Hydrangea radiata).

Smooth ( Hydrangea arborescens).

Snowy (Hydrangea radiata).

Wild (Hydrangea arborescens).

Incense cedar (Libocedrus decurrens).

Indigo,

False (Amorpha fruticosa).

Mountain (Amorpha glabra, Amorpha virgata).

Schwerin's (Amorpha schwerinii).

Tennessee (Amorpha tennesseensis).

Indigobush, (Amorpha fruticosa, Dalea spinosa).

California (Amorpha californica).

Dwarf (Amorpha microphylla).

Indian,

cherry (Rhamnus caroliniana).

currant (Symphoricarpos orbiculatus).

plum (Osmaronia cerasiformis).

Inkberry, (Ibex glabra,

Ilex verticillata).

tall (Ilex coriacea).

Inkweed (Allenrolfea occidentalis).

Inland Jersey-tea (Ceanothus ovatus).

Interior live oak (Quercus vislizenii).

Iodine bush (Allenrolfea occidentalis).
Ione bush (Ceanothus tomentosus). Iowa crab apple (Malus ioensis). Iron oak (Quercus chrysolepis, Quercus stellata).

Ironwood, (Bumelia lycioides, Bumelia tenax, Carpinus caroliniana, Cliftonia monophylla, Ostrya linowltonii, Ostrya virginiana, Prosopis chilensis).

Catalina (Lyonothamnus floribumdus).

Santa Cruz (Lyonothamnus floribundus).

Swamp (Cyrilla racemiflora).

Island,

ceanothus (Ccanothus arboreus).

cherry (Prunus lyonii).

gooseberry (Ribes viburnifolium).

live oak (Quercus tomentella).

myrtle (Ceanothus arboreus).

Islay (Prunus ilicifolia).

Ivy, (Kalmia latifolia,

Leucothoë catesbaei).

American (Parthenocissus quinquefolia).

Marine (Cissus incisa).

Serenleaf (Parthenocissus lieptaphylla).

Jack,

oak (Quercus ellipsoidalis, Quercus marilandica).

pine (Pinus banksiana).

Japanese honeysuckle (Lonicera japonica).

Jara (Baccharis glutinosa).

dulce (Baccharis glutinosa).

Jarelin brush (Microrhamnus ericoides).

Jeffrey pine (Pinus jeffreyi).

Jepson ceanothus (Ceanothus jepsonii).

Jersey pine (Pinus virginiana).

Jerusalem-thorn (Parlinsonia aculeata).

Jessamine,

False (Gelsemium sempervirens).

Yellow (Gelsemium sempervirens).

Jim brush (Ceanothus sorediatus).

Jointfir,

California (Ephedra californica).

Nevada (Ephedra nevadensis).

Texas (Ephedra texana).

Torrey (Ephedra torreyana).

Jojoba (Simmondsia chinensis).

Joshua tree (Yucca brevifolia).

Judas-tree (Cercis canadensis).

Julibrissin (Albizzia julubrissin).

Juneberry, (Amelanchier canadensis).

Low (Amelanchier humilis,

Anelanchier stolonifera).

Junebud (Cercis canadensis).

Juniper,

Alligator (Juniperus pachyphloea). Big berry (Juniperus megalocarpa). 
Juniper-Continued.

Califormia (Juniperus californica).

Coast (Juniperus lucayana).

Colorado (Juniperus scopulorum).

Dwarf (Juniperus communis).

One-seed (Juniperus monosperma).

Pinchot (Juniperus pinchotii).

Red-berry (Juniperus pinchotii).

Red-fruited ( $J u n$ ip erus erythrocarpa).

Utah (Juniperus utahensis).

Western (Juniperus occidentalis).

Kentucky,

coffeetree (Gymnocladus dioica).

viburnum (Viburnum molle).

wisteria (Wisteria macrostachya). zellow wood (Cladrastis lutea).

Kern ceanothus (Ceanothus pinetorum).

Kidneywood (Eysenhardtia polystachya).

Kidneywort (Baccharis pilularis).

King nut hickory (C'arya laciniosa).

Kinnikinnik (Arctostaphylus uva-ursi, Cornus amomum).

Klamath plum (Prunus subcordata).

Knackaway (Ehretia anacua).

Knobcone pine (Pinus attenuata).

Labrador,

tea (Ledum grocnlandicum).

tea, smooth (Ledum glandulosum). willow (Salix argyrocarpa).

Labrusca (Vitis labrusca).

Lacey oak (Quercus breviloba).

Lady-bloom (Ceanothus parryi).

Lady-bush (Ceanothus parryi).

Lambkill (Kalmia angustifolia).

Lanceleaf,

alder (Alnus oblongifolia).

cottonwood (Populus acuminata). crab apple (Malus lancifolia).

Lance-leared buckthorn (Rhammus lanceolata).

Lantana (Lantana camara).

White flowered (Lantana involucrata).

Lapland,

rhododendron (Rhododendron lapponicum).

rose bay (Rhododendron lapponicum).

Larch (Larix Laricina,

Larix lyallii,

Larix occidentalis).

American (Larix laricina).

Alpine (Larix lyallii).

Western (Larix occidentalis).

Large,

buckeye (Aesculus octandra).

tupelo gum (Nyssa aquatica).

Largeleaf holly (Ilex longipes).

Largetooth aspen (Populus grandidentata).

Large-leaved, cucumbertree (Magnolia macrophylla).
Large-leaved-Continued.

holly (Nemopanthus mucronata).

umbrella-tree (Magnolia macrophylla).

Laurel,

Big (Magnolia grandiflora).

Black (Gordonia lasianthus, Leucothaë davisiae).

California (Umbellularia californica).

Carolina cherry (Prunus caroliniana).

Mountain (Kalmia latifolia).

Narrow-leaved ( $K$ a l mia angustifolia).

Pale (Kalmia polifolia).

Sheep (Kalmia angustifolia).

Sticky (Ceanothus velutinus).

Swamp(Kalmia polifolia,

Magnolia virginiana).

Sweet (Illicium floridanum).

Laurel,

cherry (Prunus caroliniana).

greenbrier (Smilax laurifolia).

oak (Quercus imbricaria,

Quercus laurifolia,

Quercus phellos).

sumac (Rhus laurina).

tree (Persea borbonia).

Lavender, desert (Hyptis emoryi).

Lawson cypress (Chamaecyparis lawsoniana).

Leadplant (Amorpha canescens).

Leather oak (Quercus dumosa).

Leatherbark (Dirca palustris).

Leatherleaf ash (Fraxinus velutina).

Leatherwood (Cyrilla racemiflora, Dirca palustris).

Mountain (Fremontia californica).

Western (Dirca occidentalis).

Leatherfiower (Clematis viorna).

Leatherleaf (Chamaedaphne calyculata).

Lemmon,

acacia (Acacia lemmonii).

willow (Salix lemmonii).

Lemonade,

berry (Rhus integrifolia).

sumac (Rhus trilobata).

Lenscale (Atriplex lentiformis).

Lentisco (Rhus integrifolia).

Leverwood (Ostrya virginiana).

Limber pine (Pinus flexilis).

Lime-tree (Tilia glabra).

Linden (Titia glabra). American (Tilia glabra).

Linn (Titia glabra).

Liquidambar (Iiquidambar styracifua).

rittle,

mountain grape (Vitis berlandieri). muscadine grape.(Vitis munsoniana). pignut hickory (Carya microcarpa). sage (Artemisia nova).

shagbark hickory (Carya microcarpa). 
Little-Continued.

silverbell (Halesia parviflora).

waInut (Juglans rupestris). witch-hazel (Hamamelis vernalis).

Littleleaf, ash (Fraxinus greggii).

brickellbush (Brickellia microphylla). ceanothus (Ceanothus parvifolius). cherry (Prunus minutiflora). horsebean (Parkinsonia microphylla). horsebrush (Tetradymia glabrata).

Littlenut shagbark hickory (Carya microcarpa).

Live oak (Quercus virginiana).

Loblolly,

bay (Gordonia lasianthus). pine (Pinus taeda).

Locust,

Black (Gleditsia triacanthos,

Robinia pseudoacacia).

Brostly (Robinia hispida).

Clammy (Robinia viscosa).

Green (Robinia pseudoacacia).

Honey (Gleditsia triacanthos,

Prosopis glandulosa,

Prosopis chilensis,

Robinia pseudoacacia).

Mock (Amorpha californica).

New Mexico (Robinia neomexicana). Peaflower (Robinia pseudoacacia).

Post (Robinia pendoacacia).

Red (Robinia psendoacacia).

Shipmast (Robinia pseudoacacia).

Water (Gleditsia aquatica).

White (Robinia pseudoacacia).

Yellow (Cladrastis lutea,

Robinia pseudoacacia).

Lodgepole pine (Pinus contorta, Pinus murrayana).

Logwood (Condalia obovata).

Long monkeyflower (Mimulus longiflorus).

Long-flowered catclaw (Acacia greggii).

Longleaf,

pine (Pinus australis).

willow (Salix fluviatilis,

Salix interior).

Long-leaved cucumbertree (Magnolia fraseri).

Longspine horsebrush (Tetradymia spinosa).

Long-stalked greenbrier (Smila $x$ pseudochina).

Lotebush (Condalia lycioides,

Condalia obtusifolia).

Lovely fir (Abies amabilis).

Low,

asimina (Asimina pygmaea).

birch (Betula pumila).

blueberry (Vaccinium vacillans).

juneberry (Amelanchier humitis,

Amelanchier stolonifera).

sagebrush (Artemisia arbuscula).

sweet blueberry (Vaccinium angustifolium).

wild gooseberry (Ribes hirtellum).
Lowbush,

blueberry (Vaccinium angustifolium).

huckleberry (Vaccinium vacillans).

Lowland,

hickory (Carya aquatica).

white fir (Abies grandis).

Tucia gooseberry (Ribes sericeum).

Lupine,

Chamisso (Lupinus chamissonis).

Dune (Lupinus chamissonis).

Guard (Lupinus excubitus).

Mat (Lupinus breweri).

Silver (Lupinus albifrons).

Tree (Lupinus arboreus).

Lyall willow (Salix lasiandra).

Lyonia-vine (Calycocarpum lyonii).

MacDonald oak (Quercus dumosa).

MacDougal oak (Quercus pauciloba).

Mackenzie willow (Salix mackenziana).

Macnab cypress (Cupressus macnabiana).

Madrone (Arbutus menziesii). Arizona (Arbutus arizonica),

Texas (Arbutus texana).

Magnolia,

Ashe (Magnolia ashei).

Bigleaf (Magnolia macrophylla).

Cucumber (Magnolia acuminata).

Evergreen (Magnolia grandiflora).

Fraser (Magnolia fraseri).

Great-leaved (Magnolia macrophylla).

Mountain (Magnolia acuminata, Magnolia fraseri,

Magnolia pyramidata).

Pyramid (Magnolia pyramidata).

Southern (Magnolia grandiflora).

Swamp (Magnolia virginiana).

Sweet (Magnolia virginiana).

Umbrella (Magnolia tripetala).

Yellow-flower (Magnolia cordata).

Mahala mat (Ceanothus prostratus).

Mahaleb cherry (Prunus mechaleb).

Mahogany,

Alderleaf mountain (Cercocarpus alnifolius).

Arizona mountain (Cercocarpus arizonicus).

Bigleaf mountain (Cercocarpus traskiae).

Birchleaf (Cercocarpus montanus).

Birchleaf mountain (Cercocarpus betuloides).

Curlleaf mountain (Cercocarpus ledifolius ).

Desert (Cercocarpus ledifolius).

Mountain (Cercocarpus montanus).

Silver mountain (Cercocarpus argenteus).

Small-flowered mountain (Cercocarpus minutiflorus).

Small-leaf (Cercocarpus intricatus).

Trask (Cercocarpus traskiae). 
Mahogany-Continued.

birch (Betula lenta).

sumac (Rhus integrifolia).

Male,

berry (Xolisma ligustrina) .

paloverde (Parkinsonia microphylla). Mallow ninebark (Physocarpus malvaceus,

Malva rosa (Lavatera assurgentiflora). Mangla (Rhus laurina).

Manzanita,

Anderson (Arctostaphylos andersonii).

Common (Arctostaphylos manzani$t a)$.

Eastwood (Arctostaphylos glandu$\operatorname{los} a$ ).

Great-berried (Arctostaphylos glau$c a)$.

Greenleaf (Arctostaphylos patula).

Hairy (Arctostaphylos columbiana).

Heartleaf (Arctostaphylos andersonii).

Mariposa (Arctostaphylos mariposa).

Parry (Arctostaphylos manzanita).

Pine-mat (Arctostaphylos nevadensis).

Pointleaf (Arctostaphylos pungens).

Roughleaf (Arctostaphylos drupacea).

Sandmat (Arctostaphylos pumila).

Whiteleaf (Arctostaphylos viscida). Maple,

Ash-leaved (Acer negundo).

Bigleaf (Accr macrophyllum).

Bigtooth (Acer grandidentatum).

Black (Acer nigrum, Acer saccharum).

Black sugar (Acer nigrum).

Broadleaf (Acer macrophyllum).

Chalk (Acer leucoderme).

Dwarf (Acer glabrum).

Florida (Acer floridanum).

Hard (Acer saccharum).

Mountain (Acer glabrum, Acer spicatum).

Oregon (Acer macrophyllum).

Red. (Acer rubrum).

River (Acer saccharinum).

Rock (Acer saccharum).

Sierra (Acer glabrum).

Silver (Acer saccharinum).

Soft (Acer rubrum,

Acer saccharinum).

Southern sugar (Acer floridanum).

Sugar (Acer saccharum).

Swamp (Acer rubrum).

Vine (Acer circinatum).

Water (Acer rubrum).

Western sugar (Acer grandidentatum).

White (Acer saccharinum).

Whitebark (Acer leucoderme).
Mapleleaf,

arrowwood (Viburnum acerifolium).

viburnum (Viburnum acerifoliam).

Marine ivy (Cissus incisa).

Mariola (Parthenium incanum).

Mariposa manzanita (Arctostaphylos mariposa).

Marsh pine (Pinus serotina).

Martin,

ceanothus (Ceanothus martinii).

soapbloom (Ceanothus martinii).

Mat,

Mahala (Ceanothus prostratus).

Squaw (Ceanothus prostratus).

Mat lupine (Lupinus breweri).

Matrimony-vine $\quad(L y c i u m$ halimifolium).

Maul oak (Quercus chrysolepis).

Mayapple (Malvaviscus drummondii).

Maycherry (Amelanchier canadensis).

Mayplum (Prunus texana).

Mazzard (Prunus avium).

Meadow, queen (Spiraea latifolia).

spiraea (Spiraea alba).

sweet (Spiraea alba,

Spiraea latifolia,

Spiraea salicifolia).

Mearn's mockorange (Philadelphus mearnsii).

Medaddy-bush (Lonicera canadensis).

Mendocino whitethorn (Ceanothus incanus).

Menodora (Menodora spinescens).

Menzies, gooseberry (Ribes menziesii). spiraea (Spiraea menziesii).

Mesa, dalea (Dalea schottii).

hard-tack (Cercocarpus minutiflorus).

oak (Quercus engelmannii).

Mescalbean (Sophora secundiflora).

Mescat acacia (Acacia constricta).

Mesquite, (Prosopis chilensis). Arizona (Prosopis chilensis).

Dwarf (Acacia reticulata).

False (Calliandra eriophylla).

Honey (Prosopis chilensis).

Mock (Calliandra eriophylla).

Screwpod (Prosopis pubescens).

Velvet (Prosopis odorata).

Mexican,

alder (Alnus oblongifolia).

ash (Fraxinus berlandieriana).

blue oak (Quercus oblongifolia).

bluewood (Condalia mexicana).

buckeye (Ungnadia speciosa).

cherry (Prunus mexicana).

elder (Sambucus mexicana).

lead tree (Leucaena pulverulenta).

mulberry (Morus microphylla).

orange (Choisya dumosa).

persimmon (Diospyros texana).

piñon (Pinus cembroides).

plum (Prunus mexicana). 
Mexican-Continued. stone pine (Pinus cembroides). white pine (Pinus strobiformis). Mezereum (Daphne mezereum). Michigan holly (Ilex verticillata). Michaux sumac (Rhus michauxii). Miners' dogwood (Cornus sessilis). Mimosa (Albizzia julubrissin, Leucaena pulverulenta).

Pink (Mimosa borealis).

Velvetpod (Mimosa dysocarpa). Minnie-bush (Menziesia pilosa).

Missouri,

currant (Ribes odoratum).

gooseberry (Ribes missouriense, Ribes setosum).

grape (Vitis palmata).

river willow (Salix cordata). viburnum (Viburnum affine).

Mock,

mesquite (Calliandra eriophylla).

heather (Aplopappus ericoides).

locust (Amorpha californica).

Mockorange (Bumelia lycioides, Philadelphus spp.).

Mearn's (Philadelphus mearnsii).

Small-leaf (Philadelphus microphytlus).

Mockernut hickory (Carya alba).

Mohave,

dalea (Dalea arborescens).

desert-rue (Thamnosma montana).

horsebrush (Tetradymia stenolepis). thorn (Canotia holacantha).

Mohr's shinnery oak (Quercus mohriana).

Monkeyflower,

Crimson (Mimulus puniceus).

Long (Mimulus longiflorus).

Monterey, cypress (Cupressus macrocarpa). pine (Pinus radiata).

Moonseed (Menispermum canadense).

Mooseberry (Viburnum alnifolium).

Moosewood (Acer pennsylvanicum, Dirca palustris).

Morello cherry (Prunus cerasus).

Mormon tea (Ephedra viridis).

Moronel (Lonicera subspicata).

Mortonia (Mortonia utahensis).

Moss locust (Robinia hispida).

Mossycup oak (Quercus macrocarpa).

Mountain,

alder (Alnus crispa,

Alnus rhombifolia,

Alnus sinuata, Alnus tenuifolia).

ash (Fraxinus texensis).

balm (Ceanothus velutinus, Eriodictyon californicum).

balsam (Abies lasiocarpa).

birch (Betula fontinalis).

buckthorn (Bumelia monticola).

camellia (Stuartia pentagyna). cedar (Juniperus mexicana).

cherry (Prums angustifolia).

\section{Mountain-Continued.}

clematis (Clematis verticillaris). cranberry (Hugeria erythrocarpa, Vaccinium vitis-idaea).

currant (Ribes viscosissimum). dogwood (Cornus nuttallii). elder (Sambucus caerulca). false-indigo (Amorpha virgata) . fetterbush (Pieris floribunda). fly-honeysuckle (Lonicera cauriana, Lonicera villosa).

fringe (Artemisia frigida). gooseberry (Ribes montigenum, Ribes rotundifolium).

grape (Berberis acquifolium, Vitis berlandieri, Vitis rupestris).

grape, little ( $V$ itis berlandieri). grape, sweet (Vitis monticola). heather (Phyllodoce caerulea). hemlock (Tsuga mertensiana). holly (Ilex montana).

honeysuckle (Lonicera dioica).

hydrangea (Hydrangea arborescens). inđigo (Amorpha glabra, Amorpha virgata).

ironwood (Cercocarpus betuloides).

leatherwood (Fremontia californica). Mountain-lover (Pachistima canbyi). Mountain magnolia (Mfagnolia acuminata,

Magnolia fraseri, Magnolia pyramidata).

Mountain,

maple (Acer glabrum, Acer spicatum).

misery (Chamaebatia foliolosa). oak (Quercus 7elloggii,

Quercus montana).

oread (Magnolia pyramidata).

pine (Pimus pungens).

privet (Ilex montana).

meadowsweet (Spiraea virginiana).

mulberry (Morus microphylla).

redcedar (Juniperus scopulorum).

rose bay (Rhododendron catawbiense).

silverbell (Halesia monticola).

snowberry (Symphoricarpos oreophilus).

sweet pepperbush (Clethra acuminata).

spicewood (Calycanthus fertilis).

sumac (Rhus copallina).

tea (Gaultheria procubens).

white oak (Quercus douglasi,

Quercus grisea).

whitethorn (Ceanothus cordulatus). willow (Salico scouleriana).

willow, false (Salix pseudomonticola).

Mountain winterberry (Ilex montana).

Mountain-ash, (Sorbus americana).

Alpine (Sorbus occidentalis).

American (Sorbus americana). 
Mountain-ash-Continued.

European (Sorbus aucuparia).

Greene (Sorbus scopulina).

Pacific (Sorbus sitchensis).

Western (Sorbus sitchensis).

Mountain-holly (Ncmopanthus mucronata).

Mountain-laurel (Kalmia latifolia).

MI o u n t a i n-mahogany, (Cercocarpus montanus).

Alderleaf (Cercocarpus alnifolius).

Arizona (Cercocarpus arizonicus).

Bigleaf (Cercocarpus traskiae).

Birchleaf (Cercocarpus betuloides).

Curl-leaf (Cercocarpus ledifolius).

Small-flowered (Corcocarpus minutiflorus).

Silver (Cercocarpus argenteus).

Moxie plum (Chiogenes hispidula).

Mulberry,

Black (Morus nigra).

Mexican (Morus microphylla).

Mountain (Morus microphylla).

Red (Morus rubra).

Texas (Morus microphylla).

White (Morus alba).

Mulefat (Baccharis viminea).

Munson cherry (Prunus munsoniana).

Murray pine (Pinus murrajana).

Muscadine grape, (Vitis rotundifolia). Little (Vitis munsoniana).

Musk brush (Ceanothus jepsonii).

Mustang grape (Vitis candicans).

Mustard, sacred (Nicotiana glauca).

Myrtle, (Cyrilla racemiflora).

California wax (Myrica californica). Wax (Myrica cerifera).

Wild crape (Malpighia glabra).

Myrtle boxleaf (Pachistima myrsinites).

Myrtle-croton (Bernardia myricaefolia).

Myrtleleaf, croton (Bernardia myricaefolia). oak (Quercus myrtifolia).

Myrtle oak (Quercus myrtifolia).

Naked withe rod (Viburnum nudum).

Nanny plum (Viburnum lentago).

Nannyberry (Viburnum lentago, Viburnum prunifolium).

Hairy (Viburnum pubescens).

Rusty (Viburnum rufidulum).

Narrowleaf,

buckthorn (Rhamnus lanceolata).

cottonwood (Populus angustifolia). crab apple (Malus angustifolia).

goldenbush (Aplopappus linearifolius).

laurel (Kalmia angustifolia).

papaw (Asimina angustifolia).

redroot (Ceanothus ovatus).

willow (Salix exigua,

Salix longifolia).
Narrowleaf yerba santa (Eriodictyon angustifolium)

Necklace poplar (Populus deltoides, Populus sargentii).

Needle palm (Rhapidophyllum hystrix).

Nerango (Prunus texana).

Netleaf,

hollygrape (Berberis californicum). oak (Quercus diversicolor).

Nettle-tree (Celtis occidentalis).

Netvein acacia (Acacia reticulata).

Nevada, currant (Ribes nevadense).

dalea (Parosela polyadenia).

jointfir (Ephedra nevadensis).

wild almond (Prunus andersonii).

Nevin hollygrape (Berberis nevinii).

Newberry falsemallow (Horsfordia newberryi).

New Jersey-tea (Ceanothus americanus).

New Mexican,

locust (Robinia neomexicana).

rubberbush (Parthenium incanum).

shinnery oak (Quercus novomexicana).

New Mexico,

buckeye (Ungnadia speciosa). clematis (Clematis ncomexicana).

Nightshade, bitter (Solanun dulcamara).

Ninebark (Physocarpus capitatus, Physocarpus opulifolius).

Alabama (Physocarpus alabamensis).

Dwarf (Physocarpus alternans).

Mallow (Physocarpus malvaceus,

Prairie (Physocarpus intermedius).

Noble fir (Abies nobilis).

Nogal (Juglans major).

Northern,

alder (Alnus sinuata).

fox grape (Vitis labrusca).

gooseberry (Ribes oxyacanthoides).

pin oak (Quercus ellipsoidalis).

prickly-ash (Xanthoxylum americanum).

red oak (Quercus borealis).

sloe (Prunus alleghaniensis).

white cedar (Thuja occidentalis).

white pine (Pinus strobus).

Norway pine (Pinus resinosa).

Nut pine (Pinus cembroides,

Pinus edulis,

Pinus monophylla,

Pinus parryana).

Nutbrush (Simmondsia chinensis).

Nutmeg, California (Tumion californicum).

Nutmeg, hickory (Carya myristicaeformis).

Nuttall,

globemallow (Malvastrum nuttallii). horsebrush (Tetradymia nuttallii). willow (Salis scouleriana). 
Oak,

Arizona white (Quercus arizonica).

Barren (Quercus ilicifolia, Quercus marilandica).

Basket (Quercus durandii, Quercus prinus).

Bastard (Quercus coccinea, Quercus durandii).

Bastard white (Quercus austrina).

Bear (Quercus ilicifolia, Quercus sadleriana).

Black (Quercus coccinea,) Quercus emoryi).

Black scrub (Quercus ilicifolia).

Blackjack (Quercus marilandica).

Blue (Quercus douglasii).

Bluejack (Quercus cinerea).

Box white (Quercus stellata).

Boynton (Quercus boyntonii).

Bray (Quercus brayi).

Brewer (Quercus garryana).

Buck (Quercus coccinea).

Bur (Quercus macrocarpa).

California black (Quercus kelloggii).

California blue (Quercus douglasii),

California live (Quercus agrifolia).

California scrub (Quercus dumosa).

California tanbark (Quercus densiflora).

California white (Quercus lobata).

Canyon live (Quercus chrysolepis, Quercus wislizenii).

Chapman (Quercus chapmanii).

Chapman white (Quercus chapmanii).

Chestnut (Quercus montana).

Chinquapin (Quercus muehlenbergii).

Chisos red (Quercus gravesii).

Coast live (Quercus agrifolia,

Colorado white (Quercus leptophylla).

Cow (Quercus prinus).

Deer (Quercus sadleriana).

Duck (Quercus nigra).

Durand (Quercus durandii).

Durand white (Quercus durandii).

Dwarf chinquapin (Quercus prinoides).

Dyer (Quercus velutina).

Emory (Quercus emoryi).

Evergreen (Quercus engelmannii).

Evergreen white (Quercus engelmanii).

Fendler (Quercus fendleri).

Gambel (Quercus gambelii).

Garry (Quercus garryana).

Georgia (Quercus georgiana).

Grave's (Quercus gravesii).

Gray (Quercus grisea).

Havard's shinnery (Quercus havardii) .

Hedgehog (Lithocarpus densiflora).

Highland live (Quercus wislizenii).

Holly (Quercus undulata).

Huckleberry (Quercus vaccinifolia).

Interior live (Quercus wislizenii).
Oak-Continued.

Iron (Quercus chrysolepis, Quercus stellata).

Island livè (Quercus tomentella).

Jack (Quercus ellipsoidalis, Quercus marilandica).

Lacey (Quercus laceyi).

Laurel (Quercus imbricaria, Quercus laurifolia, Quercus phellos).

Laurelleaf (Quercus laurifolia).

Leather (Quercus dumosa).

Live (Quercus virginiana).

MacDonald (Quercus dumosa).

Mesa (Quercus engelmannii).

Mexican blue (Quercus oblongifolia).

Mohr's shinnery (Quercus mohriana).

Mossycup (Quercus macrocarpa).

Mountain (Quercus kelloggii, Quercus montana).

Mountain white (Quercus douglasii, Quercus grisea).

Myrtle (Quercus myrtifolia).

Myrtleleaf (Qucreus niyrtifolia).

Netleaf (Quercus diversicolor).

New Mexican shinnery (Quercus novomexicana).

Northern pin (Quercus ellipsoidalis).

Northern red (Quercus borealis).

Oregon white (Quercus garryana).

Overcup (Quercus lyrata, Quercus macrocarpa).

Palmer (Quercus palmeri).

Pin (Quercus laurifolia,

Quercus palustris,

Quercus phellos).

Possum (Quercus nigra).

Post (Quercus stellata).

Punk (Quercus nigra).

Quercitron (Quercus velutina).

Red (Quercus coccinea,

Quercus rubra,

Quercus volutina).

Rock (Quercus douglassii, Quercus montana).

Rock chestnut (Quercus montana).

Rocky Mountain shin (Quercus un dulata).

Rocky Mountain white (Quercus leptophylla,

Quercus utahensis).

Running (Quercus pumila).

Rydberg (Quercus rydbergiana).

Sadler (Quercus sadleriana).

Scarlet (Quercus coccinea).

Schneck red (Quercus shumardii).

Scrub (Quercus catesbei,

Quercus macrocarpa,

Quercus marilandica,

Quercus prinoides).

Scrub chestnut (Quercus prinoides).

Shln (Quercus mohriana,

Quercus undulata).

Shingle (Quercus imbricaria).

Shinnery (Quercus havardii). 
Oak-Continued.

Shumard red (Quercus shumardii).

Silver (Quercus hypoleuca).

Slick (Quercus velutina).

Slickbark (Quercus velutina).

Small chestnut (Quercus prinoides). Small post (Quercus margaretta).

Smoothbark (Quercus velutina).

Southern red (Quercus rubra).

Spanish (Quercus coccinea,

Quercus digitata,

Quercus rubra).

Spotted (Quercus coccinea, Quercus nigra, Quercus shumardii, Quercus texana).

Swamp (Quercus bicolor, Quercus palustris).

Swamp chestnut (Quercus prinus).

Swamp post (Quercus lyrata).

Swamp Spanish (Quercus palustris). Swamp white (Quercus bicolor, Quercus prinus).

Switch (Quercus undulata).

Tan (Lithocarpus densifiora).

Tanbark (Lithocarpus densiflora, Quercus montana, Quercus velutina).

Texas red (Quercus texana).

Toumey (Quercus toumeyi).

Turkey (Quercus cinerea, Quercus ilicifolia, Quercus rubra).

Upland willow (Quercus cinerea). Valley white (Quercus lobata).

Vasey (Quercus undulata).

Water (Quercus arkansana,

Quercus imbricaria,

Quercus laurifolia,

Quercus nigra,

Quercus palustris, Quercus phellos).

Wavyleaf (Quercus undulata).

White (Quercus alba,

Quercus durandii,

Quercus oblongifolia,

Quercus stellata).

White water (Quercus lyrata).

Whiteleaf (Quercus hypoleuca).

Wilcox (Quercus wilcoxii).

Willow (Quercus phellos).

Willowleaf (Quercus phellos).

Wislizenius (Quercus wislizenii).

Yellow (Quercus velutina).

Oakleaf hydrangea (Hydrangea quercifolia).

Oceanspray (Holodiscus discolor).

Ocotillo (Fouquieria splendens).

Ogeche,

lime (Nyssa ogeche).

plum (Nyssa ogeche).

Ohio buckeye (Aesculus glabra).

Oklahoma plum (Prunus gracilis).

Old-field,

birch (Betula populifolia).

pine (Pinus taeda).

plum (Prunus umbellata).
Oldman's beard (Hydrangea quercifolia).

Olive, Russian (Elaeagnus angustifolia).

Olive tree, wild (Halesia carolina).

One-berry (Celtis occidentalis).

One-color willow (Salix monochroma).

One-seed juniper (Juniperus monosperma).

Opopanax (Acacia farnesiana).

Yellow (Acacia farnesiana).

Opossum-wood (Halesia carolina).

Orange,

Bitter (Citrus trifoliata).

Mexican (Choisya dumosa).

Mock (Prunus caroliniana).

Osage (Maclura pomifera).

Wild (Prunus caroliniana).

Orange,

gooseberry (Ribes pinetorum).

honeysuckle (Lonicera ciliosa).

Oregon,

alder (Alnus rubra).

ash (Fraxinus oregona).

box-bush (Pachistima myrsinites).

crab apple (Malus fusca).

Douglas fir (Pseudotsuga taxifolia).

gooseberry (Ribes lobbii).

hollygrape (Berberis aquifolium, Berberis nervosa).

maple (Acer macrophyllum).

myrtle (Umbellularia californica).

pine (Pseudotsnga taxifolia).

tea-tree (Oeanothus sanguineus).

viburnum (Viburnum ellipticum).

white oak (Quercus garryana).

Oregon-grape (Berberis aquifolium,

Berberis nervosa,

Berberis repens).

Osage-orange (Maclura pomifera).

Osier,

Red (Cornus stolonifera).

Western (Cornus occidentalis).

Oso berry (Osmaronia cerasiformis).

Overcup, oak (Quercus lyrata,

Quercus macrocarpa).

Oxeye, sea (Borrichia frutescens).

Ozark chinquapin (Castanea ozarkensis).

Pachysandra (Pachysandra procumbens).

Pacific,

grape ( $\nabla$ itis californica).

mountain-ash (Sorbus sitchensis).

plum (Prunus subcordata).

waxmyrtle (Myrica californica).

yew (Taxus brevifolia).

Paintbrush, bush (Castilleja hololeuca).

Palaverde (Canotia holacantha).

Pale,

desert-thorn (Lycium pallidum).

dogwood (Cornus obliqua).

elderberry (Sambucus coerulea).

laurel (Kalmia polifolia).

silktassel (Garrya favescens).

wolfberry (Lycium pallidum). 
Palm, Texas (Sabal texana).

Palmer,

clematis (Clematis palmeri). cottonwood (Populus palmeri). goldenbush (Aplopappus palmeri). oak (Quercus palmeri).

Palmetto, cabbage (Sabal palmetto).

Paloblanco (Celtis lindheimeri, Celtis reticulata, Forestiera neomexicana).

Paloduro (Celtis reticulata).

Paloverde (Cercidium macrum, Cercidium torreyanum).

Panhandle grape (Vitis doaniana).

Panicled dogwood (Cornus paniculata).

Papaw,

Common (Asimina triloba).

Dwarf (Asimina parviflora).

Narrowleaf (Asimina angustifolia).

Small-flowered (Asimina parviflora).

Paper,

birch (Betula papyrifera, Betula populifolia).

mulberry (Broussonetia papyrifera).

Paperleaf alder (Alnus tenuifolia).

Paradise flower (Acacia greggi).

Parish,

desert-thorn (Lycium parishii).

Parry, goldenbush (Aplopappus parishii).

lenscale (Atriplex parryi).

manzanita (Arctostaphylos manzanita).

piñon (Pinus parryana).

saltbush (Atriplex parryi).

Partridge berry (Mitchella repens).

Pusture gooseberry (Ribes cynosbatii).

Pavonia (Pavonia lasiopetala).

Yeach,

Desert (Prunus andersonii).

Wild (Prunus carolinia,

Prunus texana).

Peach,

oak (Quercus phellos).

thorn (Lycium cooperi).

Peachleaf willow (Salix amygdaloides).

Peaflower locust (Robinia pseudoacacia).

Pecan (Carya pecan) .

Pencil-tree (Baccharis halimifolia).

Pentstemon,

Heartleaf (Pentstemon cordifolius).

Rothrock (Pentstemon rothrockii).

Shortflower (Pentstemon breviflorus).

Snapdragon (Pentstemon antirrhinoides).

Pepperbush,

Mountain sweet (Clethra acuminata).

Sweet (Clethra alnifolia).

Pepperidge (Cissus arborea, Nyssa sylvatica).

Peppervine (Cissus arborea).

Pepperwood (Umbellularia californica, Xanthoxylum clava-herculis).
Perfumed cherry (Prunus mahaleb).

Fersimmon (Diospyros virginiana).

Black (Diospyros texana).

Mexican (Diospyros texana).

Pickleweed (Allenrolfea occidentalis).

Piedmont rhododendron (Rhododendron minus).

Pjgeon cherry (Prunus pennsylvanica).

Pigeonberry (Amelanchier alnifolia, Amelanchier florida, Cornus alternifolia, Rhamnus californica).

Pigmy-cedar (Peucephyllum schottii).

Pignut, (Simmondsia chinensis).

hickory (Carya cordiformis,

Carya glabra,

Carya leiodermis,

Carya pallida,

Carya villosa).

Pilgrim grape (Vitis novae-angliae).

Pima ratany (Krameria parvifolia).

Pin cherry (Prunus pennsylvanica).

Pinchot juniper (Juniperus pinchottii).

Pine,

Apache (Pinus apacheca).

Arizona (Pimus arizonica).

Banks (Pinus banksiana).

Bigcone (Pinus conlteri).

Bishop (Pinus muricata).

Black (Pinus serotina,

Pinus taeda).

Bristlecone (Pinus aristata).

Carribean (Pinus caribaea).

Chihuahua (Pinus leiophylla).

Coulter (Pinus coulteri).

Digger (Pinus sabiniana).

Fat (Pinus australis).

Foxtail (Pinus aristata,

Pinus balfouriana).

Georgia (Pinus australis).

Gray (Pinus bantesiana).

Hickory (Pinus aristata).

Jack (Pinus banksiana).

Jeffrey (Pinus jeffreyi).

Jersey (Pinus virginiana).

Knobcone (Pinus attenuata).

Limber (Pinus flexilis).

Loblolly (Pinus taeda).

Lodgepole (Pinus contorta,

Pinus murrayana).

Longleaf (Pinus australis).

Marsh (Pinus serotina).

Mexican stolle (Pinus cembroides).

Mexican white (Pinus strobiformis).

Monterey (Pinus radiata).

Mountain (Pinus pungens).

Murray (Pinus murrayana).

Northern white (Pinus strobus).

Norway (Pinus resinosa).

Nut (Pinus cembroides,

Pinus edulis,

Pinus monophylla,

Pinus parryana).

Oldfield (Pinus taeda).

Oregon (Pseudotsuga taxifolia).

Pitch (Pinus rigida). 
Pine-Continued.

Pond (Pinus serotina).

Prickle-cone (Pinus muricata).

Red (Pinus resinosa,

Pseudotsuga glauca).

Rocky mountain yellow (Pinus brachyptera).

Rosemary (Pinus taeda).

Sabine (Pinus sabiniana).

Sand (Pinus clausa).

Santa Cruz Island (Pinus remorata).

Scrub (Pinus bantosiana,

Pinus virginiana).

Shore (Pinus contorta).

Shortleaf (Pinus echinata, Pinus taeda).

Singleleaf (Pinus monophylla).

Slash (Pinus caribaea).

Southern (Pinus australis).

Southern hard (Pinus australis).

Southern yellow (Pinus echinata).

Spruce (Picea mariana,

Pinus contorta,

Pinus glabra,

Tsuga canadensis).

Sugar (Pinus lambertiana).

Swamp (Pinus caribaea,

Pinus palustris).

Table-mountain (Pinus pungens).

Tamarac (Pinus murrayana).

Torrey (Pinus torreyana).

Virginia (Pinus virginiana).

Western white (Pinus monticola).

Western yellow (Pinus ponderosa).

White (Picea engelmannii,

Pinus flexilis,

Pinus glabra,

Pinus strobus).

Whitebark (Pinus albicaulis).

Yellow (Pinus australis,

Pinus echinata,

Pinus ponderosa).

bush (Aplopappus pinifolius).

Pineleaf goldenbush (Aplopappus pinifolius).

Pine-mat (Ceanothus diversifolius).

manzanita (Arctostaphylos nevadensis).

Pink,

honeysuckle (Lonicera hispidula). meadow spiraea (Spiraea latifolia). mimosa (Mimosa borealis).

sophora (Sophora affinis).

Pinkshell azalea (Rhododendron vaseyi).

Pin oak, (Quercus laurifolia, Quercus palustris, Quercus phellos).

Northern (Quercus ellipsoidalis).

Piñon (Pinus edulis,

Pinus monophylla).

Pinxter flower (Rhododendron canescens,

Rhododendron $n u d i$. florum).
Piper willow (Salix piperi).

Pipestem (Clematis lasiantha).

Pipe-vine, (Aristolochia durior, Aristolochia tomentosa).

Dutchman's (Aristolochia durior).

Californla Dutchman's (Aristolochia californica).

Woolly (Aristolochia tomentosa).

Pitch pine (Pinus rigida).

Planetree (Ptatanus occidentalis).

Planer-tree (Planera aquatica).

Plateau gooseberry (Ribes velutinum).

Plum,

Allegheny (Prunus allegheniensis).

Beach (Prunus maritima).

Big-tree (Prunus mexicana).

Bullace (Prunus umbellata).

Canada (Prunus nigra).

Chickasaw (Prunus angustifolia,

Prunus umbellata).

Creek (Prunus rivularis).

Deer (Chrysobalanus oblongifolius).

Downward (Bumelia spinifiora).

Hog (Colubrina texcnsis,

Prunus reverchonii,

Prunus umbellata).

Horse (Prunus americana, Prunus nigra).

Hortulan (Prunus hortulana).

Klamath (Prunus subcordata).

May (Prunus texana).

Mexican (Prunus mexicana).

Moxie (Chiogenes hispidula).

Nanny (Viburnum lentago).

Ogeche (Nyssa ogeche).

Oklahoma (Prunus gracitis).

Oldfield (Prunus umbellata).

Pacific (Prunus subcordata).

Porter's (Prunus allegheniensis).

Prairie (Prunus umbellata).

Saffron (Bumelia spiniflora).

Sand (Prunus texana).

Shore (Prunus maritima).

Sierra (Prunus subcordata).

Western wild (Prunus subcordata).

Wild (Prunus americana,

Prunus lanata,

Prunus nigra).

Wild garden (Prunus hortulana).

Wild goose (Prunus hortulano,

Prunus munsoniana).

Wild red (Prunus americana).

Wild yellow (Prunus americana).

Plum grape (Vitis labrusca).

Plumas bush (Ceanothus lemmonii).

Plumleaf cherry (Prunus emarginata).

Plymouth crowberry (Corema conradii).

Pointleaf manzanita (Arctostaphylos pungens).

Poison,

ash (Rhus vernix).

bay (Illicium floridanum).

dogwood (Rhus vernix).

elder (Rhus vernix).

sumac (Rhus vernix).

Poisonbean (Daubenbonia drummondii). 
Poison-ivy (Rhus toxicodendron).

Poison-oak (Rhus diversiloba, Rhus toxicodendron, Rhus vernix).

Polecat tree (Rhamnus caroliniana).

Polished willow (Salix laevigata).

Polygala,

Desert (Polygala acanthoclada).

Thorn (Polygala acanthoclada).

Pond,

brush (Forestiera acuminata).

pine (Pinus serotina).

spice (Glabraria geniculata).

Pondbush (Glabraria geniculata).

Pondcypress (Taxodium ascendens).

Ponil (Fallugia paradoxa).

Poninack (Acacia farnesiana).

Poplar,

Balsam (Populus balsamifera).

Blue (Liriodendron tulipifera).

Downy (Populus heterophylla).

Hickory (Liriodendron tulipifera).

Necklace (Populus deltoides, Populus sargentii).

Rydberg (Populus acuminata).

Silver (Populus alba).

White (Liriodendron tulipifera, Populus alba).

Yellow (Liriodendron tulipfera.

Popotillo (Ephedra antisyphilitica, Ephedra trifurca).

Poppy,

Bush (Dendromecon rigida).

Tree (Dendromecon rigida).

Porter's plum (Prunus allegheniensis).

Port Orford cedar (Chamaecyparis lawsoniana).

Possum,

grape (Vitis baileyana).

oak (Quercus nigra).

wood (Diospyros virginiana).

Possumhaw (Ilex decidua, Viburnum nudum).

Post,

cedar (Libocedrus decurrens).

locust (Robinia pseudoacacia).

oak (Quercus stellata).

Post-oak grape (Vitis lincecumii).

Poverty birch (Betula populifolia).

Powdery storax (Styrax pulverulenta).

Prairie,

acacia (Acacia angustissima).

crab apple (Malus ioensis).

guajillo (Acacia angustissima).

ninebark (Physocarpus intermedius).

plum (Prunus umbellata).

weed (Potentilla fruticosa).

willow (Salix humilis).

Pretty willow (Salix bella).

Prickle-cone pine (Pinus muricata).

Prickly,

ash (Aralia spinosa).

gooseberry (Ribes cynosbatii).

Pride of China (Melia azedarach).
Privet, (Forestiera acuminata, Ilex decidua,

Ilex longipes, Ligustrum vulgare).

Mountain (Ilex montana).

Swamp (Forestiera acuminata). andromeda (Xolisma ligustrina). lippia (Lippia ligustrina).

Punk oak (Quercus nigra).

Purple,

anise (Illicium floridanum).

azalea (Rhododendron nudiflorum).

chokeberry (Aronia arbutifolia).

dogwood (Cornus alternifolia).

haw (Condalia obovata).

virgins-bower (Clematis verticillaris).

Pumpkin ash (Fraxinus profunda).

Pussy willow (Salix discolor).

dwarf (Salix tristis).

Pyramid magnolia (Magnolia pyramidata).

Quaking aspen (Populus tremuloides).

Quarter-vine (Bignonia capreolata).

Quercitron oak (Quercus velutina).

Quinine,

bush (Cowania stansburiana,

Garrya elliptica,

Garrya favescens).

cherry (Prunus emarginata).

plant (Simmondsia chinensis).

Quinsy berry (Ribes hudsonianum).

Rabbit thorn (Lyoium pallidum ).

Rabbitberry (Shepherdia argentea).

Rabbitbrush,

Douglas (Chrysothamnus viseidiflo$r u s)$.

Rubber (Chrysothamnus nauseosus).

Spring (Tetradymia glabrata).

Sticky (Chrysothamnus paniculatus).

Sticky flower (Chrysothamnus viscidiflorus).

Rabbiteye blueberry (Vaccinium virgatum).

Raisin, wild (Viburnum cassinoides, Viburnum lentago).

Ramoceniza (Parosela spinosa).

Ramona bush (Ceanothus tomentosus).

Ramshorn (Acacia greggii).

Range ratany (Krameria glandulosa).

Ratany,

Pima (Krameria parvifolia).

Range (Krameria glandulosa).

White (Krameria grayi).

Rat-stripper (Pachistima canbyi).

Rattan vine (Berchemia scandens).

Rattlebox (Halesia carolina).

Red,

alder (Alnus rubra).

ash (Fraximus pennsylvanica).

bilberry (Vaccinium parvifolium).

birch (Betula fontinalis,

Betula nigra).

brush (Lippia berlandieri,

Quercus ilicifolia).

buckeye (Aesculus pavia). 
Red-Continued.

chokeberry (Aronia arbutifolia). cypress (Taxodium distichum). elder (Sambuous callicarpa, Sambucus pubens).

elm (Ulmus alata, UTmus fulva, Ulmus serotina).

fir (Abies magnifica, Pseudotsuga glauca, Abies nobilis, Pseudotsuga taxifolia). fir, California (Abies magnifica). fir, Shasta (Abies magnifica). grape (Vitis polmata). gum (Liquidambar styracifua). heart (Ceanothus spinosus). heather (Phyllodoce breweri, Phyllodoce empetriformis). hollygrape (Berberis haematocarpa). huckleberry (Vaccinium parvifolium). locust (Robinia pseudoacacia). maple (Acer rubrum).

moonseed (Cebatha carolina). mulberry (Morus rubra).

oak (Quercus coccinea, Quercus rubra, Quercus velutina).

pine (Pinus resinosa, Pseudotsuga glauca).

spruce (Picea rubra). sage (Trixis californica). soapbloom (Ceanothus sanguineus). twinberry (Lonicera utahensis). whortleberry (Vaccinium parvifolium).

willow (Salix laevigata, Salix lasiandra).

Redbay, (Gordonia lasianthus, Persea borbonia).

Smooth (Persea borbonia). Swamp (Persea pubescens).

Redberry, (Rhamnus crocea) bamboo (Smilax walteri). elder (Sambucus callicarpa). juniper (Juniperus pinchotii).

Redbud, (Cercis canadensis). California (Cercis occidentalis). Redbud serviceberry (Amelanchier prunifolia) .

Redbud,

Texas (Oercis reniformis).

Western (Cercis occidentalis).

Red-cardinal (Erythrina arborca).

Red cedar, (Juniperus scopulorum, Thuja plicata).

Eastern (Juniperus virginiana).

Mountain (Juniperus scopulorum).

Rocky mountain (Juniperus scopulorum).

Southern (Juniperus Iucayana).

Western (Thuja plicata).

Red-flowered,

clematis (Clematis pitcheri). currant (Ribes sanguineum).
Red-frulted juniper (Juniperus erythrocarpa).

Red-osier (Cornus stolonifera).

Redroot, (Ceanothus americanus, Ceanothus intermedius, Ceanothus ovatus).

Redshank (Adenostoma sparsifolium). grape ( $\boldsymbol{V}$ itis rufotomentosa).

Redstem,

buckthorn (Rhamnus rubra).

ceanothus (Ceanothus sanguineus).

Redwood (Sequoia sempervirens).

California (Sequoia sempervirens).

Rhododendron, (Rhododendron maximum).

Carolina (Rhododendron carolinianum).

Catawba (Rhododendron catawbiense).

Coast (Rhododendron californicum).

Lapland (Rhododendron lapponicum).

Pledmont (Rhododendron minus).

Rocky mountain (Rhododendron albiflorum).

Rosebay (Rhododendron maximum). Rhodora (Rhododendron canadense).

Ribbonwood (Adenostoma sparsifolium).

Rigid,

brickellbush (Brickellia frutescens). ceanothus (Ceanothus rigidus).

River,

birch (Betula nigra).

cottonwood (Populus sargentii).

maple (Acer saccharinum).

willow (Salix fuviatillis).

River willow, Missourl (Salix cordata,

Sali $x$ mis. souriense).

Riverbank grape ( $\nabla$ itis vulpina).

Rock,

chestnut oak (Quercus montana).

clematis (Clematis verticillaris).

elm (Ulmus racemosa).

gooseberry (Ribes quercetorum).

grape (Vitis rupestris).

maple (Acer saccharum).

nettle (Eucnide urens).

oak (Quercus douglasii,

Quercus montana).

Rockbrush (Eysenhardtia polystachya).

Rocky mountain,

redcedar (Juniperus scopulorum).

rhododendron (Rhododendron albi. florum).

red cherry (Prunus corymbulosa).

shin oak (Quercus undulata).

white oak (Quercus leptophylla,

Qucrcus utahensis).

whortleberry ( $\nabla$ accinium oreophitum) .

sellow pine (Pinus brachyptera).

Romero (Trichostema lanatum).

Rope-vine (Clematis pauciflora).

Rosa, malva (Lavatera assurgenti. flora). 
Rose-acacia (Robinia lispida).

Rosebay, (Rhododendron maximum). Lapland (Rhododendron lapponicum). Mountain (Rhododendron catawbiense).

Rosebay rhododendron (Rhododendron maximum).

Rosemary (Ceratiola ericoides). pine (Pinus taeda). willow (Salix petiolaris).

Roses (Rosa spp.).

Rosin brush (Baccharis sarothroides).

Rothrock, currant (Ribes wolfi). pentstemon (Pentstemon rothrockii).

Rough arrowwood (Viburnum scabrellum).

Roughish arrowwood (Viburnum scabrellum).

Roughleaf, cornel (Cornus asperifolia). manzanita (Arctostaphylos drupacea).

Rough-leaved, cornel (Cornus asperifolia, Cornus circinata). dogwood (Cornus asperifolia).

Round-flowered catclaw (Acacia roemeriana).

Roundleaf, gooseberry (Ribes rotundifolium). grape (Vitis helleri).

snowberry (Symphoricarpos rotundifolius).

Rubber rabbitbrush (Chrysothammus nauscosus).

Rum cherry (Prunus serotina).

Running, oak (Quercus pumila). strawberrybush (Evonymus obovatus).

Russet, alder (Alnus crispa).

buffaloberry (Shepherdia canadensis).

Russian-olive (Elaeagnus angustifolia).

Rusty, blackhaw ( $\nabla$ iburnum rufidulum). nannyberry (Viburnum rufidulum). Rustyleaf (Menziesia ferruginea).

Rydberg, oak (Quercus rydbergiana). poplar (Populus acuminata).

Sabine pine (Pinus sabiniana).

Sacred mustard (Nicotiana glauca).

Sadler oak (Quercus sadleriana).

Sage,

Ambrosia bur (Franceria ambrosiodes).

Autumn (Salvia greggii).

Bee (Hyptis emoryi).

Black (Artemisia arbuscula, Salvia mellifera).

Bladder (Salazaria mexicana).

Colorado (Artemisia tridentata).

Desert (Salvia carnosa).
Sage-Continued.

Gregg (Salvia greggii).

Hollyleaf bur (Franceria ilicifolia).

Little (Artemisia nova).

Red (Trixis californica).

Salt (Atriplex cancscens).

Sheep (Eriogonum microthecum).

Shrubby blue (Salvia ballotaeflora).

Water (Atriplex torreyi).

White (Eurotia lanata,

Salvia apiana).

White bee (Salvia apiana) .

Wolly bur (Franseria erioscentra).

Sage willow (Salix candida, Salix tristis).

Sagebrush,

Basin (Artemisia tridentata).

Big (Artemisia tridentata).

Bigelow (Artemisia bigelovii).

Bud (Artemisia spinescens).

Coastal (Artemisia californica).

Flat (Artemisia bigelovii).

Hoary (Artemisia cana).

Low (Artemisia arbuscula).

Sand (Artemisia filifolia).

Scabland (Avtemisia arbuscula, Artemisia rigida).

Silver (Artemisia cana).

Small (Artemisia nova).

Stiff (Artemisia rigida).

Threetip (Artemisia tripartita).

St.-Andrews'-cross (Ascyrum hypericoides,

Ascyrum linifolium).

St. Johnswort, shrubby (Hypericum prolificum).

St.-Peter's-wort (Ascyrum stans).

Salad tree (Cercis canadensis).

Salal, (Gaultheria shallon).

berry (Gaultheria shallon).

Saloop (Sassafras albidum).

Salt sage (Atriplex canescens).

Saltbush,

Big (Atriplex lentiformis).

Parry (Atriplex parryi).

Saltcedar (Tamarix gallica).

San Gabriel globemallow (Malvastrum gabrielense).

Sand,

cherry (Prunus pumila).

grape ( $\nabla$ itus lincecumii,

Vitus rupestris).

jack (Quercus cinerea).

pine (Pinus clausa).

plum (Prunus texana).

sagebrush (Artemisia filifolia).

scrub (Ceanothus dentatus).

Sandbar willow (Salix exigua,

Salix interior,

Sulix sessilifolia).

Sandbur (Franseria dumosa).

Sandmat manzanita (Arctostaphylos pumila).

Sandmyrtle, box (Leiophyllum buxifolium). 
Sangre de drago (Jatropha spathulata).

Santa Cruz,

Island pine (Pinus remorata).

ironwood (Lyonothamnus floribundus).

Santa Lucia fir (Abies venusta).

Sargent,

cottonwood (Populus sargentii).

cypress (Cupressus sargentii).

Sarsaparilla (Smilax lanceolata, Smilax walteri).

Wild (Snilax glauca).

Sarsaparilla vine (Smilax pumila).

Sarvisberry (Amelanchier alnifolia, Amelanchier canadensis, Amelanchier florida).

Sassafras (Sassafras albidum).

Satin willow (Salix sitchensis).

Satin-curls (Clematis catesbyana).

Saw,

brier (Smilax glauca).

palmetto (Serenoa repens).

Scabland sagebrush (Artemisia arbuscula,

Artemisiarigida).

Scale broom (Lepidospartum squamatum).

Scarlet,

buckeye (Aesculus discolor, Aesculus pavia).

oak (Quercus coccinea).

Scentless syringa (Philadelphus inodorus).

Schneck red oak (Quercus shumardii). Schwerin's indigo (Amorpha schwerinii).

Scotch broom (Oytisus scoparius).

Screwbean (Prosopis cinerascens, Prosopis pubescens).

Screwpod mesquite (Prosopis pubescens).

Scrub,

birch (Betula glandulosa). ceanothus (Ceanothus foliosus). chestnut oak (Quercus prinoides). hickory (Carya floridana).

oak (Quercus macrocarpa,

Quercus marilandica,

Quercus prinoides).

pine (Pinus banksiana,

Pinus virginiana).

Sea oxeye (Borrichia frutescens).

Sea-ash (Xanthoxylum clara-herculis).

Seaside alder (Alnus maritima).

Seepwillow (Baccharis glutinosa).

Senna (Cassia armata,

Cassia covesii).

September elm (Ulmus serotina).

Sequoia (Sequoia washingtoniana).

Serviceberry, (Amelanchier oblongifolia,

Amelanchier sanguinea).

Canada (Amelanchier canadensis).
Serviceberry-Continued.

Cluster (Amelanchier polycarpa).

Cusick (Amelanchier cusickii).

Downy (Amelanchier canadensis).

Dwarf (Amelanchier oblongifolia).

Goldman (Amelanchier goldmanii).

Small (Amelanchier humilis).

Smooth (Amelanchier laevis).

Utah (Amelanchier utahensis).

Western (Amelanchier alnifolia,

Amelanchier florida).

Seven-bark (Hydrangea arborescens,

Hydrangea quercifolia).

Sevenleaf ivy (Parthenocissus heptaphylla).

Shadblow (Amelanchier canadensis).

Shadbush (Amelanchier canadensis).

Shadscale (Atriplex canescens,

Atriplex confertifolia).

Shagbark hickory (Carya ovata).

Shankbush (Adenostoma sparsifolium).

Shasta red fir (Abies magnifica).

She-balsam (Abics fraseri).

Sheepberry (Viburnum lentago, Viburnum prunifolium).

Sheep-currant (Ribes cereum).

Sheep laurel (Kalmia angustifolia).

Sheep-nut (Simmondsia chinensis).

Sheep-sage (Eriogonum microthecum).

Shellbark hickory (Carya ovata).

Shin oak (Quercus mohriana, Quercus undulata).

Shingle oak (Quercus imbricaria).

Shining,

bumelia (Bumelia lucida).

sumac (Rhus copallina).

willow (Salix lucida).

withe-rod (Viburnum nitidum).

Shinnery oak (Quercus havardii).

Shiny willow (Salix lucida).

Shipmast locust (Robinia pseudoacacia).

Shittimwood (Bumelia lanuginosa, Bumelia lycioides).

Shoestrings (Amorpha canescens, Campsis radicans).

Shore,

pine (Pinus contorta).

plum (Prunus maritima).

Short shucks (Pinus virginiana).

Shortflower pentstemon (Pentstemon breviflorus).

Shortleaf pine (Pinus echinata,

Pinus taeda).

Shortspine horsebrush (Tetradymia spinosa).

Shrub, (Calycanthus foridus). yellow-root (Xanthorriza simplicissima).

Shrubby,

blue sage (Salvia ballotaeflora).

buckeye (Aesculus glabra).

cinquefoil (Potentilla fruticosa).

croton (Croton fruticulosus).

St. Johnswort (Hypericum prolificum). 
Shumard red oak (Quercus shumardii).

Sierra,

bearberry (Arctostaphylos nevadensis).

bladdernut (Staphylea bolanderi). coffeeberry (Rhamnus rubra). currant (Ribes nevadense). gooseberry (Ribes roealii). maple (Acer glabrum).

plum (Prunis subcordata). sweet bay (Myrica hartwegii). willow (Salix commutata, Salix orestera).

Silkbay (Persea humilis).

Silktassel,

Coast (Garrya elliptica).

Fremont (Garrya fremontii).

Pale (Garrya flavescens).

Veatch (Garrya veatchii).

Yellowleaf (Garrya flavescens).

Silktassel bush (Garrya elliptica, Garrya lindheimeri).

Silktree (Albizzia julubrissin).

Silky,

camellia (Stuartia malachodendron). cornel (Cornus amomum).

wlllow (Salix sericea,

Salix sitchensis).

Silver,

birch (Betula lutea,

Elaeagnus argentea).

bush (Elaeagnus argentea).

bush, desert (Shepherdia rotundifolia).

chain (Robinia pseudoacacia).

fir (Abies amabilis,

Abies concolor,

Abies grandis).

lupine (Lupinus albifrons).

maple (Acer saccharinum).

mountain-m a h o g a $\mathrm{n}$ y (Cercocarpus argenteus).

oak (Quercus hypoleuca).

poplar (Populus alba).

sagebrush (Artemisia cana).

willow (Salix argyrocarpa,

Salix discolor,

Salix geyeriana).

Silverbell, (Halesia carolina) .

Little (Halesia parviflora).

Mountain (Halesia monticola).

Two-wing (Halesia diptera).

Silverbell tree (Halesia carolina).

Silverberry (Elaeagnus argentea).

Silverleaf,

hydrangea (Hydrangea radiata).

willow (Salix argophylla).

Silverling (Baccharis halimifolia).

Silvery wormwood (Artemisia flifolia).

Single spruce (Picea canadensis).

Singleleaf pine (Pinus monophylla) .

Sitka,

alder (Alnus sinuata).

cypress (Chamaecyparis nootkaten-
Sitka-Continued.

spruce (Picea sitchensis).

willow (Salix sitchensis).

Skunk,

bush (Rhus trilobata).

currant (Ribes bracteosum, Ribes glandulosum. Ribes prostratum).

spruce (Picea canadensis).

Slash pine (Pinus caribaea, Pinus palustris).

Slender,

buckwheatbrush (Eriogonum microthecum).

poreleaf (Porophyllum gracile).

willow (Salix exigua).

Slíck oak (Quercus velutina).

Slickbark oak (Quercus velutina).

Slippery elm, (Ulmus fulva).

California (Fremontia californica).

Sloe (Prunus umbellata,

Sinall, Viburnum prunifolium).

chestnut oak (Quercus prinoides). cranberry (Vaccinium oxycoccus). pignut hickory (Carya microcarpa, Carya ovalis).

post oak (Quercus margaretta). sagebrush (Artemisia nova). serviceberry (Amelanchier humilis). viburnum (Viburnum obovatum).

Small's hackberry (Celtis smallii). Small-flowered,

mountain-mahogany (Cercocarpus minutiflorus).

papaw (Asimina parviflora).

Small-fruited,

hickory (Carya microcarpa).

papaw (Asimina parviflora).

Small-leaf,

mahogany (Cercocarpus intricatus).

mockorange (Philadelphus micro. phyllus).

Small-leaved horsebean (Parkinsonia microphylla).

Smilax (Smilax lanceolata).

Smith buckthorn (Rhamnus smithii).

Smoketree (Cotinus americanus,

Smooth, Parosela spinosa).

alder (Alnus rugosa).

ash (Fraxinus velutina).

azalea (Rhododendron arborescens). clematis (Clematis addisonii). cottonwood (Populus acuminata). cypress (Cupressus glabra).

gooseberry (Ribes oxyacanthoides, Ribes rotundifolium).

hydrangea (Hydrangea arborescens). labrador tea (Ledum glandulosum). redbay (Persea borbonia).

serviceberry (Amelanchier laevis).

sumac (Rhus glabra).

willow (Salix laevigata).

winterberry (Ilex laevigata).

withe rod (Viburnum nudum). 
Smoothbark,

cottonwood (Populus acuminata). oak (Quercus velutina).

Snailseed (Cebatha carolina, Cocculus diversifolius).

Snap willow (Salix fragilis).

Snapdragon pentstemon (Pentstemon antirrhinoides).

Snow gooseberry (Ribes niveum).

Snowbell (Styrax grandifolia).

Snowberry, (Symphoricarpos albus).

Mountain (Symphoricarpos oreophilus).

Roundleaf (Symphoricarpos rotundifolius).

Utah (Symphoricarpos utahensis).

Western (Symphoricarpos occidentalis).

Whortleleaf (Symphoricarpos rotundifolius).

Snowbrush (Ceanothus cordulatus, Ceanothus velutinus).

Snowdrop, (Halesia carolina). tree (Halesia diptera).

Snowflower tree (Chionanthus virginica).

Snowy hydrangea (Hydrangea radi$a t a)$.

Soapberry,

Drummond (Sapindus drummondii). Florida (Sapindus marginatus).

Western (Sapindus drummondii).

Soapbush (Porlieria angustifolia).

Soft,

arrowwood (Viburnum molle).

maple (Acer rubrum, Acer saccharinum).

Softleaf,

arrowwood (Viburnum molle).

willow (Salix sessilifolia).

Soldier berry (Ribes aureum).

Solonis grape (Vitis longii).

Sonora ironwood (Olneya tesota).

Sophora, pink (Sophora affinis).

Sorrel-tree (Oxydendrum arboreum).

Soulard crab apple (Malus soulardii).

Sour,

berry ( $R$ hus integrifolia).

buffaloberry (Shepherdia argentea). cherry (Prunus cerasus).

gum (Nyssa sylvatica).

oak (Rhus integrifolia).

tupelo (Nyssa ogeche).

tupelo gum (Nyssa ogeche).

Sour-top blueberry (Vaccinium canadense).

Sourwood (Oxydendrum arboreum).

Southern,

balsam fir (Abies fraseri).

black gum (Nyssa biflora).

blackhaw (Viburnum rufidulum).

buckthorn (Bumelia lycioides).

California black walnut (Juglans californica).

cypress (Taxodium distichum).

fox grape (Vitis rotundifolia).
Southerm-Continued.

gooseberry (Vaccinium melanocarpum).

hackberry (Celtis mississippiensis).

hard pine (Pinus australis).

magnolia (Magnolia grandiflora).

pine (Pinus australis).

prickly-ash (Xanthoxylum clava-herculis).

redcedar (Juniperus lucayana).

red oak (Quercus rubra).

shagbark hickory (Carya carolinaeseptentrionalis).

spicebush (Benzoin melissaefolium). spruce (Picea australis).

sugar maple (Acer floridanum).

white cedar (Chamaecyparis thyoides).

wild cherry (Prunus australis).

witch-hazel (Hamamelis macrophyl$l a)$.

yellow pine (Pinus echinata).

Southwestern black cherry (Prunus virens).

Spanish,

bayonet (Yucca spp.).

buckeye (Ungnadia speciosa).

dagger (Yucca spp.).

grape (Vitis berlandieri).

oak (Quercus coccinea,

Quercus digitata,

Quercus rubra).

Sparkleberry (Vaccinium arboreum).

Speckled alder (Almus incana).

Spicebush (Benzoin aestivale, Myrica cerifera).

Spineless hop sage (Graysia brandegei).

Spinescale (Atriplex spinifera).

Spiny,

greasebush (Forsellesia spinescens).

hackberry (Celtis pallida).

hop-sage (Grayia spinosa).

myrtle (Caenothus spinosus).

saltbush (Atriplex confertifolia).

Spiraea,

Douglas (Spiraea douglasii).

Dwarf (Spiraea caespitosa).

Meadow (Spiraea alba).

VirgInia (Spiraea virginiana).

Willowleaf (Spiraea salicifolia).

Sponge wood (Acacia farnesiana).

Spoonwood (Kalmia latifolia).

Spotted,

bark (Quercus shumardii).

oak (Quercus coccinea,

Quercus nigra,

Quercus shumardii,

Quercus texana).

Spring rabbitbrush (Tetradymia glabrata).

Spruce (Tsuga canadensis).

Alberta (Picea albertiana).

Bigcone (Pseudotsuga macrocarpa).

Black (Picea mariana).

Blue (Picea pungens). 
Spruce-Continued.

Bog (Picea mariana).

Brewer (Picea breweriana).

Cat (Picea canadensis).

Colorado blue (Picca pungens).

Double (Picea mariana).

Douglas (Psendotsuga glauca,

Pseudotsuga taxifolia).

Engelmann (Picea engelmannii).

Lemlock (Tsuga canadensis).

Red (Picea rubra).

Single (Picea canadensis).

Sitka (Picea sitchensis).

Skunk (Picea canadensis).

Southern (Picea australis).

Tideland (Picea sitchensis).

Weeping (Picea breweriana) .

Western white (Picea albertiana).

White (Picea canadensis,

Picea engelmannii).

Spruce pine (Picea mariana,

Pinus contorta,

Pinus glabra,

Tsuga canadensis).

Squashberry (Viburnum acerifolium, Viburnum pauciflorum).

Squaw,

apple (Peraphyllum ramosissimum).

bush (Rhus trilobata).

carpet (Ceanothus prostratus).

currant (Ribes cereum).

desert-thorn (Lycium torreyi).

huckleberry (Vaccinium stamineum).

mat (Ceanothus prostratus).

thorn (Lycium torreyi).

Stagbush (Viburnum prunifolium).

Stagger bush (Xolisma mariana).

Staghorn sumac (Rhus glabra, Rhus hyphina).

Starleaf (Choisya dumosa).

Steeplebush (Spiraea tamentosa).

Sticky,

currant (Ribes viscosissimum).

laurel (Ceanothus velutinus).

rabbitbrush (Chrysothamnus paniculatus).

Stickyflower rabbitbrush (Chrysothamnus viscidiflorus).

Stiff,

cornel (Cornus foemina).

dogwood (Cornus femina).

sagebrush (Artemisia rigida).

Stink currant (Ribes bracteosum).

Stinking,

buckeye (Aesculus glabra).

cedar (Tumion taxifolium).

fir (Abies grandis).

willow (Amorpha californica).

Stinkwood (Nyssa sylvatica).

Stone pine, Mexican (Pinus cembrotdes).

Storax, (Styrax officinalis).

American (Styrax americana).

Downy (Styrax pulverulenta).

Powdery (Styrax pulverulenta).

Sycamoreleaf (Styrax platanifolia).
Straggle bush (Ribes divaricatum).

Straggly gooseberry (Ribes divaricatum).

Strawberry, bush (Evoinymus americanus).

bush, running (Evonymus obovatus). shrub (Calycanthus foridus).

Stretch-berry (Smilax bona-nox).

Striped maple (Acer pennsylvanicum).

Styrax (Styrax americana).

Sugar,

blueberry (Vaccinium angustifoli$u m$ ).

bush (Rhus ovata).

grape (Vitis monticola,

Vitis rupestris).

maple (Acer saccharum).

maple, black (Acer nigrum).

pine (Pinus lambertiana).

sumac (Rhus ovata).

tree (Acer saccharum).

Sugarberry (Celtis mississippiensis, Celtis occidentalis, Ehretia, anacua).

Sumac,

Dwarf (Rhus copallina).

Evergreen (Rhus virens).

Fragrant (Rhus aromatica).

Laurel (Rhus laurina).

Lemonade (Rhus trilobata).

Mahogany (Rhus integrifolia).

Michaux (Rhus michauxii).

Mountain (Rhus copallina).

Poison (Rhus vernix).

Shining (Rhus copallina).

Smooth (Rhus glabra).

Staghorn (Rhus glabra, Rhus typhina).

Sugar (Rhus ovata).

Swamp (Rhus vernix).

Utah (Rhus trilobata).

Winged (Rhus copallina).

Yellow (Rhus glabra).

Summer grape (Vitis argentifolia).

Supplejack (Berchemia scandens).

Suterberry (Xanthoxylum americanum).

Swamp,

ash (Fraxinus caroliniana).

azalea (Rhododendron viscosum).

bay (Persea pubescens).

birch (Betula fontinalis,

Betula pumila).

black gum ( $N$ yssa biflora).

blueberry (Vaccinium corymbosum).

blueberry, downy (Vaccinium atrococcum).

candleberry (Myrica carolinensis).

chestnut oak (Quercus prinus).

cottonwood (Populus heterophylla). currant (Ribes lacustre).

fly-honeysuckle (Lonicera oblongifolia).

gooseberry (Ribes lacustre).

haw (Viburnum cassinoides, Viburnum nudum). 
Swamp-Continued.

hickory (Carya cordiformis).

ironwood (Cyrilla racemiflora).

laurel (Kalmia polifolia,

Magnolia virginiana).

magnolia (Magnolia virginiana).

maple (Acer rubrum).

oak (Quercus bicolor,

Quercus palustris).

pine (Pinus caribaea, Pinus palustris).

post oak (Quercus lyrata).

privet (Forestiera acuminata).

redbay (Persea pubescens).

sassafras (Magnolia virginiana).

Spanish oak (Quercus palustris).

sumac (Rhus vernix).

white oak (Quercus bicolor, Quercus prinus).

willow (Salix nigra).

wood (Dirca palustris).

Sireet,

acacia (Acacia farnesiana).

azalea (Rhododendron arborescens).

birch (Betula lenta,

Ceanothus parvifolius).

buckeye (Aesculus octandra).

cherry (Prunus avium).

crab apple (Malus coronaria).

haw (Viburnum prunifolium).

laurel (Illicium floridanum).

magnolia (Magnolia virginiana).

mountain grape (Vitis monticola).

pepperbush (Clethra alnifolia).

pepperbush, mountain (Clethra acuminata).

viburnum (Viburnum lentago).

winter grape (Vitis cinerea).

Sweetbay (Magnolia virginiana, Persea borbonia,

Symplocos tinctoria).

Sweet-bush (Cercocarpus betuloides).

Sweetfern (Myrica asplenifolia).

Sweetgale (Myrica gale).

Sweetgum (Liquidambar styracifua).

Sweetleaf (Symplocos tinctoria).

Sweetspire (Itea virginica) .

Switch oak (Quercus undulata).

Switch-ivy (Leucothoë catesbaei).

Switch-sorrel (Dodonaea avizonica).

Sycamore (Platanus occidentalis).

Arizona (Platanus wrightii).

California (Platanus racemosa).

Western (Platanus racemosa).

Sycamoreleaf storax (Styrax platanifolia).

Syringa (Philadelphus lewisii, Philadelphus serpyllifolius).

Table-mountain pine (Pinus pungens).

Tacamahac (Populus balsamifera).

Tag alder (Alnus tenuifolia).

Tall,

bilberry (Vaccinium ovalifolium).

inkberry (Ilex coriacea).

red huckleberry (Vaccinium parvifolium).

\section{| Tamarack (Larix laricina,} Larix lyalli).

pine (Pinus murrayana).

Tamarisk (Tamarix gallica).

Tanbark oak (Lithocarpus densiflora, Quercus montana, Quercus velutina).

Tan bay (Gordonia lasianthus).

Tanoak (Lithocarpus densiflora).

Tansy-bush (Chamaebatiaria millefolium).

Taparosa (Anisacanthus thurberi).

Taray (Salix taxifolia).

Tarbush (Chamaebatia foliolosa, Flourensia cernua).

Tarflower (Befaria racemosa).

Tarweed (Chamaebatia foliolosa).

Tassel bush,

Canyon (Garrya veatchii).

Dwarf (Garrya flavescens).

Utah (Garrya flavescens).

Tasseltree (Garrya elliptica).

Tassel-white (Itea virginica).

Tea, Mormon (Ephedra viridis).

Teaberry (Gaultheria procumbens).

Tealeaf willow (Salix planifolia).

Tecate cypress (Cupressus guadeloupensis).

Tennessee-indigo (Amorpha tennesseensis).

Tepopote (Ephedra antisyphilitica, Ephedra trifurca).

Tesota (Olneya tesota).

Texan, pecan (Carya texana).

sloe (Prunus tarda).

Texas,

almond (Prunus minutiflora).

ash (Fraxinus texensis).

catclaw (Acacia wrightii).

cottonwood (Populus texana).

ebony (Pithecolobium flexicaule).

elm (Ulmus crassifolia).

hickory (Carya buckleyi).

jointfir (Ephedra texana).

madrone (Arbutus texana).

mallow (Malvaviscus drumniondii).

mulberry (Morus microphylla).

palm (Sabal texana).

redbud (Cercis reniformis).

red oak (Quercus texana).

sarsaparilla (Menispermum canadense).

virgins-bower (Clematis $\quad d r u m$ mondii).

walnut (Juglans rupestris).

Thick-leaved hackberry (Celtis reticulata).

Thinleaf,

alder (Alnus sinuata,

Alnus tenuifolia).

huckleberry (Vaccinium membranaceum).

Thunberg barberry (Berberis thunbergii).

Thunderwood (Rhus vernix). 
Thurberia (Thurberia triloba).

Thorn,

Box (Lycium halimifolium).

California box (Lycium californicum).

Fire (Cotoneaster pyracantha).

Rabbit (Lycium pallidum).

Squaw (Lycium torreyi).

Thorn,

polygala (Polygala acanthoclada).

tree (Gleditsia triacanthos).

Thorny ash (Aralia spinosa).

Threetip sagebrush (Artemisia tripartita).

Tideland spruce (Picea sitchensis).

Tight-eye (Cyrilla racemiflora).

Tisswood (Halesia carolina, Persea borbonia).

Titi, (Oliftonia monophylla). Black (Cliftonia monophylla, Cyrilla racemiflora).

Tobacco, tree (Nicotiana glauca).

Tobbaco brush (Ceanothus velutinus).

Tomatilla (Lycium pallidum, Lycium torreyi).

Toothache tree (Aralia spinosa).

Torchwood (Amyris texana).

Tornillo (Prosopis pubescens).

Tolote (Bursera microphylla).

Torrey,

jointfir (Ephedra torreyana).

lenscale (Atriplex torreyi).

pine (Pinus torreyana).

Tough buckthorn (Bumelia tenax).

Toumey oak (Quercus toumcyi).

Toyon (Photinia arbutifolia).

Trailing,

bluebrush (Ceanothus diversifolius). ceanothus (Ceanothus diversifolius).

Tramp's trouble (Smilax bona-nox).

Trask mahogany (Cercocarpus traskiae).

Tree,

catclaw (Acacia wrightii).

huckleberry (Vaccinium arboreum). lupine (Lupinus arboreus). pea (Parosela spinosa). tobacco (Nicotiana glauca).

Treebine (Cissus incisa).

Tree-of-heaven (Ailanthus altissima).

Treemallow, California assurgentifolia).

Treepoppy (Dendromecon rigida).

Trembling aspen (Populus tremuloides).

Trumpet honeysuckle (Lonicera sempervirens).

Trumpetcreeper (Campsis radicans).

Trumpetflower (Bignonia capreolata, Campsis radicans, Tecoma stans).

Tuliptree (Liriodendron tulipifera).

Tupelo, (Nyssa aquatica, Nyssa sylvatica). gum (Nyssa aquatica). gum, large (Nyssa aquatica).
Tupelo-Continued.

gum, sour (Nyssa ogeche).

Sour (Nyssa ogeche).

Water (Nyssa biflora,

$$
\text { Nyssa ogeche). }
$$

Turkey,

grape (Vitis lincecumii).

oak (Quercus cinerea, Quercus ilicifolia, Quercus rubra).

shed (Forestiera pubescens).

Turpentine broom (Thamnosma montana).

Turpentineweed (Gutierrezia linearis, Gutierrezia longifolia).

Tweedy cottonwood (Populus tweedyi).

Twinberry, (Mitchella repens).

Red (Lonicera utahensis).

Twinberry honeysuckle (Lonicera involucrata).

Twinflower (Linnaea borealis).

Two-wing silverbell (Halesia diptera).

Umbrella magnolia (Magnolia tripetala).

Umbrella tree, (Cornus alternifolia. Magnolia tripetala).

Ear-leaved (Magnolia fraseri).

Large-leaved (Magnolia macrophyl. la).

Una de gato (Acacia greggii).

Undergreen willow (Salix commutata).

Unknown tree (Celtis ocoidentalis).

Upland willow oak (Quercus cinerea).

Ctah,

buddleia (Buddleia utahensis).

honeysuckle (Lonicera utahensis). juniper (Juniperus utahensis).

serviceberry (Amelanchier utahensis).

snowberry (Symphoricarpos utahensis).

sumac (Rhus trilobata).

tassel bush (Garrya flavescens).

Valley,

cottouwood (Populus wislizenii).

white oak (Quercus lobata).

willow (Salix hindsiana).

Varnish-brush (Ceanothus velutinus).

Vase-vine (Clematis viorna).

Vasey oak (Quercus undulata).

Vauquelinia (Vauquelinia californica).

Veatch silktassel (Garrya veatchii).

Veiny arrowwood (Virburnum venosum).

Veinyleaf hollygrape (Berberis nervosa).

Velvet,

ash (Fraxinus velutina).

mesquite (Prosopis odorata).

Velvetleaf,

blueberry (Vaccinium canadense). elder (Sambucus coerulea).

velvetpod mimosa ( carpa). 
Viburnum,

Downy (Viburnum pubescens).

Kentucky (Viburnum molle).

Maple-leaf (Viburnum acerifolium).

Missouri (Viburnum affine).

Oregon (Viburnum ellipticum).

Small (Viburnum obovatum).

Sweet (Viburnum lentago).

Victor gooseberry (Ribes victoris).

Vine maple (Acer circinatum).

Virginia,

clematis (Clematis virginiana).

creeper (Parthenocissus quinquefolia,

Parthenocissus vitacea).

pine (Pinus virginiana).

spiraea (Spiraea virginiana).

willow (Itea virginica) .

Virgins-bower, (Clematis igusticifolia).

Purple (Clematis verticillaris).

Texas (Clematis drummondii).

Viscid currant (Ribes viscosissimum).

Wacopy (Dirca palustris).

Wafer-ash (Ptelea trifoliata).

Wahoo (Evonymus occidentalis, Ulmus alata).

Walnut,

Arizona (Juglans major).

Black (Juglans nigra).

California (Juglans californica).

California black (Juglans hindsii) .

Desert (Juglans rupestris).

Hinds (Juglans hindsii).

Little (Juglans rupestris).

Southern California black (Juglans californica).

Texas (Juglans rupestris).

Western (Juglans rupestris).

White (Juglans cinerea).

Ward willow (Salix longipes).

Wartystem ceanothus (Ceanothus verrucosus).

Water,

ash (Fraxinus caroliniana,

Fraxinus pauciflora).

beech (Carpinus caroliniana).

birch (Betula fontinalis,

Betula nigra).

bitternut (Carya aquatica).

elm (Ulmus americana).

gum (Nyssa biflora).

hickory (Carya aquatica).

jacket (Lycium andersonii). maple (Acer rubrum).

oak (Quercus arkansana,

Quercus imbricaria,

Quercus laurifolia,

Quercus nigra,

Quercus palustris,

Qucreus phellos).

sage (Atriplex torreyi).

tupelo (Nyssa biflora,

Nyssa ogeche).

white oak (Quercus lyrata).

Water-elm (Planera aquatica).

Waterlocust (Gleditsia aquatioa).
Water-wally (Baccharis glutinosa).

Waterwillow (Baccharis emoryi).

Watson gooseberry (Ribes watsonianum).

Wavyleaf,

ceanothus (Ceanothus foliosus).

hollygrape (Berberis pinnata).

oak (Quercus undulata).

Wax currant (Ribes cereum).

Waxberry (Myrica cerifera).

Waxmyrtle, (Myrica cerifera).

Pacific (Myrica californica).

Wedgeleaf,

ceanothus (Ceanothus cuneatus). goldenbush (Aplopappus cuneatus). hornbrush (Ceanothus cuneatus).

Weeping,

oak (Quercus lobata).

spruce (Picea breweriana).

Western,

alder (Alnus rubra).

azalea (Rhododendron occidentale).

black currant (Ribes laxiflorum).

blackhaw (Viburnum ellipticum).

black willow (Salix lasiandra).

blueberry (Vaccinium occidentale).

bog blueberry (Vaccinium occidentale).

buckeye (Aesculus glabra).

burningbush (Evonymus occidentalis).

catalpa (Catalpa speciosa).

chokecherry (Prunus demissa).

chokecherry, black (Prunus de-

$m i s s a$ ).

cottonwood (Populus sargentii).

crab apple (Malus fusca,

Malus ioensis).

dogwood (Cornus nuttallii).

hackberry (Celtis reticulata).

hemlock ( $T$ suga heterophylla).

hophornbeam (Ostrya knowltonii).

huckleberry (Vaccinium occidentale).

juneberry (Amelanchier alnifolia).

juniper (Juniperus occidentalis).

larch (Larix occidentalis).

leatherwood (Dirca occidentalis).

mountain-ash (Sorbus sitchensis).

osier- (Cornus occidentalis).

paper birch (Betula papyrifera).

redbud (Cercis occidentalis).

redcedar (Thuja plicata).

sand cherry (Prunus besseyi).

serviceberry (Amelanchier alnifolia,

Amelanchier florida).

snowberry (Symphoricarpos occidentalis).

soapberry (Sapindus drummondii).

sugar maple (Acer grandidentatum).

sycamore (Platanus racemosa).

walnut (Juglans rupestris).

white pine (Pinus monticola).

white spruce (Picea albertiana).

wlld grape (Vitis californica).

wild pium (Prunus subcordata). 
Western-Continued.

yellow pine (Pinus ponderosa). yew (Taxus brevifolia).

Wheatbrush (Cliftonia monophylla).

Whin (Genista tinctoria).

White,

alder (Alnus rhombifolia,

Clethra acuminata,

Clethra alnifolia).

ash (Fraxinus americana).

ash, Biltmore (Fraxinus biltmoreana).

azalea (Rhododendron viscosum).

basswood (Tilia heterophylla).

bee-sage (Salvia apiana).

birch (Bctula papyrifera,

Betula populifolia).

brush (Lippia ligustrina).

burrobrush (Hymenoclea salsola).

bur-sage (Franseria dumosa).

cedar (Chamaecyparis lawsoniana,

Libocedrus decurrens,

Thuja occidentalis).

cedar, northern (Thuja occidentalis). cedar, southern (Chamaecyparis thyoides).

cornel (Cornus foemina).

cypress (Taxodium distichum).

dalea (Parosela emoryi).

elm (Ulmus americana).

fir (Abies concolor,

Abies grandis,

Abies lasiocarpa).

fir, Colorado (Abies concolor).

fringe (Chionanthus virginica).

gooseberry (Ribes inerme).

hickory (Carya alba).

laburnum (Robinia pseudoacacia).

lilac (Ceanothus integerrimus).

locust (Robinia pseudoacacia).

maple (Acer saccharinum).

mulberry (Morus alba).

oak (Quercus alba,

Quercus durandii,

Quercus oblongifolia,

Quercus stcllata).

pine (Pinus flexilis,

Pinus glabra,

Pinus strobus).

poplar (Liriodendron tulipifera, Populus alba).

ratany (Krameria grayi).

sage (Eurotia lanata,

Salvia apiana).

spruce (Picea canadensis,

Picea engelmannii).

swamp honeysuckle (Rhododendron viscosum).

walnut (Juglans cinerea).

willow (Salix lasiolepis).

willow, European (Salix alba).

White-back ceanothus (Ceanothus crassifolius).

Whitebark,

maple (Acer leucoderme).

pine (Pinus albicaulis).

soapbloom (Ceanothus leucodermis).
White-bay (Magnolia virginiana).

White-flowered, azalea (Rhododendron albiflorum). lantana (Lantana involucrata).

Whiteheart hickory (Carya alba).

Whiteleaf,

manzanita (Arctostaphylos viscida). oak (Qucrcus hypoleuca).

Whitestem, gooseberry (Ribes inerme). pine (Pinus albicaulis).

Whitethorn, (Ceanothus cordulatus, Ceanothus incanus).

Chaparral (Ceanothus leucodermis). Coast (Ceanothus incanus).

Mountain (Ceanothus cordulatus).

White-wicky (Kalmia cuncata).

Whitewood (Liriodendron tulipifer $a$ ).

Whortleberry,

Big (Vaccinium membranaceum).

Blue (Vaccinium ovalifolium).

Bog (Vaccinium uliginosum).

Dwarf (Vaccinium cacspitosum).

Great (Vaccinium corymbosum).

Grouse (Vaccinium scoparium).

Red (Vacoinium parvifolium).

Rocky mountain (Vaccinium orcophilum).

Whortleleaf snowberry (Symphoricarpos rotundifolius).

Wicky (Kalmia angustifolia, Kalmia carolina, Kalmia hirsuta).

Wilcox oak (Quercus wilcoxii).

Wild,

allspice (Bcn oin aestivale).

apple (Malus pumila,

Peraphyllum ranosissimum).

bamboo (Smilax auriculata).

black cherry (Prunus serotina).

black currant (Ribes floridum).

box (Gyminda latifolia).

cherry (Prunus emarginata,

Prunus serotina).

china (Sapindus marginatus).

cotton, Arizona (Thurberia triloba). crapemyrtle (Malpighia glabra).

grape (Vitis girdiana).

grape, California (Vitis californica). grape, western (Vitis californica).

hazel (Simmondsia chinensis).

hydrangea (Hydrangea arborcscens).

laurel (Symplocos tinctoria).

lilac (Ceanothus leucodermis).

lime (Tanthoxylum fagara).

olive (Osmanthus americana).

olive tree (Halesia carolina).

orange (Prunus caroliniana).

peach (Prunus caroliniana,

Prunus texana).

pepper (Ceanothus americanus).

plum (Prunus americana,

Prunus lanata,

Prunus nigra).

plum, garden (Prunus hortulana).

raisin (Viburnum cassinoides, Viburnum lentago). 
Wild-Continued.

red cherry (Prunus pennsylvanica). red plum (Prunus americana).

sarsaparilla (Calycocarpum lyonii, Smilax glauca).

snowball (Ceanothus americanus). tea (Amorpha canescens).

yellow plum (Prunus americana).

Wild Goose plum (Prunus hortulana, Prunus munsoniana)

Willow,

Acequia (Salix cxigua).

Arroyo (Salix lasiolepis).

Autumn (Salix serissima).

Balsam (Salix balsa iffera).

Barclay (Salix barclayi).

Basket (Salix purpurea).

Beaked (Salix bebbiana).

Bearberry (Salix uva-ursi)

Bebb (Salix bebbiana).

Black (Salix nigra).

Blue (Salix subcoerulea).

Blueback (Salix glaucops).

Blueleaf (Salix glaucophylla). .

Bluestem (Salix irrorata).

Bog (Salix pedicellaris).

Brewer (Salix breweri).

Caudate (Salix caudata).

Cherry (Salix monticola).

Coast (Salix hookeriana).

Coyote (Salix exigua).

Crack (Salix fragilis).

Diamond (Salix mackenziana).

Dudley (Salix gooddingii).

Dune (Salix piperi).

Dusky (Salix melanopsis).

Dwarf gray (Salix tristis).

Dwarf pussy (Salix tristis).

European white (Salix alba).

False (Baccharis angustifolia).

False mountain (Salix pseudomonticola).

Farr (Salix farrae).

Fire (Salix scouleriana).

Firmleaf (Salix pseudomyrsinites).

Fragile (Salix fragilis).

Geyer (Salix geyeriana).

Glaucous (Salix discolor).

Goodding (Salix gooddingii).

Greensides (Salix monochroma).

Gulf (Salix nigra).

Harbison (Salix harbisonii).

Heartleaf (Salix cordata).

Hoary (Salix candida).

Labrador (Salix argyrocarpa).

Lemmon's (Salix lemmonii).

Longleaf (Salix fuviatilis,

Salix longifolia).

Lyall (Salix lasiandra).

Mackenzie (Salix mackenziana).

Missouri river (Salix cordata).

Mountain (Salix scouleriana).

Narrowleaf (Salix exigua,

Salix interior).

Nuttall (Salix scouleriana).

One color (Salix monochroma).

Peachleaf (Salix amygdaloides).
Willow-Continued.

Piper (Salix piperi).

Polished (Salix laevigata).

Prairie (Salix humilis).

Pretty (Salix bella).

Pussy (Salix discolor).

Red (Salix laevigata, Salix lasiandra).

River (Salix fuviatilis).

Rosemary (Salix petiolaris).

Sage ( Salix candida, Salix tristis).

Sandbar (Salix exigua, Salix interior, Salix scssilifolia).

Satin (Salix sitchensis).

Shining (Salix lucida).

Shing (Salix lucida).

Sierra (Salix commutata, Salix orestera).

Silky (Salix sericea, Salix sitchensis).

Silver (Salix argyrocarpa, Salix discolor, Salix geyeriana).

Silverleaf (Salix argophylla).

Sitka (Salix sitchensis).

Slender (Salix exigua).

Smooth (Salix laevigata).

Snap (Salix fragilis).

Soft-leaved (Salix sessilifolia).

Swamp (Salix nigra).

Tealeaf (Salix planifolia).

Undergreen (Salix commutata).

Valley (Salix hindsiana).

Virginia (Itea virginica).

Ward (Salix longipcs).

Water (Baccharis emoryi).

Western black (Salix lasiandra).

White (Salix lasiolepis).

Wright (Salix wrightii).

Yellow (Salix lasiandra, Salix lutea).

Yewleaf (Salix taxifolia).

Willow,

baccharis (Baccharis salicina).

cottonwood (Populus angustifolia).

oak (Quercus phellos).

Willowleaf,

cherry (Prunus salicifolia).

oak (Quercus phellos).

spiraea (Spiraea salicifolia).

Wine gooseberry (Ribes inerme).

Winged,

elm (Ulmus alata).

sumac (Rhus copallina).

Wingscale (Atriplex canescens).

Winter,

currant (Ribes sanguineum).

grape ( $\nabla$ itis berlandieri, Vitis cordifolia).

grape, sweet (Vitis cinerea).

Winterberry, (Ilex decidua).

Evergreen (Ilex glabra).

Mountain (Ilex montana).

Smooth (Ilex laevigata).

Winterfat (Eurotia lanata). 
Wintergreen (Gaultheria procumbens). Bush (Gaultheria ovatifolia).

Wislizentus, cottouwood (Populus wislizenii). oak (Quercus wislizenii).

Wisteria, Kentucky (Wisteria macrostachya).

Witch-alder (Fothergilla major). Creeping (Fothergilla parvifolia). Dwarf (Fothergilla gardenii).

Witch hazel, (Hamamelis virginiana). Little (Hamamelis vernalis).

Southern (Hamamelis macrophylla).

Witch hobble (Viburnum alnifolium).

Withe rod, (Viburnum cassinoides).

Naked (Viburnum mudum).

Shining (Viburnum nitidum).

Smooth (Viburnum nudum).

Wolf,

currant (Ribes wolfii).

shed (Forestiera pubescens).

Wolfberry, (Symphoricarpos occidentalis).

Fremont (Lycium fremontii).

Pale (Lycium pallidum).

Wood ramp (Decumaria barbara).

Woodbine (Lonicera sempervirens).

Wood-waxen (Genista tinctoria).

Woolly,

buckeye (Aesculus discolor).

buckthorn (Bumelia lanuginosa).

bur-sage (Franseria eriocentra).

butterflybush (Buddleia marrubiifolia).

pignut (Carya villosa).

pipe-vine (Aristolochia tomentosa).

Woollyleaf ceanothus (Ceanothus tomentosus).

Wormwood, silvery (Artemisia flifolia).

Wright,

buckwheatbrush wrightii).

silktassel (Garrya wrightii).

willow (Salix wrightii).

Yaupon, (Ilex cassine,

$$
\text { Ilex vomitoria). }
$$

Desert (Schaefferia cuneifolia).

Yellow,

ash (Cladrastis lutea).

azalea ( $R$ hododendron calendulaceum).

birch (Betula lutea).

buckeye (Aesculus octandra).

tuckthorn '(Rhamnus caroliniana).
Yellow-Continued.

cucumbertree (Magnolia cordata).

elder (Tecoma stans).

fir (Abies grandis,

Pseudotsuga glauca,

Pseudotsuga taxifolia).

heather (Phyllodoce glanduliflora). honeysuckle (Lonicera fiava).

jessamine (Gelsemium sempervirens).

linn (Magnolia acuminata).

locust (Cladrastis lutea, Robinia pseudoacacia).

oak (Quercus velutina).

opopanax (Acacia farnesiana).

parilla (Menispermum canadense).

pine (Pinus australis,

Pinus echinata,

Yellow, Pinus ponderosa).

poplar (Liriodendron tulipifera).

sumac (Rhus glabra).

willow (Salix lasiandra, Salix lutea).

woodbine (Lonicera flava).

Yellow-flower magnolia (Magnolia cordata).

Yellowleaf silktassel (Garrya flavescens).

Yellowroot (Xanthorhiza simplicissima).

Yellow-wood (Rhamnus caroliniana, Symplocos tinctoria).

Yerba de chivata (Clematis ligusticifolia).

Yerba del oso (Rhamnus california).

Yerba del pasmo (Adenostoma sparsifolium).

Yerba-de-pasmo (Baccharis ramulosa).

Yerba de selva (Whipplea modesta).

Yerba reuma (Frankenia palmeri).

Yerba-santa, (Eriodictyon trichocalyx).

California (Eriodictyon californicum).

Narrowleaf (Eriodictyon angustifolium).

Yew,

Canada (Taxus canadensis).

Florida (Taxus floridana).

Pacific (Taxus brevifolia).

Western (Taxus brevifolia).

Yewleaf willow (Salix taxifolia).

Zorrillo (Choisya dumosa).

Zenobia (Zenobia pulverulenta). 

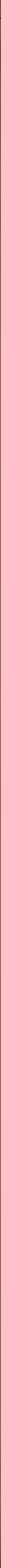
